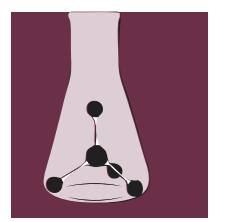

\title{
inorganics
}

\section{s-Block Metal \\ Complexes}




\section{s-Block Metal Complexes}

Special Issue Editor

Matthias Westerhausen

MDPI • Basel • Beijing $\bullet$ Wuhan $\bullet$ Barcelona $\bullet$ Belgrade

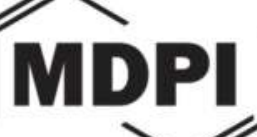


Special Issue Editor

Matthias Westerhausen

Friedrich Schiller University Jena

Germany

Editorial Office

MDPI AG

St. Alban-Anlage 66

Basel, Switzerland

This edition is a reprint of the Special Issue published online in the open access journal Inorganics (ISSN 2304-6740) from 2016-2017 (available at:

http://www.mdpi.com/journal/inorganics/special_issues/s_block_metal_complexe s).

For citation purposes, cite each article independently as indicated on the article page online and as indicated below:

Author 1; Author 2. Article title. Journal Name Year, Article number, page range.

First Edition 2017

ISBN 978-3-03842-589-2 (Pbk)

ISBN 978-3-03842-590-8 (PDF)

Articles in this volume are Open Access and distributed under the Creative Commons Attribution license (CC BY), which allows users to download, copy and build upon published articles even for commercial purposes, as long as the author and publisher are properly credited, which ensures maximum dissemination and a wider impact of our publications. The book taken as a whole is (c) 2017 MDPI, Basel, Switzerland, distributed under the terms and conditions of the Creative Commons license CC BY-NC-ND (http://creativecommons.org/licenses/by-nc-nd/4.0/). 


\section{Table of Contents}

About the Special Issue Editor . v

Preface to "s-Block Metal Complexes" .vii

\section{Markus von Pilgrim, Mihail Mondeshki and Jan Klett}

[Bis(Trimethylsilyl)Methyl]Lithium and -Sodium: Solubility in Alkanes and Complexes with O- and N- Donor Ligands

Reprinted from: Inorganics 2017, 5(2), 39; doi: 10.3390/inorganics5020039 . .1

\section{Twyla Gietz and René T. Boeré}

Backbone-Substituted $\beta$-Ketoimines and Ketoiminate Clusters: Transoid $\mathrm{Li}_{2} \mathrm{O}_{2}$ Squares and $\mathrm{D}_{2}-$ Symmetric $\mathrm{Li}_{4} \mathrm{O}_{4}$ Cubanes. Synthesis, Crystallography and DFT Calculations

Reprinted from: Inorganics 2017, 5(2), 30; doi: 10.3390/inorganics5020030.

\section{Kai-Stephan Feichtner and Viktoria H. Gessner}

Synthesis and Characterization of a Sulfonyl- and Iminophosphoryl-Functionalized Methanide and Methandiide

Reprinted from: Inorganics 2016, 4(4), 40; doi: 10.3390/inorganics4040040

Kirsten Reuter, Fabian Dankert, Carsten Donsbach and Carsten von Hänisch

Structural Study of Mismatched Disila-Crown Ether Complexes

Reprinted from: Inorganics 2017, 5(1), 11; doi: 10.3390/inorganics5010011

Sorin-Claudiu Roşca, Hanieh Roueindeji, Vincent Dorcet, Thierry Roisnel, Jean-François Carpentier and Yann Sarazin

$\mathrm{K}+\cdots \mathrm{C} \pi$ and $\mathrm{K}+\cdots \mathrm{F}$ Non-Covalent Interactions in $\pi$-Functionalized Potassium Fluoroalkoxides

Reprinted from: Inorganics 2017, 5(1), 13; doi: 10.3390/inorganics5010013

Nicholas C. Boyde, Nicholas R. Rightmire, Timothy P. Hanusa and William W. Brennessel Symmetric Assembly of a Sterically Encumbered Allyl Complex: Mechanochemical and Solution Synthesis of the Tris(allyl)beryllate, $\mathrm{K}\left[\mathrm{BeA}_{3}{ }_{3}\right]\left(\mathrm{A}^{\prime}=1,3-\left(\mathrm{SiMe}_{3}\right)_{2} \mathrm{C}_{3} \mathrm{H}_{3}\right)$

Reprinted from: Inorganics 2017, 5(2), 36; doi: 10.3390/inorganics5020036

Daniel Werner, Glen B. Deacon and Peter C. Junk

Potassium C-F Interactions and the Structural Consequences in N,N'-Bis(2,6-

difluorophenyl)formamidinate Complexes

Reprinted from: Inorganics 2017, 5(2), 26; doi: 10.3390/inorganics5020026

Dominik Naglav, Briac Tobey, Kevin Dzialkowski, Georg Jansen, Christoph Wölper and Stephan Schulz

Insights into Molecular Beryllium-Silicon Bonds

Reprinted from: Inorganics 2017, 5(2), 22; doi: 10.3390/inorganics5020022

Denis Vinduš and Mark Niemeyer

Hetero- and Homoleptic Magnesium Triazenides

Reprinted from: Inorganics 2017, 5(2), 33; doi: 10.3390/inorganics5020033 .105 
Christian P. Sindlinger, Samuel R. Lawrence, David B. Cordes, Alexandra M. Z. Slawin and Andreas Stasch

Methanediide Formation via Hydrogen Elimination in Magnesium versus Aluminium Hydride Complexes of a Sterically Demanding Bis(iminophosphoranyl)methanediide

Reprinted from: Inorganics 2017, 5(2), 29; doi: 10.3390/inorganics5020029

\section{Tim Seifert and Peter W. Roesky}

Alkali and Alkaline Earth Metal Complexes Ligated by an Ethynyl Substituted

Cyclopentadienyl Ligand

Reprinted from: Inorganics 2017, 5(2), 28; doi: 10.3390/inorganics5020028

\section{Sven Krieck and Matthias Westerhausen}

Kudos and Renaissance of s-Block Metal Chemistry

Reprinted from: Inorganics 2017, 5(1), 17; doi: 10.3390/inorganics5010017 


\section{About the Special Issue Editor}

Matthias Westerhausen obtained his diploma degree in chemistry in 1983 from the Philipps University in Marburg, Germany, and performed his Ph.D. thesis at the University of Stuttgart, Germany, under supervision of Professor Gerd Becker on acyl substituted phosphanes and arsanes. In 1987/88, he worked as a postdoctoral fellow with Professor Robert T. Paine at the University of New Mexico in Albuquerque/USA in the field of phosphanylboranes. Back at the University of Stuttgart, he finished his habilitation in the Institute of Inorganic Chemistry in December 1994 and received the venia legendi for Inorganic Chemistry in February 1995. From 1996 to 2004 he was professor at the Ludwig Maximilians University Munich where he was also vice-rector from 2001 to 2004 . Since 2004 he is teaching and researching at the Friedrich Schiller University Jena, Germany. 



\section{Preface to "s-Block Metal Complexes"}

The organic and coordination chemistry of the s-block metals experiences a vast and vivid development due to the need of strong and selective nucleophiles in industry and research. The most common reagents are organolithium and organomagnesium (Grignard) compounds that can easily be prepared or are commercially available. In order to adjust these highly reactive reagents to specific requirements, diverse concepts have been developed, based on the composition as homo- or heteroleptic complexes with homometallic or heterooligometallic centers.

The combination of different groups at one metal leads to heteroleptic and homometallic complexes such as the classic Grignard reagents R-Mg-X, Hauser bases R2N-Mg-X, and some lithium reagents like $\mathrm{RLi} \cdot \mathrm{LiX}$. The reactivity of these compounds does not only depend on $\mathrm{R}$ but is also influenced by the counter-ion $\mathrm{X}$ via aggregation-deaggregation and Schlenk equilibria. The formation of heterobimetallic compounds leads to reagents that show not only an additive combination of the reactivities of the homometallic species but the reaction patterns are often altered significantly. Fascinating strategies to produce more reactive metalating reagents are the addition of lithium halide and the synthesis of mixed metal amides forming macrocycles with monovalent (such as alkali metals) and divalent metals such as magnesium and zinc but also manganese. These macrocycles can act as hosts for deprotonated substrates referred to as "inverse crowns" by Mulvey and coworkers. These heterobimetallic compounds represent metalation reagents which often show a large reactivity with an unusual regioselectivity.

A further reactivity enhancement was achieved by combining both concepts, namely the use of heterobimetallic and heteroleptic reagents. Due to the enormous reactivity, they are often called superbases with the Lochmann-Schlosser base nBuLi-KOtBu as a well-known textbook example. A similar approach is also possible for alkali metal amides of the type [MI(NR2).KOtBu]n with MI being lithium and sodium. Generalization of this concept leads to Turbo-Hauser bases for the amides and TurboGrignard reagents for alkyl containing reagents of the types $\mathrm{R} 2 \mathrm{~N}-\mathrm{Mg}-\mathrm{X} \cdot \mathrm{Li}-\mathrm{X}$ and $\mathrm{R}-\mathrm{Mg}-\mathrm{X} \cdot \mathrm{Li}-\mathrm{X}$, respectively. Difficulties in the chemistry of these powerful metalating reagents arise from the fact that the mechanisms of the metalation reactions are much more complex and hard to predict because nearly no structural information is known about these compounds.

Another possibility to enhance the reactivity is the raise of the electronegativity difference between the s-block metal and the donor atoms of the nucleophiles. This can be realized by employing heavier sblock metals. the most attractive metals are the environmentally benign elements sodium, potassium, and calcium. In contrast to the use of these metals, beryllium is a highly toxic metal whose chemistry is strongly underdeveloped. This issue on s-block metal complexes cannot cover all aspects of this fascinating and exciting chemistry of strong nucleophiles but the articles illustrate selected facets in the field of s-block metal coordination chemistry.

Matthias Westerhausen

Special Issue Editor 

Article

\title{
[Bis(Trimethylsilyl)Methyl]Lithium and -Sodium: Solubility in Alkanes and Complexes with $\mathrm{O}$ - and $\mathrm{N}$ - Donor Ligands
}

\author{
Markus von Pilgrim, Mihail Mondeshki and Jan Klett* \\ Institut für Anorganische Chemie und Analytische Chemie, Johannes Gutenberg-Universität Mainz, \\ Duesbergweg 10-14, 55128 Mainz, Germany; pillipower@gmx.de (M.v.P.); mondeshk@uni-mainz.de (M.M.) \\ * Correspondence: klettj@uni-mainz.de; Tel.: +49-6131-25256
}

Academic Editor: Matthias Westerhausen

Received: 9 May 2017; Accepted: 6 June 2017; Published: 12 June 2017

\begin{abstract}
In contrast to alkyl compounds of lithium, which play an important role in organometallic chemistry, the corresponding heavier alkali metal compounds are less investigated. These compounds are mostly insoluble in inert solvents or undergo solvolysis in coordinating solvents due to their high reactivity. An exception from this typical behavior is demonstrated by bis(trimethylsilyl) methylsodium. This study examines alkane solutions of bis(trimethylsilyl)methyllithium and -sodium by NMR spectroscopic and cryoscopic methods. In addition, structural studies by X-ray crystallography of the corresponding compounds coordinated by $\mathrm{O}$ - and $\mathrm{N}$ - ligands (tetrahydrofuran and tetramethylethylenediamine) present possible structural motifs of the uncoordinated compounds in solution.
\end{abstract}

Keywords: lithium; sodium; alkali metals; organometallic; alkyl; NMR spectroscopy; X-ray diffraction; cryoscopy; aggregation

\section{Introduction}

Alkyl compounds of lithium play an important role in organometallic chemistry [1-5]. This group of compounds is therefore well investigated, which can also be attributed to their accessibility and solubility in a wide range of organic solvents. It was shown that the reactivity of lithium alkyl compounds depends on the degree of aggregation in solution [6]. However, the dependency between aggregation and reactivity is not trivial, as it was shown for complexes of alkyllithium coordinated by tetramethylethylenediamine (TMEDA) [7]. Corresponding heavier alkali metal compounds, despite their high reactivity, play a considerable less prominent role. The large majority of these compounds show a poor solubility in some inert solvents and a destructive reactivity in other coordinating solvents [8]. An exemption from this trend can be observed for alkali metal compounds of bis(trimethylsilyl)methane, which allow the formation and isolation of a wide range of organometallic compounds [9]. A reaction of bis(trimethylsilyl)methyllithium [ $\left.\mathrm{LiCH}\left(\mathrm{SiMe}_{3}\right)_{2}\right], \mathbf{1}$ [10], with sodium tert-butoxide [ $\mathrm{NaO} t \mathrm{Bu}$ ] produces bis(trimethylsilyl)methylsodium $\left[\mathrm{NaCH}\left(\mathrm{SiMe}_{3}\right)_{2}\right]$, 2, which is highly soluble in alkanes [11]. Another example of a soluble alkylsodium compound is 2-ethylhexylsodium, which was formed by direct synthesis and characterized in solution by ${ }^{1} \mathrm{H}$ and ${ }^{23} \mathrm{Na}-\mathrm{NMR}$ spectroscopy [12]. However, X-ray crystal structure determination of 2 showed polymeric chains of $\left[\mathrm{NaCH}\left(\mathrm{SiMe}_{3}\right)_{2}\right]_{\infty}$ in the solid state (Scheme 1 ). Compound $\mathbf{1}$ also forms polymeric chains in the solid state; the sublimed compound in the gas-phase was determined as monomeric by electron diffraction [10] (for CSD refcodes see Appendix A). The corresponding potassium compound $\left[\mathrm{KCH}\left(\mathrm{SiMe}_{3}\right)_{2}\right]$ is insoluble in alkanes, but it is possible to isolate its complexes with tetrahydrofuran (THF) [13], tert-butyl methyl ether ( $t$ BuOMe), and pentamethyldiethylenetriamine (PMDETA) [14] 
in crystalline form. X-ray diffraction revealed their structures as THF and $t \mathrm{BuOMe}$ coordinated chain-polymers $\left[\mathrm{THF}-\mathrm{KCH}\left(\mathrm{SiMe}_{3}\right)_{2}\right]_{\infty}$ and $\left[t \mathrm{BuOMe}-\mathrm{KCH}\left(\mathrm{SiMe}_{3}\right)_{2}\right]_{\infty}$, and as a PMDETA coordinated (half-open) tetramer [PMDETA-KCH( $\left.\left.\mathrm{SiMe}_{3}\right)_{2}\right]_{4}$-PMDETA].

It is unlikely that the polymeric structure of $\mathbf{1}$ or $\mathbf{2}$ is maintained in solution, so lower aggregates such as dimers, trimers, tetramers, or hexamers should be present. Similar observations were made for a range of other alkyllithium compounds in solution [15]. 1 also forms polymeric chains in solid state, but monomeric units are found in gas-phase [10]. Complexes formed by coordination of 1 with TMEDA or PMDETA were also isolated (1-TMEDA (1b) and 1-PMDETA), and the solid state structure of 1-PMDETA revealed monomeric units [16]. The understanding of the solution behavior of alkali metal alkyl compounds will allow insights into more complicated systems such as Lochmann-Schlosser superbases $[17,18]$. Recently, we reported the preparation of neopentyl potassium $\left[\mathrm{KCH}_{2} t \mathrm{Bu}\right]$, which small but existing solubility allowed us to identify corresponding mixed lithium/potassium neopentyl/tert-butoxide aggregates [19] with possible relevance for such superbasic systems. The similarities between $\mathbf{1}$ and $\mathbf{2}$ encouraged us to investigate both compounds in solution by a comparative study using NMR spectroscopic and cryoscopic methods, allowing a better understanding of why both $\mathbf{1}$ and $\mathbf{2}$ show such good solubility in non-coordinating alkanes. In addition, we examined THF and TMEDA complexes of both $\mathbf{1}$ and $\mathbf{2}$ to learn more about the structural motifs found both in the pure and the coordinated compounds.

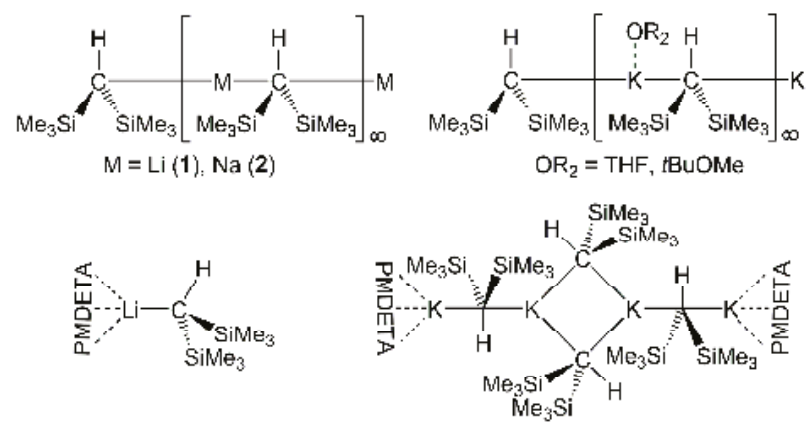

Scheme 1. Solid state structures of polymeric chains of compounds 1 [10], 2 [11] (top left), polymeric chains of $\mathrm{KCH}_{2}\left(\mathrm{SiMe}_{3}\right)_{2}-\mathrm{THF}$ and $\mathrm{KCH}_{2}\left(\mathrm{SiMe}_{3}\right)_{2}-(t \mathrm{BuOMe})$ [13] (top right), monomeric 1-PMDETA [16] (bottom left), and (half-open) tetrameric $\mathrm{KCH}_{2}\left(\mathrm{SiMe}_{3}\right)_{2}$-PMDETA [14] (bottom right).

\section{Results and Discussion}

\subsection{Bis(Trimethylsilyl)Methyllithium 1 and -Sodium 2 in Solution}

The preparation of alkyl compounds of heavier alkali metal compounds often follows a similar protocol. By mixing an alkoxide of the corresponding alkali metal with an alkyllithium compound in $n$-hexane, the immediately formed insoluble alkyl compound can be isolated by filtration [8]. The preparation for $\mathbf{2}$ stands out, because no precipitate is formed, and the alkyl sodium compound is isolated by crystallization at $-30{ }^{\circ} \mathrm{C}$ from hexane [11]. This unusual high solubility in the non-coordinating solvent should be caused by breaking of the polymeric chain found in solid state into more mobile molecular units. To obtain information about the molecular weight and aggregation degree of these molecular units, we tested solutions of $\mathbf{1}$ and $\mathbf{2}$ by cryoscopic and NMR-DOSY methods. Cryoscopic measurements under inert gas conditions were performed in cyclohexane, which combines minimal to non-existent Lewis basicity (and therefore no coordinating abilities) and a considerable high cryoscopic constant with a freezing point at a convenient temperature $\left(6.7^{\circ} \mathrm{C}\right)[20]$. This allows measurements with higher concentrations with comparatively high depression of the observed melting points (Table 1 and Table S1). The freezing point depression of 1 was measured 
only at one concentration $(0.04 \mathrm{~mol} / \mathrm{L})$ due to its low solubility in cyclohexane at this temperature. We observed a freezing point depression of 0.50 degrees, which corresponds to a molecular weight of $345 \mathrm{~g} / \mathrm{mol}$. This result points to the existence of dimeric units (open or ring-shaped dimers) in solution $(2 \times 166 \mathrm{~g} / \mathrm{mol}=332 \mathrm{~g} / \mathrm{mol}, \Delta \mathrm{M}=+3.7 \%)$. The comparable high solubility of 2 at $\sim 6{ }^{\circ} \mathrm{C}$ allowed us to study its solubility in cyclohexane in a range of concentrations $(0.021,0.041$, and $0.087 \mathrm{~mol} / \mathrm{L}$, see Table 1). The results at 0.021 and $0.041 \mathrm{~mol} / \mathrm{L}$ point to the existence of tetrameric units, while measurements at the higher concentrations of $0.087 \mathrm{~mol} / \mathrm{L}$ reveal higher molecular weights consistent with the presence of hexameric units. Cryoscopic measurements of trimethylsilylmethyllithium $\left[\mathrm{LiCH}_{2} \mathrm{SiMe}_{3}\right]$ in cyclohexane revealed a very similar behavior; depending on the concentration, it was possible to identify tetrameric or hexameric oligomers [15]. For geometric reasons, only even-numbered oligomers (dimer, tetramer, and hexamer) are considered. For tetramers and hexamers, the most likely arrangements are cages, such as face-capped tetra- or octahedrons. The basic elements of these cages are dimeric units, which can form higher oligomers following a principle called "ring-laddering" [21,22]. For this reason, the appearance of pentameric units is unlikely. However, the formation of ring-shaped trimers is possible but rarely observed for unsolvated organolithium compounds and more commonly for secondary lithium amides [23].

Table 1. Results of cryoscopic measurements of compounds $\mathbf{1}$ and $\mathbf{2}$ in cyclohexane. M(1-monomer) $166.34 \mathrm{~g} / \mathrm{mol}$; M(1-dimer) $332.68 \mathrm{~g} / \mathrm{mol}$; M(2-monomer) $182.39 \mathrm{~g} / \mathrm{mol}$; M(2-dimer) $364.76 \mathrm{~g} / \mathrm{mol}$; $\mathrm{M}(2$-tetramer) $729.52 \mathrm{~g} / \mathrm{mol} ; \mathrm{M}(2$-hexamer $) 1094.28 \mathrm{~g} / \mathrm{mol}$. Values of $\Delta \mathrm{T}[\mathrm{K}]$ are relative to the melting point of cyclohexane at $6.72{ }^{\circ} \mathrm{C}$, which was determined as a reference before each experiment.

\begin{tabular}{cccccc}
\hline Entry & Concentration $(\mathbf{m o l} / \mathbf{L})$ & $\Delta \mathbf{T}(\mathbf{K})$ & $\mathbf{M}($ Exp) $(\mathrm{g} / \mathrm{mol})$ & $\mathbf{M}$ (Oligomer) $(\mathrm{g} / \mathrm{mol})$ & $\Delta \mathbf{M}$ \\
\hline $\mathrm{Li}-1$ & 0.040 & -0.50 & 345 & 332.68 (1-dimer) & $+3.7 \%$ \\
$\mathrm{Na}-1$ & 0.021 & -0.12 & 804 & 729.52 (2-tetramer) & $+10.2 \%$ \\
$\mathrm{Na}-2$ & 0.041 & -0.29 & 663 & 729.52 (2-tetramer) & $-9.1 \%$ \\
$\mathrm{Na}-3$ & 0.087 & -0.35 & 1175 & 1094.28 (2-hexamer) & $+7.4 \%$ \\
$\mathrm{Na}-4$ & 0.087 & -0.37 & 1098 & 1094.28 (2-hexamer) & $+0.3 \%$ \\
\hline
\end{tabular}

Additionally, we studied solutions of $\mathbf{1}$ and 2 by NMR spectroscopy (Figures S1-S21). Measurements in solvents with different coordinating abilities can reveal influences on the corresponding aggregation behavior [24]. However, the results obtained by ${ }^{1} \mathrm{H},{ }^{13} \mathrm{C}$, ${ }^{29} \mathrm{Si}$, and ${ }^{7} \mathrm{Li} \mathrm{NMR}$ spectroscopy in deuterated benzene $\left[\mathrm{C}_{6} \mathrm{D}_{6}\right]$, deuterated tetrahydrofuran [D8]THF, and deuterated cyclohexane $\left[\mathrm{C}_{6} \mathrm{D}_{12}\right]$ did not reveal significant differences such as changes in chemical shifts or splitting of signals (Table 2).

Table 2. ${ }^{1} \mathrm{H},{ }^{13} \mathrm{C},{ }^{29} \mathrm{Si}$, and ${ }^{7} \mathrm{Li}$ NMR spectroscopic data of compounds $\mathbf{1}$ and 2 dissolved in $\mathrm{C}_{6} \mathrm{D}_{6}$, [D8]THF, and $\mathrm{C}_{6} \mathrm{D}_{12}$. The chemical shifts are given in ppm.

\begin{tabular}{ccccccc}
\hline \multirow{2}{*}{ Compound in Solvent } & \multicolumn{2}{c}{${ }^{\mathbf{1}} \mathbf{H}$} & \multicolumn{2}{c}{${ }^{{ }^{13} \mathbf{C}}$} & ${ }^{{ }^{29} \mathbf{S i}}$ & \multirow{2}{*}{$\mathbf{L i}$} \\
\cline { 2 - 6 } & $\mathbf{S i M e}_{3}$ & $\mathbf{C H}_{\mathbf{2}}$ & $\mathbf{S i M e}_{3}$ & $\mathbf{C H}_{\mathbf{2}}$ & $\mathbf{S i M e}_{3}$ & \\
\hline $\mathbf{1}$ in $\mathrm{C}_{6} \mathrm{D}_{6}$ & 0.15 & -2.52 & 5.1 & 2.4 & -6.6 & 2.2 \\
$\mathbf{1}$ in [D8]THF & -0.14 & -2.26 & 6.6 & 0.4 & -8.3 & 1.0 \\
$\mathbf{1}$ in $\mathrm{C}_{6} \mathrm{D}_{12}$ & 0.05 & -2.29 & 4.8 & 3.4 & -7.9 & 3.6 \\
$\mathbf{2}$ in $\mathrm{C}_{6} \mathrm{D}_{6}[11]$ & 0.20 & -2.04 & 7.0 & 0.4 & 12.4 & - \\
$\mathbf{2}$ in $\mathrm{C}_{6} \mathrm{D}_{6}$ & 0.22 & -2.01 & 7.0 & 0.0 & -11.8 & - \\
$\mathbf{2}$ in $[\mathrm{D} 8] \mathrm{THF}$ & -0.16 & -2.09 & 6.9 & -0.4 & -11.3 & - \\
$\mathbf{2}$ in $\mathrm{C}_{6} \mathrm{D}_{12}$ & 0.04 & -2.08 & 7.1 & -0.1 & -12.1 & - \\
\hline
\end{tabular}

To obtain additional information about the degree of aggregation in non-coordinating solvents parallel to the results obtained by cryoscopic measurements (see above), we carried out ${ }^{1} \mathrm{H}$ diffusion ordered spectroscopy (DOSY) NMR [25] at $21{ }^{\circ} \mathrm{C}$ to study the oligomer formation as a function of the concentration (Table 3 ) in deuterated cyclohexane $\left[\mathrm{C}_{6} \mathrm{D}_{12}\right]$ solutions of two organometallic compounds $\mathbf{1}\left[\mathrm{LiCH}\left(\mathrm{SiMe}_{3}\right)_{2}\right]$ and $\mathbf{2}\left[\mathrm{NaCH}\left(\mathrm{SiMe}_{3}\right)_{2}\right]$. Considering the basic properties 
of the compounds, inert tetrakis(trimethylsilyl)silane $\left[\mathrm{Si}\left(\mathrm{SiMe}_{3}\right)_{4}\right]$ at the same concentration as the investigated compounds for all samples was chosen as a reference. The $D$ values $\left(\mathrm{m}^{2} / \mathrm{s}\right)$ were acquired from the diffusion analyses, and the respective hydrodynamic radii were calculated using the Stokes-Einstein equation: $D=\left(k_{B} T\right) /\left(6 \pi \eta r_{\mathrm{H}}\right)$ where $k_{\mathrm{B}}$ is the Boltzmann constant, $\eta[\mathrm{kg} /(\mathrm{s} \cdot \mathrm{m})]$ is the viscosity of the solvent at the respective temperature $T(\mathrm{~K})$ and $r_{\mathrm{H}}$ the hydrodynamic radius in $\mathrm{nm}$ (for a spherical particle).

Table 3. Diffusion coefficients and calculated hydrodynamic radii for compounds $\mathbf{1}$ and $\mathbf{2}$ obtained from the ${ }^{1} \mathrm{H}$ DOSY NMR experiments in deuterated cyclohexane $\mathrm{C}_{6} \mathrm{D}_{12}$. Tetrakis(trimethylsilyl)silane $\mathrm{Si}\left(\mathrm{SiMe}_{3}\right)_{4}$ was used as a reference.

\begin{tabular}{|c|c|c|c|c|c|}
\hline Compound & Conc $(\mathrm{mol} / \mathrm{L})$ & $D\left(10^{-10} \mathrm{~m}^{2} / \mathrm{s}\right)$ & $r_{\mathrm{H}}(\mathrm{nm})$ & $D\left[\mathrm{Si}\left(\mathrm{SiMe}_{3}\right)_{4}\right]\left(10^{-10} \mathrm{~m}^{2} / \mathrm{s}\right)$ & $r_{\mathrm{H}}\left[\mathrm{Si}\left(\mathrm{SiMe}_{3}\right)_{4}\right](\mathrm{nm})$ \\
\hline 1 & 0.08 & 6.258 & 0.33 & 5.828 & 0.35 \\
\hline 1 & 0.19 & 6.020 & 0.34 & 5.781 & 0.36 \\
\hline 1 & $<0.3^{1}$ & 5.243 & 0.39 & 5.998 & 0.34 \\
\hline 2 & 0.1 & 2.877 & 0.72 & 6.295 & 0.33 \\
\hline 2 & 0.2 & 2.355 & 0.88 & 5.959 & 0.35 \\
\hline 2 & $<0.3^{1}$ & 1.920 & 1.10 & 5.454 & 0.38 \\
\hline
\end{tabular}

Increasing the concentration of the solutions for both investigated compounds leads to a slight increase in the calculated value for the hydrodynamic radius of the reference $\mathrm{Si}\left(\mathrm{SiMe}_{3}\right)_{4}$ (on average $0.35 \mathrm{~nm}$ ), which is related to a somewhat slower diffusion (Figure 1). This variation is, however, minimal and probably due to more contact with other molecules in the solution at higher concentrations. In the solution of 2 with a $0.1 \mathrm{~mol} / \mathrm{L}$ concentration, the hydrodynamic radius is determined to be approximately twice as high compared to $\mathrm{Si}\left(\mathrm{SiMe}_{3}\right)_{4}(0.72 \mathrm{~nm}$ versus ca. $0.35 \mathrm{~nm})$. This fact most probably reflects the formation of a tetramer, especially considering the difference in the molecular masses $\left(182.39 \mathrm{~g} / \mathrm{mol}\right.$ for the base compared to $320.84 \mathrm{~g} / \mathrm{mol}$ for Si$\left.\left(\mathrm{SiMe}_{3}\right)_{4}\right)$. Further stepwise increase of the solute concentration in $0.1 \mathrm{~mol} / \mathrm{L}$ steps (until saturation) results in slower diffusion, resp. noticeably higher $r_{\mathrm{H}}$ values for 2 . This we attribute to the formation of higher oligomers. It should be considered that the formation and dissociation of such complexes is fast on the NMR timescale, and the measured diffusion coefficients and the corresponding calculated hydrodynamic radii represent a weighted average of the present species in the mixture. Thus, we conclude that at a concentration of $0.2 \mathrm{~mol} / \mathrm{L}$ of $\mathrm{NaCH}\left(\mathrm{SiMe}_{3}\right)_{2}$, the maximum in the distribution of the formed oligomeric complexes is around 5 aggregated monomer units (a mixture of tetramers and hexamers), which corresponds to an average hydrodynamic radius of $0.88 \mathrm{~nm}$. A further increase in the concentration leads to a shift of this maximum to about $1.10 \mathrm{~nm}$, which is related to a predominant hexamer formation. 


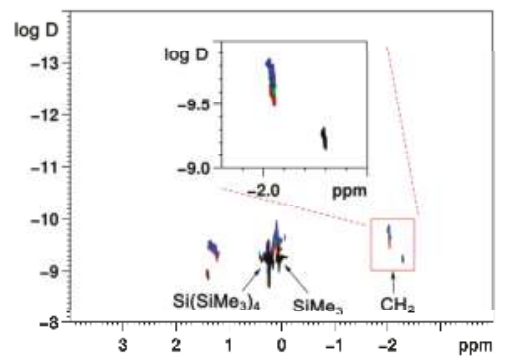

Figure 1. ${ }^{1} \mathrm{H}$ DOSY spectra of $\left(\mathrm{NaCH}\left(\mathrm{SiMe}_{3}\right)_{2}, 2,0.1 \mathrm{~mol} / \mathrm{L}\right.$ - green, $0.2 \mathrm{~mol} / \mathrm{L}$-red, $0.3 \mathrm{~mol} / \mathrm{L}$-blue and $\mathrm{LiCH}\left(\mathrm{SiMe}_{3}\right)_{2}, \mathbf{1}, 0.079 \mathrm{~mol} / \mathrm{L}$-black) with the $\mathrm{CH}$ region magnified. Increasing the concentration of $\mathbf{1}$ (only the $0.079 \mathrm{~mol} / \mathrm{L}$ concentration spectrum presented) hardly influences the diffusion behavior of $\mathbf{1}$ as dimers are presumably formed in the solution. The constant change of the diffusion coefficient of $\mathbf{2}$ as a function of the concentration reflects the formation and growth of higher aggregates.

In a parallel study, such a concentration-dependent complex growth was not detected for the solutions of 1 . At all measured concentrations, comparable $D$ and $r_{\mathrm{H}}$ values for the organometallic base and the $\mathrm{Si}\left(\mathrm{SiMe}_{3}\right)_{4}$ reference were observed (Table 3). Taking into account the molecular masses of both compounds $\left(166.34 \mathrm{~g} / \mathrm{mol}\right.$ for the $\mathrm{LiCH}\left(\mathrm{SiMe}_{3}\right)_{2}$ and $320.84 \mathrm{~g} / \mathrm{mol}$ for $\left.\mathrm{Si}\left(\mathrm{SiMe}_{3}\right)_{4}\right)$ as well as comparing with the hydrodynamic radii calculated for 2 , we conclude that a dimer is predominantly stabilized in all solutions of 1 with a corresponding $r_{\mathrm{H}}$ of $0.34 \mathrm{~nm}$. The slightly higher $r_{\mathrm{H}}$ value measured at saturation $(0.39 \mathrm{~nm})$ is most probably related to the sole amount of solute rather than with the formation of higher complexes, which, however, cannot be completely excluded. Thus, the NMR results are in good agreement with the cryoscopy measurements (Figure 2). The discrepancy between the cryoscopy and DOSY results for the concentrations of $\mathbf{2}$ resulting in hexamers can be attributed to temperature-dependent tendencies to form higher aggregates. The formation of higher aggregates of $\mathbf{2}$ seems to be thermodynamically favored, but at higher temperatures the lower aggregates are favored by entropy. 


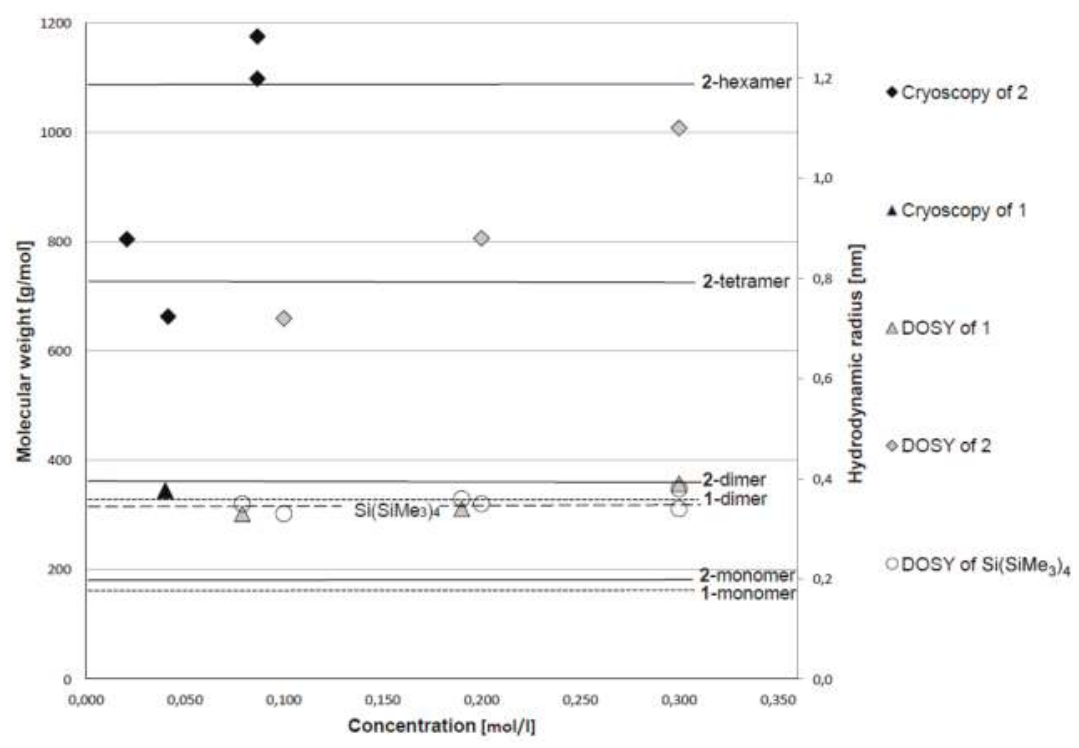

Figure 2. Graphical representation of the results of cryoscopic (at $6^{\circ} \mathrm{C}$ ) and NMR DOSY measurements (at $21^{\circ} \mathrm{C}$ ). Values for cryoscopic measurements in $[\mathrm{g} / \mathrm{mol}]$ for the molecular weight (left ordinate); the molecular weights of monomers / oligomers of $\mathbf{1}, \mathbf{2}$, and $\mathrm{Si}\left(\mathrm{SiMe}_{3}\right)_{4}$ are represented as horizontal lines (1: dotted line; 2: solid line; $\mathrm{Si}\left(\mathrm{SiMe}_{3}\right)_{4}$, only monomeric: dashed line). Values for NMR DOSY measurements in [nm] for the hydrodynamic radius (right ordinate). Results for compound 1 shown as triangles (full: cryoscopy; open: DOSY); for compound $\mathbf{2}$ shown as diamonds (full: cryoscopy; open: DOSY). Values for DOSY measurements of reference compound $\mathrm{Si}\left(\mathrm{SiMe}_{3}\right)_{4}$ are added as open circles; the right ordinate is scaled to fit the corresponding hydrodynamic radius of $0.35 \mathrm{~nm}$ to the height of the molecular weight of $\mathrm{Si}\left(\mathrm{SiMe}_{3}\right)_{4}$ with $320.84 \mathrm{~g} / \mathrm{mol}$.

\subsection{Formation of Complexes of Compounds $\mathbf{1}$ and $\mathbf{2}$ with $\mathrm{O}$ - and $\mathrm{N}$-Donors}

In order to obtain more data about possible structural motifs of $\mathbf{1}$ and $\mathbf{2}$ existing in solution, we studied complexes of $\mathbf{1}$ and $\mathbf{2}$ with THF or TMEDA in the solid state (Scheme 2). The metal atom of the alkali metal alkyl compound interacts with the carbon atoms through electron-deficient 2-electron-3-(or more)-center bonds. This makes the electrophile metal atom very susceptible to interactions with Lewis-basic ligands. The obtained structures may show structural motifs with relevance to monomeric, dimeric, or tetrameric units, due to the increased steric saturation of the coordination sphere of the metal atoms. At the same time, several possible coordination modes corresponding to metal atoms, such as linear bridging, angular bridging, or terminal coordination of the bis(trimethylsilyl)methyl groups (or metal atoms) can be studied. 


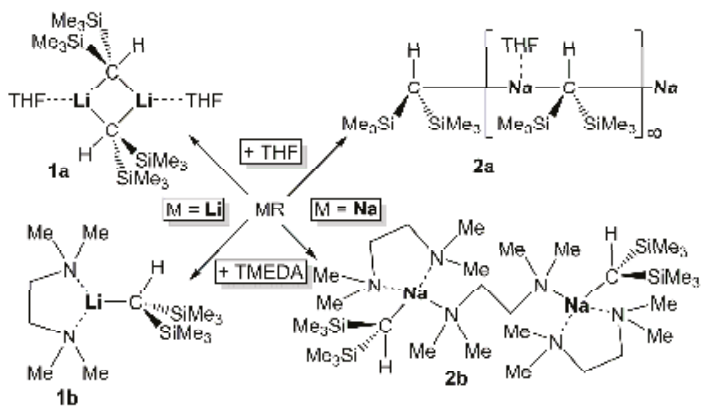

Scheme 2. Formation of compounds $\mathbf{1} \mathbf{a}, \mathbf{b}$ and $\mathbf{2} \mathbf{a}, \mathbf{b}$ by adding THF or TMEDA to solutions of the corresponding compounds $\mathbf{1}$ or $\mathbf{2}$ in $n$-hexane.

Treatment of solutions of $\mathbf{1}$ or $\mathbf{2}$ in $n$-hexane at RT with THF or TMEDA in equimolar amounts (1) $)$ or excess (1a, 2a,b) produces clear solutions, from which colorless crystals can be obtained (1a at RT, 1b at $5{ }^{\circ} \mathrm{C}, \mathbf{2} \mathbf{a}, \mathbf{b}$ at $-20{ }^{\circ} \mathrm{C}$ ) with moderate to low yields (1a: $52 \% ; \mathbf{1 b}: 34 \% ; \mathbf{2 a}: 17 \%, \mathbf{2 b}:<5 \%$ ). The absence of decomposition (ether cleavage) in the case of the mixture of $\mathbf{1}$ and $\mathbf{2}$ with THF demonstrates the low reactivity of these bis(trimethylsilyl)methyl compounds towards THF in contrast to other lithium compounds such as neopentyllithium [24] or $t$-butyllithium [26]. Crystals of compound $\mathbf{2 b}$ easily decomposed or melted at RT. Lappert et al. already described and characterized solutions of compound $\mathbf{1 b}$ in cyclohexane as monomeric units [16]. However, a solid state structure was not reported.

\subsection{NMR-Spectroscopy of Complexes of Compounds $\mathbf{1}$ and $\mathbf{2}$ with $\mathrm{O}$ - and $\mathrm{N}$-Donors}

The thermal stability and good solubility of compounds $\mathbf{1} \mathbf{a}, \mathbf{b}$ and $\mathbf{2} \mathbf{a}, \mathbf{b}$ allowed their characterization by NMR spectroscopy. To avoid any undesired metalation reactions or secondary coordination, the ${ }^{1} \mathrm{H},{ }^{13} \mathrm{C},{ }^{29} \mathrm{Si}$, and ${ }^{7} \mathrm{Li} \mathrm{NMR}$ spectra were recorded in deuterated cyclohexane $\left[\mathrm{C}_{6} \mathrm{D}_{12}\right]$ (Table 4 , Figures S22-S35).

Table 4. ${ }^{1} \mathrm{H},{ }^{13} \mathrm{C},{ }^{29} \mathrm{Si}$, and ${ }^{7} \mathrm{Li}$ NMR spectroscopic data of compounds $\mathbf{1 a}, \mathbf{b}$ and $\mathbf{2} \mathbf{a}, \mathbf{b}$ dissolved in $\mathrm{C}_{6} \mathrm{D}_{12}$. The corresponding data of compounds $\mathbf{1}$ and $\mathbf{2}$ are added for comparison. The ligand is THF or TMEDA, respectively. The chemical shifts are given in ppm.

\begin{tabular}{|c|c|c|c|c|c|c|c|c|}
\hline \multirow{2}{*}{ Compound } & \multicolumn{3}{|c|}{${ }^{1} \mathbf{H}$} & \multicolumn{3}{|c|}{${ }^{13} \mathrm{C}$} & \multirow{2}{*}{$\begin{array}{c}{ }^{29} \mathrm{Si} \\
\mathrm{SiMe}_{3}\end{array}$} & \multirow{2}{*}{${ }^{7} \mathrm{Li}$} \\
\hline & $\mathrm{SiMe}_{3}$ & $\mathrm{CH}_{2}$ & Ligand & $\mathrm{SiMe}_{3}$ & $\mathrm{CH}_{2}$ & Ligand & & \\
\hline 1 & 0.05 & -2.29 & - & 4.8 & 3.4 & - & -6.6 & 3.6 \\
\hline 1a & -0.02 & -2.39 & $\begin{array}{l}1.89\left(\beta-\mathrm{CH}_{2}\right) \\
3.88\left(\alpha-\mathrm{CH}_{2}\right)\end{array}$ & 5.7 & 2.0 & $\begin{array}{l}26.1\left(\beta-\mathrm{CH}_{2}\right) \\
69.2\left(\alpha-\mathrm{CH}_{2}\right)\end{array}$ & -6.0 & 2.9 \\
\hline $1 b$ & -0.10 & -2.05 & $\begin{array}{c}2.30(\mathrm{Me}) \\
2.37\left(\mathrm{CH}_{2}\right)\end{array}$ & 6.4 & 2.3 & $\begin{array}{c}45.9(\mathrm{Me}) \\
57.3\left(\mathrm{CH}_{2}\right)\end{array}$ & -7.9 & 3.1 \\
\hline 2 & 0.04 & -2.08 & - & 7.1 & -0.1 & - & -12.1 & - \\
\hline $2 a$ & 0.00 & -2.28 & $\begin{array}{l}1.83\left(\beta-\mathrm{CH}_{2}\right) \\
3.76\left(\alpha-\mathrm{CH}_{2}\right)\end{array}$ & 6.7 & 1.1 & $\begin{array}{l}27.0\left(\beta-\mathrm{CH}_{2}\right) \\
68.7\left(\alpha-\mathrm{CH}_{2}\right)\end{array}$ & -10.1 & - \\
\hline $2 b$ & -0.08 & -2.04 & $\begin{array}{c}2.25(\mathrm{Me}) \\
2.34\left(\mathrm{CH}_{2}\right)\end{array}$ & 6.7 & 1.0 & $\begin{array}{c}46.2(\mathrm{Me}) \\
58.0\left(\mathrm{CH}_{2}\right)\end{array}$ & -8.5 & - \\
\hline
\end{tabular}

The signal integrals in the ${ }^{1} \mathrm{H}$ NMR spectra of all four ligand-coordinated compounds $\mathbf{1 a , b}$ and $\mathbf{2 a}, \mathbf{b}$ indicate corresponding equimolar ratios of the bis(trimethylsilyl)methyl compound to the coordinating ligand close to 1:1. The evacuation during the preparation of the NMR samples did not lead to the total loss of THF or TMEDA, which confirms the readiness of the metal atoms to accept additional interactions with such donor molecules. 


\subsection{X-ray Crystallographic Measurements of Compounds $\mathbf{1} \boldsymbol{a}, \boldsymbol{b}$ and $\mathbf{2} \boldsymbol{a}, \boldsymbol{b}$}

All four compounds $\mathbf{1} \mathbf{a}, \mathbf{b}$ and $\mathbf{2} \mathbf{a}, \mathbf{b}$ crystallized in the same monoclinic space group (Table 5, Figures S36-S39). The thermal instability of single crystals of compounds $\mathbf{1} \mathbf{b}$ and $\mathbf{2} \mathbf{b}$ required sample preparation for X-ray crystallography at low temperatures [27]. The THF or TMEDA groups showed significant positional disorder in compounds $\mathbf{1 a}(0.53 / 0.47), \mathbf{1 b}(0.68 / 0.32$ and $0.75 / 0.25)$, and $\mathbf{2 b}$ $(0.78 / 0.22)[16]$. In compound $\mathbf{1 b}$, one trimethylsilyl group displayed rotational disorder $(0.5 / 0.5)$. In all four compounds, it was possible to locate the hydrogen atom of the metal bound $\mathrm{CH}$-group.

Table 5. Selected crystallographic data for compounds $\mathbf{1 a}, \mathbf{1 b}, \mathbf{2} \mathbf{a}$ and $\mathbf{2} \mathbf{b}^{[\mathrm{a}]}$.

\begin{tabular}{|c|c|c|c|c|}
\hline Compound & $1 \mathbf{a}$ & $1 b$ & $2 a$ & $2 b$ \\
\hline Formula & $\mathrm{C}_{11} \mathrm{H}_{27} \mathrm{LiOSi}_{2}$ & $\mathrm{C}_{13} \mathrm{H}_{35} \mathrm{LiN}_{2} \mathrm{Si}_{2}$ & $\mathrm{C}_{11} \mathrm{H}_{27} \mathrm{NaOSi}_{2}$ & $\mathrm{C}_{16} \mathrm{H}_{43} \mathrm{NaN}_{3} \mathrm{Si}_{2}$ \\
\hline $\mathrm{M}_{r}\left(\mathrm{~g} \cdot \mathrm{mol}^{-1}\right)$ & 238.44 & 282.55 & 254.49 & 713.39 \\
\hline Crystal system & monoclinic & monoclinic & monoclinic & monoclinic \\
\hline Space group & $P 2_{1} / n$ & $P 2_{1} / c$ & $P 2_{1} / n$ & $P 2_{1} / n$ \\
\hline$a(\AA)$ & $9.4930(9)$ & $18.7636(8)$ & $11.3470(19)$ & $10.450(4)$ \\
\hline$b(\AA)$ & $9.9165(9)$ & $13.2303(5)$ & $9.7379(17)$ & $17.414(6)$ \\
\hline$c(\AA)$ & $16.7191(14)$ & $17.7299(7)$ & $14.622(2)$ & $14.258(5)$ \\
\hline$\alpha\left({ }^{\circ}\right)$ & 90 & 90 & 90 & 90 \\
\hline$\beta\left(^{\circ}\right)$ & $92.527(2)$ & $112.040(2)$ & $90.876(5)$ & $100.824(9)$ \\
\hline$\gamma\left({ }^{\circ}\right)$ & 90 & 90 & 90 & 90 \\
\hline$V\left(\AA^{3}\right)$ & $1572.4(3)$ & $4079.8(3)$ & $1615.5(5)$ & $2548.5(16)$ \\
\hline $\mathrm{Z}$ & 4 & 8 & 4 & 6 \\
\hline$\rho_{\text {calcd }}\left(\mathrm{g} \cdot \mathrm{cm}^{-3}\right)$ & 1.007 & 0.920 & 1.046 & 0.930 \\
\hline$\mu(\mathrm{Mo} \mathrm{K \alpha})\left(\mathrm{mm}^{-1}\right)$ & 0.203 & 0.163 & 0.226 & 0.158 \\
\hline$T(\mathrm{~K})$ & 173 & 173 & 173 & 173 \\
\hline measured refl. [b] & 51,345 & 51,744 & 17,850 & 37,556 \\
\hline independent refl. & 3766 & 9687 & 3904 & 6057 \\
\hline refined parameters & 192 & 183 & 141 & 236 \\
\hline$R 1^{[\mathrm{c}]}$ & 0.0320 & 0.0449 & 0.0690 & 0.0441 \\
\hline$R 1$, all data & 0.0428 & 0.1013 & 0.1539 & 0.0932 \\
\hline$w R 2[\mathrm{~d}]$ & 0.0898 & 0.0964 & 0.1572 & 0.1034 \\
\hline$w R 2$, all data & 0.0964 & 0.1112 & 0.1894 & 0.1196 \\
\hline $\max , \min$ peaks $\left(e \AA^{-3}\right)$ & $0.369,-0.161$ & $0.270,-0.187$ & $0.910,-0.510$ & $0.265,-0.203$ \\
\hline CCDC numbers [28] & $1,548,189$ & $1,548,191$ & $1,548,190$ & $15,481,892$ \\
\hline
\end{tabular}

[a] All data were collected using Mo $K \alpha$ radiation $\left(\lambda=0.71073 \AA\right.$ ). ${ }^{[b]}$ Observation criterion: $I>2 \sigma(I)$. ${ }^{[\mathrm{c}]} R 1=\Sigma|| F_{o}|-| F_{c}|| / \Sigma\left|F_{o}\right|{ }^{[\mathrm{d}]} w R 2=\left\{\Sigma\left[w\left(F_{o}{ }^{2}-F_{c}{ }^{2}\right)^{2}\right] / \Sigma\left[w\left(F_{o}{ }^{2}\right)^{2}\right]\right\}^{1 / 2}$.

Compound 1a (Figure 3) is a dimer formed by two THF-coordinated 1-units (Table 6). The central motif is a planar $\mathrm{Li}_{2} \mathrm{C}_{2}$ ring with crystallographic inversion symmetry. This motif is similar to the THF-coordinated lithium bis(trimethylsilyl)amide, where the bis(trimethylsilyl)methyl group is replaced by the isoelectronic bis(trimethylsilyl)amide [29]. The $\mathrm{Li}_{2} \mathrm{C}_{2}$ ring has one shorter (2.204(2) $\AA$ ) and one longer (2.274(3) $\AA$ ) $\mathrm{Li}-\mathrm{C}$ bond, and the $\mathrm{C}-\mathrm{Li}-\mathrm{C}$ angle $\left(115.36(10)^{\circ}\right)$ is far wider than the corresponding $\mathrm{Li}-\mathrm{C}-\mathrm{Li}$ angle $\left(64.64(10)^{\circ}\right)$. The trigonal pyramidal bis(trimethylsilyl)methyl unit (sum of the $\mathrm{Si}-\mathrm{C}-\mathrm{Si}$ and two $\mathrm{H}-\mathrm{C}-\mathrm{Si}$ angles: $327.2^{\circ}$ ) leads to an orientation of both trimethylsilyl groups above and below, and the corresponding hydrogen atom roughly in the plane of the central $\mathrm{Li}_{2} \mathrm{C}_{2}$ ring. The lithium atom with a coordination number of $\mathrm{CN}=3$ shows an additional coordination of the oxygen atom of the THF group (Li-O 1.953(8) $\AA$ ), leading to an approximate trigonal planar arrangement $\left(\mathrm{C}-\mathrm{Li}-\mathrm{O} 137.4(7)^{\circ}\right.$ and $\left.110.5(6)^{\circ}\right)$. 


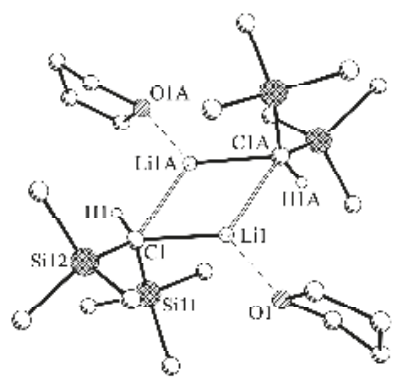

Figure 3. Molecular structure of $\mathrm{LiCH}\left(\mathrm{SiMe}_{3}\right)_{2}-\mathrm{THF}$, 1a. Selected hydrogen atoms and disordered units of minor occupancy are omitted for clarity. Symmetry operator A: $-x,-y$ and $-z$.

Table 6. Selected bond lengths $(\AA)$ and angles $\left(^{\circ}\right)$ of compounds $\mathbf{1 a}, \mathbf{b}$ and $\mathbf{2 a}, \mathbf{b}$.

\begin{tabular}{ccccc}
\hline Compound & $\mathbf{1 a} \mathbf{( M =} \mathbf{L i})$ & $\mathbf{1 b} \mathbf{( M = \mathbf { ~ } \mathbf { ) }}$ & $\mathbf{2 a} \mathbf{( M = \mathbf { N a } )}$ & $\mathbf{2 b} \mathbf{( M = \mathbf { N a } )}$ \\
\hline M1-C1 & $2.204(2)$ & $2.070(3) / 2.083(3)$ & $2.778(4)$ & $2.520(2)$ \\
M1-C1A & $2.274(3)$ & - & $2.657(4)$ & - \\
M1-O1 & $1.953(8)$ & - & $2.375(3)$ & - \\
M1-N21 & - & - & - & $2.559(2)$ \\
M1-N22 & - & - & - & $2.569(2)$ \\
M1-N31 & - & $2.054(6) / 2.133(7)$ & - & $2.635(2)$ \\
M1-N32 & - & $2.071(9) / 2.061(9)$ & - & - \\
C1-Si11 & $1.835(2)$ & $1.809(2) / 1.813(2)$ & $1.809(5)$ & $1.808(2)$ \\
C1-Si12 & $1.838(2)$ & $1.807(2) / 1.803(2)$ & $1.800(5)$ & $1.808(2)$ \\
M1-M1A & $2.395(4)$ & - & - & - \\
M1-H1 & 2.81 & $2.30 / 2.43$ & $2.68 / 2.70$ & 2.71 \\
M1-C1-M1A & $64.64(10)$ & - & $159.30(18)$ & - \\
C1-M1-C1A & $115.36(10)$ & - & $130.74(6)$ & - \\
C1-M1-O1 & $137.4(7)$ & - & $129.93(13)$ & - \\
C1A-M1-O1 & $110.5(6)$ & - & $99.33(13)$ & - \\
Si11-C1-Si12 & $117.06(7)$ & $123.25(10) / 122.48(11)$ & $127.9(3)$ & 120.91 \\
ECHSi & 327.2 & $341.1 / 341.0$ & 359.3 & 336.0 \\
\hline
\end{tabular}

X-ray crystallography as well as NMR spectroscopy revealed compound $\mathbf{1 b}$ (Figure 4) as a monomeric TMEDA-coordinated bis(trimethylsilyl)methyllithium with one TMEDA molecule per lithium atom, similar to the corresponding monomeric complex 1-PMDETA [16]. Two crystallographically independent units are found in the monoclinic cell. The distance between the lithium atoms (both with a coordination number of $\mathrm{CN}=3$ ) and the carbon of the central carbon atom of the bis(trimethylsilyl)methyl group $\mathrm{Li}-\mathrm{C}$ is 2.070(3)/2.083(3) $\AA$ shorter than the corresponding distances in polymeric 1 (2.14 to $2.22 \AA$ ) [10] or dimeric 1a (2.204(2) A). On the other hand, the Li-C distance for evaporated 1 determined by gas-phase electron diffraction is with $2.03 \AA$ shorter [10]; in monomeric 1-PMDETA, the Li-C distance is $2.14 \AA$ [16]. The similar results for both monomeric $\mathbf{1 b}$ (1-TMEDA) and 1-PMDETA with a considerable difference in the steric demand of the corresponding ligand demonstrate the spacial flexibility of the bis(trimethylsilyl)methyl group, which makes it such a useful ligand in the formation of otherwise inaccessible metal compounds. 


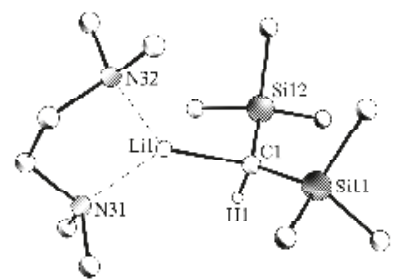

Figure 4. Molecular structure of $\mathrm{LiCH}\left(\mathrm{SiMe}_{3}\right)_{2}$-TMEDA, 1b; only one of the two independent molecules in the asymmetric unit is shown. Selected hydrogen atoms and disordered units of minor occupancy are omitted for clarity.

This difference between short $\mathrm{Li}-\mathrm{C}$ distances for monomeric units and longer $\mathrm{Li}-\mathrm{C}$ distances in oligomers can be explained by the existence of two-center two-electron bonds for the monomeric compounds, while the bonds in oligomeric and polymeric compounds should be based on three-center two-electron bonds (linear or bent). Due to the one-sided interaction of the lithium with the bis(trimethylsilyl)methyl group, the $\left(\mathrm{Me}_{3} \mathrm{Si}\right)_{2} \mathrm{CH}$ unit shows a trigonal pyramidal arrangement of the trimethylsilyl groups and the hydrogen atom $\left(\mathrm{Si}-\mathrm{C}-\mathrm{Si} 123.25(10)^{\circ}\right.$ and $122.48(11)^{\circ}$; the sum of the Si-C-Si and two H-C-Si angles: $341.1^{\circ}$ and $\left.341.0^{\circ}\right)$. The two nitrogen atoms of the TMEDA coordinate the lithium atom ( $\mathrm{Li}-\mathrm{N} 2.054(6)$ and 2.071(9) $\AA$; 2.133(7) and 2.061(9) $\AA$ ) with an N-Li-N bite angle of $88.8(2)^{\circ}$ and $87.2(2)^{\circ}$.

According to X-ray crystallographic data the sodium compound 2a (Figure 5) organizes in the solid state as a polymeric chain along the crystallographic $b$-axis consisting of THF-coordinated 2 units with sodium oxygen-interactions (Na1-O1 2.375(3) $\AA$ ). The central carbon of the $\mathrm{CH}\left(\mathrm{SiMe}_{3}\right)_{2}$ group shows a roughly linear $\left(\mathrm{Na}-\mathrm{C}-\mathrm{Na} 159.30(18)^{\circ}\right)$ coordination by two sodium atoms with slightly different bond lengths (Na1-C1 2.778(4) $\AA$; Na1A-C1 2.657(4) $\mathrm{A}$ ), leading to an approximately trigonal bipyramidal environment of the carbon atom. A very similar pattern of $\mathrm{Na}-\mathrm{C}$ distances was found in polymeric TMEDA-coordinated trimethylsilylmethylsodium with $\mathrm{Na}-\mathrm{C} 2.523 \AA$ and $2.530 \AA$ [8]. Additionally, the sodium atoms with a coordination number of $\mathrm{CN}=3$ are coordinated by the oxygen of a THF group, leading to an approximately trigonal planar environment (C1-Na1-C1A $130.74(6)^{\circ}$; $\mathrm{C} 1-\mathrm{Na} 1-\mathrm{O} 1129.93(13)^{\circ}$; $\mathrm{C} 1 \mathrm{~A}-\mathrm{Na} 1-\mathrm{O} 199.33(13)^{\circ}$; sum of angles: $360.0^{\circ}$ ) of the sodium atom. Overall, this results in a zigzag shape of the polymeric chain very similar to the structure of bis(trimethylsilyl)methylpotassium coordinated by THF [13] or the structure of parent 2. Compared to the latter, the additional interaction with the oxygen atom merely leads to the reduction of the $\mathrm{Na}-\mathrm{C}-\mathrm{Na}$ angle from $143^{\circ}$ in $\mathbf{2}$ to $130.74(6)^{\circ}$ in $\mathbf{2 a}$, and the change from a screw axis with a periodicity of four to a simple zigzag chain.

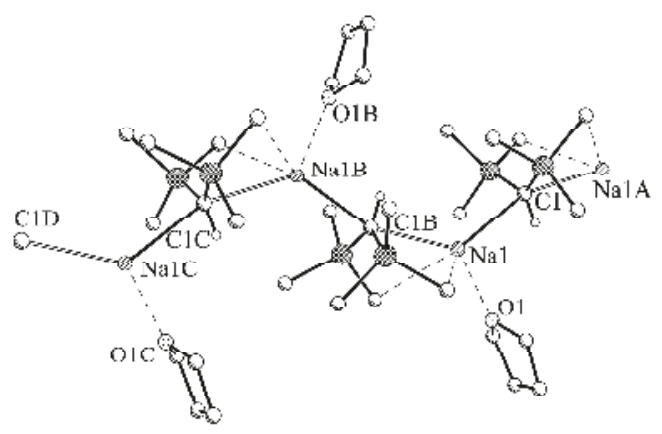

Figure 5. Trimeric section of polymeric $\left[\mathrm{NaCH}\left(\mathrm{SiMe}_{3}\right)_{2}-\mathrm{THF}\right]_{\infty}, 2 \mathbf{2}$. Selected hydrogen atoms are omitted for clarity. Symmetry operator A: $-x+0.5, y-0.5,-z+0.5$; B: $-x+0.5, y+0.5,-z+0.5$. 
The $\mathrm{CH}\left(\mathrm{SiMe}_{3}\right)_{2}$ moiety itself shows an approximate planar coordination of both $\mathrm{SiMe}_{3}$ groups and the hydrogen atom (Si11-C1-Si12 $127.9(3)^{\circ}$, sum of the Si-C-Si and two H-C-Si angles: $359.3^{\circ}$ ). In addition, the methyl groups close to the $\mathrm{Na}$ atoms give rise to $\mathrm{Na} \cdot \mathrm{Me}$ contacts with short $\mathrm{Na}-\mathrm{C}$ distances (Na1-C111 3.104(5) $\AA$ and Na1-C123 2.961(5) $\AA$ ). Compound 2a is characterized by unusually short $\mathrm{Na}-\mathrm{H}$ interactions with the hydrogen atom of the central $\mathrm{C}-\mathrm{H}$ unit $(\mathrm{Na}-\mathrm{H} 2.66 \AA / 2.70 \AA)$ which are in a similar range as the corresponding $\mathrm{Na}-\mathrm{C}$ distances.

In contrast to the composition found through ${ }^{1} \mathrm{H}$ NMR spectroscopy with an equimolar ratio 2:TMEDA of 1:1, the crystals of compound $\mathbf{2 b}$ (Figure 6) isolated for X-ray crystallography show a ratio 2:TMEDA of 2:3. The compound can be described as dimer of TMEDA-coordinated monomers of 2 . The (symmetric) sodium atoms with a coordination number $\mathrm{CN}=4$ are in close contact with a $\mathrm{CH}\left(\mathrm{SiMe}_{3}\right)_{2}$ group (Na1-C1 2.520(2) $\AA$ ). The coordination sphere of the sodium is completed to a distorted tetrahedral environment by the three nitrogen atoms of two different

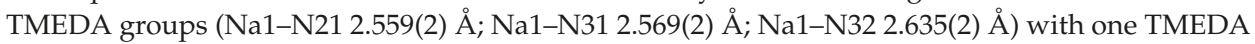
group bridging between the two symmetric monomeric units. A similar arrangement was found for TMEDA-coordinated trimethylsilyllithium [30]. The $\mathrm{CH}\left(\mathrm{SiMe}_{3}\right)_{2}$ unit shows a clear trigonal pyramidal arrangement of the $\mathrm{SiMe}_{3}$ groups and the hydrogen atom (Si-C-Si 120.91(7) ${ }^{\circ}$; the sum of the Si-C-Si and two H-C-Si angles: $336.0^{\circ}$ ).

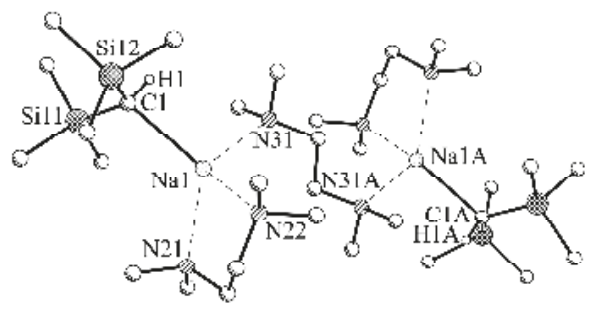

Figure 6. Molecular structure of $\left[\mathrm{NaCH}\left(\mathrm{SiMe}_{3}\right)_{2}\right]_{2}-3 \mathrm{TMEDA}, \mathbf{2 b}$. Selected hydrogen atoms and disordered units of minor occupancy are omitted for clarity. Symmetry operator A: $-x+1,-y+1,-z+2$.

\section{Materials and Methods}

\subsection{General Procedures}

$n$-Hexane, THF, and deuterated solvents were dried with potassium and distilled. TMEDA was dried with $\mathrm{CaH}_{2}$ and distilled. All synthetic work was carried out under an inert argon or nitrogen atmosphere using standard Schlenk and glove-box techniques. Bis(trimethylsilyl)methyllithium was prepared from bis(trimethylsilyl)bromomethane [31] and lithium in diethyl ether [9]. Bis(trimethylsilyl) methylsodium was synthesized following a literature procedure [11].

All ${ }^{1} \mathrm{H}$ single pulse (SP), ${ }^{1} \mathrm{H}$ correlation spectroscopy (COSY), ${ }^{1} \mathrm{H}-{ }^{13} \mathrm{C}$ heteronuclear single quantum coherence (HSQC), ${ }^{1} \mathrm{H}-{ }^{13} \mathrm{C}$ heteronuclear multiple bond correlation (HMBC), ${ }^{13} \mathrm{C}$ with power gated decoupling scheme, ${ }^{7} \mathrm{Li} \mathrm{SP}$ and ${ }^{29} \mathrm{Si} \mathrm{NMR}$ experiments were performed at $294 \mathrm{~K}$ on a Bruker Avance DRX 400 NMR spectrometer (Bruker Biospin GmbH, Rheinstetten, Germany) operating at frequencies of $400.31 \mathrm{MHz}$ for ${ }^{1} \mathrm{H}, 100.66 \mathrm{MHz}$ for ${ }^{13} \mathrm{C}, 79.53 \mathrm{MHz}$ for ${ }^{29} \mathrm{Si}$ and $155.57 \mathrm{MHz}$ for ${ }^{7} \mathrm{Li}$ and equipped with a $\mathrm{z}$-gradient dual channel inverse probe head with a gradient strength of $55 \mathrm{G} \cdot \mathrm{cm}^{-1}$. The ${ }^{1} \mathrm{H}$ spectra were referenced to the resonances of the remaining protons in the incompletely deuterated solvents $\left(\mathrm{C}_{6} \mathrm{D}_{6}\right.$, [D8]THF, and $\left.\mathrm{C}_{6} \mathrm{D}_{12}\right)$. The ${ }^{13} \mathrm{C}$ and ${ }^{29} \mathrm{Si}$ spectra were references to external TMS, while a $9.7 \mathrm{~m}$ solution of $\mathrm{LiCl}$ in $\mathrm{D}_{2} \mathrm{O}$ was used as an external reference for the ${ }^{7} \mathrm{Li}$ spectra.Stimulated echo sequence with bipolar gradient pulses and a longitudinal eddy current delay was used for the diffusion ordered spectroscopy (DOSY) experiments. The gradient strength was incremented in 16 steps from $2 \%$ to $95 \%$ of the maximum gradient strength. The diffusion time and the gradient pulse length for all measured samples were $200 \mathrm{~ms}$ and $2.8 \mathrm{~ms}$, respectively. After Fourier 
transformation and baseline correction, the diffusion dimension of the 2D DOSY spectra was processed using the Bruker Topspin 1.3 software package. The diffusion analysis was performed using the T1/T2 relaxation Topspin package. Melting points were measured on a Stuart Scientific SMP10 melting point apparatus (Cole-Parmer, Stone, UK), and Elemental analyses on an Elementar Vario EL Cube (Elementar Analysensysteme GmbH, Langenseibold, Germany). Microanalyses were carried out, but due to instability, oxidation/hydrolysis, desolvation and possibly silicon-carbide formation satisfactory elemental analysis could be obtained only for compound $\mathbf{1 b}$.

Single crystals were mounted in inert oil under a protective atmosphere by applying the X-Temp2 device [27]. Data for X-ray crystal structure determination were obtained with a Bruker SMART Apex II diffractometer (Bruker Corporation, Billerica, MA, USA) using Mo K $\alpha$ radiation $(\lambda=0.71073 \AA$ ) . All structures were refined to convergence against $F^{2}$ using programs from the SHELX family $[32,33]$.

The cryoscopic measurements were prepared in the glove-box by placing a defined amount of 1 or $\mathbf{2}$ into a sample vial, which was placed into a Schlenk flask. After connecting the Schlenk flask to the Schlenk line, a defined amount of cyclohexane was added under an argon atmosphere. A calibrated Beckmann thermometer (Amarell GmbH \& Co. KG, Kreuzwertheim, Germany) was placed into the Schlenk flask using a using a Schott Gl 25 connection system (DWK Life Sciences $\mathrm{GmbH}$, Mainz, Germany). An ice-bath was used to reach the necessary temperature.

\subsection{Syntheses}

\subsubsection{Experimental Procedure for $\left[\mathrm{LiCH}\left(\mathrm{SiMe}_{3}\right)_{2}-\mathrm{THF}\right](\mathbf{1 a})$}

Bis(trimethylsilyl)methyllithium $1(0.17 \mathrm{~g}, 1.0 \mathrm{mmol})$ was dissolved in $n$-hexane $(20 \mathrm{~mL})$, and THF $(0.16 \mathrm{~mL}, 2.0 \mathrm{mmol}, 2 \mathrm{eq})$ was added under stirring. A portion of the solvent was removed under vacuum, and the solution was stored at RT to yield a crop of colorless blocks $(0.14 \mathrm{~g}, 52 \%$ yield $)$. ${ }^{1} \mathrm{H}$ NMR $\left(400 \mathrm{MHz}, 300 \mathrm{~K}, \mathrm{C}_{6} \mathrm{D}_{12}\right): \delta=-2.39(\mathrm{~s}, 1 \mathrm{H}, \mathrm{CH}),-0.02\left(\mathrm{~s}, 18 \mathrm{H}, \mathrm{SiMe} \mathrm{e}_{3}\right), 1.89(\mathrm{~m}, 4 \mathrm{H}, \beta-\mathrm{THF})$, $3.88(\mathrm{~m}, 4 \mathrm{H}, \alpha-\mathrm{THF}) \mathrm{ppm} .{ }^{13} \mathrm{C} \mathrm{NMR}\left(100 \mathrm{MHz}, 300 \mathrm{~K}, \mathrm{C}_{6} \mathrm{D}_{12}\right): \delta=2.0(\mathrm{CH}), 5.7\left(\mathrm{SiMe}_{3}\right), 26.1(\beta-\mathrm{THF})$, $69.2(\alpha-\mathrm{THF})$ ppm. ${ }^{7} \mathrm{Li}$ NMR (155 MHz, $\left.300 \mathrm{~K}, \mathrm{C}_{6} \mathrm{D}_{12}\right): 2.9 \mathrm{ppm} .{ }^{29} \mathrm{Si} \mathrm{NMR}\left(80 \mathrm{MHz}, 300 \mathrm{~K}, \mathrm{C}_{6} \mathrm{D}_{12}\right)$ : $-6.0\left(\mathrm{SiMe}_{3}\right) \mathrm{ppm}$. Melting point: $72{ }^{\circ} \mathrm{C}$.

\subsubsection{Experimental Procedure for $\left[\mathrm{LiCH}\left(\mathrm{SiMe}_{3}\right)_{2}\right.$-TMEDA] (1b)}

Bis(trimethylsilyl)methyllithium $1(0.17 \mathrm{~g}, 1.0 \mathrm{mmol})$ was dissolved in $n$-hexane $(20 \mathrm{~mL})$, and TMEDA $(0.16 \mathrm{~mL}, 1.05 \mathrm{mmol}, 1.05 \mathrm{eq})$ was added under stirring. A portion of the solvent was removed under vacuum, and the solution was stored at $6{ }^{\circ} \mathrm{C}$ to yield a crop of colorless platelets (0.10 g, 34\% yield). ${ }^{1} \mathrm{H}$ NMR (400 MHz, $\left.300 \mathrm{~K}, \mathrm{C}_{6} \mathrm{D}_{12}\right): \delta=-2.05$ (s, $\left.1 \mathrm{H}, \mathrm{CH}\right),-0.10$ (s, $18 \mathrm{H}$, $\mathrm{SiMe}_{3}$ ), 2.30 (s, $\left.12 \mathrm{H}, \mathrm{Me}-\mathrm{TMEDA}\right), 2.37$ (s, $4 \mathrm{H}, \mathrm{CH}_{2}$-TMEDA) ppm. ${ }^{13} \mathrm{C} \mathrm{NMR}(100 \mathrm{MHz}, 300 \mathrm{~K}$, $\left.\mathrm{C}_{6} \mathrm{D}_{12}\right): \delta=2.3(\mathrm{CH}), 6.4$ (SiMe $), 45.1$ (s, $\left.12 \mathrm{H}, \mathrm{Me}-\mathrm{TMEDA}\right), 57.3$ (s, $4 \mathrm{H}, \mathrm{CH}_{2}$-TMEDA) ppm. ${ }^{7} \mathrm{Li} \mathrm{NMR}$ $\left(155 \mathrm{MHz}, 300 \mathrm{~K}, \mathrm{C}_{6} \mathrm{D}_{12}\right): 3.1 \mathrm{ppm} .{ }^{29} \mathrm{Si} \mathrm{NMR}\left(80 \mathrm{MHz}, 300 \mathrm{~K}, \mathrm{C}_{6} \mathrm{D}_{12}\right)$ : -7.9 (SiMe $)$ ppm. Melting point: $58{ }^{\circ} \mathrm{C}$. Elemental analysis (\%) calcd. for $\mathrm{C}_{13} \mathrm{H}_{35} \mathrm{LiN}_{2} \mathrm{Si}_{2}(\mathrm{M}=282.54 \mathrm{~g} / \mathrm{mol})$ : C, 55.26; H, 12.49; N, 9.92; found: C, 54.69; H, 13.54; N, 10.08 .

\subsubsection{Experimental Procedure for $\left[\mathrm{NaCH}\left(\mathrm{SiMe}_{3}\right)_{2}-\mathrm{THF}\right](2 \mathbf{a})$}

Bis(trimethylsilyl)methyllithium $2(0.07 \mathrm{~g}, 0.4 \mathrm{mmol})$ was dissolved in $n$-hexane $(5 \mathrm{~mL})$; THF $(0.07 \mathrm{~mL}, 0.9 \mathrm{mmol}, 2.2 \mathrm{eq})$ was added under stirring. A portion of the solvent was removed under vacuum, and the solution was stored at $-20^{\circ} \mathrm{C}$ to yield a crop of yellowish needles $(0.017 \mathrm{~g}$, $17 \%$ yield). The compound showed slow decomposition at room temperature. ${ }^{1} \mathrm{H}$ NMR $(400 \mathrm{MHz}$, $\left.300 \mathrm{~K}, \mathrm{C}_{6} \mathrm{D}_{12}\right): \delta=-2.28(\mathrm{~s}, 1 \mathrm{H}, \mathrm{CH}), 0.0$ (s, $\left.18 \mathrm{H}, \mathrm{SiMe} 3\right), 1.83(\mathrm{~m}, 4 \mathrm{H}, \beta$-THF), $3.76(\mathrm{~m}, 4 \mathrm{H}, \alpha-\mathrm{THF})$ ppm. ${ }^{13} \mathrm{C}$ NMR $\left(100 \mathrm{MHz}, 300 \mathrm{~K}, \mathrm{C}_{6} \mathrm{D}_{12}\right): \delta=1.1(\mathrm{CH}), 6.7\left(\mathrm{SiMe}_{3}\right), 27.0(\beta-\mathrm{THF}), 68.7(\alpha-\mathrm{THF}) \mathrm{ppm}$. ${ }^{29} \mathrm{Si} \mathrm{NMR}\left(80 \mathrm{MHz}, 300 \mathrm{~K}, \mathrm{C}_{6} \mathrm{D}_{12}\right)$ : -10.1 (SiMe 3 ) ppm. 


\subsubsection{Experimental Procedure for $\left[\mathrm{NaCH}\left(\mathrm{SiMe}_{3}\right)_{2}-\mathrm{TMEDA}\right](\mathbf{2 b})$}

Bis(trimethylsilyl)methyllithium $2(0.18 \mathrm{~g}, 1.0 \mathrm{mmol})$ was dissolved in $n$-hexane $(5 \mathrm{~mL})$, and TMEDA $(0.30 \mathrm{~mL}, 2.0 \mathrm{mmol}, 2 \mathrm{eq})$ was added under stirring. A portion of the solvent was removed under vacuum, and the solution was stored $-20^{\circ} \mathrm{C}$ to yield a crop of large colorless blocks. ${ }^{1} \mathrm{H}$ NMR $\left(400 \mathrm{MHz}, 300 \mathrm{~K}, \mathrm{C}_{6} \mathrm{D}_{12}\right): \delta=-2.04(\mathrm{~s}, 1 \mathrm{H}, \mathrm{CH}),-0.08(\mathrm{~s}, 18 \mathrm{H}, \mathrm{SiMe}), 2.25(\mathrm{~s}, 12 \mathrm{H}$, Me-TMEDA), 2.34 (s, $4 \mathrm{H}, \mathrm{CH}_{2}$-TMEDA) ppm. ${ }^{13} \mathrm{C}$ NMR $\left(100 \mathrm{MHz}, 300 \mathrm{~K}, \mathrm{C}_{6} \mathrm{D}_{12}\right): \delta=1.0(\mathrm{CH})$, 6.7 ( $\left.\mathrm{SiMe}_{3}\right), 46.2$ (s, $12 \mathrm{H}$, Me-TMEDA), 58.0 (s, $4 \mathrm{H}, \mathrm{CH}_{2}$-TMEDA) ppm. ${ }^{29} \mathrm{Si} \mathrm{NMR}(80 \mathrm{MHz}, 300 \mathrm{~K}$, $\left.\mathrm{C}_{6} \mathrm{D}_{12}\right):-8.5\left(\mathrm{SiMe}_{3}\right) \mathrm{ppm}$. Melting point: $<0{ }^{\circ} \mathrm{C}$.

\section{Conclusions}

In summary, we used cryoscopy and NMR DOSY measurements to examine solutions of bis(trimethylsilyl)methyllithium and -sodium in cyclohexane, which form polymeric chains in solid state. Bis(trimethylsilyl)methyllithium forms dimers in solution independent of its concentration. In diluted solutions, bis(trimethylsilyl)methylsodium exists as tetrameric aggregates, and more concentrated solutions reveal hexameric aggregates. This behavior reflects the high steric demand of the bis(trimethylsilyl)methyl group, which does not allow interactions with more than two lithium atoms. In the case of sodium compounds, higher flexibility results from the longer Na-C interactions and the two bulky silyl groups also contribute to the stabilization of the negative charge. This is demonstrated by the low reactivity/basicity towards THF and TMEDA, which form stable complexes with both bis(trimethylsilyl)methyllithium and -sodium. THF as a strong, but not very bulky, donor leads to an additional coordination of the corresponding lithium or sodium atom, without decreasing the numbers of alkyl-metal interactions (dimer or polymer). For both the corresponding lithium and sodium compounds, TMEDA achieves the dissociation of the existing oligomers to monomeric units by blocking interactions with other alkyllithium or -sodium units, respectively. The dimeric structure found for THF-coordinated bis(trimethylsilyl)methyllithium could be considered as a representation of the uncoordinated compound in cyclohexane solution, which was identified as dimeric. However, using coordinating ligands in combination with (trimethylsilyl)methylsodium leads to the formation monomers or dimers. This is in contrast to the cage-shaped molecules expected for soluble larger aggregates such as tetramers and hexamers, which could be identified in cyclohexane solution.

Supplementary Materials: The following are available online at www.mdpi.com/2304-6740/5/2/39/s1, Table S1: Preparation of cryoscopic measurements in cyclohexane and results, Figures S1-S21: ${ }^{1} \mathrm{H},{ }^{13} \mathrm{C},{ }^{7} \mathrm{Li}$, and ${ }^{29} \mathrm{Si} \mathrm{NMR}$ spectra of $\mathbf{1}$ and $\mathbf{2}$ in $\mathrm{C}_{6} \mathrm{D}_{6}$, [D8]THF, and $\mathrm{C}_{6} \mathrm{D}_{12}$; Figures S22-S35: ${ }^{1} \mathrm{H},{ }^{13} \mathrm{C},{ }^{7} \mathrm{Li}$, and ${ }^{29} \mathrm{Si} \mathrm{NMR}$ spectra of $\mathbf{1 a}, \mathbf{b}$ and $\mathbf{2 a}, \mathbf{b}$ in $\mathrm{C}_{6} \mathrm{D}_{12}$, Figures S36-S39: displacement ellipsoid diagrams of $\mathbf{1} \mathbf{a}, \mathbf{b}$ and $\mathbf{2} \mathbf{a}, \mathbf{b}$.

Acknowledgments: This work was supported by Internal University Research Funding of the University of Mainz. We thank Karl Klinkhammer for the generous support of this work and helpful discussions, Dieter Schollmeyer and Regine Jung-Pothmann for X-ray crystallographic measurements, and Maximilian Kaiser for help with the cryoscopic measurements.

Author Contributions: Jan Klett conceived and designed the experiments; Jan Klett and Markus von Pilgrim performed the experiments; Jan Klett and Mihail Mondeshki analyzed the data; Jan Klett wrote the manuscript.

Conflicts of Interest: The authors declare no conflict of interest.

\section{Appendix A}

The structures cited can be found in the Cambridge Crystallographic Data Centre under the following CSD-Refcodes: 1, CIMVUP; 1-PMDETA, BIYXOW; 2, PETXUH; [THF-KCH( $\left.\left(\mathrm{SiMe}_{3}\right)_{2}\right]_{\infty}$, MURHIQ; $\left[t \mathrm{BuOMe}^{-K C H}\left(\mathrm{SiMe}_{3}\right)_{2}\right]_{\infty}$, QUHNIQ; $(\mathrm{PMDETA})_{2}-\left(\mathrm{KCH}\left(\mathrm{SiMe}_{3}\right)_{2}\right)_{4}, \quad \mathrm{QUHNOW}$; $(\mathrm{TMEDA})_{3}-\left(\mathrm{NaCH}_{2} \mathrm{SiMe}_{3}\right)_{4}, \mathrm{OSESEL} ;(\mathrm{TMEDA})_{3}-\left(\mathrm{LiSiMe}_{3}\right)_{2}, \mathrm{BIJMAI}$. 


\section{References}

1. Clayden, J. Organolithiums: Selectivity for Synthesis; Elsevier Oxford: Kidlington, UK, 2002.

2. Schlosser, M. Organometallics in Synthesis-A Manual, 2nd ed.; John Wiley \& Sons, Inc.: Hoboken, NJ, USA, 2013.

3. Gessner, V.H.; Däschlein, C.; Strohmann, C. Structure formation principles and reactivity of organolithium compounds. Chemistry 2009, 15, 3320-3334. [CrossRef] [PubMed]

4. Seiferth, D. Alkyl and Aryl derivatives of the Alkali metals: Strong bases and reactive nucleophiles. 2. Wilhelm Schlenk's Organoalkali-metal chemistry. The metal displacement and the transmetalation reactions. metalation of weakly acidic hydrocarbons. Superbases. Organometallics 2009, 28, 2-33. [CrossRef]

5. Harrison-Marchand, A.; Mongin, F. Mixed AggregAte (MAA): A single concept for all dipolar organometallic aggregates. 1. Structural data. Chem. Rev. 2013, 113, 7470-7562. [CrossRef] [PubMed]

6. Reich, H.J. Role of organolithium aggregates and mixed aggregates in organolithium mechanisms. Chem. Rev. 2013, 113, 7130-7178. [CrossRef] [PubMed]

7. Collum, D.B. Is $N, N, N^{\prime}, N^{\prime}$-tetramethylethylenediamine a good ligand for lithium? Acc. Chem. Res. 1992, 25, 448-454. [CrossRef]

8. Clegg, W.; Conway, B.; Kennedy, A.R.; Klett, J.; Mulvey, R.E.; Russo, L. Synthesis and structures of [(Trimethylsilyl)methyl]sodium and -potassium with bi- and tridentate $\mathrm{N}$-donor ligands. Eur. J. Inorg. Chem. 2011, 721-726. [CrossRef]

9. Davidson, P.J.; Harris, D.H.; Lappert, M.F. Subvalent Group 4B metal alkyls and amides. Part I. The synthesis and physical properties of kinetically stable bis[bis(trimethylsilyl)methyl]-germanium(II), -tin(II), and -lead(II). J. Chem. Soc. Dalton Trans. 1976, 21, 2268-2274. [CrossRef]

10. Atwood, J.L.; Fjeldberg, T.; Lappert, M.F.; Luong-Thi, N.T.; Shakir, R.; Thorne, A.J. Molecular structures of bis(trimethylsilyl)methyl-lithium $\left[(\mathrm{LiR})_{n}, \mathrm{R}=\mathrm{CH}\left(\mathrm{SiMe}_{3}\right)_{2}\right]$ in the vapour (gas-phase electron diffraction: A monomer, $n=1$ ) and the crystal (X-Ray: A polymer, $n=\infty)$. J. Chem. Soc. Chem. Commun. 1984, 17, 1163-1165. [CrossRef]

11. Hitchcock, P.B.; Lappert, M.F.; Leung, W.-P.; Liu, D.S.; Tian, S. Synthesis and structures of the heavier alkali metal alkyls; the X-ray structures of $[\mathrm{Na}(\mu-\mathrm{R})]_{\infty}$, and $[\mathrm{Rb}(\mu-\mathrm{R})(\text { pmdeta })]_{2}\left[\mathrm{R}=\mathrm{CH}\left(\mathrm{SiMe}_{3}\right)_{2}\right.$, pmdeta $=\left(\mathrm{Me}_{2} \mathrm{NCH}_{2} \mathrm{CH}_{2}\right)_{2} \mathrm{NMe}$. J. Chem. Soc. Chem. Commun. 1993, 18, 1386-1387. [CrossRef]

12. Pakuro, N.I.; Arest-Yakubovich, A.A.; Shcheglova, L.V.; Petrovsky, P.V.; Chekulaeva, L.A. NMR spectra of a hydrocarbon-soluble organosodium compound and its lithium analogs. Rus. Chem. Bull. 1996, 45, 838-840. [CrossRef]

13. Hitchcock, P.B.; Khvostov, A.V.; Lappert, M.F. Synthesis and structures of crystalline bis(trimethylsilyl) methanide complexes of potassium, calcium and ytterbium. J. Organomet. Chem. 2002, 663, 263-268. [CrossRef]

14. Boesveld, W.M.; Hitchcock, P.B.; Lappert, M.F.; Liu, D.-S.; Tian, S. Synthesis and structures of the crystalline heavier alkali metal alkyls: X-ray structures of $\left[\mathrm{K}(\mu-\mathrm{R})\left\{\mathrm{O}(\mathrm{Me}) \mathrm{Bu}^{\mathrm{t}}\right\}\right]_{\infty},\left[(\right.$ pmdeta $) \mathrm{K}(\mu-\mathrm{R}) \mathrm{K}(\mu-\mathrm{R})_{2}$ $\mathrm{K}(\mu-\mathrm{R}) \mathrm{K}(\mathrm{pmdeta})]$, and $[\mathrm{Cs}(\mu-\mathrm{R})(\text { tmeda })]_{\infty}\left(\mathrm{R}=\mathrm{CH}\left(\mathrm{SiMe}_{3}\right)_{2}\right)$. Organometallics 2000, 19, 4030-4035. [CrossRef]

15. Lewis, H.L.; Brown, T.B. Association of alkyllithium compounds in hydrocarbon media. Alkyllithium-base interactions. J. Am. Chem. Soc. 1970, 92, 4664-4670. [CrossRef]

16. Lappert, M.F.; Engelhardt, L.M.; Raston, C.L.; White, A.H. Synthesis of $\left[\mathrm{Li}\left(\mathrm{CH}_{2} \mathrm{SiMe}_{3}\right)(\mathrm{pmdeta})\right]$ and the crystalline monomeric bulky alkyl-lithium complexes[LiR(tmeda)] and [LiR(pmdeta)][R $\left.=\mathrm{CH}\left(\mathrm{SiMe}_{3}\right)_{2}\right]$; $X$-ray crystal structure of $\left[\mathrm{Li}\left\{\mathrm{CH}\left(\mathrm{SiMe}_{3}\right)_{2}\right\}\right.$ (pmdeta)] $\left\{\right.$ tmeda $=\mathrm{Me}_{2} \mathrm{NCH}_{2} \mathrm{CH}_{2} \mathrm{NMe}_{2}$, pmdeta $=\mathrm{Me}_{2} \mathrm{~N}\left[\mathrm{CH}_{2}\right]_{2}$ $\left.\mathrm{N}(\mathrm{Me})\left[\mathrm{CH}_{2}\right]_{2} \mathrm{NMe}_{2}\right\}$. J. Chem. Soc. Chem. Commun. 1982, 1323-1324. [CrossRef]

17. Lochmann, L.; Janata, M. 50 years of superbases made from organolithium compounds and heavier alkali metal alkoxides. Cent. Eur. J. Chem. 2014, 12, 537-548. [CrossRef]

18. Unkelbach, C.; O'Shea, D.F.; Strohmann, C. Insights into the metalation of benzene and toluene by Schlosser's base: A superbasic cluster comprising PhK, PhLi, and $t$ BuOLi. Angew. Chem. Int. Ed. 2014, 53, 553-556. [CrossRef] [PubMed]

19. Benrath, P.; Kaiser, M.; Limbach, T.; Mondeshki, M.; Klett, J. Combining neopentyllithium with potassium tert-butoxide: Formation of an alkane-soluble lochmann-schlosser superbase. Angew. Chem. Int. Ed. 2016, 55, 10886-10889. [CrossRef] [PubMed] 
20. Stokes, R.H.; Tomlins, R.P. Thermodynamic functions of melting for cyclohexane. J. Chem. Thermodyn. 1974, 6, 379-386. [CrossRef]

21. Armstrong, D.R.; Barr, D.; Clegg, W.; Mulvey, R.E.; Reed, D.; Snaith, D.; Wade, K. The laddering principle in lithium amide chemistry: the crystal and molecular structure of the pyrrolididolithium adduct $\left[\mathrm{H}_{2} \mathrm{C}\left(\mathrm{CH}_{2}\right)_{3} \mathrm{NLi}\right]_{3} \mathrm{MeN}\left(\mathrm{CH}_{2} \mathrm{CH}_{2} \mathrm{NMe}_{2}\right)_{2}$. J. Chem. Soc. Chem. Commun. 1986, 11, 869-870. [CrossRef]

22. Bond, A.D. Ring-laddering and ring-stacking: Unifying concepts in the structural chemistry of organic ammonium halides. Cryst. Growth Des. 2005, 5, 755-771. [CrossRef]

23. Hevia, E.; Kennedy, A.R.; Mulvey, R.E.; Ramsay, D.L.; Robertson, S.D. Concealed cyclotrimeric polymorph of lithium 2,2,6,6-tetramethylpiperidide unconcealed: X-Ray crystallographic and NMR spectroscopic studies. Chem. Eur. J. 2013, 19, 1521-3765. [CrossRef] [PubMed]

24. Fraenkel, G.; Chow, A.; Winchester, W.R. Structure and dynamic behavior of solvated neopentyllithium monomers, dimers, and tetramers: Proton, carbon-13 and lithium-6 NMR. J. Am. Chem. Soc. 1990, 112, 6190-6198. [CrossRef]

25. Neufeld, R.; John, M.; Stalke, D. The donor-base-free aggregation of lithium diisopropyl amide in hydrocarbons revealed by a DOSY method. Angew. Chem. Int. Ed. 2015, 54, 6994-6998. [CrossRef] [PubMed]

26. Kottke, T.; Lagow, R.J. Isolation and structure analysis of neohexyllithium generated by ether cleavage: Primary and secondary coordination in alkyllithium aggregates. Organometallics 1997, 16, 789-792. [CrossRef]

27. Kottke, T.; Stalke, D. Crystal handling at low temperatures. J. Appl. Cryst. 1993, 26, 615-619. [CrossRef]

28. The Cambridge Crystallographic Data Centre. Available online: http://www.ccdc.cam.ac.uk/conts/ retrieving.html (accessed on 8 May 2017).

29. Engelhardt, L.M.; Jolly, B.S.; Junk, P.C.; Raston, C.L.; Skelton, B.W.; White, A.H. Highly hindered amido-lithium and amido-magnesium complexes. Crystal-structures of [ $\mathrm{Li}\left(\mathrm{Mu}-\mathrm{N}\left(\mathrm{SiMe}_{3}\right)_{2}\right)$ (tetrahydrofuran) $]_{2}$ and $\left[\mathrm{MgBus}\left(\mathrm{Mu}-\mathrm{N}\left(\mathrm{SiMe}_{3}\right)_{2}\right)\right]_{2}$. Aust. J. Chem. 1986, 39, 1337-1345. [CrossRef]

30. Teclé, B.; Ilsley, W.H.; Oliver, J.P. Metal-silicon bonded compounds. 16. The structure of $\left(\mathrm{LiSiMe}_{3}\right)_{2}$. $\left(\mathrm{Me}_{2} \mathrm{NCH}_{2} \mathrm{CH}_{2} \mathrm{NMe}_{2}\right)_{3}$, a highly reactive silylating agent. Organometallics 1982, 1, 875-877. [CrossRef]

31. Wiberg, N.; Wagner, G. Auf dem Wege zu einem stabilen Silaethen: Sterisch überladene Trisilylmethane $t \mathrm{Bu}_{2} \mathrm{SiX}-\mathrm{CY}\left(\mathrm{SiMe}_{3}\right)_{2}(\mathrm{X}, \mathrm{Y}=\mathrm{H}, \mathrm{Hal}, \mathrm{Li})$. Eur. J. Inorg. Chem. 1986, 119, 1455-1466. [CrossRef]

32. Sheldrick, G.M. A short history of SHELX. Acta Cryst. 2008, 64, 112-122. [CrossRef] [PubMed]

33. Müller, P.; Herbst-Irmer, R.; Spek, A.L.; Schneider, T.R.; Sawaya, M.R. Crystal Structure RefinementA Crystallographer's Guide to SHELXL; Oxford University Press: Oxford, UK, 2006.

(C) 2017 by the authors. Licensee MDPI, Basel, Switzerland. This article is an open access article distributed under the terms and conditions of the Creative Commons Attribution (CC BY) license (http:/ / creativecommons.org/licenses/by/4.0/). 
Article

\title{
Backbone-Substituted $\beta$-Ketoimines and Ketoiminate Clusters: Transoid $\mathrm{Li}_{2} \mathrm{O}_{2}$ Squares and $D_{2}$-Symmetric $\mathrm{Li}_{4} \mathrm{O}_{4}$ Cubanes. Synthesis, Crystallography and DFT Calculations
}

\author{
Twyla Gietz ${ }^{1}$ and René T. Boeré ${ }^{1,2, *}$ \\ 1 Department of Chemistry and Biochemistry, University of Lethbridge, Lethbridge, AB T1K3M4, Canada; \\ tweetersrd_22@hotmail.com \\ 2 The Canadian Centre for Research in Advanced Fluorine Technologies, University of Lethbridge, \\ Lethbridge, AB T1K3M4, Canada \\ * Correspondence: boere@uleth.ca; Tel.: +1-403-329-2045
}

Academic Editor: Matthias Westerhausen

Received: 31 March 2017; Accepted: 21 April 2017; Published: 26 April 2017

\begin{abstract}
The preparation and crystal structures of four $\beta$-ketoimines with bulky aryl nitrogen substituents (2,6-diisopropylphenyl and 2,4,6-trimethylphenyl) and varying degrees of backbone methyl substitution are reported. Backbone substitution "pinches" the chelate ring. Deprotonation with $n$-butyllithium leads to dimeric $\mathrm{Li}_{2} \mathrm{O}_{2}$ clusters, as primary laddered units, with an open transoid geometry as shown by crystal structures of three examples. The coordination sphere of each lithium is completed by one tetrahydrofuran ligand. NMR spectra undertaken in either $\mathrm{C}_{6} \mathrm{D}_{6}$ or 1:1 $\mathrm{C}_{6} \mathrm{D}_{6} / d_{8}$-THF show free THF in solution and the chemical shifts of ligand methyl groups experience significant ring-shielding which can only occur from aryl rings on adjacent ligands. Both features point to conversion to higher-order aggregates when the THF concentration is reduced. Recrystallization of the materials from hydrocarbon solutions results in secondary laddering as tetrameric $\mathrm{Li}_{4} \mathrm{O}_{4}$ clusters with a cuboidal core, three examples of which have been crystallographically characterised. These clusters are relatively insoluble and melt up to $250^{\circ} \mathrm{C}$; a consideration of the solid-state structures indicates that the clusters with 2,6-diisopropylphenyl substituents form very uniform ball-like molecular structures that will only be weakly solvated.
\end{abstract}

Keywords: $\beta$-ketoimine; $\beta$-ketoiminate; lithiation; high-nuclearity clusters; crystallography; DFT calculations; X-ray crystallography; multinuclear NMR; primary laddered units; secondary laddering

\section{Introduction}

Transition metal complexes of the deprotonated ligands derived from $\beta$-ketoimines 1 are of current interest in coordination chemistry and catalysis. Much of their use in catalysis has been in olefin polymerization [1,2]. Lanthanide alkoxides stabilized by $\beta$-ketoiminates are active in ring-opening polymerization of lactones and lactides [3]. Some research has been done into other types of reactions [4], and metal complexes of $\beta$-ketoimines have been widely used as precursors for metalloorganic chemical vapour deposition (CVD) $[5,6]$. Much less is known about their main group metal derivatives, although $\beta$-ketoiminate complexes of aluminium are a notable exception $[7,8]$. A few magnesium complexes have also been studied with interest in their use as CVD precursors [9]. Alkali metal derivatives have been used as intermediates in the synthesis of transition metal complexes [10,11], but have not been extensively reported as isolated species [12-14]. 
The structural chemistry of lithiated organoelement species has seen enormous development over 30 years of active investigation and is known to show great diversity of structures due to aggregation and Lewis base coordination. Rings, ladders and higher aggregates have been obtained [15-18]. To date, there are several structurally characterised examples of lithium $\beta$-ketoiminates. Lithiation of 4-isopropylaminopent-3-en-2-one generates in presence of hexamethylphosphortriamide (hmpa) a transoid $\mathrm{Li}_{2} \mathrm{O}_{2}$ chelate dimer of type 2 (Cambridge Crystallographic Database, CSD, refcode NOWHUK) while in absence of the Lewis base an $\mathrm{Li}_{4} \mathrm{O}_{4}$ chelated tetrameric cubane (refcode: NOWHOW) of type 3 [12]. A fluorinated $\beta$-ketoiminate with a pendent $\mathrm{Me}_{2} \mathrm{~N}^{\prime} \mathrm{CH}_{2} \mathrm{CH}_{2}$ has been structurally characterised (refcode: XUZWOE) as a cisoid $\mathrm{Li}_{2} \mathrm{O}_{2}$ dimer with the $N^{\prime}$ donors acting as an internal Lewis base [19], while a mixed copper-lithium ladder cluster was obtained from lithiated 1a and copper(I) chloride in toluene in which an oxygen from the copper chelate acts as " $\mathrm{L}$ " [20]. A similar $\mathrm{Li}_{2} \mathrm{O}_{2}$ cluster (refcode: SEKVIK) of a close analogue of ligand $\mathbf{1 b}$ (2,6-xylyl rather than Mes group) has two neutral ligands filling the coordination sphere of the lithium ions [21]. An iron(II) triflate complex derived from 1a (refcode: ISEXUA) has recently been structurally characterised [22]. Titanium chloride and chloromethyltin complexes (refcodes: LIRCAQ and DULREI) of $\mathbf{1 b}$ have also been structurally confirmed [23,24]. Similar chloroalklytin complexes of 1c have been reported [25]. Main group element complexes of $\mathbf{1 d}$ have also been structurally characterised $\left(\mathrm{GaCl}_{3}\right.$, refcode: RUYSIO and $\mathrm{SbCl}_{3}$, refcode: JOHQED) [26,27], as have complexes of this ligand with cobalt, copper and europium (refcodes: WUWDUO, WUWFAW, WUWFEA) [28].

As a continuation of our interest in heteroallyl ligands incorporating bulky substituents and their coordination chemistry [29-33], as well as in the structures and reactivities of $N^{\prime}$-imidoylcarboximidamides [34,35], we now report crystal structures for two popular $\beta$-ketoimines $\mathbf{1 a}, \mathbf{b}$ (Dipp = 2,6-diisopropylphenyl; Mes = 2,4,6-trimethylphenyl) (Scheme 1) [36] and the synthesis of two less-common analogues which have an additional methyl group at the " 3 " position of the heteropentadienes $\mathbf{1} \mathbf{c}, \mathbf{d}$. The structures of new transoid $\mathrm{Li}_{2} \mathrm{O}_{2}$ dimers $2 \mathbf{a}-\mathbf{c}$ with $\mathrm{L}=\mathrm{THF}$ and novel $D_{2}$-symmetric $\mathrm{Li}_{4} \mathrm{O}_{4}$ cubanes $\mathbf{3 b}$ - $\mathbf{d}$ are described. The relationship between dimeric and tetrameric aggregates and the preference for the common $S_{4}$ - and rare $D_{2}$-symmetric $\mathrm{Li}_{4} \mathrm{O}_{4}$ cubanes is rationalised using hybrid-DFT calculations. We have recently reported the structure of the first mixed ketoiminate-alkyl complex of magnesium derived from 1b [37].

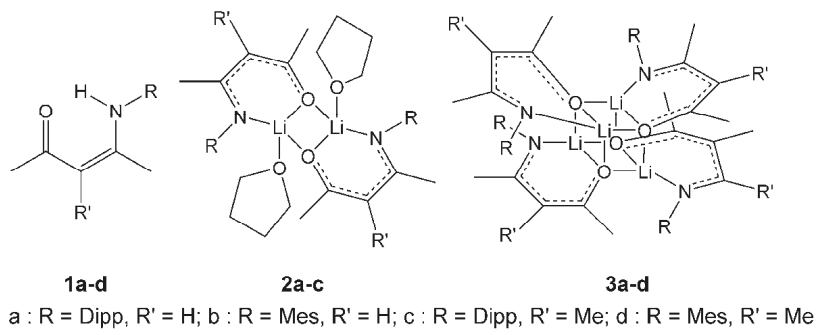

Scheme 1. Identities of the title compounds.

\section{Results and Discussion}

\subsection{Synthesis, Structures and Tautomers of $\beta$-Ketoimines}

The ketoimines $1 \mathbf{c}, \mathbf{d}$ were prepared by the $\mathrm{InBr}_{3}$-catalysed condensation of 3-methyl-2,4pentandione with the corresponding anilines $\mathrm{MesNH}_{2}$ or $\mathrm{DippNH}_{2}$ [38] and have been fully characterised in the solid and in solution; previous reports of these ligands do not seem to have provided full details. The spectroscopic properties resemble those of the previously reported 1a,b [36]. The presence of the intramolecular $\mathrm{H}$-bond is detected by broad resonances in the ${ }^{1} \mathrm{H}$ NMR at noticeably low frequencies (ranging from 11.8 to $13.2 \mathrm{ppm}$ in $\mathrm{CDCl}_{3}$ solution for the four exemplars) [39]. 
The presence in both $\mathbf{1 a}$ and $\mathbf{1 c}$ of two distinct ${ }^{i} \operatorname{Pr}$ methyl resonances suggesting that there is a lack of free rotation of the Dipp ring is also noteworthy. More interesting are the structures in the solid state which we have determined for all four species by single-crystal X-ray diffraction at low temperatures (see Figure 1 and Table 1). In each case, an NH hydrogen could be detected unambiguously in the difference Fourier map and their positions and isotropic temperature factors could be freely refined. This suggests that of the three theoretically possible tautomers (Scheme 2), all four ketoimines $\mathbf{1 a}-\mathbf{d}$ are unambiguously in the enamine form $\mathbf{B}$ in the solid state.

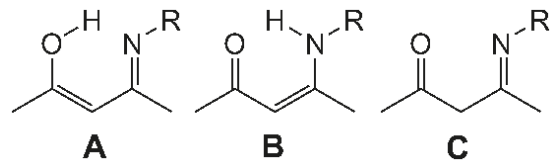

Scheme 2. Limiting tautomers for ketoimines: enol (A); enamine (B); or ketimine (C).

The structure of 1a (Figure 1a) can be compared to that of (Z)-3-((2,6-diisopropylphenyl)amino)1-phenylbut-2-en-1-one with which it shares an identical value for $d(\mathrm{~N} \cdots \mathrm{O})$ of 2.613(2) $\AA$ within experimental error (refcode NAWKUS) [40]. The packing of this structure in regular sheets through weak intermolecular contacts is more symmetrical than that found in 1a. During this work, another crystal structure of 1a was published (refcode: UZOJOJ [25]). The geometries of the two structure determinations match closely.

Table 1. Experimental ${ }^{1}$ and calculated ${ }^{2}$ bond lengths $(\AA)$ and angles $\left(^{\circ}\right)$ for $\mathbf{1 a}-\mathbf{d}$.

\begin{tabular}{|c|c|c|c|c|c|c|c|c|}
\hline \multirow{2}{*}{ Parameter } & \multicolumn{2}{|c|}{$1 \mathrm{a}$} & \multicolumn{2}{|c|}{$1 b$} & \multicolumn{2}{|c|}{$1 c$} & \multicolumn{2}{|c|}{$1 \mathrm{~d}$} \\
\hline & X-ray & Calc. & X-ray & Calc. & X-ray & Calc. & X-ray & Calc. \\
\hline $\mathrm{O}-\mathrm{C}_{2}$ & $1.2506(19)$ & 1.251 & $1.2408(18)$ & 1.250 & $1.248(2)$ & 1.252 & $1.2489(17)$ & 1.252 \\
\hline $\mathrm{C}_{2}-\mathrm{C}_{3}$ & $1.421(2)$ & 1.438 & $1.426(2)$ & 1.438 & $1.426(2)$ & 1.450 & $1.430(2)$ & 1.450 \\
\hline $\mathrm{C}_{3}-\mathrm{C}_{4}$ & $1.376(2)$ & 1.385 & $1.3827(19)$ & 1.385 & $1.388(2)$ & 1.395 & $1.3872(19)$ & 1.395 \\
\hline $\mathrm{C}_{4}-\mathrm{N}$ & $1.3406(19)$ & 1.354 & $1.3395(18)$ & 1.385 & $1.349(2)$ & 1.358 & $1.3462(17)$ & 1.358 \\
\hline $\mathrm{C}_{7}-\mathrm{C}_{3}$ & & & & & $1.512(2)$ & 1.517 & $1.512(19)$ & 1.517 \\
\hline $\mathrm{O}_{1}-\mathrm{C}_{2}-\mathrm{C}_{3}$ & $123.16(14)$ & 123.50 & $122.99(13)$ & 123.47 & $123.69(16)$ & 123.98 & $123.35(12)$ & 123.99 \\
\hline $\mathrm{C}_{2}-\mathrm{C}_{3}-\mathrm{C}_{4}$ & $123.22(14)$ & 123.04 & $123.26(13)$ & 123.07 & $120.18(14)$ & 120.40 & $120.59(12)$ & 120.46 \\
\hline $\mathrm{C}_{3}-\mathrm{C}_{4}-\mathrm{N}$ & $120.46(13)$ & 120.78 & $121.85(13)$ & 120.99 & $120.96(16)$ & 120.99 & $121.93(12)$ & 120.91 \\
\hline $\mathrm{C}_{4}-\mathrm{N}-\mathrm{C}_{6}$ & $127.46(13)$ & 126.85 & $124.92(12)$ & 126.46 & $120.8(13)$ & 128.03 & $126.29(11)$ & 128.37 \\
\hline $\mathrm{N}-\mathrm{H}$ & $0.885(19)$ & 1.030 & $0.860(19)$ & 1.031 & $0.92(2)$ & 1.032 & $0.898(17)$ & 1.033 \\
\hline $\mathrm{N} \cdots \mathrm{O}$ & $2.6139(17)$ & 2.647 & 2.6571(16) & 2.652 & $2.5485(18)$ & 2.590 & $2.5823(15)$ & 2.591 \\
\hline $\mathrm{N}-\mathrm{H} \cdots \mathrm{O}$ & $141.9(16)$ & 138.8 & $133.7(16)$ & 138.2 & $140.9(19)$ & 140.1 & $140.0(15)$ & 140.4 \\
\hline $\mathbf{N} \cdots \mathrm{O}^{\prime}$ & & & $2.9840(16)$ & - & & & & \\
\hline $\mathrm{N}-\mathrm{H} \cdots \mathrm{O}^{\prime}$ & & & $136.9(16)$ & - & & & & \\
\hline
\end{tabular}

The structure of $\mathbf{1 b}$ (Figure $\mathbf{1 b}$ ) is the sole exemplar in this set which shows additional intermolecular H-bonding to form centrosymmetric dimers with respect to crystallographic centres of inversion in space group $P 2{ }_{1} / n$ (see Figure A1 in Appendix A). The intramolecular $d(\mathrm{~N} \cdots \mathrm{O})$ value is $2.657(2)$ while between the two molecules it is 2.984(2) $\AA$. This motif is strongly reminiscent of that found in 2-(2,6-diisopropylphenylamino)cyclohex-1-enyl phenyl ketone for which the corresponding values are: $d(\mathrm{~N} \cdots \mathrm{O})$ intra- 2.598(3) and 2.614(3); inter-molecular 3.205(3) and 3.206(3) $\AA$. Thus, it is not the difference in steric bulk between the nitrogen substituents Dipp in 1a and Mes in $\mathbf{1} \mathbf{b}$ that determines these motifs, which are probably determined by crystal packing. During this work, two independent reports were published containing the same structure (refcodes: IFOWUW [41] and NABYEX [42]). The geometries of the three structure determinations match very well.

The isolated structure of 1c (Figure 1c) has a noticeably short $d(\mathrm{~N} \cdots \mathrm{O})$ value of $2.549(2) \AA$, $3 \%$ less than in 1a. Similarly, in $\mathbf{1 d}, d(\mathrm{~N} \cdots \mathrm{O})$ is $2.582(2) \AA$, which is $3 \%$ less than in $\mathbf{1 b}$. The origin 
of this "pinching-in" effect must lie with the additional backbone methyl group, such that there are three methyl groups in series along the ketoimine backbone. Although methyl groups are not considered bulky substituents, local steric pressure can be generated even by relatively small groups in close proximity [43]. Of about 150 crystal structures of $\beta$-ketoimines in the CSD, excluding those cases where two or more of the hetero-pentadiene atoms are constrained within rings, none bear a 3-methyl substituent and only three examples of substitution are found (refcodes: JEKLUA, JEKMAO, and SENBAO), each of which is a perpendicularly-oriented acyl group that is not expected to develop much steric pressure $[44,45]$.

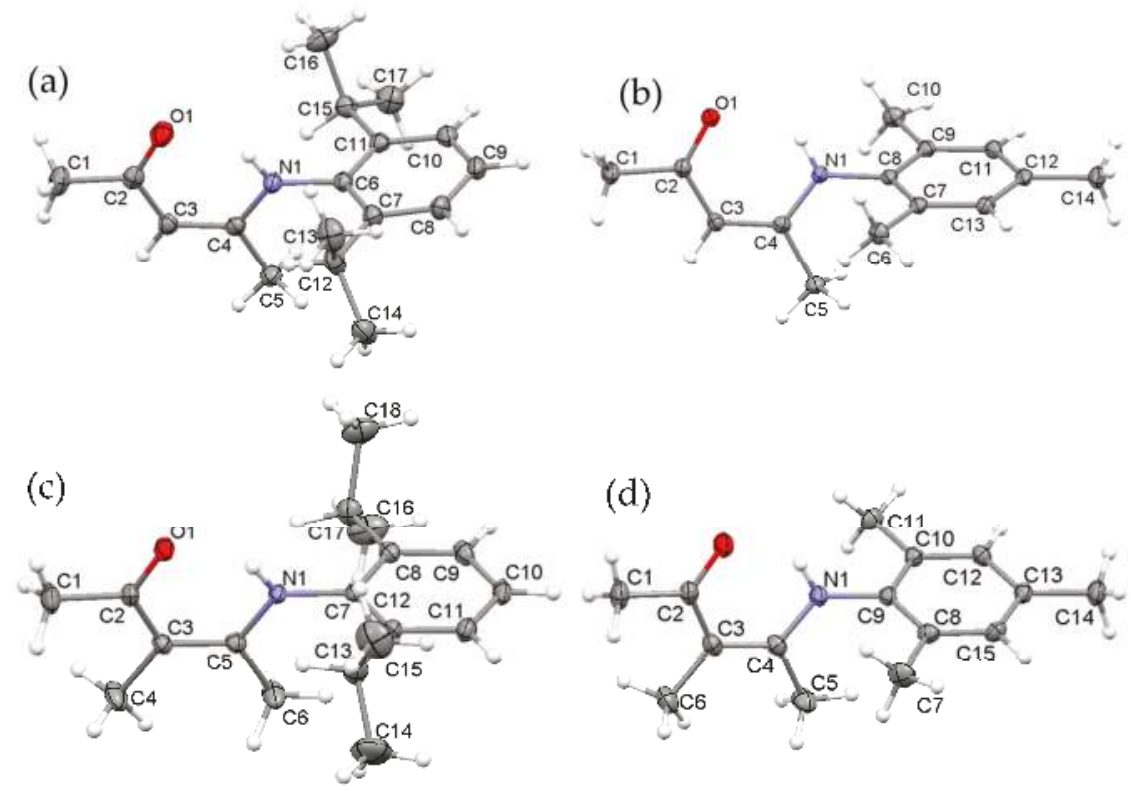

Figure 1. Displacement ellipsoids plots ( $40 \%$ probability) of the molecular structures of the ketoimine ligand precursors as found in the respective crystal structures: (a) Ligand 1a; (b) ligand 1b; (c) ligand 1c; and (d) ligand 1d. The atom numbering schemes are indicated.

In the extended structure of $\mathbf{1 c}$, the ketoimine chains form into planes that lie along the (020) Miller planes with only weak intermolecular contacts. The observed H-bonding is strictly intramolecular. The same is true of $\mathbf{1 d}$, but the crystal packing of this exemplar has the molecules arranged such that the aromatic mesityl rings of pairs of molecules are parallel-displaced edgewise at close to the ideal distances for a $\pi-\pi$ stacking interaction [46], $3.546 \AA$ from the centre of one mesityl to the plane made by the other and with an average edgewise displacement of $1.337 \AA$.

For all these $\beta$-ketoimines the $\mathrm{H}$-bonded pseudo six-member rings are rigorously planar and there is a degree of bond averaging suggestive of at least partly-delocalized $\pi$-electrons with $s p^{2}$-hybridized 2nd-row elements (Table 1). Thus, the $\mathrm{C}-\mathrm{N}$ bonds are considerably shorter than expected for a single bond (Av. $1.339 \AA$ ) while the formal $\mathrm{C}=\mathrm{C}$ double bond ( $\mathrm{Av} .1 .316 \AA$ ) prescribed by the enamine structure is significantly shorter than that found. Similarly, the formal C-C single bond (Av. $1.530 \AA$ ) is not observed; instead the value is typical of single bonds in conjugated systems (Av. $1.460 \AA$ ), while the $\mathrm{C}=\mathrm{O}$ bond is longer than normal values for ketones (Av. 1.210 $\AA$ ) [47].

The geometry of these structures is accurately reproduced by (gas phase) B3LYP/6-31G(d) calculations (Table 1) except for the $\mathrm{C}(2)-\mathrm{C}(3)$ distances in $\mathbf{1}$, d which are overestimated by $0.02 \AA$. The DFT calculations closely replicate the shortening of $d(\mathrm{~N} \cdots \mathrm{O})$ by $\sim 0.1 \AA$, supporting the notion 
that steric crowding of the backbone methyl groups causes the ring to pinch in. Recent computational studies on a model $\beta$-ketoimine 1 with substituents $\mathrm{R}_{1}=\mathrm{R}_{2}=\mathrm{R}_{4}=\mathrm{CH}_{3} ; \mathrm{R}_{2}=\mathrm{H}$ provides strong support for the preference for the enamine tautomer and moreover has demonstrated that the main factor favoring the enamine is promotion of planarity of the $\mathrm{N}$ atom so that its lone pair can be part of a delocalized $\pi$-system [48].

\subsection{Synthesis and Structures of Ketoiminate Lithium Complexes}

The neutral lithium complexes formed by deprotonation of $\mathbf{1 a}-\mathbf{d}$ with ${ }^{n} \mathrm{BuLi}$ fall into two broad classes: 2a-c which are prepared in and crystallised from THF-hexane mixed solvents and which retain coordinated THF; $3 \mathbf{b}, \mathbf{c}$ which are prepared in heptane-hexane mixed solvents and which crystallise as unsolvated species. In this system, $\mathbf{3 d}$ stands out in that it preferentially crystallises as the unsolvated cluster even in presence of THF. X-ray quality crystals of $\mathbf{2} \mathbf{a}-\mathbf{c}$ and $\mathbf{3} \mathbf{d}$ form on cooling from a THF-enriched solution; $3 b$ recrystallizes from hot toluene, and $3 c$ from hot heptanes.

\subsubsection{Transoid $\mathrm{Li}_{2} \mathrm{O}_{2}$ Clusters}

Each of the THF solvates $2 \mathbf{a}-\mathbf{c}$ consists of a ketoiminate chelated $\mathrm{Li}^{+}$ion further coordinated by one THF perpendicular to the chelate ring (Figure 2 and Table 2); these rings associate into crystallographically centrosymmetric dimers with central $\mathrm{Li}_{2} \mathrm{O}_{2}$ squares that are close to symmetrical with the "inter-monomer" Li-O distances (2a 1.917(4); 2b 1.948(3); 2c 1.898(2) and 1.908(2) A) only 1\%-3\% longer than the "intra-monomer" (2a 1.899(3); 2b 1.888(3); 2c 1.868(3) and 1.867(2) Å) values. The result is that each $\mathrm{Li}^{+}$ion is tetracoordinate but with angles severely distorted from tetrahedral values. There are no significant short contacts between any of these butterfly clusters within their unit cells. For 2c, the lattice has two crystallographically independent "monomers" in the asymmetric unit, each of which is dimerized on a lattice inversion centre. The two resultant dimers, which are crystallographically distinct, have very comparable geometric parameters and only one example is shown in Figure 2c.

Table 2. Experimental ${ }^{1}$ and calculated ${ }^{2}$ bond lengths $(\AA)$ and angles $\left(^{\circ}\right)$ for $2 \mathbf{a}-\mathbf{d}$.

\begin{tabular}{|c|c|c|c|c|c|c|c|}
\hline \multirow{2}{*}{ Parameter } & \multicolumn{2}{|c|}{$2 a$} & \multicolumn{2}{|c|}{$2 b$} & \multicolumn{2}{|c|}{$2 c$} & \multirow{2}{*}{$\begin{array}{c}2 \mathrm{~d} \\
\text { Calc. }\end{array}$} \\
\hline & X-ray & Calc. & X-ray & Calc. & X-ray & Calc. & \\
\hline $\mathrm{O}-\mathrm{C}_{2}$ & $1.2860(19)$ & 1.290 & $1.283(2)$ & 1.291 & $1.284(1)$ & 1.289 & 1.292 \\
\hline $\mathrm{C}_{2}-\mathrm{C}_{3}$ & $1.372(2)$ & 1.390 & $1.377(2)$ & 1.390 & $1.385(4)$ & 1.403 & 1.402 \\
\hline $\mathrm{C}_{3}-\mathrm{C}_{4}$ & $1.431(2)$ & 1.437 & $1.432(2)$ & 1.435 & $1.450(1)$ & 1.451 & 1.451 \\
\hline $\mathrm{C}_{4}-\mathrm{N}$ & $1.301(2)$ & 1.312 & $1.306(2)$ & 1.312 & $1.307(0)$ & 1.317 & 1.315 \\
\hline $\mathrm{C}_{7}-\mathrm{C}_{3}$ & & & & & $1.523(2)$ & 1.524 & 1.523 \\
\hline $\mathbf{L i}-\mathbf{N}$ & $2.021(3)$ & 2.065 & $2.016(3)$ & 2.022 & $2.022(2)$ & 2.041 & 2.007 \\
\hline Li-O chelate & $1.899(3)$ & 1.912 & $1.888(3)$ & 1.902 & $1.868(1)$ & 1.882 & 1.881 \\
\hline Li-O bridge & $1.917(3)$ & 1.939 & $1.948(3)$ & 1.960 & $1.903(7)$ & 1.947 & 1.947 \\
\hline $\mathrm{Li}-\mathrm{O}(\mathrm{THF})$ & $1.988(3)$ & 2.040 & 1.991(3) & 2.016 & $1.98(2)$ & 2.037 & 2.026 \\
\hline $\mathrm{O}-\mathrm{C}_{2}-\mathrm{C}_{3}$ & $125.34(16)$ & 125.76 & $125.57(16)$ & 125.81 & $125.47(4)$ & 125.47 & 125.32 \\
\hline $\mathrm{C}_{2}-\mathrm{C}_{3}-\mathrm{C}_{4}$ & $128.68(16)$ & 128.79 & $128.08(16)$ & 128.20 & $123.66(11)$ & 124.11 & 123.75 \\
\hline $\mathrm{C}_{3}-\mathrm{C}_{4}-\mathrm{N}$ & $122.86(15)$ & 123.90 & $123.40(16)$ & 123.50 & $123.66(15)$ & 124.15 & 123.82 \\
\hline $\mathrm{C}_{4}-\mathrm{N}-\mathrm{C}_{6}$ & $120.58(14)$ & 121.48 & $118.78(14)$ & 122.10 & $120.76(9)$ & 121.76 & 122.27 \\
\hline O-Li-N & $95.96(13)$ & 96.58 & $96.49(13)$ & 97.03 & $92.28(6)$ & 92.98 & 92.99 \\
\hline $\mathrm{Li}-\mathrm{O}-\mathrm{Li}$ & $85.89(13)$ & 85.76 & $86.52(13)$ & 85.57 & $88.1(15)$ & 86.73 & 85.74 \\
\hline O-Li-O & $94.11(13)$ & 94.24 & $93.48(13)$ & 94.43 & $92.0(15)$ & 93.27 & 94.26 \\
\hline O-Li-O(THF) & $107.6(11)$ & 107.81 & 112(9) & 111.02 & 108(3) & 108.96 & 112.06 \\
\hline $\mathrm{C}_{4}-\mathrm{N}-\mathrm{Li}$ & $121.68(14)$ & 119.82 & $121.33(14)$ & 121.29 & $122.92(8)$ & 122.59 & 123.92 \\
\hline $\mathrm{C}_{2}-\mathrm{O}-\mathrm{Li}$ & $123.68(14)$ & 123.27 & $124.39(14)$ & 123.70 & $126.68(19)$ & 127.04 & 127.13 \\
\hline
\end{tabular}




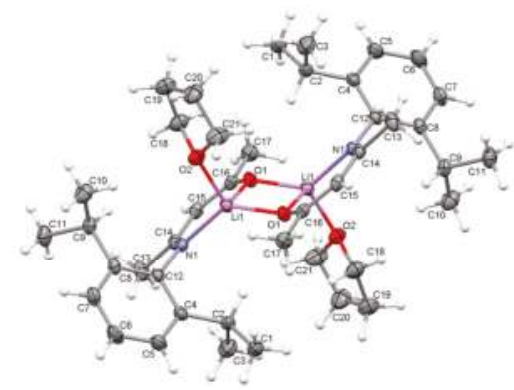

(a)

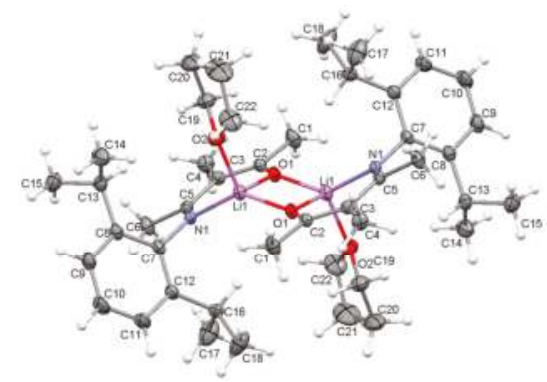

(c)

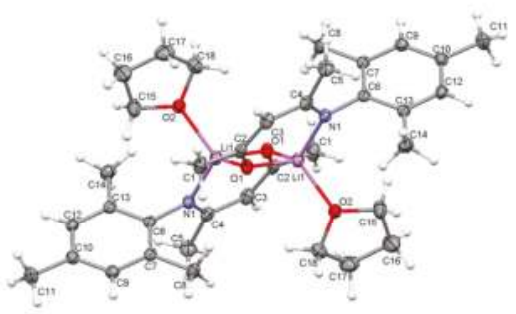

(b)

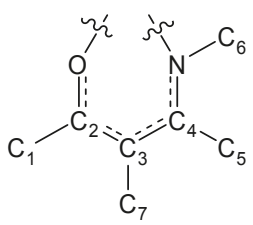

(d)

Figure 2. Displacement ellipsoids plots ( $40 \%$ probability) of the centrosymmetrically dimerized molecular structures of transoid $\mathrm{Li}_{2} \mathrm{O}_{2}$ square clusters as found in their crystal structures: (a) THF-solvated cluster 2a; (b) THF-solvated cluster 2b; and (c) one of two independent THF-solvated clusters of $\mathbf{2 c}$; (d) The atom numbering scheme is the same used in Tables 1-3 for geometrical comparisons.

The influence of the extra backbone methyl group in $2 \mathrm{c}$ is evident in these lithiated derivatives just as is the case for $\mathbf{1 c}$,d. Thus, the $d(\mathrm{~N} \cdots \mathrm{O})$ values of 2.805(1) and 2.809(1) $\AA$ are $4 \%$ shorter than those that pertain in $\mathbf{2 a}, 2.913(2)$ and $\mathbf{2 b}, 2.914(2) \AA$, due to "pinching in" of the chelate ring. This can also be seen by the fact that the $\mathrm{Li}$ atom is twice as far out of the chelate ring ligand least-squares plane (0.44 $\AA$ ) compared to $2 \mathbf{a}(0.24 \AA)$. Upon coordination to $\mathrm{Li}^{+}$, the bond lengths within the ketoiminate ligands change in predictable fashion. Thus, the $\mathrm{C}-\mathrm{O}$ distances lengthen $\sim 3 \%, \mathrm{C}_{2}-\mathrm{C}_{3}$ shorten by $\sim 4 \%$, $\mathrm{C}_{3}-\mathrm{C}_{4}$ lengthen by $\sim 4 \%$ and $\mathrm{C}_{4}-\mathrm{N}$ shorten by $\sim 3 \%$. All these changes are consistent with conversion from a limiting enamine geometry $\mathbf{B}$ towards a delocalized chelate ring.

There are several comparable $\mathrm{Li}_{2} \mathrm{O}_{2}$ butterfly complexes of ketoiminate ligands in the literature. The most comparable structures to $2 \mathbf{a}-\mathbf{c}$ are the all-aliphatic complex bis $\left(\left(\mu_{2}-N\right.\right.$ -isopropyl-2,4-dimethyl-1-oxa-5-azapenta-2,4-dienyl)-hexamethylphosphoramido-lithium (refcode: NOWHUC) which has hmpa oxygen donors in place of THF [12] and three closely-similar bis $\left(\mu_{2}-3\right.$-((aryl)imino)-1-phenylbut-1-en-1-oxy)-bis(tetrahydrofuran)-di-lithium complexes reported by Liu et al. (refcodes: SIYDAH, SIYDEL, SYDIP) [14]. In NOWHUC, the intra- (1.892) and inter-"monomer" $(1.955 \AA$ ) Li-O distances are most similar to those in $\mathbf{2 b}$. In the structure of a 2,6-xylyl ketoiminate a structure very similar to that in $\mathbf{2} \mathbf{b}$ is found (refcode: SEKVIP) [21]. In place of the two THF molecules, two neutral ligand molecules are coordinated to lithium ions via the carbonyl oxygen donors. The dimensions in this structure are very close to those in $\mathbf{2 b}$, except for the $\mathrm{Li}-\mathrm{O}$ distances which are longer $(0.024 \AA)$ for the ligand $\mathrm{O}$ and shorter for the exocyclic value $(0.012 \AA)$. 


\subsection{2. "Tetrameric" Cuboidal Clusters}

All three cubane complexes $\mathbf{3 b}-\mathbf{d}$ adopt the same basic geometry with minor distortions in which the core geometry has approximate $D_{2}$ point-group symmetry (Figure 3a). The CSD reports $21 \mathrm{Li}_{4} \mathrm{O}_{4}$ cuboidal clusters with nitrogen donors coordinated to Li. Seven of these are either non-chelating or have higher denticity. Of the remainder, eleven adopt the $S_{4}$ geometry while only two have the $D_{2}$-symmetric structure (Scheme 3).

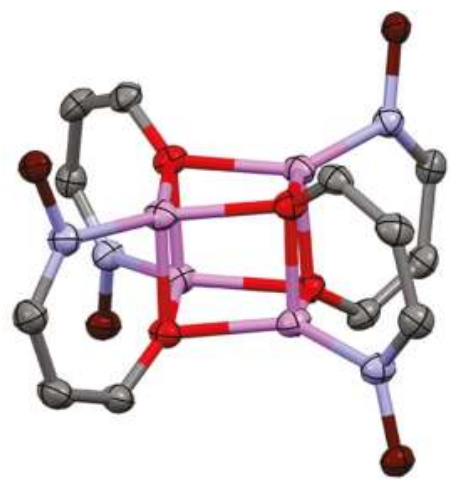

(a)

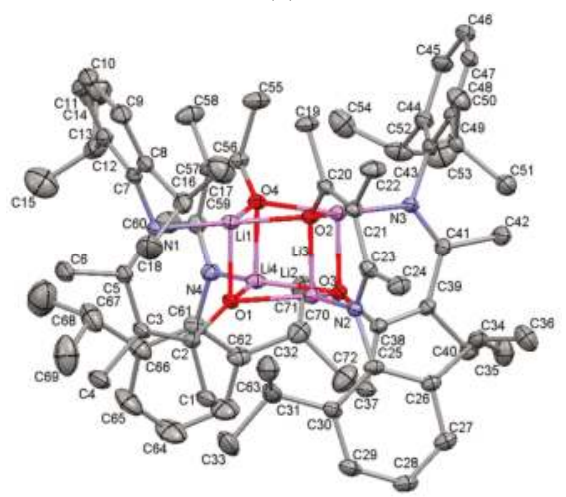

(c)

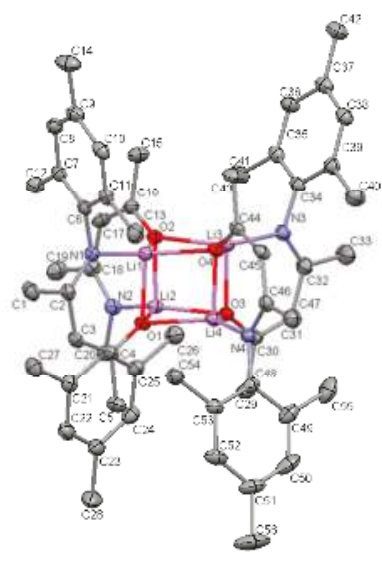

(b)

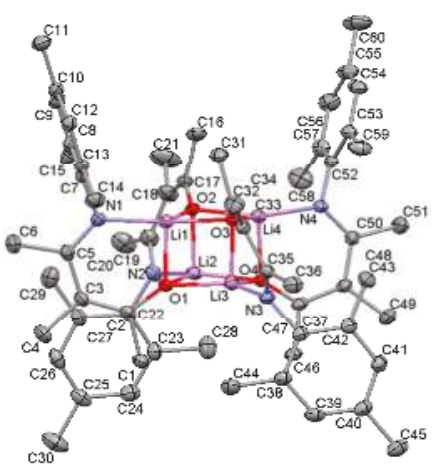

(d)

Figure 3. Displacement ellipsoids plots ( $40 \%$ probability) of the tetrameric molecular structures of cuboidal $\mathrm{Li}_{4} \mathrm{O}_{4}$ ketoiminate clusters as found in their crystal structures: (a) common cuboidal core with ipso carbon of the aromatic groups coloured brown; (b) cluster $3 \mathbf{b}$; (c) cluster $3 \mathbf{c}$; and (d) cluster $3 \mathbf{d}$. The atom numbering schemes are shown. $\mathrm{H}$ atoms on $\mathrm{C}$ have been omitted to enhance visualization of the clusters. A disordered, uncoordinated toluene molecule present in the lattice of $\mathbf{3 b}$ has been omitted and solvent presumed to be heptane was removed from the structure of $3 \mathrm{c}$ using the "SQUEEZE" method.

The structure observed in $\mathbf{3 b}$ (Figure $3 \mathbf{b}$ and Table 3 ) is remarkably symmetrical with all the ligand substituents oriented as required by the point group. Two Mes rings attached at opposite corners of the cube are directed away from the cube face and the other two face the opposite direction, each set

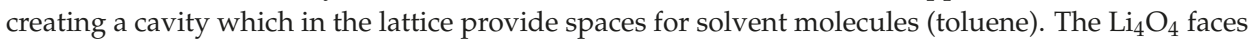


perpendicular to the $D_{2}$ principal axis are almost square, while the four parallel faces are distinctly rhomboidal ( $\angle \mathrm{Li}-\mathrm{O}-\mathrm{Li} \sim 83^{\circ}$ ). The $\mathrm{Li}-\mathrm{O}$ distances parallel to the principal axis are precisely those chelated by the ketoiminate ligand and have a mean length of 1.924(5) $\AA$. This is about $3 \%$ shorter than the mean Li-O distances for the eight bonds that are not chelated at 1.976(10) $\AA$.

The structure of 3c (Figure 3c) has the most congested ligand 1c, with Dipp groups on nitrogen as well as the extra backbone methyl substituent. The same basic high-symmetry geometry is adopted as found for $\mathbf{3 b}$ but the "square" face perpendicular to the principal axis is distinctly distorted into an envelope conformation. This results in the structure being overall much squatter than of the previous example, and not just because of the absence of the substituents at position 4 on the aromatic rings. Here too the four chelated Li-O distances (mean value, 1.874(3) $\AA$ ) are shorter (by 7\%) than the eight bridging distances (mean value, 2.01(4) $\AA$ ). However, the chelate rings remain close to planar with only a very small deviation of $\mathrm{Li}$ out of the average chelate planes. The crystal packing leads to smaller voids but these appear to contain disordered heptane molecules (NMR evidence) which we could not model accurately and which in the end were excluded from the electron-density maps.

Table 3. Experimental ${ }^{1}$ and calculated $\left(\mathrm{D}_{2} \text { and } \mathrm{S}_{4}\right)^{2}$ average bond lengths $(\AA)$ and angles $\left({ }^{\circ}\right)$ for $3 \mathbf{a}-\mathbf{d}$.

\begin{tabular}{|c|c|c|c|c|c|c|c|c|c|}
\hline \multirow{2}{*}{ Parameter } & \multirow{2}{*}{$\begin{array}{l}3 \mathrm{a} \\
\mathrm{D}_{2}\end{array}$} & \multicolumn{2}{|c|}{$3 b$} & \multicolumn{3}{|c|}{$3 c$} & \multicolumn{3}{|c|}{$3 d$} \\
\hline & & X-ray & $\mathrm{D}_{2}$ & X-ray & $\mathrm{D}_{2}$ & $\mathrm{~S}_{4}$ & X-ray & $\mathrm{D}_{2}$ & $\mathrm{~S}_{4}$ \\
\hline $\mathrm{O}-\mathrm{C}_{2}$ & 1.305 & $1.303(2)$ & 1.306 & $1.310(2)$ & 1.310 & 1.307 & $1.310(3)$ & 1.308 & 1.308 \\
\hline $\mathrm{C}_{2}-\mathrm{C}_{3}$ & 1.378 & $1.366(2)$ & 1.382 & $1.370(3)$ & 1.392 & 1.395 & $1.374(1)$ & 1.392 & 1.394 \\
\hline $\mathrm{C}_{3}-\mathrm{C}_{4}$ & 1.443 & $1.440(2)$ & 1.442 & $1.460(7)$ & 1.464 & 1.461 & $1.454(2)$ & 1.458 & 1.457 \\
\hline $\mathrm{C}_{4}-\mathrm{N}$ & 1.311 & $1.302(3)$ & 1.308 & $1.309(2)$ & 1.314 & 1.318 & $1.305(4)$ & 1.312 & 1.314 \\
\hline $\mathrm{C}_{7}-\mathrm{C}_{3}$ & & & & $1.524(4)$ & 1.525 & 1.525 & $1.522(4)$ & 1.524 & 1.524 \\
\hline Li-N & 2.078 & $1.988(4)$ & 2.002 & $2.012(5)$ & 2.056 & 2.036 & $1.968(12)$ & 1.983 & 2.003 \\
\hline Li-O chelate & 1.914 & $1.924(5)$ & 1.931 & $1.874(3)$ & 1.878 & 1.881 & $1.903(15)$ & 1.897 & 1.887 \\
\hline Li-O bridge & 2.026 & $1.976(10)$ & 1.997 & $2.01(4)$ & 2.046 & 2.049 & $1.98(2)$ & 2.014 & 2.036 \\
\hline $\mathrm{O}-\mathrm{C}_{2}-\mathrm{C}_{3}$ & 125.1 & $125.15(16)$ & 125.3 & $124.8(4)$ & 124.9 & 124.91 & $125.2(3)$ & 125.3 & 125.5 \\
\hline $\mathrm{C}_{2}-\mathrm{C}_{3}-\mathrm{C}_{4}$ & 129.1 & $127.82(37)$ & 128.9 & $124.0(3)$ & 124.1 & 125.32 & $123.9(6)$ & 124.4 & 124.7 \\
\hline $\mathrm{C}_{3}-\mathrm{C}_{4}-\mathrm{N}$ & 124.3 & $122.77(24)$ & 123.6 & $123.5(3)$ & 124.8 & 124.96 & 123.3(3) & 123.8 & 124.1 \\
\hline $\mathrm{C}_{4}-\mathrm{N}-\mathrm{C}_{6}$ & 120.7 & $120.29(98)$ & 121.5 & 119.1(11) & 120.8 & 120.58 & 121(1) & 122.0 & 121.4 \\
\hline $\mathrm{O}-\mathrm{Li}-\mathrm{N}$ & 96.0 & $94.77(71)$ & 97.3 & $91.3(4)$ & 92.3 & 96.08 & $92.7(5)$ & 93.9 & 94.7 \\
\hline Li-O-Li & 87.7 & $85.7(19)$ & 85.8 & $86(3)$ & 86.5 & 87.37 & $84.8(14)$ & 85.4 & 85.0 \\
\hline $\mathrm{O}-\mathrm{Li}-\mathrm{O}$ & 91.9 & $94(2)$ & 94.0 & $94(3)$ & 93.2 & 92.57 & $95.0(15)$ & 94.4 & 94.0 \\
\hline $\mathrm{C}_{4}-\mathrm{N}-\mathrm{Li}$ & 120.3 & $124.1(6)$ & 121.7 & $125.7(4)$ & 123.6 & 119.91 & $123.9(9)$ & 124.8 & 122.7 \\
\hline $\mathrm{C}_{2}-\mathrm{O}-\mathrm{Li}$ & 125.1 & 125.1(8) & 123.1 & $130.2(4)$ & 130.0 & 126.04 & $125(3)$ & 127.2 & 125.9 \\
\hline
\end{tabular}

The structure of $\mathbf{3 d}$ (Figure $3 \mathrm{~d}$ ) is the most distorted of the three by a significant margin. The lithium atoms are distinctly out of the best plane of the ligand atoms, either causing or the result of twisting of the chelate rings. However, here too the four chelated $\mathrm{Li}-\mathrm{O}$ distances (mean value, 1.903(15) $\AA$ ) are shorter than the bridging Li-O distances (mean value, 1.98(2) $\AA$ ) but the difference is only $4 \%$. The chelate rings are twisted away from the principal axis which allows for a smaller ligand bite angle and consequently the Li atoms are $0.494 \AA$ out of the least squares plane generated by the five chelate ring atoms.

The shorter $d(\mathrm{~N} \cdots \mathrm{O})$ values for the clusters derived from the backbone-methyl ligands 1c,d are maintained in the cubane clusters. Thus, the average $d(\mathrm{~N} \cdots \mathrm{O})$ value in $\mathbf{3 b}$ is $2.878(13)$, in $3 \mathbf{c}$ $2.780(7)$ and 3d 2.800(2) $\AA$, which is again shorter by about 3\%-4\% when using the methylated ligands. Unsurprisingly this is reflected in a smaller average $\mathrm{N}-\mathrm{Li}-\mathrm{O}$ bite angle for the methylated ligands. The bond distances within the chelate rings in $\mathbf{3 b}-\mathbf{d}$ become even more averaged than in $\mathbf{2 a - c}$. The $\mathrm{O}-\mathrm{C}_{2}$ distances are noticeably longer, presumably because the oxygen is now donating to three lithium ions in the cubane. The geometrical parameters are very well simulated in the DFT calculations, which provides substantial confidence that $3 \mathbf{a}$, for which no crystal structure was obtained, will have a similar geometry. 
There are two previously reported ketoiminate $\mathrm{Li}_{4} \mathrm{O}_{4}$ cluster structures in the CSD. Tetrakis $\left(\mu_{3}-N\right.$-isopropyl-2,4-dimethyl-1-oxa-5-azapenta-2,4-dienyl)-tetralithium (refcode: NOWHOW) adopts the $S_{4}$-symmetric geometry [12], while tetrakis( $\mu_{3}-4$-((3-methoxyphenyl)imino)pent -2-en-2-olato)-tetra-lithium (refcode: WUQFAR) adopts the $D_{2}$ geometry as observed for $\mathbf{3 b}-\mathbf{d}$ [13]. These clusters also possess shorter average Li-O distances within the chelate rings (1.905(5) and 1.915(5) $\AA$, respectively) than for the bridging bonds (2.00(2) and 1.961(1) $\AA$ ).

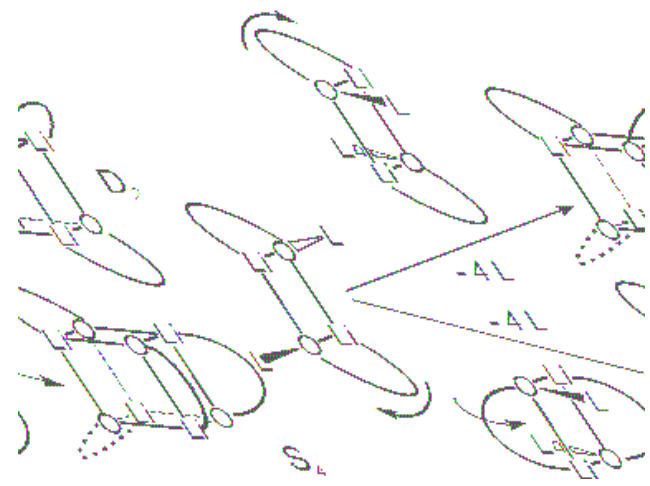

Scheme 3. Dimerization paths of the transoid rings of $\mathbf{2}$ to achieve the known limiting cubane geometries with $\mathrm{D}_{2}$ or $\mathrm{S}_{4}$ symmetry. Note that $\mathbf{3 b}-\mathbf{d}$ all adopt the $\mathrm{D}_{2}$ geometry.

\subsection{Formation and Isomer Selection of $\mathrm{Li}_{4} \mathrm{O}_{4}$ Clusters}

Conceptually, the clusters, whether they adopt the observed $D_{2}$ or the much more commonly observed $S_{4}$ geometry in the tetramers, are the results of combining the molecular squares discussed above for $\mathbf{2} \mathbf{a}-\mathbf{c}$ - the primary laddered units [18] — as diagrammed in Scheme 3. Since the dimers are all transoid, the face to face combination requires not only the displacement of the two coordinated THF molecules ("L" in Scheme 3) but also folding back of one of the two chelate rings because the observed cubane structures contain cisoid rings. The possible final geometries are obtained from the $\mathrm{Li}_{2} \mathrm{O}_{2}$ squares by combining two cisoid rings face-to-face, either in register (top) resulting in $D_{2}$, or out of register (bottom) yielding $S_{4}$. The evidence from synthesis is that formation of the cuboidal clusters is suppressed in THF solution but becomes more favourable on reducing the mole fraction of the coordinating solvent. Note also that the formation of each cubane releases four equivalents of THF, suggesting a likely entropic driving force for the forward reaction.

The evidence from solution NMR obtained in $\mathrm{C}_{6} \mathrm{D}_{6}$ or $1: 1 \mathrm{C}_{6} \mathrm{D}_{6} / \mathrm{THF}-d_{8}$ mixtures shows chemical shifts for free THF for $\mathbf{2} \mathbf{a}-\mathbf{c}$. Moreover, the NMR spectra of $\mathbf{2} \mathbf{b}$ and $\mathbf{3} \mathbf{b}$ in $\mathrm{C}_{6} \mathrm{D}_{6}$ are identical. This suggests that in these solvents, the formation of the $D_{2}$ cuboidal clusters is favoured. It is furthermore the case that both $3 \mathbf{a}$ and $3 \mathbf{c}$ (in which the aromatic group on $\mathrm{N}$ is Dipp) are insoluble in $\mathrm{C}_{6} \mathrm{D}_{6}$ but soluble in the mixed solvent. By contrast, $3 \mathbf{b}$ and $\mathbf{3 d}$ (with Mes on $\mathrm{N}$ ) dissolve in $\mathrm{C}_{6} \mathrm{D}_{6}$. This is contrary to the behaviour of most Dipp compounds, which tend to be very soluble in hydrocarbon solvents. To explain this anomaly, space filling models of the two types of cluster were examined (see Figure A2 in Appendix A). These show a very clear difference in molecule structure, with the Dipp-based structures adopting a very compact spheroidal geometry possessing a very smooth surface that may be difficult to solvate, whereas the Mes-based complexes have large clefts that could be accessed by benzene solvent molecules, aiding solvation.

For confirmation of the hypothesis that the solution forms for all four complexes are the cuboidal $\mathrm{Li}_{4} \mathrm{O}_{4}$ geometry, consider the coordination chemical shifts for the $\mathrm{C} 1$ and $\mathrm{C} 5$ methyl groups (see labels in Figure $2 \mathrm{~d}$ ). The $\mathrm{C} 1$ methyl group ( $\beta$ to the oxygen atom in the ligand) is shifted to higher frequency by from 0.41 to $0.56 \mathrm{ppm}$, whereas the $C 5$ group ( $\beta$ to the nitrogen atom) changes little from the 
free-ligand values. A consideration of the geometries of the transoid $\mathrm{Li}_{2} \mathrm{O}_{2}$ square and cuboidal $\mathrm{Li}_{4} \mathrm{O}_{4}$ structures indicates that only in the latter do the $\mathrm{C} 1$ methyl groups experience significant ring-shielding from the aryl rings of an adjacent ketoiminate ligand (methyl carbon to ring-centroid distances average in the solid-state structures to 4.557 (3b), 4.432 (3c) and 3.881 (3d) $\AA$. Both the distances and the orientation of the aromatic rings in the transoid dimers are markedly less favourable for ring-shielding. Very similar effects and geometrical factors apply for the five-coordinate aluminium bis ketoiminates reported by Yu et al. [7]. In four structurally characterised complexes of ligands $\mathbf{1 a}, \mathbf{b}$ with methyl, ethyl, chloro and fluoro-aluminiums (refcodes BAMFAX, BAMFEB, BAMFIF and BAMFOL, respectively) the average methyl carbon to ring-centroid distances are 3.903, 3.927, 3.904 and $3.912 \AA$; the corresponding $\Delta \delta$ are $+1.17,+1.17,+1.21$ and $+1.21 \mathrm{ppm}$ (see representative structure diagrams in Figure A3 in Appendix A). The larger ring-shielded shifts are consistent with the short distances and a more favourable orientation over the ring centres in these structures compared to $\mathbf{3 b} \mathbf{b} \mathbf{d}$. Note that, by contrast, the monomeric dialkylaluminium complexes of ligand 1a also reported by Yu et al., which cannot experience ring shielding, show no upfield shift compared to the free ligands in the same solvent [7]. The ${ }^{7} \mathrm{Li}$ NMR evidence is less conclusive than that obtained from ${ }^{1} \mathrm{H}$, although possible time-scale differences make comparisons difficult. There is only one lithium resonance in each case, and the frequencies are quite similar. For the samples measured in 1:1 $\mathrm{C}_{6} \mathrm{D}_{6} / \mathrm{THF}-d_{8}$, mixture, sharp singlets are observed around $+2.5 \mathrm{ppm}(2 \mathrm{a}, 2 \mathbf{c}, 3 \mathbf{b})$ but samples in pure $\mathrm{C}_{6} \mathrm{D}_{6}$ can be sharp $(\mathbf{2} \mathbf{b} / \mathbf{3 b})$ or very broad $(\mathbf{2} \mathbf{c}, \mathbf{3 d})$. Low solubility appears to strongly affect the latter two spectra. Overall, though the presence of $\mathbf{2} \leftrightarrow \mathbf{3}$ exchange for samples which contain THF cannot be excluded, the dominant species as judged from the ${ }^{1} \mathrm{H}$ NMR signals (C1 methyl and THF peaks) appear to be 3 .

Relatively simple DFT calculations (B3LYP/6-31G(d)) in the gas-phase were undertaken to help explain the observed chemistry. Good matches could be obtained for the geometries of all the ligands and complexes, and the geometries of the missing complexes (2d, 3a) were included computationally (see results compiled in Tables 1-3). Using these computed structures, the energetics of the conversions of 2 to 3 in the gas phase were computed. The outcomes favour 2 over 3 by 104, 99, 133 and $70 \mathrm{~kJ} \cdot \mathrm{mol}^{-1}$ for a-d, respectively. Evidently these results do not agree with experiment; the inclusion of solvation energies might change these results, but also the entropy associated with the release of THF molecules in the formation of $\mathbf{3}$ may be significant.

DFT was also used to help explain the preference for the $D_{2}$ over the $S_{4}$ geometry for the cuboidal clusters 3 . Such calculations were only undertaken for $3 \mathbf{c}, \mathbf{d}$ and the corresponding $S_{4}$ structures $3 \mathbf{c}^{\prime}$ and $\mathbf{3} \mathbf{d}^{\prime}$. Representative results are shown in Figure 4; the energies calculated for $3 \mathbf{c}^{\prime}$ and $\mathbf{3} \mathbf{d}^{\prime}$ are 23 and $41 \mathrm{~kJ} \cdot \mathrm{mol}^{-1}$ higher than for $\mathbf{3 c}$ and $\mathbf{3 d}$. A consideration of the optimized computed structures suggests that the origin of the difference is steric as there are significant steric clashes in the $S_{4}$ structures that are absent in the preferred $D_{2}$ geometries (see Scheme 4 ).

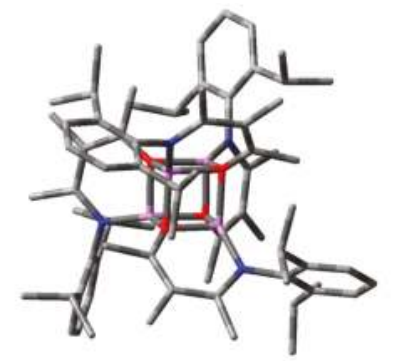

(a)

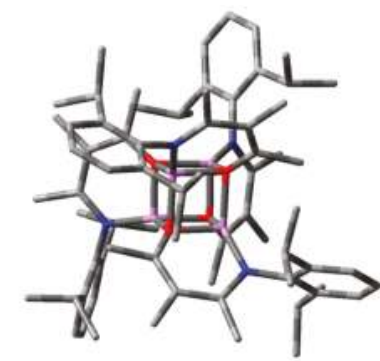

(b)

Figure 4. DFT calculated structures of 3c: (a) in the crystallographically determined $\mathrm{D}_{2}$ geometry; and $(\mathbf{b})$ in the alternate $\mathrm{S}_{4}$ geometry $\left(\mathbf{3} \mathbf{c}^{\prime}\right)$. Hydrogen atoms are omitted. 


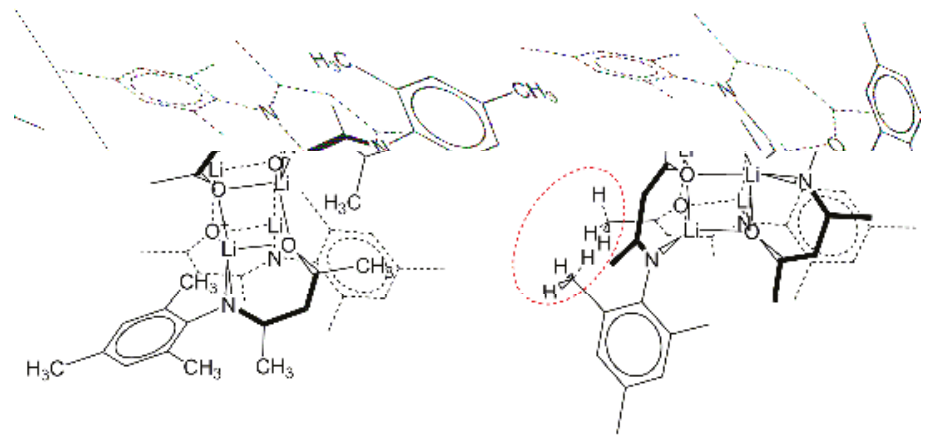

Scheme 4. DFT calculated structures of the cubane clusters $3 b$ with (left) $D_{2}$ or (right) $S_{4}$ symmetry imposed. Note the significant steric clashes in the minimized $\mathrm{S}_{4}$ geometry (dashed red lines).

\section{Materials and Methods}

\subsection{General Methods}

All experimental procedures were performed under a nitrogen atmosphere using modified Schlenk techniques, unless otherwise noted. 2,6-Diisopropylaniline, 2,4,6-trimethylaniline, 2,4-pentanedione, 3-methyl-2,4-pentandione, indium tribromide, 1.6 $\mathrm{M} n$-butyl lithium in hexane (Aldrich, Saint Louis, MO, USA), aluminium chloride (Merck, Kenilworth, NJ, USA), and benzene- $d_{6}$ (CDN Isotopes $0.8 \mathrm{~mL}$ ampules) were used as received. Solvents were reagent grade, or better, and were used as received (methanol, hexanes, pentane, chloroform), distilled from sodium/benzophenone (tetrahydrofuran), or obtained from an MBraun Solvent Purification System (heptane, toluene, benzene, methylene chloride). Infrared spectra were recorded on a Bruker Alpha-P diamond ATR spectrometer (East Milton, ON, Canada) as neat samples. ${ }^{1} \mathrm{H},{ }^{13} \mathrm{C}$, and ${ }^{7} \mathrm{Li}$ NMR spectra were recorded on a Bruker AvanceII spectrometer operating at 300.13, 75.47 and $116.64 \mathrm{MHz}$, respectively. HSQC and HMBC were used to assist with assigning the carbon NMR signals where needed. ${ }^{1} \mathrm{H}$ NMR are referenced to tetramethylsilane (TMS), ${ }^{13} \mathrm{C}$ NMR are referenced to $\mathrm{CDCl}_{3}$ or $\mathrm{C}_{6} \mathrm{D}_{6}$ and ${ }^{7} \mathrm{Li} \mathrm{NMR}$ are referenced to an external $9.7 \mathrm{~mol} / \mathrm{kg} \mathrm{LiCl}$ in $\mathrm{D}_{2} \mathrm{O}$ solution; coupling constants are expressed in $\mathrm{Hz}$. X-ray crystal data were collected on a Bruker Smart Apex II, with solution and refinement using the Shelxtl 6.14 software package. Mass spectra was obtained using a Varian 4000 GC/MS/MS (Palo Alto, CA, USA). Elemental analyses were obtained using an Elementar Vario Micro Cube (Langenselbold, Germany). The ketoimines $\mathbf{1 a} \mathbf{a} \mathbf{b}$ were synthesized by the literature methods [38].

\subsection{Synthesis of Ketoimines}

\subsubsection{4-((2,6-Diisopropylphenyl)amino)-3-methyl-3-methyl-pent-3-en-2-one 1c}

In a round bottom flask $5.00 \mathrm{~g}(43.5 \mathrm{mmol})$ of 3-methyl-2,4-pentandione, $8.85 \mathrm{~g}(43.5 \mathrm{mmol})$ 2,6-diisopropylaniline, and $0.154 \mathrm{~g}(0.435 \mathrm{mmol})$ of $\mathrm{InBr}_{3}$ were combined and allowed to stir overnight. The cloudy solution was then diluted with $60 \mathrm{~mL}$ of distilled water, extracted 3 times with $25 \mathrm{~cm}^{3}$ of ethyl acetate, the organic layers combined and then dried with magnesium sulphate. The solvent was removed under reduced pressure to give colourless solid and orange liquid. The solid was filtered off and recrystallized from hexanes giving pale yellow plates of $1 \mathrm{c}(2.063 \mathrm{~g}, 17.3 \%)$. M.p. $122-129^{\circ} \mathrm{C}$; (Found: C, 78.5; H, 9.6; N, 5.1. $\mathrm{C}_{18} \mathrm{H}_{27} \mathrm{NO}$ requires $\mathrm{C}, 78.7 ; \mathrm{H}, 9.7 ; \mathrm{N}, 5.4 \%$ ); $v_{\max }\left(\right.$ neat) $/ \mathrm{cm}^{-1}$ : 2960s, $2924 \mathrm{~m}, 2867 \mathrm{~m}, 1598 \mathrm{vs}, 1555 \mathrm{vs}, 1464 \mathrm{~s}, 1422 \mathrm{~s}, 1384 \mathrm{~s}, 1352 \mathrm{vs}, 1262 \mathrm{vs}, 1235 \mathrm{~s}, 1169 \mathrm{~s}, 1099 \mathrm{~m}, 1053 \mathrm{~m}$, 966vs, 814vs, 776vs, 709s, 590m, 445m, 414m. NMR $\delta\left({ }^{1} \mathrm{H}, \mathrm{CDCl}_{3}, 25^{\circ} \mathrm{C}\right): 13.18(1 \mathrm{H}, \mathrm{br} \mathrm{s}, \mathrm{NH})$, $7.28(1 \mathrm{H}, \mathrm{t}, J=7.44$, para $\mathrm{CH}), 7.17(2 \mathrm{H}, \mathrm{d}, J=7.44$, meta $\mathrm{CH}), 3.01\left(2 \mathrm{H}\right.$, sept, $\left.J=6.87, \mathrm{CHCH}_{3}\right)$, $2.24\left(3 \mathrm{H}, \mathrm{s}, \mathrm{CH}_{3} \mathrm{C}(\mathrm{O}) \mathrm{C}\right), 1.92\left(3 \mathrm{H}, \mathrm{s}, \mathrm{C}(\mathrm{O}) \mathrm{CCH}_{3}\right), 1.70\left(3 \mathrm{H}, \mathrm{s}, \mathrm{C}(\mathrm{NDipp}) \mathrm{CH}_{3}\right), 1.18(6 \mathrm{H}, \mathrm{d}, J=6.87$, 
$\left.\mathrm{CHCH}_{3}\right), 1.14\left(6 \mathrm{H}, \mathrm{d}, \mathrm{J} 6.87, \mathrm{CHCH}_{3}\right) .8\left({ }^{13} \mathrm{C}_{,} \mathrm{CDCl}_{3}, 25^{\circ} \mathrm{C}\right): 196.02(\mathrm{C}=\mathrm{O}), 161.83(\mathrm{C}-\mathrm{N}), 146.46\left(\mathrm{C}_{\text {ortho }}\right)$, $134.59\left(\mathrm{C}_{\text {ipso }}\right), 127.96\left(\mathrm{C}_{\text {para }}\right), 123.62\left(\mathrm{C}_{\text {meta }}\right), 98.79\left(\mathrm{C}(\mathrm{O}) \mathrm{C}\left(\mathrm{CH}_{3}\right) \mathrm{C}\right), 28.69\left(\mathrm{CH}_{3} \mathrm{C}(\mathrm{O}) \mathrm{C}\right), 28.62\left(\mathrm{CHCH}_{3}\right)$, $24.65\left(\mathrm{CHCH}_{3}\right), 22.91\left(\mathrm{CHCH}_{3}\right), 16.72\left(\mathrm{C}(\mathrm{NDipp}) \mathrm{CH}_{3}\right), 14.98\left(\mathrm{C}(\mathrm{O}) \mathrm{CCH}_{3} \mathrm{C}\right) ; \mathrm{m} / \mathrm{z}(\mathrm{EI}) 273\left(\mathrm{M}^{+}, 18 \%\right)$, 202 (DippNCCH$\left.{ }_{3}{ }^{+}, 100 \%\right), 187\left(\right.$ DippNC $\left.^{+}, 24 \%\right), 160\left(\mathrm{C}_{12} \mathrm{H}_{16}{ }^{+}, 20 \%\right)$.

\subsubsection{4-((2,4,6-Trimethylphenyl)amino)-3-methyl-pent-3-en-2-one 1d}

Procedure as for $1 \mathrm{c}$ from $5.00 \mathrm{~g}(43.5 \mathrm{mmol})$ of 3-methyl-2,4-pentanedione, $5.88 \mathrm{~g}$ ( $43.5 \mathrm{mmol})$ of 2,4,6-trimethylaniline, and $0.154 \mathrm{~g}(0.4344 \mathrm{mmol}) \mathrm{InBr}_{3}$; removal of the solvent gave an orange liquid from which crystals formed after 2 days. The solid was filtered off and recrystallized from hexanes to give faintly orange plates of $\mathbf{1 d}\left(3.619\right.$ g, 36.0\%). M.p. $64-68{ }^{\circ} \mathrm{C}$; (Found: C, 77.7; H, 8.8; N, 6.1. $\mathrm{C}_{15} \mathrm{H}_{21} \mathrm{NO}$ requires $\mathrm{C}, 77.4 ; \mathrm{H}, 8.8 ; \mathrm{N}, 6.4 \%$; $v_{\max }$ (neat) $/ \mathrm{cm}^{-1}$ : 2947w, 2914w, 2859w, 1595s, 1538vs, $1487 \mathrm{~s}, 1435 \mathrm{~m}, 1417 \mathrm{~m}, 1387 \mathrm{~m}, 1367 \mathrm{~m}, 1350 \mathrm{~m}, 1263 \mathrm{vs}, 1198 \mathrm{~s}, 1147 \mathrm{w}, 967 \mathrm{vs}, 884 \mathrm{~m}, 857 \mathrm{~s}, 814 \mathrm{~m}, 760 \mathrm{~m}$, $696 \mathrm{~m}, 588 \mathrm{~m}, 532 \mathrm{w}, 482 \mathrm{~m}$. NMR $\delta\left({ }^{1} \mathrm{H}, \mathrm{CDCl}_{3}, 25^{\circ} \mathrm{C}\right): 12.99(1 \mathrm{H}, \mathrm{br} \mathrm{s}, \mathrm{NH}), 6.89(2 \mathrm{H}, \mathrm{s}, \mathrm{CH}), 2.28(3 \mathrm{H}, \mathrm{s}$, para $\left.\mathrm{CH}_{3}\right), 2.22\left(3 \mathrm{H}, \mathrm{s}, \mathrm{CH}_{3} \mathrm{C}(\mathrm{O}) \mathrm{C}\right), 2.13\left(6 \mathrm{H}\right.$, s, ortho $\left.\mathrm{CH}_{3}\right), 1.91\left(3 \mathrm{H}, \mathrm{s}, \mathrm{C}(\mathrm{O}) \mathrm{CCH}_{3}\right), 1.70\left(\mathrm{~s}, 3 \mathrm{H} ; \mathrm{CH}_{3}\right.$ on $\left.\mathrm{C}(\mathrm{NMes}) \mathrm{CH}_{3}\right) . \delta\left({ }^{13} \mathrm{C}, \mathrm{CDCl}_{3}, 25^{\circ} \mathrm{C}\right): 195.91(\mathrm{C}=\mathrm{O}), 161.60(\mathrm{C}-\mathrm{N}), 136.57\left(\mathrm{C}_{\text {para }}\right), 135.80\left(\mathrm{C}_{\text {ipso }}\right)$, $134.91\left(\mathrm{C}_{\text {ortho }}\right), 128.92\left(\mathrm{C}_{\text {meta }}\right), 98.85\left(\mathrm{C}(\mathrm{O}) \mathrm{C}\left(\mathrm{CH}_{3}\right) \mathrm{C}(\mathrm{NMes}), 28.60\left(\mathrm{CH}_{3} \mathrm{C}(\mathrm{O}) \mathrm{C}\right), 21.02\left(\right.\right.$ para $\left.\mathrm{CH}_{3}\right)$, 18.40 (ortho $\left.\mathrm{CH}_{3}\right), 16.03$ (C(NMes) $\left.\mathrm{CH}_{3}\right), 14.92\left(\mathrm{C}(\mathrm{O}) \mathrm{CCH}_{3}\right) ; \mathrm{m} / z$ (EI) $232\left(\mathrm{MH}^{+}, 100 \%\right), 231\left(\mathrm{M}^{+}, 30 \%\right.$ ), $160\left(\mathrm{MesNCCH}_{3}{ }^{+}, 10 \%\right)$.

\subsection{Synthesis of the Ketoimide Lithium Complexes}

\subsubsection{Lithium Ketoiminate Complex 2a}

A solution of $1.006 \mathrm{~g}(3.878 \mathrm{mmol})$ of $1 \mathrm{a}$ in $8 \mathrm{~mL}$ of dry THF in a Schlenk tube was cooled in an ice/salt bath and $2.5 \mathrm{~mL}$ ( $4.000 \mathrm{mmol})$ of $1.6 \mathrm{M} \mathrm{BuLi}$ in hexanes was added via syringe. Stirring was continued with cooling for $30 \mathrm{~min}$. and then overnight at RT. THF was removed by vacuum until solid started to come out of solution, after which the tube was heated to redissolve the solid and placed in the freezer $\left(-10^{\circ} \mathrm{C}\right)$ to give colourless plates of $2 \mathrm{a}(0.322 \mathrm{~g}, 24.6 \%)$ suitable for X-ray crystallography. M.p. $229-230{ }^{\circ} \mathrm{C}$, dec. $270{ }^{\circ} \mathrm{C}$. NMR $\delta\left({ }^{1} \mathrm{H}, 1: 1\right.$ THF: $\left.\mathrm{C}_{6} \mathrm{D}_{6}, 25^{\circ} \mathrm{C}\right): 1: 30$ ligand:THF): $7.11(2 \mathrm{H}, \mathrm{d}, J=7.25$, meta $\mathrm{CH}), 7.02(1 \mathrm{H}, \mathrm{t}, J=7.25$, para $\mathrm{CH}), 4.82(\mathrm{~s}, 1 \mathrm{H}$; backbone $\mathrm{CH}), 3.59(122 \mathrm{H}, \mathrm{m}, \mathrm{THF}), 3.16(2 \mathrm{H}$, septet, $\left.J=6.82, \mathrm{CHCH}_{3}\right), 1.66\left(\mathrm{~s}, 3 \mathrm{H} ; \mathrm{CH}_{3} \mathrm{C}(\mathrm{O}) \mathrm{C}\right), 1.61(122 \mathrm{H}, \mathrm{m}, \mathrm{THF}), 1.55\left(3 \mathrm{H}, \mathrm{s}, \mathrm{C}(\mathrm{NDipp}) \mathrm{CH}_{3}\right)$, $1.19\left(6 \mathrm{H}, \mathrm{d}, J=6.82, \mathrm{CHCH}_{3}\right), 1.14 \mathrm{ppm}\left(6 \mathrm{H}, \mathrm{d}, J=6.82, \mathrm{CHCH}_{3}\right) . \delta\left({ }^{13} \mathrm{C}, 1: 1 \mathrm{THF}: \mathrm{C}_{6} \mathrm{D}_{6}, 2{ }^{\circ} \mathrm{C}\right)$ : $178.48(C-\mathrm{O}), 168.22(\mathrm{CN}), 148.84\left(C_{\text {ipso }}\right), 140.32\left(C_{\text {ortho }}\right), 123.72\left(C_{\text {para }}\right), 123.52\left(C_{\text {meta }}\right), 96.51$ (backbone $\mathrm{CH}), 28.60\left(\mathrm{CH}_{3} \mathrm{C}(\mathrm{O}) \mathrm{C}\right), 28.17\left(\mathrm{CHCH}_{3}\right), 24.64\left(\mathrm{CHCH}_{3}\right), 24.56\left(\mathrm{CHCH}_{3}\right), 23.09\left(\mathrm{C}(\mathrm{NDipp}) \mathrm{CH}_{3}\right) .8\left({ }^{7} \mathrm{Li}\right.$, 1:1 THF: $\left.\mathrm{C}_{6} \mathrm{D}_{6}, 25^{\circ} \mathrm{C}\right): 2.14$.

\subsubsection{Lithium Ketoiminate Complex 2b}

Procedure as for $\mathbf{2 a}$ from $1.005 \mathrm{~g}(4.624 \mathrm{mmol})$ of $\mathbf{1 b}$ in $9 \mathrm{~mL}$ of THF and $3.0 \mathrm{~mL}$ (4.800 mmol) of 1.6 $\mathrm{M} \mathrm{BuLi}$ in hexanes to give colourless blocks of $\mathbf{2 b}(0.440 \mathrm{~g}, 31.2 \%)$ suitable for crystallography. M.p. 272-274 ${ }^{\circ} \mathrm{C}$ dec. NMR $\delta\left({ }^{1} \mathrm{H}, \mathrm{C}_{6} \mathrm{D}_{6}, 25^{\circ} \mathrm{C}\right): 6.84(2 \mathrm{H}, \mathrm{s}$, meta $\mathrm{CH}), 5.02(1 \mathrm{H}, \mathrm{s}, \mathrm{CH}$ mesityl), $3.57(\mathrm{~m}, 5 \mathrm{H}$, THF), $2.20\left(3 \mathrm{H}, \mathrm{s}\right.$, para $\left.\mathrm{CH}_{3}\right), 2.11\left(6 \mathrm{H}, \mathrm{s}\right.$, ortho $\left.\mathrm{CH}_{3}\right), 1.52\left(3 \mathrm{H}, \mathrm{s}\right.$, ligand $\left.\mathrm{CH}_{3}\right), 1.49\left(3 \mathrm{H}, \mathrm{s}\right.$, ligand $\left.\mathrm{CH}_{3}\right)$, $1.41(5 \mathrm{H}, \mathrm{m}, \mathrm{THF}) .8\left({ }^{13} \mathrm{C}, \mathrm{C}_{6} \mathrm{D}_{6}, 25^{\circ} \mathrm{C}\right): 176.27(\mathrm{C}-\mathrm{O}), 169.14(\mathrm{C}=\mathrm{N}), 147.41,138.22,132.35,129.66,129.28$, 128.56, 128.25, 126.03, 99.20 (backbone $\mathrm{CH}), 28.30\left(\mathrm{CH}_{3}-\mathrm{CO}\right), 22.00$ (para- $\left.\mathrm{CH}_{3}\right), 21.76\left(\mathrm{CH}_{3}\right.$ toluene), $21.32\left(\mathrm{CH}_{3}-\mathrm{CN}\right), 18.52$ (ortho- $\left.\mathrm{CH}_{3}\right) . \delta\left({ }^{7} \mathrm{Li}, \mathrm{C}_{6} \mathrm{D}_{6}, 2{ }^{\circ} \mathrm{C}\right): 2.76 \mathrm{ppm}$.

\subsubsection{Lithium Ketoiminate Complex 2c}

Procedure as for $2 \mathrm{a}$ from $0.930 \mathrm{~g}(3.40 \mathrm{mmol})$ of $\mathbf{1 c}$ in $10 \mathrm{~mL}$ of THF, and $2.2 \mathrm{~mL}(3.5 \mathrm{mmol})$ of 1.6 M BuLi in hexanes to give colourless blocks of $2 \mathrm{c}(0.333 \mathrm{~g} 13.9 \%)$ suitable for crystallography. m.p. $139-145^{\circ} \mathrm{C}$. NMR $\delta\left({ }^{1} \mathrm{H}, 1: 1\right.$ THF: $\mathrm{C}_{6} \mathrm{D}_{6}, 25^{\circ} \mathrm{C}$, containing 1:26 ligand:THF) $7.10(2 \mathrm{H}, \mathrm{d}, J$ 7.49, meta $\mathrm{CH}), 7.00(1 \mathrm{H}, \mathrm{t}, J$ 7 7.49, para $\mathrm{CH}), 3.59(106 \mathrm{H}, \mathrm{m}, \mathrm{THF}), 3.11\left(2 \mathrm{H}\right.$, sept, J 6.86, $\left.\mathrm{CHCH}_{3}\right), 1.85(3 \mathrm{H}, \mathrm{s}$, $\left.\mathrm{C}(\mathrm{O}) \mathrm{CCH}_{3}\right), 1.74\left(3 \mathrm{H}, \mathrm{s}, \mathrm{CH}_{3} \mathrm{C}(\mathrm{O}) \mathrm{C}\right), 1.68\left(3 \mathrm{H}, \mathrm{s}, \mathrm{C}(\mathrm{NDipp}) \mathrm{CH}_{3}\right), 1.63(106 \mathrm{H}, \mathrm{m}, \mathrm{THF}), 1.16(6 \mathrm{H}, \mathrm{d}, J$ 
6.86, $\left.\mathrm{CHCH}_{3}\right), 1.10 \mathrm{ppm}\left(6 \mathrm{H}, \mathrm{d}, J 6.86, \mathrm{CHCH}_{3}\right) . \delta\left({ }^{13} \mathrm{C}, 1: 1\right.$ THF: $\left.\mathrm{C}_{6} \mathrm{D}_{6}, 25 \mathrm{C}\right): 175.21(\mathrm{C}-\mathrm{O}), 169.21(\mathrm{C}-\mathrm{N})$, $149.42\left(C_{\text {ipso }}\right), 140.10\left(C_{\text {ortho }}\right), 123.59\left(C_{\text {meta }}\right), 123.43\left(C_{\text {para }}\right), 98.02\left(\mathrm{C}(\mathrm{O}) C\left(\mathrm{CH}_{3}\right) \mathrm{C}\right), 68.13(\mathrm{THF})$, $28.21\left(\mathrm{CHCH}_{3}\right), 27.97\left(\mathrm{CH}_{3} \mathrm{C}(\mathrm{O}) \mathrm{C}\right), 26.24(\mathrm{THF}), 24.56\left(\mathrm{CHCH}_{3}\right), 24.33\left(\mathrm{CHCH}_{3}\right), 21.73\left(\mathrm{C}(\mathrm{NDipp}) \mathrm{CH}_{3}\right)$, $17.85\left(\mathrm{C}(\mathrm{O}) \mathrm{CCH}_{3} \mathrm{C}\right) . \delta\left({ }^{7} \mathrm{Li}, 1: 1\right.$ THF: $\left.\mathrm{C}_{6} \mathrm{D}_{6}, 25^{\circ} \mathrm{C}\right): 1.33 ; \delta\left({ }^{7} \mathrm{Li}, \mathrm{C}_{6} \mathrm{D}_{6}, 25^{\circ} \mathrm{C}\right): 2.76(\mathrm{br})$.

\subsubsection{Lithium Ketoiminate Complex $3 \mathbf{b}$ Toluene Solvate}

A solution of $0.997 \mathrm{~g}(4.59 \mathrm{mmol})$ of $\mathbf{1 b}$ in $10 \mathrm{~mL}$ of heptane at $0{ }^{\circ} \mathrm{C}$ was treated with $3.0 \mathrm{~mL}$ $(4.8 \mathrm{mmol})$ of $1.6 \mathrm{M} \mathrm{BuLi}$ in hexanes and then heated to $70{ }^{\circ} \mathrm{C}$ to dissolve all solids. After removal of solvent in vacuum, the residue was dissolved in a minimum amount of boiling toluene and placed in the freezer $\left(-10^{\circ} \mathrm{C}\right)$ to give colourless blocks of $3 \mathrm{~b}-\mathrm{C}_{7} \mathrm{H}_{8}$ suitable for $\mathrm{X}$-ray crystallography (m.p. $245-250{ }^{\circ} \mathrm{C}$ dec.) The NMR data showed that the crystals lost some of the toluene over time to reduce to a ratio of 0.4:1. The elemental analysis was performed during the same week as the NMR was performed; therefore, the elemental analysis data given are for the $0.4: 1$ ratio crystal. Found: $\mathrm{C}, 76.1$; $\mathrm{H}, 8.0 ; \mathrm{N}, 6.0 . \mathrm{C}_{58.8} \mathrm{H}_{74.8} \mathrm{~N}_{4} \mathrm{O}_{4} \mathrm{Li}_{4}$ requires: $\mathrm{C}, 76.0 ; \mathrm{H}, 8.2 ; \mathrm{N}, 6.0$. NMR: $\delta\left({ }^{1} \mathrm{H}\right)\left(\mathrm{C}_{6} \mathrm{D}_{6}, 2{ }^{\circ} \mathrm{C}\right) 7.16-7.00$ $\left(2 \mathrm{H}, \mathrm{m}\right.$, solvate $\left.\mathrm{C}_{7} \mathrm{H}_{8}\right), 6.84\left(2 \mathrm{H}\right.$, s, solvate $\left.\mathrm{C}_{7} \mathrm{H}_{8}\right), 5.02(1 \mathrm{H}, \mathrm{s}$, backbone $\mathrm{CH}), 2.20\left(3 \mathrm{H}\right.$, s, solvate $\left.\mathrm{C}_{7} \mathrm{H}_{8}\right)$, $2.11\left(6 \mathrm{H}\right.$, s, ortho $\left.\mathrm{CH}_{3}\right), 1.52$ (s, $3 \mathrm{H}$, Me on backbone), 1.49 (s, $3 \mathrm{H}$, Me on backbone). $\delta\left({ }^{13} \mathrm{C}, \mathrm{C}_{6} \mathrm{D}_{6}, 25^{\circ} \mathrm{C}\right)$ : $176.27(\mathrm{C}-\mathrm{O}), 169.14(\mathrm{C}=\mathrm{N}), 147.41,138.22,132.35,129.66,129.28,128.56,128.25,126.03,99.20(\mathrm{CH}$ on bb), $28.30\left(\mathrm{CH}_{3}-\mathrm{CO}\right), 22.00$ (para- $\left.\mathrm{CH}_{3}\right), 21.76\left(\mathrm{CH}_{3}\right.$ toluene), $21.32\left(\mathrm{CH}_{3}-\mathrm{CN}\right), 18.52$ (ortho- $\left.\mathrm{CH}_{3}\right) .8\left({ }^{7} \mathrm{Li}\right.$, $\left.\mathrm{C}_{6} \mathrm{D}_{6}, 25^{\circ} \mathrm{C}\right): 2.76$.

\subsubsection{Lithium Ketoiminate Complex 3c Solvate}

Procedure as for $\mathbf{3 b}$ from $0.508 \mathrm{~g}(1.858 \mathrm{mmol})$ of $\mathbf{1 c}$ and $1.2 \mathrm{~mL}(1.92 \mathrm{mmol})$ of $1.6 \mathrm{M}$ BuLi, heated to $80{ }^{\circ} \mathrm{C}$ to dissolve. The reaction was then allowed to cool to room temperature which resulted in the formation of white needle-like crystals (m.p. $124.8-131.8^{\circ} \mathrm{C}$, dec.) suitable for crystallography. These crystals do not dissolve in $\mathrm{C}_{6} \mathrm{D}_{6}$ at $25^{\circ} \mathrm{C}$; in 1:1 $\mathrm{C}_{6} \mathrm{D}_{6} / \mathrm{THF}-d_{8}$, the same NMR spectrum is obtained as recorded for $2 \mathrm{c} . \delta\left({ }^{7} \mathrm{Li}, \mathrm{C}_{6} \mathrm{D}_{6}, 25^{\circ} \mathrm{C}\right): \delta=2.45$ (br).

\subsubsection{Lithium Ketoiminate Complex 3d}

Procedure as for $2 \mathrm{a}$ from $0.706 \mathrm{~g}(3.05 \mathrm{mmol}) \mathbf{1 d}$ in $10 \mathrm{~mL}$ of THF and $2.0 \mathrm{~mL}(3.2 \mathrm{mmol})$ of 1.6 $\mathrm{M} \mathrm{BuLi}$ in hexanes. After removal of THF in vacuum, the residue was dissolved on heating in $4 \mathrm{~mL}$ of heptane and $0.7 \mathrm{~mL}$ of dry THF placed in the freezer $\left(-10^{\circ} \mathrm{C}\right)$ to give in yellow crystals of $3 \mathrm{~d}$ suitable for X-ray crystallographic study. m.p. $244-250{ }^{\circ} \mathrm{C}$, dec. NMR: $\delta\left({ }^{1} \mathrm{H}\right)\left(\mathrm{C}_{6} \mathrm{D}_{6}, 25{ }^{\circ} \mathrm{C}\right) 6.86(2 \mathrm{H}, \mathrm{s}$, meta $\mathrm{CH}),(1 \mathrm{H}, \mathrm{s}$, backbone $\mathrm{CH}), 2.21\left(3 \mathrm{H}, \mathrm{s}\right.$, para $\left.\mathrm{CH}_{3}\right), 2.18\left(6 \mathrm{H}, \mathrm{s}\right.$, ortho $\left.\mathrm{CH}_{3}\right), 1.92(3 \mathrm{H}, \mathrm{s}$, backbone $\left.\mathrm{CH}_{3}\right), 1.61\left(3 \mathrm{H}, \mathrm{s}\right.$, backbone $\left.\mathrm{CH}_{3}\right), 1.56\left(3 \mathrm{H}, \mathrm{s}\right.$, backbone $\left.\mathrm{CH}_{3}\right) . \delta\left({ }^{13} \mathrm{C}_{1} \mathrm{C}_{6} \mathrm{D}_{6}, 25^{\circ} \mathrm{C}\right): 172.69,170.08$, $147.83,132.03,129.24,129.07,127.51,100.64,27.36,21.35,20.83,18.25,17.85 .8\left({ }^{7} \mathrm{Li}, \mathrm{C}_{6} \mathrm{D}_{6},{ }^{2} 5^{\circ} \mathrm{C}\right):+1.44$.

\subsection{X-ray Crystallography}

Crystals of $\mathbf{1 a}-\mathbf{d}, \mathbf{2 a}-\mathbf{c}$ and $\mathbf{3 b}-\mathbf{d}$ were mounted on glass fibres in Paratone ${ }^{\mathrm{TM}}$ oil and cooled to $173 \mathrm{~K}$ in a cold gas stream of the Bruker Kryoflex apparatus and reflection data were collected on an Apex II CCD area-detector diffractometer. Data collection was controlled by APEX2, cell refinement and data reduction was performed with SAINT-Plus and a multiscan absorption correction was applied in each case using SADABS [49]. The structures were solved with SHELXS97 and refined with SHELXTL [50]. Key crystal and refinement data are reported in Table A1 (Appendix B), while archival data are provided in the ESI as CIF files. H atoms were refined using a riding model with the exception of the $\mathrm{N}(1)-\mathrm{H}$ atoms in $\mathbf{1 a}-\mathbf{d}$ which were refined freely with isotropic temperature factors. The structure of $\mathbf{3 b}$ contains free toluene in the lattice that is disordered in a typical "head-to-tail" fashion [51] with refined occupancy of 78:22 and retains a high degree of thermal motion even at $173 \mathrm{~K}$. Solvent in the lattice of $3 \mathrm{c}$ was even more poorly defined and we ended up subtracting its contribution to the E-density map using the SQUEEZE routine of PLATON (details in the CIF file) [52]. This lattice solvent is the likely source for higher residuals in both the integration and final refinements for this structure; 
the model for 3c itself seems to be robust despite these factors and the "conventional" R-factor (6.54\%) is in the normal range. CCDC 1540147-1540156 contain the data deposition for the crystal structures. These data can be obtained, free of charge, via http:/ / www.ccdc.cam.ac.uk/products/csd/request/ (or from the Cambridge Crystallographic Data Centre, 12 Union Road, Cambridge CB2 1EZ, UK (Fax: +44-1223-336033 or e-mail: deposit@ccdc.cam.ac.uk)).

\subsection{Computation}

DFT calculations for the molecules were done using B3LYP with the 6-31G(d) basis set using Gaussian 03 and visualized with Gaussview 4.1.2 for Windows [53]. All the geometries could be minimized and frequency calculations verified that these are at least local minima for all cases, except for $4 \mathbf{c}$, for which the geometry never fully converged. The minimized structures are included with the X-ray geometries in the archival CIF file available as ESI.

\section{Conclusions}

This work reports a detailed structural comparison for two types of ketoiminate complexes of lithium from crystal structures obtained during synthesis. From solutions strongly enriched in THF, transoid $\mathrm{Li}_{2} \mathrm{O}_{2}$ squares are generally obtained, with each lithium cation further coordinated by a THF solvent molecule. Changes in structures of the free ligands and the complexes are observed between the common 3,5-dimethylketomines and the more sterically bulky 3,4,5-trimethylketoimines, with shorter cross-ring $\mathrm{O} \cdots \mathrm{N}$ distances in free and coordinated chelate rings. More curious was the observation that with ligand $\mathbf{1 d}$, the cuboidal $\mathrm{Li}_{4} \mathrm{O}_{4}$ structure is formed in the presence of THF. Similar complexes could be obtained for $\mathbf{3 b}$, $\mathbf{d}$ by excluding THF entirely and replacing it with only hydrocarbon solvents. The NMR evidence in either pure deuterated benzene or in benzene/THF mixtures fits for the desolvated cubane structures as the dominant solution species under these conditions. DFT calculations show that the gas-phase energetic preference is for the transoid square complexes; however, this does not take the solvation and especially the entropic preference for the desolvated cubanes into consideration. Whereas Dipp and Mes-substituents are generally regarded as quite similar, the structures of the cuboidal clusters show significant differences between clusters formed from the two classes of ligands. The unexpectedly low solubility of the Dipp derivatives seems to be correlated with a more uniform cluster geometry and a very smooth, unbroken, surface. These results, which contradict the normal solubility trends for Dipp- and Mes-derivatives, will be of interest to those wishing to use the lithium salts as reaction intermediates for ligand transfer to other metals: these lithium $\beta$-ketoiminates are likely to be considerably more reactive when produced and handled in donating solvents such as THF than if they are prepared for use in a non-polar and non-coordinating solvent. With regards to functional properties, it would appear that the external ligand "sheathing" effects can play significant roles and should not be ignored by an undue focus on just the common $\mathrm{Li}_{4} \mathrm{O}_{4}$ core structures.

Supplementary Materials: The following are available online at www.mdpi.com/2304-6740/5/2/30/s1, electronic file in CIF format with crystal coordinate data for $\mathbf{1 a}-\mathbf{d}, \mathbf{2 a}-\mathbf{c}, \mathbf{4 b}-\mathbf{d}$, and DFT optimized geometries from B3LYP/6-31G(d) calculations for $1 \mathbf{a}-\mathbf{d}, \mathbf{2} \mathbf{a}-\mathbf{d}, 3 \mathbf{a}-\mathbf{d}$ and $3 \mathbf{c}^{\prime}, 3 \mathbf{d}^{\prime}$ computed with the alternative $S_{4}$ geometry.

Acknowledgments: We thank the Natural Sciences and Engineering Research Council (Canada) for funding. The diffractometer was purchased with the help of NSERC and the University of Lethbridge. We thank A. Elizabeth Baker for providing valuable assistance and Tony Montina who provided support and training for the high-field NMR experiments. No funding for open access publishing was received.

Author Contributions: Twyla Gietz and René T. Boeré conceived and designed the experiments; Twyla Gietz performed the experiments; Twyla Gietz and René T. Boeré analyzed the data; and Twyla Gietz and René T. Boeré wrote the paper.

Conflicts of Interest: The authors declare no conflict of interest. 


\section{Appendix A}

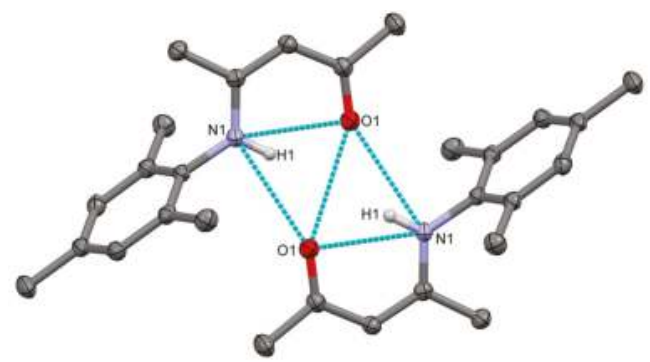

Figure A1. Depiction of the hydrogen-bonding that forms a centrosymmetric dimer in the structure of $\mathbf{1 b}$. The dihedral angle between the $\mathrm{N}_{1}-\mathrm{O}_{1}-\mathrm{N}_{1}{ }^{\prime}-\mathrm{O}_{1}{ }^{\prime}$ and the $\mathrm{O}_{1}-\mathrm{C}_{2}-\mathrm{C}_{3}-\mathrm{C}_{4}-\mathrm{N}_{1}$ planes is only $16.5^{\circ}$.

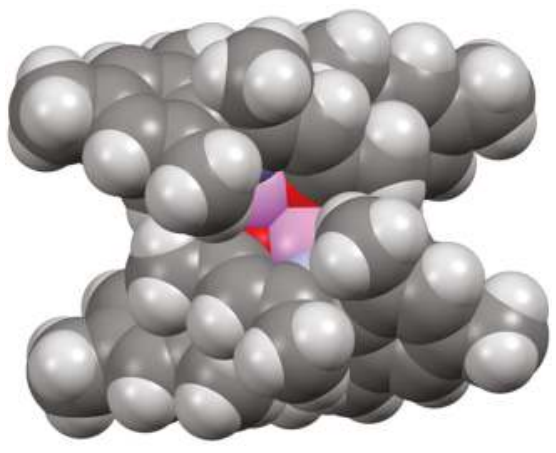

(a)

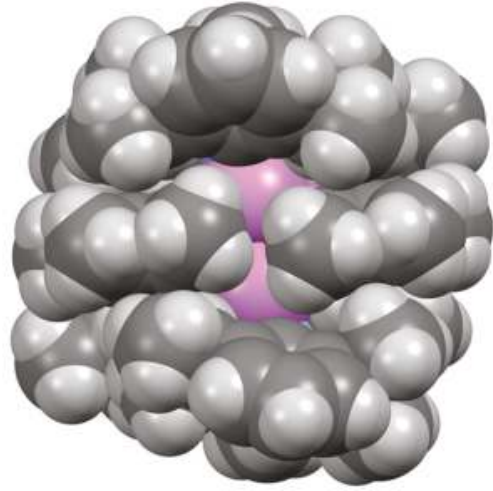

(b)

Figure A2. Space-filling depictions of the cuboidal $\mathrm{Li}_{4} \mathrm{O}_{4}$ ketoiminate clusters (a) $\mathbf{3 b}$ and (b) $\mathbf{3 c}$, emphasizing the globular nature of the latter and the more angular and clefted nature of the former.

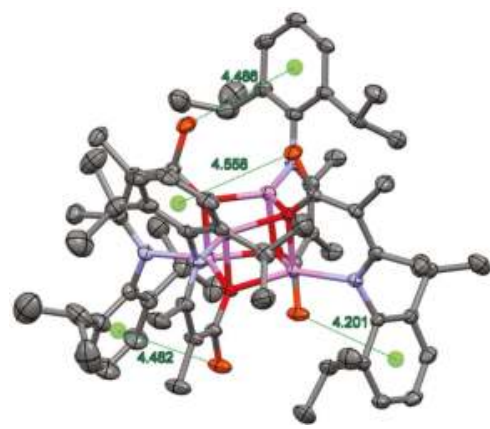

(a)

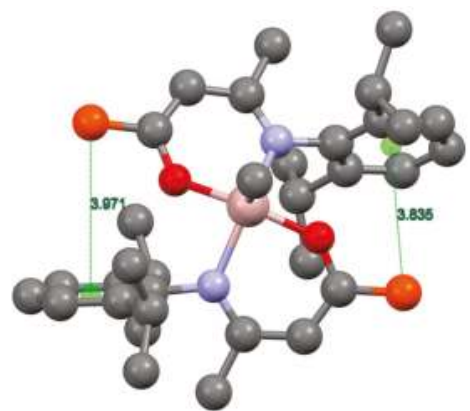

(b)

Figure A3. Orientation and distance of ketoiminate methyl carbon atoms (coloured orange) to aryl ring centroids (light green) of the adjacent ligands. Contrast the longer distances and poorer orientation in (a) $3 \mathbf{b}$ with the more favourable situation in (b) the structure with the refcode BAMFAX (see [7]). 


\section{Appendix B}

Table A1. Crystal data, structure collection and refinement data for X-ray crystallography ${ }^{1}$.

(A)

\begin{tabular}{|c|c|c|c|c|}
\hline Parameter & $1 \mathrm{a}$ & $1 b$ & 1c & $1 d$ \\
\hline Formula & $\mathrm{C}_{17} \mathrm{H}_{25} \mathrm{NO}$ & $\mathrm{C}_{14} \mathrm{H}_{19} \mathrm{NO}$ & $\mathrm{C}_{18} \mathrm{H}_{27} \mathrm{NO}$ & $\mathrm{C}_{15} \mathrm{H}_{21} \mathrm{NO}$ \\
\hline FW, amu & 259.38 & 217.30 & 273.41 & 231.33 \\
\hline $\mathrm{T}, \mathrm{K}$ & $173(2)$ & $173(2)$ & $173(2)$ & $173(2)$ \\
\hline$\lambda, \AA$ & 0.71073 & 0.71073 & 0.71073 & 0.71073 \\
\hline Crystal system & orthorhombic & monoclinic & orthorhombic & monoclinic \\
\hline Space group & Pccn & $P 2_{1} / n$ & $P 2{ }_{1} 2_{1} 2_{1}$ & $\mathrm{C} 2 / \mathrm{c}$ \\
\hline Cell: $a, \AA$ & $12.3641(12)$ & $10.0068(6)$ & $6.7423(4)$ & $18.8762(17)$ \\
\hline$b, \AA$ & $16.3858(16)$ & $9.8961(6)$ & $13.9706(8)$ & $8.0097(7)$ \\
\hline$c, \AA$ & $15.4945(15)$ & $12.7933(8)$ & $18.0631(10)$ & $19.0037(17)$ \\
\hline$\alpha$, & 90 & 90 & 90 & 90 \\
\hline$\beta$, & 90 & $99.1380(10)$ & 90 & $107.5430(10)$ \\
\hline$\gamma,{ }^{\circ}$ & 90 & 90 & 90 & 90 \\
\hline $\mathrm{V}, \AA^{3}$ & $3139.1(5)$ & $1250.82(13)$ & $1701.44(17)$ & $2739.6(4)$ \\
\hline Z & 8 & 4 & 4 & 8 \\
\hline$D_{\text {calc }}, \mathrm{g} / \mathrm{cm}^{3}$ & 1.098 & 1.154 & 1.067 & 1.112 \\
\hline$\mu, \mathrm{mm}^{-1}$ & 0.067 & 0.072 & 0.065 & 0.069 \\
\hline$F(000)$ & 1136 & 472 & 600 & 1008 \\
\hline Cryst. size, $\mathrm{mm}^{3}$ & $0.54 \times 0.41 \times 0.20$ & $0.27 \times 0.25 \times 0.14$ & $0.42 \times 0.20 \times 0.14$ & $0.43 \times 0.34 \times 0.16$ \\
\hline$\theta \min , \max ,{ }^{\circ}$ & $2.06,26.73$ & $2.41,27.10$ & $1.84,27.40$ & $2.25,27.48$ \\
\hline$h \min , \max$ & $-15,15$ & $-12,12$ & $-8,8$ & $-24,24$ \\
\hline$k \min , \max$ & $-20,20$ & $-12,12$ & $-18,18$ & $-10,10$ \\
\hline$l \mathrm{~min}, \max$ & $-19,19$ & $-16,16$ & $-23,23$ & $-24,24$ \\
\hline $\mathrm{Rfl}_{\text {all }}$ & 40165 & 17205 & 24505 & 19053 \\
\hline $\mathrm{Rfl}_{\text {indep }}, \mathrm{R}_{\mathrm{int}}$ & $3338,0.0561$ & $2762,0.0254$ & $2224,0.0285$ & $3153,0.0240$ \\
\hline Compl., $\theta,{ }^{\circ}$ & $100,26.73$ & $99.9,27.10$ & $100,25.25$ & $99.9,27.48$ \\
\hline Abs corr. & \multicolumn{4}{|c|}{ semi-empirical from equivalents } \\
\hline Max/min trans. & $0.9868,0.9646$ & $0.9914,0.9378$ & $0.9916,0.9279$ & $0.9918,0.9169$ \\
\hline Data & 3338 & 2762 & 2224 & 3153 \\
\hline Restraints & 0 & 0 & 0 & 0 \\
\hline Parameters & 182 & 153 & 191 & 163 \\
\hline GOF & 1.032 & 1.047 & 1.031 & 1.053 \\
\hline$R_{1}(I>2 \sigma I)$ & 0.0428 & 0.0462 & 0.0407 & 0.0465 \\
\hline$w R_{2}$ (all data) & 0.1201 & 0.1349 & 0.1172 & 0.1402 \\
\hline Max, $\min , e \cdot \AA^{-3}$ & $0.20,-0.21$ & $0.26,-0.31$ & $0.20,-0.18$ & $0.26,-0.22$ \\
\hline
\end{tabular}

(B)

\begin{tabular}{cccc}
\hline Parameter & $\mathbf{2 a}$ & $\mathbf{2 b}$ & $\mathbf{2}$ \\
\hline Formula & $\mathrm{C}_{42} \mathrm{H}_{64} \mathrm{Li}_{2} \mathrm{~N}_{2} \mathrm{O}_{4}$ & $\mathrm{C}_{36} \mathrm{H}_{52} \mathrm{Li}_{2} \mathrm{~N}_{2} \mathrm{O}_{4}$ & $\mathrm{C}_{44} \mathrm{H}_{68} \mathrm{Li}_{2} \mathrm{~N}_{2} \mathrm{O}_{4}$ \\
$\mathrm{FW}$, amu & 674.83 & 590.68 & 702.88 \\
$T, \mathrm{~K}$ & $173(2)$ & $173(2)$ & $173(2)$ \\
$\lambda, \AA$ & 0.71073 & 0.71073 & 0.71073 \\
Crystal system & triclinic & monoclinic & monoclinic \\
Space group & $P \overline{1}$ & $P 2_{1} / c$ & $P 2_{1} / n$ \\
Cell: $a, \AA$ & $9.4060(8)$ & $8.0148(5)$ & $20.843(5)$ \\
$b, \AA$ & $10.7931(9))$ & $15.0628(9)$ & $10.495(2)$ \\
$c^{\circ} \AA$ & $11.9959(10)$ & $14.5918(9)$ & $21.365(5)$ \\
$\alpha,{ }^{\circ}$ & $69.0400(10$ & 90 & 90 \\
$\beta^{\circ}$ & $73.6160(10)$ & $103.8550(10)$ & $112.886(2)$ \\
$\gamma^{\circ}$ & $67.0160(10)$ & 90 & 90 \\
$V^{\circ} \AA^{3}$ & $1032.50(15)$ & $1710.35(18)$ & $4305.7(17)$ \\
$Z$ & 1 & 2 & 4 \\
$D_{\text {calc }}, \mathrm{g} / \mathrm{cm}^{3}$ & 1.085 & 1.147 & 1.084 \\
$\mu, m^{-1}$ & 0.067 & 0.073 & 0.067 \\
$F(000)$ & 368 & 640 & 1536 \\
\hline
\end{tabular}


Table A1. Cont.

(B)

\begin{tabular}{|c|c|c|c|}
\hline Parameter & $2 a$ & $2 b$ & $2 \mathrm{c}$ \\
\hline Cryst. size, $\mathrm{mm}^{3}$ & $0.36 \times 0.20 \times 0.12$ & $0.39 \times 0.18 \times 0.11$ & $0.46 \times 0.19 \times 0.17$ \\
\hline$\theta \min , \max ,^{\circ}$ & $1.84,26.03$ & $1.97,27.48$ & $1.75,27.48$ \\
\hline$h \min , \max$ & $-11,11$ & $-10,10$ & $-27,27$ \\
\hline$k \min , \max$ & $-13,13$ & $-19,19$ & $-13,13$ \\
\hline$l \min , \max$ & $-14,14$ & $-18,18$ & $-27,27$ \\
\hline $\mathrm{Rfl}_{\mathrm{all}}$ & 10854 & 19537 & 60577 \\
\hline $\mathrm{Rfl}_{\text {indep }}, \mathrm{R}_{\text {int }}$ & $4040,0.0245$ & $3919,0.0373$ & $9865,0.0250$ \\
\hline Compl.,\%; $\theta,^{\circ}$ & $99.6,25.25$ & $100.0,25.25$ & $99.9,27.48$ \\
\hline Abs corr. & \multicolumn{3}{|c|}{ semi-empirical from equivalents } \\
\hline Max/min trans. & $0.9918,0.9136$ & $0.9916,0.8956$ & $0.9918,0.9266$ \\
\hline Data & 4040 & 3919 & 9865 \\
\hline Restraints & 0 & 0 & 0 \\
\hline Parameters & 232 & 204 & 483 \\
\hline GOF & 1.035 & 1.025 & 1.030 \\
\hline$R_{1}(I>2 \sigma I)$ & 0.0464 & 0.0495 & 0.0453 \\
\hline$w R_{2}$ (all data) & 0.1274 & 0.1409 & 0.1285 \\
\hline Max, min, $e \cdot \AA^{-3}$ & $0.23,-0.19$ & $0.24,-0.25$ & $0.32,-0.21$ \\
\hline
\end{tabular}

(C)

\begin{tabular}{|c|c|c|c|}
\hline Parameter & $3 b$ & $3 c$ & $3 d$ \\
\hline Formula & $\mathrm{C}_{56} \mathrm{H}_{72} \mathrm{Li}_{4} \mathrm{~N}_{4} \mathrm{O}_{4} \cdot \mathrm{C}_{7} \mathrm{H}_{8}$ & $\mathrm{C}_{72} \mathrm{H}_{104} \mathrm{Li}_{4} \mathrm{~N}_{4} \mathrm{O}_{4}$ & $\mathrm{C}_{60} \mathrm{H}_{80} \mathrm{Li}_{4} \mathrm{~N}_{4} \mathrm{O}_{4}$ \\
\hline FW, amu & 985.07 & 1117.35 & 949.04 \\
\hline$T, \mathrm{~K}$ & $173(2)$ & $173(2)$ & $173(2)$ \\
\hline$\lambda, \AA$ & 0.71073 & 0.71073 & 0.71073 \\
\hline Crystal system & orthorhombic & monoclinic & monoclinic \\
\hline Space group & $P 2_{1} 2_{1} 2_{1}$ & $P 2_{1} / n$ & $P 2_{1} / n$ \\
\hline Cell: $a, \AA$ & $13.7530(9)$ & $14.3398(14)$ & $13.0543(11)$ \\
\hline$b, \AA$ & $18.3062(13)$ & 27.504(3) & $26.647(2)$ \\
\hline$c, \AA$ & $24.0904(17)$ & $19.8735(19)$ & $16.4965(14)$ \\
\hline$\alpha,{ }^{\circ}$ & 90 & 90 & 90 \\
\hline$\beta,{ }^{\circ}$ & 90 & $107.4870(10)$ & $91.2180(10)$ \\
\hline$\gamma, \circ$ & 90 & 90 & 90 \\
\hline$V, \AA^{3}$ & $6065.1(7)$ & $7475.9(13)$ & $5737.1(8)$ \\
\hline Z & 4 & 4 & 4 \\
\hline$D_{\text {calc }}, \mathrm{g} / \mathrm{cm}^{3}$ & 1.079 & 0.993 & 1.099 \\
\hline$\mu, \mathrm{mm}^{-1}$ & 0.065 & 0.059 & 0.067 \\
\hline$F(000)$ & 2120 & 2432 & 2048 \\
\hline Cryst. size, $\mathrm{mm}^{3}$ & $0.48 \times 0.40 \times 0.24$ & $0.69 \times 0.27 \times 0.13$ & $0.40 \times 0.22 \times 0.22$ \\
\hline$\theta \min , \max ,{ }^{\circ}$ & $1.69,27.48$ & $1.66,25.03$ & $1.75,27.48$ \\
\hline$h \min , \max$ & $-17,17$ & $-17,17$ & $-16,16$ \\
\hline$k \min , \max$ & $-23,23$ & $-32,32$ & $-34,34$ \\
\hline$l \min , \max$ & $-31,31$ & $-23,23$ & $-21,21$ \\
\hline Measured rfl & 70155 & 88683 & 82309 \\
\hline Indep. rfl, $\mathrm{R}_{\text {int }}$ & 76040.0372 & $13200,0.0921$ & $13161,0.0572$ \\
\hline Compl., $\% ; \theta, \circ$ & $100.0,25.25$ & $100.0,25.03$ & $100.0,27.48$ \\
\hline Abs corr. & \multicolumn{3}{|c|}{ semi-empirical from equivalents } \\
\hline Max/min trans. & $0.9842,0.9692$ & $0.9918,0.8738$ & $0.9843,0.9016$ \\
\hline Data & 7604 & 13200 & 13161 \\
\hline Restraints & 84 & 0 & 0 \\
\hline Parameters & 762 & 785 & 673 \\
\hline GOF & 1.039 & 0.985 & 1.011 \\
\hline$R_{1}(I>2 \sigma I)$ & 0.0386 & 0.0654 & 0.0532 \\
\hline$w R_{2}$ (all data) & 0.1077 & 0.1786 & 0.1478 \\
\hline Max, $\min , e \cdot \AA^{-3}$ & $0.21,-0.16$ & $0.25,-0.19$ & $0.26,-0.19$ \\
\hline
\end{tabular}

${ }^{1}$ See deposited CIF files for full data. 


\section{References}

1. Cho, M.H.; Yoon, J.S.; Lee, I.M. Efficient bimodal ring-opening polymerization of $\varepsilon$-caprolactone catalyzed by titanium complexes with $N$-alkoxy- $\beta$-ketoiminate ligands. Bull. Korean Chem. Soc. 2007, 28, 2471-2476.

2. Wang, L.Y; Wu, Q. Ethylene polymerization catalyzed by Pd-based $\beta$-ketoiminato complexes/MAO systems. Eur. Polym. J. 2007, 43, 3970-3975. [CrossRef]

3. Peng, H.; Zhang, Z.; Qi, R.; Yao, Y.; Zhang, Y.; Shen, Q.; Cheng, Y. Synthesis, reactivity, and characterization of sodium and rare-earth metal complexes bearing a dianionic $N$-aryloxo-functionalized $\beta$-ketoiminate ligand. Inorg. Chem. 2008, 47, 9828-9835. [CrossRef] [PubMed]

4. Lee, D.H.; Cho, M.H.; Kwon, I.H.; Jun, I.C.; Lee, I.M.; Jin, M.J. Palladium phosphanyl- $\beta$-ketoiminate complexes as highly active catalysts for Heck coupling reaction. Catal. Commun. 2008, 9, 1517-1520. [CrossRef]

5. Lim, S.W.; Lee, J.C.; Shon, D.S.; Lee, W.I.; Lee, I.M. A study on the development of chemical vapor deposition precursors. 4. Syntheses and characterization of new $N$-alkoxo- $\beta$-ketoiminate complexes of niobium and tantalum. Chem. Mater. 2002, 14, 1548-1554. [CrossRef]

6. Lim, S.W.; Choi, B.; Min, Y.S.; Lee, S.S. A study on the development of CVD precursors V—Syntheses and characterization of new $N$-alkoxy- $\beta$-ketoiminate complexes of titanium. J. Organomet. Chem. 2004, 689, 224-237. [CrossRef]

7. Yu, R.C.; Hung, C.H.; Huang, J.H.; Lee, H.Y.; Chen, J.T. Four- and five-coordinate aluminum ketiminate complexes: Synthesis, characterization, and ring-opening polymerization. Inorg. Chem. 2002, 41, 6450-6455. [CrossRef] [PubMed]

8. Kuo, P.C.; Chen, I.C.; Chang, J.C.; Lee, M.T.; Hu, C.H.; Hung, C.H.; Lee, H.M.; Huang, J.H. Hydroalumination of carbon dioxide, carbon disulfide, and phenyl isocyanate with an aluminum ketiminate compound. Eur. J. Inorg. Chem. 2004, 24, 4898-4906. [CrossRef]

9. Ouattara, T.S.; Butcher, R.J.; Matthews, J.S. Synthesis and characterization of bis[4-N-(cyclohexylimino)-2pentanonato]magnesium(II). J. Coord. Chem. 2005, 58, 461-465. [CrossRef]

10. Jones, D.; Roberts, A.; Cavell, K.; Keim, W.; Englert, U.; Skelton, B.; White, A. Synthesis of new adducts and co-ordination complexes of zirconium and titanium containing $\beta$-aminoketone ligands. Crystal structures of isostructural adducts $\mathrm{MCl} 4 \cdot 2 \mathrm{Pr}^{i} \mathrm{HNCMe}=\mathrm{CHCMe}=\mathrm{O}(\mathrm{M}=\mathrm{Ti}$ or $\mathrm{Zr})$ and the complex $[\mathrm{Zr}(\mathrm{PhNCMe}$ $=\mathrm{CHCMe}=\mathrm{O})_{2} \mathrm{Cl}_{2}$ ]. J. Chem. Soc. Dalton Trans. 1998, 2, 255-262. [CrossRef]

11. Hsu, S.; Chang, J.; Lai, C.; Hu, C.; Lee, H.M.; Lee, G.; Peng, S.; Huang, J. Terminal titanium-ligand multiple bonds. Cleavages of $\mathrm{CdO}$ and $\mathrm{CdS}$ double bonds with Ti imido complexes. Inorg. Chem. 2004, 43, 6786-6792. [CrossRef] [PubMed]

12. Brehon, M.; Cope, E.K.; Mair, F.S.; Nolan, P.; O'Brien, J.E.; Pritchard, R.G.; Wilcock, D.J. Structural studies of lithiated enaminones: the 1-oxa-5-azapentadienyllithium fluxional heterocubane $\left[\left(\operatorname{Pr}^{i} \mathrm{NCMeCHCMeOLi}\right)_{4}\right]$ and its dimeric hexamethylphosphoric triamide complex [ $\left.\left\{\mathrm{Pr}^{i} \mathrm{NCMeCHCMeOLi} \cdot \mathrm{OP}\left(\mathrm{NMe}_{2}\right)_{3}\right\}_{2}\right]$. J. Chem. Soc. Dalton Trans. 1997, 19, 3421-3425. [CrossRef]

13. Olejník, R.; Padělková, Z.; Horáček, M.; Ružiča, A. Structure of $\beta$-diketiminates and $\beta$-aminoketones made from anisidines or chloroanilines: tin and lithium complexes. Main Group Met. Chem. 2012, 35, 13-27. [CrossRef]

14. Liu, Z.; Chen, H.-X.; Huang, D.; Zhang, Y.; Yao, Y.-M. A facile route to lithium complexes supported by $\beta$-ketoiminate ligands and their reactivity. J. Organomet. Chem. 2014, 749, 7-12. [CrossRef]

15. Clegg, W.; Dale, S.H.; Graham, D.V.; Harrington, R.W.; Hevia, E.; Hogg, L.M.; Kennedy, A.R.; Mulvey, R.E. Structural variations in bimetallic sodium-magnesium and sodium-zinc ketimides, and a sodium-zinc alkide-alkoxide-amide: Connections to ring-stacking, ring-laddering, and inverse crown concepts. Chem. Commun. 2007, 16, 1641-1643. [CrossRef] [PubMed]

16. Gregory, K.; Schleyer, P.v.R.; Snaith, R. Structures of organonitrogen-lithium compounds: Recent patterns and perspectives in organolithium chemistry. Adv. Inorg. Chem. 1991, 37, 47-142.

17. Mulvey, R.E. Meldola Medal Lecture. Ring-stacking and ring-laddering in organonitrogenlithium compounds: The development of concepts with wide applicability throughout lithium structural chemistry. Chem. Soc. Rev. 1991, 20, 167-209. [CrossRef]

18. Downward, A.; Chivers, T. Applications of the laddering principle-A two-stage approach to describe lithium heterocarboxylates. Eur. J. Inorg. Chem. 2001, 9, 2193-2201. [CrossRef] 
19. Neculai, D.; Neculai, A.M.; Roesky, H.W.; Magul, J.; Bunkòczi, G. Synthesis and structure of a new fluorinated $\beta$-ketoiminato ligand and its lithium derivative. J. Fluor. Chem. 2002, 118, 131-134. [CrossRef]

20. Hsu, S.-H.; Li, C.-Y.; Chiu, Y.-W.; Chiu, M.-C.; Lien, Y.-L.; Kuo, P.-C.; Lee, H.M.; Huang, J.-H.; Cheng, C.-P. Synthesis and characterization of $\mathrm{Cu}(\mathrm{I})$ and $\mathrm{Cu}(\mathrm{II})$ complexes containing ketiminate ligands. J. Organomet. Chem. 2007, 692, 5421-5428. [CrossRef]

21. Lyashenko, G.; Saischek, G.; Judmaier, M.E.; Volpe, M.; Baumgartner, J.; Belaj, F.; Jancik, V.; Herbst-Irmer, R.; Mosch-Zanetti, N.C. Oxo-molybdenum and oxo-tungsten complexes of Schiff bases relevant to molybdoenzymes. Dalton Trans. 2009, 29, 5655-5665. [CrossRef] [PubMed]

22. Granum, D.M.; Riedel, P.J.; Crawford, J.A.; Mahle, T.K.; Wyss, C.M.; Begej, A.K.; Arulsamy, N.; Pierce, B.S.; Mehn, M.P. Synthesis and characterization of sterically encumbered $\beta$-ketoiminate complexes of iron(II) and zinc(II). Dalton Trans. 2011, 40, 5881-5890. [CrossRef] [PubMed]

23. Kakaliou, L.; Scanlon, W.J., IV; Qian, B.; Baek, S.W.; Smith, M.R., III; Motry, D.H. Five- and six-coordinate group 4 compounds stabilized by $\beta$-ketiminate and diketiminate ligands: Syntheses and comparisons between solid-state and solution structures. Inorg. Chem. 1999, 38, 5964-5977. [CrossRef] [PubMed]

24. Rat, C.; Comsa, C.; Silvestru, C. Dichlorido[(Z)-4-(2,6-diisopropylanilino)pent-3-en-2-one]dimethyltin(IV). Acta Crystallogr. Sect. E Struct. Rep. Online 2010, 66, m130. [CrossRef] [PubMed]

25. Comşa, C.; Cristea, A.; Varga, R.A.; Silvestru, C. Organotin(IV) complexes of $\beta$-ketimines. Crystal and molecular structure of $\mathrm{OC}(\mathrm{Me}) \mathrm{CHC}(\mathrm{Me}) \mathrm{NHR}-4\left[\mathrm{R}=\mathrm{C}_{6} \mathrm{H}_{3}{ }^{i} \mathrm{Pr}_{2-2}{ }^{\prime}, 6^{\prime} ; \mathrm{C}_{6} \mathrm{H}_{4} \mathrm{Me}-4^{\prime}\right], \mathrm{Bu}_{2} \mathrm{SnCl}_{2}(\mathrm{~L})$ and $\left[\left\{\mathrm{Me}_{2} \mathrm{SnCl}_{2}(\mathrm{~L})\right]_{2}\left[\mathrm{~L}=\mathrm{OC}(\mathrm{Me}) \mathrm{CHC}(\mathrm{Me}) \mathrm{NH}\left(\mathrm{C}_{6} \mathrm{H}_{3}{ }^{\mathrm{i}} \mathrm{Pr}_{2-2}{ }^{\prime}, 6^{\prime}\right)-4\right]\right.$. Rev. Roum. Chim. 2010, 55, 811-822.

26. Lugo, A.F.; Richards, A.F. Ketiminate-supported LiCl cages and group 13 complexes. Eur. J. Inorg. Chem. 2010, 13, 2025-2035. [CrossRef]

27. Lesikar, L.A.; Gushwa, A.F.; Richards, A.F. Synthesis, characterization, and steric hindrance comparisons of selected transition and main group metal $\beta$-ketoiminato complexes. J. Organomet. Chem. 2008, 693, 3245-3255. [CrossRef]

28. Lugo, A.F.; Richards, A.F. Ketiminato and ketimine $\mathrm{Co}, \mathrm{Eu}, \mathrm{Cu}$ and Fe complexes. Inorg. Chim. Acta 2010, 363, 2104-2112. [CrossRef]

29. Boeré, R.T.; Klassen, V.; Wolmershäuser, G. Synthesis of some very bulky $N, N^{\prime}$-disubstituted amidines and initial studies of their coordination chemistry. J. Chem. Soc. Dalton Trans. 1998, 24, 2341-2345. [CrossRef]

30. Boeré, R.T.; Klassen, V.; Wolmershäuser, G. Superamidines 2. Synthesis of the bulky ligand N,N'-bis-(2,6diisopropylphenyl)-trifluoroacetamidine and its molybdenum carbonyl complex. Can. J. Chem. 2000, 78, 583-589. [CrossRef]

31. Boeré, R.E.; Boeré, R.T.; Masuda, J.; Wolmershäuser, G. Preparation, X-ray structure, and dynamic solution behaviour of $N, N^{\prime}, N^{\prime \prime}$-tris(2,6-diisopropylphenyl)-guanidine, and its reaction with molybdenum carbonyl. Can. J. Chem. 2000, 78, 1613-1619. [CrossRef]

32. Boeré, R.T.; Cole, M.L.; Junk, P.C.; Masuda, J.D.; Wolmershäuser, G. An N,P-disubstituted-2aminophosphaalkene and lithium and potassium complexes of the deprotonated "phosphaamidinate" anion. Chem. Commun. 2004, 22, 2564-2565. [CrossRef] [PubMed]

33. Boeré, R.T.; Cole, M.L.; Junk, P.C. The syntheses and structures of some main group complexes of the sterically hindered $N, N^{\prime}$-bis(2,6-diisopropylphenyl)-4-toluamidinate ligand. New J. Chem. 2005, 29, 128-134. [CrossRef]

34. Boeré, R.T.; Roemmele, T.L.; Suduweli Kondage, S.; Zhou, J.; Parvez, M. Five related $N^{\prime}-(2,2,2-$ trichloroethanimidoyl)benzene-1-carboximidamides. Acta Cryst. 2011, C67, o273-o277.

35. Roemmele, T.L.; Boeré, R.T. 4-Methyl- $N^{\prime}$-(2,2,2-trichloroethanimidoyl)benzene-1-carboximidamide. Acta Cryst. 2011, E67, o3137. [CrossRef] [PubMed]

36. Vitanova, D.V.; Hampel, F.; Hultzsch, K.C. Rare earth metal complexes based on $\beta$-diketiminato and novel linked bis( $\beta$-diketiminato) ligands: Synthesis, structural characterization and catalytic application in epoxide $/ \mathrm{CO}_{2}$-copolymerization. J. Organomet. Chem. 2005, 690, 5182-5197. [CrossRef]

37. Boeré, R.T.; Gietz, T. Butylbis[ $\mu-4-(2,4,6$-trimethylphenylamino)pent-3-en-2-onato][4-(2,4,6trimethylphenylamino)pent-3-en-2-onato]dimagnesium. Acta Cryst. 2009, E65, m1137-m1138. [CrossRef] [PubMed]

38. Zhang, Z.-H.; Yin, L.; Wang, Y.-M. A general and efficient method for the preparation of $\beta$-enamino ketones and esters catalyzed by indium tribromide. Adv. Synth. Catal. 2006, 348, 184-190. [CrossRef] 
39. Dudek, G.O.; Holm, R.H. Nuclear magnetic resonance studies of keto-enol equilibria. III. $\alpha, \beta$-unsaturated- $\beta$ ketoamines. J. Am. Chem. Soc. 1962, 84, 2691-2696. [CrossRef]

40. Benito-Garagorri, D.; Kirchner, K.; Mereiter, K. CCDC 274968: Experimental Crystal Structure Determination; Cambridge Crystallographic Data Centre: Cambridge, UK, 2006. [CrossRef]

41. Wright, J.A. CCDC 661234: Experimental Crystal Structure Determination; Cambridge Crystallographic Data Centre: Cambridge, UK, 2008. [CrossRef]

42. Lin, T.-H.; Das, K.; Datta, A.; Leu, W.-J.; Hsiao, H.-C.; Lin, C.-H.; Guh, J.-H.; Huang, J.-H. Synthesis and characterization of ruthenium compounds incorporating keto-amine ligands. The applications of catalytic transfer hydrogenation and cancer cell inhibition. J. Organomet. Chem. 2016, 807, 22-28. [CrossRef]

43. Boeré, R.T.; Zhang, Y. Extremely bulky triarylphosphines incorporating 2,6-diisopropylphenyl substituents; consideration of steric shielding and steric pressure. J. Organomet. Chem. 2005, 690, 2651-2657. [CrossRef]

44. Zhang, L.; Brookhart, M.; White, P.S. Synthesis, characterization, and ethylene polymerization activities of neutral nickel(II) complexes derived from anilino-substituted enone ligands bearing trifluoromethyl and trifluoroacetyl substituents. Organometallics 2006, 25, 1868-1874. [CrossRef]

45. Kascheres, C.; Negri, G.; Gambardella, M.T.P.; Santos, R.H.A. X-ray crystal structure and AM1 optimized sctructure for 4-methylamino-3-diphenylacetyl-3-penten-2-one. J. Braz. Chem. Soc. 1994, 5, 31-37. [CrossRef]

46. Kabak, M.; Elmali, A.; Elerman, Y. Tautomeric properties, conformations and structure of $\mathrm{N}$-(2-hydroxyphenyl)4-amino-3-penten-2-on. J. Mol. Struct. 1998, 470, 295-300. [CrossRef]

47. Lide, D.R. Handbook of Chemistry and Physics, 85th ed.; CRC Press: Boca Raton, FL, USA, 2004.

48. Raissi, H.; Bakavol, M.; Jimenez-Fabian, I.; Tajabadi, J.; Mdoshfeghi, E.; Jalbout, A.F. Effect of substitution on the intramolecular hydrogen bonding of 4-amino-3-penten-2-one: Ab initio, AIM and NBO studies. J. Mol. Struct. THEOCHEM 2007, 847, 47-51. [CrossRef]

49. APEX2, SAINT-Plus and SADABS; Bruker AXS Inc.: Madison, WI, USA.

50. Sheldrick, G.M. A short history of SHELX. Acta Cryst. 2008, A64, 112-122. [CrossRef] [PubMed]

51. Müller, P. (Ed.) Crystal Structure Refinement: A Crystallographer's Guide to SHELXL; OUP: Oxford, UK, 2006.

52. Spek, A.L. PLATON-A multipurpose crystallographic tool. Acta Cryst. 1990, A46, C34.

53. Frisch, M.J.; Trucks, G.W.; Schlegel, H.; Scuseria, G.E.; Robb, M.A.; Cheeseman, J.R.; Montgomery, J.A., Jr.; Vreven, T.; Kudin, K.N; Burant, J.C.; et al. Gaussian 03, Revision C.02; Gaussian, Inc.: Wallingford, CT, USA, 2004.

(C) 2017 by the authors. Licensee MDPI, Basel, Switzerland. This article is an open access article distributed under the terms and conditions of the Creative Commons Attribution (CC BY) license (http:/ / creativecommons.org/licenses/by/4.0/). 
Article

\title{
Synthesis and Characterization of a Sulfonyl- and Iminophosphoryl-Functionalized Methanide and Methandiide
}

\author{
Kai-Stephan Feichtner and Viktoria H. Gessner* \\ Lehrstuhl für Anorganische Chemie II, Ruhr-Universität Bochum, Universitätsstraße 150, \\ 44780 Bochum, Germany; kai-stephan.feichtner@rub.de \\ * Correspondence: viktoria.gessner@rub.de; Tel.: +49-234-32-24174
}

Academic Editor: Matthias Westerhausen

Received: 2 November 2016; Accepted: 29 November 2016; Published: 2 December 2016

\begin{abstract}
The synthesis of $\left[\mathrm{H}_{2} \mathrm{C}\left(\mathrm{PPh}_{2}=\mathrm{NSiMe}_{3}\right)\left(\mathrm{SO}_{2} \mathrm{Ph}\right)\right](\mathbf{1})$ and its mono- and dimetalation are reported. Due to the strong anion-stabilizing abilities of the iminophosphoryl and the sulfonyl group monometalation to $\mathbf{1}-\mathrm{K}$ and dimetalation to $\mathbf{1}-\mathbf{L i}_{2}$ proceed smoothly with potassium hydride and methyllithium, respectively. Both compounds could be isolated in high yields and were characterized by NMR spectroscopy as well as XRD analysis. The methanide 1-K forms a coordination polymer in the solid state, while in case of the methandiide a tetrameric structure is observed. The latter features an unusual structural motif consisting of two $\left(\mathrm{SO}_{2} \mathrm{Li}\right)_{2}$ eight-membered rings, which are connected with each other via the methandiide carbon atoms and additional lithium atoms. With increasing metalation a contraction of the P-C-S linkage is observed, which is well in line with the increased charge at the central carbon atom and involved electrostatic interactions.
\end{abstract}

Keywords: methandiides; lithium; potassium; molecular structures

\section{Background}

In the past 20 years, methandiides with a doubly metalated carbon atom $\left(\mathrm{R}_{2} \mathrm{CM}_{2}\right.$ with $\mathrm{M}$ mostly being $\mathrm{Li}$ ) have attracted intense research interest in organometallic chemistry. This is mainly due to their applicability as ligands for the preparation of carbene-type complexes by simple salt metathesis reactions [1-3]. Thereby, methandiides revealed to be highly efficient ligand systems stabilizing a variety of carbene complexes with main group metals [4-7], early and late transition metals [8-12] as well as lanthanides and actinides [13-16]. The first dilithium compound, which was employed in this chemistry, was the bis(iminophosphorano) system $\left\{\mathrm{Li}_{2}\left(\operatorname{bipm}^{\mathrm{TMS}}\right)\right\}_{2}\left(\mathrm{~A}, \mathrm{bipm}^{\mathrm{TMS}}=\mathrm{C}\left(\mathrm{PPh}_{2} \mathrm{NSiMe}_{3}\right)_{2}\right)$, which was simultaneously reported by the groups of Cavell and Stephan in 1999 (Figure 1) [17,18]. Unlike all other methandiides reported before [19-21], A was found to be conveniently accessible by double deprotonation and isolable in high yields, thus allowing its application in carbene complex synthesis [22]. The high stability and facile synthesis of $\mathbf{A}$ can be explained by the strong anion-stabilizing ability of the $\mathrm{P}(\mathrm{V})$ moieties as well as the additional nitrogen donor side-arms, which efficiently coordinate lithium to form stable complexes. Analogously, the corresponding thiophosphoryl system $\mathbf{B}$ reported by Le Floch also proved to be a stable and powerful ligand system [23-25]. More recently, our group has focused on non-DPPM derived methandiides, to expand the carbene chemistry of these compounds also to ligands with other substituents. The dilithium compound $\mathbf{C}$ with a sulfonyl functionality turned out to be easily accessible and similarly stable than the bis(phosphonium)-substituted systems [26]. The weaker coordination ability of the sulfonyl group also gave way to the formation of transition-metal complexes with open coordination-sides [27-29]. 

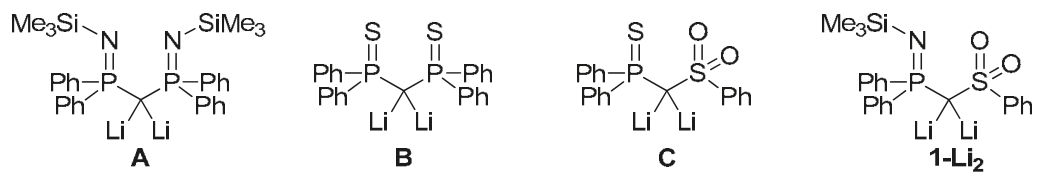

Figure 1. Isolated dilithiomethanes used as ligands for carbene complex formation.

Besides their applicability in carbene complex chemistry, methandiides are also interesting reagents because of their structural properties. Analogous to simple organolithium reagents [30-32], structure formation is dominated by the presence or absence of additional donor functions within the molecule. Non-functionalized methandiides typically form polymeric structures to complete the coordination sphere of lithium, such as in the case of parent dilithiomethane, $\mathrm{H}_{2} \mathrm{CLi}_{2}$ [33], or dilithiated fluorene D (Figure 2) [20]. In contrast, donor side-arms lead to the formation of defined cluster structures [19]. For instance, the DPPM-based systems A and B and derivatives thereof typically form dimeric structures with a central structural motif consisting of a $\mathrm{Li}_{4}$ and $\mathrm{Li}_{2} \mathrm{C}_{2}$ four-membered ring perpendicular to each other $[17,18,34-38]$. This motif is also present in the structures of the heavier alkali metal derivatives $[39,40]$. An interesting monomeric structure was isolated by the introduction of the sterically demanding Dipp substitutents (Dipp = 2,6-Di(iso-propyl)phenyl) into the bipm framework together with TMEDA as additional Lewis base [41]. Most interestingly, this compound showed in contrast to the van't Hoff rule a planar rather than a tetrahedral geometry at the metalated carbon atom. Such a planar carbon environment was already predicted by Schleyer and coworkers on the basis of theoretical studies [42]. The unsymmetrical methandiide $\mathbf{C}$ was found to form a complex molecular structure, which however also showed a strong deviation from the ideal tetrahedral geometry of carbon [26].
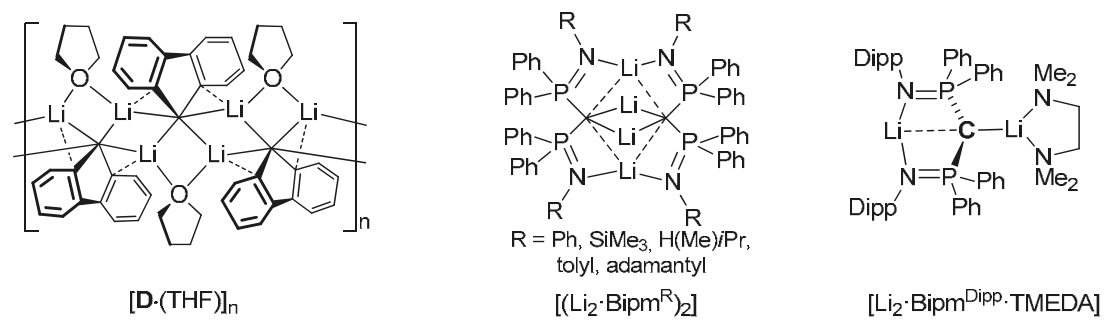

Figure 2. Structures of dilithium methandiides.

Overall, small changes in the structure of methandiides can easily lead to big differences in their reactivity and the structure formation in the solid state. For example, replacement of the sulfonyl group in $\mathbf{C}$ by a sulfoximine moiety lead to an increased reactivity and decreased stability of the methandiide as well as the formation of a different structure in the solid state, which hampered its utilization as ligand in transition-metal chemistry [43]. However, due to the efficiency of methandiide $\mathbf{C}$ as ligand in carbene complexes, we became interested in the preparation of the iminophosphoryl derivative 1- $\mathbf{L i}_{2}$ (Figure 1). Besides its syntheses we particularly addressed the elucidation of the molecular structures of the mono- and dimetallated compounds in comparison to the thiophosphoryl system.

\section{Results}

\subsection{Synthesis of the Protonated Precursor 1}

In order to examine the influence of the electronic and steric properties of the iminophosphoryl group on the accessibility, reactivity and structure of methandiide $\mathbf{1}-\mathbf{L i}_{\mathbf{2}}$ we chose the protonated precursor 
1 with a sterically demanding trimethylsilyl (TMS) group at the imino nitrogen atom, since this group has most often been used in other methandiide systems. To this end, the synthetic strategy outlined in Figure 3 was used. At first, phenyl methyl sulfone was deprotonated with $n$-butyl lithium and reacted with chlorodiphenylphosphine, followed by a subsequent oxidation of the phosphine moiety with $\mathrm{H}_{2} \mathrm{O}_{2}$ [27]. Recrystallization from ethanol afforded phosphine oxide 2 as a colourless solid in $87 \%$ yield. Next, phosphine oxide 2 was treated with oxalyl bromide in DCM. After filtration, phosphine bromide 3 could be isolated as a colourless to slightly yellow solid in 91\% yield [44]. Compound 3 shows a single signal in the ${ }^{31} \mathrm{P}\left\{{ }^{1} \mathrm{H}\right\}$ NMR spectrum at $18.7 \mathrm{ppm}$ in deuterated DMSO and a characteristic doublet at $5.10 \mathrm{ppm}$ with a coupling constant of ${ }^{2} \mathrm{JH}_{\mathrm{PH}}=9.95 \mathrm{~Hz}$ in the ${ }^{1} \mathrm{H}$ NMR spectrum. The formation of the iminophosphoryl moiety was achieved by treatment of phosphine bromide 3 with hexamethyldisilazane (HMDS) and subsequent deprotonation with $\mathrm{NEt}_{3}$ [45]. Recrystallization from toluene/hexane yielded the $\alpha$-iminophosphoryl-substituted sulfone 1 as colourless crystals in $88 \%$ yield. The ${ }^{31} \mathrm{P}\left\{{ }^{1} \mathrm{H}\right\} \mathrm{NMR}$ spectrum exhibits a single signal at $-12.7 \mathrm{ppm}$ and the hydrogen atoms of the methylene bridge resonate as a doublet at $3.94 \mathrm{ppm}$ with a coupling constant of ${ }^{2} J_{\mathrm{PH}}=9.79 \mathrm{~Hz}$. The crystal structure of iminophosphoryl 1 is depicted in Figure 3. 1 crystallizes in the triclinic space group P-1 and shows typical bond lengths and angles compared to those in related compounds. Sole exception is the P1-N1-Si1 angle with an high value of 160.4(9) ${ }^{\circ}$ [46-49]. In comparison, the symmetric bis(iminophosphoryl)methane, $\left(\mathrm{Me}_{3} \mathrm{SiNPPh}_{2}\right)_{2} \mathrm{CH}_{2}$, featured an angle of $138.5(1)^{\circ}$.
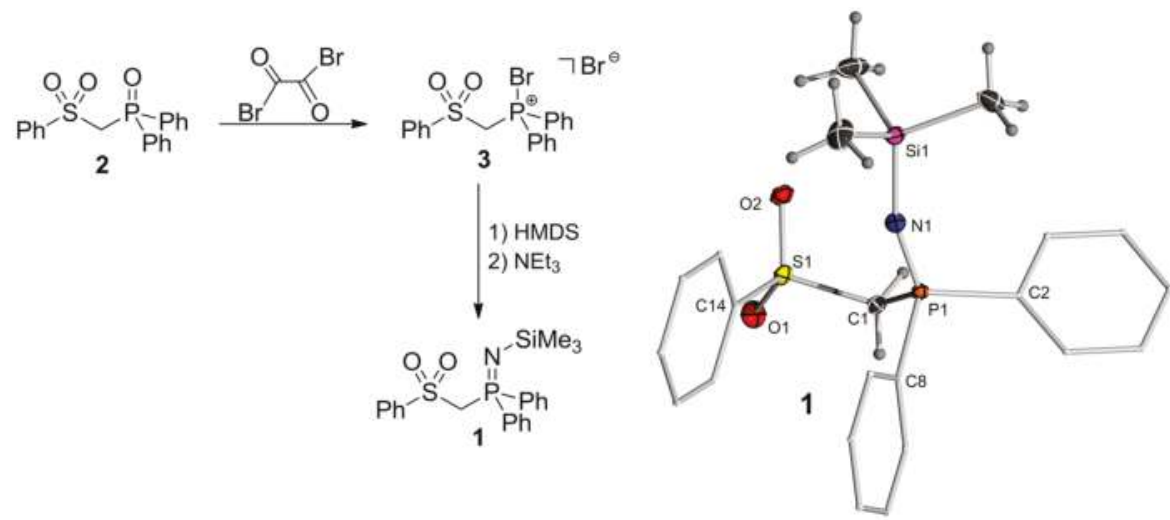

Figure 3. Synthesis of the $\alpha$-iminophosphoryl-substituted sulfone $\mathbf{1}$ and molecular structure of $\mathbf{1}$. Ellipsoids drawn at the 50\% probability level. Hydrogen atoms (except for those at C1) omitted for clarity. Selected bond lengths $(\AA)$ and angles $\left({ }^{\circ}\right)$ : C1-S1 1781(2), C1-P1 1844(2), S1-O1 1446(1), S1-O2 1.439(1), P1-N1 1.523(1), N1-Si1 1.681(1), S1-C14 1.763(2), P1-C2 1.819(2), P1-C8 1.816(2), S1-C1-P1 117.2(1), P1-N1-Si1 160.3(1).

\subsection{Preparation of Methanide $\mathbf{1}-\mathbf{K}$ and Methandiide $\mathbf{1}-\mathbf{L i}_{\mathbf{2}}$}

To evaluate the effects of the sulfonyl and the iminophosphoryl group on the deprotonation behavior of compound $\mathbf{1}$ we next aimed at the synthesis of the corresponding mono- and dimetallated species (Figure 4). Single deprotonation was selectively achieved with a series of different metal bases, as evidenced by a single new signal in the ${ }^{31} \mathrm{P}\left\{{ }^{1} \mathrm{H}\right\}$ NMR spectrum at $-1.18 \mathrm{ppm}$ and the signal of the methanide hydrogen at $2.38 \mathrm{ppm}$ with a coupling constant of ${ }^{2} J_{\mathrm{PH}}=10.8 \mathrm{~Hz}$ in the ${ }^{1} \mathrm{H}$ NMR spectrum. Convenient isolation of the methanide could be achieved by employment of $\mathrm{KH}$, which allowed the isolation of 1-K as a colourless solid in $89 \%$ yield. 1-K is stable over weeks under inert gas atmosphere and exhibits—despite the TMS functionalization — a remarkably low solubility in common organic solvents. Thus all NMR studies had to be performed in deuterated DMSO. Crystals suitable for X-ray 
diffraction analysis could be obtained by diffusion of pentane into a saturated solution of compound $\mathbf{1 - K}$ in THF.

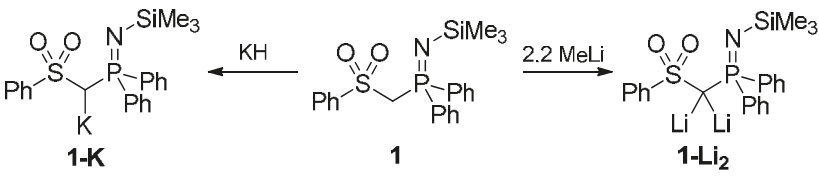

Figure 4. Synthesis of $1-\mathrm{K}$ and $1-\mathrm{Li}_{2}$.

1-K crystallizes as a coordination polymer in the triclinic space group $P$ - 1 . This observation is well in line with the poor solubility of monoanion 1-K. The asymmetric unit contains a dimeric structural motif with one non-coordinating THF molecule (not shown in Figure 5). The two monomeric subunits of this pseudo $C_{2}$-symmetric dimer $\left(K_{1}-K_{2}=C_{2}\right.$ axis $)$ are connected via two potassium atoms. Both show a slightly different coordination environment: While potassium atom $\mathrm{K} 1$ is coordinated by the nitrogen atoms of both iminophosphoryl substituents, the oxygen and the phenyl group of the sulfonyl moieties and two protons of a TMS-group, potassium atom K2 is solely coordinated by the oxygens of the sulfonyl moieties and the iminophosphoryl phenyl rings. Completion of the coordination sphere of $\mathrm{K} 2$ is finally achieved through coordination of the sulfonyl groups of two adjacent dimers, thus leading to the polymeric structure in the solid state. The potassium atoms show no contacts to the carbon atoms of the methylene groups which leads to a planar geometry with sums of angles of $359(4)^{\circ}$ and $360(6)^{\circ}$ with slightly widened P-C-S angles of $120.09(18)^{\circ}$ and $123.05(18)^{\circ}$, respectively, compared to the neutral compound 1 (from 117.17(8)). The most important feature of the molecular structure of $\mathbf{1 - K}$ is the shortening of the C-P bonds (from 1.8441(15) $\AA$ to

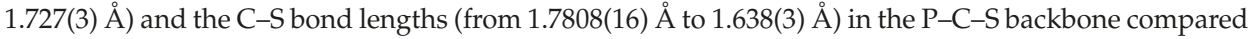
to the protonated precursor 1 . This can be explained with electrostatic interactions between the negativ charge at the methylene carbon and the positive charges at the phosphorous and the sulfur. At the same time, an elongation of the P-N bond from 1.5229(13) $\AA$ to $1.569(2) \AA$ and $1.562(2) \AA$, respectively, can be observed which is due to negative hyperconjugation of the lone pair of the methanide carbon into the antibonding $\sigma^{*}$ orbitals of the P-N bonds.

The preparation of the dianionic species $\mathbf{1}-\mathbf{L i}_{\mathbf{2}}$ was achieved by reaction with a slight excess of $\mathrm{MeLi}$ in $\mathrm{Et}_{2} \mathrm{O}$. Addition of MeLi to a suspension of $\mathbf{1}$ in $\mathrm{Et}_{2} \mathrm{O}$ led to a complete solvation followed by the formation of a colourless solid after a few minutes. Removal of the supernatant solution and drying of the obtained solid in vacuo gave dianionic species $\mathbf{1 - L i _ { 2 }}$ in $78 \%$ yield. The ${ }^{31} \mathrm{P}\left\{{ }^{1} \mathrm{H}\right\} \mathrm{NMR}$ spectrum shows a single signal at $7.63 \mathrm{ppm}$. The ${ }^{1} \mathrm{H}$ NMR spectrum confirms the successful double deprotonation through the absence of the protons of the methylene bridge and shows additional coordinating diethyl ether. The ${ }^{7} \mathrm{Li}$ NMR spectrum shows two signals at 0.19 and 1.67 ppm thus indicating the formation of an unsymmetrical structure with different coordination spheres of the two lithium atoms. This assumption is further supported by the presence of two separate sets of signals for the two phosphorous bound phenyl rings speaking for a diastereotopic behavior. X-ray quality crystals could be obtained by performing the reaction without stirring in a larger volume of solvent leading to the direct crystallization of the product. The crystal structure of methandiide 1- $\mathbf{L i}_{2}$ is shown in Figure 6. 


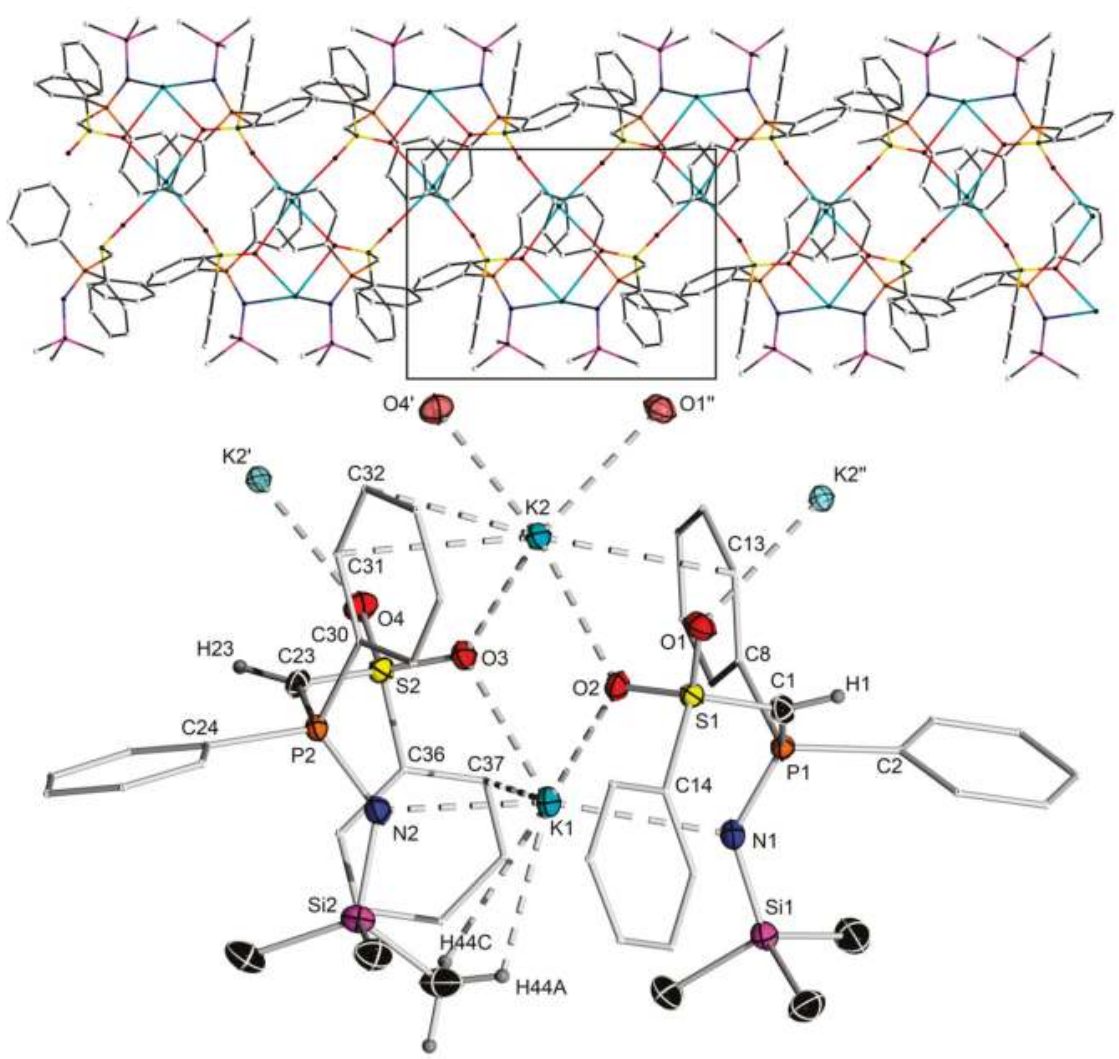

Figure 5. Polymeric structure of monometalated system 1-K (top); and highlighted asymmetric unit (bottom). Ellipsoids drawn at the 50\% probability level. Hydrogen atoms (except for the methylene bridge) and solvent molecule omitted for clarity. Connecting atoms of neighboring asymmetric units shown for clarity. Selected bond lengths $(\AA)$ and angles $\left({ }^{\circ}\right)$ : C1-P1 1728(3), C1-S1 1.637(3), P1-N1 1.569(2), P1-C2 1.820(3), P1-C8 1.823(3), N1-Si2 1.691(2), S1-O1 1.446(2), S1-O2 1.4602(19), S1-C14 1.787(3), C23-P2 1.726(3), C23-S2 1.639(3), P2-C24 1.813(3), P2-C30 1.820(3), P2-N2 1.562(2), N2-Si2 1.683(2), S2-O3 1.462(2), S2-O4 1.444(2), S2-C36 1.790(3), K1-N1 2.843(2), K1-N2 2.817(2), K1-O2 2.611(2), K1-O3 2.704(2), K1-C37 3.262(3), K1-H44A 2.84(3), K1-H44C 2.94(4), K2-O2 2.6907(19), K2-O3 2.711(2), K2-C13 3.354(3), K2-C31 3.223.(3), K2-C32 3.321(3), K2-O1” 2.703(2), K2-O4' 2.593(2), P1-C1-S1 123.05(18), P1-N1-Si1 134.44(15), P1-C1-H1 120(2), H1-C1-S1, 116(2), P2-C23-S2 120.09(18), P2-N2-Si2 133.31(15), P2-C23-H23 119(3), H23-C23-S2 121(3). 

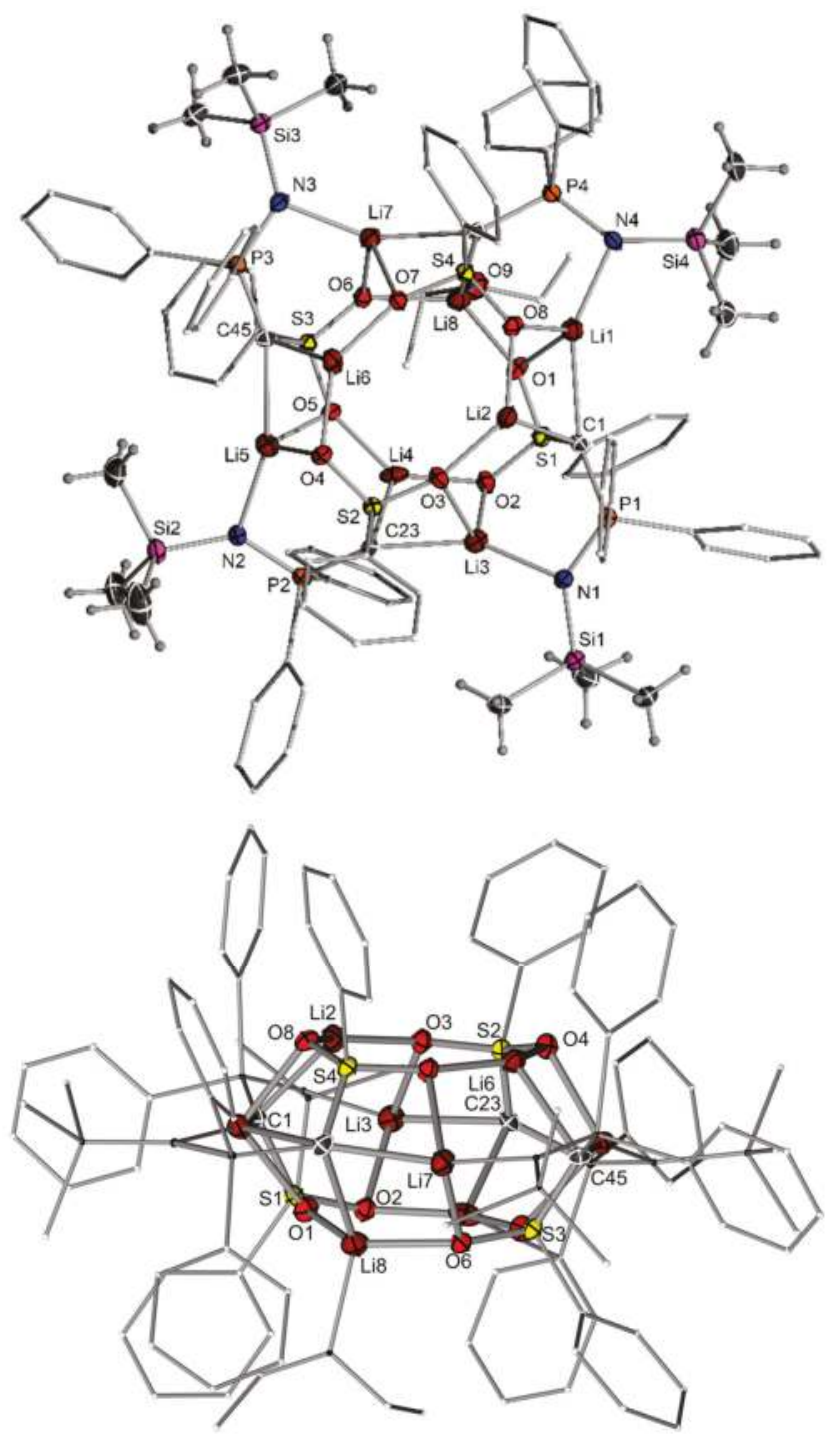

Figure 6. Displays of the crystal structure of methandiide 1-Li 2 . Ellipsoids drawn at the $50 \%$ probability level. Non-coordinating diethyl ether molecules and hydrogen atoms omitted for clarity. For bond lengths and angles, see Figure 7.

Methandiide 1- $\mathbf{L i}_{2}$ crystallizes in the monoclinic space group $P 2{ }_{1} / \mathrm{c}$. The asymmetric unit consists of a pseudo-tetrameric complex, whose S4 symmetry however is broken due to the coordination of only one additional diethyl ether molecule (to Li8). The central structural motif is formed by two almost planar $\left(\mathrm{SO}_{2} \mathrm{Li}\right)_{2}$ eight-membered rings, which are connected with each other via the methandiide carbon atoms and additional four lithium atoms. The four lithium atoms of the $\left(\mathrm{SO}_{2} \mathrm{Li}\right)_{2}$ rings are solely coordinated by the sulfonyl moieties and the methanide carbon atoms. These lithium atoms are only three-fold coordinated, except for Li8, which is also coordinated by the ether molecule. The other four lithium atoms (Li1, Li3, Li5 and Li7) are coordinated by the sulfonyl oxygen atoms, the methanide 
atom and the nitrogen atom of the iminophosphoryl group, thus having a coordination number of four. Overall, this complexation formally leads to two different types of lithium atoms bound to each methandiide carbon atom, which is well in line with the two signals observed in the ${ }^{7} \mathrm{Li}$ NMR spectrum. A detailed view of a monomeric subunit can be seen in Figure 7.

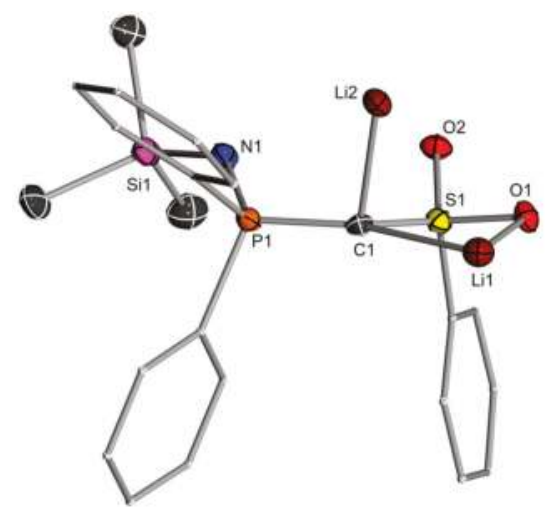

Figure 7. Monomeric subunit of methandiide 1-Li 2 . Ellipsoids drawn at the $50 \%$ probability level. Hydrogen atoms omitted for clarity. Selected bond lengths $(\AA)$ and angles $\left(^{\circ}\right)$ : C1-S1 1.601(3), C1-P1 1.714(3), C1-Li1 2.337(6), C1-Li2 2.200(6), S1-O1 1.490(2), S1-O2 1.499(2) S1-C14 1.788(3), P1-N1 1.583(3), P1-C2 1.831(3), P1-C8 1.827(3), N1-Si1 1.700(3), O1-Li1 2.050(6), O1-Li8 1.898(6), O2-Li4 1.885(6), Li2-O8 1.889(6), Li2-O3 1.862(6), S1-C1-P1 121.98(19), P1-N1-Si1 137.57(17).

The Li-C bond lengths with an average value of 2.235(6) $\AA$ are in the expected range compared to known methandiides featuring sulfonyl or iminophosphoryl groups $[3,17,26]$. The Li-N contacts are (with an average bond length of $2.006 \AA$ ) a bit shorter than those found in other iminophosphoryl stabilized geminal dianions, while the Li-O bonds (with an average length of 1.973(6) A) are well in line with reported data $[3,17]$. The central P-C-S backbone shows an even stronger contraction than in the monoanionic species 1-K, with an average P-C bond length of 1.714(3) $\AA$ and an average S-C bond length of 1.608(3) A speaking for even stronger electrostatic interactions (for a comparison of all bond length, see Table 1). The same strengthening can be observed for the negative hyperconjugation effects, which lead to even further elongated bond lengths for the P-N and especially S-O bonds with average values of 1.586(3) $\AA$ and 1.494(2) $\AA$ respectively. These observations are consistent with those reported for other mono- and dimetallated systems [14-20]. For example, the bond length changes in 1- $\mathbf{L i}_{\mathbf{2}}$ are similar to those found in the corresponding thiophosphoryl compound C (Table 1), despite of the different structures formed in the solid state [26].

Table 1. Comparison of structural parameters (average values for $\mathrm{S}-\mathrm{O}$ bonds, $\mathbf{1 - K}$ and $\mathbf{1}-\mathbf{L i}_{2}$ ).

\begin{tabular}{ccccc}
\hline Bond & $\mathbf{1}$ & $\mathbf{1 - K}$ & $\mathbf{1 - \mathbf { L i } _ { \mathbf { 2 } }}$ & $\mathbf{C}$ \\
\hline $\mathrm{C}-\mathrm{S}(\AA)$ & $1.7807(16)$ & $1.638(3)$ & $1.608(3)$ & $1.613(3)$ \\
$\mathrm{C}-\mathrm{P}(\AA)$ & $1.8441(15)$ & $1.727(3)$ & $1.714(3)$ & $1.710(3)$ \\
$\mathrm{P}-\mathrm{N}(\AA)$ & $1.5229(13)$ & $1.566(2)$ & $1.586(3)$ & - \\
$\mathrm{S}-\mathrm{O}(\AA)$ & $1.4427(11)$ & $1.453(2)$ & $1.494(2)$ & $1.501(2)$ \\
\hline
\end{tabular}

Another interesting feature of the crystal structure of $\mathbf{1}-\mathbf{L i}_{\mathbf{2}}$ concerns the coordination environments of the methandiide carbon atoms which strongly deviate from an ideal tetrahedron. As shown in Figure 7, C(1), S(1), P(1) and $\mathrm{Li}(1)$ are almost in one plane, while $\mathrm{Li}(2)$ is coordinating almost orthogonally to that plane with an $\mathrm{Li}-\mathrm{C}-\mathrm{Li}$ angle of $72.9(2)^{\circ}$. This has also been observed in the 
crystal structure of methandiide $\mathbf{C}$. On the basis of theoretical methods [26] this coordination mode can be explained by the two methandiide lone pairs populating two different orbitals, one of $\mathrm{sp}^{2}$ - and the other of p-symmetry.

\section{Experimental Section}

\subsection{General Procedures}

All experiments were carried out under a dry, oxygen-free argon atmosphere using standard Schlenk techniques. Solvents were dried over sodium or potassium (or over $\mathrm{P}_{4} \mathrm{O}_{10}, \mathrm{CH}_{2} \mathrm{Cl}_{2}$ ) and distilled prior to use. $\mathrm{H}_{2} \mathrm{O}$ is distilled water. Organolithium reagents were titrated against diphenylacetic acid prior use. ${ }^{1} \mathrm{H},{ }^{7} \mathrm{Li},{ }^{13} \mathrm{C},{ }^{31} \mathrm{P}$ NMR spectra were recorded on Avance-500, Avance-400 or Avance-300 spectrometers (Bruker Biospin $\mathrm{GmbH}$, Rheinstetten, Germany) at $22{ }^{\circ} \mathrm{C}$ if not stated otherwise. All values of the chemical shift are in ppm regarding the $\delta$-scale. All spin-spin coupling constants $(J)$ are printed in Hertz $(\mathrm{Hz})$. To display multiplicities and signal forms correctly the following abbreviations were used: $\mathrm{s}=$ singulet, $\mathrm{d}=$ doublet, $\mathrm{t}=$ triplet, $\mathrm{m}=$ multiplet, $\mathrm{br}=\mathrm{broad}$ signal. Signal assignment was supported by DEPT and HMQC experiments. Elemental analyses were performed on an Elementar vario MICRO-cube elemental analyzer. All reagents were purchased from Sigma-Aldrich (Munich, Germany), ABCR (Karlsruhe, Germany)) or Acros Organics/Fisher Scientific GmbH (Nidderau, Germany) and used without further purification. Phosphine oxide 2 was, synthesized according to literature procedure [27].

\subsection{Syntheses}

Synthesis of Bromide 3. Compound 3 was prepared in analogues fashion to literature procedure [44]. Phosphine oxide 2 (5.00 g, $14.0 \mathrm{mmol}$ ) was dissolved in $40 \mathrm{~mL}$ DCM. Oxalyl bromide $(6.06 \mathrm{~g}, 28.0 \mathrm{mmol})$ was slowly added via syringe and the resulting suspension stirred at room temperature over night until no further gas evolution could be observed. The reaction mixture was filtrated and the resulting solid washed three times with DCM (10 mL) giving phosphine bromide 3 as an off white solid $(6.39 \mathrm{~g}, 12.7 \mathrm{mmol}, 91 \%) .{ }^{1} \mathbf{H}$ NMR: (400.1 $\mathrm{MHz}, \mathrm{d}_{6}$-DMSO): $\delta=5.11\left(\mathrm{~d},{ }^{2} J_{\mathrm{HP}}=9.91 \mathrm{~Hz}, 2 \mathrm{H} ; \mathrm{SCH}_{2} \mathrm{P}\right), 7.46-7.56\left(\mathrm{~m}, 8 \mathrm{H} ; \mathrm{CH}_{\mathrm{Ph} \text {,meta,para }}\right), 7.64-7.68(\mathrm{~m}, 1 \mathrm{H}$; $\left.\mathrm{CH}_{\text {Ph,meta,para }}\right), 7.77-7.88$ (m, 6H; $\left.\mathrm{CH}_{\text {Ph,ortho }}\right) .{ }^{13} \mathrm{C}\left\{{ }^{1} \mathrm{H}\right\}$ NMR: $\left(75.5 \mathrm{MHz}, \mathrm{d}_{6}\right.$-DMSO): $\delta=54.6(\mathrm{~d}$, $\left.{ }^{1} J_{\mathrm{CP}}=57.4 \mathrm{~Hz} ; \mathrm{SCP}\right), 127.8\left(\mathrm{CH}_{\mathrm{SPh}, \text { meta }}\right), 128.4\left(\mathrm{~d},{ }^{3} J_{\mathrm{CP}}=12.3 \mathrm{~Hz} ; \mathrm{CH}_{\mathrm{PPh}, \text { meta }}\right), 128.8\left(\mathrm{CH}_{\mathrm{SPH}, \text { ortho }}\right)$, $130.6\left(\mathrm{~d},{ }^{2} J_{\mathrm{CP}}=9.93 \mathrm{~Hz} ; \mathrm{CH}_{\mathrm{PPh}, \text { ortho }}\right), 131.9\left(\mathrm{~d},{ }^{4} J_{\mathrm{CP}}=2.54 \mathrm{~Hz} ; \mathrm{CH}_{\mathrm{PPh} \text {,para }}\right), 132.62\left(\mathrm{~d},{ }^{1} J_{\mathrm{CP}}=104.66 \mathrm{~Hz}\right.$; $\left.C_{\text {PPh,ipso }}\right), 133.6\left(\mathrm{CH}_{\mathrm{SPh} \text {,para }}\right), 141.1$ ( $\left.\mathrm{C}_{\mathrm{SPh}, \text { ipso }}\right) .{ }^{31} \mathbf{P}\left\{{ }^{1} \mathrm{H}\right\}$ NMR: $\left(162.0 \mathrm{MHz}, \mathrm{d}_{6}\right.$-DMSO): $\delta=18.7$. See also Figures S1 and S2 in the Supplementary Materials.

Synthesis of Compound 1. Compound 1 was prepared in analogues fashion to literature procedure [45]. $6.73 \mathrm{~g}(13.4 \mathrm{mmol})$ of Bromide 3 were suspended in $40 \mathrm{~mL} \mathrm{MeCN}$ and cooled to $-40{ }^{\circ} \mathrm{C}$. $2.89 \mathrm{~g}$ (17.9 mmol) HMDS were added under light exclusion and the reaction mixture slowly warmed to room temperature and stirred overnight. The solvent was removed in vacuo and the residue suspended in $30 \mathrm{~mL}$ toluene. $2.72 \mathrm{~g}$ (26.9 mmol) Triethylamine were added and the reaction mixture stirred overnight. The solution was filtered and the solvent removed under reduced pressure. Recrystallization of the crude product in toluene/hexane (1:2) gave way to the product as a white crystalline solid (5.5 g, $11.7 \mathrm{mmol}, 88 \%) .{ }^{1} \mathrm{H}$ NMR: (300.2 MHz, $\left.\mathrm{C}_{6} \mathrm{D}_{6}\right): \delta=0.31\left(\mathrm{~d},{ }^{4} J_{\mathrm{HP}}=0.48 \mathrm{~Hz}, 9 \mathrm{H} ; \mathrm{Si}\left(\mathrm{CH}_{3}\right)_{3}\right)$, $3.94\left(\mathrm{~d},{ }^{2} J_{\mathrm{HP}}=9.79 \mathrm{~Hz}, 2 \mathrm{H} ; \mathrm{SCH}_{2} \mathrm{P}\right), 6.80-7.05\left(\mathrm{~m}, 9 \mathrm{H} ; \mathrm{CH}_{\mathrm{SPh} \text {,meta, para }} / \mathrm{CH}_{\mathrm{PPh} \text {,meta, para }}\right), 7.46-7.53(\mathrm{~m}$, 4H; $\left.\left.\mathrm{CH}_{\text {PPh,ortho }}\right), 7.75-7.78\left(\mathrm{~m}, 2 \mathrm{H} ; \mathrm{CH}_{\text {,SPh,ortho }}\right) .{ }^{13} \mathrm{C}^{1}{ }^{1} \mathrm{H}\right\}$ NMR: $\left(75.5 \mathrm{MHz}, \mathrm{C}_{6} \mathrm{D}_{6}\right): \delta=4.13(\mathrm{~d}$, $\left.{ }^{4} J_{\mathrm{CP}}=3.38 \mathrm{~Hz} ; \mathrm{Si}\left(\mathrm{CH}_{3}\right)_{3}\right), 58.9\left(\mathrm{~d},{ }^{1} J_{\mathrm{CP}}=57.8 \mathrm{~Hz} ; \mathrm{SCH}_{2} \mathrm{P}\right), 128.35\left(\mathrm{CH}_{\mathrm{SPh}, \text { para }}\right), 128.5\left(\mathrm{CH}_{\mathrm{SPh} \text {,meta }}\right)$, $128.7\left(\mathrm{~d},{ }^{3} J_{\mathrm{CP}}=8.73 \mathrm{~Hz} ; \mathrm{CH}_{\mathrm{PPh}, \text { meta }}\right), 131.3\left(\mathrm{~d},{ }^{4} J_{\mathrm{CP}}=2.96 \mathrm{~Hz} ; \mathrm{CH}_{\mathrm{PPh}, \text { para }}\right), 131.5\left(\mathrm{~d},{ }^{2} J_{\mathrm{CP}}=10.6 \mathrm{~Hz}\right.$; $\left.\mathrm{CH}_{\mathrm{PPh}, \text { ortho }}\right), 133.1\left(\mathrm{CH}_{\mathrm{SPh}, \text { ortho }}\right), 134.6\left(\mathrm{~d},{ }^{1} J_{\mathrm{CP}}=104.4 \mathrm{~Hz} ; C_{\mathrm{PPh}, \text { ipso }}\right), 142.1\left(\mathrm{C}_{\mathrm{SPh}, \text { ipso }}\right) .{ }^{31} \mathbf{P}\left\{{ }^{1} \mathbf{H}\right\} \mathbf{N M R}$ : (121.5 MHz, $\mathrm{C}_{6} \mathrm{D}_{6}$ ): $\delta=-12.7$. Anal. Calc. for $\mathrm{C}_{19} \mathrm{H}_{17} \mathrm{Br}_{2} \mathrm{O} 2 \mathrm{PS}: \mathrm{C}, 61.80 ; \mathrm{H}, 6.13 ; \mathrm{N}, 3.28$. Found: $\mathrm{C}$, 62.06; H, 6.10; N, 3.20. See also Figures S3-S5 in the Supplementary Materials. 
Synthesis of 1-K. $1.00 \mathrm{~g}$ (2.35 mmol) iminophosphorane 1 and $94.0 \mathrm{mg} \mathrm{KH}$ were suspended in $20 \mathrm{~mL} \mathrm{Et}_{2} \mathrm{O}$ and the reaction mixture stirred at room temperature until no further gas formation could be observed. The resulting suspension was filtrated and removal of the solvent gave Monoanion 1-K as a colourless solid (974 mg, $2.09 \mathrm{mmol}, 89 \%) .{ }^{\mathbf{1}} \mathbf{H}$ NMR: $\left(300.2 \mathrm{MHz}, \mathrm{d}_{6}\right.$-DMSO): $\delta=-0.19$ $\left(9 \mathrm{H} ; \mathrm{Si}\left(\mathrm{CH}_{3}\right)_{3}\right), 2.38\left(\mathrm{~d},{ }^{2} J_{\mathrm{HP}}=10.8 \mathrm{~Hz}, 1 \mathrm{H} ; \mathrm{SCHKP}\right), 7.17-7.25\left(\mathrm{~m}, 9 \mathrm{H} ; \mathrm{CH}_{\text {Ph,meta,para }}\right), 7.63-7.74(\mathrm{~m}$, $\left.\left.6 \mathrm{H} ; \mathrm{CH}_{\mathrm{Ph} \text {,ortho }}\right) .{ }^{13} \mathrm{C}^{1}{ }^{1} \mathrm{H}\right\}$ NMR: $\left(75.5 \mathrm{MHz}, \mathrm{d}_{6}\right.$-DMSO): $\delta=4.86\left(\mathrm{~d},{ }^{3} \mathrm{~J}_{\mathrm{CP}}=3.40 \mathrm{~Hz} ; \mathrm{Si}\left(\mathrm{CH}_{3}\right)_{3}\right)$, $46.3\left(\mathrm{~d},{ }^{1} J_{\mathrm{CP}}=127.1 \mathrm{~Hz}\right), 124.8\left(\mathrm{CH}_{\mathrm{SPh}, \text { meta }}\right), 126.7\left(\mathrm{~d},{ }^{3} J_{\mathrm{CP}}=11.5 \mathrm{~Hz} ; \mathrm{CH}_{\mathrm{PPh}, \text { meta }}\right), 127.2\left(\mathrm{CH}_{\mathrm{SPh}, \text { ortho }}\right)$, $127.6\left(\mathrm{CH}_{\mathrm{SPh} \text {,para }}\right), 128.2\left(\mathrm{~d},{ }^{4} J_{\mathrm{CP}}=1.69 \mathrm{~Hz} ; \mathrm{CH}_{\mathrm{PPh} \text {,para }}\right), 131.3\left(\mathrm{~d},{ }^{2} J_{\mathrm{CP}}=9.86 \mathrm{~Hz} ; \mathrm{CH}_{\mathrm{PPh}, \text { ortho }}\right)$, $142.4\left(\mathrm{~d},{ }^{1} J_{\mathrm{CP}}=105.6 \mathrm{~Hz} ; C_{\mathrm{PPh}, \text { ipso }}\right) 153.5\left(C_{\mathrm{SPh}, \mathrm{ipso}}\right) .{ }^{31} \mathbf{P}\left\{{ }^{1} \mathbf{H}\right\}$ NMR: $\left(121.5 \mathrm{MHz}, \mathrm{d}_{6}\right.$-DMSO): $\delta=-1.18$. Anal. Calcd. for $\mathrm{C}_{22} \mathrm{H}_{25} \mathrm{KNO}_{2}$ PSSi: C, 56.75; H, 5.41; N, 3.01; S, 6.88. Found: C, 57.01; H, 5.42; N, 3.22; $\mathrm{S}, 6.69$. See also Figures $\mathrm{S} 6$ and $\mathrm{S} 7$ in the Supplementary Materials.

Preparation of $1-\mathrm{Li}_{2}$. $600 \mathrm{mg}(1.40 \mathrm{mmol})$ of precursor 1 were suspended in $4 \mathrm{~mL} \mathrm{Et}_{2} \mathrm{O}$. $1.80 \mathrm{~mL}$ ( $3.09 \mathrm{mmol}, 1.59 \mathrm{M}$ solution in $\mathrm{Et}_{2} \mathrm{O}$ ) $\mathrm{MeLi}$ were added and the reaction mixture stirred at room temperature until no further gas evolution could be observed giving a colourless suspension. The supernatant solvent was removed via cannula and the colourless product dried under reduced pressure (501 mg, $1.09 \mathrm{mmol}, 78 \%) .{ }^{1} \mathrm{H}$ NMR: (500.1 MHz, $\left.\mathrm{C}_{6} \mathrm{D}_{6}\right): \delta=0.25\left(9 \mathrm{H} ; \mathrm{Si}\left(\mathrm{CH}_{3}\right)_{3}\right)$,

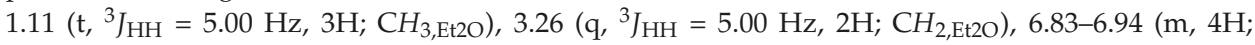
$\left.\mathrm{CH}_{\mathrm{SPh} \text {,meta,para }} / \mathrm{CH}_{\mathrm{PPh} \text {,meta,para }}\right), 7.10-7.23$ (m, 7H; $\left.\mathrm{CH}_{\mathrm{SPh} \text {,meta,para }} / \mathrm{CH}_{\mathrm{PPh} \text {,ortho,meta,para }}\right), 8.02-8.04$ (m, 2H; $\left.\left.\mathrm{CH}_{\mathrm{SPh}, \text { ortho }}\right), 8.23-8.27\left(\mathrm{~m}, 2 \mathrm{H} ; \mathrm{CH}_{\mathrm{PPh}, \text { ortho }}\right) .{ }^{13} \mathrm{C}^{1}{ }^{1} \mathrm{H}\right\}$ NMR: $\left(125.8 \mathrm{MHz}, \mathrm{C}_{6} \mathrm{D}_{6}\right): \delta=4.74(\mathrm{~d}$, $\left.{ }^{3} J_{\mathrm{CP}}=3.69 \mathrm{~Hz} ; \mathrm{Si}\left(\mathrm{CH}_{3}\right)_{3}\right), 15.6\left(\mathrm{CH}_{3, \mathrm{Et} 2 \mathrm{O}}\right), 52.4\left(\mathrm{~d},{ }^{1} J_{\mathrm{CP}}=53.3 \mathrm{~Hz} ; \mathrm{SCP}\right), 65.9\left(\mathrm{CH}_{2, \mathrm{Et} 2 \mathrm{O}), 126.0}\right.$ $\left(\mathrm{CH}_{\mathrm{SPh}, \text { meta }}\right), 127.4\left(\mathrm{~d},{ }^{3} J_{\mathrm{CP}}=11.8 \mathrm{~Hz} ; \mathrm{CH}_{\mathrm{PPh}, \text { meta }}\right), 128.4\left(\mathrm{~d},{ }^{3} J_{\mathrm{CP}}=11.5 \mathrm{~Hz} ; \mathrm{CH}_{\mathrm{PPh}, \text { meta }}\right), 128.5$ ( $\left.\mathrm{CH}_{\mathrm{SPh} \text {,para }}\right), 129.0$ (br, $\left.\mathrm{CH}_{\mathrm{PPh} \text {,para }}\right), 129.5\left(\mathrm{CH}_{\mathrm{SPh}, \text { ortho }}\right), 130.4$ (br; $\left.\mathrm{CH}_{\mathrm{PPh}, \text { para }}\right), 131.2\left(\mathrm{~d},{ }^{2} J_{\mathrm{CP}}=7.25 \mathrm{~Hz}\right.$; $\left.\mathrm{CH}_{\mathrm{PPh} \text {,ortho }}\right), 131.3\left(\mathrm{~d},{ }^{2} J_{\mathrm{CP}}=10.73 \mathrm{~Hz} ; \mathrm{CH}_{\mathrm{PPh} \text {,ortho }}\right), 141.2\left(\mathrm{~d},{ }^{1} J_{\mathrm{CP}}=64.4 \mathrm{~Hz} ; \mathrm{C}_{\mathrm{PPh}, \text { ipso }}\right), 142.0(\mathrm{~d}$, $\left.{ }^{1} J_{\mathrm{CP}}=81.7 \mathrm{~Hz} ; C_{\mathrm{PPh}, \text { ipso }}\right), 151.5\left(\mathrm{~d},{ }^{3} J_{\mathrm{CP}}=2.36 \mathrm{~Hz} ; \mathrm{C}_{\mathrm{SPh}, \mathrm{ipso}}\right) .{ }^{31} \mathbf{P}\left\{{ }^{1} \mathbf{H}\right\}$ NMR: $\left(202.5 \mathrm{MHz}, \mathrm{C}_{6} \mathrm{D}_{6}\right): \delta=7.63$. ${ }^{7} \mathrm{Li}\left\{{ }^{1} \mathrm{H}\right\}$ NMR: $\left(194.4 \mathrm{MHz}, \mathrm{C}_{6} \mathrm{D}_{6}\right): \delta=0.19$, 1.67. Anal. Calcd. for $\mathrm{C}_{24} \mathrm{H}_{29} \mathrm{Li}_{2} \mathrm{~N}_{1} \mathrm{O}_{2.5} \mathrm{P}_{1} \mathrm{~S}_{1} \mathrm{Si}_{1}: \mathrm{C}, 60.49$; H, 6.13; N, 2.94; S, 6.73. Found: C, 60.27; H, 5.93; N, 3.1 2; S, 6.59. See also Figures S8-S10 in the Supplementary Materials.

\subsection{X-ray Crystallography}

General. Data collection of the compound was conducted with a Bruker APEX2-CCD (D8 threecircle goniometer). The structures were solved using direct methods, refined with the Shelx software package [50] and expanded using Fourier techniques. The crystal of the compound was mounted in an inert oil (perfluoropolyalkylether). Crystal structure determination were effected at 100 K. Crystallographic data (excluding structure factors) have been deposited with the Cambridge Crystallographic Data Centre as supplementary publication no. CCDC 1514516-1514518. Copies of the data can be obtained free of charge on application to Cambridge Crystallographic Data Centre, 12 Union Road, Cambridge CB2 1EZ, UK; (fax: (+44)-1223-336-033; email: deposit@ccdc.cam.ac.uk).

Crystal data for compound 1. $\mathrm{C}_{22} \mathrm{H}_{26} \mathrm{NO}_{2} \mathrm{PSSi} ; M_{\mathrm{r}}=427.56$; colourless block; $0.40 \times 0.30 \times 0.29 \mathrm{~mm}^{3}$; triclinic; space group P-1; $a=99.2087(4), b=10.5543(4), c=12.6990(5) \AA ; V=1079.35(8) \AA^{3} ; Z=2$; $\rho_{\text {calcd }}=1.316 \mathrm{~g} \cdot \mathrm{cm}^{-3} ; \mu=0.298 \mathrm{~mm}^{-1} ; F(000)=452 ; T=100(2) \mathrm{K} ; R_{1}=0.0290$ and $w R^{2}=0.1137 ; 3796$ unique reflections $(\theta<25.00)$ and 262 parameters. See also Tables S1-S3 in the Supplementary Materials.

Crystal data for compound 1-K. $\mathrm{C}_{48} \mathrm{H}_{58} \mathrm{~K}_{2} \mathrm{~N}_{2} \mathrm{O}_{5} \mathrm{P}_{2} \mathrm{~S}_{2} \mathrm{Si}_{2} ; M_{\mathrm{r}}=1003.40$; colourless needle; $0.15 \times 0.05 \times 0.04 \mathrm{~mm}^{3}$; triclinic; space group $P-1 ; a=11.2841(10), b=15.3705(14), c=16.8163(15) \AA$; $V=2489.2(4) \AA^{3} ; Z=2 ; \rho_{\text {calcd }}=1.339 \mathrm{~g} \cdot \mathrm{cm}^{-3} ; \mu=0.433 \mathrm{~mm}^{-1} ; F(000)=1056 ; T=100(2) \mathrm{K} ; R_{1}=0.0408$ and $w R^{2}=0.0917 ; 8770$ unique reflections $(\theta<24.998)$ and 605 parameters. See also Tables S1, S4 and S5 in the Supplementary Materials.

Crystal data for compound 1- $\mathrm{Li}_{2} . \mathrm{C}_{98} \mathrm{H}_{121} \mathrm{Li}_{8} \mathrm{~N}_{4} \mathrm{O}_{10.50} \mathrm{P}_{4} \mathrm{~S}_{4} \mathrm{Si}_{4} ; M_{\mathrm{r}}=1942.98$; colourless needle; $0.15 \times 0.06 \times 0.06 \mathrm{~mm}^{3} ;$ monoclinic; space group $P 22_{1} / \mathrm{c} ; a=25.265(3), b=18.972(2), c=24.452(3) \AA$; $V=10,485(2) \AA^{3} ; Z=4 ; \rho_{\text {calcd }}=1.231 \mathrm{~g} \cdot \mathrm{cm}^{-3} ; \mu=0.254 \mathrm{~mm}^{-1} ; F(000)=4100 ; T=100(2) \mathrm{K}$; 
mboxemphR $R_{1}=0.0494$ and $w R^{2}=0.0947 ; 18,468$ unique reflections $(\theta<24.997)$ and 1254 parameters. See also Tables S1, S6 and S7 in the Supplementary Materials.

\section{Conclusions}

In summary, we reported on the synthesis and metalation of the iminophosphoryl and sulfonyl-functionalized methane $\mathbf{1}$. The corresponding potassium methanide $\mathbf{1 - K}$ and dilithium compound $\mathbf{1 - \mathbf { L i } _ { 2 }}$ are easily accessible by standard deprotonation reactions and isolable in high-yields as solid materials. XRD analysis allowed the elucidation of their molecular structures, showing typical bond length changes reflecting the electronic structure. 1-K formed a coordination polymer in solid state, while the methandiide was found to crystallize as well-defined pseudo-tetrameric complex with an unusual structural motif. The facile synthesis of $\mathbf{1}-\mathbf{L i}_{2}$ and the formation of a well-defined structure in solid state are both advantageous for its application as ligand in carbene complex chemistry.

Supplementary Materials: The following are available online at www.mdpi.com/2304-6740/4/4/40/s1, NMR spectra of all isolated compounds (Figures S1-S10) as well as crystallographic details for the compounds 1, 1-K and $\mathbf{1} \mathbf{L i}_{2}$ (Tables S1-S7, Figures S11-S13).

Acknowledgments: We are grateful to the German Science Foundation (Emmy Noether grant: DA1402/1-1) and the Fonds der Chemischen Industrie for financial support.

Author Contributions: Kai-Stephan Feichtner synthesized and characterized all compounds, Kai-Stephan Feichtner and Viktoria H. Gessner prepared the manuscript and planned the research.

Conflicts of Interest: The authors declare no conflict of interest.

\section{References}

1. Gessner, V.H.; Becker, J.; Feichtner, K.-S. Carbene Complexes Based on Dilithium Methandiides. Eur. J. Inorg. Chem. 2015, 2015, 1841-1859. [CrossRef]

2. Harder, S. Geminal dianions stabilized by phosphonium substituents. Coord. Chem. Rev. 2011, 255, 1252-1267. [CrossRef]

3. Liddle, S.T.; Mills, D.P.; Wooles, A.J. Early metal bis(phosphorus-stabilised)carbene chemistry. Chem. Soc. Rev. 2011, 40, 2164-2176. [CrossRef] [PubMed]

4. Orzechowski, L.; Jansen, G.; Harder, S. Synthesis, Structure, and Reactivity of a Stabilized Calcium Carbene: $\mathrm{R}_{2}$ CCa. J. Am. Chem. Soc. 2006, 128, 14676-14684. [CrossRef] [PubMed]

5. Orzechowski, L.; Harder, S. Isolation of an Intermediate in the Catalytic Trimerization of Isocyanates by a Monomeric Calcium Carbene with Chelating Iminophosphorane Substituents. Organometallics 2007, 26, 2144-2148. [CrossRef]

6. Thirumoorthi, R.; Chivers, T.; Vargas-Baca, I. S,C,S-Pnictogen bonding in pincer complexes of the methanediide [C( $\left.\left.\mathrm{Ph}_{2} \mathrm{PS}\right)_{2}\right]^{2-}$. Dalton Trans. 2011, 40, 8086-8088. [CrossRef] [PubMed]

7. Chivers, T.; Konu, J.; Thirumoorthi, R. PCP-bridged chalcogen-centred anions: Coordination chemistry and carbon-based reactivity. Dalton Trans. 2012, 41, 4283-4295. [CrossRef] [PubMed]

8. Cantat, T.; Mézailles, N.; Ricard, L.; Jean, Y.; Le Floch, P. A Bis(thiophosphinoyl)methanediide Palladium Complex: Coordinated Dianion or Nucleophilic Carbene Complex? Angew. Chem. Int. Ed. 2004, 43, 6382-6385. [CrossRef] [PubMed]

9. Gessner, V.H.; Meier, F.; Uhrich, D.; Kaupp, M. Synthesis and Bonding in Carbene Complexes of an Unsymmetrical Dilithio Methandiide: A Combined Experimental and Theoretical Study. Chem. Eur. J. 2013, 19, 16729-16739. [CrossRef] [PubMed]

10. Babu, R.P.K.; McDonald, R.; Cavell, R.G. The first hafnium methandiide complexes: The assembly of an entire triad of group 4 metal "pincer" bis(phosphinimine) complexes possessing the $\mathrm{M}=\mathrm{C}$ carbene-ylide structure. Chem. Commun. 2000, 6, 481-482. [CrossRef]

11. Leung, W.-P.; So, C.-W.; Wang, J.-Z.; Mak, T.C.W. A novel synthesis of metallogermacyclopropane and molybdenum bis(iminophosphorano)carbene complexes from bisgermavinylidene. Chem. Commun. 2003, 2, 248-249. [CrossRef] 
12. Cadierno, V.; Diez, J.; García-Álvarez, J.; Gimeno, J. ( $\eta^{6}$-Arene)-Ruthenium(II) Complexes Containing Methanide and Methandiide Anions of $\mathrm{Ph}_{2} \mathrm{P}(=\mathrm{S}) \mathrm{CH}_{2} \mathrm{P}(=\mathrm{NR}) \mathrm{Ph}_{2}$ : Unprecedented Insertion of Isocyanide into a Ruthenium-Carbene Bond. Organometallics 2008, 27, 1809-1822. [CrossRef]

13. Aparna, K.; Ferguson, M.; Cavell, R.G. A Monomeric Samarium Bis(Iminophosphorano) Chelate Complex with a S=C Bond. J. Am. Chem. Soc. 2000, 122, 726-727. [CrossRef]

14. Cantat, T.; Arliguie, T.; Noël, A.; Thuéry, P.; Ephritikhine, M.; Le Floch, P.; Mézailles, N. The U=C Double Bond: Synthesis and Study of Uranium Nucleophilic Carbene Complexes. J. Am. Chem. Soc. 2009, 131, 963-972. [CrossRef] [PubMed]

15. Cooper, O.J.; Mills, D.P.; McMaster, J.; Moro, F.; Davies, E.S.; Lewis, W.; Blake, A.J.; Liddle, S.T. Uranium-Carbon Multiple Bonding: Facile Access to the Pentavalent Uranium Carbene $\left[\mathrm{U}\left\{\mathrm{C}\left(\mathrm{PPh}_{2} \mathrm{NSiMe}_{3}\right)_{2}\right\}(\mathrm{Cl})_{2}(\mathrm{I})\right]$ and Comparison of $\mathrm{U}^{\mathrm{V}}=\mathrm{C}$ and $\mathrm{U}^{\mathrm{IV}}=\mathrm{C}$ Bonds. Angew. Chem. Int. Ed. 2011, 50, 2383-2386. [CrossRef] [PubMed]

16. Mills, D.P.; Moro, F.; McMaster, J.; van Slageren, J.; Lewis, W.; Blake, A.J.; Liddle, S.T. A delocalized arene-bridged diuranium single-molecule magnet. Nat. Chem. 2011, 3, 454-460. [CrossRef] [PubMed]

17. Aparna, K.; Babu, R.P.K.; McDonald, R.; Cavell, R.G. $\left[\mathrm{Ph}_{2} \mathrm{P}\left(\mathrm{NSiMe}_{3}\right)\right]_{2} \mathrm{CLi}_{2}$ : A Dilithium Dianionic Methanide Salt with an Unusual $\mathrm{Li}_{4} \mathrm{C}_{2}$ Cluster Structure. Angew. Chem. Int. Ed. 1999, 38, 1483-1484.

18. Ong, C.M.; Stephan, D.W. Lithiations of Bis-diphenyl-N-trimethylsilylphosphiniminomethane: An X-ray Structure of a 1,1-Dilithiomethane Derivative. J. Am. Chem. Soc. 1999, 121, 2939-2940. [CrossRef]

19. Gais, H.-J.; Vollhardt, J. Solid-state and solution structure of dilithium trimethyl[(phenylsulfonyl)methyl] silane, a true dilithiomethane derivative. J. Am. Chem. Soc. 1988, 110, 978-980. [CrossRef]

20. Linti, G.; Rodig, A.; Pritzkow, H. 9,9-Dilithiofluorene: The First Crystal-Structure Analysis of an $\alpha, \alpha$-Dilithiated Hydrocarbon. Angew. Chem. Int. Ed. 2002, 41, 4503-4505. [CrossRef]

21. Müller, J.F.K.; Neuburger, M.; Spingler, B. Structural Investigation of a Dilithiated Phosphonate in the Solid State. Angew. Chem. Int. Ed. 1999, 38, 92-94. [CrossRef]

22. Cavell, R.G.; Kamalesh Babu, R.P.; Kasani, A.; McDonald, R. Novel Metal-Carbon Multiply Bonded Twelve-Electron Complexes of Ti and Zr Supported by a Bis(Phosphoranimine) Chelate. J. Am. Chem. Soc. 1999, 121, 5805-5806. [CrossRef]

23. Cantat, T.; Ricard, L.; Le Floch, P.; Mézailles, N. Phosphorus-Stabilized Geminal Dianions. Organometallics 2006, 25, 4965-4976. [CrossRef]

24. Chen, J.-H.; Guo, J.; Li, Y.; So, C.-W. Synthesis and Structure of $\left[\mathrm{Li}_{2} \mathrm{C}\left(\mathrm{PPh}_{2}=\mathrm{NSiMe}_{3}\right)\left(\mathrm{PPh}_{2}=\mathrm{S}\right)\right]$ : A Geminal Dianionic Ligand. Organometallics 2009, 28, 4617-4620. [CrossRef]

25. Heuclin, H.; Fustier-Boutignon, M.; Ho, S.Y.-F.; Le Goff, X.-F.; Carenco, S.; So, C.-W.; Mézailles, N. Synthesis of Phosphorus(V)-Stabilized Geminal Dianions. The Cases of Mixed $\mathrm{P}=\mathrm{X} / \mathrm{P} \rightarrow \mathrm{BH}_{3}(\mathrm{X}=\mathrm{S}, \mathrm{O})$ and $\mathrm{P}=\mathrm{S} / \mathrm{SiMe}_{3}$ Derivatives. Organometallics 2013, 32, 498-508. [CrossRef]

26. Schröter, P.; Gessner, V.H. Tetrahedral versus Planar Four-Coordinate Carbon: A Sulfonyl-Substituted Methandiide. Chem. Eur. J. 2012, 18, 11223-11227. [CrossRef] [PubMed]

27. Becker, J.; Gessner, V.H. Synthesis and Electronic Structure of Carbene Complexes Based on a SulfonylSubstituted Dilithio Methandiide. Organometallics 2014, 33, 1310-1317. [CrossRef]

28. Becker, J.; Modl, T.; Gessner, V.H. Methandiide as Non-Innocent Ligand in Carbene Complexes: From the Electronic Structure to Bond Activation Reactions and Cooperative Catalysis. Chem. Eur. J. 2014, 20, 11295-11299. [CrossRef] [PubMed]

29. Weismann, J.; Waterman, R.; Gessner, V.H. Metal-Ligand Cooperativity in a Methandiide Derived Iridium Carbene Complex. Chem. Eur. J. 2016, 22, 3846-3855. [CrossRef] [PubMed]

30. Gessner, V.H.; Däschlein, C.; Strohmann, C. Structure Formation Principles and Reactivity of Organolithium Compounds. Chem. Eur. J. 2009, 15, 3320-3335. [CrossRef] [PubMed]

31. Harrison-Marchand, A.; Mongin, F. Mixed AggregAte (MAA): A Single Concept for All Dipolar Organometallic Aggregates. 1. Structural Data. Chem. Rev. 2013, 113, 7470-7562. [CrossRef] [PubMed]

32. Stey, T.; Stalke, D. Lead structures in lithium organic chemistry. In The Chemistry of Organolithium Compounds; Rappoport, Z., Marek, I., Eds.; John Wiley \& Sons: New York, NY, USA, 2004; pp. 47-120.

33. Stucky, G.D.; Eddy, M.M.; Harrison, W.H.; Lagow, R.; Kawa, H.; Cox, D.E. Some Observations Concerning the Structure of Dilithiomethane. J. Am. Chem. Soc. 1990, 112, 2425-2427. [CrossRef]

34. Feichtner, K.-S.; Gessner, V.H. Synthesis and stability of Li/Cl carbenoids based on bis(iminophosphoryl) methanes. Dalton Trans. 2014, 43, 14399-14408. [CrossRef] [PubMed] 
35. Demange, M.; Boubekeur, L.; Auffrant, A.; Mézailles, N.; Ricard, L.; Le Goff, R.; Le Floch, P. A new and convenient approach towards bis(iminophosphoranyl)methane ligands and their dicationic, cationic, anionic and dianionic derivatives. New J. Chem. 2006, 30, 1745-1754. [CrossRef]

36. Cooper, O.J.; McMaster, J.; Lewis, W.; Blake, A.J.; Liddle, S.T. Synthesis and structure of $\left[\mathrm{U}\left\{\mathrm{C}\left(\mathrm{PPh}_{2} \mathrm{NMes}_{2}\right\}_{2}\right]\right.$ (Mes = 2,4,6- $\mathrm{Me}_{3} \mathrm{C}_{6} \mathrm{H}_{2}$ ): A homoleptic uranium bis(carbene) complex with two formal $\mathrm{U}=\mathrm{C}$ double bonds. Dalton Trans. 2010, 39, 5074-5076. [CrossRef] [PubMed]

37. Sindlinger, C.P.; Stasch, A. Syntheses, structures and flexible coordination of sterically demanding di- and "tri"-lithiated methandiides. Dalton Trans. 2014, 43, 14334-14345. [CrossRef] [PubMed]

38. Hull, K.L.; Noll, B.C.; Henderson, K.W. Structural Characterization and Dynamic Solution Behavior of the Disodio and Lithio-Sodio Geminal Organodimetallics $\left[\left\{\left\{\mathrm{Ph}_{2} \mathrm{P}\left(\mathrm{Me}_{3} \mathrm{Si}\right) \mathrm{N}_{2} \mathrm{CNa}_{2}\right\}_{2}\right]\right.$ and $\left[\left\{\left\{\mathrm{Ph}_{2} \mathrm{P}\left(\mathrm{Me}_{3} \mathrm{Si}\right) \mathrm{N}\right\}_{2} \mathrm{CLiNa}_{2}\right]\right.$. Organometallics 2006, 25, 4072-4074. [CrossRef]

39. Orzechowski, L.; Jansen, G.; Harder, S. Methandiide Complexes $\left(\mathrm{R}_{2} \mathrm{CM}_{2}\right)$ of the Heavier Alkali Metals ( $\mathrm{M}=$ Potassium, Rubidium, Cesium): Reaching the Limit? Angew. Chem. Int. Ed. 2009, 48, 3825-3829. [CrossRef] [PubMed]

40. Hull, K.L.; Carmichael, I.; Noll, B.C.; Henderson, K.W. Homo- and Heterodimetallic Geminal Dianions Derived from the Bis(phosphinimine) $\left\{\mathrm{Ph}_{2} \mathrm{P}\left(\mathrm{NSiMe}_{3}\right)\right\}_{2} \mathrm{CH}_{2}$ and the Alkali Metals Li, Na, and K. Chem. Eur. J. 2008, 14, 3939-3953. [CrossRef] [PubMed]

41. Cooper, O.J.; Wooles, A.J.; McMaster, J.; Lewis, W.; Blake, A.J.; Liddle, S.T. A Monomeric Dilithio Methandiide with a Distorted trans-Planar Four-Coordinate Carbon. Angew. Chem. Int. Ed. 2010, 49, 5570-5573. [CrossRef] [PubMed]

42. Collins, J.B.; Dill, J.D.; Jemmis, E.D.; Apeloig, Y.; Schleyer, P.v.R.; Seeger, R.; Pople, J.A. Stabilization of Planar Tetracoordinate Carbon. J. Am. Chem. Soc. 1976, 98, 5419-5427. [CrossRef]

43. Feichtner, K.-S.; Englert, S.; Gessner, V.H. Preparation and Isolation of a Chiral Methandiide and its Application as Cooperative Ligand in Bond Activation. Chem. Eur. J. 2016, 22, 506-510. [CrossRef] [PubMed]

44. Nikitin, K.; Müller-Bunz, H.; Gilheany, D. Direct evidence of a multicentre halogen bond: Unexpected contraction of the P-XXX-P fragment in triphenylphosphine dihalides. Chem. Commun. 2013, 49, 1434-1436. [CrossRef] [PubMed]

45. Mardersteig, H.G.; Meinel, L.; Nöth, H. N-Diphenylphosphino-triphenylphosphazen. Z. Anorg. Allg. Chem. 1969, 368, 254-261. [CrossRef]

46. Müller, A.; Möhlen, M.; Neumüller, B.; Faza, N.; Massa, W.; Dehnicke, K. Die Kristallstrukturen der silylierten Phosphanimine $\mathrm{Me}_{3} \mathrm{SiNP}\left(\mathrm{c}-\mathrm{C}_{6} \mathrm{H}_{11}\right)_{3}$ und $\left(\mathrm{Me}_{3} \mathrm{SiNPPh}_{2}\right)_{2} \mathrm{CH}_{2}$. Z. Anorg. Allg. Chem. 1999, 625, 1748-1751. [CrossRef]

47. Holink, E.; Stewart, J.C.; Wei, P.; Stephan, D.W. Ti and Zr bidentate bis-phosphinimide complexes. Dalton Trans. 2003, 3, 3968-3974. [CrossRef]

48. Holthausen, M.H.; Mallov, I.; Stephan, D.W. Phosphinimine-substituted boranes and borenium ions. Dalton Trans. 2014, 43, 15201-15211. [CrossRef] [PubMed]

49. Armstrong, A.; Chivers, T.; Parvez, M.; Boeré, R.T. Stable Cubic Phosphorus-Containing Radicals. Angew. Chem. Int. Ed. 2004, 43, 502-505. [CrossRef] [PubMed]

50. Sheldrick, G.M. A short history of SHELX. Acta Crystallogr. 2008, 64, 112-122. [CrossRef] [PubMed]

(C) 2016 by the authors. Licensee MDPI, Basel, Switzerland. This article is an open access article distributed under the terms and conditions of the Creative Commons Attribution (CC BY) license (http:/ / creativecommons.org/licenses/by/4.0/). 
Article

\title{
Structural Study of Mismatched Disila-Crown Ether Complexes
}

\author{
Kirsten Reuter, Fabian Dankert, Carsten Donsbach and Carsten von Hänisch * \\ Fachbereich Chemie and Wissenschaftliches Zentrum für Materialwissenschaften (WZMW), \\ Philipps-Universität Marburg, Hans-Meerwein Straße 4, D-35032 Marburg, Germany; \\ kirsten.reuter@staff.uni-marburg.de (K.R.); Dankert@students.uni-marburg.de (F.D.); \\ donsbach@students.uni-marburg.de (C.D.) \\ * Correspondence: haenisch@chemie.uni-marburg.de; Tel.: +49-0-6421-282-5612 \\ Academic Editor: Matthias Westerhausen \\ Received: 21 December 2016; Accepted: 2 February 2017; Published: 9 February 2017
}

\begin{abstract}
Mismatched complexes of the alkali metals cations $\mathrm{Li}^{+}$and $\mathrm{Na}^{+}$were synthesized from 1,2-disila[18]crown-6 (1 and 2 ) and of $\mathrm{K}^{+}$from 1,2,4,5-tetrasila[18]crown-6 (4). In these alkali metal complexes, not all crown ether $\mathrm{O}$ atoms participate in the coordination, which depicts the coordination ability of the $\mathrm{C}-$, $\mathrm{Si} / \mathrm{C}-$, and $\mathrm{Si}$-bonded $\mathrm{O}$ atoms. Furthermore, the inverse case- the coordination of the large $\mathrm{Ba}^{2+}$ ion by the relatively small ligand 1,2-disila[15]crown-5-was investigated, yielding the dinuclear complex 5 . This structure represents a first outlook on sandwich complexes based on hybrid crown ethers.
\end{abstract}

Keywords: hybrid crown ether; siloxane; disilane; mismatch complex; host-guest chemistry

\section{Introduction}

The nature of the $\mathrm{Si}-\mathrm{O}$ bond has been intensively studied over the past six decades. In the 1960s especially, the large valence angle in disiloxanes and the unusual short $\mathrm{Si}-\mathrm{O}$ bond length, e.g., in $\mathrm{O}\left(\mathrm{SiH}_{2} \mathrm{Me}_{2}\right)_{2}$, were issued in numerous publications [1,2]. The low basicity of siloxanes was originally attributed to an electron-withdrawing tendency of the silyl groups of the type $\mathrm{p}(\mathrm{O}) \rightarrow \mathrm{d}(\mathrm{Si})$ [3-5]. This approach was later discarded in favor of hyperconjugation interactions between $\mathrm{p}(\mathrm{O}) \rightarrow \sigma^{*}(\mathrm{Si}-\mathrm{C})[6-8]$. Alternatively, in an opposed model based on calculations of the electron density function, the $\mathrm{Si}-\mathrm{O}$ bond was described as essentially ionic due to the high difference in electronegativity between $\mathrm{Si}$ and $\mathrm{O}[9,10]$. Careful theoretical studies on the basicity of $\mathrm{O}\left(\mathrm{SiH}_{2} \mathrm{Me}_{2}\right)_{2}$ and $\mathrm{OEt}_{2}$ revealed that the lower electrostatic attraction in siloxanes results from the repulsion between the positively charged $\mathrm{Si}$ atoms and Lewis acids [11]. This proceeding has recently been extended on cyclosiloxanes [12], which were previously described as pseudo crown ethers or inorganic crown ethers [13-15]. However, the structural analogy to organic crown ethers is poor, since siloxanes feature $\mathrm{O}$ atoms linked by $-\mathrm{SiMe}_{2}-$ rather than $-\mathrm{CH}_{2} \mathrm{CH}_{2}-$. Additionally, organic ring-contracted crown ethers exhibit an eminently reduced coordination ability, as has been shown in the referencing of [17]crown-6, in which only one $-\mathrm{CH}_{2} \mathrm{CH}_{2}-$ unit was replaced by $-\mathrm{CH}_{2}-[16,17]$. Consequently, higher comparability between organic crown ethers and cyclosiloxanes can be provided by extension of the $-\mathrm{SiMe}_{2}-$ unit to $-\mathrm{SiMe}_{2} \mathrm{SiMe}_{2}-$. Recent studies of hybrid [12]crown-4 featuring one or two disilane fragments in a residuary organic crown ether framework revealed an increasing coordination ability towards $\mathrm{Li}^{+}$in the series $\mathrm{C}-\mathrm{O}-\mathrm{C}<\mathrm{C}-\mathrm{O}-\mathrm{Si}<\mathrm{Si}-\mathrm{O}-\mathrm{Si}$ (Scheme 1) $[18,19]$.

Another deviation between the hitherto discussed cyclosiloxanes and organic crown ethers concerns the substituents at $\mathrm{Si}$ and $\mathrm{C}$. Up to date, neither cyclosiloxanes with H-substituents at the $\mathrm{Si}$ atoms nor permethylated crown ethers have been synthesized, which complicates a meaningful comparison of the two types of ligands. Calculation of the energy changes for crown 
ethers, cyclosiloxanes and hybrid crown ethers going from the free ligand geometries to complex geometries-determined as relaxation energy_-revealed that $\mathrm{SiMe}_{2}$ or $\mathrm{Si}_{2} \mathrm{Me}_{4}$ containing ligands require steadily more energy for adopting the complex geometry $[12,18,19]$. The complex stability is directly affected by the relaxation energy, which is in the case of the hybrid crown ethers compensated by the particularly high donor ability of the $\mathrm{O}$ atoms [18].

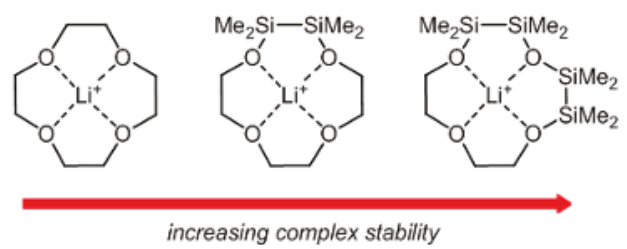

Scheme 1. Binding modes and relative binding affinities of $\mathrm{Li}^{+}$in [12]crown-4, 1,2-disila[12]crown-4, and 1,2,4,5-tetrasila[12]crown-4.

The hitherto described hybrid crown ethers exhibit up to three different types of $\mathrm{O}$ atoms-all $\mathrm{C}-, \mathrm{C} / \mathrm{Si}-$, and all Si-bonded ones (Scheme 1). To experimentally explore the competition between the basicity of the inequivalent $\mathrm{O}$ atoms and the energy effort for reaching the ligand geometry in the complex, we performed complexation reactions using small alkali and alkaline earth metal ions and comparatively large ligands. As a result, the ligand exceeds with its ring diameter the ionic radius of the Lewis acid. Since particularly Si-based crown ethers show limited flexibility $[11-15,18$, 19], we expected not all $\mathrm{O}_{\text {crown }}$ atoms to participate in the coordination of the metal center [20-22]. The first mismatch structure of a hybrid crown ether was very recently published and is constituted of 1,2-disila[18]crown-6 and $\mathrm{Ca}(\mathrm{OTf})_{2}\left(\mathrm{OTf}={ }^{-} \mathrm{OSO}_{2} \mathrm{CF}_{3}\right)$ [23]. Therein, one of the $\mathrm{C}$-bonded $\mathrm{O}$ atoms does not participate in the coordination of $\mathrm{Ca}^{2+}$, showing the preference of the metal ion to be coordinated by the $\mathrm{Si} / \mathrm{C}$-linked $\mathrm{O}$ atoms. This preference depicts the coordination ability of the $\mathrm{O}$ atoms in partially Si-based crown ethers and is a matter of investigation in this work.

\section{Results and Discussion}

\subsection{Mismatch Complexes Involving 1,2-Disila[18]crown-6 with $\mathrm{Li}^{+}$and $\mathrm{Na}^{+}$}

The hybrid ligand 1,2-disila[18]crown-6 was synthesized in a single step reaction from 1,2-dichlorodisilane and pentaethylene glycol (Scheme 2). Prior studies have shown that $\mathrm{Li}^{+}$matches well with 1,2-disila[12]crown-4 and $\mathrm{Na}^{+}$with 1,2-disila[15]crown-5 [18], so that the two cations together with 1,2-disila[18]crown-6 are supposed to fulfil the criteria of a mismatch. Reaction of 1,2-disila[18]crown-6 with lithium hexafluorophosphat in a 1:1 stoichiometry yielded a highly viscous oil. After freezing at $-196^{\circ} \mathrm{C}$ and subsequent storage at $-35^{\circ} \mathrm{C}$ for 3 days, Compound 1 crystallized in the space group $P 2_{1} / c$ in the form of colorless planks. In the solid-state structure of Compound $\mathbf{1}$, $\mathrm{Li}^{+}$is coordinated by five of the six crown ether $\mathrm{O}$ atoms (Figure 1). The non-coordinating completely carbon-bonded $\mathrm{O}$ atom $\mathrm{O} 5$ shows an atomic distance of 295.7(5) pm to the $\mathrm{Li}^{+}$cation. $\mathrm{The} \mathrm{PF}_{6}$ anion does not interact with the cation. The coordination polyhedron can be described as a distorted trigonal bipyramid (Figure 2). The three equatorial $\mathrm{O}$ atoms $(\mathrm{O} 2, \mathrm{O} 4, \mathrm{O} 6)$ establish shorter bond lengths to the cation than the two axial $\mathrm{O}$ atoms. The shortest $\mathrm{Li}-\mathrm{O}$ bond length has a value of 194.9(5) pm (Li1-O6), while the longest bond length measures 224.8(5) pm (Li1-O1). Compared to the hitherto known lithium complexes of hybrid sila-crown ethers, the Li1-O1 bond length is elongated, which may be the result of the strongly twisted ligand. Typically, the $\mathrm{O}$ atoms in sila-crown ethers complexes adopt an approximately planar conformation [13-15,18,19]. The disilane fragment in $\mathbf{1}$ is roughly coplanar to the thereon bonded $\mathrm{O}$ atoms $\mathrm{O} 1$ and $\mathrm{O} 2$, but the organic part of the ligand is strongly twisted and is wrapped around the metal center. 


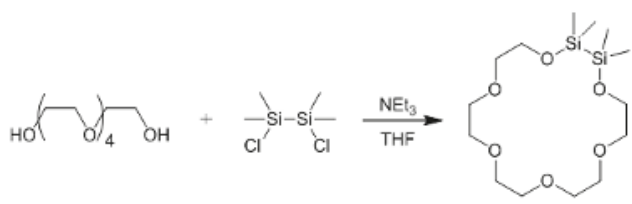

Scheme 2. Synthesis path for 1,2-disila[18]crown-6 [18].

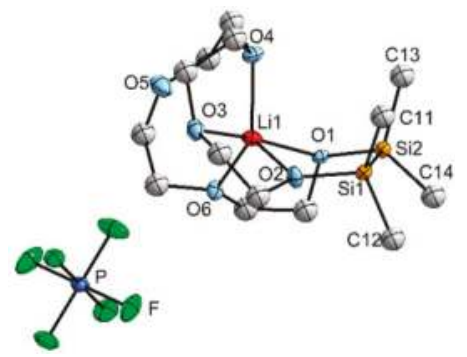

Figure 1. Molecular structure of [Li(1,2-disila[18]crown-6)]PF 6 (1) in the crystal. Thermal ellipsoids represent the $50 \%$ probability level. Hydrogen atoms are omitted for clarity. Selected bond lengths (pm) and angles ( ${ }^{\circ}$ ): Si1-Si2: 235.1(1), Si1-O1: 168.9(2), Si2-O2: 167.9(2), Li1-O1: 224.8(5), Li1-O2: 200.4(5), Li1-O3: 212.1(5), Li1․OO5: 295.7(5), Li1-O6: 194.9(5), O3-Li1-O1: 169.4(2), O2-Li1-O4: 115.9(2), O2-Li1-O6: 111.6(2), O4-Li1-O6: 132.5(2), O1-Li1-O4: 102.3(2), O1-Li1-O2: 88.9(2), O1-Li1-O6: 79.5(2), C11-Si2-Si1-C13: 9.6(1), C12-Si2-Si1-C14: 8.9(1).

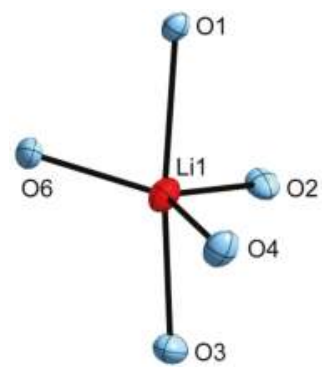

Figure 2. Trigonal bipyramidal coordination polyhedron of the lithium cation in [Li(1,2-disila[18]crown-6)]PF 6 (1).

Trigonal bipyramidal coordination is common for mismatched crown ether complexes of lithium [24,25], while in [12]crown-4 complexes the square-pyramid [26,27] or in sandwich complexes the square antiprism is the usual coordination polyhedron [28]. In prior studies on sila-crown ether complexes, it was already shown that the Me groups at the $\mathrm{Si}$ atoms take in a roughly eclipsed conformation $[18,19,23]$. In 1, the Me groups adopt with dihedral angles of $9.6(1)^{\circ}$ for C11-Si2-Si1-C13, and $8.9(1)^{\circ}$ for $\mathrm{C} 12-\mathrm{Si} 2-\mathrm{Si} 1-\mathrm{C} 14$ the expected conformation of the complex. As a result, the attractive electrostatic interaction between the $\mathrm{Si} / \mathrm{C}$-bonded $\mathrm{O}$ atoms and the $\mathrm{Li}^{+}$cation must compensate for the required energy effort of the ecliptic arrangement. The ${ }^{29} \mathrm{Si}\left\{{ }^{1} \mathrm{H}\right\}-\mathrm{NMR}$ signal shifts from $\delta=11.4 \mathrm{ppm}$ in the free ligand to $\delta=15.6 \mathrm{ppm}$ in $\mathbf{1}$, indicating a strong electrostatic interaction between $\mathrm{Li}^{+}$ and $\mathrm{O} 1$ and $\mathrm{O} 2$. The strong shift also reflects the hard Lewis acidity in comparison to $\mathrm{K}^{+}$, since in [K(1,2-disila[18]crown-6) $\left.\mathrm{PF}_{6}\right]$ the respective ${ }^{29} \mathrm{Si}\left\{{ }^{1} \mathrm{H}\right\}$-NMR signal is at $\delta=13.0 \mathrm{ppm}$ [18].

By an analogous reaction of $\mathrm{NaPF}_{6}$ with 1,2-disila[18]crown-6, single crystals in form of colorless blocks were obtained from dichloromethane/benzene (2:1). [Na(1,2-disila[18]crown-6) $\left.\mathrm{PF}_{6}\right]$ (2) 
crystallizes in the triclinic space group $P \overline{1}$ as a monomeric contact ion pair (Figure 3). $\mathrm{Na}^{+}$is coordinated by five of the six crown ether $\mathrm{O}$ atoms and additionally by two $\mathrm{F}$ atoms of the $\mathrm{PF}_{6}$ anion. The coordination sphere of $\mathrm{Na}^{+}$cannot be assigned to a hitherto described polyhedron as a result of its strong distortion. Compared to $\mathrm{K}^{+}$, the ionic radius of $\mathrm{Na}^{+}$is still too small for the cavity diameter of 1,2-disila[18]crown-6. As a result, $\mathrm{O} 1$ is with a distance of 453.2(3) pm not participating in the coordination of the metal ion. This leads to a strong distortion of the ring system, as O1 is located significantly beneath the mean plane of the other crown ether $\mathrm{O}$ atoms. Additionally, the Me groups at the Si atoms show a staggered arrangement, which is the common structure in free hybrid crown ethers [18]. In the case of Compound 2, the electrostatic attraction between $\mathrm{O} 1$ and $\mathrm{Na}^{+}$apparently does not compensate for the adoption of an ecliptic arrangement, so the cation is preferably coordinated by the $\mathrm{C}$-bonded $\mathrm{O}$ atoms. The coordinating Si- and C-linked $\mathrm{O}$ atom $\mathrm{O} 2$ establishes a bond length of 238.5(3) pm to the metal, while the completely C-linked $\mathrm{O}$ atoms show values between 237.0(3) and 247.3(2) pm. The ${ }^{29} \mathrm{Si}\left\{{ }^{1} \mathrm{H}\right\}-\mathrm{NMR}$ signal of Compound 2 appears at $\delta=14.3 \mathrm{ppm}$ and, according to the respective Lewis acidity of $\mathrm{Li}^{+}$and $\mathrm{Na}^{+}$, is less low-field shifted compared to 1 .

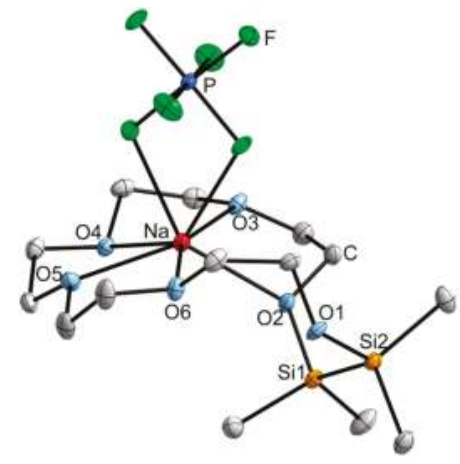

Figure 3. Molecular structure of $\left[\mathrm{Na}\left(1,2\right.\right.$-disila[18]crown-6) $\left.\mathrm{PF}_{6}\right]$ (2) in the crystal. Thermal ellipsoids represent the $50 \%$ probability level. Hydrogen atoms are not displayed. Selected bond lengths

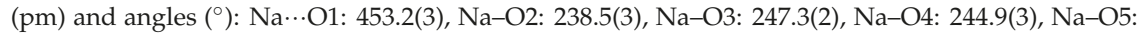
237.0(3), Si1-Si2: 235.8(1), Si2-O1: 166.2(3), Si1-O2: 167.5(2), Si2-O1-C10: 122.7(2), Si1-O2-C1: 121.7(2), C4-O4-C5: 113.5(2), C13-Si1-Si2-C11: 66.0(2), C14-Si1-Si2-C12: 65.6(2).

\subsection{Determination of $\Delta E_{\text {geom }}$ in 1,2-Disila[18]crown-6 Complexes}

As was shown in prior studies, hybrid crown ethers require steadily more energy than organic crown ethers for adopting the ligand structure within the complex $[18,19,23]$. The increase in relaxation energy was partially attributed to the sterically disfavored ecliptic arrangement of the Me groups bonded at the Si atoms. That was found to be the predominant conformation in the hybrid crown ether complex structures. The mismatched complexes $\mathbf{1}$ and $\mathbf{2}$ offer two different coordination modes of the Si/C-bonded O atoms: In the case of the Li-complex 1, both Si-bonded $\mathrm{O}$ atoms participate in the coordination, while in the Na-complex 2, only one of the Si/C-bonded O atoms binds to the metal center, which results in a staggered arrangement of the Me groups. It follows that 1,2-disila[18]crown-6 is expected to exhibit considerable different energy levels in the complex structures 1 and 2 . The energy difference $\Delta E_{\text {geom }}$ was determined by DFT calculations, implemented in Turbomole V7.0 [28], using the BP86 functional [29-32] and the def2-TZVP basis set with inclusion of dispersion interactions [33,34]. Accordingly, the energy of the ligand increases by $77.58 \mathrm{~kJ} \cdot \mathrm{mol}^{-1}$ for adopting the structure found within [Li(1,2-disila[18]crown-6)] ${ }^{+}$and by $29.24 \mathrm{~kJ} \cdot \mathrm{mol}^{-1}$ for $\left[\mathrm{Na}(1,2-\text { disila[18]crown-6) }]^{+}\right.$. The electrostatic attraction between the Si/C-bonded $\mathrm{O}$ atoms and $\mathrm{Na}^{+}$ does not compensate for the ecliptic conformation of the Me groups. By contrast, $\mathrm{Li}^{+}$must exhibit a significantly increased electrostatic attraction to the hybrid-bonded $\mathrm{O}$ atoms. The mismatched 
hybrid crown ether complexes $\mathbf{1}$ and $\mathbf{2}$ therefore suggest that the cation exerts a major impact on the coordination modes of the ligand.

The optimized structure of the free ligand 1,2-disila[18]crown-6 shows, as expected, a staggered conformation of the methyl groups at the silicon atoms. The DFT calculated structures of the cations in Compounds 1 and 2 exhibit only very small differences in the structural parameter in comparison to the structures obtained by X-ray diffraction (see XYZ data in the ESI).

\subsection{Mismatch Involving 1,2,4,5-Tetrasila[18]crown-6 and $\mathrm{K}^{+}$}

The synthesis of hybrid crown ethers with a higher amount of disilane units was very recently described for 1,2,4,5-tetrasila[12] crown-4 [19]. In an analogous reaction of $\mathrm{O}\left(\mathrm{Si}_{2} \mathrm{Me}_{4} \mathrm{Cl}\right)_{2}$ with tetraethylene glycol, the ligand 1,2,4,5-tetrasila[18]crown-6 (3) was synthesized using high dilution of the agents to prevent polymerization (Scheme 3). Compound 3 is a highly viscous, colorless oil. Through the presence of two disilane units, the ring size is further increased in comparison to 1,2-disila[18]crown-6. In the ${ }^{29} \mathrm{Si}\left\{{ }^{1} \mathrm{H}\right\}-\mathrm{NMR}$ spectrum, Compound 3 shows two signals which can be assigned to the two types of $\mathrm{Si}$ atoms: The $\mathrm{Si}-\mathrm{O}-\mathrm{Si}$ entity appears at $\delta=2.1 \mathrm{ppm}$, the $\mathrm{C}-\mathrm{O}-\mathrm{Si}$ entity is low-field shifted and appears at $\delta=11.0 \mathrm{ppm}$.

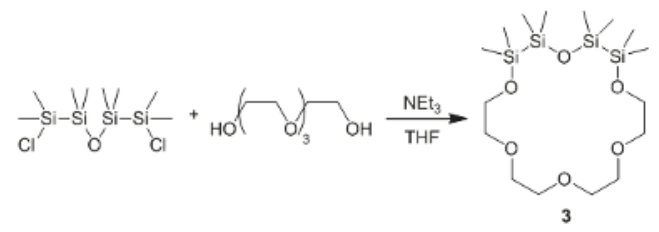

Scheme 3. Synthesis path of 1,2,4,5-tetrasila[18]crown-6 (3).

Treatment of 3 with $\mathrm{KPF}_{6}$ yielded the corresponding, highly water sensitive complex [K(1,2,4,5-tetrasila[18]crown-6) $\left.\mathrm{PF}_{6}\right]$ (4). Different to the hitherto known hybrid disila-crown ether complexes, 4 is directly after removal of the volatiles an oily compound, which crystallizes within $18 \mathrm{~h}$ at ambient temperature in form of colorless planks in the space group $P 2_{1} / n$.

As observed in the $\mathrm{Na}^{+}$complex 2, Compound 4 is a monomeric contact ion pair (Figure 4). The cation is coordinated by five of the six crown ether $\mathrm{O}$ atoms and three $\mathrm{F}$ atoms of the anion, giving a coordination number of eight. The incorporation of two disilane units into the ring system leads to an increased ring diameter so that $\mathrm{K}^{+}$, which commonly matches perfectly with [18]crown-6, has a too small ionic radius for the ligand 3. The inorganic part sticks out, showing an interatomic distance of 505.5(2) pm between the completely Si substituted O atom O2 and the metal ion. The Me groups at the Si atoms adopt an approximately staggered conformation with average dihedral angles of $84.2(2)^{\circ}$ at $\mathrm{Si} 1 / \mathrm{Si} 2$ and $59.8(2)^{\circ}$ at $\mathrm{Si} 3 / \mathrm{Si} 4$. Worth mentioning is the unusual orientation of Si4: In all hitherto known sila-crown ether complexes, the $\mathrm{Si}$ atoms bonded to coordinating $\mathrm{O}$ atoms are approximately arranged in plane with the crown ether $\mathrm{O}$ atoms $[12-15,18,19,23]$. In contrast to this, $\mathrm{Si} 4$ is considerably located beneath the mean plane of the coordinating $\mathrm{O}$ atoms. The Si/C-bonded $\mathrm{O}$ atoms $\mathrm{O} 1$ and $\mathrm{O} 3$ show $\mathrm{O}-\mathrm{K}$ bond lengths of 283.8(2) and 279.4(2) pm, whereas the fully $\mathrm{C}$-substituted $\mathrm{O}$ atoms $\mathrm{O} 4-\mathrm{O} 6$ establish average bond lengths of 273.7(2) pm. It can therefore be assumed that $\mathrm{K}^{+}$is stronger coordinated by the carbon-based part of the hybrid crown ether 3 . Compared to $\left[\mathrm{K}\left(1,2-\right.\right.$ disila[18]crown-6) $\left.\mathrm{PF}_{6}\right]$, which incorporates only one disilane unit and in which all crown ether atoms are participating in the coordination, the mean $\mathrm{O}-\mathrm{K}$ bond lengths are in 4 considerably shorter [18]. This can be related to the coordination number of 8 in 4 compared to 9 in $\left[\mathrm{K}\left(1,2-\right.\right.$ disila[18]crown-6) $\left.\mathrm{PF}_{6}\right]$. The Si2-O2-Si3 bond angle is $143.8(1)^{\circ}$, this is a typical value for siloxanes [1,2]. Also the Si4-O3-C9 bond angle of $123.3(2)^{\circ}$ is in the expected range $[18,19]$. Only the Si1-O1-C16 angle is with $117.8(1)^{\circ}$ smaller than usually observed and is similar to that found in C-O-C bindings, e.g., C14-O6-C15 with 112.3(2) ${ }^{\circ}$. 


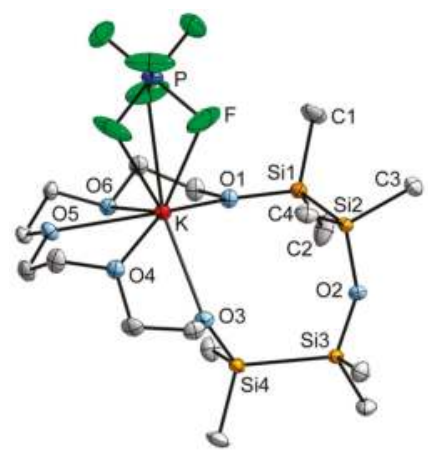

Figure 4. Molecular structure of $\left[\mathrm{K}\left(1,2,4,5\right.\right.$-tetrasila[18]crown-6) $\left.\mathrm{PF}_{6}\right]$ (4) in the crystal. Thermal ellipsoids represent the $50 \%$ probability level. Hydrogen atoms are not displayed. Selected bond lengths (pm)

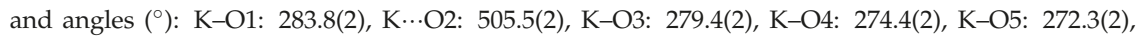
K-O6: 274.3(2), Si1-Si2: 234.9(1), Si1-O1: 166.5(2), Si2-O2: 164.5(2), Si3-O2: 165.2(2), Si4-O3: 166.7(2); Si4-O3-C9: 123.3(2), Si2-O2-Si3: 143.8(1), Si1-O1-C16: 117.8(1), C14-O6-C15: 112.3(2), C1-Si1-Si2-C4: 84.1(2), C2-Si1-Si2-C3: 84.2(1), C6-Si3-Si4-C8: 59.5(1), C5-Si3-Si4-C7: 60.1(1).

The reluctance of $\mathrm{K}^{+}$to interact with the Si-substituted $\mathrm{O}$ atoms was also observed in solution and can be deducted from the shifts in the ${ }^{29} \mathrm{Si}\left\{{ }^{1} \mathrm{H}\right\}-\mathrm{NMR}$ spectrum: The resonance signal of $\mathrm{Si} 2 / \mathrm{Si} 3$ shows only a slight low-field shift to $\delta=2.7 \mathrm{ppm}(\Delta(\delta)=0.6 \mathrm{ppm})$ and the signal of Si1/Si4 appears at $\delta=11.9 \mathrm{ppm}(\Delta(\delta)=0.9 \mathrm{ppm})$. In comparison, the ${ }^{29} \mathrm{Si}\left\{{ }^{1} \mathrm{H}\right\}$-NMR signals of 1,2-disila[18]crown-6 shift from $\delta=11.4 \mathrm{ppm}$ in the free ligand to $\delta=13.0 \mathrm{ppm}$ in the potassium complex [18]. The small shift of the ${ }^{29} \mathrm{Si}\left\{{ }^{1} \mathrm{H}\right\}$ signal indicates that also in solution $\mathrm{O} 2$ shows only minor interaction with the $\mathrm{K}^{+}$ion, owing to the high energy effort of $\mathrm{Si}_{2} \mathrm{Me}_{4}$ fragments to adopt the ecliptic geometry.

\subsection{The Inverse Case: 1,2-Disila[15]crown-5 and $\mathrm{Ba}^{2+}$}

Beside experiments involving large ligands with comparatively small cations, we also investigated the inverse mismatch case, i.e., 1,2-disila[15]crown-5 with $\mathrm{BaOTf}_{2}\left(\mathrm{OTf}={ }^{-} \mathrm{OSO}_{2} \mathrm{CF}_{3}\right)$. Prior studies revealed that $\mathrm{Ba}^{2+}$ perfectly matches with 1,2-disila[18]crown-6 and 1,2-disila-benzo[18]crown-6. In the corresponding complex, $\mathrm{Ba}^{2+}$ is located in one plane with the coordinating $\mathrm{O}$ atoms and is saturated by two triflate groups, which are arranged upon and beneath the crown ether mean plane [23]. Reaction of 1,2-disila[15]crown-5 with $\mathrm{BaOTf}_{2}$ in 1:1 stoichiometry yielded colorless blocks of $\left[\mathrm{Ba}(1,2-\mathrm{disila}[15] \text { crown-5)OTf }]_{2}\right]_{2}(5)$ in the triclinic space group $P \overline{1}$. Different to the hitherto known sila-crown ether complexes, 5 forms a dinuclear complex (Figure 5). The four triflate anions act as bridges between the two metal centers and participate in the saturation of the coordination sphere with four $\mathrm{O}$ atoms, respectively. Furthermore, $\mathrm{Ba}^{2+}$ is coordinated by the five crown ether $\mathrm{O}$ atoms, giving a coordination number of 9. The ion $\mathrm{Ba}(1)$ is located 156.8(2) pm above the calculated mean plane of the $\mathrm{O}_{\text {crown }}$ atoms, which reflects the small ring diameter of 1,2-disila[15]crown-5 compared to the ionic radius of $\mathrm{Ba}^{2+}$. The disilane units of the crown ethers show in opposite directions to each other as a result of the sterically demanding methyl groups. The typical approximately ecliptic arrangement of the methyl groups in sila-crown ethers complexes can also be found in Compound 5. However, the dihedral angles have values of $26.1(3)^{\circ}$ and $22.8(3)^{\circ}$ and accordingly show stronger deviations from the ideal ecliptic arrangement compared to those found in other hybrid-crown ether complexes. The Si/C-bonded O atoms O1 and O5 establish bond lengths of 283.4(1) and 286.5(1) pm to the cation and are in a similar range with C-bonded $\mathrm{O}$ atoms, which show $\mathrm{O}-\mathrm{Ba}$ bonds between 280.4(1) and $287.7(1) \mathrm{pm} . \mathrm{Ba}^{2+}$ is furthermore strongly coordinated by the triflate $\mathrm{O}$ atoms since the bonding to $\mathrm{Ba}(1)$ has an average value of 275.7(4) pm. Another indication for the weak coordination of $\mathrm{Ba}^{2+}$ by 
1,2-disila[15]crown-5 was revealed by mass spectrometric analysis: Only [Na(1,2-disila[15]crown-5)] ${ }^{+}$ was detected. $\mathrm{Na}^{+}$is a common impurity in mass spectrometers, so $\mathrm{Ba}^{2+}$ was immediately replaced.

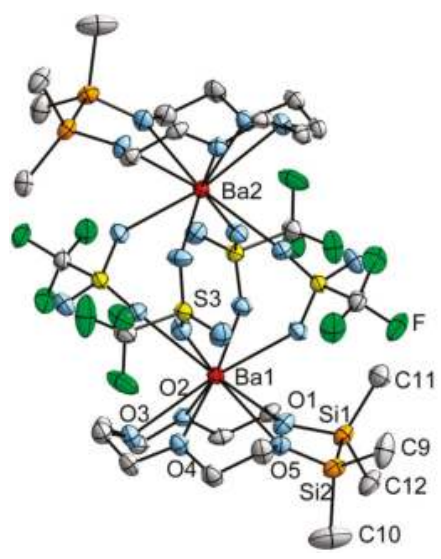

Figure 5. Molecular structure of $\left[\mathrm{Ba}(1,2 \mathrm{disila}[15] \text { crown-5)OTf }]_{2}(5)\right.$ in the crystal. Thermal ellipsoids represent the $50 \%$ probability level. Hydrogen atoms are not displayed. Selected bond lengths (pm) and angles $\left({ }^{\circ}\right)$ : Ba1-O1: 283.4(1), Ba1-O2: 287.7(1), Ba1-O3: 280.4(1), Ba1-O4: 287.7(4), Ba1-O5: 286.5(1),

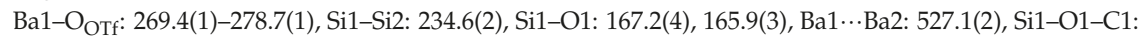
121.5(3), Si2-O5-C8: 121.6(3), C4-O3-C5: 114.9(4), C11-Si1-Si2-C9: 26.1(3), C12-Si1-Si2-C10: 22.8(3).

\section{Materials and Methods}

\subsection{General Experimental Technique}

All working procedures were conducted under exclusion of oxygen and moisture using Schlenk techniques under a nitrogen atmosphere. Solvents were dried and freshly distilled before use. Nuclear magnetic resonance (NMR) spectra were recorded with BRUKER Model AVANCE HD300, BRUKER Model DRX400, or BRUKER Model AVANCE500 spectrometers (Bruker Corporation, Rheinstetten, Germany) and were visualized with MestReNova [35]. Infrared (IR) spectra were recorded in attenuated total reflectance (ATR) mode on a BRUKER model ALPHA FT-IR. MS spectrometry was measured on a LTQ-FT (ESI, Thermo Fischer Scientific, Darmstadt, Germany) or on a JEOL AccuTOF-GC (LIFDI, JEOL, Freising, Germany). Elemental analysis data cannot be provided due to the presence of fluorine in the samples, which harm the elemental analysis devices. The ligands 1,2-disila[18]crown-6 and 1,2-disila[15]crown-5 [18] and $\mathrm{O}\left(\mathrm{Si}_{2} \mathrm{Me}_{4} \mathrm{Cl}\right)_{2}$ [19] were prepared by reported methods.

\subsection{Computational Details}

Calculations were performed with Turbomole V7.0 [28]. The resolution of identity (RI) approximation, dispersion corrections [29-32], and the conductor-like screening (COSMO) model [36] were applied, the latter with default settings. For all calculations the BP86 functional and def2-TZVP basis set $[33,34]$ were chosen.

\subsection{Crystal Structures}

Data collection was performed on a Bruker D8 Quest or a Stoe IPDS II diffractometer at 100(2) K with Mo K $\alpha$ radiation and graphite monochromatization. Structure solution was done by direct methods, refinement with full-matrix-least-squares against $F^{2}$ using shelxs-2014, shelxl-2014, shelxt-2014, and olex2 software (Table 1) [37,38]. The presentation of crystal structures was done 
with Diamond4.2.2 [39]. CCDC 1517535 (1), 1517536 (2), 1517537 (4), and 1517538 (5) contain the supplementary crystallographic data for this paper. These data can be obtained free of charge from The Cambridge Crystallographic Data Centre via www.ccdc.cam.ac.uk/data_request/cif.

Table 1. Crystal Structure Data.

\begin{tabular}{|c|c|c|c|c|}
\hline Empirical Formula & $\mathrm{C}_{14} \mathrm{H}_{30} \mathrm{Li}_{1} \mathrm{O}_{6} \mathrm{Si}_{2} \mathrm{~F}_{6} \mathrm{P}_{1}$ & $\mathrm{C}_{14} \mathrm{H}_{32} \mathrm{~F}_{6} \mathrm{Na}_{1} \mathrm{O}_{6} \mathrm{P}_{1} \mathrm{Si}_{2}$ & $\mathrm{C}_{16} \mathrm{H}_{40} \mathrm{~F}_{6} \mathrm{~K}_{1} \mathrm{O}_{6} \mathrm{Si}_{4} \mathrm{P}_{1}$ & $\mathrm{C}_{28} \mathrm{H}_{55} \mathrm{Ba}_{2} \mathrm{~F}_{12} \mathrm{O}_{22} \mathrm{~S}_{4} \mathrm{Si}_{4}$ \\
\hline $\begin{array}{l}\text { Formula weight } \\
\left(\mathrm{g} \cdot \mathrm{mol}^{-1}\right)\end{array}$ & 502.47 & 520.53 & 624.91 & 1487.00 \\
\hline Crystal color, shape & colorless plank & colorless block & colorless plank & colorless block \\
\hline Crystal size (mm) & $0.134 \times 0.189 \times 0.382$ & $0.060 \times 0.271 \times 0.284$ & $0.138 \times 0.140 \times 0.539$ & $0.232 \times 0.245 \times 0.509$ \\
\hline Crystal system & monoclinic & triclinic & monoclinic & triclinic \\
\hline Space group & $P 2_{1} / c$ & $P \overline{1}$ & $P 2_{1} / n$ & $P \overline{1}$ \\
\hline Formula units & 4 & 2 & 4 & 2 \\
\hline Temperature (K) & $100(2)$ & $100(2)$ & $100(2)$ & $100(2)$ \\
\hline Unit cell dimensions & $\begin{array}{c}a=9.189(1) \\
b=23.663(1) \\
c=10.608(1) \\
\beta=94.332(1)\end{array}$ & $\begin{aligned} a & =8.512(1) \\
b & =11.468(1) \\
c & =13.996(1) \\
\alpha & =105.64(1) \\
\beta & =103.51(1) \\
\gamma & =103.20(1)\end{aligned}$ & $\begin{array}{c}a=9.379(1) \\
b=22.608(2) \\
c=14.906(1) \\
\beta=104.62(1)\end{array}$ & $\begin{array}{l}a=11.269(2) \\
b=12.458(3) \\
c=20.817(4) \\
\alpha=78.69(3) \\
\beta=83.62(3) \\
\gamma=78.63(3)\end{array}$ \\
\hline Cell volume $\left(\AA^{3}\right)$ & $2300.0(2)$ & $1215.83(17)$ & $3058.4(4)$ & $2801.6(11)$ \\
\hline Pcalc $\left(\mathrm{g} / \mathrm{cm}^{3}\right)$ & 1.451 & 1.422 & 1.357 & 1.763 \\
\hline$\mu(\mathrm{Mo} \mathrm{K} \alpha)\left(\mathrm{mm}^{-1}\right)$ & 0.298 & 0.301 & 0.446 & 1.739 \\
\hline $2 \theta$ range & $2.384-25.299$ & $2.578-25.237$ & $2.289-25.319$ & $1.695-26.373$ \\
\hline Reflections measured & 47204 & 13274 & 86701 & 24025 \\
\hline $\begin{array}{l}\text { Independent } \\
\text { Reflections }\end{array}$ & $4181[$ Rint $=0.0402]$ & $4422[\operatorname{Rint}=0.0882]$ & $5566[\operatorname{Rint}=0.0290]$ & $11417[$ Rint $=0.0848]$ \\
\hline$R 1(I>2 \sigma(I))$ & 0.0455 & 0.0535 & 0.0191 & 0.0435 \\
\hline$w R 2$ (all data) & 0.1103 & 0.1504 & 0.0360 & 0.1091 \\
\hline GooF & 1.023 & 1.021 & 0.800 & 0.926 \\
\hline $\begin{array}{c}\text { Largest diff. peak and } \\
\text { hole }\left(\mathrm{e} \cdot \AA^{-3}\right)\end{array}$ & $1.02 /-0.65$ & $0.60 /-0.56$ & $0.60 /-0.61$ & $1.61 /-2.25$ \\
\hline
\end{tabular}

\subsection{Experimental Section}

$\mathrm{Li}$ (1,2-disila[18]crown-6)] $\mathrm{PF}_{6}$ (1): At ambient temperature, $159 \mathrm{mg}$ (1.05 mmol, 1 equiv) of $\mathrm{LiPF}_{6}$ was added to $370 \mathrm{mg}$ (1.1 mmol, 1 equiv) of 1,2-disila[18]crown-6 in $15 \mathrm{~mL}$ of dichloromethane. The suspension was stirred for $18 \mathrm{~h}$ and was subsequently filtered. The solvent was removed under reduced pressure, and the residue was washed with $n$-pentane. The resulting colorless greasy solid was recrystallized with traces of dichloromethane after freezing at $-196^{\circ} \mathrm{C}$ and subsequently storage at $-35{ }^{\circ} \mathrm{C}$ for 3 days. $45 \%$ ( $275 \mathrm{mg}, 0.5 \mathrm{mmol}$ ) of 1 was obtained in form of colorless planks. ${ }^{1} \mathrm{H}$ NMR $\left(300 \mathrm{MHz}, \mathrm{CD}_{2} \mathrm{Cl}_{2}\right): \delta=0.34\left(\mathrm{~s}, 12 \mathrm{H}, \mathrm{CH}_{3}\right), 3.71-3.73\left(\mathrm{~m}, 4 \mathrm{H}, \mathrm{CH}_{2}\right), 3.76\left(\mathrm{~s}, 12 \mathrm{H}, \mathrm{CH}_{2}\right), 3.81-3.82 \mathrm{ppm}$ $\left(\mathrm{m}, 4 \mathrm{H}, \mathrm{CH}_{2}\right) ;{ }^{13} \mathrm{C}\left\{{ }^{1} \mathrm{H}\right\} \mathrm{NMR}\left(75 \mathrm{MHz}, \mathrm{CD}_{2} \mathrm{Cl}_{2}\right): \delta=-0.5\left(\mathrm{~s}, \mathrm{CH}_{3}\right), 61.7\left(\mathrm{~s}, \mathrm{CH}_{2}\right), 68.1\left(\mathrm{~s}, \mathrm{CH}_{2}\right), 68.2(\mathrm{~s}$, $\left.\mathrm{CH}_{2}\right), 68.4\left(\mathrm{~s}, \mathrm{CH}_{2}\right), 71.4 \mathrm{ppm}\left(\mathrm{s}, \mathrm{CH}_{2}\right) ;{ }^{29} \mathrm{Si}\left\{{ }^{1} \mathrm{H}\right\} \mathrm{NMR}\left(\mathrm{CD}_{2} \mathrm{Cl}_{2}\right): \delta=15.6 \mathrm{ppm}(\mathrm{s}) ;{ }^{7} \operatorname{Li~NMR}(194 \mathrm{MHz}$, $\left.\mathrm{CD}_{2} \mathrm{Cl}_{2}\right): \delta=-0.9 \mathrm{ppm}(\mathrm{s}) ;{ }^{31} \mathrm{P}\left\{{ }^{1} \mathrm{H}\right\} \mathrm{NMR}\left(117 \mathrm{MHz}, \mathrm{CD}_{2} \mathrm{Cl}_{2}\right): \delta=-144.0 \mathrm{ppm}\left(\mathrm{h},{ }^{1} J_{\mathrm{PF}}=710 \mathrm{~Hz}\right) ;$ ${ }^{19} \mathrm{~F} \mathrm{NMR}\left(283 \mathrm{MHz}, \mathrm{CD}_{2} \mathrm{Cl}_{2}\right): \delta=-73.7 \mathrm{ppm}\left(\mathrm{d},{ }^{1} J_{\mathrm{PF}}=710 \mathrm{~Hz}\right)$. IR $\tilde{v}=2962(\mathrm{w}), 2885(\mathrm{vw}), 1456(\mathrm{vw})$, 1410(vw), 1351(vw), 1258(m), 1057(s), 1011(s), 923(w), 789(vs), 701(w), 661(w), 635(w), 556(m), 466(m). MS $\left(\mathrm{ESI}^{+}\right): \mathrm{m} / z$ 359.1893\% $[M]^{+}-\mathrm{PF}_{6}(95)$.

[Na(1,2-disila[18]crown-6)PF 6 (2): At ambient temperature, $48 \mathrm{mg}$ (0.3 mmol, 1 equiv) of $\mathrm{NaPF}_{6}$ was added to $100 \mathrm{mg}$ ( $0.28 \mathrm{mmol}, 1$ equiv) of 1,2-disila[18]crown- 6 in $10 \mathrm{~mL}$ of dichloromethane. The suspension was stirred for $1 \mathrm{~h}$, followed by filtration and removal of the solvent. The residue was washed twice with $10 \mathrm{~mL}$ of $n$-pentane and was dried in vacuo. Recrystallization from dichloromethane: benzene (2:1) at $-35^{\circ} \mathrm{C}$ yielded $44 \%(64 \mathrm{mg}, 0.12 \mathrm{mmol})$ of 2 in form of colorless blocks after 1 day. ${ }^{1} \mathrm{H}$ NMR (300 MHz, $\left.\mathrm{CD}_{2} \mathrm{Cl}_{2}\right): \delta=0.29\left(\mathrm{~s}, 12 \mathrm{H}, \mathrm{CH}_{3}\right), 3.61-3.63\left(\mathrm{~m}, 4 \mathrm{H}, \mathrm{CH}_{2}\right), 3.67\left(\mathrm{~s}, 12 \mathrm{H}, \mathrm{CH}_{2}\right)$, 3.80-3.83 ppm (m, 4H, CH $) ;{ }^{13} \mathrm{C}\left\{{ }^{1} \mathrm{H}\right\} \mathrm{NMR}\left(75 \mathrm{MHz}, \mathrm{CD}_{2} \mathrm{Cl}_{2}\right): \delta=-0.4\left(\mathrm{~s}, \mathrm{CH}_{3}\right), 62.8\left(\mathrm{~s}, \mathrm{CH}_{2}\right), 69.9$ $\left(\mathrm{s}, \mathrm{CH}_{2}\right), 72.0\left(\mathrm{~s}, \mathrm{CH}_{2}\right), 72.9 \mathrm{ppm}\left(\mathrm{s}, \mathrm{CH}_{2}\right) ;{ }^{29} \mathrm{Si}\left\{{ }^{1} \mathrm{H}\right\} \mathrm{NMR}\left(\mathrm{CD}_{2} \mathrm{Cl}_{2}\right): \delta=14.3 \mathrm{ppm}(\mathrm{s}) ;{ }^{31} \mathrm{P}\left\{{ }^{1} \mathrm{H}\right\} \mathrm{NMR}$ $\left(117 \mathrm{MHz}, \mathrm{CD}_{2} \mathrm{Cl}_{2}\right): \delta=-143.9 \mathrm{ppm}\left(\mathrm{h},{ }^{1} J_{\mathrm{PF}}=710 \mathrm{~Hz}\right) ;{ }^{19} \mathrm{~F} \mathrm{NMR}\left(283 \mathrm{MHz}, \mathrm{CD}_{2} \mathrm{Cl}_{2}\right): \delta=-74.8 \mathrm{ppm}$ $\left(\mathrm{d},{ }^{1} J_{\mathrm{PF}}=710 \mathrm{~Hz}\right)$. IR $\tilde{v}=2912(\mathrm{w}), 2880(\mathrm{w}), 1457(\mathrm{w}), 1399(\mathrm{w}), 1350(\mathrm{w}), 1291(\mathrm{w}), 1250(\mathrm{~m}), 1131(\mathrm{~s})$, 
1082(s), 1056(s), 955(s), 931(m), 834(vs), 816(vs), 794(s), 771(s), 740(m), 720(m), 635(m), 556(s), 504(w), 471(w). MS $\left(\mathrm{ESI}^{+}\right): \mathrm{m} / \mathrm{z} 375.1634 \%[\mathrm{M}]^{+}-\mathrm{PF}_{6}(100)$.

1,2,4,5-Tetrasila[18]crown-6 (3): $0.7 \mathrm{~mL}$ (4.1 mmol, 1 equiv) of tetraethylene glycol and $1.1 \mathrm{~mL}$ (8.2 mmol, 2 equiv) of $\mathrm{NEt}_{3}$ in $50 \mathrm{~mL}$ of THF was simultaneously, with $1.30 \mathrm{~g}$ ( $4.1 \mathrm{mmol}, 1$ equiv) of $\mathrm{O}\left(\mathrm{Si}_{2} \mathrm{Me}_{4} \mathrm{Cl}\right)_{2}$ in $50 \mathrm{~mL}$ of THF, dropped into a three-neck flask with $50 \mathrm{~mL}$ of stirred THF. The resulting white suspension was stirred for $12 \mathrm{~h}$. Subsequently, the solvent was removed under reduced pressure, the product was extracted with $50 \mathrm{~mL}$ of $n$-pentane followed by filtration. The solvent was removed in vacuo, and $85 \%(1.5 \mathrm{~g}, 3.5 \mathrm{mmol})$ of 3 was obtained in form of a colorless oil. ${ }^{1} \mathrm{H}$ NMR $\left(300 \mathrm{MHz}, \mathrm{CD}_{2} \mathrm{Cl}_{2}\right): \delta=0.20\left(\mathrm{~s}, 12 \mathrm{H}, \mathrm{CH}_{3}\right), 0.22\left(\mathrm{~s}, 12 \mathrm{H}, \mathrm{CH}_{3}\right), 3.54-3.56\left(\mathrm{~m}, 4 \mathrm{H}, \mathrm{CH}_{2}\right), 3.60\left(\mathrm{~s}, 8 \mathrm{H}, \mathrm{CH}_{2}\right)$, 3.72-3.76 ppm (m, $\left.4 \mathrm{H}, \mathrm{CH}_{2}\right) ;{ }^{13} \mathrm{C}\left\{{ }^{1} \mathrm{H}\right\} \mathrm{NMR}\left(75 \mathrm{MHz}, \mathrm{CD}_{2} \mathrm{Cl}_{2}\right): \delta=-0.5\left(\mathrm{~s}, \mathrm{CH}_{3}\right), 2.9\left(\mathrm{~s}, \mathrm{CH}_{3}\right), 63.9(\mathrm{~s}$, $\left.\mathrm{CH}_{2}\right), 71.2\left(\mathrm{~s}, \mathrm{CH}_{2}\right), 71.6\left(\mathrm{~s}, \mathrm{CH}_{2}\right), 73.1\left(\mathrm{~s}, \mathrm{CH}_{2}\right) ;{ }^{29} \mathrm{Si}\left\{{ }^{1} \mathrm{H}\right\} \mathrm{NMR}\left(\mathrm{CD}_{2} \mathrm{Cl}_{2}\right): \delta=2.1(\mathrm{~s}, \mathrm{SiOSi}), 11.0 \mathrm{ppm}(\mathrm{s}$, COSi). IR $\tilde{v}=2949(\mathrm{w}), 2867(\mathrm{w}), 1456(\mathrm{w}), 1400(\mathrm{w}), 1350(\mathrm{w}), 1294(\mathrm{w}), 1246(\mathrm{~m}), 1091(\mathrm{~s}), 1031(\mathrm{~s})$, 947(m), 826(m), 797(s), 761(s), 682(m), 660(m), 635(m), 553(w), 546(w). MS (ESI $\left.{ }^{+}\right): m / z ~ 441.1977 \% ~[M H]^{+}(15)$.

[K(1,2,4,5-tetrasila[18]crown-6) $\left.\mathrm{PF}_{6}\right]$ (4): $58 \mathrm{mg}\left(0.32 \mathrm{mmol}, 1\right.$ equiv) of $\mathrm{KPF}_{6}$ was added to a stirred solution of $140 \mathrm{mg}$ ( $0.32 \mathrm{mmol}, 1$ equiv) of 1,2,4,5-tetrasila[18]crown-6 in $15 \mathrm{~mL}$ of dichloromethane. The resulting suspension was stirred for $12 \mathrm{~h}$ at ambient temperature, followed by filtration. The solvent was removed in vacuo, and the product was obtained in form of a colorless, highly viscous oil. After $18 \mathrm{~h}$ at ambient temperature, colorless blocks were obtained, yielding $61 \%$ (120 $\mathrm{mg}, 0.2 \mathrm{mmol})$ of 4. ${ }^{1} \mathrm{H}$ NMR $\left(300 \mathrm{MHz}, \mathrm{CD}_{2} \mathrm{Cl}_{2}\right): \delta=0.08\left(\mathrm{~s}, 12 \mathrm{H}, \mathrm{CH}_{3}\right), 0.23\left(\mathrm{~s}, 12 \mathrm{H}, \mathrm{CH}_{3}\right), 3.54-3.57\left(\mathrm{~m}, 4 \mathrm{H}, \mathrm{CH}_{2}\right)$, $3.62\left(\mathrm{~s}, 8 \mathrm{H}, \mathrm{CH}_{2}\right), 3.73-3.77 \mathrm{ppm}\left(\mathrm{m}, 4 \mathrm{H}, \mathrm{CH}_{2}\right) ;{ }^{13} \mathrm{C}\left\{{ }^{1} \mathrm{H}\right\} \mathrm{NMR}\left(75 \mathrm{MHz}, \mathrm{CD}_{2} \mathrm{Cl}_{2}\right): \delta=-0.6\left(\mathrm{~s}, \mathrm{CH}_{3}\right), 2.8$ $\left(\mathrm{s}, \mathrm{CH}_{3}\right), 63.6\left(\mathrm{~s}, \mathrm{CH}_{2}\right), 71.0\left(\mathrm{~s}, \mathrm{CH}_{2}\right), 71.1\left(\mathrm{~s}, \mathrm{CH}_{2}\right), 73.1 \mathrm{ppm}\left(\mathrm{s}, \mathrm{CH}_{2}\right) ;{ }^{29} \mathrm{Si}\left\{{ }^{1} \mathrm{H}\right\} \mathrm{NMR}\left(\mathrm{CD}_{2} \mathrm{Cl}_{2}\right): \delta=2.7$ (s, SiOSi), $11.9 \mathrm{ppm}(\mathrm{s}, \mathrm{COSi}) ;{ }^{31} \mathrm{P}\left\{{ }^{1} \mathrm{H}\right\} \mathrm{NMR}\left(117 \mathrm{MHz}, \mathrm{CD}_{2} \mathrm{Cl}_{2}\right): \delta=-143.9 \mathrm{ppm}\left(\mathrm{h},{ }^{1} J_{\mathrm{PF}}=710 \mathrm{~Hz}\right)$; ${ }^{19} \mathrm{~F}$ NMR $\left(283 \mathrm{MHz}, \mathrm{CD}_{2} \mathrm{Cl}_{2}\right): \delta=-73.8 \mathrm{ppm}\left(\mathrm{d},{ }^{1} J_{\mathrm{PF}}=710 \mathrm{~Hz}\right)$. IR $\tilde{v}=2948(\mathrm{w}), 2886(\mathrm{w}), 1470(\mathrm{w})$, 1458(w), 1401(w), 1360(w), 1349(w), 1301(w), 1247(m), 1126(m), 1110(m), 1095(m), 1085(m), 1065(m), 1051(m), 1017(m), 945(m), 931(m), 916(m), 825(vs), 797(vs), 762(vs), 738(m), 719(w), 684(m), 659(m), 555(s), 441(w), 427(w), 414(w). MS (ESI $\left.{ }^{+}\right): m / z 479.1531 \%[M]^{+}-\mathrm{PF}_{6}(100)$.

[Ba(1,2-disila[15]crown-5)OTf $]_{2}$ (5): $119 \mathrm{mg}\left(0.27 \mathrm{mmol}, 1\right.$ equiv) of $\mathrm{BaOTf}_{2}$ was added to $84 \mathrm{mg}$ ( $0.27 \mathrm{mmol}, 1$ equiv) of 1,2-disila[15]crown- 5 in $15 \mathrm{~mL}$ of dichloromethane. The suspension was stirred for $18 \mathrm{~h}$ followed by filtration. The solvent was removed under reduced pressure, and the residue was washed twice with $15 \mathrm{~mL}$ of $n$-pentane. The product was recrystallized from dichloromethane and pentane (2:5). After 1 day at ambient temperature, colorless plates of 5 were obtained with $22 \%$ $(87 \mathrm{mg}, 0.06 \mathrm{mmol})$ yield. ${ }^{1} \mathrm{H}$ NMR $\left(300 \mathrm{MHz}, \mathrm{CD}_{2} \mathrm{Cl}_{2}\right): \delta=0.37\left(\mathrm{~s}, 24 \mathrm{H}, \mathrm{CH}_{3}\right), 3.71-4.04 \mathrm{ppm}(\mathrm{m}, 32 \mathrm{H}$, $\left.\mathrm{CH}_{2}\right) ;{ }^{13} \mathrm{C}\left\{{ }^{1} \mathrm{H}\right\} \mathrm{NMR}\left(75 \mathrm{MHz}, \mathrm{CD}_{2} \mathrm{Cl}_{2}\right): \delta=-0.8\left(\mathrm{~s}, \mathrm{CH}_{3}\right), 62.0\left(\mathrm{~s}, \mathrm{CH}_{2}\right), 69.0\left(\mathrm{~s}, \mathrm{CH}_{2}\right), 70.3\left(\mathrm{~s}, \mathrm{CH}_{2}\right)$, $72.6\left(\mathrm{~s}, \mathrm{CH}_{2}\right), 120.9 \mathrm{ppm}\left(\mathrm{q},{ }^{1} J_{\mathrm{CF}}=322 \mathrm{~Hz}, \mathrm{CF}_{3}\right) ;{ }^{19} \mathrm{~F} \mathrm{NMR}\left(283 \mathrm{MHz}, \mathrm{CD}_{2} \mathrm{Cl}_{2}\right): \delta=-79.4 \mathrm{ppm}\left(\mathrm{s}, \mathrm{CF}_{3}\right)$; ${ }^{29} \mathrm{Si}\left\{{ }^{1} \mathrm{H}\right\} \operatorname{NMR}\left(\mathrm{CD}_{2} \mathrm{Cl}_{2}\right): \delta=17.8 \mathrm{ppm}(\mathrm{s}) ; \mathrm{IR} \tilde{v}=2952(\mathrm{w}), 2869(\mathrm{w}), 1468(\mathrm{w}), 1358(\mathrm{w}), 1263(\mathrm{~s}), 1228(\mathrm{~s})$, 1171(s), 1156(s), 1121(m), 1084(s), 1061(s), 1030(s), 948(s), 917(m), 867(m), 838(s), 793(s), 770(s), 728(s), 631(s), 575(s), 515(s), 454(w), 416(w); MS (LIFDI $\left.{ }^{+}\right):$m/z 331.136\% [1,2-disila[15]crown-5+Na] ${ }^{+}(100)$.

\section{Conclusions}

In this work, the competing coordination ability of $\mathrm{C}_{-}, \mathrm{Si} / \mathrm{C}-$, and fully Si-bonded $\mathrm{O}$ atoms was studied. 1,2-disila[18]crown-6 as well as 1,2,4,5-tetrasila[18]crown-6 turned out to be suitable ligands, since the presence of $\mathrm{Si}_{2}$ units further increases the ring diameter in comparison to the organic crown ether [18]crown-6. Single crystals of [Li(1,2-disila[18]crown-6)]PF 6 (1) and of [Na(1,2-disila[18]crown-6) $\left.\mathrm{PF}_{6}\right](2)$ were obtained and revealed a divergent coordination of the cation. In 1 , the highly flexible ligand completely saturates the coordination sphere of $\mathrm{Li}^{+}$, while the $\mathrm{PF}_{6}$ anion does not show any interaction with the cation. $\mathrm{The}^{+} \mathrm{i}^{+}$ion is preferably coordinated by the $\mathrm{Si}$ - and $\mathrm{C}$-bonded $\mathrm{O}$ atoms. Contrary to that, $\mathrm{Na}^{+}$shows stronger interaction with the $\mathrm{C}$-bonded $\mathrm{O}$ atoms of 1,2-disila[18]crown-6. Only one of the $\mathrm{Si} / \mathrm{C}$-bonded $\mathrm{O}$ atoms participates in the coordination. As a result, the Me groups of the Si-based part of the ligand remain in the staggered conformation, which is also the preferred geometry of the free ligand [18]. Contrary to Compound 1, the interaction of the 
$\mathrm{Si} / \mathrm{C}$-bonded $\mathrm{O}$ atoms with the cation does not compensate for the required change of conformation. The energy effort of 1,2-disila[18]crown-6 for adopting the geometry of the $\mathrm{Li}^{+}$and $\mathrm{Na}^{+}$complex was determined by DFT calculations. $\Delta E_{\text {geom }}$, in the case of 1 , has a value of $77.58 \mathrm{~kJ} \cdot \mathrm{mol}^{-1}$, which is considerably increased. In contrast, the ligand shows with $29.24 \mathrm{~kJ} \cdot \mathrm{mol}^{-1}$ smaller energy changes by coordination of $\mathrm{Na}^{+}$, which can be partially attributed to the staggered arrangement of the Si-bonded methyl groups. It follows that the electrostatic attraction between the hybrid-bonded $\mathrm{O}$ atoms and $\mathrm{Na}^{+}$ do not compensate for the required energy effort of the ecliptic arranged methyl groups. The Lewis acids therefore show a major impact on the coordinative properties of the different types of $\mathrm{O}$ atoms within hybrid crown ethers.

Similar coordination modes were also found in 1,2,4,5-tetrasila[18]crown-6 (3), which incorporates three types of O atoms: $\mathrm{C}-, \mathrm{Si} / \mathrm{C}-$, and Si-bonded ones. Ordinary, $\mathrm{K}^{+}$perfectly fits in [18]crown-6 and 1,2-disila[18]crown-6 [18]. The presence of two disilane units leads to a further increase of the ligand such that 3 does not match with $\mathrm{K}^{+}$. The completely Si-bonded $\mathrm{O}$ atom, which requires the highest amount of energy to adopt the complex geometry [19], does not participate in the coordination. The complexation of the heavier homologue $\mathrm{Rb}^{+}$by 3 is an issue of current investigation. In this study, no superiority in coordination ability of each of the different types of $\mathrm{O}$ atoms was found.

The experiment on the inverse case, e.g., small ligands with large cations in 1:1 stoichiometry, leads to the dinuclear complex (5), which is bridged by four triflate anions. This crystal structure represents an initial outlook on the ability of disila-crown ethers to build sandwich complexes. Therefore, reactions in 2:1 stoichiometry of ligand to salt are crucial.

Supplementary Materials: The following are available online at www.mdpi.com/2304-6740/5/1/11/s1, Figures S1-S3: Calculated structure of 1,2-disila[18]crown-6, [Li(1,2-disila[18]crown-6)]+, [Na(1,2-disila[18]crown-6)] ; Tables S1-S3: XYZ data of 1,2-disila[18]crown-6, [Li(1,2-disila[18]crown-6)]+, [Na(1,2-disila[18]crown-6)] .

Acknowledgments: This work was financially supported by the Deutsche Forschungsgemeinschaft (DFG).

Author Contributions: Kirsten Reuter performed the syntheses and analytics of Compounds 1-4, DFT calculations, and interpretations and wrote the paper; Fabian Dankert conducted the synthesis and characterization of Compound 5; Carsten Donsbach accomplished the measurement, crystal structure solution, and refinement of 5; Carsten von Hänisch contributed to interpretation and led the over-arching research project.

Conflicts of Interest: The authors declare no conflict of interest.

\section{References}

1. Liebau, F. Untersuchungen über die Grösse des Si-O-Si-Valenzwinkels. Acta Cryst. 1961, 14, 1103-1109. [CrossRef]

2. Almenningen, A.; Bastiansen, O.; Ewing, V.; Hedberg, K.; Trætteberg, M. The Molecular Structure of Disiloxane, $\left(\mathrm{SiH}_{3}\right)_{2} \mathrm{O}$. Acta Chem. Scand. 1963, 17, 2455-2460. [CrossRef]

3. Stone, F.G.A.; Seyferth, D. The Chemistry of Silicon Involving Probable Use of $d$-Type Orbitals. J. Inorg. Nucl. Chem. 1955, 1, 112-118. [CrossRef]

4. Craig, D.P.; Maccoll, A.; Nyholm, R.S.; Orgel, L.E. Chemical bonds involving d-orbitals. Part I. J. Chem. Soc. 1954, 332-353. [CrossRef]

5. Emeléus, H.J.; Onyszchuk, M. The Reaction of Methyldisoxanes and 1:1 Dimethyldisilthiane with Boron and Hydrogen Halides. J. Chem. Soc. 1958, 604-609. [CrossRef]

6. Pitt, C.G. Hyperconjugation and its Role in Group IV Chemistry. J. Organomet. Chem. 1973, 61, 49-70. [CrossRef]

7. Shambayati, S.; Schreiber, S.L.; Blake, J.F.; Wierschke, S.G.; Jorgenson, W.L. Structure and basicity of silyl ethers: A crystallographic and ab initio inquiry into the nature of silicon-oxygen interactions. J. Am. Chem. Soc. 1990, 112, 697-703. [CrossRef]

8. Cypryk, M.; Apeloig, Y. Ab Initio Study of Silyloxonium Ions. Organometallics 1997, 16, 5938-5949. [CrossRef]

9. Gillespie, R.J.; Johnson, S.A. Study of Bond Angles and Bond Lenghts in Disiloxane and Related Molecules in Terms of the Topology of the Electron Density and Its Laplacian. Inorg. Chem. 1997, 36, 3031-3039. [CrossRef] [PubMed] 
10. Grabowski, S.J.; Hesse, M.F.; Paulmann, C.; Luger, P.; Beckmann, J. How to Make the Ionic Si-O Bond More Covalent and the Si-O-Si Linkage a Better Acceptor for Hydrogen Bonding. Inorg. Chem. 2009, 48, 4384-4393. [CrossRef] [PubMed]

11. Passmore, J.; Rautiainen, J.M. On The Lower Basicity of Siloxanes Compared to Ethers. Eur. J. Inorg. Chem. 2012, 6002-6010. [CrossRef]

12. Cameron, T.S.; Decken, A.; Krossing, I.; Passmore, J.; Rautiainen, J.M.; Wang, X.; Zeng, X. Reactions of a Cyclodimethyldisiloxane $\left(\mathrm{Me}_{2} \mathrm{SiO}\right)_{6}$ with Silver Salts of Weakly Coordinating Anions; Crystal Structures of $\left.\left[\mathrm{Ag}\left(\mathrm{Me}_{2} \mathrm{SiO}\right)_{6}\right][\mathrm{Al}]\left([\mathrm{Al}]=\mathrm{FAl}\left\{\mathrm{OC}\left(\mathrm{CF}_{3}\right)_{3}\right\}_{3}\right],\left[\mathrm{Al}\left\{\mathrm{OC}\left(\mathrm{CF}_{3}\right)_{3}\right\}_{4}\right]\right)$ and Their Comparison with $[\mathrm{Ag}(18-\mathrm{Crown}-6)]_{2}\left[\mathrm{SbF}_{6}\right]_{2}$. Inorg. Chem. 2013, 52, 3113-3126. [CrossRef] [PubMed]

13. Decken, A.; Passmore, J.; Wang, W. Cyclic Dimethylsiloxanes as Pseudo Crown Ethers: Syntheses and Characterization of $\mathrm{Li}\left(\mathrm{Me}_{2} \mathrm{SiO}\right)_{5}\left[\mathrm{Al}\left\{\mathrm{OC}\left(\mathrm{CF}_{3}\right)_{3}\right\}_{4}\right], \mathrm{Li}\left(\mathrm{Me}_{2} \mathrm{SiO}\right)_{6}\left[\mathrm{Al}\left\{\mathrm{OC}\left(\mathrm{CF}_{3}\right)_{3}\right\}_{4}\right]$ and $\mathrm{Li}\left(\mathrm{Me}_{2} \mathrm{SiO}\right)_{6}\left[\mathrm{Al}\left\{\mathrm{OCC}\left(\mathrm{CF}_{3}\right)_{2} \mathrm{Ph}\right\}_{4}\right]$. Angew. Chem. Int. Ed. 2006, 45, 2773-2777. [CrossRef] [PubMed]

14. Ritch, J.S.; Chivers, T. Silicon Analogues of Crown Ethers and Cryptands: A New Chapter in Host-Guest Chemistry? Angew. Chem. Int. Ed. 2007, 46, 4610-4613. [CrossRef] [PubMed]

15. Von Hänisch, C.; Hampe, O.; Weigend, F.; Stahl, S. Stepwise Synthesis and Coordination Compound of an Inorganic Cryptand. Angew. Chem. Int. Ed. 2007, 46, 4775-4779. [CrossRef] [PubMed]

16. Inoue, Y.; Ouchi, M.; Hakushi, T. Molecular Design of Crown Ethers. 3. Extraction of Alkaline Earth and Heavy Metal Picrates with 14- to 17-Crown-5 and 17- to 22-Crown-6. Bull. Chem. Soc. Jpn. 1985, 58, 525-530. [CrossRef]

17. Ouchi, M.; Inoue, Y.; Kanzaki, T.; Hakushi, T. Ring-contracted Crown Ethers: 14-Crown-5, 17-Crown-6, and Their Sila-analogues. Drastic Decrease in Cation-binding Ability. Bull. Chem. Soc. Jpn. 1984, 57, 887-888. [CrossRef]

18. Reuter, K.; Buchner, M.R.; Thiele, G.; von Hänisch, C. Stable Alkali-Metal Complexes of Hybrid Disila-Crown Ethers. Inorg. Chem. 2016, 55, 4441-4447. [CrossRef] [PubMed]

19. Reuter, K.; Thiele, G.; Hafner, T.; Uhlig, F.; von Hänisch, C. Synthesis and coordination ability of a partially silicon based crown ether. Chem. Commun. 2016, 52, 13265-13268. [CrossRef] [PubMed]

20. Dalley, N.K.; Lamb, J.D.; Nazarenko, A.Y. Crystal Structure of the Complex of 1,4,7,10,13,16-Hexacyclooctadecane with Lithium Picrate Dihydrate. Supramol. Chem. 1997, 8, 345-350.

21. Chadwick, S.; Ruhlandt-Senge, K. The Remarkable Structural Diversity of Alkali Metal Pyridine-2-thiolates with Mismatched Crown Ethers. Chem. Eur. J. 1998, 4, 1768-1780. [CrossRef]

22. Akutagawa, T.; Hasegawa, T.; Nakamura, T.; Takeda, S.; Inabe, T.; Sugiura, K.; Sakata, Y.; Underhill, A.E. Ionic Channel Structures in $\left[\left(\mathrm{M}^{+}\right)_{x}([18] \text { crown-6)][Ni(dmit })_{2}\right]_{2}$ Molecular Conductors. Chem. Eur. J. 2001, 7, 4902-4912. [CrossRef]

23. Dankert, F.; Reuter, K.; Donsbach, C.; von Hänisch, C. A Structural Study of Alkaline Earth Metal Complexes with Hybrid Disila-Crown Ethers. Dalton Trans. 2017. [CrossRef] [PubMed]

24. Olsher, U.; Izatt, R.M.; Bradshaw, J.S.; Dalley, N.K. Coordination chemistry of lithium ion: A crystal and molecular structure review. Chem. Rev. 1991, 91, 137-164. [CrossRef]

25. Gingl, F.; Hiller, W.; Strähle, J. [Li(12-Krone-4)]Cl: Kristallstruktur und IR-Spektrum. Z. Anorg. Allg. Chem. 1991, 606, 91-96. [CrossRef]

26. Liddle, S.T.; Clegg, W. A homologous series of crown-ether-complexed alkali metal amides as discrete ion-pair species: Synthesis and structures of $\left[M(12-c r o w n-4)_{2}\right][\mathrm{PyNPh} \cdot \mathrm{PyN}(\mathrm{H}) \mathrm{Ph}](M=\mathrm{Li}, \mathrm{Na}$ and $\mathrm{K})$. Polyhedron 2003, 22, 3507-3513. [CrossRef]

27. Feldmann, C.; Okrut, A. Two Tricyclic Polychalcogenides in $\left[\mathrm{Li}(12 \text {-crown- } 4)_{2}\right]_{2}\left[\mathrm{Sb}_{2} \mathrm{Se}_{12}\right]$ and [Li(12-crown-4) $\left.{ }_{2}\right]_{4}\left[\mathrm{Te}_{12}\right] \cdot(12$-crown-4)2. Z. Anorg. Allg. Chem. 2009, 635, 1807-1811. [CrossRef]

28. Turbomole, version 7.0; Turbomole Is a Development of University of Karlsruhe and Forschungszentrum Karlsruhe 1989-2007, Turbomole GmbH 2016. Turbomole GmbH: Karlsruhe, Germany, 2007.

29. Weigend, F.; Ahlrichs, R. Balanced bass sets of split valence, triple zeta valence and quadruple zeta valence quality for H to Rn: Design and assessment of accuracy. Phys. Chem. Chem. Phys. 2005, 7, 3297-3305. [CrossRef] [PubMed]

30. Weigend, F. Accurate Coulomb-fitting basis sers for H to Rn. Phys. Chem. Chem. Phys. 2006, 8, 1057-1065. [CrossRef] [PubMed]

31. Dolg, M.; Stoll, H.; Savin, A.; Preuss, H. Energy-adjusted pseudopotentials for the rare earth elements. Theoret. Chim. Acta 1989, 75, 173-194. [CrossRef] 
32. Stoll, H.; Metz, B.; Dolg, M. Relativistic energy-consistent pseudopotentials-Recent developments. J. Comput. Chem. 2002, 23, 767-778. [CrossRef] [PubMed]

33. Grimme, S.; Antony, J.; Ehrlich, S.; Krieg, H. A consistent and accurate ab initio parametrization of density functional dispersion correction (DFT-D) for the 94 elements H-Pu. J. Chem. Phys. 2010, 132, 154104-154119. [CrossRef] [PubMed]

34. Grimme, S.; Ehrlich, S.; Goerigk, L. Effect of the damping function in dispersion corrected density functional theory. J. Comput. Chem. 2011, 32, 1456-1465. [CrossRef] [PubMed]

35. Willcott, M.R. MestRe Nova. J. Am. Chem. Soc. 2009, 131, 13180. [CrossRef]

36. Klamt, A.; Schüürmann, G. COSMO: A new approach to dielectric screening in solvents with explicit expressions for the screening energy and its gradient. J. Chem. Soc. Perkin. Trans. 1993, 2, 799-805. [CrossRef]

37. Sheldrick, G.M. SHELXL14; Program for the Refinement of Crystal Structures; Universität Göttingen: Göttingen, Germany, 2014.

38. Dolomanov, O.V.; Bourhis, L.J.; Hildea, R.J.; Howard, J.A.K.; Puschmann, H. Olex2: A complete structure solution, refinement and analysis program. J. Appl. Crystallogr. 2009, 42, 339-341. [CrossRef]

39. Putz, H.; Brandenburg, K. Diamond-Crystal and Molecular Structure Visualization; Crystal Impact: Bonn, Germany, 2012.

(C) 2017 by the authors. Licensee MDPI, Basel, Switzerland. This article is an open access article distributed under the terms and conditions of the Creative Commons Attribution (CC BY) license (http:/ / creativecommons.org/licenses/by/4.0/). 
Article

\title{
$\mathrm{K}^{+} \ldots \mathrm{C}_{\pi}$ and $\mathrm{K}^{+} \ldots \mathrm{F}$ Non-Covalent Interactions in $\pi$-Functionalized Potassium Fluoroalkoxides
}

\author{
Sorin-Claudiu Roşca, Hanieh Roueindeji, Vincent Dorcet, Thierry Roisnel, \\ Jean-François Carpentier * and Yann Sarazin * \\ Institut des Sciences Chimiques de Rennes, UMR 6226 CNRS-Université de Rennes 1, Campus de Beaulieu, \\ 35042 Rennes, France; srosca@chem.ubc.ca (S.-C.R.); hanieh.roueindeji@univ-rennes1.fr (H.R.); \\ vincent.dorcet@univ-rennes1.fr (V.D.); thierry.roisnel@univ-rennes1.fr (T.R.) \\ * Correspondence: jean-francois.carpentier@univ-rennes1.fr (J.-F.C.); yann.sarazin@univ-rennes1.fr (Y.S.); \\ Tel.: +33-223-235-950 (J.-F.C.); +33-223-233-019 (Y.S.)
}

Academic Editor: Matthias Westerhausen

Received: 16 February 2017; Accepted: 3 March 2017; Published: 7 March 2017

\begin{abstract}
Secondary interactions stabilize coordinatively demanding complexes of s-block metals. The structures of potassium fluoroalkoxides that, in addition to intra- and intermolecular $\mathrm{K}^{+} \ldots \mathrm{F}$ contacts, also exhibit $\mathrm{K}^{+} \ldots \mathrm{C}_{\pi}$ interactions with tethered $\pi$ ligands, are reported. A potassium-arene, a rare potassium-alkyne, and a potassium-olefin complex have been prepared by deprotonation of functionalized $\alpha, \alpha$-bis(trifluoromethyl)alcohols with $\mathrm{KN}\left(\mathrm{SiMe}_{2} \mathrm{R}\right)_{2}$. They all feature a cuboid $\mathrm{K}_{4} \mathrm{O}_{4}$ core with $\mu^{3}$-bridging $O$ atoms, and multiple stabilizing $\mathrm{K}^{+} \ldots \mathrm{F}$ contacts in the range 2.71-3.33 $\AA$. The potassium-arene complex shows $\eta^{2}, \eta^{3}$, and $\eta^{6} \mathrm{~K}^{+} \ldots \mathrm{C}_{\pi}$ (arene) interactions in the range 3.35-3.47 $\AA$. The potassium-alkyne and potassium-olefin compounds are stabilized by $\eta^{2}$ interactions with the unsaturated carbon-carbon bond, in the range 3.17-3.49 $\AA$ and 3.15-3.19 respectively. Comparison with the parent complex devoid of a flanking $\pi$ ligand illustrates the role of $\mathrm{K}^{+} \ldots \mathrm{C}_{\pi}$ interactions.
\end{abstract}

Keywords: alkoxide ligands; potassium complexes; secondary interactions; potassium-fluorine contacts; potassium- $\mathrm{C}_{\pi}$ interactions; $\pi$ ligands

\section{Introduction}

Complexes of the electropositive alkali and alkalino-earth metals are characterized by ionic bonding between the cation and the ligands and co-ligands. In addition to regular (weakly) bonding interactions in, for instance, amido or alkoxo salts of these elements, there has been a growing awareness in the past 10-15 years that non-covalent interactions can help towards the stabilization of these species, especially as the size and coordinative demand of the metal increase upon descending groups 1 or 2 . The concept of so-called secondary interactions, which are essentially weak donor-acceptor interactions between the cation and charge-neutral $C_{\pi}$, halide, $\mathrm{H}$, or other neutral atom or group of atoms, was highlighted in a landmark article by Ruhlandt-Senge and coworkers in 2010 [1]. This and other groups have in particular prepared many a compound of alkali metals (M) featuring one or more $\mathrm{M}^{+} \ldots \mathrm{F}[2-6]$ and, perhaps more prominently, $\mathrm{M}^{+} \ldots \mathrm{C}_{\pi}$ (arene) $[4,7]$ intramolecular interactions. Of note, the importance of $\mathrm{M}^{+} \ldots \mathrm{C}_{\pi}$ (arene) in biological structures, supramolecular assemblies, and catalytic and ion transportation processes has long been established [8-14]. Many such complexes have been structurally characterized; there are nearly 300 referenced X-ray structures to date in the Cambridge Structural Database (CSD) for $\eta^{6}$-coordinated $\mathrm{K}^{+} \ldots \mathrm{C}_{\pi}$ (arene) compounds alone.

As part of our program aimed at implementing the large alkaline earths $(\mathrm{Ae}=\mathrm{Ca}, \mathrm{Sr}, \mathrm{Ba})$ in molecular catalysis, we prepared some time ago several heteroleptic amido-Ae aryloxides and fluoroalkoxides stabilized by secondary interactions, particularly intramolecular $\mathrm{Ae}^{2+} \ldots \mathrm{F}$ contacts and 
$\beta-\mathrm{Si}-\mathrm{H} \cdots \mathrm{Ae}^{2+}$ agostic distortions when using the $\mathrm{N}\left(\mathrm{SiMe}_{2} \mathrm{H}\right)^{-}$amido co-ligand [15-18]. More recently, we have prepared Ae-olefin and Ae-alkyne fluoroalkoxo complexes that both exhibit strong intramolecular $\mathrm{Ae}^{2+} \ldots \mathrm{C}_{\pi}$ in the solid state and in solution $[19,20]$. We have also shown that multiple $\mathrm{Ae}^{2+} \ldots \mathrm{F}, \beta-\mathrm{Si}-\mathrm{H} \cdots \mathrm{Ae}^{2+}$, and $\mathrm{Ae}^{2+} \ldots \mathrm{C}_{\pi}$ secondary interactions could be combined within the same molecular structure to yield electron-deficient, yet stable, Ae complexes.

In the course of this work, we have prepared and structurally characterized several unusual homometallic potassium fluoroalkoxides that display intramolecular $\mathrm{K}^{+} \ldots \mathrm{C}_{\pi}$ (arene), $\mathrm{K}^{+} \ldots \mathrm{C}_{\pi}$ (olefin), and $\mathrm{K}^{+} \ldots \mathrm{C}_{\pi}$ (alkyne) interactions with tethered $\pi$ ligands. $\mathrm{K}^{+}$-arene complexes are indeed well known. However, structurally authenticated $\mathrm{K}^{+}-\left(\eta^{2}\right.$-alkyne) complexes (13 structures in the CSD at the time of writing) are mostly limited to heterobimetallic acetylides such as $\left[\left(\mathrm{C}_{5} \mathrm{HMe}_{4}\right)_{2} \mathrm{Ti}\left(\eta^{1}-\mathrm{C} \equiv \mathrm{C}-\right.\right.$ $\left.\left.\mathrm{SiMe}_{3}\right)_{2}\right]^{-}[\mathrm{K}]^{+}[21]$ or $\left[\left\{\left(\mathrm{Me}_{3}-\operatorname{tacn}\right) \mathrm{Cr}(\mathrm{C} \equiv \mathrm{CH})_{3}\right\}_{2} \mathrm{~K}^{+}\left[\mathrm{CF}_{3} \mathrm{SO}_{3}\right]^{-}\right.$bearing a $\mathrm{N}$-methyl-substituted triazacyclonane ligand ( $\mathrm{Me}_{3} \mathrm{Tacn}$ ) [22]. The sole example of homometallic complex is the polymeric $\left[\left\{\left(\mathrm{C}_{5} \mathrm{Me}_{4}\right)_{2} \mathrm{SiMe}_{2} \mathrm{C} \equiv \mathrm{CPh}\right\} \mathrm{K} \cdot \mathrm{THF}\right]_{\infty}[23] . \mathrm{K}^{+}-\left(\eta^{2}\right.$-olefin) complexes are more common (46 examples in the $\mathrm{CSD})$, with representative examples including $\left[\mathrm{Sn}\left\{\left(\mathrm{Me}_{3} \mathrm{Si}\right) \mathrm{CHCH}=\mathrm{CH}\left(\mathrm{SiMe}_{3}\right)\right\}_{3}\right]^{-}[\mathrm{K} \cdot \mathrm{THF}]^{+}[24]$, $\left[\mathrm{Zn}\left\{\left(\mathrm{Me}_{3} \mathrm{Si}\right) \mathrm{CHCH}=\mathrm{CH}\left(\mathrm{SiMe}_{3}\right)\right\}_{3}\right]^{-}[\mathrm{K}]^{+}[25],\left[\mathrm{Zn}\left(\mathrm{CH}_{2} \mathrm{SiMe}_{3}\right)(\mathrm{TMP})\left(\mathrm{CH}=\mathrm{CH}_{2}\right)\right]^{-}[\mathrm{K} \cdot \mathrm{PTMEDA}]^{+}[26]$, or the rare homometallic $\left[\mathrm{KC}_{60}(\mathrm{THF})_{5}\right] \cdot 2 \mathrm{THF}$ fulleride [27].

In this context, the structural motifs of several polymetallic potassium fluoroalkoxides displaying strong intramolecular interactions with pendant olefin, alkyne, or arene are discussed in the following. The structure of the parent complex where the ligand is devoid of dangling $\pi$ groups is also presented for comparison.

\section{Results}

The fluoroalcohols $\left\{\mathrm{RO}^{1}\right\} \mathrm{H}-\left\{\mathrm{RO}^{4}\right\} \mathrm{H}$ bearing two strongly electron-withdrawing $\mathrm{CF}_{3}$ groups in $\alpha$ position to the hydroxyl can be prepared in high yield by treatment of 2,2-bis(trifluoromethyl)oxirane with the appropriate amine in $\mathrm{Et}_{2} \mathrm{O}[16,20]$. They were reacted with an equimolar amount of the potassium precursors $\left[\mathrm{KN}\left(\mathrm{SiMe}_{3}\right)_{2}\right]$ or $\left[\mathrm{KN}\left(\mathrm{SiMe}_{2} \mathrm{H}\right)_{2}\right]$ to afford the corresponding potassium fluoroalkoxides in 33\%-85\% isolated (non-optimized) yields (Scheme 1). The resulting compounds $\left[\left\{\mathrm{RO}^{x}\right\} \mathrm{K}\right]_{4}$ were obtained as colorless, analytically pure solids $\left(x=1,[1]_{4} ; x=2,[2]_{4} ; x=3\right.$, $\left.[3]_{4} ; x=4,[4]_{4}\right)$. They all crystallized as tetranuclear complexes in a $\mathrm{K}_{4} \mathrm{O}_{4}$ cubane arrangement (vide infra). Their composition was established by X-ray crystallography and was corroborated by NMR spectroscopy. Their purity was confirmed by combustion analyses. All complexes are soluble in common organic solvents, including aliphatic hydrocarbons.

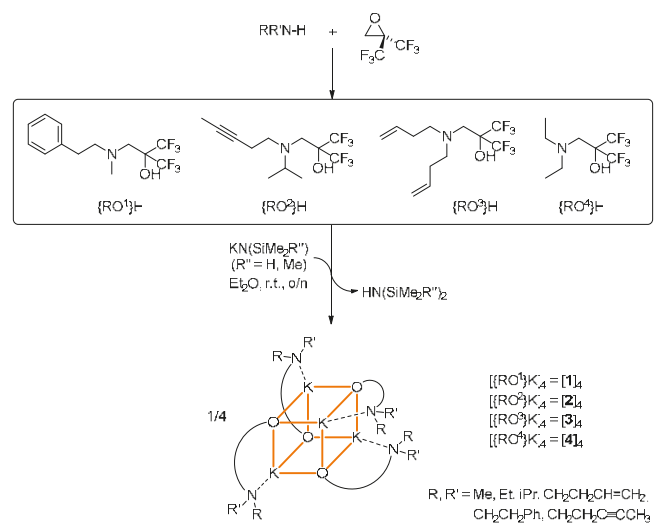

Scheme 1. Fluoroalcohols used in this study, with a synthetic scheme for the preparation of the tetranuclear potassium fluoroalkoxides $\left[\left\{\mathrm{RO}^{x}\right\} \mathrm{K}\right][1]_{4}-[4]_{4}$. A representation of the cuboid structures of these complexes is given; $\mathrm{K}^{+} \ldots \mathrm{F}$ and $\mathrm{K}^{+} \ldots \mathrm{C}_{\pi}$ secondary interactions not displayed. 


\subsection{Potassium-Arene Complex $\left[\left\{R \mathrm{R}^{1}\right\} \mathrm{K}\right]_{4}\left([1]_{4}\right)$}

The compound $\left[\left\{\mathrm{RO}^{1}\right\} \mathrm{K}\right]$ crystallized as the distorted cubane $\left[\left\{\mathrm{RO}^{1}\right\} \mathrm{K}\right]_{4}\left([1]_{4}\right)$, a multinuclear structure typical of potassium alkoxides (Figure 1) $[6,18,28,29]$. Two $\mathrm{K}_{4} \mathrm{O}_{4}$ cuboid motifs are associated through bridging $\mathrm{K} \cdots \mathrm{F}$ interactions to generate a centrosymmetric macromolecular edifice containing eight potassium ions. The distances to the bridging fluorine atoms K2-F76' (2.963(1) A), K2-F76 (3.171(1) $\AA$ ), and K2-F77' (3.279(2) $\AA$ ) are well below the sum of van der Waals radii for potassium $(2.75 \AA)$ and fluorine $(1.47 \AA)$, testifying to substantial interactions. They are also below the accepted distance for significant K-F interactions (ca. $3.40 \AA$ ) [30].

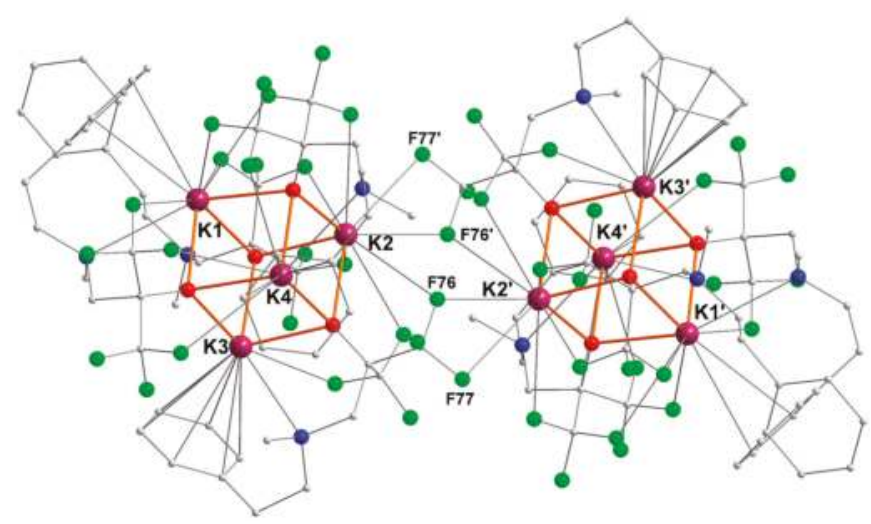

Figure 1. Representation of the molecular solid-state structure of the potassium-arene complex $\left[\left\{\mathrm{RO}^{1}\right\} \mathrm{K}\right]_{4}\left([1]_{4}\right)$. Color code: purple, K; green, F; blue, N; red, O; grey, C. H atoms omitted for clarity.

A simplified view of the coordination pattern in $[1]_{4}$ is depicted in Figure 2 . In each of the two identical cubanes, each potassium atom is coordinated by three oxygen atoms in $\mu^{3}$-positions, with characteristic $d_{\mathrm{K}-\mathrm{O}}$ bond distances in the range $2.611(2)-2.825(2) \AA$.

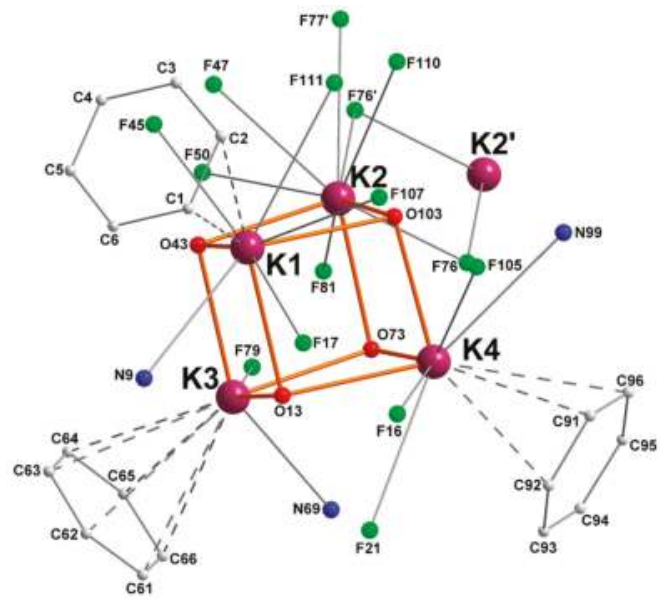

Figure 2. Simplified representation of the molecular solid-state structure of complex $\left[\left\{\mathrm{RO}^{1}\right\} \mathrm{K}\right]_{4}\left([1]_{4}\right)$. Color code: purple, K; green, F; blue, N; red, O; grey, C. Hydrogen atoms are omitted for clarity. Only the heteroatoms and aryl substituents interacting with potassium are depicted. 
The nitrogen atoms N9, N69, and N99 are bound to K1, K3, and K4, respectively; there are not any nitrogen atoms coordinated to $\mathrm{K} 2$. In addition, each metal ion is stabilized by multiple $\mathrm{K}^{+} . . . \mathrm{F}$ contacts: $\mathrm{K} 1, \mathrm{~K} 2, \mathrm{~K} 3$, and $\mathrm{K} 4$ are respectively involved in four, seven, one, and three such interactions. They range from very strong $\left(d_{\mathrm{K}-\mathrm{F}}=2.806(1) \AA\right.$ for $\left.\mathrm{K} 3\right)$ to mild $\left(d_{\mathrm{K}-\mathrm{F}}=3.324(2) \AA\right.$ for $\left.\mathrm{K} 4\right)$ [31]. Another prominent feature of this complex is the presence of $\mathrm{K}^{+} \ldots \mathrm{C}_{\pi}$ (arene) intramolecular interactions with three capping aromatic rings from the tethered side-arms of the ligands. Hence, K1, K3, and $\mathrm{K} 4$ show respectively $\eta^{2}, \eta^{6}$, and $\eta^{3} \pi$-interactions with the aromatic substituents. Such $\mathrm{K}^{+} \ldots \mathrm{C}_{\pi}$ (arene) contacts, all below $3.48 \AA$, are not uncommon for potassium $[4,9,11,13]$. A summary of relevant metric parameters for $[1]_{4}$ is given in Table 1 .

Table 1. Key metric parameters in the potassium-arene complex $\left[\left\{\mathrm{RO}^{1}\right\} \mathrm{K}\right]_{4}\left([\mathbf{1}]_{4}\right)$.

\begin{tabular}{|c|c|c|c|c|}
\hline $\mathbf{K}_{i}$ & $\mathrm{~K}_{i}-\mathrm{O}(\AA)$ & $\mathrm{K}_{i}-\mathrm{N}(\AA)$ & $\mathrm{K}_{i} \cdots \mathrm{F}(\AA)$ & $\mathrm{K}_{i} \cdots \mathrm{C}_{\pi}$ (arene) (Å) \\
\hline K1 & $\begin{array}{l}\text { O13 }=2.6600(16) \\
\text { O43 }=2.7493(15) \\
\text { O103 }=2.7989(15)\end{array}$ & $\mathrm{N} 9=3.174(2)$ & $\begin{aligned} \mathrm{F} 17 & =2.8804(16) \\
\mathrm{F} 45 & =2.8507(15) \\
\mathrm{F} 107 & =2.9548(17) \\
\mathrm{F} 111 & =3.2131(16)\end{aligned}$ & $\begin{array}{l}\mathrm{C} 1=3.4177(30) \\
\mathrm{C} 2=3.4631(33)\end{array}$ \\
\hline K2 & $\begin{array}{l}\mathrm{O} 43=2.6856(15) \\
\mathrm{O} 73=2.6927(15) \\
\mathrm{O} 103=2.6136(15)\end{array}$ & $\mathrm{n} / \mathrm{a}$ & $\begin{aligned} \mathrm{F} 47 & =2.9987(15) \\
\text { F50 } & =2.8312(14) \\
\text { F76 } & =3.1711(14) \\
F^{\prime} 76^{\prime} & =2.9632(14) \\
F_{7} & =3.2792(16) \\
\text { F81 } & =3.0715(15) \\
\text { F110 } & =3.0715(15)\end{aligned}$ & $\mathrm{n} / \mathrm{a}$ \\
\hline K3 & $\begin{array}{l}\mathrm{O} 13=2.6301(15) \\
\mathrm{O} 43=2.7087(15) \\
\mathrm{O} 73=2.6869(14)\end{array}$ & $\mathrm{N} 69=3.1033(19)$ & $\mathrm{F} 79=2.8062(13)$ & $\begin{aligned} \text { C61 } & =3.4535(24) \\
\text { C62 } & =3.4738(25) \\
\text { C63 } & =3.4296(25) \\
\text { C64 } & =3.3749(24) \\
\text { C65 } & =3.3688(24) \\
\text { C66 } & =3.413(2)\end{aligned}$ \\
\hline K4 & $\begin{array}{l}\mathrm{O} 13=2.8254(15) \\
\mathrm{O} 73=2.7305(13) \\
\mathrm{O} 103=2.6112(16)\end{array}$ & $\mathrm{N} 99=3.159(2)$ & $\begin{aligned} \mathrm{F} 16 & =3.0642(17) \\
\mathrm{F} 21 & =3.3244(16) \\
\mathrm{F} 105 & =3.0760(17)\end{aligned}$ & $\begin{array}{c}\text { C91 }=3.3482(25) \\
\text { C92 }=3.4120(33) \\
\text { C96 }=3.449(2)\end{array}$ \\
\hline
\end{tabular}

n/a: not applicable.

NMR spectroscopy did not provide information regarding the structure of $[1]_{4}$ in solution. Its ${ }^{1} \mathrm{H}$ NMR spectrum in $\left[\mathrm{D}_{6}\right]$ benzene features broad resonances. In the ${ }^{19} \mathrm{~F}$ NMR spectrum, a unique, sharp singlet is detected at $-76.34 \mathrm{ppm}$, indicating that all $\mathrm{CF}_{3}$ groups are equivalent on the NMR time-scale; there was no indication for the persistence of $\mathrm{K}^{+} \ldots \mathrm{F}$ interactions in solution. ${ }^{1} \mathrm{H}$ DOSY NMR measurements proved erratic, hence provided limited help in assessing the nuclearity of the complex in solution; they were, however, consistent with the existence of a multinuclear species.

\subsection{Potassium-Alkyne Complex $\left[\left\{R \mathrm{O}^{2}\right\} \mathrm{K}_{4}\left([2]_{4}\right)\right.$}

The potassium fluoroalkoxide $\left[\left\{\mathrm{RO}^{2}\right\} \mathrm{K}\right]$ bearing a dangling alkynyl side-arm recrystallized from pentane as the tetranuclear $\left[\left\{\mathrm{RO}^{2}\right\} \mathrm{K}\right]_{4}\left([2]_{4}\right)$ showing also a $\mathrm{K}_{4} \mathrm{O}_{4}$ cuboid arrangement (Figure 3). Besides the presence of multiple $\mathrm{K}^{+} \ldots \mathrm{F}$ interactions (three or four per potassium), one of its main characteristic is the presence of $\eta^{2}-K^{+} \ldots C_{\pi}$ (alkyne) interactions, in the range 3.131(3)-3.495(3) A. Remarkably, none of the nitrogen atoms of the ligand backbones coordinates onto a potassium center $\left(d_{\mathrm{K}-\mathrm{N}}>3.832(2) \AA\right.$, and generally over $\left.4.5 \AA\right)$, thus highlighting the key contributions of $\mathrm{K}^{+} \ldots \mathrm{F}$ and $\mathrm{K}^{+} \ldots \mathrm{C}_{\pi}$ (alkyne) secondary interactions in this complex. Of interest, $[2]_{4}$ is a rare example of non-acetylide potassium-alkyne complex, the sole other occurrence being $\left[\left\{\left(\mathrm{C}_{5} \mathrm{Me}_{4}\right)_{2} \mathrm{SiMe}_{2} \mathrm{C} \equiv \mathrm{CPh}\right\} \mathrm{K} \cdot \mathrm{THF}\right]_{\infty}[23]$. However, the $\mathrm{K}^{+} \ldots \mathrm{C}_{\pi}$ (alkyne) interatomic distances in [2] (in the range 3.131(3)-3.495(3) $\AA$, see Table 2) are, for most of them, much shorter than in this latter 
compound (3.406 and $3.470 \AA$ ). On the other hand, they are much longer than in $\mathrm{K}^{+} \ldots \mathrm{C}_{\pi}$ (acetylide) compounds, where it often approximates $2.95-3.10 \AA[21,22,31]$.

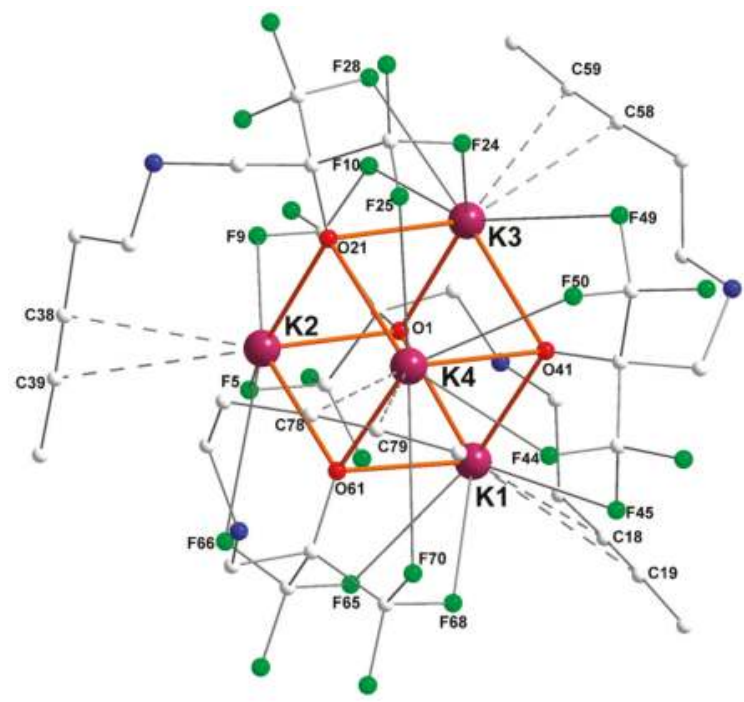

Figure 3. Representation of the molecular solid-state structure of the potassium-alkyne complex $\left[\left\{\mathrm{RO}^{2}\right\} \mathrm{K}\right]_{4}\left([2]_{4}\right)$. Color code: purple, K; green, F; blue, N; red, O; grey, C. H atoms omitted for clarity.

Table 2. Key metric parameters in the potassium-alkyne complex $\left[\left\{\mathrm{RO}^{2}\right\} \mathrm{K}\right]_{4}\left([2]_{4}\right)$.

\begin{tabular}{|c|c|c|c|}
\hline $\mathbf{K}_{i}$ & $\mathrm{~K}_{i}-\mathrm{O}(\AA)$ & $\mathrm{K}_{i} \cdots \mathrm{F}(\AA)$ & $\mathrm{K}_{i} \cdots \mathrm{C}_{\pi}$ (alkyne) (A) \\
\hline K1 & $\begin{array}{l}\mathrm{O} 1=2.6880(14) \\
\mathrm{O} 41=2.6298(13) \\
\mathrm{O} 61=2.7262(14)\end{array}$ & $\begin{array}{l}\mathrm{F} 45=3.2152(14) \\
\text { F65 }=2.8043(14) \\
\text { F68 }=2.7585(14)\end{array}$ & $\begin{array}{l}\mathrm{C} 18=3.172(2) \\
\mathrm{C} 19=3.427(2)\end{array}$ \\
\hline K2 & $\begin{array}{l}\mathrm{O} 1=2.7275(14) \\
\mathrm{O} 21=2.7106(13) \\
\mathrm{O} 61=2.6296(14)\end{array}$ & $\begin{array}{c}\text { F5 }=2.9529(14) \\
\text { F9 }=2.7144(14) \\
\text { F66 }=3.1664(16)\end{array}$ & $\begin{array}{l}\text { C38 }=3.213(2) \\
\text { C39 }=3.341(2)\end{array}$ \\
\hline K3 & $\begin{array}{l}\mathrm{O} 1=2.6628(14) \\
\mathrm{O} 21=2.7979(14) \\
\mathrm{O} 41=2.6794(14)\end{array}$ & $\begin{array}{l}\mathrm{F} 10=3.1002(16) \\
\text { F24 }=2.7792(14) \\
\text { F28 }=2.8195(15) \\
\text { F49 }=3.3239(13)\end{array}$ & $\begin{array}{l}\text { C58 }=3.278(2) \\
C 59=3.495(3)\end{array}$ \\
\hline K4 & $\begin{array}{l}\mathrm{O} 21=2.6876(14) \\
\mathrm{O} 41=2.8169(14) \\
\mathrm{O} 61=2.6401(14)\end{array}$ & $\begin{array}{l}\text { F25 }=2.9942(16) \\
\text { F44 }=2.6820(13) \\
\text { F50 }=2.9804(14) \\
\text { F70 }=3.3078(15)\end{array}$ & $\begin{array}{l}C 78=3.131(3) \\
C 79=3.216(4)\end{array}$ \\
\hline
\end{tabular}

Relevant metric parameters for $[2]_{4}$ are collated in Table 2. Examination of the $\mathrm{K}_{\mathrm{i}} \cdots \mathrm{C}_{\pi}$ (alkyne) distances shows large discrepancies, with K4-C78 and K1-C18 being as short as 3.131(3) and 3.172(2) $\AA$, respectively, whereas K3-C59 reaches 3.495(3) A. One should note that for each potassium, the distance to the "internal" $\mathrm{C}_{\pi}$ (alkyne) atom is systematically much shorter than that to the "external" one (internal and external $C_{\pi}$ (alkyne) atoms are respectively in $\gamma$ and $\delta$ positions to the nitrogen atom), hence indicating a dissymmetric binding mode for the alkyne. As seen for $[1]_{4}$, the intensity of $\mathrm{K}^{+} \ldots \mathrm{F}$ interactions also varies largely in [2] $]_{4}$, in the range 2.682(1)-3.324(1) $\AA$. The $\mathrm{C} \equiv \mathrm{C}$ bond lengths in $[2]_{4}$, in the region 1.153(5)-1.7179(4) $\AA$, are unexceptional and are typical of non-coordinated $\left(-\mathrm{CX}_{2}\right)-\mathrm{C} \equiv \mathrm{C}-\mathrm{CH}_{3}$ fragments. 
The solution NMR data (recorded in $\left[\mathrm{D}_{6}\right]$ benzene) for $[2]_{4}$ did not inform us about the nuclearity of the complex in solution. A sharp singlet is observed at $-77.32 \mathrm{ppm}$ in the ${ }^{19} \mathrm{~F}$ NMR spectrum, and the resonances at $78.19\left(\mathrm{C} \equiv \mathrm{C}-\mathrm{CH}_{3}\right)$ and $76.94\left(\mathrm{C} \equiv \mathrm{C}-\mathrm{CH}_{3}\right)$ ppm in the ${ }^{13} \mathrm{C}\left\{{ }^{1} \mathrm{H}\right\} \mathrm{NMR}$ spectrum did not provide useful information about the potential coordination/dissociation of the alkyne in solution.

\subsection{Potassium-Alkene Complex $\left[\left\{R \mathrm{R}^{3}\right\} K\right]_{4}\left([3]_{4}\right)$}

The potassium-alkene complex $\left[\left\{\mathrm{RO}^{3}\right\} \mathrm{K}\right]$ also crystallized as the tetranuclear cubane $\left[\left\{\mathrm{RO}^{3}\right\} \mathrm{K}\right]_{4}$ $\left([3]_{4}\right)$ in the tetragonal space group $P-42_{1} c$ (Figure 4). The four potassium centers are therefore symmetrically equivalent. Each exhibits $\eta^{2}$-coordination of an olefin and two $\mathrm{K}^{+} \ldots \mathrm{F}$ intramolecular interactions $\left(\mathrm{K} 1-\mathrm{F} 1=3.062(2) \AA, \mathrm{K} 1-\mathrm{F} 2^{\prime}=2.928(2) \AA\right)$. For each ligand, only one of the olefins is coordinated to potassium $(\mathrm{K} 1-\mathrm{C} 12=3.192(4)$ and $\mathrm{K} 1-\mathrm{C} 13=3.148(4) \AA)$, whereas the second olefinic tether (corresponding to $\mathrm{C} 8$ and $\mathrm{C} 9$ ) is remote from the metal ion. The two $\mathrm{K}^{+}-\mathrm{C}_{\pi}$ (alkene) distances in $[3]_{4}$ are very comparable. They are in the range of those measured in $\left[\mathrm{Sn}\left\{\left(\mathrm{Me}_{3} \mathrm{Si}\right) \mathrm{CHCH}=\mathrm{CH}\left(\mathrm{SiMe}_{3}\right)\right\}_{3}\right]^{-}[\mathrm{K} \cdot \mathrm{THF}]^{+}(3.065(8)$ and 3.164(8) $\AA$ ) [24], in the fulleride $\left[\mathrm{KC}_{60}(\mathrm{THF})_{5}\right] \cdot 2$ THF (3.204(1) and 3.356(1) $\AA$ ) [27], in $\left[\mathrm{Zn}\left\{\left(\mathrm{Me}_{3} \mathrm{Si}\right) \mathrm{CHCH}=\mathrm{CH}\left(\mathrm{SiMe}_{3}\right)\right\}_{3}\right]^{-}\left[\mathrm{K}^{+}\right.$ (2.942(3)-3.283(3) ̊) [25], or in $\left[\mathrm{Zn}\left(\mathrm{CH}_{2} \mathrm{SiMe}_{3}\right)(\mathrm{TMP})\left(\mathrm{CH}=\mathrm{CH}_{2}\right)\right]^{-}[\mathrm{K} \cdot \mathrm{PTMEDA}]^{+}(2.985(4)$ and 3.167(3) $\AA$ ) [26], although the $\mathrm{K}^{+}$-olefin interaction was much more dissymmetric in these complexes. The main metric parameters for $[3]_{4}$ are summarized in Table 3.

The ${ }^{19} \mathrm{~F}$ NMR spectrum of $[3]_{4}$ displays a sharp singlet at $-75.86 \mathrm{ppm}$ for all $\mathrm{CF}_{3}$ groups. The ${ }^{1} \mathrm{H}$ and especially ${ }^{13} \mathrm{C}\left\{{ }^{1} \mathrm{H}\right\}$ spectra $\left(\delta_{13 \mathrm{C}}=137.70\right.$ and $116.01 \mathrm{ppm}$ for the $\mathrm{C}_{\pi}$ (alkene) atoms) did not show differences between the two types of olefins, coordinated and dissociated; this suggests that they either exchange very fast on the NMR time-scale, or that the tetranuclear arrangement is disrupted in $\left[\mathrm{D}_{6}\right]$ benzene.

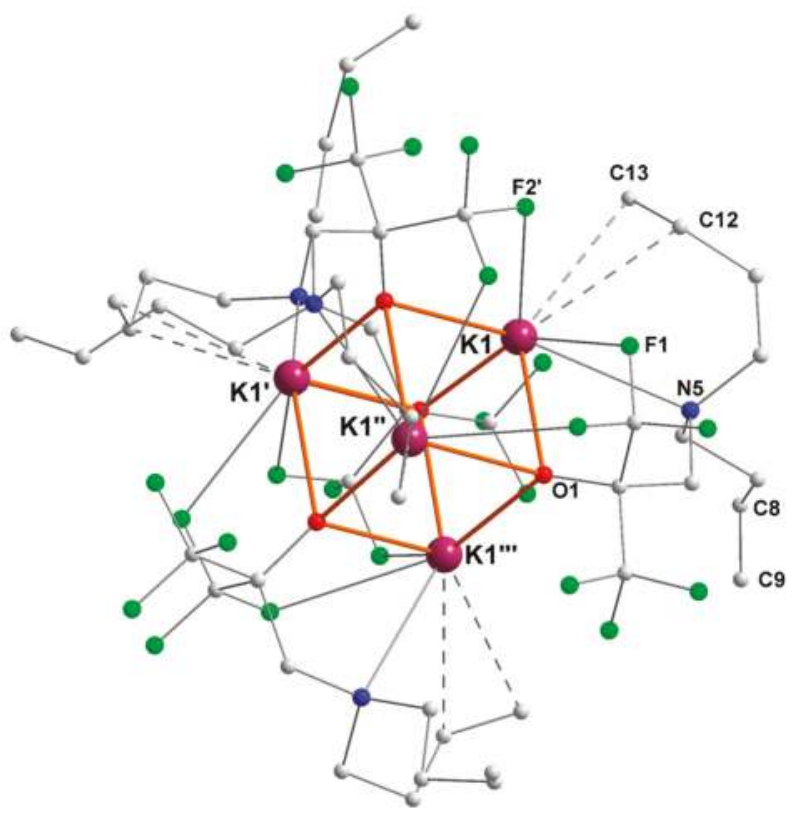

Figure 4. Representation of the molecular solid-state structure of the potassium-alkene complex $\left[\left\{\mathrm{RO}^{3}\right\} \mathrm{K}_{4}\left([3]_{4}\right)\right.$. Color code: purple, $\mathrm{K}$; green, F; blue, N; red, O; grey, C. H atoms omitted for clarity. 
Table 3. Key metric parameters in the potassium-alkene complex $\left[\left\{\mathrm{RO}^{3}\right\} \mathrm{K}\right]_{4}\left([3]_{4}\right)$.

\begin{tabular}{cccc}
\hline $\mathbf{K} 1-\mathbf{O}(\AA)$ & $\mathbf{K} 1-\mathbf{N}(\AA)$ & $\mathbf{K} 1 \cdots \mathbf{F}(\AA)$ & K1 $\cdots \mathbf{C}_{\boldsymbol{\pi}}$ (alkene) $(\AA)$ \\
\hline $\mathrm{O} 1=2.635(2)$ & $\mathrm{N} 5=3.031(3)$ & $\mathrm{F} 1=3.062(2)$ & $\mathrm{C} 12=3.192(4)$ \\
$\mathrm{O} 1^{\prime}=2.625(2)$ & & $\mathrm{F}^{\prime}=2.928(2)$ & $\mathrm{C} 13=3.148(4)$ \\
$\mathrm{O} 1^{\prime \prime}=2.765(2)$ & & & \\
\hline
\end{tabular}

Since one of the two tethered olefins in the ligand $\left\{\mathrm{RO}^{3}\right\}^{-}$is not directly involved in the coordination sphere of $\mathrm{K}^{+}$, we prepared a related proteo-ligand $\left\{\mathrm{RO}^{5}\right\} \mathrm{H}$ having only one dangling olefinic group, and where the other one is replaced by an isopropyl group. This new ligand led to the clean preparation of a compound of composition $\left[\left\{\mathrm{RO}^{5}\right\} \mathrm{K}\right]_{n}$ according to NMR spectroscopy and elemental analysis; however, all attempts to grow X-ray-quality crystals proved unsuccessful, and we could not obtain useful information in the solid state.

\subsection{Potassium complex $\left[\left\{R O^{4}\right\} K\right]_{4}\left([4]_{4}\right)$}

The potassium complex $\left\{\mathrm{RO}^{4}\right\} \mathrm{K}$, where the ancillary ligand is devoid of $\pi$ ligand, crystallized as the tetranuclear $\left[\left\{\mathrm{RO}^{4}\right\} \mathrm{K}\right]_{4}\left([4]_{4}\right)$ with a distorted $\mathrm{K}_{4} \mathrm{O}_{4}$ cuboid core (Figure 5). Each potassium is involved in several intermolecular (e.g., K2-F11 $\# 2$, K2-F33" ${ }^{\# 3}, \mathrm{~K} 3-\mathrm{F} 32^{\# 1}, \mathrm{~K} 4-\mathrm{F} 35^{\# 4}, \mathrm{~K} 2^{\prime}-\mathrm{F} 11, \mathrm{~K} 3^{\prime \prime}-\mathrm{F} 2$, $\left.\mathrm{K} 4^{\prime \prime \prime}-\mathrm{F} 35\right)$ and intramolecular $\mathrm{K}^{+} \ldots \mathrm{F}$ interactions, leading to the formation of infinite two-dimensional layer coordination polymers. In addition to the array of $\mathrm{K}^{+} \ldots \mathrm{F}$ contacts, all potassium centers are coordinated by three $\mu^{3}$-bridging oxygen atoms. K1 and K3 are also coordinated by a nitrogen atom (N4 and N3, respectively), but K2 and K4 are not. As a result, and to compensate for an otherwise overwhelming electron deficiency, $\mathrm{K} 2$ and $\mathrm{K} 4$ exhibit six $\mathrm{K}^{+} \ldots \mathrm{F}$ interactions each. This is more than for $\mathrm{K} 1$ and $\mathrm{K} 3$, which respectively feature two and five interactions.

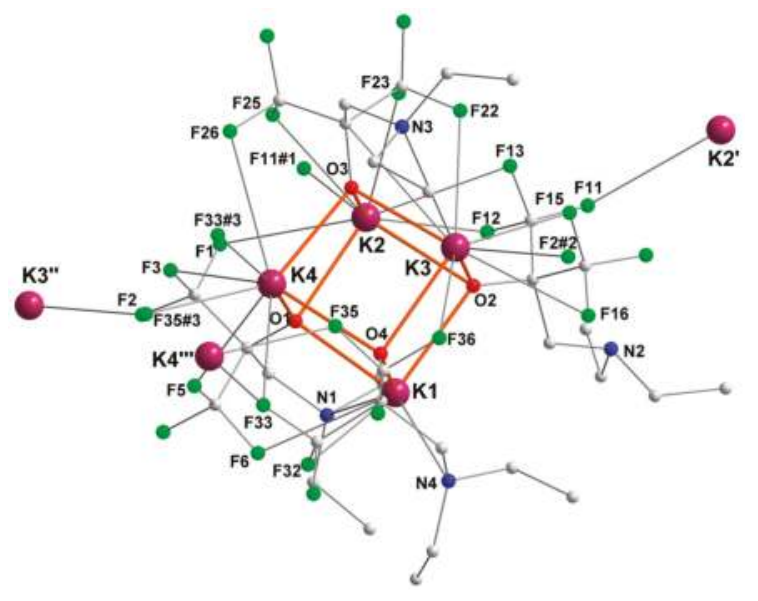

Figure 5. Representation of the molecular solid-state structure of the potassium complex $\left[\left\{\mathrm{RO}^{4}\right\} \mathrm{K}\right]_{4}$ $\left([4]_{4}\right)$. Only the main component of disordered ethyl groups is depicted. Color code: purple, K; green, F; blue, N; red, O; grey, C. H atoms omitted for clarity.

Table 4 displays the key metric parameters in $[4]_{4}$. All $\mathrm{K}^{+}-\mathrm{O}$ bond lengths are in the same range, 2.586(2)-2.767(2) $\AA$. The $\mathrm{K}^{+}-\mathrm{N}$ bond is weaker for $\mathrm{K} 3(\mathrm{~K} 3-\mathrm{N} 3=3.162(2) \AA$ ) than for $\mathrm{K} 1(\mathrm{~K} 1-\mathrm{N} 4=2.974(2) \AA)$, which explains the greater number of $\mathrm{K}^{+} \ldots \mathrm{F}$ contacts for the former.

There is a unique sharp singlet at $-76.38 \mathrm{ppm}$ for all $\mathrm{CF}_{3}$ groups in the ${ }^{19} \mathrm{~F}$ NMR spectrum of $[4]_{4}$, and its ${ }^{1} \mathrm{H}$ NMR spectrum features only three resonances at $2.70(\mathrm{~s}), 2.56(\mathrm{q})$, and $0.82(\mathrm{t}) \mathrm{ppm}$. We could not obtain reliable information as to the nuclearity of the complex in solution. 
Table 4. Key metric parameters in the potassium complex $\left[\left\{\mathrm{RO}^{4}\right\} \mathrm{K}\right]_{4}\left([4]_{4}\right)$.

\begin{tabular}{|c|c|c|c|}
\hline $\mathbf{K}_{i}$ & $\mathrm{~K}_{i}-\mathrm{O}(\AA)$ & $\mathrm{K}_{i}-\mathrm{N}(\AA)$ & $\mathrm{K}_{i} \cdots \mathrm{F}(\AA)$ \\
\hline $\mathrm{K} 1$ & $\begin{array}{l}\mathrm{O} 1=2.5862(16) \\
\mathrm{O} 2=2.7289(16) \\
\mathrm{O} 4=2.6800(16)\end{array}$ & $\mathrm{N} 4=2.9742(19)$ & $\begin{array}{c}\mathrm{F} 6=3.0859(17) \\
\mathrm{F} 32=3.1388(15)\end{array}$ \\
\hline $\mathrm{K} 2$ & $\begin{array}{l}\mathrm{O} 1=2.6237(16) \\
\mathrm{O} 2=2.7311(16) \\
\mathrm{O} 3=2.7092(16)\end{array}$ & & $\begin{array}{c}\mathrm{F} 1=3.2086(18) \\
\mathrm{F} 11^{\# 1}=3.132(2) \\
\mathrm{F} 12=3.0195(19) \\
\mathrm{F} 13=3.128(2) \\
\mathrm{F} 23=2.7488(16) \\
\mathrm{F} 25=2.9952(17)\end{array}$ \\
\hline $\mathrm{K} 3$ & $\begin{array}{l}\mathrm{O} 2=2.7675(16) \\
\mathrm{O} 3=2.5884(16) \\
\mathrm{O} 4=2.6698(16)\end{array}$ & $\mathrm{N} 3=3.162(2)$ & $\begin{array}{c}\mathrm{F} 22^{\# 2}=2.8409(15) \\
\mathrm{F} 15=2.8113(17) \\
\mathrm{F} 16=3.314(2) \\
\mathrm{F} 22=2.9606(18) \\
\mathrm{F} 36=3.376(2)\end{array}$ \\
\hline K4 & $\begin{array}{l}\mathrm{O} 1=2.6872(16) \\
\mathrm{O} 3=2.5936(16) \\
\mathrm{O} 4=2.7204(16)\end{array}$ & & $\begin{array}{c}\mathrm{F} 3=3.1502(17) \\
\text { F5 }=2.9039(17) \\
\text { F26 }=3.2365(19) \\
\text { F33 }=3.0363(16) \\
\text { F33 } \\
\text { F33 }^{\# 3}=3.1629(16) \\
=2.9690(15)\end{array}$ \\
\hline $\begin{array}{l}\mathrm{K} 2^{\prime} \\
\mathrm{K} 3^{\prime \prime}\end{array}$ & $\begin{array}{l}1 \\
1\end{array}$ & $\begin{array}{l}1 \\
1\end{array}$ & $\begin{array}{c}\mathrm{F} 11=3.132(2) \\
\mathrm{F} 2=2.8408(15)\end{array}$ \\
\hline $\mathrm{K} 4^{\prime \prime \prime}$ & 1 & 1 & $\begin{array}{l}\text { F33 }=3.1629(16) \\
\text { F35 }=2.9690(15)\end{array}$ \\
\hline
\end{tabular}

${ }^{1}$ Only the intermolecular $\mathrm{K}^{+}-\mathrm{F}$ contacts are given.

\section{Discussion}

Compared to the polymeric $[4]_{4}$-where electron depletion at the potassium centers is compensated solely by a large number of $\mathrm{K}^{+} \ldots \mathrm{F}$ intramolecular and intermolecular interactions, resulting in the formation of two-dimensional networks—-the presence of $\pi$ ligands in [1 $]_{4}$ (arene), $[2]_{4}$ (alkyne), and [3] $]_{4}$ (alkene) profoundly influences the coordination pattern of these compounds. A comparison of the structural and metric parameters for these complexes shows that as the number of $\mathrm{K}^{+} \ldots \mathrm{C}_{\pi}$ interactions increases, one generally observes a lowering of the number or the strength of $\mathrm{K}^{+} \ldots \mathrm{F}$ contacts. This is perhaps best epitomized in the structure of the arene complex $[1]_{4}$, where the four potassium centers display different coordination environments.

Beyond structural considerations, this work shows that, other than the well-known $\mathrm{K}^{+} \ldots \mathrm{C}_{\pi}$ (arene) interaction, alkenes and alkynes efficiently provide stabilization to potassium alkoxides. The potassium-alkyne complex described here is the only one of this type. This is in line with the recent account of the utilization of $\pi$ ligands in alkaline-earth chemistry $[19,20]$. In an attempt to extend the range of potential $\pi$ ligands for $s$-block metals, we have also prepared a ligand possessing a dangling allene moiety. However, we have so far been unable to grow $\mathrm{X}$-ray-quality crystals for the resulting potassium complex. One should note that independently of the mode of coordination $\left(\eta^{2}, \eta^{3}\right.$, or $\left.\eta^{6}\right)$ of the arene in $[1]_{4}$, the $\mathrm{K}^{+} \ldots \mathrm{C}_{\pi}$ (arene) distances are considerably longer than the distances to the coordinated alkyne and alkene in complexes $[2]_{2}$ and $[3]_{2}$. Density-functional theory (DFT) computations would be very useful to probe the respective intensities of the interactions between the $\pi$ ligands and the potassium ions in these complexes, but they are precluded owing to the structural complexity of these polynuclear species, and because we have no reliable information about their structures in solution. For the same reason, bond valence sum analysis, which can be a convenient way to analyze the bonding pattern for a given complex [32], was also rendered prohibitively complicated. 
We found no indication by NMR spectroscopy, especially ${ }^{13} \mathrm{C}\left\{{ }^{1} \mathrm{H}\right\} \mathrm{NMR}$, of any degree of covalence in the interaction between $\mathrm{K}^{+}$and the three different types of $\pi$ ligands. Instead, this interaction is thought to be purely electrostatic, as seen for alkaline earths [19], and it occurs without any detectable polarization of the carbon-carbon unsaturated bonds [33].

The present results constitute further support in favor of Ruhlandt-Senge's statement that secondary interactions are a key tool to satisfy coordinative demands of electropositive elements, and eventually yield stable and unusual molecular compounds [1]. The interactions $\mathrm{K}^{+} \ldots \mathrm{C}_{\pi}$ and $\mathrm{K}^{+} \ldots \mathrm{F}$ described here complement other non-covalent interactions reported before, such as agostic $\beta-\mathrm{Si}-\mathrm{H} \cdots \mathrm{K}^{+}$distortions seen in $\left[\mathrm{KN}\left(\mathrm{SiMe}_{2} \mathrm{H}\right)_{2}\right]_{\infty}[15]$. These (and other related) potassium fluoroalkoxides are convenient synthetic precursors for the introduction of the ligands onto other metals, such as alkaline earths or lanthanides, via salt metathesis reactions. We are continuing our efforts in this field, and are seeking to combine these types of interactions to yield stable alkali and alkaline-earth compounds. One route we are currently investigating is the use of enantiomerically pure chiral fluoroalkoxides to direct the formation of specific architectures.

\section{Materials and Methods}

\subsection{General Protocols}

All manipulations were performed under inert atmosphere using standard Schlenk techniques or in a dry, solvent-free glove-box (Jacomex; $\mathrm{O}_{2}<1$ ppm, $\mathrm{H}_{2} \mathrm{O}<5$ ppm). $\mathrm{HN}\left(\mathrm{SiMe}_{3}\right)_{2}$ (abcr; Karlsruhe, Germany) and $\mathrm{HN}\left(\mathrm{SiMe}_{2} \mathrm{H}\right)_{2}$ (abcr) were dried over $\mathrm{CaH}_{2}$ and distilled prior to use. The compounds $\left[\mathrm{KN}\left(\mathrm{SiMe}_{3}\right)_{2}\right]$ and $\left[\mathrm{K}\left(\mathrm{N}\left(\mathrm{SiMe}_{2} \mathrm{H}\right)_{2}\right]\right.$ were prepared following literature protocols [15]. The proteo-ligands $\left\{\mathrm{RO}^{1}\right\} \mathrm{H}-\left\{\mathrm{RO}^{3}\right\} \mathrm{H}$ were obtained as described earlier $[16,20]$. The new $\left\{\mathrm{RO}^{4}\right\} \mathrm{H}$ was obtained following the same protocols, using $\mathrm{HNEt}_{2}$ as starting material; see the Supplementary Materials (Sections S1-S9) for detail. 2,2-Bis(trifluoromethyl)oxirane was purchased from Synquest Laboratories (Alachua, FL, USA) and used as received. Solvents (THF, $\mathrm{Et}_{2} \mathrm{O}, \mathrm{CH}_{2} \mathrm{Cl}_{2}$, pentane, and toluene) were purified and dried (water content all below $10 \mathrm{ppm}$ ) over alumina columns (MBraun SPS). THF was further distilled under argon from sodium mirror/benzophenone ketyl prior to use. All deuterated solvents (Eurisotop, Saclay, France) were stored in sealed ampoules over activated $3 \AA$ molecular sieves and were thoroughly degassed by several freeze-thaw-vacuum cycles.

NMR spectra were recorded on Bruker AM-400 and AM-500 spectrometers (Bruker BioSpin, Wissembourg, France) at the University of Rennes 1. All ${ }^{1} \mathrm{H}$ and ${ }^{13} \mathrm{C}\left\{{ }^{1} \mathrm{H}\right\}$ chemicals shifts were determined using residual signals of the deuterated solvents and were calibrated vs. $\mathrm{SiMe}_{4}$. Assignment of the resonances was carried out using $1 \mathrm{D}\left({ }^{1} \mathrm{H},{ }^{13} \mathrm{C}\left\{{ }^{1} \mathrm{H}\right\}\right)$ and $2 \mathrm{D}$ (COSY, HMBC, HMQC) NMR experiments. Coupling constants are given in hertz. ${ }^{19} \mathrm{~F}\left\{{ }^{1} \mathrm{H}\right\}$ chemical shifts were determined by external reference to an aqueous solution of $\mathrm{NaBF}_{4}$.

Elemental analyses performed on a Carlo Erba 1108 Elemental Analyzer at the London Metropolitan University by Stephen Boyer were the average of two independent measurements.

The November 2016 CSD database (CSDV37) was used for the searches of XRD structures.

\subsection{Synthesis of Complex $\left[\left\{R O^{1}\right\} K\right]_{4}\left([1]_{4}\right)$}

$\mathrm{KN}\left(\mathrm{SiMe}_{3}\right)_{2}(0.06 \mathrm{~g}, 0.33 \mathrm{mmol})$ was added with a bent finger to a solution of $\left\{\mathrm{RO}^{1}\right\} \mathrm{H}(0.10 \mathrm{~g}$, $0.33 \mathrm{mmol})$ in $\mathrm{Et}_{2} \mathrm{O}(10 \mathrm{~mL})$. The reaction mixture was stirred at room temperature overnight. Volatiles were removed in vacuo to afford a sticky solid. Stripping with pentane $(3 \times 3 \mathrm{~mL})$ afforded the title compound as a white solid $(0.080 \mathrm{~g}, 69 \%)$. The compound was recrystallized from a concentrated pentane solution at $-30{ }^{\circ} \mathrm{C} .{ }^{1} \mathrm{H}$ NMR $\left(500.13 \mathrm{MHz},\left[\mathrm{D}_{6}\right]\right.$ benzene, $\left.298 \mathrm{~K}\right): \delta 7.21-7.14(\mathrm{~m}$, $2 \mathrm{H}, m-\mathrm{C}_{6} \mathrm{H}_{5}$ ), 7.12-7.08 (overlapping $\mathrm{m}, 3 \mathrm{H}, p-\mathrm{C}_{6} \mathrm{H}_{5}$, and $o-\mathrm{C}_{6} \mathrm{H}_{5}$ ), 2.66-2.60 (br m, $2 \mathrm{H}, \mathrm{NCH}_{2} \mathrm{CH}_{2}$ ), 2.56-2.52 (overlapping $\mathrm{m}, 4 \mathrm{H}, \mathrm{CH}_{2} \mathrm{C}\left(\mathrm{CF}_{3}\right)_{2}$, and $\left.\mathrm{NCH}_{2} \mathrm{CH}_{2}\right), 2.18\left(\mathrm{~s}, 3 \mathrm{H}, \mathrm{NCH}_{3}\right) \mathrm{ppm} .{ }^{13} \mathrm{C}\left\{{ }^{1} \mathrm{H}\right\} \mathrm{NMR}$ $\left(125.73 \mathrm{MHz}\right.$, [D $\mathrm{D}_{6}$ benzene, $\left.298 \mathrm{~K}\right): \delta 140.22,129.06,128.30,126.69\left(\right.$ all $\left.\mathrm{C}_{6} \mathrm{H}_{5}\right), 127.62\left(\mathrm{q},{ }^{1} J_{\mathrm{C}-\mathrm{F}}=294.2 \mathrm{~Hz}\right.$, $\left.\mathrm{CF}_{3}\right), 81.24$ (hept, $\left.{ }^{2} J_{\mathrm{C}-\mathrm{F}}=22.6 \mathrm{~Hz}, \mathrm{C}\left(\mathrm{CF}_{3}\right)_{2}\right), 63.64\left(\mathrm{NCH}_{2} \mathrm{CH}_{2}\right), 60.61\left(\mathrm{CH}_{2} \mathrm{C}\left(\mathrm{CF}_{3}\right)_{2}\right), 45.33\left(\mathrm{NCH}_{3}\right)$, 
$34.06\left(\mathrm{NCH}_{2} \mathrm{CH}_{2}\right)$ ppm. ${ }^{19} \mathrm{~F}\left\{{ }^{1} \mathrm{H}\right\} \mathrm{NMR}(376.49 \mathrm{MHz}$, [D $]$ ]benzene, $\left.298 \mathrm{~K}\right): \delta-76.34$ (s, $\left.6 \mathrm{~F}, \mathrm{CF}_{3}\right) \mathrm{ppm}$. Elemental analysis for $\mathrm{C}_{13} \mathrm{H}_{14} \mathrm{~F}_{6} \mathrm{KNO}\left(353.35 \mathrm{~g} \cdot \mathrm{mol}^{-1}\right.$ ): calc. C $44.2 \%, \mathrm{H} 4.0 \%, \mathrm{~N} 4.0 \%$; found $\mathrm{C} 44.3 \%$, H $3.8 \%$, N $3.9 \%$.

\subsection{Synthesis of Complex $\left[\left\{R O^{2}\right\} K\right]_{4}\left([2]_{4}\right)$}

$\mathrm{KN}\left(\mathrm{SiMe}_{3}\right)_{2}(0.08 \mathrm{~g}, 0.44 \mathrm{mmol})$ was added in solid portions with a bent finger to a solution of $\left\{\mathrm{RO}^{2}\right\} \mathrm{H}(0.13 \mathrm{~g}, 0.44 \mathrm{mmol})$ in $\mathrm{Et}_{2} \mathrm{O}(10 \mathrm{~mL})$. The reaction mixture was stirred at room temperature overnight. Volatiles were removed under vacuum and the resulting oil was stripped with pentane $(3 \times 3 \mathrm{~mL})$ to afford the title compound as a colorless solid. The compound was recrystallized from a concentrated pentane solution at $-30{ }^{\circ} \mathrm{C}$. Yield $50 \mathrm{mg}(33 \%) .{ }^{1} \mathrm{H}$ NMR $\left(400.13 \mathrm{MHz}\right.$, [ $\left.\mathrm{D}_{6}\right]$ benzene, $298 \mathrm{~K}): \delta 2.92\left(\mathrm{hept}, 1 \mathrm{H},{ }^{3} \mathrm{~J}_{\mathrm{H}-\mathrm{H}}=6.8 \mathrm{~Hz}, \mathrm{CH}\left(\mathrm{CH}_{3}\right)_{2}\right), 2.80\left(\mathrm{t}, 2 \mathrm{H},{ }^{3} \mathrm{~J}_{\mathrm{H}-\mathrm{H}}=6.5 \mathrm{~Hz}, \mathrm{NCH}_{2} \mathrm{CH}_{2}\right), 2.71(\mathrm{~s}, 2 \mathrm{H}$, $\left.\mathrm{CH}_{2} \mathrm{C}\left(\mathrm{CF}_{3}\right)_{2}\right), 2.39\left(\mathrm{~m}, 2 \mathrm{H}, \mathrm{NCH}_{2} \mathrm{CH}_{2}\right), 1.60\left(\mathrm{t}, 3 \mathrm{H},{ }^{2} \mathrm{~J}_{\mathrm{H}-\mathrm{H}}=2.3 \mathrm{~Hz}, \mathrm{C} \equiv \mathrm{C}-\mathrm{CH}_{3}\right), 0.92\left(\mathrm{~d}, 6 \mathrm{H},{ }^{3} \mathrm{~J}_{\mathrm{H}-\mathrm{H}}=6.5 \mathrm{~Hz}\right.$, $\left.\mathrm{CH}\left(\mathrm{CH}_{3}\right)_{2}\right)$ ppm. $\left.{ }^{13} \mathrm{C}_{\{}{ }^{1} \mathrm{H}\right\} \mathrm{NMR}\left(100.63 \mathrm{MHz},\left[\mathrm{D}_{6}\right]\right.$ benzene, $\left.298 \mathrm{~K}\right): \delta 127.81\left(\mathrm{q},{ }^{1} \mathrm{~J}_{\mathrm{C}-\mathrm{F}}=294.8 \mathrm{~Hz}\right.$,

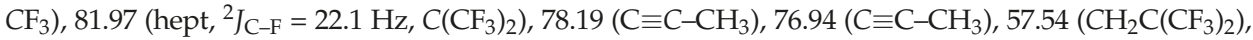
$51.91\left(\mathrm{CH}\left(\mathrm{CH}_{3}\right)_{2}\right), 51.63\left(\mathrm{NCH}_{2} \mathrm{CH}_{2}\right), 19.51\left(\mathrm{NCH}_{2} \mathrm{CH}_{2}\right), 18.26\left(\mathrm{CH}\left(\mathrm{CH}_{3}\right)_{2}\right), 3.06\left(\mathrm{C} \equiv \mathrm{C}-\mathrm{CH}_{3}\right) \mathrm{ppm} .{ }^{19} \mathrm{~F}\left\{{ }^{1} \mathrm{H}\right\}$ NMR (376.47 MHz, [ $\mathrm{D}_{6}$ ]benzene, $\left.298 \mathrm{~K}\right):-77.32$ (s, 6F, $\mathrm{CF}_{3}$ ) ppm. Elemental analysis for $\mathrm{C}_{12} \mathrm{H}_{16} \mathrm{~F}_{6} \mathrm{KNO}$ (343.35 g. $\mathrm{mol}^{-1}$ ): calc. C $42.0 \%, \mathrm{H} 4.7 \%, \mathrm{~N} 4.1 \%$; found C $42.0 \%, \mathrm{H} 4.4 \%, \mathrm{~N} 4.1 \%$.

\subsection{Synthesis of Complex $\left[\left\{R \mathrm{R}^{3}\right\} \mathrm{K}\right]_{4}\left([3]_{4}\right)$}

$\mathrm{KN}\left(\mathrm{SiMe}_{2} \mathrm{H}\right)_{2}(0.11 \mathrm{~g}, 0.65 \mathrm{mmol})$ was added in solid portions with a bent finger to a solution of $\left\{\mathrm{RO}^{3}\right\} \mathrm{H}(0.21 \mathrm{~g}, 0.67 \mathrm{mmol})$ in $\mathrm{Et}_{2} \mathrm{O}(10 \mathrm{~mL})$. The reaction mixture was stirred at room temperature overnight. Volatiles were removed under vacuum and the resulting oil was stripped with pentane $(3 \times 4 \mathrm{~mL})$ to afford the title compound as a colorless oil. In a matter of days, the oil crystallized and the title compound was isolated as off-white crystals. Yield $(161 \mathrm{mg}, 72 \%) .{ }^{1} \mathrm{H}$ NMR (400.13 MHz, [D $D_{6}$ ]benzene, $\left.298 \mathrm{~K}\right): \delta 5.79\left(\mathrm{ddt}, 2 \mathrm{H},{ }^{3} J_{\mathrm{H}-\mathrm{H}}(\right.$ trans $)=17.4 \mathrm{~Hz},{ }^{3} J_{\mathrm{H}-\mathrm{H}}($ cis $)=9.9 \mathrm{~Hz}$, $\left.{ }^{3} J_{\mathrm{H}-\mathrm{H}}=6.7 \mathrm{~Hz}, \mathrm{CH}=\mathrm{CH}_{2}\right), 5.13-5.01\left(\mathrm{~m}, 4 \mathrm{H}, \mathrm{CH}=\mathrm{CH}_{2}\right), 2.76\left(\mathrm{~s}, 2 \mathrm{H}, \mathrm{CH}_{2} \mathrm{C}\left(\mathrm{CF}_{3}\right)_{2}\right), 2.62(\mathrm{t}, 4 \mathrm{H}$, $\left.{ }^{3} J_{\mathrm{H}-\mathrm{H}}=6.4 \mathrm{~Hz}, \mathrm{NCH}_{2} \mathrm{CH}_{2}\right), 2.06\left(\mathrm{q},{ }^{3} \mathrm{~J}_{\mathrm{H}-\mathrm{H}}=6.4 \mathrm{~Hz}, 4 \mathrm{H}, \mathrm{NCHCH}_{2}\right) \mathrm{ppm} .{ }^{13} \mathrm{C}\left\{{ }^{1} \mathrm{H}\right\} \mathrm{NMR}(100.63 \mathrm{MHz}$, [D $\mathrm{D}_{6}$ ]benzene, $\left.298 \mathrm{~K}\right): \delta 137.70\left(\mathrm{CH}=\mathrm{CH}_{2}\right), 127.78\left(\mathrm{q},{ }^{1} \mathrm{~J}_{\mathrm{C}-\mathrm{F}}=295.3 \mathrm{~Hz}, \mathrm{CF}_{3}\right), 116.01\left(\mathrm{CH}=\mathrm{CH}_{2}\right)$, 81.58 (hept, $\left.{ }^{2} J_{\mathrm{C}-\mathrm{F}}=22.4 \mathrm{~Hz}, \mathrm{C}\left(\mathrm{CF}_{3}\right)_{2}\right), 61.03\left(\mathrm{CH}_{2} \mathrm{C}\left(\mathrm{CF}_{3}\right)_{2}\right), 53.12\left(\mathrm{NCH}_{2} \mathrm{CH}_{2}\right), 29.79\left(\mathrm{NCH}_{2} \mathrm{CH}_{2}\right) \mathrm{ppm}$. ${ }^{19} \mathrm{~F}\left\{{ }^{1} \mathrm{H}\right\}$ NMR $\left(376.49 \mathrm{MHz},\left[\mathrm{D}_{6}\right]\right.$ benzene, $\left.298 \mathrm{~K}\right): \delta-75.86\left(\mathrm{~s}, 6 \mathrm{~F}, \mathrm{CF}_{3}\right) \mathrm{ppm}$. Elemental analysis for $\mathrm{C}_{12} \mathrm{H}_{16} \mathrm{~F}_{6} \mathrm{KNO}\left(343.35 \mathrm{~g} \cdot \mathrm{mol}^{-1}\right.$ ): calc. C $42.0 \%, \mathrm{H} 4.7 \%, \mathrm{~N} 4.1 \%$; found C $42.1 \%, \mathrm{H} 4.6 \%, \mathrm{~N} 4.2 \%$.

\subsection{Synthesis of Complex $\left[\left\{R \mathrm{R}^{4}\right\} \mathrm{K}\right]_{4}\left([4]_{4}\right)$}

$\mathrm{KN}\left(\mathrm{SiMe}_{2} \mathrm{H}\right)_{2}(0.16 \mathrm{~g}, 0.80 \mathrm{mmol})$ was added with a bent finger to a solution of $\left\{\mathrm{RO}^{4}\right\} \mathrm{H}(0.20 \mathrm{mg}$, $0.80 \mathrm{mmol})$ in $\mathrm{Et}_{2} \mathrm{O}(10 \mathrm{~mL})$. The reaction mixture was stirred overnight at room temperature. The volatiles were removed in vacuo to yield $\left[\left\{\mathrm{RO}^{4}\right\} \mathrm{K}\right]_{4}$ as a colorless solid $(0.20 \mathrm{~g}, 85 \%)$. X-ray-quality crystals were obtained from a concentrated pentane solution at $-30{ }^{\circ} \mathrm{C} .{ }^{1} \mathrm{H}$ NMR $(400.16 \mathrm{MHz}$, [D $\mathrm{D}_{6}$ ]benzene, $\left.298 \mathrm{~K}\right): \delta 2.70\left(\mathrm{~s}, 2 \mathrm{H}, \mathrm{CH}_{2} \mathrm{C}\left(\mathrm{CF}_{3}\right)_{2}\right), 2.56\left(\mathrm{q}, 4 \mathrm{H},{ }^{3} \mathrm{~J}_{\mathrm{H}-\mathrm{H}}=6.9 \mathrm{~Hz}, \mathrm{NCH}_{2} \mathrm{CH}_{3}\right), 0.82$ $\left(\mathrm{t}, 6 \mathrm{H},{ }^{3} \mathrm{~J}_{\mathrm{H}-\mathrm{H}}=7.0 \mathrm{~Hz}, \mathrm{NCH}_{2} \mathrm{CH}_{3}\right) \mathrm{ppm} .{ }^{13} \mathrm{C}\left\{{ }^{1} \mathrm{H}\right\} \mathrm{NMR}\left(100.62 \mathrm{MHz},\left[\mathrm{D}_{6}\right]\right.$ benzene, $\left.298 \mathrm{~K}\right)$ : $\delta 129.30\left(\mathrm{q},{ }^{1} J_{\mathrm{C}-\mathrm{F}}=295.3 \mathrm{~Hz}, \mathrm{CF}_{3}\right), 81.91\left(\mathrm{hept},{ }^{2} J_{\mathrm{CF}}=22.8 \mathrm{~Hz}, \mathrm{C}\left(\mathrm{CF}_{3}\right)_{2}\right), 58.97\left(\mathrm{CH}_{2} \mathrm{C}_{\left.\left(\mathrm{CF}_{3}\right)_{2}\right), 47.36}\right.$ $\left(\mathrm{NCH}_{2} \mathrm{CH}_{3}\right), 10.01\left(\mathrm{NCH}_{2} \mathrm{CH}_{3}\right)$ ppm. $\left.{ }^{19} \mathrm{~F}^{1}{ }^{1} \mathrm{H}\right\}$ NMR (376.49 MHz, [D 6 ]benzene, $\left.298 \mathrm{~K}\right): \delta-76.38$ (s, $\left.6 \mathrm{~F}, \mathrm{CF}_{3}\right) \mathrm{ppm}$. Elemental analysis for $\mathrm{C}_{8} \mathrm{H}_{12} \mathrm{~F}_{6} \mathrm{KNO}\left(291.28 \mathrm{~g} \cdot \mathrm{mol}^{-1}\right)$ : calc. C $33.0 \%, \mathrm{H} 4.1 \%, \mathrm{~N} 4.8 \%$; found C $32.9 \%, \mathrm{H} 4.0 \%, \mathrm{~N} 4.9 \%$.

\subsection{X-Ray Diffraction Crystallography}

X-ray diffraction data were collected at $150 \mathrm{~K}$ using a Bruker APEX CCD diffractometer with graphite-monochromated Mo K $\alpha$ radiation $(\lambda=0.71073 \AA)$ at the University of Rennes 1 . A combination $\omega$ and $\Phi$ scans was carried out to obtain at least a unique data set. The crystal structures were solved by direct methods, and remaining atoms were located from difference Fourier synthesis followed by 
full-matrix least-squares based on F2 (programs SIR97 and SHELXL-97) [34,35]. Carbon-, oxygen-, and nitrogen-bound hydrogen atoms were placed at calculated positions and forced to ride on the attached atom. The hydrogen atom contributions were calculated, but not refined. All non-hydrogen atoms were refined with anisotropic displacement parameters. The locations of the largest peaks in the final difference Fourier map calculation as well as the magnitude of the residual electron densities were of no chemical significance. The crystallographic data for all compounds are available as CIF files from the Cambridge Crystallographic Database Centre (CCDC numbers 1530195-1530198). A summary of crystallographic data is given in Table 5 .

Table 5. Summary of crystallographic data for $[1]_{4}-[4]_{4}$.

\begin{tabular}{|c|c|c|c|c|}
\hline & $\begin{array}{c}{\left[\left\{\mathrm{RO}^{1}\right\} \mathrm{K}\right]_{4}} \\
\left([1]_{4}\right)\end{array}$ & $\begin{array}{l}{\left[\left\{\mathrm{RO}^{2}\right\} \mathrm{K}\right]_{4}} \\
\left([2]_{4}\right)\end{array}$ & $\begin{array}{c}{\left[\left\{\mathrm{RO}^{3}\right\} \mathrm{K}\right]_{4}} \\
\left([3]_{4}\right)\end{array}$ & $\begin{array}{c}{\left[\left\{\mathrm{RO}^{4}\right\} \mathrm{K}\right]_{4}} \\
\left([4]_{4}\right)\end{array}$ \\
\hline $\begin{array}{l}\text { Formula } \\
\text { CCDC }\end{array}$ & $\begin{array}{c}\mathrm{C}_{104} \mathrm{H}_{112} \mathrm{~F}_{48} \mathrm{~K}_{8} \mathrm{~N}_{8} \mathrm{O}_{8} \\
1530195\end{array}$ & $\begin{array}{c}\mathrm{C}_{48} \mathrm{H}_{64} \mathrm{~F}_{24} \mathrm{~K}_{4} \mathrm{~N}_{4} \mathrm{O}_{4} \\
1530196\end{array}$ & $\begin{array}{c}\mathrm{C}_{48} \mathrm{H}_{64} \mathrm{~F}_{24} \mathrm{~K}_{4} \mathrm{~N}_{4} \mathrm{O}_{4} \\
1530197\end{array}$ & $\begin{array}{c}\mathrm{C}_{32} \mathrm{H}_{48} \mathrm{~F}_{24} \mathrm{~K}_{4} \mathrm{~N}_{4} \mathrm{O}_{4} \\
1530198\end{array}$ \\
\hline Molecular weight & 2826.82 & 1373.43 & 1373.43 & 1165.14 \\
\hline Crystal system & monoclinic & triclinic & tetragonal & monoclinic \\
\hline Space group & $P 2{ }_{1} / n$ & $P-1$ & $P-421 c$ & $P 2{ }_{1} / n$ \\
\hline$a(\AA)$ & $14.2195(4)$ & $13.9764(4)$ & $13.5114(14)$ & $18.9136(8)$ \\
\hline$b(\AA)$ & $11.8504(4)$ & $14.1787(4)$ & 13.511 & $10.7740(5)$ \\
\hline$c(\AA)$ & $39.8155(13)$ & $16.1077(4)$ & $17.556(3)$ & $24.7556(9)$ \\
\hline$\alpha\left({ }^{\circ}\right)$ & 90 & $84.8310(10)$ & 90 & 90 \\
\hline$\beta\left(^{\circ}\right)$ & $97.5260(10)$ & $81.5600(10)$ & 90 & $108.265(2)$ \\
\hline$\gamma\left({ }^{\circ}\right)$ & 90 & $80.1870(10)$ & 90 & 90 \\
\hline $\mathrm{V}\left(\AA^{3}\right)$ & $6651.4(4)$ & $3104.31(15)$ & $3205.0(6)$ & $4790.4(4)$ \\
\hline Z & 2 & 2 & 8 & 4 \\
\hline Density $\left(\mathrm{g} / \mathrm{cm}^{3}\right)$ & 1.411 & 1.469 & 1.423 & 1.616 \\
\hline Absorption coefficient $\left(\mathrm{mm}^{-1}\right)$ & 0.378 & 0.402 & 0.389 & 0.505 \\
\hline$F(000)$ & 2880 & 1408 & 1408 & 2368 \\
\hline Crystal size, $\mathrm{mm}$ & $0.51 \times 0.23 \times 0.15$ & $0.490 \times 0.410 \times 0.280$ & $0.39 \times 0.27 \times 0.10$ & $0.410 \times 0.150 \times 0.120$ \\
\hline \multirow[t]{2}{*}{$\theta$ range, deg } & 2.92 to 27.48 & 2.922 to 27.521 & 3.02 to 27.50 & 2.953 to 27.483 \\
\hline & $-18<h<18$ & $-18<h<18$ & $-17<h<13$ & $-24<h<24$ \\
\hline \multirow[t]{2}{*}{ Limiting indices } & $-15<k<12$ & $-17<k<18$ & $-17<k<17$ & $-13<k<13$ \\
\hline & $-51<l<51$ & $-19<l<20$ & $-22<l<18$ & $-32<l<31$ \\
\hline$R($ int $)$ & 0.055 & 0.0318 & 0.0886 & 0.0550 \\
\hline Reflections collected & 59,233 & 35,803 & 17,470 & 57,371 \\
\hline Reflec. Unique $[I>2 \sigma]$ & 15,220 & 14,178 & 3501 & 10,958 \\
\hline Completeness to $\theta(\%)$ & 99.8 & 99.3 & 99.6 & 99.8 \\
\hline Data/restraints/param. & $15,220 / 0 / 797$ & $14,178 / 0 / 759$ & $3501 / 0 / 191$ & $10,958 / 4 / 668$ \\
\hline Goodness-of-fit & 0.989 & 1.010 & 0.963 & 1.056 \\
\hline$R_{1}[I>2 \sigma]$ (all data) & $0.0453(0.0797)$ & $0.0418(0.0625)$ & $0.0466(0.1014)$ & $0.0402(0.0681)$ \\
\hline${ }_{w} R_{2}[I>2 \sigma]$ (all data) & $0.1054(0.1185)$ & $0.0989(0.1101)$ & $0.0794(0.0942)$ & $0.0968(0.1166)$ \\
\hline Largest difference $\mathrm{e} \cdot \mathrm{A}^{-3}$ & $0.27 \&-0.301$ & $0.901 \&-0.894$ & $0.234 \&-0.222$ & $0.844 \&-0.667$ \\
\hline
\end{tabular}

Supplementary Materials: The following are available online at www.mdpi.com/2304-6740/5/1/13/s1, CIF and checkCIF files of $\left[\left\{\mathrm{RO}^{x}\right\} \mathrm{K}\right]_{4}\left([1]_{4}-[4]_{4}\right)$, Sections S1-S9.

Acknowledgments: Sorin-Claudiu Roşca thanks the French Agence Nationale de la Recherche for a PhD grant (GreenLAkE, ANR-11-BS07-009-01).

Author Contributions: Sorin-Claudiu Roşca, Jean-François Carpentier and Yann Sarazin conceived and designed the experiments; Sorin-Claudiu Roşca and Hanieh Roueindeji performed the experiments; Vincent Dorcet and Thierry Roisnel carried out the X-ray crystal structure determinations and the interpretation of the crystal data; Sorin-Claudiu Roşca, Hanieh Roueindeji, Jean-François Carpentier and Yann Sarazin analyzed the data; Yann Sarazin wrote the paper.

Conflicts of Interest: The authors declare no conflict of interest. 


\section{References}

1. Buchanan, W.D.; Allis, D.G.; Ruhlandt-Senge, K. Synthesis and stabilization-Advances in organoalkaline earth metal chemistry. Chem. Commun. 2010, 46, 4449-4465. [CrossRef] [PubMed]

2. Samuels, J.A.; Lobkovsky, E.B.; Streib, W.E.; Folting, K.; Huffman, J.C.; Zwanziger, J.W.; Caulton, K.G. Organofluorine binding to sodium and thallium(I) in molecular fluoroalkoxide compounds. J. Am. Chem. Soc. 1993, 115, 5093-5104. [CrossRef]

3. Samuels, J.A.; Folting, K.; Huffman, J.C.; Caulton, K.G. Structure/volatility correlation of sodium and zirconium fluoroalkoxides. Chem. Mater. 1996, 7, 929-935. [CrossRef]

4. Buchanan, W.D.; Nagle, E.D.; Ruhlandt-Senge, K. $\pi$-Coordination as a structure determining principle: Structural characterization of $[\mathrm{K}(\mathrm{Odpp})]_{\infty}$, and $\left\{\left[\mathrm{K}_{2}(\mathrm{Odpp})_{2} \mathrm{H}_{2} \mathrm{O}_{2}\right\}_{\infty}\right.$. Main Group Chem. 2009, 8, $263-273$. [CrossRef]

5. Buchanan, W.D.; Ruhlandt-Senge, K. M ..F Interactions and heterobimetallics: Furthering the understanding of heterobimetallic stabilization. Chem. Eur. J. 2013, 19, 10708-10715. [CrossRef] [PubMed]

6. Lum, J.S.; Tahsini, L.; Golen, J.A.; Moore, C.; Rheingold, A.L.; Doerrer, L.H. K ‥F/O Interactions bridge copper(I) fluorinated alkoxide complexes and facilitate dioxygen activation. Chem. Eur. J. 2013, 19, 6374-6384. [CrossRef] [PubMed]

7. Weinert, C.S.; Fanwick, P.E.; Rothwell, I.P. Synthesis of group 1 metal 2,6-Diphenylphenoxide complexes $\left[\mathrm{M}\left(\mathrm{OC}_{6} \mathrm{H}_{3} \mathrm{Ph}_{2}-2,6\right)\right](\mathrm{M}=\mathrm{Li}, \mathrm{Na}, \mathrm{K}, \mathrm{Rb}, \mathrm{Cs})$ and structures of the solvent-free complexes $\left[\mathrm{Rb}\left(\mathrm{OC}_{6} \mathrm{H}_{3} \mathrm{Ph}_{2}-2,6\right)\right]_{x}$ and $\left[\mathrm{Cs}\left(\mathrm{OC}_{6} \mathrm{H}_{3} \mathrm{Ph}_{2}-2,6\right)\right]_{x}$ : One-dimensional extended arrays of metal aryloxides. Inorg. Chem. 2003, 42, 6089-6094. [CrossRef] [PubMed]

8. Dougherty, D.A. Cation- $\pi$ interactions in chemistry and biology: A new view of benzene, Phe, Tyr, and Trp. Science 1996, 271, 163-168. [CrossRef] [PubMed]

9. Ma, J.C.; Dougherty, D.A. The cation- $\pi$ interaction. Chem. Rev. 1997, 97, 1303-1324. [CrossRef] [PubMed]

10. Salonen, L.M.; Ellermann, M.; Diederich, F. Aromatic rings in chemical and biological recognition: Energetics and structures. Angew. Chem. Int. Ed. 2011, 50, 4808-4842. [CrossRef] [PubMed]

11. Watt, M.M.; Collins, M.S.; Johnson, D.W. Ion $-\pi$ interactions in ligand design for anions and main group cations. Acc. Chem. Res. 2013, 46, 955-966. [CrossRef] [PubMed]

12. Mahadevi, A.S.; Sastry, G.N. Cation $-\pi$ interaction: Its role and relevance in chemistry, biology, and material science. Chem. Rev. 2013, 113, 2100-2138. [CrossRef] [PubMed]

13. Dougherty, D.A. The Cation- $\pi$ interaction. Acc. Chem. Res. 2013, 46, 885-893. [CrossRef] [PubMed]

14. Kennedy, C.R.; Lin, S.; Jacobsen, E.N. The cation- $\pi$ Interaction in small-molecule catalysis. Angew. Chem. Int. Ed. 2016, 55, 12596-12624. [CrossRef] [PubMed]

15. Sarazin, Y.; Roşca, D.; Poirier, V.; Roisnel, T.; Silvestru, A.; Maron, L.; Carpentier, J.-F. Bis(dimethylsilyl)-amide complexes of the alkaline-earth metals stabilized by $\beta$-Si-H agostic interactions: Synthesis, characterization, and catalytic activity. Organometallics 2010, 29, 6569-6577. [CrossRef]

16. Sarazin, Y.; Liu, B.; Roisnel, T.; Maron, L.; Carpentier, J.-F. Discrete, solvent-free alkaline-earth metal cations: Metal ‥Fluorine interactions and ROP catalytic activity. J. Am. Chem. Soc. 2011, 133, 9069-9087. [CrossRef] [PubMed]

17. Liu, B.; Roisnel, T.; Carpentier, J.-F.; Sarazin, Y. When Bigger Is Better: Intermolecular hydrofunctionalizations of activated alkenes catalyzed by heteroleptic alkaline earth complexes. Angew. Chem. Int. Ed. 2012, 51, 4943-4946. [CrossRef] [PubMed]

18. Roşca, S.-C.; Roisnel, T.; Dorcet, V.; Carpentier, J.-F.; Sarazin, Y. Potassium and well-defined neutral and cationic calcium fluoroalkoxide complexes: Structural features and reactivity. Organometallics 2014, 33, 5630-5642. [CrossRef]

19. Roşca, S.-C.; Dinoi, C.; Caytan, E.; Dorcet, V.; Etienne, M.; Carpentier, J.-F.; Sarazin, Y. Alkaline earth-olefin complexes with secondary interactions. Chem. Eur. J. 2016, 22, 6505-6509. [CrossRef] [PubMed]

20. Roşca, S.-C.; Caytan, E.; Dorcet, V.; Roisnel, T.; Carpentier, J.-F.; Sarazin, Y. $\pi$ Ligands in alkaline earth complexes. Organometallics 2017, under revision.

21. Varga, V.; Hiller, J.; Polášek, M.; Thewalt, U.; Mach, K. Synthesis and structure of Titanium(III) Tweezer complexes with embedded alkali metal ions: $\left[\left(\mathrm{C}_{5} \mathrm{HMe}_{4}\right)_{2} \mathrm{Ti}\left(\eta^{1}-\mathrm{C} \equiv \mathrm{C}-\mathrm{SiMe}_{3}\right)_{2}\right]^{-} \mathrm{M}^{+}(\mathrm{M}=\mathrm{Li}, \mathrm{Na}, \mathrm{K}$, and Cs $)$. J. Organomet. Chem. 1996, 515, 57-64. [CrossRef] 
22. Berben, L.A.; Long, J.R. Synthesis and alkali metal ion-binding properties of a Chromium(III) Triacetylide complex. J. Am. Chem. Soc. 2002, 124, 11588-11589. [CrossRef] [PubMed]

23. Chadha, P.; Dutton, J.L.; Ragogna, P.J. Synthesis and reactivity of bis-alkynyl appended metallocenes of Ti, Fe, and Co. Can. J. Chem. 2010, 88, 1213-1221. [CrossRef]

24. Layfield, R.A.; García, F.; Hannauer, J.; Humphrey, S.M. Ansa-Tris(allyl) Complexes of alkali metals: Tripodal analogues of cyclopentadienyl and ansa-metallocene ligands. Chem. Commun. 2007. [CrossRef] [PubMed]

25. Gren, C.K.; Hanusa, T.P.; Rheingold, A.L. Threefold cation $-\pi$ bonding in trimethylsilylated allyl complexes. Organometallics 2007, 26, 1643-1649. [CrossRef]

26. Kennedy, A.R.; Klett, J.; Mulvey, R.E.; Wright, D.S. Synergic sedation of sensitive anions: Alkali-mediated zincation of cyclic ethers and ethene. Science 2009, 326, 706-708. [CrossRef] [PubMed]

27. Kromer, A.; Wedig, U.; Roduner, E.; Jansen, M.; Amsharov, K.Y. Counterintuitive anisotropy of electron transport properties in $\mathrm{KC}_{60}\left(\mathrm{TH}_{\mathrm{F}}\right)_{5}$. 2 THF Fulleride. Angew. Chem. Int. Ed. 2013, 52, 12610-12614. [CrossRef] [PubMed]

28. Boyle, T.J.; Andrews, N.L.; Rodriguez, M.A.; Campana, C.; Yiu, T. Structural variations of potassium aryloxides. Inorg. Chem. 2003, 42, 5357-5366. [CrossRef] [PubMed]

29. Veith, M.; Belot, C.; Huch, V.; Guyard, L.; Knorr, M.; Khatyr, A.; Wickleder, C. Syntheses, crystal structures, and physico-chemical studies of sodium and potassium alcoholates bearing thienyl substituents and their derived luminescent Samarium(III) alkoxides. Z. Anorg. Allg. Chem. 2010, 636, 2262-2275. [CrossRef]

30. Plenio, H. The coordination chemistry of the CF unit in fluorocarbons. Chem. Rev. 1997, 97, 3363-3384. [CrossRef] [PubMed]

31. Schiefer, M.; Hatop, H.; Roesky, H.W.; Schmidt, H.-G.; Noltemeyer, M. Organoaluminates with three terminal phenylethynyl groups and their interactions with alkali metal cations. Organometallics 2002, 21, 1300-1303. [CrossRef]

32. Brown, I.D. Recent developments in the methods and applications of the bond valence model. Chem. Rev. 2009, 109, 6858-6919. [CrossRef] [PubMed]

33. Carpentier, J.-F.; Maryin, V.P.; Luci, J.; Jordan, R.F. Solution structures and dynamic properties of chelated $\mathrm{d}^{0}$ Metal Olefin Complexes $\left\{\eta^{5}: \eta^{1}-\mathrm{C}_{5} \mathrm{R}_{4} \mathrm{SiMe}_{2} \mathrm{NtBu}\right\} \mathrm{Ti}\left(\mathrm{OCMe}_{2} \mathrm{CH}_{2} \mathrm{CH}_{2} \mathrm{CHCH}_{2}\right)^{+}(\mathrm{R}=\mathrm{H}, \mathrm{Me})$ : Models for the $\left\{\eta^{5}: \eta^{1}-C_{5} R_{4} S_{i M e}{ }_{2} \mathrm{NtBu}\right\} \mathrm{Ti}\left(\mathrm{R}^{\prime}\right)\left(\right.$ olefin) ${ }^{+}$intermediates in "constrained geometry" catalysts. J. Am. Chem. Soc. 2001, 123, 898-909. [CrossRef] [PubMed]

34. Altomare, A.; Burla, M.C.; Camalli, M.; Cascarano, G.L.; Giacovazzo, C.; Guagliardi, A.; Moliterni, A.G.G.; Polidori, G.; Spagna, R. SIR97: A new tool for crystal structure determination and refinement. Appl. Crystallogr. 1999, 32, 115-119. [CrossRef]

35. Sheldrick, G.M. SHELXL-97, Program for Refinement of Crystal Structures; University of Göttingen: Göttingen, Germany, 1997.

(c) 2017 by the authors. Licensee MDPI, Basel, Switzerland. This article is an open access article distributed under the terms and conditions of the Creative Commons Attribution (CC BY) license (http:/ / creativecommons.org/licenses/by/4.0/). 
Article

\title{
Symmetric Assembly of a Sterically Encumbered Allyl Complex: Mechanochemical and Solution Synthesis of the Tris(allyl)beryllate, $\mathrm{K}\left[\mathrm{BeA}_{3}{ }_{3}\right]$ $\left(\mathrm{A}^{\prime}=1,3-\left(\mathrm{SiMe}_{3}\right)_{2} \mathrm{C}_{3} \mathrm{H}_{3}\right)$
}

\author{
Nicholas C. Boyde ${ }^{1}$, Nicholas R. Rightmire ${ }^{1}$, Timothy P. Hanusa ${ }^{1, *}$ and William W. Brennessel ${ }^{2}$ \\ 1 Department of Chemistry, Vanderbilt University, Nashville, TN 37235, USA; \\ nicholas.c.boyde@vanderbilt.edu (N.C.B.); nicholas.r.rightmire@vanderbilt.edu (N.R.R.) \\ 2 Department of Chemistry, University of Rochester, Rochester, NY 14627, USA; \\ william.brennessel@rochester.edu \\ * Correspondence: t.hanusa@vanderbilt.edu
}

Academic Editor: Matthias Westerhausen

Received: 23 April 2017; Accepted: 23 May 2017; Published: 27 May 2017

\begin{abstract}
The ball milling of beryllium chloride with two equivalents of the potassium salt of bis(1,3-trimethylsilyl)allyl anion, $\left.\mathrm{K}_{\mathrm{A}} \mathrm{A}^{\prime}\right]\left(\mathrm{A}^{\prime}=\left[1,3-\left(\mathrm{SiMe}_{3}\right)_{2} \mathrm{C}_{3} \mathrm{H}_{3}\right]\right)$, produces the tris(allyl)beryllate $\mathrm{K}\left[\mathrm{BeA}_{3}^{\prime}\right]$ (1) rather than the expected neutral $\mathrm{BeA}_{2}^{\prime}$. The same product is obtained from reaction in hexanes; in contrast, although a similar reaction conducted in $\mathrm{Et}_{2} \mathrm{O}$ was previously shown to produce the solvated species $\mathrm{BeA}_{2}^{\prime}\left(\mathrm{OEt}_{2}\right)$, it can produce 1 if the reaction time is extended $(16 \mathrm{~h})$. The tris(allyl)beryllate is fluxional in solution, and displays the strongly downfield ${ }^{9} \mathrm{Be}$ NMR shift expected for a three-coordinate Be center $(\delta 22.8 \mathrm{ppm})$. A single crystal X-ray structure reveals that the three allyl ligands are bound to beryllium in an arrangement with approximate $C_{3}$ symmetry $(\mathrm{Be}-\mathrm{C}(\operatorname{avg})=1.805(10) \AA)$, with the potassium cation engaging in cation $-\pi$ interactions with the double bonds of the allyl ligands. Similar structures have previously been found in complexes of zinc and tin, i.e., $M\left[M^{\prime} \mathrm{A}^{\prime}{ }_{3} \mathrm{~L}\right]\left(M^{\prime}=\mathrm{Zn}, M=\mathrm{Li}, \mathrm{Na}, \mathrm{K} ; M^{\prime}=\mathrm{Sn}, M=\mathrm{K} ; \mathrm{L}=\mathrm{thf}\right)$. Density functional theory (DFT) calculations indicate that the observed $C_{3}$-symmetric framework of the isolated anion $\left(\left[\mathrm{BeA}_{3}^{\prime}\right]^{-}\right.$) is $20 \mathrm{~kJ} \cdot \mathrm{mol}^{-1}$ higher in energy than a $C_{1}$ arrangement; the $\mathrm{K}^{+}$counterion evidently plays a critical role in templating the final conformation.
\end{abstract}

Keywords: allyl ligands; beryllium; coordination modes; mechanochemistry; X-ray diffraction; density functional theory calculations

\section{Introduction}

The physical and chemical properties of first-row elements often differ appreciably from their second-row and heavier counterparts; for the group 2 metals, the outlier ("black sheep" [1]) designation belongs to beryllium. To a considerably greater extent than its heavier congeners, even magnesium, the small size of the $\mathrm{Be}^{2+}$ cation $\left(0.27 \AA\right.$ for $\mathrm{CN}=4$; cf. $0.57 \AA$ for $\left.\mathrm{Mg}^{2+}\right)$ [2] and its corresponding high charge/size ratio ensures its bonds will be strongly polarized and possess substantial covalent character. Not surprisingly, beryllium compounds with the same ligand sets commonly have different structures from those of the other, more electropositive alkaline earth (Ae) metals. The bis(trimethylsilyl)amides of $\mathrm{Mg}-\mathrm{Ba}$, for example, have a common dimeric bridged structure, [ $\mathrm{Ae}\left(\mathrm{N}\left(\mathrm{SiMe}_{3}\right)\left(\mu-\mathrm{N}\left(\mathrm{SiMe}_{3}\right)_{2}\right]_{2}[3]\right.$, whereas that of beryllium is a two-coordinate monomer [4]. Similarly, the bis(cyclopentadienyl) complex $\mathrm{Cp}_{2}$ Be has an $\eta^{1}, \eta^{5}$-Cp structure [5] that is unlike that of the heavier metallocenes [6]. Investigation of these differences, and indeed research with all beryllium compounds, has traditionally been limited 
because of concerns about toxicity [7], but that has not prevented its compounds from serving as useful benchmarks of the steric and electronic consequences of crowded metal environments [8-10].

One of these consequences is the relative stability of $\eta^{1}$ - vs. $\eta^{3}$-bonded allyl ligands in compounds of highly electropositive metals. We found some time ago that the bulky allyl $\left[\mathrm{A}^{\prime}\right]^{-}\left(\mathrm{A}^{\prime}=\left[1,3-\left(\mathrm{SiMe}_{3}\right)_{2} \mathrm{C}_{3} \mathrm{H}_{3}\right]\right)$ can be used to form the ether adduct $\mathrm{BeA}_{2}^{\prime} \cdot \mathrm{OEt}_{2}$, which displays $\eta^{1}$-bonded $\mathrm{A}^{\prime}$ ligands in the solid state [11]. The compound is fluxional in solution, and exhibits symmetric, " $\pi$-type" bonding in its NMR spectra (e.g., only one peak is observed for the $\mathrm{SiMe}_{3}$ groups). Density functional theory (DFT) calculations suggested that a base-free $\mathrm{Be}\left(\mathrm{C}_{3} \mathrm{H}_{3} \mathrm{E}_{2}\right)_{2}\left(\mathrm{E}=\mathrm{H}, \mathrm{SiH}_{3}\right)$ complex would be more slightly more stable with delocalized, $\pi$-type allyls than with monodentate, sigma-bonded ligands (Scheme 1 ). If so, beryllium allyls would join those of magnesium, in which monodentate allyl ligands are uniformly found in complexes that are ether-solvated [12], but that in the absence of ethers, cation- $\pi$ interactions with the metal can create "slipped- $\pi$ " bonding [13].
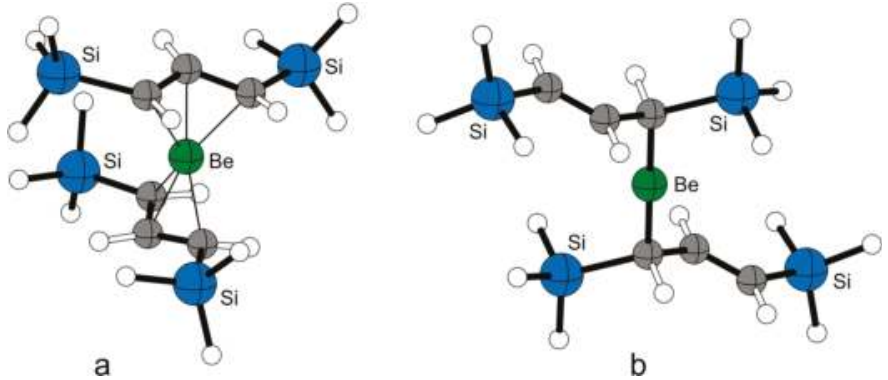

Scheme 1. Optimized geometries of $\mathrm{Be}\left(1,3-\left(\mathrm{SiH}_{3}\right)_{2} \mathrm{C}_{3} \mathrm{H}_{3}\right)_{2}$. At the B3PW91/aug-cc-pVDZ level, the $\pi$-bound structure (a) is $4.0 \mathrm{kcal} \cdot \mathrm{mol}^{-1}$ lower in energy $\left(\Delta G^{\circ}\right)$ than the $\sigma$-bound geometry (b) [11].

The coordinated ether in $\mathrm{BeA}_{2}^{\prime} \cdot \mathrm{OEt}_{2}$ proved impossible to remove without destroying the complex [11], and thus we investigated mechanochemical methods of synthesis as a means to bypass the use of ethereal solvents [14]. As detailed below, an unsolvated neutral complex was not isolated via this route, and the beryllate anion that was produced instead has structural parallels with previously described -ate complexes of $\mathrm{Zn} \mathrm{[15]} \mathrm{and} \mathrm{Sn} \mathrm{[16].} \mathrm{In} \mathrm{all} \mathrm{of} \mathrm{these} \mathrm{species,} \mathrm{the} \mathrm{alkali} \mathrm{metal}$ counterion, usually $\mathrm{K}^{+}$but sometimes $\mathrm{Na}^{+}$and $\mathrm{Li}^{+}$, appears to play a critical role in the assembly of the symmetric complexes.

\section{Results and Discussion}

\subsection{Solid-State Synthesis}

The reaction of $\mathrm{BeCl}_{2}$ and $\mathrm{K}\left[\mathrm{A}^{\prime}\right]$ was conducted mechanochemically with a planetary ball mill, followed by an extraction with hexanes. Initial investigations used 2:1 molar ratios of $\mathrm{BeCl}_{2}$ and $\mathrm{K}\left[\mathrm{A}^{\prime}\right]$, based on the assumption that the product formed would be $\mathrm{BeA}_{2}{ }_{2}$ (Equation (1)). Although the reagents are off-white $\left(\mathrm{K}\left[\mathrm{A}^{\prime}\right]\right)$ and white $\left(\mathrm{BeCl}_{2}\right)$, the ground reaction mixture $(15 \mathrm{~min} / 600 \mathrm{rpm})$ is orange. Extraction with hexanes, followed by filtration, yielded an orange filtrate and ultimately a dark orange, highly air-sensitive solid (1) on drying.

$$
2 \mathrm{~K}\left[\mathrm{~A}^{\prime}\right]+\mathrm{BeCl}_{2} \stackrel{8}{\longrightarrow} \mathrm{BeA}_{2}^{\prime}+2 \mathrm{KCl}(\text { expected })
$$

A single crystal analysis (described below) revealed that $\mathbf{1}$ is the potassium tris(allyl)beryllate, $\mathrm{K}\left[\mathrm{BeA}_{3}^{\prime}\right]$. This forms in spite of the fact that the 2:1 ratio of reagents used is not optimum for its production. As detailed below, conducting the reaction with 1:1 and 3:1 molar ratios of $\mathrm{K}\left[\mathrm{A}^{\prime}\right]$ and $\mathrm{BeCl}_{2}$ 
still yields 1 as the sole hexane-extractable product. It is possible that the excess halide is captured in the form of polyhalide anions such as $\left[\mathrm{BeCl}_{4}\right]^{2-}$ or $\left[\mathrm{Be}_{2} \mathrm{Cl}_{6}\right]^{2-}[17]$, although these have not been definitively identified.

\subsection{Synthesis in Solution}

The reaction of $\mathrm{K}\left[\mathrm{A}^{\prime}\right]$ and $\mathrm{BeCl}_{2}$ was also examined in solution, using diethyl ether and hexanes. These results are summarized in Table 1. Previous reactions with diethyl ether involved stirring for $2 \mathrm{~h}$ at room temperature, which formed $\mathrm{BeA}_{2}^{\prime} \cdot \mathrm{OEt}_{2}$ from a 2:1 reaction (\#5); Schlenk equilibrium was observed in a 1:1 mixture that was allowed to react for one hour (\#4). When the 2:1 reaction in $\mathrm{Et}_{2} \mathrm{O}$ is allowed to proceed for $16 \mathrm{~h}$, however, the formation of $\mathbf{1}$ is observed (\#6) exclusively. Reaction in hexanes mimics the solid-state reactions, in that $\mathbf{1}$ is the exclusively detected organoberyllium product from a 1:1 reaction after $1 \mathrm{~h}(\# 7)$. Longer reactions and a higher ratio of $\mathrm{K}\left[\mathrm{A}^{\prime}\right]$ to $\mathrm{BeCl}_{2}$ (e.g., 3:1) do not change this outcome.

Table 1. Summary of $\mathrm{K}\left[\mathrm{A}^{\prime}\right]$ and $\mathrm{BeCl}_{2}$ reactions; amounts of reagents given as molar ratios.

\begin{tabular}{cccccc}
\hline No. & $\mathbf{K}\left[\mathbf{A}^{\prime}\right]: \mathbf{B e C l}_{\mathbf{2}}$ & Medium $^{a}$ & Time & Organoberyllium Product(s) & Yield $\mathbf{( \% )}^{\boldsymbol{b}}$ \\
\hline 1 & $1: 1$ & 8 & $15 \mathrm{~min}$ & $\mathrm{~K}\left[\mathrm{BeA}_{3}^{\prime}\right]$ & 97 \\
2 & $2: 1$ & 8 & $15 \mathrm{~min}$ & $\mathrm{~K}\left[\mathrm{BeA}_{3}^{\prime}\right]$ & 21 \\
3 & $3: 1$ & 8 & $15 \mathrm{~min}$ & $\mathrm{~K}\left[\mathrm{BeA}_{3}^{\prime}\right]$ & 25 \\
4 & $1: 1$ & $\mathrm{Et}_{2} \mathrm{O}$ & $1 \mathrm{~h}$ & $2^{\prime} \mathrm{BeCl} \rightleftarrows \mathrm{BeA}_{2}^{\prime}+\mathrm{BeCl}$ & $\mathrm{n} / \mathrm{a}^{c, d}$ \\
5 & $2: 1$ & $\mathrm{Et}_{2} \mathrm{O}$ & $2 \mathrm{~h}$ & $\mathrm{BeA}_{2}^{\prime} \cdot \mathrm{OEt}_{2}$ & $77^{c}$ \\
6 & $2: 1$ & $E_{2} \mathrm{O}$ & $16 \mathrm{~h}$ & $\mathrm{~K}\left[\mathrm{BeA}_{3}^{\prime}\right]$ & 98 \\
7 & $1: 1$ & hexanes & $1 \mathrm{~h}$ & $\mathrm{~K}\left[\mathrm{BeA}_{3}^{\prime}\right]$ & 24 \\
\hline
\end{tabular}

a 8 = ball milling at $600 \mathrm{rpm}$. The symbol for mechanical milling has been proposed in ref. [14]; ${ }^{b}$ Unrecrystallized; limiting reagent taken into account; ${ }^{c}$ Ref. $[11] ;{ }^{d}$ Products were observed with ${ }^{9} \mathrm{Be}$ NMR, and were not isolated.

\subsection{NMR Spectroscopy}

The ${ }^{1} \mathrm{H}$ NMR spectrum of $\mathbf{1}$ displays resonances typical of a " $\pi$-bound" $\mathrm{A}^{\prime}$ ligand, with a triplet representing $\mathrm{H}_{(\beta)}$, a broad resonance $\left(v_{1 / 2}=39 \mathrm{~Hz}\right.$, presumably an unresolved doublet) representing the equivalent $\mathrm{H}_{(\alpha)}$ and $\mathrm{H}_{(\gamma)}$, and a singlet for the two equivalent trimethylsilyl groups (Figure 1). The appearance of such a symmetric spectrum even when $\sigma$-bound ligands are expected is consistent with a high degree of fluxionality, as was also observed in the $\sigma$-bound complex $\mathrm{BeA}_{2}^{\prime} \cdot\left(\mathrm{Et}_{2} \mathrm{O}\right)$ [11]. The triplet resonance of the allyl ligands, at $\delta 6.97$, is shifted downfield from that of $\mathrm{BeA}_{2}^{\prime} \cdot\left(\mathrm{Et}_{2} \mathrm{O}\right)(\delta 6.53)$; the resonance at $\delta 3.19$ is slightly upfield (cf. $\delta 3.33$ in $\mathrm{BeA}_{2}^{\prime} \cdot\left(\mathrm{Et}_{2} \mathrm{O}\right)$ ). The NMR chemical shifts for $\mathbf{1}$ are in line with those observed for other $\mathrm{M}\left[\mathrm{M}^{\prime} \mathrm{A}_{3}^{\prime}\right]$ complexes (Table 2). In particular, the NMR shifts of the allyl ligands are sensitive both to the identity of the central divalent metal and to that of alkali metal counterion, evidence that the compounds exist as contact ion pairs in solution. Compound 1 and $\mathrm{K}\left[\mathrm{ZnA}_{3}^{\prime}\right]$ share the greatest similarities, which may reflect their having the same counterion $\left(\mathrm{K}^{+}\right)$ and central metals of similar electronegativity ( $\chi$ Be (1.57); Zn (1.65)) [18].

John and co-workers have demonstrated that ${ }^{9} \mathrm{Be}$ NMR chemical shift values can be diagnostic for coordination numbers in solution [19]. Typically, organoberyllium complexes with low formal coordination numbers, such as $\mathrm{BeMe}_{2} \cdot \mathrm{Et}_{2} \mathrm{O}$ (coordination number 3, $\delta 20.8 \mathrm{ppm}$ in $\mathrm{Et}_{2} \mathrm{O}$ ), are observed well downfield of 0 ppm. $\mathrm{BeA}_{2}^{\prime} \cdot\left(\mathrm{Et}_{2} \mathrm{O}\right)$ has a ${ }^{9} \mathrm{Be}$ chemical shift of $818.2 \mathrm{ppm}$, which is consistent with a three-coordinate geometry in solution [11]. It should be noted, however, that the correlation between coordination number and ${ }^{9} \mathrm{Be}$ chemical shift is not exact, and can be strongly influenced by the electronic properties of the ligands. The 2-coordinate complex beryllium bis( $N, N^{\prime}$-bis(2,6-diisopropylphenyl)-1,3,2-diazaborolyl), for example, has an extreme downfield shift of $\delta 44 \mathrm{ppm}$ [20], whereas the 2-ccordinate $\mathrm{Be}\left(\mathrm{N}\left(\mathrm{SiMe}_{3}\right)_{2}\right.$ displays a ${ }^{9} \mathrm{Be}$ NMR shift at $\delta 12.3$ ppm [4]. Nevertheless, the ${ }^{9} \mathrm{Be}$ of $\mathbf{1}$ is at $\delta 22.8 \mathrm{ppm}$, which to our knowledge is the most positive shift yet reported for a three-coordinate species. DFT methods were used to predict 
the ${ }^{9} \mathrm{Be}$ chemical shift value of 1 (B3LYP-D3/6-311+G(2d,p)//B3LYP-D3/6-31G(d)). It was calculated at $\delta 25.9 \mathrm{ppm}$, in reasonable agreement with the observed value (referenced to $\left[\mathrm{Be}\left(\mathrm{OH}_{2}\right)_{4}\right]^{2+}$ with an isotropic shielding constant of $108.98 \mathrm{ppm}$ ).

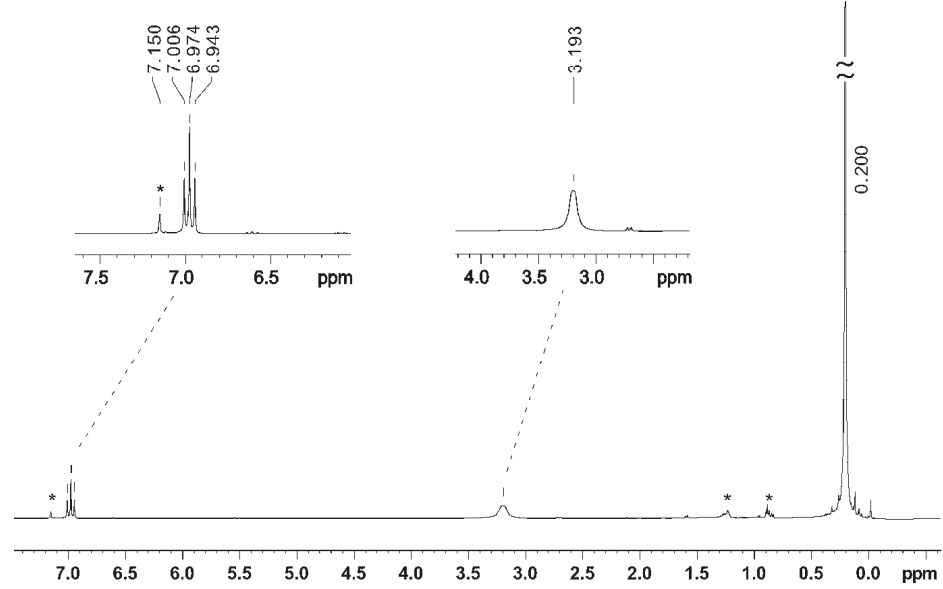

Figure 1. ${ }^{1} \mathrm{H}$ NMR spectrum (500 Mhz) of isolated 1, recorded in $\mathrm{C}_{6} \mathrm{D}_{6}$. The starred peaks represent impurities: $\delta 7.15$ (residual protons of $\mathrm{C}_{6} \mathrm{D}_{6}$ ); $\delta 0.9$ and $\delta 1.3$, residual hexanes.

Table 2. ${ }^{1} \mathrm{H}$ NMR shifts (ppm) and bond distances in $\mathrm{M}\left[\mathrm{M}^{\prime} \mathrm{A}_{3}^{\prime}\right]$ complexes.

\begin{tabular}{ccccccc}
\hline Complex & $\delta \mathbf{H}_{(\alpha)} / \mathbf{H}_{(\gamma)}$ & $\delta \mathbf{H}_{(\beta)}$ & $\delta \mathbf{S i M e}_{3}$ & $\mathbf{M}-\mathbf{C}(\sigma) \AA$ & $\mathbf{M}^{\prime} \cdots \mathbf{C}($ olefin) $\AA$ & Ref. \\
\hline $\mathrm{Li}\left[\mathrm{ZnA}_{3}^{\prime}\right]$ & 6.46 & 3.50 & 0.15 & $2.117(3)^{b}$ & $2.745(4), 2.268(3)^{b}$ & {$[15]$} \\
$\mathrm{Na}\left[\mathrm{ZnA}_{3}^{\prime}\right]$ & 7.59 & 4.00 & 0.16 & $2.103(3)$ & $2.857(3), 2.567(3)$ & {$[15]$} \\
$\left.\mathrm{K}_{3} \mathrm{BeA}_{3}^{\prime}\right]$ & 6.97 & 3.19 & 0.20 & $1.805(10)$ & $3.153(7), 2.940(7)$ & this work \\
$\left.\mathrm{K}_{\mathrm{ZnA}}^{\prime}{ }_{3}\right]$ & 7.05 & 3.42 & 0.23 & $2.068(4)$ & $3.205(3), 2.945(3)$ & {$[15]$} \\
$\mathrm{K}(\mathrm{thf})\left[\mathrm{SnA}_{3}^{\prime}\right]$ & 6.43 & 4.42 & $0.42,0.23^{a}$ & $2.344(7)$ & $3.201(7), 3.164(8), 3.065(8)$ & {$[16]$} \\
\hline
\end{tabular}

${ }^{a}$ Two resonances are observed for the $\mathrm{SiMe}_{3}$ groups, as the $\mathrm{A}^{\prime}$ ligands are not fluxional; ${ }^{b}$ Distance(s) affected by crystallographic disorder.

\subsection{Solid State Structure}

The structure of 1 was determined from single crystal $X$-ray diffraction. In the solid state, 1 exhibits approximate $C_{3}$-symmetry, with $\sigma$-bound $\mathrm{A}^{\prime}$ ligands and a potassium cation engaging in cation- $\pi$ interactions with the three double bonds of the allyls. It is isostructural with the previously reported $M\left[\mathrm{ZnA}_{3}^{\prime}\right](M=\mathrm{Li}, \mathrm{Na}, \mathrm{K})$ and $\mathrm{K}(\mathrm{thf})\left[\mathrm{SnA}_{3}{ }_{3}\right]$ complexes $[15,16]$. The beryllium center is in a nearly planar trigonal environment (sum of $\mathrm{C}-\mathrm{Be}-\mathrm{C}^{\prime}$ angles $=357.7^{\circ}$ ) (Figure 2).

The average Be-C distance of 1.805(10) Å has few direct points of comparison with other molecules, as $\mathbf{1}$ is only the second crystallographically characterized $\left[\mathrm{BeR}_{3}\right]^{-}$complex, the other being lithium tri-tert-butylberyllate [21]. The latter's Be center, like that in $\mathbf{1}$, is in a nearly perfectly planar trigonal environment (sum of $\mathrm{C}-\mathrm{Be}-\mathrm{C}$ angles $=359.9^{\circ}$ ). In the solid state, however, tri-tert-butylberyllate is a dimer, $\left[\mathrm{Li}\left\{\mathrm{Be}\left(t-\mathrm{C}_{4} \mathrm{H}_{9}\right)_{3}\right\}\right]_{2}$, with some corresponding distortions in the $\mathrm{Be}-\mathrm{C}$ bond lengths; Be-C distances range from 1.812(4) $\AA$ to 1.864(4) $\AA$, averaging to 1.843(6) $\AA$. The Be-C length in 1 is indistinguishable from the $\mathrm{Be}-\mathrm{C}_{\text {carbene }}$ length of $1.807(4) \AA$ in the $\left[\mathrm{Ph}_{2} \mathrm{Be}(\mathrm{IPr})\right](\mathrm{IPr}=1,3-\mathrm{bis}(2,6-$ di-isopropylphenyl)-imidazol-2-ylidene) complex, which also has a three-coordinate Be center [22]. The anionic methyl groups in $\left[\mathrm{Ph}_{2} \mathrm{Be}(\mathrm{IPr})\right]$ are at a noticeably shorter distance, however (1.751(6) $\AA$, ave.). A similar relationship between the $\mathrm{Be}-\mathrm{C}_{\text {carbene }}$ and $\mathrm{Be}-\mathrm{CH}_{3}$ bond lengths exists in the related $\left[\mathrm{Me}_{2} \mathrm{Be}(\mathrm{IPr})\right][23]$ and $\left[\mathrm{Me}_{2} \mathrm{Be}(\mathrm{IMes})\right]$ (IMes $=N, N^{\prime}$-bis(2,4,6-trimethylphenyl)imidazol-1-ylidene) 
complexes [1]. A comparison of the Be-C length in $\mathbf{1}$ could also be made with the Be-C distance of $1.84 \AA$ in lithium tetramethylberyllate, $\mathrm{Li}_{2}\left[\mathrm{BeMe}_{4}\right]$, although the bond distance would be expected to be slightly longer in the latter owing to the higher coordination number of beryllium and the greater negative charge [24].

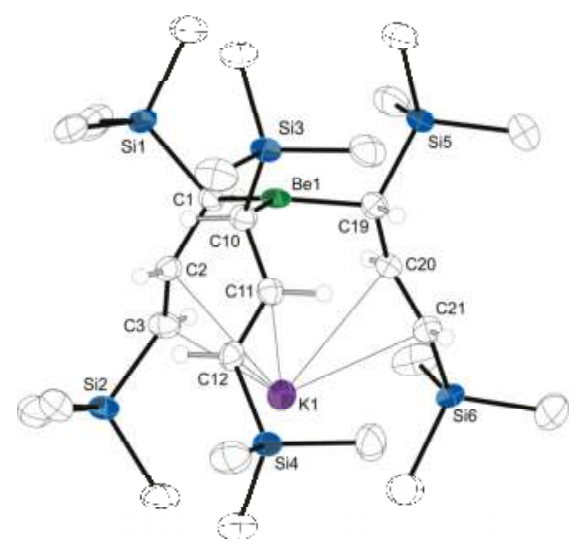

Figure 2. Thermal ellipsoid plot of 1, illustrating the numbering scheme used in the text. Ellipsoids are drawn at the $50 \%$ level, and for clarity, hydrogen atoms have been removed from the trimethylsilyl groups. Selected bond distances $(\AA)$ and angles (deg): Be1-C1, 1.795(6); Be1-C10, 1.810(6); Be1-C19, 1.811(6); C(2)-C(3), 1.351(5); C(11)-C(12), 1.350(5); C(20)-C(21), 1.358(5); K(1)-C(2), 3.138(4); $\mathrm{K}(1)-\mathrm{C}(3), 2.940(4) ; \mathrm{K}(1)-\mathrm{C}(11), 3.206(4) ; \mathrm{K}(1)-\mathrm{C}(12), 2.943(4) ; \mathrm{K}(1)-\mathrm{C}(20), 3.114(4) ; \mathrm{K}(1)-\mathrm{C}(21), 2.938(4)$; C(1)-Be(1)-C(10), 119.1(3); C(1)-Be(1)-C(19), 119.0(3); C(10)-Be(1)-C(19), 119.4(3).

The $C-C$ and $C=C$ bonds in the alkyl groups in 1 are localized at 1.475(5) $\AA$ and 1.353(9) $\AA$, respectively. The $\mathrm{K}^{+} \ldots \mathrm{C}$ (olefin) contacts average 3.153(7) $\AA$ and 2.940(7) $\AA$ to the carbon atoms $\beta$ $(\mathrm{C} 2, \mathrm{C} 11$, and $\mathrm{C} 20)$ and $\gamma(\mathrm{C} 3, \mathrm{C} 12$, and $\mathrm{C} 21)$ to the beryllium atom, respectively. These distances are comparable to, but slightly shorter than, the range of $\mathrm{K}^{+} \ldots \mathrm{C}$ contacts found in the related zincate structure (3.205(3) $\AA$ and 2.945(3) $\AA$, respectively), which reflects the shorter $\mathrm{M}-\mathrm{C}_{(\alpha)}$ bonds in 1 . The distance between Be and K (3.59 $)$ is long enough to rule out significant metal-metal interactions.

\subsection{Computational Investigations}

It has previously been suggested that the occurrence of $C_{3}$-symmetric $M\left[M^{\prime} \mathrm{A}_{3}^{\prime} \mathrm{L}\right]\left(M^{\prime}=\mathrm{Zn}, M=\mathrm{Li}\right.$, $\mathrm{Na}, \mathrm{K} ; M^{\prime}=\mathrm{Sn}, M=\mathrm{K} ; \mathrm{L}=\mathrm{thf}$ ) complexes is the result of a templating effect of the associated alkali metal counterion [25]. The rationale for this proposal is that the neutral $M^{\prime}{ }_{3}(M=\mathrm{As}, \mathrm{Sb}, \mathrm{Bi})$ complexes always occur in two diastereomeric forms, with $R, R, R$ (equivalently, $S, S, S$ ) and $R, R, S$ (or $S, S, R$ ) arrangements of the allyl ligands around the central element. The anionic $\left[\mathrm{MA}_{3}{ }^{\prime}\right]^{-}$complexes, in contrast, are always found in the $C_{3}$-symmetric $R, R, R$ (or $S, S, S$ ) configuration, and it is not unreasonable to assume that the counterion is responsible for the difference.

A DFT investigation was undertaken to explore the possible origins of this effect. The geometry of the free $\left[\mathrm{BeA}_{3}^{\prime}\right]^{-}$anion was optimized with calculations employing the dispersion-corrected APF-D functional [26]. Three confirmations were examined: the $C_{3}$-symmetric form $(S, S, S)$ found in the X-ray crystal structure of 1 , a related $S, S, S$ form with one $A^{\prime}$ ligand rotated antiparallel to the other two ( $C_{1}$ symmetry), and a $R, R, S$ form, also with one ligand antiparallel to the other two, derived from the structure of the neutral $\mathrm{AlA}_{3}^{\prime}$ complex (Figure 3) [27]. 


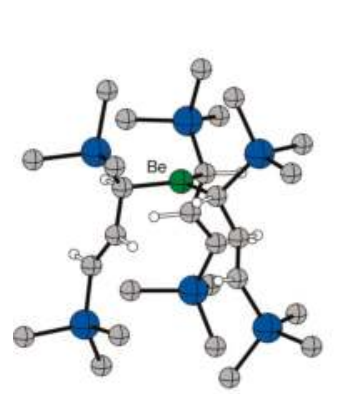

a

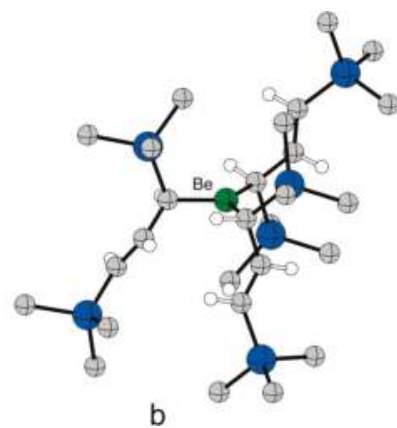

b

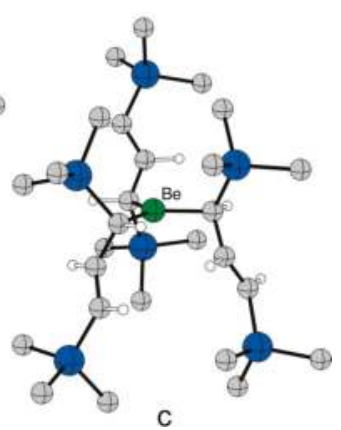

C

Figure 3. Geometry optimized structures of $\left[\mathrm{BeA}_{3}\right]^{-}$anions: (a) as found in the crystal structure of $\mathbf{1}$; (b) related $S, S, S$ form with one $\mathrm{A}^{\prime}$ ligand rotated ( $C_{1}$ symmetry); and (c) $R, R, S$ form derived from the structure of $\mathrm{AlA}_{3}^{\prime}$.

Not surprisingly, the calculated structures possess similar average Be-C bond lengths, ranging from $1.782 \AA$ (the $C_{3}$-symmetric form (Figure 3a)) to $1.788 \AA$ (for the rotated $S, S, S$ form (Figure $3 \mathrm{~b})$ ). Energetically, the $R, R, S$ form is the most stable; the rotated $S, S, S$ form is $10.1 \mathrm{~kJ} \cdot \mathrm{mol}^{-1}$ higher in energy $\left(\Delta G^{\circ}\right)$, and the $C_{3}$-symmetric form is higher still $\left(20.3 \mathrm{~kJ} \cdot \mathrm{mol}^{-1}\right.$ in $\left.\Delta \mathrm{G}^{\circ}\right)$. The origin of these energy differences is not immediately obvious, but it may be related to the relative amounts of interligand congestion present. The low energy $R, R, S$ form, for example, has no Me $\cdots \mathrm{Me}^{\prime}$ contacts less than $4.0 \AA$, the sum of the van der Waals radii [18]. In contrast, the $C_{3}$ symmetric form has multiple contacts between methyl groups of less than $4.0 \AA$, including two as short as $3.76 \AA$. At this level of theory, the energetics of the free anions do not provide a rationale for the exclusive formation of the $S, S, S$ form.

Not surprisingly, incorporation of the $\mathrm{K}^{+}$ion into the complex alters the relative stability of the species. The optimized geometries of the $C_{3}$-symmetric $\mathrm{K}\left[\mathrm{BeA}_{3}\right]$ found in the $\mathrm{X}$-ray crystal structure of 1 and a related $S, S, R$ form were calculated similarly to the isolated anions, and are depicted in Figure 4 .
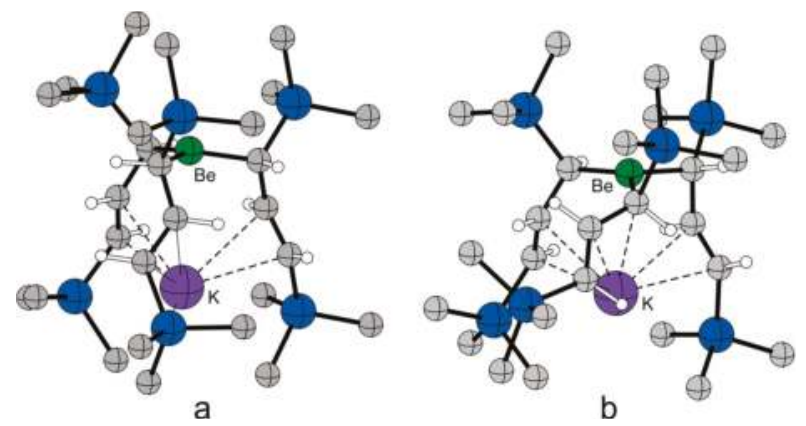

Figure 4. Geometry optimized structures of the $\mathrm{K}\left[\mathrm{BeA}_{3}{ }_{3}\right]$ complex: (a) as found in the crystal structure of $\mathbf{1}$; and (b) related $S, S, R$ form.

The $C_{3}$-symmetric form is $6.1 \mathrm{~kJ} \cdot \mathrm{mol}^{-1}$ more stable than the $S, S, R$ form. This is not a consequence of closer $\mathrm{K}^{+} \ldots(\mathrm{C}=\mathrm{C})$ distances, which are nearly the same (avg. $3.91 \AA$ in the $C_{3}$ form; $2.86 \AA$ in the $S, S, R$ arrangement). The asymmetric arrangement of the ligands in the $S, S, R$ form does lead to closer interligand $C \cdots C$ contacts in the allyl frameworks, however, as small as $3.37 \AA$, whereas there are no similar contacts less than $3.78 \AA$ in the $C_{3}$ form. The somewhat greater stability of the $C_{3}$ form, possibly coupled with greater ease of crystal packing, may contribute to the exclusive appearance of 
that form in the crystal structure. It is likely that a similar analysis holds for the isostructural $\mathrm{Zn}$ and Sn complexes.

The failure to produce an unsolvated $\mathrm{BeA}_{2}{ }_{2}$ in the absence of a coordinating solvent (i.e., either mechanochemically or in hexanes) was also examined computationally with the aid of the Solid-G program [28]. Both $\mathrm{BeA}_{2}^{\prime} \cdot \mathrm{Et}_{2} \mathrm{O}$ and $\mathbf{1}$ are found to have coordination sphere coverage $\left(\mathrm{G}_{\text {complex }}\right.$ ) above $90 \%$ (i.e., $97.0 \%$ (Figure $5 \mathrm{a}$ ) and $92.6 \%$ (Figure $5 \mathrm{~b}$ ), respectively). Although the coverage of the metal center in the hypothetical $\mathrm{BeA}^{\prime}{ }_{2}$ varies somewhat with the angle between the ligands, the minimum energy position depicted in Figure $5 c$ ( $C_{2}$ symmetry) has only $78.7 \%$ coverage. It is not unreasonable to assume that a monomeric $\mathrm{BeA}_{2}{ }_{2}$ may be too coordinately unsaturated to be readily isolable, and will bind an ethereal solvent molecule during synthesis, or, if that is not available, an additional $\mathrm{A}^{\prime}$ ligand, counterbalanced with a $\mathrm{K}^{+}$ion.

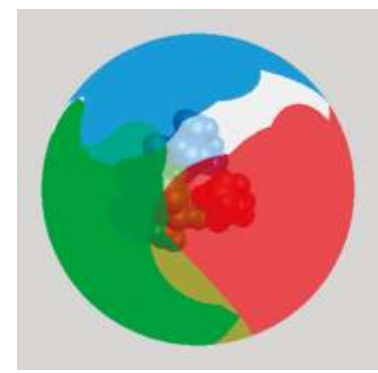

(a)

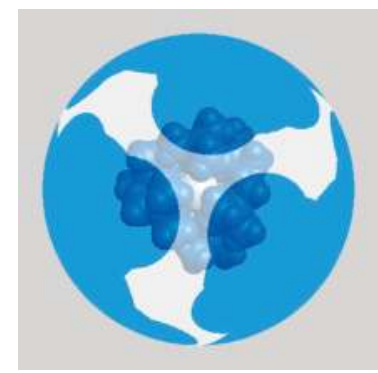

(b)

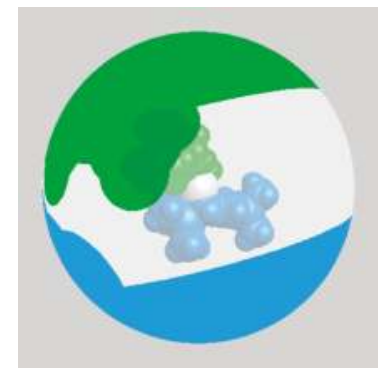

(c)

Figure 5. Visualization of the extent of coordination sphere coverage $\left(\mathrm{G}_{\text {complex }}\right)$ of: (a) $\mathrm{BeA}_{2}^{\prime} \cdot \mathrm{Et}_{2} \mathrm{O}$ (the coverage from the two allyls are assigned blue and green; that from the ether is in red); (b) 1 (all three allyls are in blue); and (c) $\mathrm{BeA}_{2}^{\prime}$, using optimized coordinates (APF-D/6-311G(2d) (Be); 6-31G(d) (other atoms)) and the program Solid-G [28]. The $\mathrm{G}_{\text {complex }}$ value takes into account the net coverage; regions of the coordination sphere where the projections of the ligands overlap are counted only once.

\section{Materials and Methods}

General Considerations: All syntheses were conducted under rigorous exclusion of air and moisture using Schlenk line and glovebox techniques. (NOTE: Beryllium salts are toxic and should be handled with appropriate protective equipment.) After grinding was completed, the jars were opened according to glovebox procedures to protect the compounds and to prevent exposure to dust [10]. Proton $\left({ }^{1} \mathrm{H}\right)$ and carbon $\left({ }^{13} \mathrm{C}\right)$ spectra were obtained on Bruker DRX-500 or DRX-400 spectrometers (Karlsruhe, Germany), and were referenced to residual resonances of $\mathrm{C}_{6} \mathrm{D}_{6}$. Beryllium $\left({ }^{9} \mathrm{Be}\right)$ spectra were obtained on a Bruker DRX-500 at 70.2 MHz, and were referenced to $\mathrm{BeSO}_{4}(\mathrm{aq})$. Combustion analysis was performed by ALS Environmental, Tucson, AZ, USA. Beryllium chloride was purchased from Strem, stored under an $\mathrm{N}_{2}$ atmosphere and used as received. The $\mathrm{K}\left[\mathrm{A}^{\prime}\right]\left(\mathrm{A}^{\prime}=1,3-\left(\mathrm{SiMe}_{3}\right)_{2} \mathrm{C}_{3} \mathrm{H}_{3}\right)$ reagent was synthesized as previously described $[29,30]$. Toluene, hexanes, and diethyl ether were distilled under nitrogen from potassium benzophenone ketyl [31]. Deuterated benzene $\left(\mathrm{C}_{6} \mathrm{D}_{6}\right)$ was distilled from $\mathrm{Na} / \mathrm{K}(22 / 78)$ alloy prior to use. Stainless steel (440 grade) ball bearings $(6 \mathrm{~mm}$,) were thoroughly cleaned with hexanes and acetone prior to use. Planetary milling was performed with a Retsch model PM100 mill (Haan, Germany), $50 \mathrm{~mL}$ stainless steel grinding jar type C, and safety clamp for air-sensitive grinding.

\subsection{Mechanochemical Synthesis of $K\left[B e A_{3}^{\prime}\right]$ (1)}

Solid $\mathrm{BeCl}_{2}$ (56.7 mg, $0.71 \mathrm{mmol}$ ) and $\mathrm{K}^{\mathrm{A}}$ ] $(319 \mathrm{mg}, 1.42 \mathrm{mmol}$ ) were added to a $50 \mathrm{~mL}$ stainless steel grinding jar (type C). The jar was charged with stainless steel ball bearings (6 mm dia, 50 count) 
and closed tightly with the appropriate safety closer device under an $\mathrm{N}_{2}$ atmosphere. The reagents were milled for $15 \mathrm{~min}$ at $600 \mathrm{rpm}$, resulting in a light orange solid. The product was extracted under an inert atmosphere with minimal hexanes $(<100 \mathrm{~mL})$ and filtered through a medium porosity ground glass frit, providing a dark orange filtrate. Drying under vacuum yielded a dark orange solid (61.5 mg, $21 \%$ yield of $\left.\mathrm{K}_{\left[\mathrm{BeA}^{\prime}\right.}\right]$ ) which was recrystallized by the slow evaporation of toluene over one month to provide dark orange-brown crystals of 1 suitable for single crystal X-ray diffraction. For a 3:1 $\mathrm{K}\left[\mathrm{A}^{\prime}\right]: \mathrm{BeCl}_{2}$ reaction, $812 \mathrm{mg}(3.62 \mathrm{mmol}) \mathrm{K}\left[\mathrm{A}^{\prime}\right]$ and $95.2 \mathrm{mg}(1.19 \mathrm{mmol}) \mathrm{BeCl}_{2}$ were added to a grinding jar. After extraction, $183 \mathrm{mg}$ ( $25 \%$ yield) of orange solid was collected. Anal. Calcd. (\%) for $\mathrm{C}_{27} \mathrm{H}_{63} \mathrm{BeKSi}_{6}$ : C, 53.65; H, 10.51; Be, 1.49. Found: C, 52.09; H, 9.79; Be, 1.04. The values are somewhat low, possibly from the high air-sensitivity of the compound, but the $\mathrm{C}: \mathrm{H}$ molar ratio is 2.34:1.00, close to the expected 2.33:1.00. ${ }^{1} \mathrm{H}$ NMR $\left(500 \mathrm{MHz}, \mathrm{C}_{6} \mathrm{D}_{6}, 298 \mathrm{~K}\right): \delta 0.20\left(\mathrm{~s}, 54 \mathrm{H}, \mathrm{SiMe}_{3}\right) ; 3.19$ (br s $\left(v_{1 / 2}=39 \mathrm{~Hz}\right)$, $\left.6 \mathrm{H}, \mathrm{H}_{(\alpha, \gamma)}\right) ; 6.97\left(\mathrm{t}, 3 \mathrm{H}, J_{1}=16 \mathrm{~Hz}, \mathrm{H}_{(\beta)}\right) .{ }^{13} \mathrm{C} \mathrm{NMR}\left(100 \mathrm{MHz}, \mathrm{C}_{6} \mathrm{D}_{6}, 298 \mathrm{~K}\right): \delta 1.02\left(\mathrm{~s}, \mathrm{SiMe}_{3}\right) ; 70.71(\mathrm{~s}$, $\left.\mathrm{C}_{(\alpha, \gamma)}\right) ; 166.09\left(\mathrm{~s}, \mathrm{C}_{(\beta)}\right) .{ }^{9} \mathrm{Be} \operatorname{NMR}\left(70.2 \mathrm{MHz}, \mathrm{C}_{6} \mathrm{D}_{6}, 298 \mathrm{~K}\right) ; \delta 22.8(\mathrm{~s})\left(v_{1 / 2}=360 \mathrm{~Hz}\right)$.

\subsection{General Procedures for Synthesis of $K\left[\mathrm{BeA}_{3}{ }_{3}\right](1)$ with Solvents}

Reactions were performed for either 1 or $16 \mathrm{~h}$, and were run under inert atmosphere at room temperature. The ratio of $\mathrm{K}\left[\mathrm{A}^{\prime}\right]$ and $\mathrm{BeCl}_{2}$ was varied such that the reactions of emphasis were $1: 1$, 2:1, and 3:1. A general reaction involved dissolving the beryllium chloride (ca. $0.1 \mathrm{~g}$ ) in the solvent of choice (Et ${ }_{2} \mathrm{O}$ or hexanes); to this solution solid $\mathrm{K}\left[\mathrm{A}^{\prime}\right]$ was added slowly and solvent was used to quantitatively transfer all material. Upon mixing, the solution was allowed to stir for the given time. In the case of $\mathrm{Et}_{2} \mathrm{O}$, the solvent was removed in vacuo, and the resulting material was extracted with hexanes, filtered through a medium porosity glass frit, and then dried in vacuo. In the case of reaction in hexanes, the reaction mixture was filtered through a medium porosity fritted glass filter, and the hexane was removed in vacuo. The resulting material in all cases was then analyzed with ${ }^{1} \mathrm{H}$ and ${ }^{9} \mathrm{Be}$ NMR.

\subsection{Procedures for X-ray Crystallography}

A crystal $\left(0.20 \times 0.20 \times 0.08 \mathrm{~mm}^{3}\right)$ was placed onto the tip of a thin glass optical fiber and mounted on a Bruker SMART APEX II CCD platform diffractometer (Karlsruhe, Germany) for a data collection at 100.0(5) K [32]. The structure was solved using SIR2011 [33] and refined using SHELXL-2014/7 [34]. The space group $P \overline{1}$ was determined based on intensity statistics. A direct-methods solution was calculated that provided most non-hydrogen atoms from the E-map. Full-matrix least squares/difference Fourier cycles were performed which located the remaining non-hydrogen atoms. All non-hydrogen atoms were refined with anisotropic displacement parameters. The allylic hydrogen atoms were found from the difference Fourier map and refined freely. All other hydrogen atoms were placed in ideal positions and refined as riding atoms with relative isotropic displacement parameters.

\subsection{General Procedures for Calculations}

All calculations were performed with the Gaussian 09W suite of programs [35]; an ultrafine grid was used for all cases (Gaussian keyword: int = ultrafine). Each conformation of the $\left[\mathrm{BeA}_{3}^{\prime}\right]^{-}$ complexes was studied with the APF-D functional, a global hybrid with $23 \%$ exact exchange [26]. The $6-31+\mathrm{G}(\mathrm{d})$ basis set was used for $\mathrm{C}, \mathrm{H}, \mathrm{Si}$; the $6-311+\mathrm{G}(2 \mathrm{~d})$ basis was used for Be. For the neutral $\mathrm{K}\left[\mathrm{BeA}_{3}^{\prime}\right]$ conformations, the APF-D functional was used with the 6-31G(d) basis set for C,H,Si; $6-311 G(2 d)$ was used for Be and $\mathrm{K}$. The nature of the stationary points was determined with analytical frequency calculations; all of these optimized geometries were found to be minima $\left(N_{\text {imag }}=0\right)$. For the Solid-G calculations, the structures were preoptimized with the APF-D/6-311G(2d) (Be,K); 6-31G(d) $(\mathrm{C}, \mathrm{H}, \mathrm{Si})$ protocol. 


\section{Conclusions}

The generation of products from reagents that are not in the optimum stoichiometric ratio is a known feature of some Group 2 reactions [36,37], a testament to the role that kinetic factors play in s-block chemistry. It is perhaps not surprising that when mechanochemical activation is used with alkaline earth reagents, a nonstoichiometric product such as the organoberyllate $\mathbf{1}$ is formed, as grinding and milling environments are often far from equilibrium [38-41]. However, the fact that 1 is also generated in hexanes indicates how non-ethereal synthesis can reveal features of reactions that are obscured when they are conducted in coordinating solvents. It is now apparent that the production of the previously described $\mathrm{BeA}_{2}{ }_{2} \cdot \mathrm{Et}_{2} \mathrm{O}$, which was the expected complex from a 2:1 reaction of $\mathrm{K}\left[\mathrm{A}^{\prime}\right]$ and $\mathrm{BeCl}_{2}$ in diethyl ether [11], actually depends critically on the presence of the solvent to prevent further reaction of the beryllium center with an additional $\mathrm{A}^{\prime}$ ligand. (In a preliminary study, the reaction of $\mathrm{K}\left[\mathrm{A}^{\prime}\right]$ and $\mathrm{BeCl}_{2}$ in a 2:1 molar ratio in THF $(1 \mathrm{~h})$ was found not to produce $\mathrm{K}\left[\mathrm{BeA}_{3}^{\prime}\right]$. A species with a ${ }^{9} \mathrm{Be} \mathrm{NMR}$ shift of $\delta 16.6 \mathrm{ppm}$ was present instead, tentatively identified as $\mathrm{BeA}_{2}^{\prime}$ (thf). If correct, this indicates that $\mathrm{THF}$, like $\mathrm{Et}_{2} \mathrm{O}$, can block the formation of the tris(allyl) anion with $\mathrm{Be}$ ). Without such ethereal solvent support, whether conducted mechanochemically or in hexanes, the reaction between $\mathrm{K}\left[\mathrm{A}^{\prime}\right]$ and $\mathrm{BeCl}_{2}$ rapidly forms the kinetic product $\mathbf{1}$.

Parallels of the beryllium chemistry to the related tris(allyl) -ate complexes of $\mathrm{Zn}$ and Sn are instructive, although they cannot be pushed too far. All the $\left[\mathrm{MA}_{3}\right]^{-}$species possess approximate $C_{3}$ symmetry, and it is likely that the associated alkali metal cation is intimately involved in templating their constructions. The formation of the zinc species $\mathrm{K}\left[\mathrm{ZnA}^{\prime}{ }_{3}\right]$ is also similar to that of $\mathbf{1}$ in that it is formed from the reaction of 2 equiv. of $\mathrm{K}\left[\mathrm{A}^{\prime}\right]$ and $\mathrm{ZnCl}_{2}$, i.e., in a non-stoichiometric reaction [15]. However, both it and $\mathrm{K}(\mathrm{thf})\left[\mathrm{SnA}_{3}^{\prime}\right]$ are synthesized in THF, so it is clear that the driving force for -ate formation compared to that for the neutral $(\mathrm{Zn}, \mathrm{Sn}) \mathrm{A}_{2}^{\prime}$ species is greater than that for 1 . This may reflect the somewhat lesser covalency of Be-C versus $\mathrm{Zn}-\mathrm{C}$ and $\mathrm{Sn}-\mathrm{C}$ bonds, and the greater robustness of $\mathrm{M}^{2+} \leftarrow: \mathrm{OR}_{2}$ interactions with beryllium.

Supplementary Materials: The following are available online at http://www.mdpi.com/2304-6740/5/2/36/s1: CIF and checkCIF file, and fractional coordinates of geometry-optimized structures.

Acknowledgments: Financial support by the National Science Foundation (CHE-1112181), The American Chemical Society-Petroleum Research Fund (56027-ND3), and a Discovery Grant of Vanderbilt University is gratefully acknowledged.

Author Contributions: The project concept was devised equally by all authors. Nicholas C. Boyde and Nicholas R. Rightmire performed the experiments and analyzed the resulting data. William W. Brennessel obtained and solved the single crystal X-ray data. The manuscript was written by Timothy P. Hanusa, with contributions from all the co-authors.

Conflicts of Interest: The authors declare no conflict of interest.

\section{References}

1. Arrowsmith, M.; Hill, M.S.; Kociok-Köhn, G. Activation of N-Heterocyclic Carbenes by $\left\{\mathrm{BeH}_{2}\right\}$ and $\{\mathrm{Be}(\mathrm{H})(\mathrm{Me})\}$ Fragments. Organometallics 2015, 34, 653-662. [CrossRef]

2. Shannon, R.D. Revised effective ionic radii and systematic studies of interatomic distances in halides and chalcogenides. Acta Crystallogr. Sect. A 1976, 32, 751-767. [CrossRef]

3. Westerhausen, M. Synthesis and Spectroscopic Properties of Bis(trimethylsilyl)amides of the Alkaline-earth Metals Magnesium, Calcium, Strontium, and Barium. Inorg. Chem. 1991, 30, 96-101. [CrossRef]

4. Naglav, D.; Neumann, A.; Blaser, D.; Wolper, C.; Haack, R.; Jansen, G.; Schulz, S. Bonding situation in $\mathrm{Be}\left[\mathrm{N}\left(\mathrm{SiMe}_{3}\right)_{2}\right]_{2}$-An experimental and computational study. Chem. Commun. 2015, 51, 3889-3891. [CrossRef] [PubMed]

5. Nugent, K.W.; Beattie, J.K.; Hambley, T.W.; Snow, M.R. A precise Low-temperature crystal structure of bis(cyclopentadienyl)beryllium. Aust. J. Chem. 1984, 37, 1601-1606. [CrossRef]

6. Burkey, D.J.; Hanusa, T.P. Structural Lessons from Main-Group Metallocenes. Comments Inorg. Chem. 1995, 17, 41-77. [CrossRef] 
7. Civic, T.M. Beryllium Metal Toxicology: A Current Perspective. In Encyclopedia of Inorganic and Bioinorganic Chemistry; John Wiley \& Sons, Ltd.: Hoboken, NJ, USA, 2011.

8. Hanusa, T.P.; Bierschenk, E.J.; Engerer, L.K.; Martin, K.A.; Rightmire, N.R. 1.37-Alkaline Earth Chemistry: Synthesis and Structures. In Comprehensive Inorganic Chemistry II, 2nd ed.; Reedijk, J., Poeppelmeier, K., Eds.; Elsevier: Amsterdam, The Netherlands, 2013; pp. 1133-1187.

9. Iversen, K.J.; Couchman, S.A.; Wilson, D.J.D.; Dutton, J.L. Modern organometallic and coordination chemistry of beryllium. Coord. Chem. Rev. 2015, 297-298, 40-48. [CrossRef]

10. Naglav, D.; Buchner, M.R.; Bendt, G.; Kraus, F.; Schulz, S. Off the Beaten Track-A Hitchhiker's Guide to Beryllium Chemistry. Angew. Chem. Int. Ed. 2016, 55, 10562-10576. [CrossRef] [PubMed]

11. Chmely, S.C.; Hanusa, T.P.; Brennessel, W.W. Bis(1,3-trimethylsilylallyl)beryllium. Angew. Chem. Int. Ed. 2010, 49, 5870-5874. [CrossRef] [PubMed]

12. Solomon, S.A.; Muryn, C.A.; Layfield, R.A. s-Block metal complexes of a bulky, donor-functionalized allyl ligand. Chem. Commun. 2008, 3142-3144. [CrossRef] [PubMed]

13. Chmely, S.C.; Carlson, C.N.; Hanusa, T.P.; Rheingold, A.L. Classical versus Bridged Allyl Ligands in Magnesium Complexes: The Role of Solvent. J. Am. Chem. Soc. 2009, 131, 6344-6345. [CrossRef] [PubMed]

14. Rightmire, N.R.; Hanusa, T.P. Advances in Organometallic Synthesis with Mechanochemical Methods. Dalton Trans. 2016, 45, 2352-2362. [CrossRef] [PubMed]

15. Gren, C.K.; Hanusa, T.P.; Rheingold, A.L. Threefold Cation $-\pi$ Bonding in Trimethylsilylated Allyl Complexes. Organometallics 2007, 26, 1643-1649. [CrossRef]

16. Layfield, R.A.; Garcia, F.; Hannauer, J.; Humphrey, S.M. Ansa-tris(allyl) complexes of alkali metals: Tripodal analogues of cyclopentadienyl and ansa-metallocene ligands. Chem. Commun. 2007, 5081-5083. [CrossRef] [PubMed]

17. Neumüller, B.; Weller, F.; Dehnicke, K. Synthese, Schwingungsspektren und Kristallstrukturen der Chloroberyllate $\left(\mathrm{Ph}_{4} \mathrm{P}\right)_{2}\left[\mathrm{BeCl}_{4}\right]$ und $\left(\mathrm{Ph}_{4} \mathrm{P}\right)_{2}\left[\mathrm{Be}_{2} \mathrm{Cl}_{6}\right]$. Z. Anorg. Allg. Chem. 2003, 629, 2195-2199. [CrossRef]

18. Allred, A.L. Electronegativity values from thermochemical data. J. Inorg. Nucl. Chem. 1961, 17, $215-221$. [CrossRef]

19. Plieger, P.G.; John, K.D.; Keizer, T.S.; McCleskey, T.M.; Burrell, A.K.; Martin, R.L. Predicting ${ }^{9}$ Be Nuclear Magnetic Resonance Chemical Shielding Tensors Utilizing Density Functional Theory. J. Am. Chem. Soc. 2004, 126, 14651-14658. [CrossRef] [PubMed]

20. Arnold, T.; Braunschweig, H.; Ewing, W.C.; Kramer, T.; Mies, J.; Schuster, J.K. Beryllium bis(diazaborolyl): Old neighbors finally shake hands. Chem. Commun. 2015, 51, 737-740. [CrossRef] [PubMed]

21. Wermer, J.R.; Gaines, D.F.; Harris, H.A. Synthesis and molecular structure of lithium tri-tert-butylberyllate, $\mathrm{Li}\left[\mathrm{Be}\left(\text { tert- } \mathrm{C}_{4} \mathrm{H}_{9}\right)_{3}\right]$. Organometallics 1988, 7, 2421-2422. [CrossRef]

22. Gottfriedsen, J.; Blaurock, S. The First Carbene Complex of a Diorganoberyllium: Synthesis and Structural Characterization of $\mathrm{Ph}_{2} \mathrm{Be}\left(i-\mathrm{Pr}\right.$-carbene) and $\mathrm{Ph}_{2} \mathrm{Be}\left(n-\mathrm{Bu} \mathrm{H}_{2} \mathrm{O}\right)$. Organometallics 2006, 25, 3784-3786. [CrossRef]

23. Arrowsmith, M.; Hill, M.S.; Kociok-Köhn, G.; MacDougall, D.J.; Mahon, M.F. Beryllium-Induced C-N Bond Activation and Ring Opening of an N-Heterocyclic Carbene. Angew. Chem. Inter. Ed. 2012, 51, 2098-2100. [CrossRef] [PubMed]

24. Weiss, E.; Wolfrum, R. Über metall-alkyl-verbindungen VIII. Die kristallstruktur des lithium-tetramethylberyllats. J. Organomet. Chem. 1968, 12, 257-262. [CrossRef]

25. Rightmire, N.R.; Bruns, D.L.; Hanusa, T.P.; Brennessel, W.W. Mechanochemical Influence on the Stereoselectivity of Halide Metathesis: Synthesis of Group 15 Tris(allyl) Complexes. Organometallics 2016, 35, 1698-1706. [CrossRef]

26. Austin, A.; Petersson, G.A.; Frisch, M.J.; Dobek, F.J.; Scalmani, G.; Throssell, K. A Density Functional with Spherical Atom Dispersion Terms. J. Chem. Theory Comp. 2012, 8, 4989-5007. [CrossRef] [PubMed]

27. Rightmire, N.R.; Hanusa, T.P.; Rheingold, A.L. Mechanochemical Synthesis of $\left[1,3-\left(\mathrm{SiMe}_{3}\right)_{2} \mathrm{C}_{3} \mathrm{H}_{3}\right]_{3}(\mathrm{Al}, \mathrm{Sc})$, a Base-Free Tris(allyl)aluminum Complex and Its Scandium Analogue. Organometallics 2014, 33, 5952-5955. [CrossRef]

28. Guzei, I.A.; Wendt, M. An improved method for the computation of ligand steric effects based on solid angles. Dalton Trans. 2006, 3991-3999. [CrossRef] [PubMed]

29. Fraenkel, G.; Chow, A.; Winchester, W.R. Dynamics of solvated lithium(+) within exo,exo-[1,3-bis (trimethylsilyl)allyl]lithium $N, N, N^{\prime}, N^{\prime}$-tetramethylethylenediamine complex. J. Am. Chem. Soc. 1990, 112, 1382-1386. [CrossRef] 
30. Harvey, M.J.; Hanusa, T.P.; Young, V.G., Jr. Synthesis and Crystal Structure of a Bis(allyl) Complex of Calcium, $\left[\mathrm{Ca}\left\{\mathrm{C}_{3}\left(\mathrm{SiMe}_{3}\right)_{2} \mathrm{H}_{3}\right\}_{2} \cdot(\mathrm{thf})_{2}\right]$. Angew. Chem. Int. Ed. 1999, 38, 217-219. [CrossRef]

31. Perrin, D.D.; Armarego, W.L.F. Purification of Laboratory Chemicals, 3rd ed.; Pergamon: Oxford, UK, 1988.

32. APEX2; Version 2014.11-0; Bruker AXS: Madison, WI, USA, 2013.

33. Burla, M.C.; Caliandro, R.; Camalli, M.; Carrozzini, B.; Cascarano, G.L.; Giacovazzo, C.; Mallamo, M.; Mazzone, A.; Polidori, G.; Spagna, R. SIR2011: A New Package for Crystal Structure Determination and Refinement; Version 1.0; Istituto di Cristallografia: Bari, Italy, 2012.

34. Sheldrick, G.M. SHELXL-2014/7; University of Göttingen: Göttingen, Germany, 2014.

35. Frisch, M.J.; Trucks, G.W.; Schlegel, H.B.; Scuseria, G.E.; Robb, M.A.; Cheeseman, J.R.; Scalmani, G.; Barone, V.; Mennucci, B.; Petersson, G.A.; et al. Gaussian 09W; Revision D.01; Gaussian, Inc.: Wallingford CT, USA, 2009.

36. Glock, C.; Görls, H.; Westerhausen, M. $N, N, N^{\prime}, N^{\prime}$-Tetramethylethylendiamine adducts of amido calcium bases-Synthesis of monomeric [(tmeda)Ca $\left.\left\{\mathrm{N}\left(\mathrm{SiMe}_{3}\right)_{2}\right\}_{2}\right],\left[(\right.$ tmeda $\left.) \mathrm{Ca}\left\{\mathrm{NiPr}_{2}\right\}_{2}\right]$, and dimeric Hauser base-type $[(\mathrm{tmeda}) \mathrm{Ca}(\mathrm{tmp})(\mu-\mathrm{I})]_{2}$ (tmp = 2,2,6,6-tetramethylpiperidide). Inorg. Chim. Acta 2011, 374, 429-434. [CrossRef]

37. Fitts, L.S.; Bierschenk, E.J.; Hanusa, T.P.; Rheingold, A.L.; Pink, M.; Young, V.G. Selective modification of the metal coordination environment in heavy alkaline-earth iodide complexes. New J. Chem. 2016, 40, 8229-8238. [CrossRef]

38. Hernández, J.G.; Friščić, T. Metal-catalyzed organic reactions using mechanochemistry. Tetrahedron Lett. 2015, 56, 4253-4265. [CrossRef]

39. Boldyreva, E. Mechanochemistry of inorganic and organic systems: What is similar, what is different? Chem. Soc. Rev. 2013, 42, 7719-7738. [CrossRef] [PubMed]

40. Wang, G.-W. Mechanochemical organic synthesis. Chem. Soc. Rev. 2013, 42, 7668-7700. [CrossRef] [PubMed]

41. Waddell, D.C.; Thiel, I.; Clark, T.D.; Marcum, S.T.; Mack, J. Making kinetic and thermodynamic enolates via solvent-free high speed ball milling. Green Chem. 2010, 12, 209-211. [CrossRef]

(C) 2017 by the authors. Licensee MDPI, Basel, Switzerland. This article is an open access article distributed under the terms and conditions of the Creative Commons Attribution (CC BY) license (http:/ / creativecommons.org/licenses/by/4.0/). 
Article

\title{
Potassium C-F Interactions and the Structural Consequences in $N, N^{\prime}$-Bis(2,6- difluorophenyl)formamidinate Complexes
}

\author{
Daniel Werner ${ }^{1}$, Glen B. Deacon ${ }^{2, *}$ and Peter C. Junk ${ }^{3, *}$ \\ 1 Institut für Anorganische Chemie, University of Tübingen (EKUT) Auf der Morgenstelle 18, 72076 Tübingen, \\ Germany; daniel.werner@uni-tuebingen.de \\ 2 School of Chemistry, Monash University, Clayton, Victoria 3800, Australia \\ 3 College of Science \& Engineering, James Cook University, Townsville, Queensland 4811, Australia \\ * Correspondence: glen.deacon@monash.edu (G.B.D.); peter.junk@jcu.edu.au (P.C.J.)
}

Academic Editor: Matthias Westerhausen

Received: 27 March 2017; Accepted: 11 April 2017; Published: 17 April 2017

\begin{abstract}
Treatment of $\mathrm{K}\left[\mathrm{N}\left(\mathrm{SiMe}_{3}\right)_{2}\right]$ with $N, N^{\prime}$-bis(2,6-difluorophenyl)formamidine (DFFormH) in toluene, resulted in the formation of $[\mathrm{K}(\mathrm{DFForm})]_{\infty}(\mathbf{1})$ as a poorly soluble material. Upon dissolution in thf and layering with $n$-hexane, $\mathbf{1}$ was crystallised and identified as a two-dimensional polymer, in which all fluorine and nitrogen atoms, and also part of one aryl group, bridge between four symmetry equivalent potassium ions, giving rise to a completely unique $\mu_{4}-\left(N, N^{\prime}, F, F^{\prime}\right):\left(N, N^{\prime}\right): \eta^{4}(A r-C(2,3,4,5,6)):\left(F^{\prime \prime}, F^{\prime \prime \prime}\right)$ DFForm coordination. The two-dimensional nature of the polymer could be deconstructed to one dimension by crystallisation from neat the at $-35{ }^{\circ} \mathrm{C}$, giving $\left[\mathrm{K}_{2}(\mathrm{DFForm})_{2}(\mathrm{thf})_{2}\right]_{\infty}(2)$, where the thf molecules bridge the monomeric units. Complete polymer dissociation was observed when 1 was crystallised from toluene $/ n$-hexane mixtures in the presence of 18-crown-6, giving [K(DFForm)(18-crown-6)] (3), which showed unprecedented $\mathrm{k}\left(N, \mathrm{C}_{\text {ispo }}, \mathrm{F}\right)$ DFForm coordination, rather than the expected $\mathrm{k}\left(N, N^{\prime}\right)$ coordination.
\end{abstract}

Keywords: potassium; formamidinate; C-F bond; coordination chemistry

\section{Introduction}

With the ability to adopt numerous coordination modes, flexible $N, N^{\prime}$-bis(aryl)formamidinates (and by extension aryl-functionalised amidinates) have earned a special place in coordination chemistry [1-5]. Not only does the anionic NCHN bite provide a variety of different nitrogen-based coordination modes (e.g., monodentate $\kappa(N)$, bidentate $\kappa\left(N, N^{\prime}\right)$, or various bridging modes e.g., $\mu-1 \kappa(N): 2 \kappa\left(N^{\prime}\right), \mu-1 \kappa\left(N, N^{\prime}\right): 2 \kappa\left(N, N^{\prime}\right)$ to list a few) [6,7], the nitrogen-bound aromatic substituents can also provide additional coordination modes. The potential to form metal-arene interactions, such as $\eta^{6}$ coordination, has been largely observed in group one chemistry [8-13], though some examples are known in $f$-block chemistry [14]. In almost all examples of this aromatic coordination, the phenyl rings contained alkyl-substituents in either the 2,6 positions (e.g., $i \mathrm{Pr}, \mathrm{Et}, \mathrm{Me}$ ), or in the $2,4,6$ positions (e.g., Me). This is likely due to a combination of steric pressure, which starves the metal centre from coordination of additional donors, and increased electron donation from the aromatic ring caused by the alkyl substituents. Another means to engage the aromatic component in coordination is through the addition of donor functionalities (e.g., OMe, F), especially in the ortho-positions, thereby transforming the formamidinate ligand into a tri- [15-17], or tetra-dentate (e.g., $N, N^{\prime}, X$ or $\left.N, N^{\prime}, X, X^{\prime}\right)$ [17], chelate, with examples across a variety of different metal classes [18]. For $s$-block chemistry however, the use of such ligands has been restricted to very few examples, namely the use of $N, N^{\prime}$-bis(2-fluorophenyl)formamidine (FForm) [19]. 
Nearly 15 years ago, FForm was complexed to the group one metals $\mathrm{Li}, \mathrm{Na}$, and $\mathrm{K}$ [19]. Akin to the transition metal complexes of Cotton and co-workers [20], the presence of the fluorine atom on the ortho-position of the aromatic rings permitted an additional coordinating site. This further led to partial, or complete, exclusion of bound donor molecules (e.g., $\mathrm{Et}_{2} \mathrm{O}$, thf), by the formation of either binuclear, or for potassium, polymeric constructs (e.g., $\left[\mathrm{Na}(\mathrm{FForm})\left(\mathrm{Et}_{2} \mathrm{O}\right)\right]_{2}$ or $\left.[\mathrm{K}(\mathrm{FForm})]_{\infty}\right)[19]$. This contrasts the group one complexes of the non-fluorinated $N, N^{\prime}$-di(aryl)formamidinate ligands [21-23], which readily retain coordinating solvent. Since then, we have expanded the use of fluorinated formamidinate ligands to $f$-block chemistry $[9,16,17,24-28]$, in a variety of different contexts [5]. One of the fluorinated formamidinate ligands used was $N, N^{\prime}$-bis(2,6-difluorophenyl)formamidinate (DFForm) in both trivalent [16,17], and divalent [16] rare-earth complexes. Despite the presence of the additional fluorine atoms, the observation of any M-F interaction was rare, typically only occurred in unsolvated species, and interactions were displaced on coordination of donor solvents [16,17]. It is likely that the smaller ionic radii of the trivalent rare-earths, compared with the larger potassium ion [29], create a significant strain in the NCHN bite of the DFForm ligand when it coordinates the fluorine atoms, and therefore donor solvent coordination is preferred. Although DFForm has been used in some transition metal complexes, it has no precedent in s-block chemistry. We hypothesised that the additional two fluorine atoms over FForm could engage in further coordination chemistry, generating different coordination modes from FForm, and quite spectacular results have been obtained by way of new formamidinate binding modes.

\section{Results and Discussion}

Treatment of $\mathrm{K}\left[\mathrm{N}\left(\mathrm{SiMe}_{3}\right)_{2}\right]$ with DFFormH in toluene resulted in the formation of a colourless, poorly soluble white powder. Upon dissolution in thf, concentration, and layering with $n$-hexane, white crystals of targeted $[K(D F F o r m)]_{\infty}(\mathbf{1}$, Scheme 1i) were obtained. The structure of $\mathbf{1}$ was determined by X-ray crystallography, revealing that $\mathbf{1}$ is a two-dimensional polymer. The binding of the DFForm ligand in $\mathbf{1}$ is complex, and is discussed starting from the asymmetric unit (ASU), and then extending in both dimensions of the polymeric network.

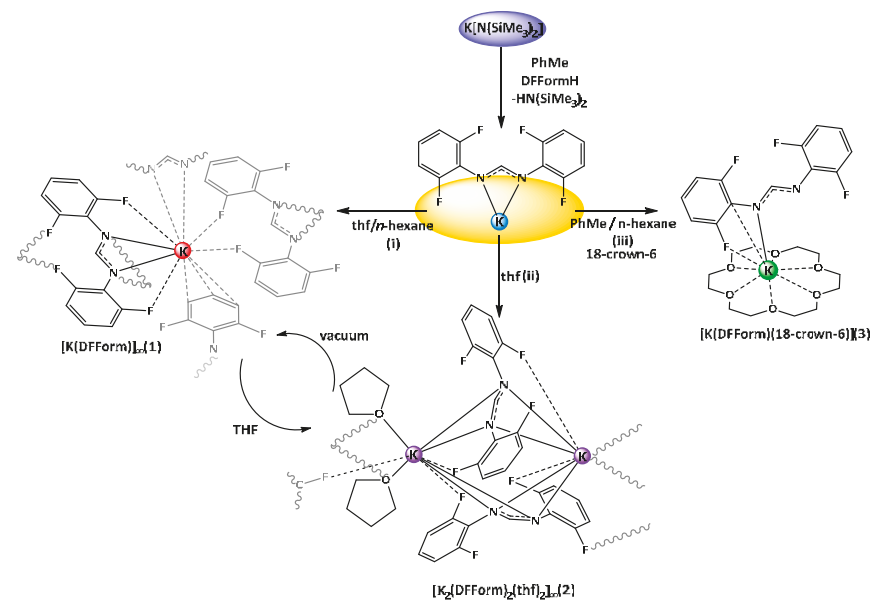

Scheme 1. Synthesis of K(DFForm) complexes (1-3) by protonolysis and crystallisation from different solvent mixtures. (i) thf, $n$-hexane, at room temperature; (ii) neat thf, crystallisation at $-35^{\circ} \mathrm{C}$; (iii) toluene, $n$-hexane, crystallisation at room temperature. The diagram further indicates the different bonding modes of the DFForm ligand in complexes, such as the $\left(F, N, N^{\prime}, F^{\prime}\right)$ or arene-K interactions in 1, the twisted $1 \kappa\left(F, N, N^{\prime},\right): 2 \kappa\left(N, N^{\prime}, F^{\prime}\right)$ DFForm coordination in 2 , or the unusual $\left(N, C_{\mathrm{ipso}}, F\right)$ coordination in 3. 
Complex 1 crystallised in the triclinic space group $P-1$, with only one potassium ion and one DFForm ligand in the ASU (Figure 1A). The DFForm ligand of the ASU is bound $\left(F, N, N^{\prime}, F^{\prime}\right)$ to the ASU potassium ion. This tetradentate binding of the DFForm ligand contrasts that of the FForm ligand in $[K(F F o r m)]_{\infty}[19]$, where the ASU contains one FForm ligand bound $\eta^{4}(N,(\mathrm{Ar}-\mathrm{C} 6,5), F)$ to potassium. As the $\mathrm{K}$ ion is bound by the DFForm NCHN bite in an almost symmetrical manner, and does not favour one nitrogen donor (as observed in [K(FForm)], the $\mathrm{K} \cdots \mathrm{F}-\mathrm{C}$ bonding is weak, and thus the $\mathrm{C}-\mathrm{F}$ bonds in $\mathbf{1}$ (of either $\mathrm{C} 1 / \mathrm{F} 1$ or $\mathrm{C} 9 / \mathrm{F} 3$, Figure 1) are almost unchanged from those of DFFormH (C-F: 1.3596(17)-1.3625(18)) [30]. By contrast, the asymmetrical NCHN binding of FForm to $\mathrm{K}$ in $[\mathrm{K}(\mathrm{FForm})]_{\infty}$ (along with the coordination across the aromatic component), brings the fluorine atom into a closer proximity to the potassium atom (K-F: 3.029(4)), and weakens the C-F bond (C-F: 1.377(6) $\AA$ ) [19]. Another example of such tetradentate $\left(F, N, N^{\prime}, F^{\prime}\right)$ DFForm coordination was observed in the homoleptic cerium DFForm complex, [Ce(DFForm) $)_{3}$ [ [17], where one of three DFForm ligands is tetradentate, with the other two being tri-dentate $\left(F, N, N^{\prime}\right)$. In this example, all Ce $\cdots \mathrm{F}-\mathrm{C}$ interactions were identical at $2.92 \AA$ (range: $2.9187(13)-2.9213(13)$ ), and consequentially each C-F bond was also strained to a similar degree (range: 1.374(1)-1.376(1) $\AA$ ). However, considering that a ten-coordinate cerium(III) is smaller than a nine-coordinate potassium (difference in ionic radii: $-0.3 \AA$ ) [29], the tetradentate DFForm ligand for the cerium complex had to bend the aryl-rings towards the cerium ion to bring the fluorine atoms into proximity, causing a strain on the $\mathrm{C}_{i p s o}-\mathrm{N}-\mathrm{CH}$ angle (range: $\left.126.4(2)^{\circ}-128.3(2)^{\circ}\right)$. However, due to the larger ionic radii of potassium, this phenomenon is not observed in $\mathbf{1}$ (range: $\left.120.39(9)^{\circ}-120.75(9)^{\circ}\right)$.

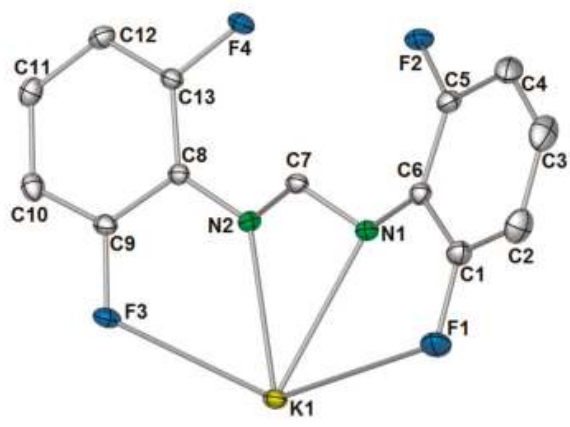

A

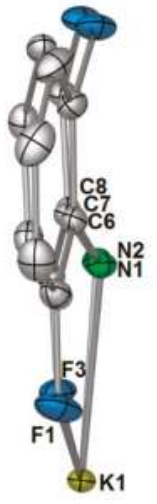

B

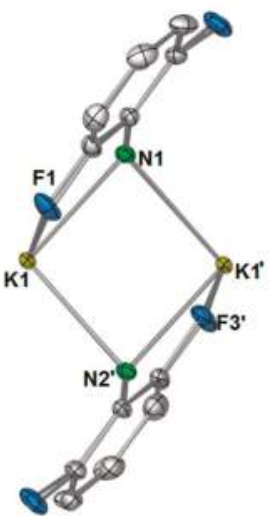

C

Figure 1. (A) Asymmetric unit of $[\mathrm{K}(\mathrm{DFForm})] \infty$ (1). Selected bond lengths $(\AA)$ and angles $\left(^{\circ}\right)$ : K1-F1: 3.3692(8), K1-N1: 2.8102(9), K1-N2: 2.8057(9), K1-F3: 3.3957(8), C1-F1: 1.3609(13), C9-F3: 1.3581(12), F1-K1-N1: 50.73(2), F3-K1-N2: 50.24(2). Ellipsoids were shown at the 50\% probability level, and hydrogen atoms were removed for clarity; (B) side view of K(DFForm) showing that the DFForm ligand is not flat; (C) simplification of the $\mu-\left(N, N^{\prime}, F, F^{\prime}\right):\left(N, N^{\prime}\right)$ bridging of the DFForm ligand. Selected bond lengths $(\AA)$ and angles $\left({ }^{\circ}\right)$ : K1-N1': 2.8102(9), K1-N2': 2.9048(9), K1-K1': 3.4871(4), $\mathrm{K} 1-\left(\mathrm{N} 1 / \mathrm{N} 2_{\text {cent }}\right)-\mathrm{K} 1^{\prime}$ : 84.02(1), N1/2 cent $^{-\mathrm{K} 1-\mathrm{N} 1} 1^{\prime} / 2^{\prime}$ cent: $95.98(1)$.

The differences in coordination between the DFForm and FForm ligands to potassium becomes considerably more apparent with expansion of the coordination mode of the ligands through bridging. Initial extension of the coordination of the DFForm ligand in $\mathbf{1}$ shows that the nitrogen atoms are further bridging to an adjacent potassium ion in a $\mu-\left(N, N^{\prime}\right):\left(N, N^{\prime}\right)$ manner (Figure $1 \mathrm{C}$, also Figure 2A). Such formamidinate bridging is known for other $s$ - and $f$-block complexes $[16,22,31]$. This bridging is mirrored by a symmetry equivalent DFForm ligand, generating a potassium 
nitrogen based cube of volume: $6.78 \AA^{3}$ (Figure 1C). In stark contrast, the FForm system shows a twisted $\mu-\left(N, C_{i p s o} C_{o r t h o}, F\right):\left(N, N^{\prime}, F^{\prime}\right)$ FForm binding, where the NCHN bite is shared asymmetrically across two anent potassium atoms. It should be further noted that the aromatic group, nitrogen atoms, and backbone/ipso carbon atoms of DFForm are not flat and that the DFForm ligand is tilted (Figure 1B). The two nitrogen atoms coordinate to potassium in an almost symmetrical manner, but $\mathrm{C} 7$ is puckered away from the nitrogen atoms (K1-N1/2(cent)-C7: $\left.141.10(8)^{\circ}\right)$, so it is almost in line with the two ipso carbon atoms of the phenyl rings (C6-C7-C8: 177.26(6) , c.f. $\left(\mathrm{K}(\mathrm{FForm})\right.$ : $\left.168.9(3)^{\circ}\right)$. This puckered nature of the DFForm ligand is typical of other formamidinate complexes which bridge in a $\mu-\left(N, N^{\prime}\right):\left(N, N^{\prime}\right)$ fashion (e.g., $[\mathrm{K}(p-\text { TolForm })(\mathrm{dme})]_{\infty}$ (K1-N1/2(cent)-C" $7^{\prime \prime}: 144.8(3)^{\circ}, p$-TolForm $=N, N^{\prime}$-bis(4-methylphenyl)formamidinate) [32].

The polymeric network of $\mathbf{1}$ is complicated. One might expect that, as the DFForm ligand bridges in a $\mu-\left(N, N^{\prime}\right):\left(N, N^{\prime}\right)$ manner between potassium ions, and that this is the repeating dinuclear unit (e.g., $\left.\left[K_{2}\left(\mu-\left(N, N^{\prime}\right):\left(N, N^{\prime}\right) \text {-DFForm }\right)_{2}\right]_{\infty}\right)$, but this is not the case. Instead, one dimension of the polymer is generated through aromatic interactions of one 2,6-difluorophenyl group (Figure 2A), where the aromatic ring of $\mathrm{N} 2$ binds to $\mathrm{K}^{\prime}$, and the aromatic ring (but without the ipso carbon) of $\mathrm{N} 2$ ' coordinates to $\mathrm{K} 1$, both in a $\eta^{5}(\mathrm{C} 2,3,4,5,6)$ manner. Thus, this direction of the polymeric network has an " $\mathrm{A}, \mathrm{B}$ " alternating potassium ion arrangement where $\mathrm{A}=\mathrm{K}$ and $\mathrm{B}=\mathrm{K}^{\prime}$ and $\mathrm{K}^{\prime \prime}$ (Figure 2). For the FForm system, the one and only dimension of the polymeric network is generated by additional nitrogen based bonding to two other potassium ions, namely through one $(N, F)$ interaction, and one $\left(N^{\prime}, C_{\text {ispo }}{ }^{\prime}\right)$ interaction, making the overall coordination of each FForm ligand shared across four potassium ions as $\mu_{4}-\left(N, C_{i p s o} C_{\text {ortho }}, F\right):\left(N, N^{\prime}, F^{\prime}\right):(N, F):\left(N^{\prime}, C_{i s p o}{ }^{\prime}\right)$. The DFForm ligand is also further bridging to a fourth symmetry equivalent potassium ion, and this binding is completely different from that in the FForm system.

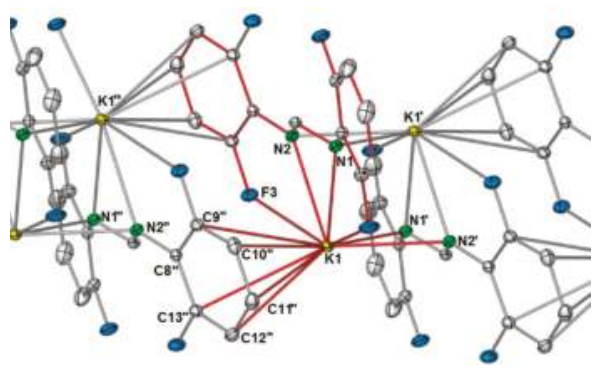

A

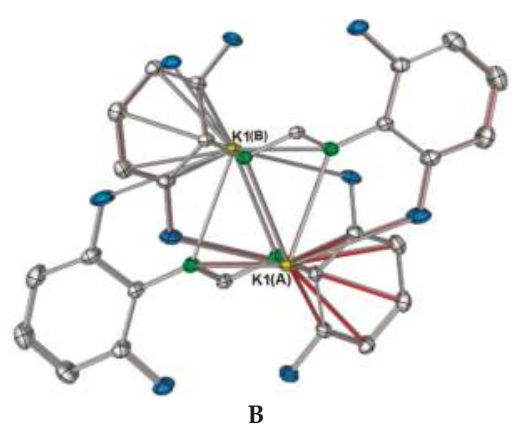

B

Figure 2. Growth of one dimension of the $[\mathrm{K}(\mathrm{DFF} \text { orm })]_{\infty}(\mathbf{1})$ polymer network through aromatic interactions, the red bonds indicate the connectivity to the ASU potassium ion and DFForm ligand. (A) View along the side of the polymer; Selected bond lengths $(\AA)$ and angles $\left({ }^{\circ}\right)$ : K1-C9': 3.4980(11), K1-C10': 3.3220(11), K1-C11": 3.2417(11), K1-C12": 3.3569(11), K1-C13": 3.5066(10); (B) view down the $a$-axis of the polymeric network of $\mathbf{1}$.

As shown in Figure 2A, there is an apparent coordination gap in axial positions of the potassium ions, and it is in this position that the other two fluorine atoms (namely, F2 and F4) of the DFForm ligand become relevant, and expand the one-dimensional polymeric network into a two-dimensional polymer. The further fluorine atoms (F2 and F4) coordinate to an adjacent potassium ion in a $\mu-\left(F^{\prime \prime}, F^{\prime \prime \prime}\right)$ manner, generating a ten-membered ring (Figure 3A). Because of this additional coordination, the DFForm ligand is nearly planar across the $\mathrm{K}$ and $\mathrm{K}^{\prime \prime \prime}$ atoms, with the bond angle of $\mathrm{K}-\mathrm{N} 1 / \mathrm{N}_{\text {cent }}-\mathrm{K}^{\prime \prime \prime}$ being $175.66(1)^{\circ}$. Although the auxiliary fluorine atoms are coordinated at a considerably shorter distance than the $\mathrm{K}-\mathrm{F} 1$ and $\mathrm{K}-\mathrm{F} 3$ analogues, there is still only a minor shortening of the C-F bonds from those of DFFormH (C-F: 1.3596(17)-1.3625(18)) [30]). 


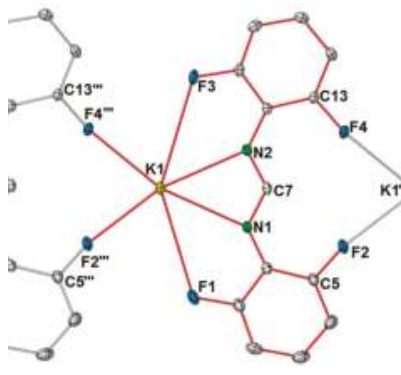

A
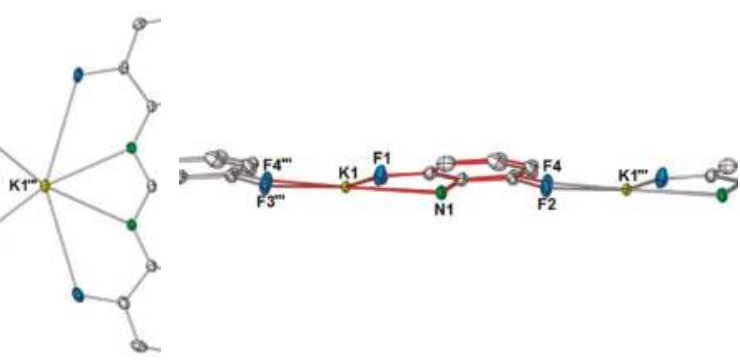

Figure 3. Simplified diagram of the bonding of the auxiliary fluorine atoms (F2, F4) to an adjacent potassium ion, expanding the polymeric network into a second direction (across the $b$ axis). (A) Top view of bonding showing the formation of a ten-membered ring upon fluorine coordination; (B) side view of auxiliary fluorine bonding (or side view of $b$-axis), highlighting the different planes within the DFForm ligand. Selected bond lengths $(\AA)$ and angles $\left(^{\circ}\right)$ : K1-F2 ${ }^{\prime \prime \prime}: 2.7110(8), \mathrm{K} 1-\mathrm{F} 4^{\prime \prime \prime}$ : 2.7422(7), C5-F2: 1.3641(14), C13-F4: 1.3656(11), K1-K1'"': 7.5357(2), K1-N1/2 cent-K1"'!: 175.66(1), $\mathrm{K} 1-\mathrm{C} 7-\mathrm{K} 1^{\prime \prime \prime}:$ 171.37(3), K1-F2/4 ${ }_{\text {cent }}-\mathrm{K}^{\prime \prime \prime}:$ 176.69(1).

In summation, each DFForm ligand binds four symmetry equivalent potassium ions in a $\mu_{4}-1 \kappa\left(N, N^{\prime}, F, F^{\prime}\right): 2 \kappa\left(N, N^{\prime}\right): 3 \eta^{5}(A r-C(2,3,4,5,6)): 4 \kappa\left(F^{\prime \prime}, F^{\prime \prime \prime}\right)$ manner, giving the potassium ion a coordination number of 11 . Such an interesting binding mode exemplifies how the simple addition of other donors to a ligand system can dramatically alter the coordination network. Furthermore, it appears the $\mathbf{1}$ is the first crystallographically characterised example across all metal classes, where one $N, N^{\prime}$-bis(aryl)formamidinate ligand generates a two-dimensional polymer network, all other examples are restricted to one dimension [18]. The complete polymeric network of $\mathbf{1}$ is displayed in Figure 4, showing both how the DFForm bridges across four potassium ions (Figure 4A) and the two dimensions of the polymer (Figure 4B,C).

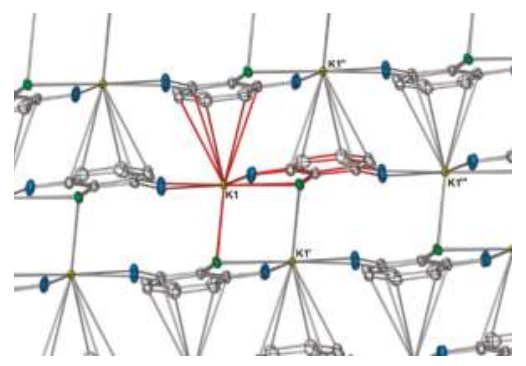

A

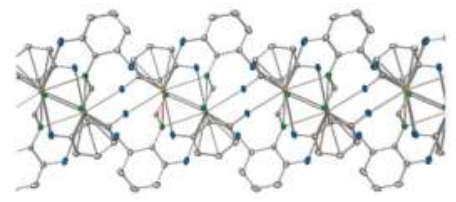

B

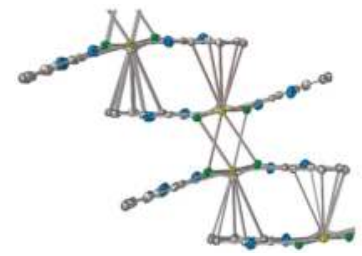

C

Figure 4. Excerpt pictures from the polymeric network of 1; red-coloured bonds indicate the connectivity to the potassium atom of the ASU and the bonds of the DFForm ligand of the ASU. (A) Complete DFForm bonding network across four potassium atoms; (B,C) Simplified directions of the polymeric network showing the bridging through fluorine, nitrogen, and aromatic carbon atoms ((B) showing nitrogen-based bridging, (C) showing aryl group-based bridging).

Crystals of 1 were air- and moisture-sensitive, but under an inert atmosphere the compound appeared stable. Complex $\mathbf{1}$ was repeatedly obtained by simple exposure of thf solutions of 
"[K(DFForm)(thf $\left.)_{x}\right]$ " to vacuum, giving 1 upon drying. The poor solubility in non-coordinating solvents made analysis by ${ }^{1} \mathrm{H}$ NMR and ${ }^{19} \mathrm{~F}$ NMR spectroscopy difficult, giving only broad resonances in both spectra ( $\mathrm{NCHN}$ at $8.88 \mathrm{ppm}$ and F2,6 at $-127.2 \mathrm{ppm}$ ). All fluorine atoms of the DFForm ligand are equivalent, but clear spectra were generated when 1 was dissolved in thf- $\mathrm{d}_{8}$. In this solvent, the $\mathrm{NCHN}$ resonance appeared as a pentet, owing to ${ }^{5} \mathrm{~J}_{\mathrm{H}-\mathrm{F}}$ coupling with the ortho-fluorine atoms, as the pentet collapsed to a singlet with ${ }^{19} \mathrm{~F}$ decoupling. A broadening of the $\mathrm{F}$ resonance (corresponding to F1-F4) was also observed in the ${ }^{19} \mathrm{~F}$ NMR spectrum when it was performed without ${ }^{1} \mathrm{H}$ decoupling. It is likely that upon dissolution in thf- $\mathrm{d}_{8}$, the polymeric network is dissociated, and a simpler DFForm coordination mode is adopted e.g., $\left[\mathrm{K}(\mathrm{DForm})(\mathrm{thf})_{x}\right](2<x<6)$. Attempts to crystallise a potential monomeric derivative were not successful, but upon concentration of a thf solution of $\mathbf{1}$, and storage at $-35^{\circ} \mathrm{C}$, crystals of a thf-coordinated species were isolated, namely $\left[\mathrm{K}_{2}(\mathrm{DFForm})_{2}(\mathrm{thf})_{2}\right]_{\infty}$ (2, Scheme 1ii), identified as a one-dimensional polymer. Complex $\mathbf{2}$ is probably a transient intermediate between the putative monomeric $\left[\mathrm{K}(\mathrm{DFForm})(\mathrm{thf})_{x}\right]$ solution species and polymeric 1 .

$\mathrm{X}$-ray data for 2 were solved and refined in the monoclinic space group $P 2_{1}$, with two potassium ions, two DFForm ligands, and two coordinating thf molecules occupying the asymmetric unit (Figure 5A). For the ASU component, the two DFForm ligands bridge between both potassium centres in a $\mu-1 \mathrm{k}\left(N, N^{\prime}, F\right): 2 \mathrm{k}\left(N, N^{\prime}, F^{\prime}\right)$ manner, and $\mathrm{N} 1$ and $\mathrm{N} 3$ coordinate closer to $\mathrm{K} 1$, and $\mathrm{N} 2$ and $\mathrm{N} 4$ coordinate closer to $\mathrm{K} 2$. The $\mathrm{K} \cdots \mathrm{F}-\mathrm{C}$ coordination in this arrangement is overall shorter than those observed for the tetradentate $\left(N, N^{\prime}, F, F^{\prime}\right)$ DFForm coordination in 1, but longer than the auxiliary fluorine $\mathrm{K} \cdots \mathrm{F}-\mathrm{C}$ coordination in $\mathbf{1}$. All the $\mathrm{C}-\mathrm{F}$ bond lengths exhibit only a slight elongation, with the exception of the C13-F4 bond, which is notably longer than the others. An explanation behind the elongation of only C13-F4 is due to the involvement of this fluorine atom in additional bridging to an adjacent potassium atom. This, in conjunction with the two bridging thf ligands, leads to a one-dimensional polymer (Figure 5B).

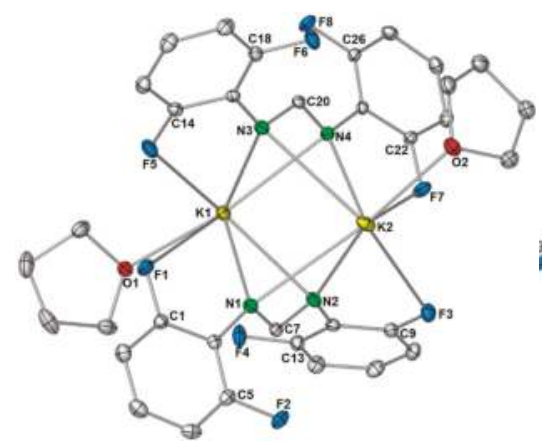

A

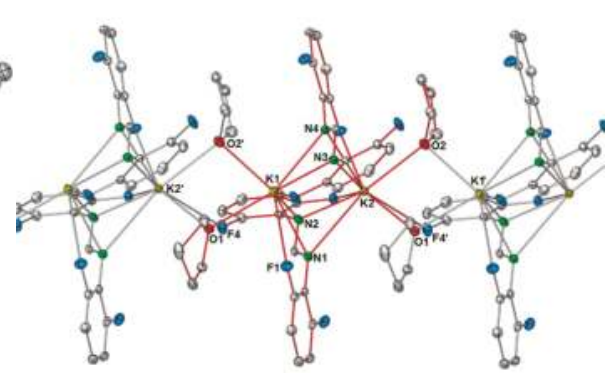

B

Figure 5. Molecular structure of $\left[\mathrm{K}_{2}(\mathrm{DFForm})_{2}(\mathrm{thf})_{2}\right]_{\infty}$ (2). Ellipsoids are shown at $50 \%$ probability; hydrogen atoms and lattice solvent were removed for clarity. (A) Asymmetric unit. (B) Growth of the one-dimensional polymer chain; red bonding indicates the ASU. Selected bond lengths $(\AA)$ and angles $\left(^{\circ}\right)$ K1-N1: 2.7921(13), K1-N2: 2.9118(13), K1-N3: 2.7504(13), K1-N4: 3.0472(12), K1-F1: 3.3090(9), K1-F5: 3.1141(10), K1-O1: 2.7830(11), K1-O2': 2.9351(13), K2-N1: 3.2913(12), K2-N2: 2.7581(13), K2-N3: 3.2957(13), K2-N4: 2.8039(13), K2-F3: 3.3678(10), K2-F4': 3.2276(11), K2-F7: 2.9353(9), K2-O2: 2.8039(12), K2-O1': 2.8172(11): C1-F1: 1.3575(19), C5-F2: 1.3644(16), C9-F3: 1.3610(17), C13-F4: 1.3724(14), C14-F5: 1.3608(18), C18-F6: 1.3675(16), C22-F7: 1.3578(16), C26-F8: 1.3640(15), K1-C7-K2: 70.41(3), K1-C20-K2: 68.86(3), O1-K1-K2: 147.97(3), O2-K2-K1: 136.59(3). K1-O1-K2': 98.05(4), K1-O2'-K2': 101.41(3).

The thf ligands in 2 bridge in an almost symmetrical manner between the two potassium atoms, though $\mathrm{O} 2^{\prime}$ coordinates closer to $\mathrm{K} 2^{\prime}$ than $\mathrm{K} 1$. This type of $\mu-1 \mathrm{~K}(O): 2 \mathrm{~K}(O)$ bridging of two thf molecules is no stranger to group one chemistry [18], for example in the 
polymeric sodium diphenyloxidomethanide $\left(\mathrm{Ph}_{2} \mathrm{CO}\right)^{2-}$ polymer $\left[\mathrm{Na}_{2}\left(\mathrm{Ph}_{2} \mathrm{CO}\right)(\mathrm{thf})_{2}\right]$ [33], or the potassium 2,4,6-tris(trifluoromethyl)phenolate $\left(\mathrm{OAr}{ }^{\mathrm{CF} 3}\right)$ complex $\left[\mathrm{K}_{2}\left(\mathrm{OAr}^{\mathrm{CF} 3}\right)_{2}\left(\mathrm{thf}_{4}(\mu \text {-O-thf })_{2}\right]\right.$ [34]. However, examples where the polymeric structure is generated by two thf ligands connecting the dinuclear units is restricted to only one other example in group one chemistry, namely $\left[\mathrm{K}_{4}(\mathrm{COT})_{2}(\mathrm{thf})_{6}\right]_{\infty}$ [35]. One difference between the COT (cyclooctatetraenyl) system and $\mathbf{2}$ is that asymmetric bridging of the thf ligands is more apparent, as both thf ligands favour one metal centre over the other (e.g., K1-O1: 2.839(3), K1-O2: 2.846(5), K2-O1:2.781(3), K2-O2: 2.783(4)). It should also be noted that there are examples where three thf ligands, not two, bridge the monomeric units to create a polymeric network [32,36]. Exposure of crystalline 2 to vacuum immediately causes fracturing of the crystals, giving $\mathbf{1}$. Furthermore, when crystals of $\mathbf{2}$ are isolated and allowed to stand at room temperature, some degree of thf liberation is apparent as the elemental analysis performed on these crystals gave a lower than expected carbon value. The best fit was obtained when the composition was calculated with loss of $0.4 \mathrm{thf}$ molecules from 2. By examining the structure of 2, it seems that upon the liberation of bound thf, the DFForm ligand changes from the asymmetric $\mu-1 \kappa\left(N, N^{\prime}, F\right): 2 \kappa\left(N, N^{\prime}, F^{\prime}\right)$ coordination to a $\mu-\left(N, N^{\prime}, F, F^{\prime}\right):\left(N, N^{\prime}\right)$ binding mode, and the auxiliary fluorine and aromatic carbon atoms become free to engage with adjacent potassium ions, building the complex polymeric network of 1 . Owing to the rapid loss of thf from 2, additional characterisation was difficult. Dissolution in $\mathrm{C}_{6} \mathrm{D}_{6}$ gave rapid formation of a powder, presumably 1 , as a large excess of thf was observed in the ${ }^{1} \mathrm{H}$ NMR spectrum.

Although no monomeric $\left[\mathrm{K}(\mathrm{DFForm})(\mathrm{thf})_{x}\right]$ species could be obtained from thf, we exploited the well-known affinity of 18 -crown- 6 for the potassium ion. Treatment of 1 with 18-crown-6 and crystallisation from a $n$-hexane/toluene solution, gave monomeric [K(DFForm)(18-crown-6)] (3). The structure was determined by X-ray crystallography, where the data were solved and refined in the monoclinic space group $P 2_{1} / n$, with two molecules occupying the asymmetric unit (only one is depicted in Figure 6). The most surprising feature of this structure is the $\mathrm{k}(N, C, F)$ coordination of the DFForm ligand to the potassium centre, as opposed to the expected $k\left(N, N^{\prime}\right)$ coordination that is observed in [K(p-TolForm)(18-crown-6)] [32], and in several other $\mathrm{C}\{\mathrm{NCXN}\}^{-} \mathrm{C}$ based ligand systems [18], such as [K(pyr)(18-crown-6)] (pyr $=1,3,4,6,7,8$-hexahydro-2H-pyrimido[1,2-a]pyrimidide) [37]. The ipso carbon-potassium bond length (Figure 6) lies in the expected range for such interactions. For example, the ipso-carbon potassium interactions observed in the bimetallic 2,6-diphenylphenolate complex [ $\left.\mathrm{KCa}\left(\mathrm{OAr}{ }^{\mathrm{Ph}}\right)_{3}\right]$, has a $\mathrm{K}-\mathrm{C}_{i p s o}$ bond lengths of 3.391(6) $\AA$ [38] and the $\mathrm{K}-\mathrm{C}_{i p s o}$ bond length in the phenylthiolato complex $\left[\mathrm{K}_{2} \mathrm{Fe}(\mathrm{SPh})_{4}\right]$ is 3.477 (5) $\AA$ [39]. Despite the non-binding of N2, there is still charge delocalisation across the NCN bite, as there is only a slight shortening of the free C7-N2 bond, making it far too long for a formal double bond (e.g., DFForm $\left(\mathrm{CPh}_{3}\right)$ : C=N: 1.2762(12) $\AA$ ) [17].

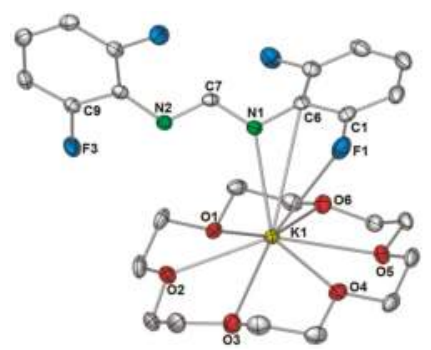

Figure 6. Molecular structure of [K(DFForm)(18-crown-6)] (3). Ellipsoids shown at 50\% probability with hydrogen atoms omitted for clarity. Selected bond lengths (Å): K1-N1: 2.7994(12), K1-C6: 3.4836(14), K1-C1(non-bonding): 3.6886(15), K1-F1: 3.2809(11), K1-N2(non-bonding): 3.9843(13), K1-O(crown): range: 2.8255(11)-2.9525(11), average: 2.89. C1-F1: 1.3584(18), C1-C6:1.401(2), C9-F3: 1.3576(16), C7-N1: 1.3224(18), C7-N2: 1.3161(18). 


\section{Materials and Methods}

\subsection{General Experimental Details}

All reactions were undertaken using Schlenk line and glove box techniques. Solvents (thf, toluene, hexane, $\mathrm{C}_{6} \mathrm{D}_{6}$, thf- $\mathrm{d}_{8}$ ) were purified by distillation over sodium or sodium benzophenone, and were degassed prior to use. NMR experiments were recorded on a Bruker Avance 300 spectrometer or a Bruker AVII+400 machine (Billerica, MA, USA). ${ }^{1} \mathrm{H}$ NMR resonances were referenced to tetramethylsilane by way of the residual ${ }^{1} \mathrm{H}$ resonance of $\mathrm{C}_{6} \mathrm{D}_{6}$ (and ${ }^{19} \mathrm{~F}$ coupled unless specified otherwise). ${ }^{19} \mathrm{~F}-\mathrm{NMR}$ data were ${ }^{1} \mathrm{H}$ decoupled (unless specified otherwise) and referenced to external $\mathrm{CFCl}_{3}$. Microanalyses were performed by the elemental analysis service of London Metropolitan University or by an Elementar Vario Micro cube (Elementar, Langenselbold, Germany) by Wolfgang Bock of Tübingen University. IR spectra were recorded on a Perkin-Elmer 1600 Fourier transform infrared spectrometer $\left(\tilde{v}=4000-500 \mathrm{~cm}^{-1}\right)$, as either mulls in sodium-dried Nujol, or a Nicolet 6700 FTIR spectrometer (Thermo Nicolet, Madison, WI, USA) or using a DRIFT chamber with dry $\mathrm{KBr}$ /sample mixtures and $\mathrm{KBr}$ windows. $\mathrm{K}\left[\left(\mathrm{NSiMe}_{3}\right)_{2}\right]$ was purchased from Sigma-Aldrich (St Louis, MO, USA) and used as received. $N, N^{\prime}$-bis(2,6-difluorophenyl)formamidine (DFFormH) was synthesised by a published procedure [40], 18-crown-6 was purchased from Sigma-Aldrich and used as received.

[K(DFForm) $]_{\infty}$ (1): K[(NSiMe $\left.)_{2}\right](0.25 \mathrm{~g}, 1.3 \mathrm{mmol})$ and DFFormH $(0.33 \mathrm{~g}, 1.2 \mathrm{mmol})$ were each dissolved in toluene and combined with stirring, immediately forming a white, poorly soluble powder. The supernatant solution was decanted and the resulting powder was dried in vacuo. After the addition of thf, the powder dissolved, and then the solution was concentrated and layered with $n$-hexane. Colourless white block crystals grew overnight and were suitable for X-ray diffraction, revealing the composition $[\mathrm{K}(\mathrm{DFF} \text { orm })]_{\infty}(\mathbf{1}$, Yield $=0.30 \mathrm{~g}, 80 \%) .{ }^{1} \mathrm{H} \mathrm{NMR}\left(\mathrm{C}_{6} \mathrm{D}_{6}, 400 \mathrm{MHz}, 25{ }^{\circ} \mathrm{C}\right)$ : $\delta 8.88$ (br s, $1 \mathrm{H}, \mathrm{NCHN}), 6.68(\mathrm{~m}, 4 \mathrm{H}, \mathrm{Ar}-H(3,5)), 6.63(\mathrm{~m}, 2 \mathrm{H}, \mathrm{Ar}-H(4)) .{ }^{19} \mathrm{~F} \mathrm{NMR}\left(\mathrm{C}_{6} \mathrm{D}_{6}, 25{ }^{\circ} \mathrm{C}\right)$ : $\delta-127.2$ (br s). ${ }^{1} \mathrm{H}$ NMR (thf-d $8,400 \mathrm{MHz}, 25^{\circ} \mathrm{C}$ ): $\delta 8.92\left(\mathrm{p}^{5} J_{\mathrm{H}-\mathrm{F}}: 3.09 \mathrm{~Hz}, 1 \mathrm{H}, \mathrm{NCHN}\right), 6.68(\mathrm{~m}, 4 \mathrm{H}$, Ar- $H(3,5)), 6.46(\mathrm{~m}, 2 \mathrm{H}, \mathrm{Ar}-H(4)) .{ }^{1} \mathrm{H} \mathrm{NMR}$ (thf-d $8,400 \mathrm{MHz}, 25{ }^{\circ} \mathrm{C},{ }^{19} \mathrm{~F}$ decoupled): $\delta 8.89$ (s, $1 \mathrm{H}$, $\mathrm{NCHN}), 6.68(\mathrm{~m}, 4 \mathrm{H}, \mathrm{Ar}-H(3,5)), 6.46(\mathrm{~m}, 2 \mathrm{H}, \mathrm{Ar}-H(4)) .{ }^{19} \mathrm{~F} \mathrm{NMR}\left(\right.$ thf-d, $\left.25{ }^{\circ} \mathrm{C}\right): \delta-127.8(\mathrm{~s}) .{ }^{19} \mathrm{~F} \mathrm{NMR}$ (thf-d $\mathrm{d}_{8}, 25^{\circ} \mathrm{C}, \mathrm{F}-\mathrm{H}$ coupled) -127.8 (br s). IR (DRIFT): $v 1612$ (m), 1562 (vs), 1513 (s), 1477 (s), 1464 (s), 1395 (w), 1326 (m), 1287 (w), 1254 (m), 1231 (m), 1199 (s), $1062(\mathrm{w}), 1005$ (m), 984 (s), $954(\mathrm{w}), 922(\mathrm{w})$, $828(\mathrm{w}), 779(\mathrm{~m}), 766(\mathrm{~m})$. Elemental analysis $\left(\mathrm{C}_{13} \mathrm{H}_{7} \mathrm{~F}_{4} \mathrm{KN}_{2}, 306.31 \mathrm{~g} \cdot \mathrm{mol}^{-1}\right)$ : calcd.: C 50.97, H 2.30, N 9.15, found: C 50.81, H 2.34, N 9.07.

$\left[K_{2}(\text { DFForm })_{2}(\text { thf })_{2}\right]_{\infty}$ (2): $\mathbf{1}(0.10 \mathrm{~g}, 0.32 \mathrm{mmol})$ was dissolved in minimal thf and concentrated in vacuo, giving colourless crystals that were not suitable for $\mathrm{X}$-ray diffraction. The concentrated solution was stored at $-35^{\circ} \mathrm{C}$, where large colourless block crystals grew of $\left[\mathrm{K}_{2}(\mathrm{DFForm})_{2}(\text { thf })_{2}\right](2)$, suitable for $\mathrm{X}$-ray diffraction. Upon exposure to vacuum, the crystals fractured and a white powder was obtained, likely consisting of a mixture of 1 and 2 . (Yield $=0.11 \mathrm{~g}, 89 \%)$. ${ }^{1} \mathrm{H} \mathrm{NMR}\left(\mathrm{C}_{6} \mathrm{D}_{6}, 400 \mathrm{MHz}\right.$, $25{ }^{\circ} \mathrm{C}$, formation of insoluble white powder upon solvent addition, giving a large excess of thf in solution): $\delta 1.42\left(\mathrm{~m}, 232 \mathrm{H}\right.$, thf- $\left.\beta-\mathrm{CH}_{2}\right), 3.57\left(\mathrm{~m}, 232 \mathrm{H}\right.$, thf- $\left.\alpha-\mathrm{CH}_{2}\right), 6.36(\mathrm{~m}, 2 \mathrm{H}, \mathrm{Ar}-\mathrm{H} 4) 6.67(\mathrm{~m}, 4 \mathrm{H}$, $\operatorname{Ar}-H(3,5)), 8.88$ (br s, $1 \mathrm{H}, \mathrm{NCHN}) .{ }^{19} \mathrm{~F} \mathrm{NMR}\left(\mathrm{C}_{6} \mathrm{D}_{6}, 25^{\circ} \mathrm{C}\right): \delta-127.1$ (br s). IR (DRIFT): $v 1613$ (m), 1564 (vs), 1551 (vs), 1514 (m), 1477 (vs), 1464 (vs), 1395 (w), 1325 (s), 1254 (m), 1231 (w), 1200 (s), 1062 (w), $1005(\mathrm{w}), 984.6(\mathrm{~s}), 955(\mathrm{w}), 922(\mathrm{w}), 827(\mathrm{w}), 799(\mathrm{w}), 766(\mathrm{~m}), 742(\mathrm{w}), 716(\mathrm{~m})$. Elemental analysis calcd (\%) (for $\mathrm{C}_{34} \mathrm{H}_{30} \mathrm{~F}_{8} \mathrm{~K}_{2} \mathrm{~N}_{4} \mathrm{O}_{2}, 756.81 \mathrm{~g} \cdot \mathrm{mol}^{-1}$, pre-dried powder under vacuum). C 53.95, $\mathrm{H}$ 4.00, $\mathrm{N}$ 7.40, found: C 49.64, H 2.74, N 8.44. When the crystals were dried by slow evaporation in a glove box, a composition of $\left[\mathrm{K}_{2}(\mathrm{DFForm})_{2}(\mathrm{thf})_{1.6}\right]$ was supported, calcd. $\left(\mathrm{C}_{58.4} \mathrm{H}_{40.8} \mathrm{~F}_{8} \mathrm{~K}_{2} \mathrm{~N}_{4} \mathrm{O}_{1.6}, 727.96 \mathrm{~g} \cdot \mathrm{mol}^{-1}\right)$ : C 53.46, H 3.71, N 7.69 found: C 53.08, H 3.66, N 7.35.

[K(DFForm)(18-crown-6)] (3): If $1(\sim 0.10 \mathrm{~g}, 0.32 \mathrm{mmol})$ was crystallised from toluene/hexane solutions in the presence of one equivalent of 18-crown-6 $(\sim 0.09 \mathrm{~g}, 0.34 \mathrm{mmol})$, pale yellow block crystals of [K(DFForm)(18-crown-6)] (3) developed. (Yield $=\sim 0.07 \mathrm{~g}, 34 \%) .{ }^{1} \mathrm{H}$ NMR $\left(\mathrm{C}_{6} \mathrm{D}_{6}, 300 \mathrm{MHz}\right.$ $303.2 \mathrm{~K}): \delta 9.15$ (s, $1 \mathrm{H}, \mathrm{NCHN}), 6.84$ (m, 4 H, Ar-H(3,5)), 6.42 (m, 2 H, Ar-H(4)), 3.22 (br s, 24 H, 
18-crown-6). ${ }^{19} \mathrm{~F}$ NMR $\left(\mathrm{C}_{6} \mathrm{D}_{6}, 303.2 \mathrm{~K}\right): \delta=-125.81$ (br s). IR (Nujol): $\tilde{v}=1588$ (vs), 1540 (vs), 1259 (vs), 1193 (m), 1096 (s), 1004 (s), 956 (m), 818 (m). Elemental analysis returned poor C H N values. $\left(\mathrm{C}_{25} \mathrm{H}_{31} \mathrm{~F}_{4} \mathrm{KN}_{2} \mathrm{O}_{6}, 570.62 \mathrm{~g} \cdot \mathrm{mol}^{-1}\right)$ : calcd. C 52.62, H 5.47, N 4.91, found: C 46.87, H 4.93, N 5.21.

\subsection{X-ray Crystallography}

All compounds were examined on a "Bruker APEX-II CCD" diffractometer at 100.15 or $150.15 \mathrm{~K}$, mounted on a fibre loop in Paratone-N. Absorption corrections were completed using Apex II program suite [41]. Structural solutions were obtained by charge flipping $(1,2,3)$ [42] methods, and refined using full matrix least squares methods against $F^{2}$ using SHELX2013 [43], within the OLEX 2 graphical interface [43]. CCDC numbers: 1 (1540263), 2 (1540264), 3 (1540265).

[K(DFForm) $]_{\infty}$ (1): $\mathrm{C}_{13} \mathrm{H}_{7} \mathrm{~F}_{4} \mathrm{KN}_{2}(M=306.31 \mathrm{~g} / \mathrm{mol})$ : triclinic, space group $P-1$ (no. 2), $a=7.4437(2) \AA, b=7.5357(2) \AA, c=11.8891(3) \AA, \alpha=100.6590(10)^{\circ}, \beta=101.9020(10)^{\circ}, \gamma=101.1070(10)^{\circ}$, $V=622.56(3) \AA^{3}, Z=2, T=100(2) \mathrm{K}, \mu(\mathrm{MoK} \alpha)=0.466 \mathrm{~mm}^{-1}$, Dcalc $=1.634 \mathrm{~g} / \mathrm{cm}^{3}, 10877$ reflections measured $\left(5.66^{\circ} \leq 2 \Theta \leq 60.48^{\circ}\right), 3657$ unique $\left(R_{\text {int }}=0.0152, R_{\text {sigma }}=0.0174\right)$ which were used in all calculations. The final $R_{1}$ was $0.0279(>2 \sigma(\mathrm{I}))$ and $w R_{2}$ was 0.0734 (all data). Note: NCHN hydrogen atom manually assigned from identified $\mathrm{Q}$ peak.

[K K $_{2}$ (DFForm) $\left.)_{2}(\text { thf })_{2}\right]_{\infty}$ (2): $\mathrm{C}_{34} \mathrm{H}_{30} \mathrm{~F}_{8} \mathrm{~K}_{2} \mathrm{~N}_{4} \mathrm{O}_{2}(M=756.82 \mathrm{~g} / \mathrm{mol})$ : monoclinic, space group $P 2_{1}$ (no. 4), $a=7.55040(10) \AA, b=19.8885(3) \AA, c=11.6408(2) \AA, \beta=105.4479(6)^{\circ}, V=1684.90(4) \AA^{3}$, $\mathrm{Z}=4, T=100.1 \mathrm{~K}, \mu(\mathrm{MoK} \alpha)=0.364 \mathrm{~mm}^{-1}$, Dcalc $=1.492 \mathrm{~g} / \mathrm{cm}^{3}, 17983$ reflections measured $\left(3.62^{\circ} \leq 2 \Theta \leq 60.66^{\circ}\right), 8299$ unique $\left(R_{\text {int }}=0.0136, R_{\text {sigma }}=0.0201\right)$, which were used in all calculations. The final $R_{1}$ was $0.0262(>2 \sigma(\mathrm{I}))$ and $w R_{2}$ was 0.0652 (all data).

2[K(DFForm)(18-crown-6)] (3): $\mathrm{C}_{50} \mathrm{H}_{62} \mathrm{~F}_{8} \mathrm{~K}_{2} \mathrm{~N}_{4} \mathrm{O}_{12}(M=1141.23)$ : note: two molecules present in the asymmetric unit. monoclinic, space group $P 2_{1} / \mathrm{n}$ (no. 14), $a=10.9773(4) \AA, b=15.3047(5) \AA$, $c=31.3860(10) \AA, \beta=93.674(2)^{\circ}, V=5262.1(3) \AA^{3}, Z=4, T=123.15 \mathrm{~K}, \mu(\mathrm{MoK} \alpha)=0.273 \mathrm{~mm}^{-1}$, Dcalc $=1.441 \mathrm{~g} / \mathrm{mm}^{3}, 78411$ reflections measured $(2.6 \leq 2 \Theta \leq 56.76), 13119$ unique $\left(R_{\text {int }}=0.0369\right.$, $\left.R_{\text {sigma }}=0.0266\right)$ which were used in all calculations. The final $R_{1}$ was $0.0321(\mathrm{I}>2 \sigma(\mathrm{I}))$ and $w R_{2}$ was 0.1146 (all data).

\section{Conclusions}

Complexation of $N, N^{\prime}$-bis(2,6-difluorophenyl)formamidinate to potassium generates a species which rapidly liberated coordinated thf, giving a two-dimensional polymeric network $[\mathrm{K}(\mathrm{DFForm})]_{\infty}(\mathbf{1})$, based on a complex and unprecedented formamidinate binding mode. This binding was shown to be completely different from the analogous $[K(F F o r m)]_{\infty}$ (FForm: $N, N^{\prime}$-bis(2-fluorophenyl)formamidinate) mono-directional polymer. With access to two additional auxiliary o-fluorine atoms (namely F2 and F4), a new dimension for the polymeric network could be generated, which was further reinforced by potassium-arene interactions and nitrogen-based bridging of the DFForm ligand. The formation of this network was so favourable that it could be generated by simple $n$-hexane layering of thf solutions, or the evaporation of thf solutions to dryness, and is the first example of a two-dimensional polymeric $N, N^{\prime}$-bis(aryl)formamidinate network. A likely transient species between a monomeric thf solution derivative [K(DFForm)(thf $\left.)_{x}\right]$ and 1 was also obtained and identified as a one-dimensional polymer with two bridging thf ligands, namely $\left[\mathrm{K}_{2}(\mathrm{DFForm})_{2}(\mathrm{thf})_{2}\right]_{\infty}$ (2). Complex 2 lost thf in the solid state, slowly forming $\mathbf{1}$ upon storage at room temperature. A monomeric derivative of $\mathbf{1}$ was obtained through use of 18 -crown-6, giving [K(DFForm)(18-crown-6)] (3), which showed a highly unexpected $\mathrm{k}\left(\mathrm{N}, \mathrm{C}_{\text {ispo }}, F\right)$ coordination. Such examples as these highlight the strong affinity of potassium for donor atoms, especially fluorine, and how the simple addition of more fluorine atoms to a ligand system can expand the coordination network of the ligand, and can generate unexpected structural consequences.

Supplementary Materials: The following are available online at www.mdpi.com/2304-6740/5/2/26/s1, CIFs and CIF checked files. 
Acknowledgments: We thank the ARC (DP16010640) for funding, and Professor Reiner Anwander for use of the elemental analysis and IR services of Tuebingen University.

Author Contributions: The project concept was devised equally by all authors. Daniel Werner performed the experiments and analyzed the resulting data. The materials were provided by Glen B. Deacon and Peter C. Junk. The manuscript was written by Daniel Werner and edited by Glen B. Deacon and Peter C. Junk.

Conflicts of Interest: The authors declare no conflict of interest.

\section{References}

1. Edelmann, F.T. Chapter two-Recent progress in the chemistry of metal amidinates and guanidinates: Syntheses, catalysis and materials. In Advances in Organometallic Chemistry; Anthony, F.H., Mark, J.F., Eds.; Academic Press: London, UK, 2013; Volume 61, pp. 55-374.

2. Edelmann, F.T. Chapter 3 advances in the coordination chemistry of amidinate and guanidinate ligands. In Advances in Organometallic Chemistry; Anthony, F.H., Mark, J.F., Eds.; Academic Press: London, UK, 2008; Volume 57, pp. 183-352.

3. Junk, P.C.; Cole, M.L. Alkali-metal bis(aryl)formamidinates: A study of coordinative versatility. Chem. Commun. 2007, 16, 1579-1590. [CrossRef] [PubMed]

4. Cotton, F.A.; Daniels, L.M.; Murillo, C.A. A systematic approach in the preparation of compounds with $\sigma_{2}-\pi_{4}$ vanadium-to-vanadium triple bonds: Synthesis, reactivity, and structural characterization. Inorg. Chem. 1993, 32, 2881-2885. [CrossRef]

5. Deacon, G.B.; Hossain, M.E.; Junk, P.C.; Salehisaki, M. Rare-earth $N, N^{\prime}$-diarylformamidinate complexes. Coord. Chem. Rev. 2017. [CrossRef]

6. Cotton, F.A.; Daniels, L.M.; Murillo, C.A. The first complex with a $\sigma_{2} \pi_{4}$ triple bond between vanadium atoms in a ligand framework of fourfold symmetry- $\left[\mathrm{V}_{2}\left\{\left(p-\mathrm{CH}_{3} \mathrm{C}_{6} \mathrm{H}_{4}\right) \mathrm{NC}(\mathrm{H}) \mathrm{N}\left(p-\mathrm{C}_{6} \mathrm{H}_{4} \mathrm{CH}_{3}\right)\right\}_{4}\right]$. Angew. Chem. Int. Ed. 1992, 31, 737-738. [CrossRef]

7. Cotton, F.A.; Daniels, L.M.; Maloney, D.J.; Matonic, J.H.; Murillo, C.A. Divalent metal chloride formamidine complexes, $\mathrm{M}_{11}=\mathrm{Fe}, \mathrm{Co}$ and Pt. Syntheses and structural characterization. Polyhedron 1994, 13, 815-823. [CrossRef]

8. Lyhs, B.; Bläser, D.; Wölper, C.; Schulz, S. Syntheses and X-ray crystal structures of organoantimony diazides. Chem. Eur. J. 2011, 17, 4914-4920. [CrossRef] [PubMed]

9. Deacon, G.B.; Junk, P.C.; Wang, J.; Werner, D. Reactivity of bulky formamidinatosamarium(II or III) complexes with $\mathrm{C}=\mathrm{O}$ and $\mathrm{C}=\mathrm{S}$ bonds. Inorg. Chem. 2014, 53, 12553-12563. [CrossRef] [PubMed]

10. Jones, C.; Mills, D.P.; Rivard, E.; Stasch, A.; Woodul, W.D. Synthesis and crystal structures of anionic gallium(II) and gallium(III) heterocyclic compounds derived from a gallium(I) $n$-heterocyclic carbene analogue. J. Chem. Crystallogr. 2010, 40, 965-969. [CrossRef]

11. Cole, M.L.; Davies, A.J.; Jones, C.; Junk, P.C. Persistent $\pi$-arene interactions in bulky formamidinate complexes of potassium. J. Organomet. Chem. 2007, 692, 2508-2518. [CrossRef]

12. Cole, M.L.; Junk, P.C. Potassium complexes of the 'super' formamidine $\left(2,6-\mathrm{pr}_{2}{ }^{i} \mathrm{C}_{6} \mathrm{H}_{3}\right) \mathrm{NC}(\mathrm{H}) \mathrm{NH}(2,6-$ $\left.\mathrm{pr}_{2}{ }^{i} \mathrm{C}_{6} \mathrm{H}_{3}\right)$, Hdippform.: Synthesis and molecular structure of $\left[\left\{\mathrm{K}(\text { DippForm })_{2} \mathrm{~K}(\mathrm{thf})_{2}\right\}_{n}\right] \cdot n$ thf and [K(DippForm)(thf $\left.)_{3}\right] \cdot$ HDippForm. J. Organomet. Chem. 2003, 666, 55-62. [CrossRef]

13. Baldamus, J.; Berghof, C.; Cole, M.L.; Evans, D.J.; Hey-Hawkins, E.; Junk, P.C. Attenuation of reactivity by product solvation: Synthesis and molecular structure of $\left[\mathrm{K}\left\{\left(\eta^{6}-\mathrm{Mes}\right) \mathrm{NC}(\mathrm{H}) \mathrm{N}(\mathrm{Mes})\right\}\left\{\left(\eta^{6}-\right.\right.\right.$ Mes)NHC(H)N(Mes)], the first formamidinate complex of potassium. J. Chem. Soc. Dalton Trans. 2002, 14, 2802-2804. [CrossRef]

14. Hamidi, S.; Jende, L.N.; Martin Dietrich, H.; Maichle-Mössmer, C.; Törnroos, K.W.; Deacon, G.B.; Junk, P.C.; Anwander, R. C-H bond activation and isoprene polymerization by rare-earth-metal tetramethylaluminate complexes bearing formamidinato $n$-ancillary ligands. Organometallics 2013, 32, 1209-1223. [CrossRef]

15. Kulkarni, N.V.; Elkin, T.; Tumaniskii, B.; Botoshansky, M.; Shimon, L.J.W.; Eisen, M.S. Asymmetric bis(formamidinate) group 4 complexes: Synthesis, structure and their reactivity in the polymerization of $\alpha$-olefins. Organometallics 2014, 33, 3119-3136. [CrossRef]

16. Deacon, G.B.; Junk, P.C.; Werner, D. Enhancing the value of free metals in the synthesis of lanthanoid formamidinates: Is a co-oxidant needed? Chem. Eur. J. 2016, 22, 160-173. [CrossRef] [PubMed] 
17. Werner, D.; Deacon, G.B.; Junk, P.C.; Anwander, R. Cerium(III/IV)formamidinate chemistry, and a stable cerium(IV) diolate. Chem. Eur. J. 2014, 20, 4426-4438. [CrossRef] [PubMed]

18. Allen, F.H. The cambridge structural database: A quarter of a million crystal structures and rising. Acta Crystallogr. Sec. B 2002, 58, 380-388. [CrossRef]

19. Cole, M.L.; Evans, D.J.; Junk, P.C.; Smith, M.K. Structural studies of $N, N^{\prime}$-di(ortho-fluorophenyl)formamidine group 1 metallation. Chem. Eur. J. 2003, 9, 415-424. [CrossRef] [PubMed]

20. Cotton, F.A.; Murillo, C.A.; Pascual, I. Quadruply bonded dichromium complexes with variously fluorinated formamidinate ligands. Inorg. Chem. 1999, 38, 2182-2187. [CrossRef] [PubMed]

21. Cole, M.L.; Davies, A.J.; Jones, C.; Junk, P.C. Lithium and sodium N,N'-di(2,6-dialkylphenyl)formamidinate complexes. J. Organomet. Chem. 2004, 689, 3093-3107. [CrossRef]

22. Cole, M.L.; Junk, P.C.; Louis, L.M. Synthesis and structural characterisation of some novel lithium and sodium $N, N^{\prime}$-di(para-tolyl)formamidinate complexes. J. Chem. Soc. Dalton Trans. 2002, 3906-3914. [CrossRef]

23. Cole, M.L.; Davies, A.J.; Jones, C.; Junk, P.C. Mononuclear formamidinate complexes of lithium and sodium. Z. Anorg. Allg. Chem. 2011, 637, 50-55. [CrossRef]

24. Cole, M.L.; Deacon, G.B.; Forsyth, C.M.; Junk, P.C.; Konstas, K.; Wang, J.; Bittig, H.; Werner, D. Synthesis, structures and reactivity of lanthanoid(II)formamidinates of varying steric bulk. Chem. Eur. J. 2013, 19, 1410-1420. [CrossRef] [PubMed]

25. Werner, D.; Zhao, X.; Best, S.P.; Maron, L.; Junk, P.C.; Deacon, G.B. Bulky ytterbium formamidinates stabilise complexes with radical ligands, and related samarium "tetracyclone" chemistry. Chem. Eur. J. 2017, 23, 2084-2102. [CrossRef] [PubMed]

26. Deacon, G.B.; Junk, P.C.; Werner, D. The synthesis and structures of rare earth 2-fluorophenyland 2,3,4,5-tetrafluorophenyl- $N, N^{\prime}$-bis(aryl)formamidinate complexes. Polyhedron 2016, A103, 178-186. [CrossRef]

27. Cole, M.L.; Deacon, G.B.; Forsyth, C.M.; Junk, P.C.; Konstas, K.; Wang, J. Steric modulation of coordination number and reactivity in the synthesis of lanthanoid(III)formamidinates. Chem. Eur. J. 2007, 13, 8092-8110. [CrossRef] [PubMed]

28. Deacon, G.B.; Junk, P.C.; Werner, D. Lanthanoid induced C-F activation of all fluorine atoms of one $\mathrm{CF}_{3}$ group. Eur. J. Inorg. Chem. 2015, 9, 1484-1489. [CrossRef]

29. Shannon, R.D. Revised effective ionic radii and systematic studies of interatomic distances in halides and chalcogenides. Acta Cryst. 1976, A32, 155-169. [CrossRef]

30. Krackl, S.; Inoue, S.; Driess, M.; Enthaler, S. Intermolecular hydrogen-fluorine interaction in dimolybdenum triply bonded complexes modified by fluorinated formamidine ligands for the construction of 2D- and 3D-networks. Eur. J. Inorg. Chem. 2011, 13, 2103-2111. [CrossRef]

31. Deacon, G.B.; Junk, P.C.; Macreadie, L.K.; Werner, D. Structural and reactivity consequences of reducing steric bulk of $N, N^{\prime}$-diarylformamidinates coordinated to lanthanoid ions. Eur. J. Inorg. Chem. 2014, 5240-5250. [CrossRef]

32. Baldamus, J.; Berghof, C.; Cole, M.L.; Evans, D.J.; Hey-Hawkins, E.; Junk, P.C. N,N'-di(tolyl)formamidinate complexes of potassium: Studies of ancillary donor imposed molecular and supramolecular structure. J. Chem. Soc. Dalton Trans. 2002, 22, 4185-4192. [CrossRef]

33. Geier, J.; Ruegger, H.; Grutzmacher, H. Sodium compounds of the benzophenone dianion (diphenyloxidomethanide). Dalton Trans. 2006, 1, 129-136. [CrossRef] [PubMed]

34. Brooker, S.; Edelmann, F.T.; Kottke, T.; Roesky, H.W.; Sheldrick, G.M.; Stalke, D.; Whitmire, K.H. Comparison of the X-ray crystal structures of the sodium and potassium 2,4,6-tris(trifluoromethyl)phenoxides (RO-) and 2,4,6-tris(trifluoromethyl)benzenethiolates (RS-); $\left[\mathrm{Na}(\mathrm{OR})(\text { thf })_{2}\right]_{2},\left[\mathrm{k}(\mathrm{OR})(\mathrm{thf})_{2}(\mu \text {-thf) }]_{2},\left[\mathrm{Na}(\mathrm{SR})(\text { thf })_{2} \cdot 0.25\right.\right.$ thf $]$ and $[\mathrm{K}(\mathrm{SR})(\mathrm{thf})]($ thf $=$ tetrahydrofuran). J. Chem. Soc. Chem. Commun. 1991, 3, 144-146.

35. Hu, N.; Gong, L.; Jin, Z.; Chen, W. Crystal structure of cyclooctatetraenylpotassium, $\mathrm{C}_{8} \mathrm{H}_{8} \mathrm{~K}_{2} \cdot\left(\mathrm{OC}_{4} \mathrm{H}_{8}\right)_{3}$. J. Organomet. Chem. 1988, 352, 61-66. [CrossRef]

36. Antolini, F.; Hitchcock, P.B.; Khvostov, A.V.; Lappert, M.F. Synthesis and structures of alkali metal amides derived from the ligands $\left[\mathrm{N}\left(\mathrm{SiMe}_{2} \mathrm{Ph}\right)\left(\mathrm{SiMe}_{3}\right)\right]^{-},\left[\mathrm{N}(\mathrm{tbu})\left(\mathrm{SiMe}_{3}\right)\right]^{-},\left[\mathrm{N}(\mathrm{Ph})\left(2-\mathrm{C}_{5} \mathrm{H}_{4} \mathrm{~N}\right)\right]^{-}$, and $\left[\mathrm{N}\left(2-\mathrm{C}_{5} \mathrm{H}_{4} \mathrm{~N}\right)_{2}\right]^{-}$. Eur. J. Inorg. Chem. 2003, 18, 3391-3400. [CrossRef]

37. Coles, M.P.; Hitchcock, P.B. Bicyclic guanidinates in mono- and di-valent metal complexes, including group $1 / 2$ and group $1 / 12$ heterometallic systems. Aus. J. Chem. 2013, 66, 1124-1130. [CrossRef] 
38. Zuniga, M.F.; Deacon, G.B.; Ruhlandt-Senge, K. Developments in heterobimetallic s-block systems: Synthesis and structural survey of molecular $\mathrm{M} / \mathrm{AE}(\mathrm{M}=\mathrm{Li}, \mathrm{Na}, \mathrm{K}, \mathrm{Cs} ; \mathrm{AE}=\mathrm{Ca}, \mathrm{Sr})$ aryloxo complexes. Inorg. Chem. 2008, 47, 4669-4681. [CrossRef] [PubMed]

39. Yu, X.-Y.; Jin, G.-X.; Weng, L.-H. Phenylthiolate as a $\sigma$ and $\pi$ donor ligand: Synthesis of a 3-D organometallic coordination polymer $\left[\mathrm{K}_{2} \mathrm{Fe}(\mathrm{SPh})_{4}\right]_{n}$. Chem. Commun. 2004, 13, 1542-1543. [CrossRef] [PubMed]

40. Roberts, R.M. Acid Catalyzed Reaction of Diarylformamidines with Ethyl Orthoformate. J. Am. Chem. Soc. 1949, 71, 3848-3849. [CrossRef]

41. Sheldrick, G.M. SADABS; program for empirical absorption correction; University of Gottingen: Gottingen, Germany, 1996

42. Dolomanov, O.V.; Bourhis, L.J.; Gildea, R.J.; Howard, J.A.K.; Puschmann, H. OLEX2: A complete structure solution, refinement and analysis program. J. Appl. Cryst. 2009, 42, 339-341. [CrossRef]

43. Sheldrick, G.M. A short history of SHELX. Acta. Crystallogr. 2008, A64, 112. [CrossRef] [PubMed]

(c) 2017 by the authors. Licensee MDPI, Basel, Switzerland. This article is an open access article distributed under the terms and conditions of the Creative Commons Attribution (CC BY) license (http:/ / creativecommons.org/licenses/by/4.0/). 
Article

\title{
Insights into Molecular Beryllium-Silicon Bonds
}

\author{
Dominik Naglav, Briac Tobey, Kevin Dzialkowski, Georg Jansen, Christoph Wölper and \\ Stephan Schulz * \\ Faculty of Chemistry and Center for NanoIntegration (CENIDE), University of Duisburg-Essen, \\ DE-45117 Essen, Germany; Dominik.Naglav@uni-due.de (D.N.); briac.tobey@uni-due.de (B.T.); \\ kevin.dzialkowski@stud.uni-due.de (K.D.); georg.jansen@uni-due.de (G.J.); \\ christoph.woelper@uni-due.de (C.W.) \\ * Correspondence: stephan.schulz@uni-due.de; Tel.: +49-201-183-4635
}

Academic Editor: Matthias Westerhausen

Received: 23 March 2017; Accepted: 4 April 2017; Published: 10 April 2017

\begin{abstract}
We present the synthesis of two silyl beryllium halides HypSiBeX (thf) $\left(\mathrm{HypSi}=\mathrm{Si}\left(\mathrm{SiMe}_{3}\right)_{3}\right.$, $\mathrm{X}=\mathrm{Cl} \mathbf{2 a}, \mathrm{I} 4 \mathbf{a}$ ) and the molecular structure of $\mathbf{2 a}$ as determined by single crystal X-ray diffraction. Compounds $2 \mathrm{a}$ and $\mathbf{4 a}$ were characterized via multi-nuclear NMR spectroscopy $\left({ }^{1} \mathrm{H},{ }^{9} \mathrm{Be},{ }^{13} \mathrm{C},{ }^{29} \mathrm{Si}\right)$, and the bonding situation was further investigated using quantum chemical calculations (with the addition of further halides $\mathrm{X}=\mathrm{F} \mathbf{1 b}, \mathrm{Cl} \mathbf{2 b}, \mathrm{Br} \mathbf{3 b}, \mathrm{I} \mathbf{4 b}$ ). The nature of the beryllium silicon bond in the context of these compounds is highlighted and discussed.
\end{abstract}

Keywords: beryllium; silicon; main group metal complexes; X-ray diffraction; multi-nuclear NMR spectroscopy; quantum chemical calculations

\section{Introduction}

The organometallic and coordination chemistry of beryllium has gained attention as several groups, including ours, started to focus their research on this rather unknown and hitherto neglected element [1]. In the last five years, many groundbreaking discoveries, including the first compound with beryllium in the formal oxidation state 0 by the Braunschweig group [2], a beryllium-induced $\mathrm{C}-\mathrm{N}$ bond activation in an $\mathrm{N}$-heterocyclic carbene [3], the structural characterization of the long known $\mathrm{Be}\left(\mathrm{N}\left(\mathrm{SiMe}_{3}\right)_{2}\right)_{2}[4]$, the synthesis of the first bis(diphenylphosphinimino)methanide and -methanediide beryllium complexes [5], and the synthesis of ether-free beryllium organyls [6], were reported. Even in the field of material chemistry and catalysis, groups around the world started to investigate the unique properties of beryllium compounds [7]. The prejudices and reservations that people might have against beryllium due to its potential risks were discussed and elucidated in our recently reported review [8].

Part of our research focuses on the synthesis of heteroleptic beryllium compounds bearing at least one halide of the RBeX type ( $\mathrm{R}=$ organic substituent, $\mathrm{X}=\mathrm{F}, \mathrm{Cl}, \mathrm{Br}, \mathrm{I})$ and their structural characterization via single crystal $\mathrm{X}$-ray diffraction, multi-nuclear NMR, and quantum mechanical calculations to achieve a deeper understanding of the bonding nature in beryllium compounds $[4,9,10]$. This led to several publications, which highlight the subtle influences of the substituents on the chemical and electronic properties of the resulting compounds. We extended these studies now to silicon-containing substituents, the heavier congener of carbon. To the best of our knowledge, compounds of the type $\mathrm{R}^{\prime} \mathrm{BeX}\left(\mathrm{R}=\mathrm{SiR}_{3}, \mathrm{X}=\mathrm{F}, \mathrm{Cl}, \mathrm{Br}\right.$, I) with a beryllium-silicon bond have to date rarely been studied [11,12]. Our findings are presented in this work to blaze a trail for research on the chemistry of beryllium-silicon compounds and for a deeper understanding of the beryllium-silicon bond. 


\section{Results and Discussion}

\subsection{Synthesis}

The reaction of $\mathrm{LiSi}\left(\mathrm{SiMe}_{3}\right) \cdot(\mathrm{thf})_{2.6}$ with $\mathrm{BeX}_{2}(\mathrm{X}=\mathrm{Cl}$, I) in a 1:1 mixture of dry toluene/thf at $60{ }^{\circ} \mathrm{C}$ led to the formation of $\mathbf{2 a}$ and $\mathbf{4 a}$ after stirring for $16 \mathrm{~h}$ (Scheme 1), which was confirmed by ${ }^{9} \mathrm{Be}$ NMR spectroscopy. All volatiles were removed under reduced pressure, and the residue was dried for $2 \mathrm{~h}$ in an oil-pump vacuum. The residue was then dissolved in a small amount of dry toluene and filtrated, and the compounds were crystallized at $-28{ }^{\circ} \mathrm{C}$ (yield: $2 \mathbf{a} 83 \%, 4 a$ 87\%). 2a and $4 \mathbf{a}$ were obtained as colorless crystalline solids, which dissolve easily in a number of typical coordinating $\left(\mathrm{Et}_{2} \mathrm{O}, \mathrm{THF}\right)$ and non-coordinating solvents (hexane, cyclohexane, toluene) and were characterized by multi-nuclear NMR spectroscopy $\left({ }^{1} \mathrm{H},{ }^{9} \mathrm{Be},{ }^{13} \mathrm{C},{ }^{29} \mathrm{Si}\right.$; Figures S1-S8).

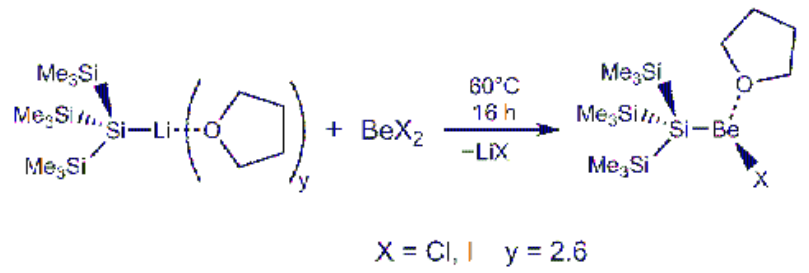

Scheme 1. Synthesis of $2 \mathrm{a}$ and $4 \mathbf{a}$.

\subsection{NMR-Spectroscopy}

The ${ }^{9}$ Be NMR shifts underline that the tetrahedral geometry of the complexes that is found in the solid state is also preserved in solution. The thf molecules are still coordinating with the beryllium. An overview of typical ${ }^{9} \mathrm{Be}$ NMR shifts of several heteroleptic complexes of the general type RBeX depending on the coordination mode is given in Table 1, which also includes ether-coordinated $\mathrm{BeX}_{2}\left(\mathrm{OEt}_{2}\right)_{2}(\mathrm{X}=\mathrm{Cl}, \mathrm{Br})$, which adopt tetrahedral structures both in solution and in the solid state $[13,14]$, silyl-substituted compounds $\mathrm{CpBeSiR}_{3}$ and $\mathrm{Be}\left[\mathrm{N}\left(\mathrm{SiMe}_{3}\right)_{2}\right]_{2}$, respectively.

Table 1. Overview of typical ${ }^{9} \mathrm{Be}$ NMR shifts depending on their complex geometry and their respective coordination modes.

\begin{tabular}{|c|c|c|c|c|c|}
\hline Compound & $\begin{array}{c}{ }^{9} \text { Be NMR Shifts } \\
\text { ( } \delta \text { in ppm) }\end{array}$ & Solvent & Coordination Mode & Coordination Number & Literature \\
\hline$\left(\mathrm{Me}_{3} \mathrm{Si}\right)_{3} \mathrm{SiBeCl}$ (thf) & 2.45 & thf $-d_{8}$ & tetrahedral & 4 & this work \\
\hline$\left(\mathrm{Me}_{3} \mathrm{Si}\right)_{3} \mathrm{SiBeI} \cdot(\mathrm{thf})$ & -0.92 & thf $-d_{8}$ & tetrahedral & 4 & this work \\
\hline $\mathrm{BeCl}_{2}\left(\mathrm{OEt}_{2}\right)_{2}$ & 2.6 & $\mathrm{C}_{6} \mathrm{D}_{6}$ & tetrahedral & 4 & [13] \\
\hline $\mathrm{BeBr}_{2}\left(\mathrm{OEt}_{2}\right)_{2}$ & 3.0 & $\mathrm{C}_{6} \mathrm{D}_{6}$ & tetrahedral & 4 & [13] \\
\hline $\mathrm{CpBeSiMe}_{3}$ & -27.70 & $\mathrm{C}_{6} \mathrm{D}_{6}$ & aromatic $\left(\eta^{5}\right)$ & 6 & {$[12]$} \\
\hline $\mathrm{CpBe}\left(\mathrm{SiMe}_{2} \mathrm{SiMe}_{3}\right)$ & -27.20 & $\mathrm{C}_{6} \mathrm{D}_{6}$ & aromatic $\left(\eta^{5}\right)$ & 6 & [12] \\
\hline $\mathrm{TpBeF}$ & 4.54 & thf- $d_{8} / \mathrm{C}_{7} \mathrm{D}_{8} 3: 5$ & tetrahedral & 4 & [9] \\
\hline $\mathrm{TpBeCl}$ & 4.95 & thf- $d_{8}$ & tetrahedral & 4 & [9] \\
\hline $\mathrm{TpBeBr}$ & 5.15 & thf- $-d_{8} / \mathrm{C}_{6} \mathrm{D}_{6} 1: 3$ & tetrahedral & 4 & [9] \\
\hline TpBeI & 4.66 & thf- $-d_{8}$ & tetrahedral & 4 & [9] \\
\hline $\mathrm{Tp}^{t \mathrm{Bu}} \mathrm{BeCl}$ & 2.7 & $\mathrm{C}_{6} \mathrm{D}_{6}$ & tetrahedral & 4 & [15] \\
\hline $\mathrm{Tp}^{t \mathrm{Bu}} \mathrm{BeBr}$ & 2.4 & $\mathrm{C}_{6} \mathrm{D}_{6}$ & tetrahedral & 4 & {$[15]$} \\
\hline $\mathrm{Tp}^{t \mathrm{Bu}} \mathrm{BeI}$ & 1.3 & $\mathrm{C}_{6} \mathrm{D}_{6}$ & tetrahedral & 4 & [15] \\
\hline $\mathrm{Cp} * \mathrm{BeCl}$ & -14.88 & $\mathrm{C}_{6} \mathrm{D}_{6}$ & aromatic $\left(\eta^{5}\right)$ & 6 & [10] \\
\hline $\mathrm{Cp} * \mathrm{BeBr}$ & -14.81 & $\mathrm{C}_{6} \mathrm{D}_{6}$ & aromatic $\left(\eta^{5}\right)$ & 6 & [10] \\
\hline $\mathrm{Cp}$ *BeI & -15.78 & $\mathrm{C}_{6} \mathrm{D}_{6}$ & aromatic $\left(\eta^{5}\right)$ & 6 & {$[10]$} \\
\hline DDPBeCl & 12.2 & $\mathrm{C}_{6} \mathrm{D}_{6}$ & trigonal planar & 3 & {$[16,17]$} \\
\hline DDPBeI & 13.4 & $\mathrm{C}_{6} \mathrm{D}_{6}$ & trigonal planar & 3 & {$[16,17]$} \\
\hline $\mathrm{Ph}_{2} \mathrm{P}(\mathrm{NDipp})_{2} \mathrm{BeCl}$ & 11.36 & $\mathrm{C}_{6} \mathrm{D}_{6}$ & trigonal planar & 3 & {$[18]$} \\
\hline
\end{tabular}


Table 1. Cont.

\begin{tabular}{|c|c|c|c|c|c|}
\hline Compound & $\begin{array}{l}\text { Be NMR Shifts } \\
\text { ( } \delta \text { in ppm) }\end{array}$ & Solvent & Coordination Mode & Coordination Number & Literature \\
\hline $\mathrm{Ph}_{2} \mathrm{P}(\mathrm{NDipp})_{2} \mathrm{BeBr}$ & 11.94 & $\mathrm{C}_{6} \mathrm{D}_{6}$ & trigonal planar & 3 & [18] \\
\hline $\mathrm{Ph}_{2} \mathrm{P}(\mathrm{NDipp})_{2} \mathrm{BeI}$ & 11.53 & $\mathrm{C}_{6} \mathrm{D}_{6}$ & trigonal planar & 3 & {$[18]$} \\
\hline TerphenylBeCl$\cdot\left(\mathrm{Et}_{2} \mathrm{O}\right)$ & 12.8 & $\mathrm{C}_{6} \mathrm{D}_{6}$ & trigonal planar & 3 & [13] \\
\hline TerphenylBeBr$\cdot\left(\mathrm{Et}_{2} \mathrm{O}\right)$ & 13.4 & $\mathrm{C}_{6} \mathrm{D}_{6}$ & trigonal planar & 3 & [13] \\
\hline$\left[1,3-\left(\mathrm{SiMe}_{3}\right) 2 \mathrm{C}_{3} \mathrm{H}_{3}\right]_{2} \mathrm{Be} \cdot\left(\mathrm{Et}_{2} \mathrm{O}\right)$ & 18.2 & $\mathrm{C}_{6} \mathrm{D}_{6}$ & trigonal planar & 3 & [19] \\
\hline $\mathrm{Be}\left[\mathrm{N}\left(\mathrm{SiMe}_{3}\right)_{2}\right]_{2}$ & 12.3 & $\mathrm{C}_{6} \mathrm{D}_{6}$ & linear & 2 & {$[4]$} \\
\hline $\mathrm{Be}\left[\mathrm{N}\left(\mathrm{SiMe}_{3}\right)_{2}\right]_{2}$ & 9.6 & the $-d_{8}$ & linear & 2 & {$[4]$} \\
\hline $\mathrm{Be}\left[\mathrm{N}\left(\mathrm{SiMe}_{3}\right)_{2}\right]_{2}$ & 12.4 & tol- $d_{8}$ & linear & 2 & [4] \\
\hline
\end{tabular}

$\mathrm{Cp}=$ cyclopentadienyl $\left(\mathrm{C}_{5} \mathrm{H}_{5}\right), \mathrm{Tp}=1$-Tris(pyrazolyl)borate, $\mathrm{Tp}^{t} \mathrm{Bu}=$ Tris(3-tert-butylpyrazolyl)hydroborato, $\mathrm{Cp}^{*}=$ Pentamethylcyclopentadienyl ( $\left.\mathrm{C}_{5} \mathrm{Me}_{5}\right), \mathrm{DDP}=2$-((2,6-diisopropylphenyl)amino)-4-((2,6-diisopropylphenyl)imino)pent-2-enyl), $\mathrm{Ph}_{2} \mathrm{P}$ (NDipp) $)_{2}=\mathrm{N}, \mathrm{N}^{\prime}$-bis(2,6-diisopropylphenyl) aminoiminodi(phenyl) phosphorane, Terphenyl = 2,6-di(2,4,6-trimethylphenyl)phenyl.

\subsection{Solid State Structure}

Compound 2a crystallizes in the monoclinic space group $P 2_{1} / n$ with the molecule placed on the special position. Be is coordinated by $\mathrm{Cl}$, its symmetry equivalent, a thf molecule, and a hypersilyl ligand in a slightly distorted tetrahedral fashion (Figure 1). Crystallographic data of $2 \mathbf{a}$ are given in Tables S1-S5.

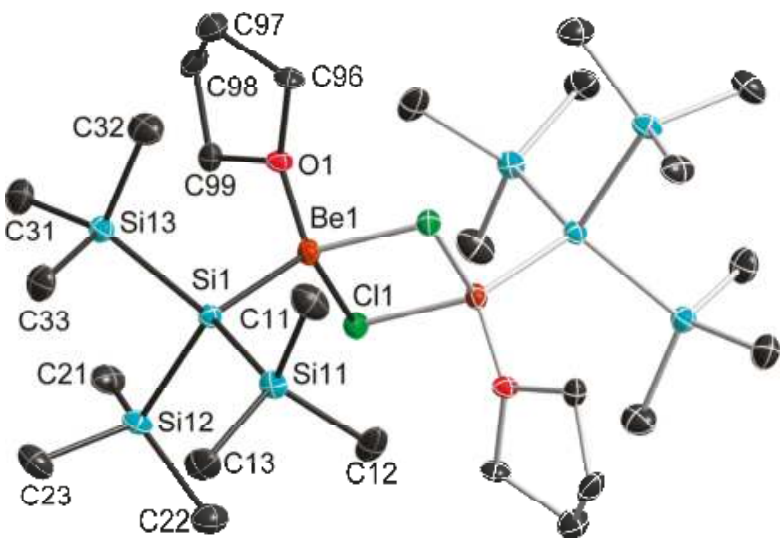

$(2 \mathbf{a})$

Figure 1. Solid-state structures of $\mathbf{2 a}$ (pale colored part generated by inversion); thermal ellipsoids are shown at $50 \%$ probability levels.

The bond angles around the central Be atom range from $96.5(2)^{\circ}$ to $118.5(2)^{\circ}$, and the largest ones involve the central $\mathrm{Si}$ of the hypersilyl group. This distortion most likely results from the vast steric demand of the hypersilyl group. The $\mathrm{Cl}$ atom bridges the $\mathrm{Be} 1$ and its symmetry equivalent in a slightly asymmetric manner, as the difference between both $\mathrm{Be}-\mathrm{Cl}$ bonds is about $0.1 \AA$. The $\mathrm{Be}-\mathrm{Cl}$ bond lengths in 2a (2.099(5), 2.112(5) $\AA$ ) match well with the mean value of 2.02(7) $\AA$ for $\mathrm{Be}-\mathrm{Cl}$ single bonds found in 48 structures with tetrahedrally coordinated Be atoms in the CSD [20]. The Be-O bond length also agrees with the mean value of 1.62(5) $\AA$ (187 hits), but weakly bonded thf molecules show Be-O bond lengths of up to $1.737 \AA$ [21]. To the best of our knowledge, $\mathrm{CpBeSiMe}_{3}$ [12] and $\mathrm{Be}\left(\mathrm{Si}^{t} \mathrm{Bu}_{3}\right)_{2}[11]$ are the only compounds containing a Be-Si bond that to date have been structurally characterized. From these structure determinations, three independent values for the bond lengths are available (2.1930(10) $\AA, 2.2085(10) \AA \mathrm{Be}\left(\mathrm{Si}^{\mathrm{t}} \mathrm{Bu}_{3}\right)_{2}$ [22], and 2.185(2) $\AA \mathrm{CpBeSiMe} 3$ [12]). The fourth value available now from $2 \mathbf{a}$ is in the same order but slightly larger $(2: 239(5) \AA)$, which may again be attributed to the high steric demand of the hypersilyl group. The $\mathrm{Si}-\mathrm{Si}$ bond lengths and $\mathrm{Si}-\mathrm{Si}-\mathrm{Si}$ 
bond angles within the hypersilyl substituent are almost identical to those previously reported for compounds containing this specific substituent.

\subsection{Quantum Chemical Calculations}

Quantum chemical calculations were performed to gain a deeper understanding of the bonding situation in the heteroleptic complexes HypSiBeX.(thf) (HypSi $\left.=\mathrm{Si}\left(\mathrm{SiMe}_{3}\right)_{3}, \mathrm{X}=\mathrm{F} \mathbf{1 b}, \mathrm{Cl} \mathbf{2 b}, \mathrm{Br} \mathbf{3 b}, \mathrm{I} \mathbf{4 b}\right)$. The crystal structure of $\mathbf{2} \mathbf{a}$ was used as a starting point to model the gas phase structures of $\mathbf{1} \mathbf{b}-\mathbf{4} \mathbf{b}$. Geometries of these model structures were then optimized using RI-DFT [23-26] methods with the B3-LYP functional [27,28] and TZVPP basis sets [29] and third generation Becke-Johnson-damped dispersion correction [30,31]. To further investigate the influence of the coordination mode of Be on the NMR shift of this compound, additional model systems without the coordinated thf molecules were designed (1c-4c) and optimized with the same methods. NMR chemical shifts of $\mathbf{1 b}-\mathbf{4 b}$ and $\mathbf{1 c}-\mathbf{4 c}$ were calculated via GIAO methods [32]. Shared electron number (SEN) [33] calculations, electron localization function (ELF) [34,35] plots and localized orbital locator (LOL) [36] plots were performed for $\mathbf{1 b}-\mathbf{4 b}$.

The gas phase structures of $\mathbf{1} \mathbf{b}-\mathbf{4} \mathbf{b}$ (Figure 2 ) are very similar to the crystal structure of $\mathbf{2} \mathbf{a}$. They each show dimeric structures, in which the Be atom adopts distorted tetrahedral coordination environments, and approximately show an inversion center between the two halide ligands (Figures S17-S20, Table S6). The two Be-X units approximately form a rhombus. Table 2 summarizes important bond lengths and angles of $\mathbf{2} \mathbf{a}$ in comparison to those calculated for $\mathbf{1 b}-\mathbf{4} \mathbf{b}$.
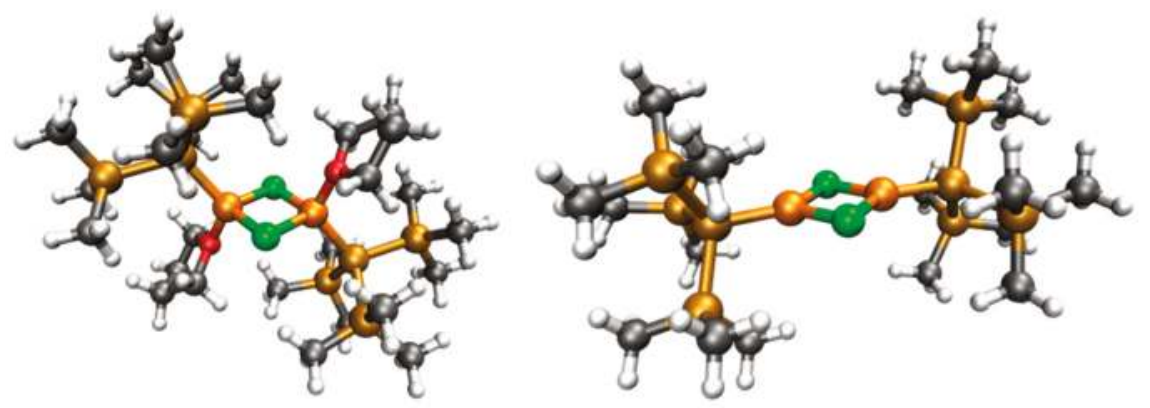

Figure 2. Calculated gas phase structure of $\mathbf{2 b}$ (left) and $2 \mathbf{c}$ (right); $X$ displayed in green, Be in orange; $\mathrm{Si}$ in ocher, $\mathrm{C}$ in grey, $\mathrm{O}$ in red and $\mathrm{H}$ in white.

Table 2. Overview of calculated and observed bond lengths $[\AA]$ and angles $\left[{ }^{\circ}\right]$ for $\mathbf{2 a}$ and $\mathbf{1 b}-\mathbf{4} \mathbf{b}$.

\begin{tabular}{cccccc}
\hline & $\mathbf{1 b}^{\mathbf{1}}$ & $\mathbf{2 a}$ & $\mathbf{2 b}^{\mathbf{1}}$ & $\mathbf{3 b}^{\mathbf{1}}$ & $\mathbf{4 b}^{\mathbf{1}}$ \\
\hline Be-X & 1.614 & $2.101^{1}$ & 2.112 & 2.292 & 2.531 \\
Be-Si & 2.249 & $2.239(5)$ & 2.222 & 2.213 & 2.203 \\
Be-O & 1.670 & $1.654(5)$ & 1.670 & 1.655 & 1.649 \\
X-Be-X & 90.60 & $96.5(2)$ & 97.4 & 98.2 & 99.0 \\
Be-X-Be & 89.4 & $83.5(2)$ & 82.6 & 81.8 & 81.0 \\
Si-Be-X & 118.0 & $116.0(2)$ & 114.6 & 113.6 & 112.0 \\
Si-Be-X & 123.5 & $118.5(2)$ & 118.9 & 118.0 & 116.8 \\
Si-Be-O & 113.4 & $116.4(3)$ & 115.7 & 117.1 & 118.5 \\
Be-X-X-Be & 180.0 & $180.0(3)$ & 179.6 & 180.0 & 180.0 \\
X-X-Be-Si & 129.1 & $126.2(4)$ & 136.7 & 125.5 & 123.8 \\
\hline \multicolumn{5}{c}{ Values are averaged. }
\end{tabular}


The Be-X bond lengths increase with increasing atomic number from F to I, while the Be-Si and Be-O bond lengths marginally decrease, which could be due to slightly reduced steric stress. In accord with Bent's rule and the steric demand of the halogen atoms, the $\mathrm{X}-\mathrm{Be}-\mathrm{X}$ angle increase with decreasing electronegativity and increasing atomic radii of the halide ion $(X)$ from fluoride to iodide and the Be-X-Be angles consequently decrease. Moreover, the other angles also vary slightly. The crystal structure of $\mathbf{2 a}$ is in good agreement with the calculated gas phase structure of $\mathbf{2} \mathbf{b}$ for most displayed values. Slight differences in the $\mathrm{Cl}-\mathrm{Cl}-\mathrm{Be}-\mathrm{Si}$ dihedral angle can be attributed to packing effects.

The gas phase structures of $\mathbf{1 c}-\mathbf{4} \mathbf{c}$, which have been calculated without any coordinating thf molecule, show trigonally coordinated Be atoms (Figures S21-S24). For 1c-3c, the two Be-X units approximately lie in a rhombus (Be-X-X-Be dihedral angle of $179.7^{\circ}$ to $178.5^{\circ}$ ), while that rhombus is significantly folded in $4 \mathrm{c}\left(\mathrm{Be}-\mathrm{X}-\mathrm{X}-\mathrm{Be}\right.$ dihedral angle of $\left.163.6^{\circ}\right)$. Similarly, Be and the halide substituents lie approximately in the same plane for $1 c-3 c\left(X-X-B e-S i\right.$ dihedral angle of $179.3^{\circ}$ to $\left.178.7^{\circ}\right)$, while $4 c$ shows a significant deviation from planarity $\left(X-X-B e-S i\right.$ dihedral angle of $\left.170.3^{\circ}\right)$.

The calculated NMR chemical shifts (Table 3 ) of $\mathbf{1 b}-\mathbf{4 b}$ and $\mathbf{1} \mathbf{c}-\mathbf{4} \mathbf{c}$ are not very close to the measured signals, but fall in line with our calculations of other beryllium shifts, which tend to be higher than measured signals. Nonetheless, it can be clearly seen that there is a difference between the calculated chemical shifts of these substances for the thf-coordinated $\mathbf{1 b} \mathbf{-} \mathbf{4} \mathbf{b}$ in comparison to the thf-free 1c-4c. Unfortunately, the shifts of these species overlap and one cannot clearly distinguish between thf-containing or thf-less species just by checking these theoretical values. Thus, a comparison with other measured Be-containing species is needed to evaluate or predict coordination modes.

Table 3. Overview of calculated and observed NMR shifts for 1-4.

\begin{tabular}{ccccc}
\hline & $\mathbf{1}$ & $\mathbf{2}$ & $\mathbf{3}$ & $\mathbf{4}$ \\
\hline $\mathbf{a}$ & - & 2.45 & - & -0.92 \\
$\mathbf{b}$ & 6.90 & 10.62 & 12.14 & 15.93 \\
$\mathbf{c}$ & 14.01 & 25.53 & 29.16 & 24.78 \\
\hline
\end{tabular}

The Be-Si bonds were investigated by looking at their shared electron number (SEN) values. The values range from 1.42 for $\mathbf{1 b}$ and 1.36 for $\mathbf{2 b}$ and $\mathbf{3 b}$, to 1.31 for $\mathbf{4 b}$. These values are within the typical range for covalent bonds between $\mathrm{Si}-\mathrm{Si}, \mathrm{Si}-\mathrm{C}$ and $\mathrm{C}-\mathrm{H}$ in these molecules, which suggests that the Be-Si bond is quite covalent. This is exemplified further by looking at electron localization function (ELF) and localized orbital locator (LOL) plots (see also Figures S9-S16) of the Be-Si-Cl plane in Figure 3, where a Be-Si bond electron pair can clearly be seen around $(x, y)=(6.58,4.52)$ bohr.
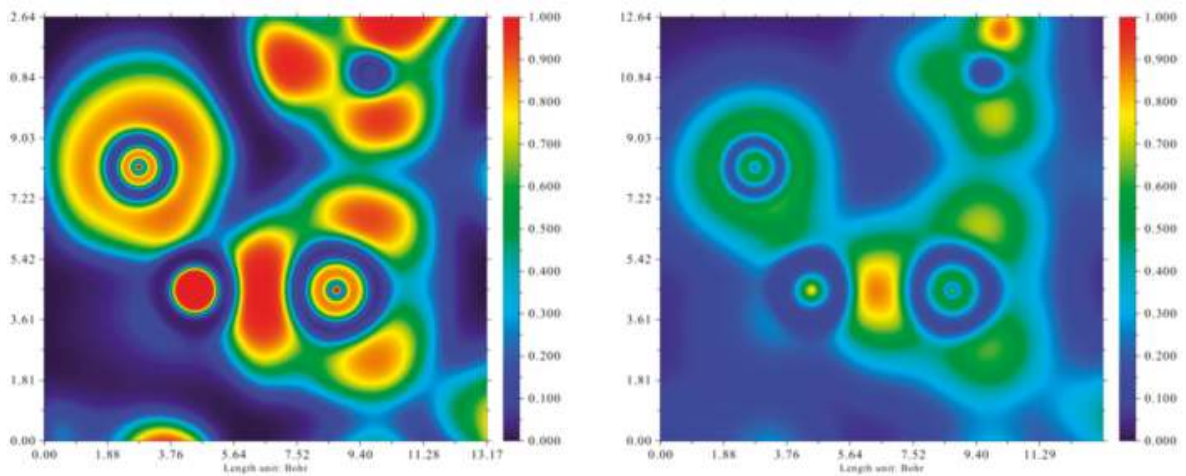

Figure 3. 2D-plots of the Si-Be-Cl plane: (left) ELF; (right) LOL. 


\section{Materials and Methods}

Beryllium and its compounds are regarded as highly toxic and carcinogenic and they also have an allergic potential if inhaled with the risk of causing chronic beryllium disease (CBD) [37]. They should therefore be handled with appropriate safety precautions [8]. All experiments described herein were performed in fume hoods, in gloveboxes, or with advanced Schlenk techniques under extremely dry and oxygen-free (Caution) Ar atmosphere. HypSiLi·(thf) 2.6 was prepared in accordance with a procedure found in the literature [38]. The amount of coordinated thf in the HypSiLi.(thf) $)_{2.6}$ was determined by adding a definite amount of $1,3,5$-tri- ${ }^{t} \mathrm{Bu}$-benzene to the solution of the ligand in $\mathrm{C}_{6} \mathrm{D}_{6}$, followed by comparative integration of the signals. $\mathrm{BeCl}_{2}$ and $\mathrm{BeI}_{2}$ were synthesized from the elements at elevated temperatures followed by high-temperature, high-vacuum fractional sublimation [39]. NMR spectra were recorded on a Bruker Avance 300 spectrometer (Karlsruhe, Germany) at $25{ }^{\circ} \mathrm{C}$ at $300.1 \mathrm{MHz}\left({ }^{1} \mathrm{H}\right), 42.4 \mathrm{MHz}\left({ }^{9} \mathrm{Be}\right), 75.5 \mathrm{MHz}\left({ }^{13} \mathrm{C}\right)$, and $59.6 \mathrm{MHz}\left({ }^{29} \mathrm{Si}\right) .{ }^{1} \mathrm{H}$ and ${ }^{13} \mathrm{C}\left\{{ }^{1} \mathrm{H}\right\}-\mathrm{NMR}$ spectra were referenced to internal $\mathrm{C}_{6} \mathrm{D}_{5} \mathrm{H}\left(\delta\left({ }^{1} \mathrm{H}\right)=7.154 \mathrm{ppm} ; \delta\left({ }^{13} \mathrm{C}\right)=128.0 \mathrm{ppm}\right),{ }^{9} \mathrm{Be}-\mathrm{NMR}$ was referenced to external $\mathrm{BeSO}_{4}$ in $\mathrm{D}_{2} \mathrm{O}\left(\delta\left({ }^{9} \mathrm{Be}\right)=0 \mathrm{ppm}\right)$ and ${ }^{29} \mathrm{Si}$ spectra were referenced to an external standard of neat $\mathrm{Si}\left(\mathrm{CH}_{3}\right)_{4}\left(\delta\left({ }^{29} \mathrm{Si}\right)=0 \mathrm{ppm}\right)$. Elemental analyses were not determined because of the potential toxicity of the complexes. The purity of the compounds was verified by NMR spectroscopy. All reactions were performed under an argon atmosphere.

\section{General Procedure for the Synthesis of HypSiBeX.(thf) $(X=\mathrm{Cl} 2 a, I 4 a)$}

Equimolar amounts of HypSiLi·(thf $)_{2.6}(0.221 \mathrm{~g}, 0.5 \mathrm{mmol})$ and $\mathrm{BeX}_{2}(\mathrm{X}=\mathrm{Cl} 0.040 \mathrm{~g}, 0.5 \mathrm{mmol}$, I $0.131 \mathrm{~g}, 0.5 \mathrm{mmol})$ were dissolved in a mixture of toluene $(20 \mathrm{~mL})$ and thf $(1 \mathrm{~mL})$. The resulting solution was heated to $60{ }^{\circ} \mathrm{C}$ and stirred for $16 \mathrm{~h}$. After that, all volatiles were removed in vacuum, and the residue was dried for an additional $2 \mathrm{~h}$ in an oil-pump vacuum. The residue was extracted with $2 \mathrm{~mL}$ of toluene and $1 \mathrm{~mL}$ of thf and filtrated by using a Teflon cannula, which was covered with a glass micro fiber filter (Whatman ${ }^{\circledR}$, ME14 $2 \mathrm{LE}$ Maidenstone, Kent, UK). Compounds 2a and 4a were obtained after storage of the clear solutions at $-28{ }^{\circ} \mathrm{C}$ for $12 \mathrm{~h}$.

HypSiBeCl.(thf) (2a): Yield: $140 \mathrm{mg}(96 \%) .{ }^{1} \mathrm{H}$ NMR $\left(300 \mathrm{MHz}\right.$, thf- $\left.d_{8}, 25^{\circ} \mathrm{C}\right): \delta=0.18(\mathrm{~s}, 27 \mathrm{H}, \mathrm{Me})$, 1.72 (s (broad), 0.54H, thf), 3.58 (s (broad), 0.62H, thf). ${ }^{9} \mathrm{Be} N M R\left(\mathrm{C}_{6} \mathrm{D}_{6}, 42.2 \mathrm{MHz}, 25{ }^{\circ} \mathrm{C}\right): \delta=2.45$ (s). ${ }^{13} \mathrm{C}$ NMR (125 MHz, $\left.\mathrm{C}_{6} \mathrm{D}_{6}, 25{ }^{\circ} \mathrm{C}\right): \delta=1.68$ (s, Me), 25.46 (thf), 67.58 (thf). ${ }^{29} \mathrm{Si} \mathrm{NMR}\left(59.6 \mathrm{MHz}, \mathrm{C}_{6} \mathrm{D}_{6}\right.$, $\left.25^{\circ} \mathrm{C}\right): \delta=-82.05\left(\mathrm{~s},\left(\mathrm{Me}_{3} \mathrm{Si}\right)_{3} \mathrm{Si},-12.99\left(\mathrm{~s},\left(\mathrm{Me}_{3} \mathrm{Si}\right)_{3} \mathrm{Si}\right)\right.$.

HypSiBeI-(thf) (4a): Yield: $157 \mathrm{mg}(93 \%) .{ }^{1} \mathrm{H}$ NMR $\left(300 \mathrm{MHz}\right.$, thf- $\left.d_{8}, 25^{\circ} \mathrm{C}\right): \delta=0.17(\mathrm{~s}, 27 \mathrm{H}, \mathrm{Me})$, 1.74 (quint., $5.83 \mathrm{H}$, thf), 3.58 (quint., $5.03 \mathrm{H}$, thf). ${ }^{9} \mathrm{Be} \mathrm{NMR}\left(\mathrm{C}_{6} \mathrm{D}_{6}, 42.2 \mathrm{MHz}, 25{ }^{\circ} \mathrm{C}\right.$ ): $\delta=-0.92$ (s). ${ }^{13} \mathrm{C} \mathrm{NMR}\left(125 \mathrm{MHz}, \mathrm{C}_{6} \mathrm{D}_{6}, 25{ }^{\circ} \mathrm{C}\right): \delta=1.87$ (Me), 25.37 (thf), 67.46 (thf). ${ }^{29} \mathrm{Si} \mathrm{NMR}\left(59.6 \mathrm{MHz}, \mathrm{C}_{6} \mathrm{D}_{6}\right.$, $\left.25^{\circ} \mathrm{C}\right): \delta=-83.94\left(\mathrm{~s},\left(\mathrm{Me}_{3} \mathrm{Si}\right)_{3} \mathrm{Si},-14.91\left(\mathrm{~s}\left(\mathrm{Me}_{3} \mathrm{Si}\right)_{3} \mathrm{Si}\right)\right.$.

Single crystal X-ray diffraction. $\left[\begin{array}{llllll}\mathrm{C}_{26} & \mathrm{H}_{70} & \mathrm{Be}_{2} & \mathrm{Cl}_{2} & \mathrm{O}_{2} & \mathrm{Si}_{8}\end{array}\right], M=728.46$, colorless crystal $(0.07 \mathrm{~mm} \times 0.05 \mathrm{~mm} \times 0.05 \mathrm{~mm}) ;$ monoclinic, space group $P 21 / n ; a=10.3667(7) \AA, b=18.8628(12)$ $\AA, c=11.3870(7) \AA ; \alpha=90^{\circ}, \beta=98.150(4)^{\circ}, \gamma=90^{\circ}, V=2204.2(2) \AA^{3} ; Z=2 ; \mu=0.386 \mathrm{~mm}^{-1}$; $\varrho_{\text {calc }}=1.098 \mathrm{~g} \cdot \mathrm{cm}^{-3} ; 17848$ reflections $\left(\theta_{\max }=26.46^{\circ}\right), 4491$ unique $\left(R_{\text {int }}=0.1159\right) ; 190$ parameters; largest max./min in the final difference Fourier synthesis $0.451 \mathrm{e} \cdot \AA^{-3} /-0.407 \mathrm{e} \cdot \AA^{-3} ; \max . / \min$. transmission $0.75 / 0.67 ; R_{1}=0.0564(I>2 \sigma(I)), w R_{2}=0.1242$ (all data).

The crystal was mounted on a nylon loop in inert oil. Data were collected on a Bruker AXS D8 Kappa diffractometer with APEX2 detector (mono-chromated MoK $\alpha$ radiation, $\lambda=0.71073 \AA$ ). The structure was solved by Direct Methods (SHELXS-97) [40] and refined anisotropically by full-matrix least-squares on $F^{2}$ (SHELXL-2014) [41,42]. Absorption correction was performed semi-empirically from equivalent reflections on basis of multi-scans (Bruker AXS APEX2, Karlsruhe, Germany). Hydrogen atoms were refined using rigid methyl groups.

CCDC-1539267 contains the supplementary crystallographic data for this paper. These data can be obtained free of charge from The Cambridge Crystallographic Data Centre via www.ccdc.cam.ac. uk/data_request/cif. 


\section{Conclusions}

We successfully synthesized compounds of the general type HypSiBeX $\cdot($ thf $)\left(\mathrm{HypSi}=\mathrm{Si}\left(\mathrm{SiMe}_{3}\right)_{3}\right.$, $X=\mathrm{Cl} 2 \mathbf{a}, \mathrm{I} 4 \mathbf{4}$ ) bearing a Be-Si-bond and structurally characterized (2a), the third example of such a compound. The bond lengths in 2 a were compared with those obtained from quantum chemical calculations, which were expanded to the other halides as well as on the solvent-free complexes. Further analysis of the calculated data provided a deeper insight into so far not properly investigated Be-Si bond and demonstrated that the Be-Si-bond is mainly covalent (SEN: 1.4-1.3). The calculated ${ }^{9} \mathrm{Be}$ NMR shifts shows that tetrahedral coordination mode is also present in solution, which fits well to the reported ${ }^{9}$ Be NMR shifts of comparable compounds.

Supplementary Materials: The following are available online at www.mdpi.com/2304-6740/5/2/22/s1, Figures S1-S24, Tables S1-S6, cif and checkcif files.

Acknowledgments: Stephan Schulz thanks the University of Duisburg-Essen for financial support and Dieter Bläser for collecting the crystallographic data.

Author Contributions: Dominik Naglav, Kevin Dzialkowski, and Stephan Schulz conceived and designed the experiments; Dominik Naglav and Kevin Dzialkowski performed the experiments; Christoph Wölper analyzed the X-ray structure; Briac Tobey and Georg Jansen performed and analyzed the quantum mechanical calculations; Dominik Naglav and Kevin Dzialkowski analyzed the NMR data; Dominik Naglav, Briac Tobey, Kevin Dzialkowski, Christoph Wölper, and Stephan Schulz wrote the paper.

Conflicts of Interest: The authors declare no conflict of interest.

\section{References}

1. Iversen, K.J.; Couchman, S.A.; Wilson, D.J.; Dutton, J.L. Modern organometallic and coordination chemistry of beryllium. Coord. Chem. Rev. 2015, 297-298, 40-48. [CrossRef]

2. Arrowsmith, M.; Braunschweig, H.; Celik, M.A.; Dellermann, T.; Dewhurst, R.D.; Ewing, W.C.; Hammond, K.; Kramer, T.; Krummenacher, I.; Mies, J.; et al. Neutral zero-valent s-block complexes with strong multiple bonding. Nat. Chem. 2016, 8, 638-642. [CrossRef] [PubMed]

3. Arrowsmith, M.; Hill, M.S.; Kociok-Kohn, G.; MacDougall, D.J.; Mahon, M.F. Beryllium-induced C-N bond activation and ring opening of an N-heterocyclic carbene. Angew. Chem. Int. Ed. Engl. 2012, 51, 2098-2100. [CrossRef] [PubMed]

4. Naglav, D.; Neumann, A.; Bläser, D.; Wölper, C.; Haack, R.; Jansen, G.; Schulz, S. Bonding situation in $\mathrm{Be}\left(\mathrm{N}\left(\mathrm{SiMe}_{3}\right)_{2}\right)_{2}$-An experimental and computational study. Chem. Commun. 2015, 51, 3889-3891. [CrossRef] [PubMed]

5. Bayram, M.; Naglav, D.; Wölper, C.; Schulz, S. Synthesis and Structure of Bis(diphenylphosphinimino)methanide and Bis(diphenylphosphinimino)methanediide Beryllium Complexes. Organometallics 2016, 35, 2378-2383. [CrossRef]

6. Buchner, M.R.; Müller, M.; Rudel, S.S. Beryllium Phosphine Complexes: Synthesis, Properties, and Reactivity of $\left(\mathrm{PMe}_{3}\right)_{2} \mathrm{BeCl}_{2}$ and $\left(\mathrm{Ph}_{2} \mathrm{PC}_{3} \mathrm{H}_{6} \mathrm{PPh}_{2}\right) \mathrm{BeCl}_{2}$. Angew. Chem. Int. Ed. Engl. 2017, 56, 1130-1134. [CrossRef] [PubMed]

7. Zhu, H.; Li, Y.; Zhu, G.; Su, H.; Chan, S.H.; Sun, Q. $\mathrm{Be}_{12} \mathrm{O}_{12}$ Nano-cage as a Promising Catalyst for $\mathrm{CO}_{2}$ Hydrogenation. Sci. Rep. 2017, 7, 40562. [CrossRef] [PubMed]

8. Naglav, D.; Buchner, M.R.; Bendt, G.; Kraus, F.; Schulz, S. Off the Beaten Track-A Hitchhiker's Guide to Beryllium Chemistry. Angew. Chem. Int. Ed. Engl. 2016, 55, 10562-10576. [CrossRef] [PubMed]

9. Naglav, D.; Bläser, D.; Wölper, C.; Schulz, S. Synthesis and characterization of heteroleptic 1-tris(pyrazolyl)borate beryllium complexes. Inorg. Chem. 2014, 53, 1241-1249. [CrossRef] [PubMed]

10. Naglav, D.; Tobey, B.; Neumann, A.; Bläser, D.; Wölper, C.; Schulz, S. Synthesis, Solid-State Structures, and Computational Studies of Half-Sandwich $\mathrm{Cp}{ }^{*} \mathrm{BeX}(\mathrm{X}=\mathrm{Cl}, \mathrm{Br}$, I) Compounds. Organometallics 2015, 34, 3072-3078. [CrossRef]

11. Lerner, H.-W.; Scholz, S.; Bolte, M.; Wiberg, N.; Nöth, H.; Krossing, I. Synthesis and Structures of Alkaline-Earth Metal Supersilanides: ${ }^{t} \mathrm{Bu}_{3} \mathrm{SiMX}$ and ${ }^{t} \mathrm{Bu}_{3} \mathrm{Si}-\mathrm{M}-\mathrm{Si}^{t} \mathrm{Bu}_{3}(\mathrm{M}=\mathrm{Be}, \mathrm{Mg} ; \mathrm{X}=\mathrm{Cl}, \mathrm{Br})$. Eur. J. Inorg. Chem. 2003, 2003, 666-670. [CrossRef] 
12. Saulys, D.A.; Powell, D.R. Synthesis, Experimental/Theoretical Characterization, and Thermolysis Chemistry of $\mathrm{CpBe}\left(\mathrm{SiMe}_{3}\right)$, a Molecule Containing an Unprecedented Beryllium-Silicon Bond. Organometallics 2003, 22, 407-413. [CrossRef]

13. Niemeyer, M.; Power, P.P. Synthesis, ${ }^{9}$ Be NMR Spectroscopy, and Structural Characterization of Sterically Encumbered Beryllium Compounds. Inorg. Chem. 1997, 36, 4688-4696. [CrossRef] [PubMed]

14. Ruhlandt-Senge, K.; Bartlett, R.A.; Olmstead, M.M.; Power, P.P. Synthesis and Structural Characterization of the Beryllium Compounds [Be(2,4,6- $\left.\left.\mathrm{Me}_{3} \mathrm{C}_{6} \mathrm{H}_{2}\right)_{2}\left(\mathrm{OEt}_{2}\right)\right]$, $\left[\mathrm{Be}\left\{\mathrm{O}\left(2,4,6-t-\mathrm{Bu}_{3} \mathrm{C}_{6} \mathrm{H}_{2}\right\}\left(\mathrm{OEt}_{2}\right)\right]\right.$, and $\left[\mathrm{Be}\left\{\mathrm{S}\left(\mathrm{S}\left(2,4,6-t-\mathrm{Be}_{3} \mathrm{C}_{6} \mathrm{H}_{2}\right)\right\}_{2}(\mathrm{thf})\right]_{2}(\mathrm{THF})\right] \mathrm{PhMe}$ and Determination of the Structure of $\left[\mathrm{BeCl}_{2}\left(\mathrm{OEt}_{2}\right)_{2}\right]$. Inorg. Chem. 1993, 32, 1724-1728. [CrossRef]

15. Han, R.; Parkin, G. [Tris(3-tert-butylpyrazolyl)hydroborato]beryllium hydride: Synthesis, structure, and reactivity of a terminal beryllium hydride complex. Inorg. Chem. 1992, 31, 983-988. [CrossRef]

16. Arrowsmith, M.; Hill, M.S.; Kociok-Kohn, G.; MacDougall, D.J.; Mahon, M.F.; Mallov, I. Three-coordinate beryllium beta-diketiminates: Synthesis and reduction chemistry. Inorg. Chem. 2012, 51, 13408-13418. [CrossRef] [PubMed]

17. Arrowsmith, M.; Crimmin, M.R.; Hill, M.S.; Kociok-Kohn, G. Beryllium derivatives of a phenyl-substituted beta-diketiminate: A well-defined ring opening reaction of tetrahydrofuran. Dalton Trans. 2013, 42, 9720-9726. [CrossRef] [PubMed]

18. Naglav, D.; Tobey, B.; Dzialkowski, K.; Jansen, G.; Neumann, A.; Bläser, D.; Wölper, C.; Schulz, S. Synthesis and Characterization of Heteroleptic Diiminophosphinate Beryllium Complexes. Unpublished results. 2017.

19. Chmely, S.C.; Hanusa, T.P.; Brennessel, W.W. Bis(1,3-trimethylsilylallyl)beryllium. Angew. Chem. Int. Ed. Engl. 2010, 49, 5870-5874. [CrossRef] [PubMed]

20. Allen, F.H. The Cambridge Structural Database: A quarter of a million crystal structures and rising. Acta Crystallogr. Sect. A Found. Crystallogr. 2002, 58, 380-388. [CrossRef]

21. Lorenz, V.; Fischer, A.; Edelmann, F.T. Silsesquioxane chemistry, The first beryllium silsesquioxane: Synthesis and structure of $\left[\mathrm{Cy}_{7} \mathrm{Si}_{7} \mathrm{O}_{12} \mathrm{BeLi}\right]_{2}$ 2THF. Inorg. Chem. Commun. 2000, 3, 292-295. [CrossRef]

22. Lerner, W.; Goethe-Universität Frankfurt, Frankfurt, Germany. Supply of the value for the second independent molecule. Personal Communication, 2017.

23. Treutler, O.; Ahlrichs, R. Efficient molecular numerical integration schemes. J. Chem. Phys. 1995, 102, 346-354. [CrossRef]

24. Eichkorn, K.; Treutler, O.; Öhm, H.; Häser, M.; Ahlrichs, R. Auxiliary basis sets to approximate Coulomb potentials. Chem. Phys. Lett. 1995, 240, 283-290. [CrossRef]

25. Eichkorn, K.; Weigend, F.; Treutler, O.; Ahlrichs, R. Auxiliary basis sets for main row atoms and transition metals and their use to approximate Coulomb potentials. Theor. Chim. Acta 1997, 97, 119-124. [CrossRef]

26. Von Arnim, M.; Ahlrichs, R. Performance of parallel TURBOMOLE for density functional calculations. J. Comput. Chem. 1998, 19, 1746-1757. [CrossRef]

27. Becke, A.D. Density-functional thermochemistry. III. The role of exact exchange. J. Chem. Phys. 1993, 98, 5648-5652. [CrossRef]

28. Stephens, P.J.; Chabalowski, C.F.; Frisch, M.J. Ab Initio Calculation of Vibrational Absorption and Circular Dichroism Spectra Using Density Functional Force Fields. J. Chem. Phys. Chem. 1994, 98, 11623-11627. [CrossRef]

29. Weigend, F.; Ahlrichs, R. Balanced basis sets of split valence, triple zeta valence and quadruple zeta valence quality for H to Rn: Design and assessment of accuracy. Phys. Chem. Chem. Phys. PCCP 2005, 7, 3297-3305. [CrossRef] [PubMed]

30. Grimme, S.; Antony, J.; Ehrlich, S.; Krieg, H. A consistent and accurate ab initio parametrization of density functional dispersion correction (DFT-D) for the 94 elements H-Pu. J. Chem. Phys. 2010, 132, 154104. [CrossRef] [PubMed]

31. Grimme, S.; Ehrlich, S.; Goerigk, L. Effect of the damping function in dispersion corrected density functional theory. J. Comput. Chem. 2011, 32, 1456-1465. [CrossRef] [PubMed]

32. Kollwitz, M.; Gauss, J. A direct implementation of the GIAO-MBPT(2) method for calculating NMR chemical shifts. Application to the naphthalenium and anthracenium ions. Chem. Phys. Lett. 1996, 260, 639-646. [CrossRef]

33. Davidson, E.R. Electronic Population Analysis of Molecular Wavefunctions. J. Chem. Phys. 1967, 46, 3320-3324. [CrossRef] 
34. Becke, A.D.; Edgecombe, K.E. A simple measure of electron localization in atomic and molecular systems. J. Chem. Phys. 1990, 92, 5397-5403. [CrossRef]

35. Silvi, B.; Savin, A. Classifaction of chemical bonds based on topological analysis of electron localization functions. Nature 1994, 371, 683-686. [CrossRef]

36. Schmider, H.; Becke, A. Chemical content of the kinetic energy density. J. Mol. Struct. THEOCHEM 2000, 527, 51-61. [CrossRef]

37. Kumberger, O.; Schmidbaur, H. Warum ist Beryllium so toxisch? Chem. Unserer Zeit 1993, 27, 310-316. [CrossRef]

38. Gutekunst, G.; Brook, A.G. Tris(trimethylsilyl)silyllithium·3 thf: A stable crystalline silyllithium reagent. J. Organomet. Chem. 1982, 225, 1-3. [CrossRef]

39. Brauer, G. Handbuch der Präparativen Anorganischen Chemie, 3rd ed.; Ferdinand Enke: Stuttgart, Germany, 1975; Volume 1.

40. Sheldrick, G.M. Phase annealing in SHELX-90: Direct methods for larger structures. Acta Crystallogr. A Found. Crystallogr. 1990, 46, 467-473. [CrossRef]

41. Sheldrick, G.M. A short history of SHELX. Acta Crystallogr. Sect A Found. Crystallogr. 2008, 64, 112-122. [CrossRef] [PubMed]

42. Hubschle, C.B.; Sheldrick, G.M.; Dittrich, B. ShelXle: A Qt graphical user interface for SHELXL. J. Appl. Crystallogr. 2011, 44, 1281-1284. [CrossRef] [PubMed]

(C) 2017 by the authors. Licensee MDPI, Basel, Switzerland. This article is an open access article distributed under the terms and conditions of the Creative Commons Attribution (CC BY) license (http:/ / creativecommons.org/licenses/by/4.0/). 
Article

\title{
Hetero- and Homoleptic Magnesium Triazenides
}

\author{
Denis Vinduš and Mark Niemeyer * \\ Institut für Anorganische und Analytische Chemie, Johannes Gutenberg-Universität Mainz, Duesbergweg 10-14, \\ 55128 Mainz, Germany; denis_vindus@gmx.de \\ * Correspondence: niemeyer@uni-mainz.de; Tel.: +49-6131-39-26020
}

Academic Editor: Matthias Westerhausen

Received: 3 April 2017; Accepted: 24 April 2017; Published: 1 May 2017

\begin{abstract}
Using monoanionic triazenide ligands derived from biphenyl and $m$-terphenyl substituted triazenes Dmp (Tph) $\mathrm{N}_{3} \mathrm{H}(\mathbf{1 a}),\left(\mathrm{Me}_{4} \mathrm{Ter}\right)_{2} \mathrm{~N}_{3} \mathrm{H}(\mathbf{1 b})$ or Dmp $(\mathrm{Mph}) \mathrm{N}_{3} \mathrm{H}(\mathbf{1 c})\left(\mathrm{Dmp}=2,6-\mathrm{Mes}_{2} \mathrm{C}_{6} \mathrm{H}_{3}\right.$ with Mes $=2,4,6-\mathrm{Me}_{3} \mathrm{C}_{6} \mathrm{H}_{2} ; \mathrm{Me}_{4} \mathrm{Ter}=2,6-\left(3,5-\mathrm{Me}_{2} \mathrm{C}_{6} \mathrm{H}_{3}\right)_{2} \mathrm{C}_{6} \mathrm{H}_{3} ; \mathrm{Mph}=2-\mathrm{MesC}_{6} \mathrm{H}_{4} ; \mathrm{Tph}=2-\mathrm{TripC}_{6} \mathrm{H}_{4}$ with Trip = 2,4,6-i- $\left.\operatorname{Pr}_{3} \mathrm{C}_{6} \mathrm{H}_{2}\right)$, several magnesium triazenides were synthesized. Heteroleptic complexes $\left[\mathrm{Mg}\left(\mathrm{N}_{3} \mathrm{Ar}_{2}\right) \mathrm{I}\left(\mathrm{OEt}_{2}\right)\right]\left(\mathrm{Ar}_{2}=\mathrm{Dmp} / \mathrm{Tph}(\mathbf{2} \mathbf{a}),\left(\mathrm{Me}_{4} \mathrm{Ter}\right)_{2}(\mathbf{2} \mathbf{b})\right.$ were obtained from metalation of the corresponding triazenes with di- $n$-butylmagnesium followed by reaction with iodine in diethyl ether as the solvent in high yields. Replacing diethyl ether by $n$-heptane afforded trinuclear compounds $\left[\mathrm{Mg}_{3}\left(\mathrm{~N}_{3} \mathrm{Ar}_{2}\right)_{2} \mathrm{I}_{4}\right](\mathbf{3} \mathbf{a}, \mathbf{3 b})$ in low yields in which a central $\mathrm{MgI}_{2}$ fragment is coordinated by two iodomagnesium triazenide moieties. Two unsolvated homoleptic magnesium compounds $\left[\mathrm{Mg}\left(\mathrm{N}_{3} \mathrm{Ar}_{2}\right)_{2}\right](\mathbf{4 b}, 4 \mathbf{c})$ were obtained from di- $n$-butylmagnesium and triazenes $\mathbf{1} \mathbf{b}$ or $\mathbf{1 c}$ in a $1: 2$ ratio. Depending on the nature of the substituents, the magnesium center either shows the expected tetrahedral or a rather unusual square planar coordination.
\end{abstract}

Keywords: magnesium complexes; magnesium iodide; $\mathrm{N}$ ligands; sterically-crowded ligands; triazenide ligands

\section{Introduction}

The quest for suitable ligand systems that are able to stabilize unsolvated monomeric metal complexes is one of the most intensely-studied fields of coordination and organometallic chemistry [1]. Exploration of this area is motivated by potential applications of these reactive complexes in catalysis and organic synthesis. Well-known examples of monoanionic chelating $\mathrm{N}$-donor ligands that have been used extensively include the $\beta$-diketiminate [2] and amidinate [3] ligand systems. Much less attention has been given to the closely-related triazenides [4]. During the last decade, we reported the preparation of derivatives of diaryl-substituted, sterically-crowded triazenido ligands that are bulky enough to prevent undesirable ligand redistribution reactions [5-12]. These ligands allowed structurally characterizing the first examples of aryl compounds of the heavier alkaline earth metals $\mathrm{Ca}$, Sr and $\mathrm{Ba}[5]$ and unsolvated pentafluorophenyl organyls of the divalent lanthanides $\mathrm{Yb}$ and Eu [6]. The different degree of metal $\cdots \pi$-arene interactions to pending aromatic substituents accounts for the unusual "inverse" aggregation behavior of alkali metal triazenides in their solid-state structures [7]. A series of homologous potassium and thallium triazenides crystallizes in isomorphous cells and represents the first examples of isostructural molecular species reported for these elements [8]. Recently, using the same type of ligands, a spectacular series of pnicogen(I) triazenides for the elements $\mathrm{P}$, As and $\mathrm{Sb}$ was published by Schulz et al. [13].

In this paper, we describe the synthesis and characterization of several heteroleptic and homoleptic magnesium triazenides. The latter are the first examples of unsolvated magnesium triazenides, whereas the former are potential precursors for magnesium(I) triazenides. A small number of magnesium triazenides, mainly using less bulky substituents, has been reported before [11,14-16]. 
With relatively small $p$-tolyl and slightly bigger mesityl substituents, two additional THF molecules are required to provide electronic and steric saturation of the Lewis acetic metal centers in the six-coordinate magnesium complexes $\left[\mathrm{Mg}\left(\mathrm{N}_{3} \mathrm{Ar}_{2}\right)_{2}(\mathrm{thf})_{2}\right](\mathrm{Ar}=p$ - Tol [14], Mes [15]) published by the groups of Walsh and Westerhausen, respectively. The use of 2,6-di-iso-propylphenyl (Dip) substituted triazenide by Gibson et al. afforded the five-coordinate magnesium etherate $\left[\mathrm{Mg}\left(\mathrm{N}_{3} \mathrm{Dip}_{2}\right)_{2}\left(\mathrm{OEt}_{2}\right)\right]$ [16], which was prepared as the aforementioned compounds by metalation of the corresponding triazene with di-n-butylmagnesium. For the Dip derivative, attempts to synthesize a monosubstituted triazenide were not successful. Even in the presence of an excess of di- $n$-butylmagnesium, the bis-triazenido complex was obtained as a result of ligand redistribution reactions. However, using the dimesityl substituted triazene and the chelating donor 1,2-bis(dimethylamino)ethane (TMEDA), Westerhausen et al. succeeded at isolating a heteroleptic complex of the composition [ $\mathrm{Mes}_{2} \mathrm{~N}_{3} \mathrm{Mg} n \mathrm{Bu}$ (tmeda)] [15]. Another heteroleptic magnesium triazenide [Dmp(Tph) $\mathrm{N}_{3} \mathrm{MgI}($ thf $\left.)\right]$ was obtained in our group by an alternative synthetic approach via redox transmetallation between the iodomercury triazenide $\left[\mathrm{Dmp}(\mathrm{Tph}) \mathrm{N}_{3} \mathrm{HgI}\right]$ and magnesium metal [11].

\section{Results and Discussion}

\subsection{Syntheses and Spectroscopic Characterization}

The heteroleptic iodomagnesium triazenides $\mathbf{2} \mathbf{a}$ and $\mathbf{2} \mathbf{b}$ are accessible in diethyl ether as the solvent via metalation of the diaryltriazenes Dmp(Tph) $\mathrm{N}_{3} \mathrm{H}(\mathbf{1 a})$ or $\left(\mathrm{Me}_{4} \mathrm{Ter}\right)_{2} \mathrm{~N}_{3} \mathrm{H}(\mathbf{1 b})\left(\mathrm{Dmp}=2,6-\mathrm{Mes}_{2} \mathrm{C}_{6} \mathrm{H}_{3}\right.$ with Mes = 2,4,6- $\mathrm{Me}_{3} \mathrm{C}_{6} \mathrm{H}_{2} ; \mathrm{Me}_{4} \mathrm{Ter}=2,6-\left(3,5-\mathrm{Me}_{2} \mathrm{C}_{6} \mathrm{H}_{3}\right)_{2} \mathrm{C}_{6} \mathrm{H}_{3} ; \mathrm{Tph}=2-\operatorname{TripC}_{6} \mathrm{H}_{4}$ with Trip = 2,4,6-i- $\left.\mathrm{Pr}_{3} \mathrm{C}_{6} \mathrm{H}_{2}\right)$ with one equivalent of di-n-butylmagnesium, followed by addition of iodine (Scheme 1a). After crystallization, the complexes $\left[\mathrm{Mg}\left(\mathrm{N}_{3} \mathrm{Ar}_{2}\right) \mathrm{I}\left(\mathrm{OEt}_{2}\right)\right]\left(\mathrm{Ar}_{2}=\mathrm{Dmp} / \mathrm{Tph}(\mathbf{2 a}),\left(\mathrm{Me}_{4} \mathrm{Ter}\right)_{2}(\mathbf{2} \mathbf{b})\right)$ are isolated in good yields. Repeating the same reactions in the non-coordinating solvent $n$-heptane afforded trinuclear donor-free complexes $\left[\mathrm{Mg}_{3}\left(\mathrm{~N}_{3} \mathrm{Ar}_{2}\right)_{2} \mathrm{I}_{4}\right]\left(\mathrm{Ar}_{2}=\mathrm{Dmp} / \mathrm{Tph}(\mathbf{3 a}),\left(\mathrm{Me}_{4} \mathrm{Ter}\right)_{2}(\mathbf{3 b})\right)$ as the least soluble compounds in low isolated yields. Heteroleptic complexes $\left[\mathrm{Mg}\left(\mathrm{N}_{3} \mathrm{Ar}_{2}\right) \mathrm{I}\right]$ (Ia, Ib) (Scheme 1b) are possible intermediates that might rearrange via Schlenk-type equilibria and ligand redistribution reactions to $\mathbf{3 a}$ and $\mathbf{3 b}$. Analysis of the better soluble fractions in the mother liquor by NMR experiments showed the presence of other moieties, most probably a mixture of homo- and hetero-leptic compounds. However, it was not possible to separate these main products by crystallization. A more rational synthetic approach to homoleptic magnesium triazenides consists of the reaction of di- $n$-butylmagnesium with the corresponding triazene in a 1:2 ratio to give $\left[\mathrm{Mg}\left\{\mathrm{N}_{3}\left(\mathrm{Me}_{4} \mathrm{Ter}\right)_{2}\right\}_{2}\right](4 \mathbf{b})$ or $\left[\mathrm{Mg}\left\{\mathrm{N}_{3}(\mathrm{Dmp}) \mathrm{Mph}\right\}_{2}\right](4 \mathrm{c})$ in good to excellent yields (Scheme 1c). The corresponding homoleptic magnesium triazenide derived from triazene 1a could not be obtained by this route. This is in accordance with earlier observations that homoleptic alkaline earth metal triazenides with the $\left[\mathrm{N}_{3}(\mathrm{Dmp}) \mathrm{Tph}\right]$ ligand are accessible for the heavier elements strontium and barium only, due to steric crowding [10].

The pale yellow (3a, $3 \mathbf{b}, \mathbf{4 b})$ or deep yellow $(\mathbf{2} \mathbf{a}, \mathbf{2} \mathbf{b}, \mathbf{4})$ complexes are moisture-sensitive and, with the exception of $\mathbf{3 b}$, possess good or moderate solubility in aromatic or aliphatic hydrocarbons. They show considerable thermal stability, but decompose, presumably with $\mathrm{N}_{2}$ evolution, at higher temperature. The most thermally-stable compound is the homoleptic complex 4c, which decomposes above $300{ }^{\circ} \mathrm{C}$. The IR spectra show strong $v_{\text {as }} \mathrm{N}_{3}$ absorptions in the range of $1255-1282 \mathrm{~cm}^{-1}$, which is indicative of the triazenido groups acting as chelating ligands. In the ${ }^{1} \mathrm{H}$ NMR spectra of $\mathbf{2} \mathbf{b}$ and $\mathbf{3} \mathbf{a}$, the expected sets of signals are observed at ambient temperature. However, more complex temperature-dependent spectra are found for $\mathbf{2 a}, \mathbf{4 b}$ and $\mathbf{4 c}$. For heteroleptic complex $\mathbf{2 a}$ at $273 \mathrm{~K}$, five and three well-separated resonances are observed for the methyl groups of the 2,4,6-tri-iso-propylphenyl and 2,4,6-trimethylphenyl substituents, respectively. Warming of the NMR sample results in broadening, coalescence and finally resharpening to three and two resonances at $373 \mathrm{~K}$. This behavior can be explained by hindered rotation around the $\mathrm{N}-\mathrm{C}(\operatorname{aryl})$ bonds (cf. Figures S1 and S2 in the Supplementary Materials). For the homoleptic complexes $4 \mathbf{b}$ and 
4c, the high-temperature ${ }^{1} \mathrm{H}$ NMR data indicate free (for $4 \mathrm{c}$ at $373 \mathrm{~K}$ ) or almost free (for $4 \mathrm{~b}$ at $338 \mathrm{~K}$ ) rotation around the N-C(aryl) bonds since some broadening of the resonances is still observed (cf. Figures S3b and S4 in the Supplementary Materials). For $4 b$, an interesting feature in the ${ }^{1} \mathrm{H} N M R$ spectrum at ambient temperature is a low-field shifted resonance at $7.64 \mathrm{ppm}$ that moves to higher field at elevated temperatures. It has been noted before [7] that the presence of low-field shifted signals in biphenyl-substituted triazenes indicates short intermolecular $\mathrm{C}-\mathrm{H} \cdots \mathrm{N}$ contacts at the NNN backbone of the ligands and therefore is a very sensitive probe for conformational preferences in solution. In the case of $4 \mathrm{~b}$, a C $-\mathrm{H} \cdots \mathrm{N}$ interaction of $2.48 \AA$ between the central nitrogen atom $\mathrm{N} 2$ and a hydrogen atom of the ortho- $\mathrm{C}_{6} \mathrm{H}_{3} \mathrm{Me}_{2}$ ring in the solid-state structure correlates with the observed low-field resonance in solution.

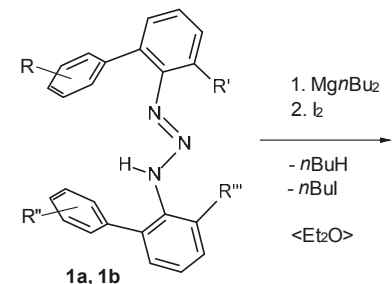

1a, 1b

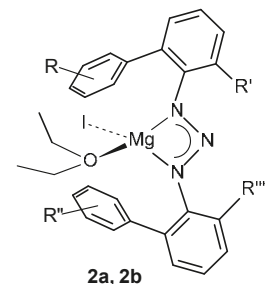

2a, 2b
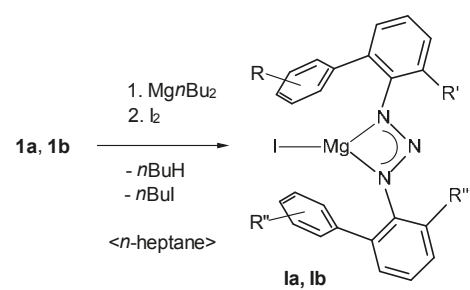

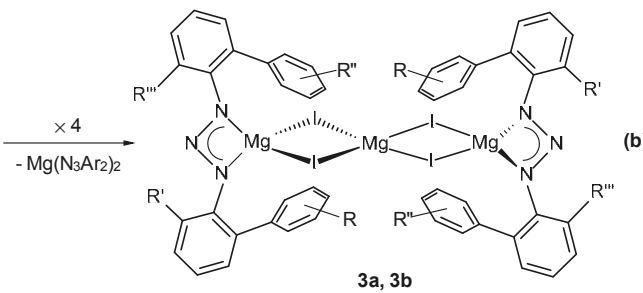

$3 a, 3 b$ (a)

(b)

\footnotetext{
1a, 2a, 3a: $\quad \mathrm{R}=2,4,6-\mathrm{Me}_{3}, \mathrm{R}^{\prime}=2,4,6-\mathrm{Me}_{3} \mathrm{C}_{6} \mathrm{H}_{2}, \mathrm{R}^{\prime \prime}=2,4,6-\mathrm{Pr}_{3}, \mathrm{R}^{\prime \prime}=\mathrm{H}$

1b, 2b, 3b, 4b: R= R" = 3,5-Mer, R' = R"' = 3,5-Me $\mathrm{C}_{6} \mathrm{H}_{3}$

1c, 4c: $\quad \mathrm{R}=\mathrm{R}^{\prime \prime}=2,4,6-\mathrm{Me}_{3}, \mathrm{R}^{\prime}=2,4,6-\mathrm{Me}_{3} \mathrm{C}_{6} \mathrm{H}_{2}, \mathrm{R}^{\prime \prime}=\mathrm{H}$
}

Scheme 1. Syntheses of Compounds $2 a$ and $2 b(a), 3 a$ and $3 b(b)$ and $4 b$ and $4 c(c)$.

\subsection{Structural Studies}

All compounds were examined by X-ray crystallography, and their molecular structures and selected bond parameters are shown in Figures 1-3. In the heteroleptic iodomagnesium triazenides $\mathbf{2 a}$ and $\mathbf{2} \mathbf{b}$, the magnesium atoms possess a very distorted tetrahedral coordination by two nitrogen atoms N1 and N3 of a $\eta^{2}$-bonded triazenide ligand, an iodine atom I and the oxygen atom O53 (2a) or O73 (2b) of a diethyl ether molecule (Figure 1). The degree of distortion is reflected by interligand angles in the wide range $61.45(6)^{\circ}-132.64(5)^{\circ}(2 \mathbf{a})$ and $61.04(7)^{\circ}-143.56(7)^{\circ}(2 \mathbf{b})$, respectively. In an alternative and possibly more appropriate description that assigns only one coordination site, represented by the central nitrogen atom N2, to the small-bite triazenido ligand, the metal 
atoms show trigonal planar coordination with corresponding angles of $105.39(5)^{\circ}-128.51(4)^{\circ}(2 \mathbf{a})$ and $108.36(6)^{\circ}-125.04(5)^{\circ}(\mathbf{2 b})$, respectively. The relatively small variation of the N1-N2 and N2-N3

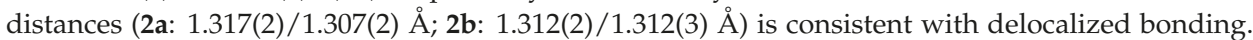
Nonetheless, coordination of the triazenide ligand is slightly asymmetric for $2 \mathrm{a}$ with $\mathrm{Mg}-\mathrm{N}$ bond lengths of 2.1151(16) $\AA$ and 2.0880(16) $\AA$. A more symmetric coordination with Mg-N distances of 2.101(2) $\AA$ and 2.0958(19) $\AA$ is observed for the magnesium atom in 2b. Interestingly, the $\mathrm{Mg}-\mathrm{N}$ bond length correlates with the conformation of the triazenide ligand. Thus, a coplanar arrangement of the substituted arene rings with respect to the central triazaallyl fragment as reflected by a CCNN torsion angle close to $0^{\circ}$ increases the basicity of the bonded nitrogen atom. Therefore, for $\mathbf{2 a}$, the shortest $\mathrm{Mg}-\mathrm{N}$ distance to the biphenyl substituted nitrogen atom N3 of 2.0880(16) $\AA$ corresponds to the smallest torsion angle N2-N3-C31-C36 of $18.0(3)^{\circ}$.

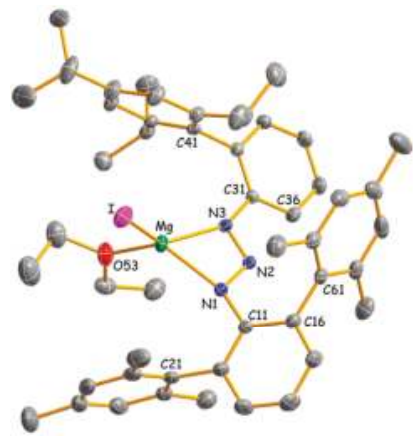

(a)

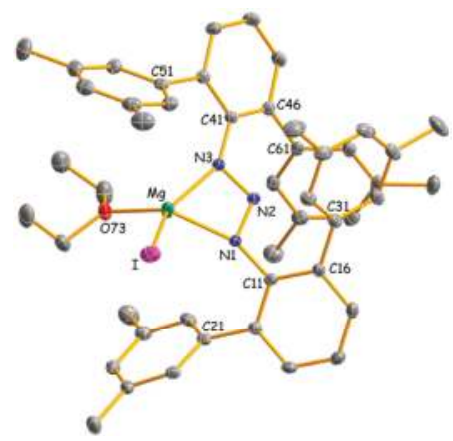

(b)

Figure 1. Molecular structures of $\mathbf{2 a}$ (a) and $\mathbf{2 b}(\mathbf{b})$ with thermal ellipsoids set to $30 \%$ probability. Hydrogen atoms have been omitted for clarity. Selected bond lengths $(\AA)$, angles and dihedral angles $\left({ }^{\circ}\right)$ for $\mathbf{2 a}(\mathbf{2 b})$ : Mg-N1/N3 = 2.1151(16)/2.0880(16) $(2.101(2) / 2.0958(19)), \mathrm{Mg}-\mathrm{I}=2.6438(7)$ (2.6596(9)), $\mathrm{Mg}-\mathrm{O}=2.0157(15)(1.996(2)), \mathrm{N} 1-\mathrm{N} 2=1.317(2)(1.312(2)), \mathrm{N} 2-\mathrm{N} 3=1.307(2)(1.312(3))$, $\mathrm{N} 1-\mathrm{Mg}-\mathrm{N} 3=61.45(6)(61.04(7)), \mathrm{N} 1-\mathrm{Mg}-\mathrm{I}=113.36(5)(103.83(6)), \mathrm{N} 1-\mathrm{Mg}-\mathrm{O}=125.70(7)(123.70(9))$, $\mathrm{N} 3-\mathrm{Mg}-\mathrm{I}=132.64(5)(143.56(7)), \mathrm{N} 3-\mathrm{Mg}-\mathrm{O}=114.51(6)(107.24(8)), \mathrm{I}-\mathrm{Mg}-\mathrm{O}=105.39(5)$ (108.36(6)), N2-N1-C11-C16 = 35.7(3) (37.8(3)), N2-N3-C31-C36 = 18.0(3) (N2-N3-C41-C46 = 27.0(3)).

In the rather unusual trinuclear $\mathrm{MgI}_{2}$ addition compounds $\mathbf{3} \mathbf{a}$ and $\mathbf{3 b}$, a central four-coordinate magnesium atom $\mathrm{Mg} 2$ is bridged by four iodine atoms to two terminal magnesium centers Mg1 and Mg3 (Figure 2). Each of the latter is additionally coordinated via two nitrogen atoms by a chelating triazenido ligand. The three metal atoms form a nearly perfect linear arrangement with an angle of $178.5^{\circ}$ for $3 \mathbf{a}$ and $179.1^{\circ}$ for $\mathbf{3 b}$. Notably, there appear to be no previous reports on molecular compounds that contain such a trinuclear $\mathrm{Mg}_{3} \mathrm{I}_{4}{ }^{2+}$ or even an $\mathrm{MgI}_{4}{ }^{2-}$ fragment [17]. However, the terminal $\left[\left(\mathrm{Ar}_{2} \mathrm{~N}_{3}\right) \mathrm{MgI}_{2}\right]^{2-}$ fragments may be compared with related dimeric complexes of the general composition $\left[(\mathrm{L}) \mathrm{Mg}-\mu-\mathrm{I}_{2} \mathrm{Mg}(\mathrm{L})\right]$ where $\mathrm{L}$ represents bulky amido, diketiminato, diiminophosphinato or guanidinato ligands [18-22]. In $\mathbf{3} \mathbf{a}$ and $\mathbf{3 b}$, the coordination spheres of the central magnesium atoms feature distorted tetrahedral geometries with I-Mg2-I angles in the range $96.24(6)^{\circ}-120.55(8)^{\circ}(3 a)$ and $98.09(4)^{\circ}-116.70(5)^{\circ}(3 \mathbf{b})$, respectively. As expected, the average Mg2-I distance of 2.741(2) $\AA$ (3a) and 2.7209(13) $\AA$ (3b) is shorter than the corresponding value of 2.9183(5) $\AA$ in the solid state structure of $\mathrm{MgI}_{2}$ [23] that adopts the $\mathrm{CdI}_{2}$ type of structure with hexa-coordinate magnesium atoms. For the gas phase structure of molecular di-coordinate magnesium diiodide, the $\mathrm{Mg}-\mathrm{I}$ distance was determined by electron diffraction to $2.52 \pm 0.03 \AA$ [24]. Moreover, if only one coordination site is assigned to the small-bite angle triazenido ligands, a distorted trigonal planar coordination results for the terminal magnesium atoms as can be judged by the sum of the angles around Mg1 and Mg3 in the 
range of $358.2^{\circ}-360.0^{\circ}$. Alternatively, if the triazenido ligands are viewed as bidentate, the resulting four-coordination of $\mathrm{Mg} 1$ and $\mathrm{Mg} 3$ is somehow intermediate between tetrahedral and square planar geometry. A more precise description of these distortions uses the $\tau_{4}$ parameter [25]:

$$
\tau_{4}=\frac{360^{\circ}-(\alpha+\beta)}{141^{\circ}}
$$

It is defined as the sum of angles $\alpha$ and $\beta$, the two largest angles in the four-coordinate species, subtracted from $360^{\circ}$ and all divided by $141^{\circ}$. The values of $\tau_{4}$ will range from zero for a perfect square planar to 1.00 for a perfect tetrahedral geometry. Intermediate structures fall within the range of 0-1.00. By using Equation (1), $\tau_{4}$ parameters of 0.62/0.87/0.64 (0.40/0.91/0.62) are calculated for $\mathrm{Mg} 1 / \mathrm{Mg} 2 / \mathrm{Mg} 3$ in complex 3a (3b), respectively. Therefore, a transition from tetrahedral to square planar coordination is evident for $\mathrm{Mg} 1 \mathrm{in} \mathbf{3 b}$. This is also reflected by the interplanar angle of $38.2^{\circ}$ between the $\mathrm{Mg} 1 / \mathrm{I} 1 / \mathrm{I} 2$ and $\mathrm{Mg} 1 / \mathrm{N} 1 / \mathrm{N} 3$ planes.

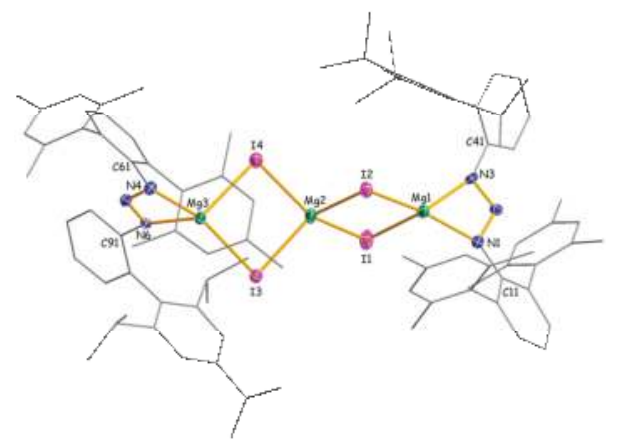

(a)

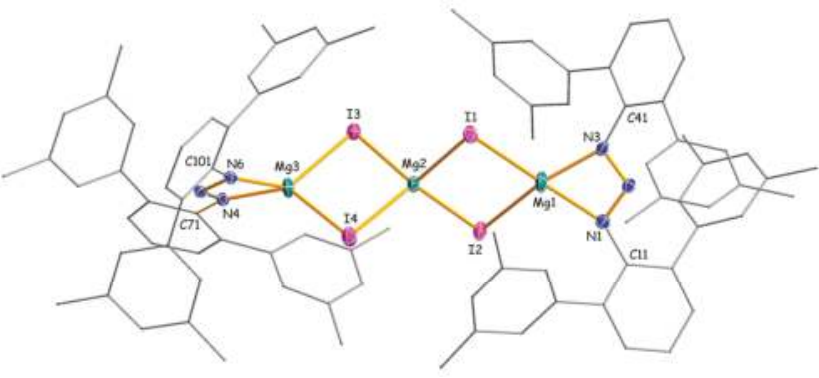

(b)

Figure 2. Molecular structures of $\mathbf{3 a}(\mathbf{a})$ and $\mathbf{3 b}(\mathbf{b})$ with thermal ellipsoids set to $30 \%$ probability. Hydrogen atoms have been omitted and carbon atoms are reduced in size for clarity. Selected bond lengths $(\AA)$ and angles $\left({ }^{\circ}\right)$ for 3a (3b): Mg1-I1 = 2.794(2) (2.8014(13)), Mg1-I2 = 2.7446(19) (2.7865(13)), Mg2-I1 = 2.736(2) (2.7097(12)), Mg2-I2 = 2.753(2) (2.7143(12)), Mg2-I3 = 2.738(2) (2.7302(13)), Mg2-I4 = 2.735(2) (2.7294(12)), Mg3-I3 = 2.7390(18) (2.7564(12)), Mg3-I4 = 2.7811(19) (2.7767(13)), Mg1-N1/N3 = 2.075(4)/2.073(5) (2.093(3)/2.057(3)), Mg3-N4/N6 = 2.068(5)/2.074(4) (2.057(3)/2.074(3)), av. N-N = $1.314(5)(1.311(4))$ N1-Mg1-N3 = 62.54(17) (61.65(11)), N1-Mg1-I1 = 110.00(14) (146.66(10)), N1-Mg1-I2 = 143.16(16) (107.59(9)), N3-Mg1-I1 = 117.06(15) (105.10(9)), N3-Mg1-I2 = 128.89(14) (156.88(10)), I1-Mg1-I2 = 95.08(5) (94.29(4)), I1-Mg2-I2 = 96.24(6) (98.09(4)), I1-Mg2-I3 = 112.88(7) (114.83(5)), I1-Mg2-I4 = 113.90(8) (113.57(4)), I2-Mg2-I3 = 120.55(8) (115.56(4)), I2-Mg2-I4 = 117.21(7) (116.70(5)), I3-Mg2-I4 = 97.16(6) (99.07(4)), N4-Mg3-N6 = 62.28(17) (61.90(10)), N4-Mg3-I3 = 140.98(16) (122.96(9)), N4-Mg3-I4 = 109.31(15) (135.71(10)), N6-Mg3-I3 = 129.39(14) (136.28(10)), N6-Mg3-I4 = 118.75(15) (102.76(9)), I3-Mg3-I4 = 96.06(5) (97.30(3)). 
Homoleptic packing complexes $\mathbf{4 b} \cdot\left(\mathrm{C}_{7} \mathrm{H}_{16}\right)$ and $\mathbf{4} \mathbf{c} \cdot\left(\mathrm{C}_{7} \mathrm{H}_{8}\right)_{0.5}$ crystallize as monomers with four-coordinate metal atoms in which the triazenide ligands are coordinated in a chelating $\eta^{2}$-fashion (Figure 3). There are no significant interactions between the complexes and the co-crystallized $n$-heptane or toluene solvent molecules. In $\mathrm{C}_{2}$-symmetric $4 \mathbf{b}$, the two-fold axis runs almost parallel to the NNN plane through the magnesium atom, whereas $\mathrm{C}_{1}$-symmetric $4 \mathrm{c}$ has no additional crystallographically-imposed symmetry. Interestingly, the magnesium atom in $4 \mathrm{c}$ shows a distorted tetrahedral coordination with an average $\mathrm{Mg}-\mathrm{N}$ distance of 2.086(2) $\AA$, whereas a distorted square planar coordination around the magnesium center with a significant longer average $\mathrm{Mg}-\mathrm{N}$ distance of 2.128(2) $\AA$ is observed for $4 \mathbf{b}$. The different coordination is reflected by the interplanar angle $\gamma$, which is defined as the angle between the two MgNN planes (e.g., for $4 \mathrm{c}$, angle between the plane normals through the atoms $\mathrm{Mg} / \mathrm{N} 1 / \mathrm{N} 3$ and $\mathrm{Mg} / \mathrm{N} 4 / \mathrm{N6}$ ), of $83.6^{\circ}(4 \mathbf{c})$ and $9.6^{\circ}(\mathbf{4 b})$, or alternatively, by the $\tau_{4}$ parameter of $0.51(4 \mathbf{c})$ and $0.20(4 \mathbf{b})$. These values may be compared with the corresponding parameters in previously-published homoleptic magnesium amidinates [16,26-30], guanidinates [20] and $\beta$-diketiminates [31-33], as summarized in Table 1. For the six known magnesium amidinates, considered to possess tetrahedral metal coordination, $\gamma$ angles and $\tau_{4}$ parameters are observed in the range of $54.1^{\circ}-89.5^{\circ}$ and $0.40^{\circ}-0.60^{\circ}$, respectively. The relatively small values for $\tau_{4}$, compared to the ideal value of 1.00 , can be rationalized by the small bite angles of the amidinate and triazenide ligands that enforce "flattened tetrahedral" geometries. In contrast, higher values in the range of $0.83-0.92$ are found for $\beta$-diketiminates that have larger bite angles with more separated $\mathrm{N}$ donor atoms.

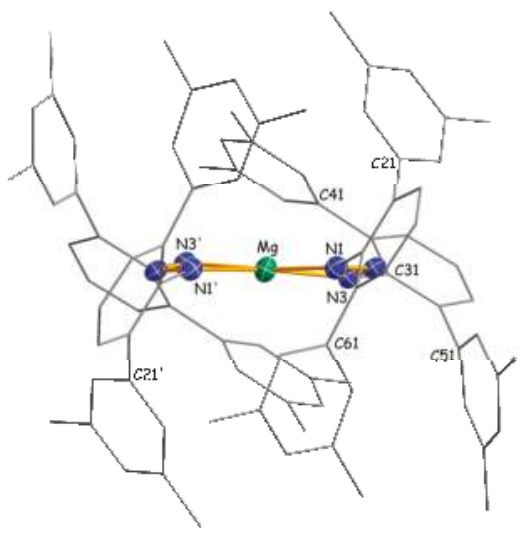

(a)

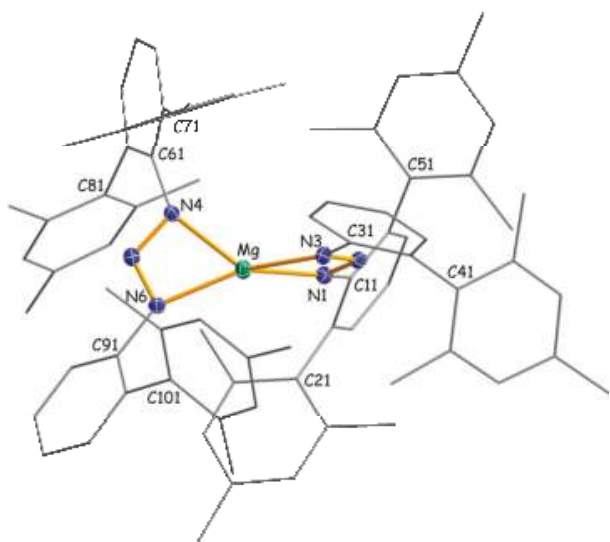

(b)

Figure 3. Molecular structures of $4 \mathbf{b}$ (a) and $4 \mathbf{c}(\mathbf{b})$ with thermal ellipsoids set to $30 \%$ probability. Hydrogen atoms and co-crystallized solvents have been omitted and carbon atoms are reduced in size for clarity. Selected bond lengths $(\AA)$, angles and dihedral angles $\left(^{\circ}\right)$ for $\mathbf{4 b}$ (symmetry operation $\left.\left({ }^{\prime}\right):-x+1 / 2, y,-z+1 / 2\right): \quad \mathrm{Mg}-\mathrm{N} 1=2.131(2), \mathrm{Mg}-\mathrm{N} 3=2.125(2), \mathrm{Mg}-\mathrm{N} 2=2.579(2)$, $\mathrm{N} 1-\mathrm{N} 2=1.316(3), \mathrm{N} 2-\mathrm{N} 3=1.318(3), \mathrm{N} 1-\mathrm{Mg}-\mathrm{N} 3=60.97(8), \mathrm{N} 1-\mathrm{Mg}-\mathrm{N} 1^{\prime}=106.11(13), \mathrm{N} 3-\mathrm{Mg}-\mathrm{N} 3^{\prime}=$ 132.43(13), N1-Mg-N3' = 165.96(10), N1-N2-N3 = 110.1(2), N2-N1-C11 = 109.6(2), N2-N3-C31 = 112.7(2), N2-N1-C11-C12 = 54.7(3), N2-N3-C31-C36 = 54.6(3). Selected bond lengths $(\AA)$, angles and dihedral angles $\left({ }^{\circ}\right)$ for $4 \mathrm{c}: \mathrm{Mg}-\mathrm{N} 1=2.0863(19), \mathrm{Mg}-\mathrm{N} 3=2.0770(19), \mathrm{Mg}-\mathrm{N} 2=2.568(2)$, $\mathrm{Mg}-\mathrm{N} 4=2.1151(19), \mathrm{Mg}-\mathrm{N} 6=2.0673(19), \mathrm{Mg}-\mathrm{N} 5=2.555(2), \mathrm{N} 1-\mathrm{N} 2$ = 1.315(2), N2-N3 = 1.323(2), N4-N5 = 1.312(2), N5-N6 = 1.324(2), N1-Mg-N3 = 61.39(7), N4-Mg-N6 = 61.81(7), N1-Mg-N4 = 120.68(8), N1-Mg-N6 = 138.30(8), N3-Mg-N4 = 135.20(8), N3-Mg-N6 = 150.35(8), N2-N1-C11-C16 = $-46.7(3), \mathrm{N} 2-\mathrm{N} 3-\mathrm{C} 31-\mathrm{C} 32=-25.8(3), \mathrm{N} 5-\mathrm{N} 4-\mathrm{C} 61-\mathrm{C} 66=-60.7(3), \mathrm{N} 5-\mathrm{N} 6-\mathrm{C} 91-\mathrm{C} 96=35.5(3)$. 
Table 1. Interplanar angles and $\tau_{4}$ parameters [25] in four-coordinate magnesium triazenides, amidinates, guanidinates and $\beta$-diketiminates.

\begin{tabular}{|c|c|c|c|}
\hline Compound $^{1}$ & $\gamma\left({ }^{\circ}\right)$ & $\tau_{4}$ & Ref. \\
\hline \multicolumn{4}{|l|}{ Triazenides } \\
\hline$\left[\mathrm{Mg}\left\{\mathrm{N}_{3}\left(\mathrm{Me}_{4} \mathrm{Ter}\right)_{2}\right\}_{2}\right] \mathbf{4 b}$ & 9.6 & 0.20 & \\
\hline $\begin{array}{c}{\left[\mathrm{Mg}\left\{\mathrm{N}_{3}((\mathrm{Dmp}) \mathrm{Mph})_{2}\right\}_{2}\right] 4 \mathrm{c}} \\
\text { Amidinates }\end{array}$ & 83.6 & 0.51 & \\
\hline$\left[\mathrm{Mg}\{\operatorname{DipN}\{\mathrm{C}(p \mathrm{Tol})\} \mathrm{NDip}\}_{2}\right]$ & 13.3 & 0.10 & {$[26]$} \\
\hline$\left[\mathrm{Mg}\left\{\mathrm{DipN}\{\mathrm{C}(\mathrm{Me})\} \mathrm{NDip}_{2}\right]_{2}{ }^{2}\right.$ & $54.1 / 54.9$ & $0.40 / 0.41$ & [16] \\
\hline$\left[\mathrm{Mg}\left\{\mathrm{DipN}\{\mathrm{C}(\mathrm{cHex})\} \mathrm{NDip}_{2}\right]\right.$ & 61.3 & 0.45 & [27] \\
\hline$\left[\mathrm{Mg}\left\{\mathrm{DipN}\left\{\mathrm{C}\left(3,5-\mathrm{Me}_{2} \mathrm{C}_{6} \mathrm{H}_{3}\right)\right\} \mathrm{NDip}\right\}_{2}\right]$ & 76.4 & 0.56 & [27] \\
\hline$\left[\mathrm{Mg}\{\operatorname{MesN}\{\mathrm{C}(t \mathrm{Bu})\} \mathrm{NMes}\}_{2}\right]$ & 80.3 & 0.57 & [28] \\
\hline$\left[\mathrm{Mg}\{t \mathrm{BuN}\{\mathrm{C}(\mathrm{Ph})\} \mathrm{N} t \mathrm{Bu}\}_{2}\right]$ & 89.5 & 0.58 & [29] \\
\hline$\left[\mathrm{Mg}\{i \operatorname{PrN}\{\mathrm{C}(\mathrm{Dmp})\} \mathrm{NiPr}\}_{2}\right]$ & 88.1 & 0.60 & [30] \\
\hline \multicolumn{4}{|l|}{ Guanidinates } \\
\hline $\begin{array}{c}{\left[\mathrm{Mg}\left\{\text { MesN }\{\mathrm{C}(\mathrm{N} c \mathrm{Hex})\} \mathrm{NMes}_{2}\right]\right.} \\
\beta \text {-Diketiminates }\end{array}$ & 8.6 & 0.06 & [20] \\
\hline$\left[\mathrm{Mg}\left(\mathrm{HC}\left\{\mathrm{C}(\mathrm{Me}) \mathrm{N}\left(\mathrm{NiPr}_{2}\right)\right\}_{2}\right)_{2}\right]$ & 89.5 & 0.83 & [31] \\
\hline$\left[\mathrm{Mg}\left(\mathrm{HC}\{\mathrm{C}(\mathrm{Me}) \mathrm{N}(i \mathrm{Pr})\}_{2}\right)_{2}\right]$ & 88.9 & 0.88 & [32] \\
\hline$\left[\mathrm{Mg}\left(\mathrm{HC}\{\mathrm{C}(\mathrm{Me}) \mathrm{N}(t \mathrm{Bu})\}_{2}\right)_{2}\right]$ & 88.4 & 0.92 & [32] \\
\hline$\left[\mathrm{Mg}\left(\mathrm{HC}\left\{\mathrm{C}(\mathrm{Ph}) \mathrm{N}\left(\mathrm{SiMe}_{3}\right)\right\}_{2}\right)_{2}\right]$ & 89.0 & 0.92 & [33] \\
\hline
\end{tabular}

Magnesium complexes with square planar coordinated metal atoms are quite uncommon and usually restricted to ligands with rigid geometry, such as porphyrins [34-38]. Rare examples of planar magnesium compounds with non-rigid ligands are Lappert's 1-azallyl complex $\left[\mathrm{Mg}\left(\mathrm{Me}_{3} \mathrm{SiNC}(t \mathrm{Bu}) \mathrm{C}(\mathrm{H}) \mathrm{SiMe}_{3}\right)_{2}\right]$ [33], Junk's amidinate [Mg\{DipN $\left.\{\mathrm{C}(p \mathrm{Tol})\} \mathrm{NDip}_{2}\right]$ [26] and Kays' guanidinate $\left[\mathrm{Mg}\{\mathrm{MesN}\{\mathrm{C}(\mathrm{NcHex})\} \mathrm{NMes}\}_{2}\right]$ [20]. It has been argued that interligand repulsion between peripheric substituents is responsible for the square planar coordination in these compounds. Moreover, it is known that attractive dispersion forces may contribute to unusual coordination geometries [39-41]. Therefore, it is reasonable to assume that a combination of repulsive and attractive interligand interactions accounts for the different metal coordination in $4 \mathbf{b}$ and $4 \mathrm{c}$. Notably, the propensity of the $\left[\left(\mathrm{Me}_{4} \mathrm{Ter}\right)_{2} \mathrm{~N}_{3}\right]^{-}$ligand to support square planar coordination is not limited to magnesium. A similar complex with a square planar coordinated $\mathrm{Yb}$ (II) center was characterized in our group [42].

In order to shed some light on the relative energetic levels of tetrahedral or square planar coordinated magnesium triazenides, DFT calculations were performed for suitable model compounds. Unfortunately, we did not succeed to locate stationary points for both geometries with the same ligand systems. Therefore, simple phenyl substituted model complexes $\mathbf{5}_{\mathrm{T}}$ and $\mathbf{5}_{\mathrm{SP}}$ were calculated using the B3LYP functional and 6-311+G* basis sets. The experimentally-determined geometries of $4 \mathbf{b}$ and $4 \mathrm{c}$ were taken as the starting point, after replacing the bulky biphenyl and terphenyl substituents by phenyl groups. A minimum on the potential energy surface with $S_{4}$ symmetry corresponds to the tetrahedral isomer $5_{\mathrm{T}}\left(\gamma=90^{\circ}, \tau_{4}=0.60\right)$. Since it was at first not possible to locate a stationary point for a square planar isomer, the conformation of the starting geometry was partly frozen by fixing $\mathrm{NNMgN}$ and NNCC torsion angles to the experimentally-determined values. The resulting energy-minimized $\mathrm{C}_{1}$-symmetric isomer $5_{\mathrm{SP}}\left(\gamma=9.7^{\circ}, \tau_{4}=0.07\right)$ is energetically disfavored over $\mathbf{5}_{\mathrm{T}}$ by $+60.7 \mathrm{KJ} \cdot \mathrm{mol}^{-1}$.

Table 2 summarizes some pertinent bond parameters in structurally-characterized magnesium triazenides. Overall, the expected correlation between coordination number and $\mathrm{Mg}-\mathrm{N}$ bond length is observed. However, two exceptions are noteworthy. Firstly, in distorted square planar coordinated $4 \mathbf{b}$, the $\mathrm{Mg}-\mathrm{N}$ distance of $2.128 \AA$ is significantly longer than the corresponding values in distorted tetrahedral coordinated metal complexes that fall within the range of 2.070-2.102 A. Secondly, in Westerhausen's heteroleptic five-coordinate magnesium complex $\left[\mathrm{Mg}(n \mathrm{Bu})\left\{\mathrm{N}_{3}(\mathrm{Mes})_{2}\right\}\right.$ (tmeda)] [15], the Mg-N bond length is longer than the average values in Gibson's 
five-coordinate magnesium compound $\left[\mathrm{Mg}\left\{\mathrm{N}_{3}(\mathrm{Dip})_{2}\right\}_{2}\left(\mathrm{OEt}_{2}\right)\right][16]$ and in the six-coordinate metal bis(THF) adducts $\left[\mathrm{Mg}\left\{\mathrm{N}_{3}(\mathrm{Ar})_{2}\right\}_{2}(\mathrm{thf})_{2}\right](\mathrm{Ar}=p \mathrm{Tol}$ [14], Mes [15]). The elongated bond may be attributed to the competition of the moderate nucleophilic triazenide ligand with the powerful carbanionic ligand. In addition, there appears to be some correlation between the $\mathrm{N}-\mathrm{Mg}-\mathrm{N}$ angle and the coordination number. Slightly more acute angles are observed for higher coordinated magnesium atoms. In contrast, there seems to be no clear correlation between steric crowding inside the complexes and the size of the average $\mathrm{N}-\mathrm{Mg}-\mathrm{N}$ or $\mathrm{Mg}-\mathrm{N}-\mathrm{C}$ angle.

Table 2. Important structural parameters (av. values $\left(\AA^{\circ},{ }^{\circ}\right)$ ) in magnesium triazenides.

\begin{tabular}{|c|c|c|c|c|c|}
\hline Compound ${ }^{1}$ & Cn & $\mathrm{Mg}-\mathrm{N}$ & N-Mg-N & $\mathrm{Mg}-\mathrm{N}-\mathrm{C}$ & Ref. \\
\hline$\left[\mathrm{Mg}\left\{\mathrm{N}_{3}(\mathrm{Dmp}) \mathrm{Tph}\right\} \mathrm{I}\left(\mathrm{OEt}_{2}\right)\right] \mathbf{2 a}$ & 4 & 2.102 & 61.5 & 151.4 & \\
\hline$\left[\mathrm{Mg}\left\{\mathrm{N}_{3}\left(\mathrm{Me}_{4} \mathrm{Ter}\right)_{2}\right\} \mathrm{I}\left(\mathrm{OEt}_{2}\right)\right] \mathbf{2 b}$ & 4 & 2.098 & 61.0 & 147.3 & \\
\hline$\left.\left[\mathrm{Mg}_{3} \mathrm{I}_{4}\left\{\mathrm{~N}_{3}(\mathrm{Dmp}) \mathrm{Tph}\right)\right\}_{2}\right] \mathbf{3 a}$ & 4 & 2.074 & 62.4 & 152.0 & \\
\hline$\left[\mathrm{Mg}_{3} \mathrm{I}_{4}\left\{\mathrm{~N}_{3}\left(\mathrm{Me}_{4} \mathrm{Ter}\right)_{2}\right\}_{2}\right] 3 \mathbf{b}$ & 4 & 2.070 & 61.8 & 148.9 & \\
\hline$\left[\mathrm{Mg}\left\{\mathrm{N}_{3}\left(\mathrm{Me}_{4} \mathrm{Ter}\right)_{2}\right\}_{2}\right] \mathbf{4 b}$ & 4 & 2.128 & 61.0 & 151.3 & \\
\hline$\left.\left[\mathrm{Mg}\left\{\mathrm{N}_{3}(\mathrm{Dmp}) \mathrm{Mph}\right)\right\}_{2}\right] 4 \mathrm{c}$ & 4 & 2.086 & 61.6 & 145.5 & \\
\hline$\left[\mathrm{Mg}\left\{\mathrm{N}_{3}(\mathrm{Dmp}) \mathrm{Tph}\right\} \mathrm{I}(\mathrm{thf})\right]$ & 4 & 2.093 & 61.9 & 147.0 & [11] \\
\hline$\left[\mathrm{Mg}\left\{\mathrm{N}_{3}(\mathrm{Dip})_{2}\right\}_{2}\left(\mathrm{OEt}_{2}\right)\right]$ & 5 & 2.137 & 60.2 & 150.6 & [16] \\
\hline$\left[\mathrm{Mg}(n \mathrm{Bu})\left\{\mathrm{N}_{3}(\mathrm{Mes})_{2}\right\}\right.$ (tmeda) $]$ & 5 & 2.202 & 58.2 & 150.3 & [15] \\
\hline$\left[\mathrm{Mg}\left\{\mathrm{N}_{3}(p \mathrm{Tol})_{2}\right\}_{2}(\mathrm{thf})_{2}\right]$ & 6 & 2.183 & 58.8 & 149.6 & [14] \\
\hline$\left[\mathrm{Mg}\left\{\mathrm{N}_{3}(\mathrm{Mes})_{2}\right\}_{2}(\mathrm{thf})_{2}\right]$ & 6 & 2.181 & 59.1 & 150.2 & [15] \\
\hline
\end{tabular}

${ }_{1}$ Dip = 2,6-i $\mathrm{Pr}_{2} \mathrm{C}_{6} \mathrm{H}_{3} ;$ Dmp = 2,6-Mes ${ }_{2} \mathrm{C}_{6} \mathrm{H}_{3} ;$ Mes = 2,4,6- $\mathrm{Me}_{3} \mathrm{C}_{6} \mathrm{H}_{2} ; \mathrm{Me}_{4} \mathrm{Ter}=2,6-\left(3,5-\mathrm{Me}_{2} \mathrm{C}_{6} \mathrm{H}_{3}\right)_{2} \mathrm{C}_{6} \mathrm{H}_{3}$; $\mathrm{Mph}=2-\mathrm{MesC}_{6} \mathrm{H}_{4} ; p$ Tol $=p$-tolyl; Tph $=2-\operatorname{TripC}_{6} \mathrm{H}_{4}$ with Trip $=2,4,6-i-\mathrm{Pr}_{3} \mathrm{C}_{6} \mathrm{H}_{2}$

Finally, it may be noted that complexes $2 a-4 c$ show no significant secondary interactions to the carbon atoms of pending aryl substituents as previously observed in triazenides of the heavier alkaline earth metals $[5,10]$.

\section{Materials and Methods}

\subsection{General Procedures}

All manipulations were performed by using standard Schlenk techniques under an inert atmosphere of purified argon. Solvents were dried and purified using an MBraun 800 solvent purification system. The triazenes Dmp $(\mathrm{Tph}) \mathrm{N}_{3} \mathrm{H}$ [5], $\left(\mathrm{Me}_{4} \mathrm{Ter}\right)_{2} \mathrm{~N}_{3} \mathrm{H}$ [8] or Dmp $(\mathrm{Mph}) \mathrm{N}_{3} \mathrm{H}$ [5] were synthesized as previously described. NMR spectra were recorded on Bruker AM200, AM400 or Biospin DRX 400 instruments (Karlsruhe, Germany) and referenced to solvent resonances. IR spectra have been obtained in the range of $4000-200 \mathrm{~cm}^{-1}$ with a Varian 3100 FT-IR spectrometer (Palo Alto, CA, USA). Melting points were determined under Ar atmosphere in sealed glass tubes.

\subsection{Syntheses}

\subsubsection{Experimental Procedure for $\left[\mathrm{Mg}\left\{\mathrm{N}_{3}(\mathrm{Dmp}) \mathrm{Tph}\right\}\left(\mathrm{OEt}_{2}\right)\right](\mathbf{2 a})$}

To a stirred solution of triazene $1 \mathrm{a}(1.27 \mathrm{~g}, 2.0 \mathrm{mmol})$ in $60 \mathrm{~mL}$ of diethyl ether, a $1.0 \mathrm{M}$ solution of di- $n$-butylmagnesium in $n$-heptane $(2.0 \mathrm{~mL}, 2.0 \mathrm{mmol})$ was added, and stirring was continued for $30 \mathrm{~min}$. To the resulting bright yellow solution, iodine $(0.51 \mathrm{~g}, 2.0 \mathrm{mmol})$ was added. The solution was stirred for another $3 \mathrm{~h}$ until the typical iodine color disappeared. The volume of the obtained yellow solution was reduced to incipient crystallization under reduced pressure. Storage at room temperature overnight afforded 2a as yellow needles. Yield: $1.6 \mathrm{~g}(1.86 \mathrm{mmol}, 93 \%)$; m.p.: $175{ }^{\circ} \mathrm{C}($ dec. $) ;{ }^{1} \mathrm{H}$ NMR $\left(200.1 \mathrm{MHz}\right.$, [D $\mathrm{D}_{8}$ toluene, $\left.373 \mathrm{~K}\right): \delta 0.69\left(\mathrm{t},{ }^{3} \mathrm{~J}_{\mathrm{HH}}=7.1 \mathrm{~Hz}, 6 \mathrm{H},\left(\mathrm{CH}_{3} \mathrm{CH}_{2}\right)_{2} \mathrm{O}\right), 0.95\left(\mathrm{~d},{ }^{3} J_{\mathrm{HH}}=6.6 \mathrm{~Hz}, 6 \mathrm{H}\right.$, $\left.\mathrm{CH}\left(\mathrm{CH}_{3}\right)_{2}\right), 1.07\left(\mathrm{~d},{ }^{3} J_{\mathrm{HH}}=6.8 \mathrm{~Hz}, 6 \mathrm{H}, \mathrm{CH}\left(\mathrm{CH}_{3}\right)_{2}\right), 1.27\left(\mathrm{~d},{ }^{3} J_{\mathrm{HH}}=7,1 \mathrm{~Hz}, 6 \mathrm{H}, \mathrm{CH}\left(\mathrm{CH}_{3}\right)_{2}\right), 2.05(\mathrm{~s}, 12 \mathrm{H}$, $\left.o-\mathrm{CH}_{3}\right), 2.15\left(\mathrm{~s}, 6 \mathrm{H}, p-\mathrm{CH}_{3}\right), 2.50\left(\mathrm{sep},{ }^{3} \mathrm{~J}_{\mathrm{HH}}=6.8 \mathrm{~Hz}, 2 \mathrm{H}, o-\mathrm{CH}\left(\mathrm{CH}_{3}\right)_{2}\right), 2.83\left(\mathrm{sep}, 1 \mathrm{H}, p-\mathrm{CH}\left(\mathrm{CH}_{3}\right)_{2}\right)$, $3.14\left(\mathrm{q}, 4 \mathrm{H},{ }^{3} \mathrm{~J}_{\mathrm{HH}}=7.1 \mathrm{~Hz},\left(\mathrm{CH}_{3} \mathrm{CH}_{2}\right)_{2} \mathrm{O}\right), 6.3-7.0\left(\mathrm{~m}, 13 \mathrm{H}\right.$, various Aryl-H). ${ }^{13} \mathrm{C} \mathrm{NMR}(62.9 \mathrm{MHz}$, 
[D $\mathrm{D}_{6}$ ]benzene): $\delta 13.7\left(\left(\mathrm{CH}_{3} \mathrm{CH}_{2}\right)_{2} \mathrm{O}\right), 21.3\left(o-\mathrm{CH}_{3}\right), 21.9\left(\mathrm{br}, p-\mathrm{CH}_{3}\right), 24.3,24.5,25.4\left(o+p-\mathrm{CH}\left(\mathrm{CH}_{3}\right)_{2}\right)$, 30.7 (br, o- $\left.\mathrm{CH}\left(\mathrm{CH}_{3}\right)_{2}\right), 34.9\left(p-\mathrm{CH}\left(\mathrm{CH}_{3}\right)_{2}\right), 66.5\left(\left(\mathrm{CH}_{3} \mathrm{CH}_{2}\right)_{2} \mathrm{O}\right), 120.9$ (m-Mes), 123.9, 124.8, 127.6, 130.7, 132.1 (aromatic CH), 131.7, 133.4, 134.7, 136.1, 139.5, 143.7, 147.1 (aromatic C). IR (Nujol, cm ${ }^{-1}$ ) $\widetilde{v}=1664 \mathrm{w}, 1609 \mathrm{~m}, 1595 \mathrm{sh}, 1583 \mathrm{w}, 1564 \mathrm{~m}, 1509 \mathrm{w}, 1415 \mathrm{~s}, 1362 \mathrm{~m}, 1261 \mathrm{vs}, 1184 \mathrm{~m}, 1106 \mathrm{~m}, 1093 \mathrm{~m}, 1080 \mathrm{w}$, $1056 \mathrm{w}, 1032 \mathrm{~s}, 1016 \mathrm{~m}, 977 \mathrm{w}, 938 \mathrm{~m}, 901 \mathrm{~m}, 884 \mathrm{w}, 872 \mathrm{~m}, 853 \mathrm{~s}, 834 \mathrm{~m}, 803 \mathrm{~m}, 787 \mathrm{~s}, 762 \mathrm{~s}, 750 \mathrm{~s}, 724 \mathrm{~m}$, 690m, 653s, 602w, 589m, 576w, 562w, 538m, 520m, 491m, 475m, 440m, 382s, 290m. Anal. Calcd. for $\mathrm{C}_{49} \mathrm{H}_{62} \mathrm{~N}_{3} \mathrm{MgIO}: \mathrm{C}, 68.41 ; \mathrm{H}, 7.26 ; \mathrm{N}, 4.88$. Found: $\mathrm{C}, 67.73 ; \mathrm{H}, 6.99 ; \mathrm{N}, 4.92$.

\subsubsection{Experimental Procedure for $\left[\mathrm{Mg}\left\{\mathrm{N}_{3}\left(\mathrm{Me}_{4} \mathrm{Ter}\right)_{2}\right\} \mathrm{I}\left(\mathrm{OEt}_{2}\right)\right](\mathbf{2 b})$}

The synthesis was accomplished in a manner similar to the preparation of $\mathbf{2 a}$ using triazene $1 \mathbf{b}(0.61 \mathrm{~g}, 1.0 \mathrm{mmol})$, a $1.0 \mathrm{M}$ solution of di- $n$-butylmagnesium in $n$-heptane $(1.0 \mathrm{~mL}, 1.0 \mathrm{mmol})$ and iodine $(0.25 \mathrm{~g}, 1.0 \mathrm{mmol})$. Storage of the obtained solution at room temperature overnight afforded $\mathbf{2 b}$ as yellow blocks. Yield: $0.74 \mathrm{~g}(0.88 \mathrm{mmol}, 88 \%)$; m.p.: $170{ }^{\circ} \mathrm{C}$ (dec.); ${ }^{1} \mathrm{H}$ NMR $(400.1$ $\mathrm{MHz},\left[\mathrm{D}_{6}\right.$ ] benzene): $\delta 0.51$ (br s, $\left.6 \mathrm{H},\left(\mathrm{CH}_{3} \mathrm{CH}_{2}\right)_{2} \mathrm{O}\right), 2.27\left(\mathrm{~s}, 24 \mathrm{H}, m-\mathrm{CH}_{3}\right), 2.95\left(\mathrm{q},{ }^{3} \mathrm{~J}_{\mathrm{HH}}=6.7 \mathrm{~Hz}, 4 \mathrm{H}\right.$, $\left.\left(\mathrm{CH}_{3} \mathrm{CH}_{2}\right)_{2} \mathrm{O}\right), 6.70\left(\mathrm{~s}, 4 \mathrm{H}, p-\mathrm{C}_{6} \mathrm{H}_{3} \mathrm{Me}_{2}\right), 6.86\left(\mathrm{t},{ }^{3} \mathrm{JHH}_{\mathrm{HH}}=7.6 \mathrm{~Hz}, 2 \mathrm{H}, \mathrm{p}-\mathrm{C}_{6} \mathrm{H}_{3}\right), 6.98\left(\mathrm{~s}, 8 \mathrm{H}, o-\mathrm{C}_{6} \mathrm{H}_{3} \mathrm{Me}_{2}\right)$, $7.10\left(\mathrm{~d},{ }^{3} \mathrm{~J}_{\mathrm{HH}}=7.6 \mathrm{~Hz}, 4 \mathrm{H}, \mathrm{o}-\mathrm{C}_{6} \mathrm{H}_{3}\right) .{ }^{13} \mathrm{C}$ NMR $\left(100.6 \mathrm{MHz},\left[\mathrm{D}_{6}\right]\right.$ benzene): $\delta 14.0\left(\left(\mathrm{CH}_{3} \mathrm{CH}_{2}\right)_{2} \mathrm{O}\right), 21.8$ $\left(m-\mathrm{CH}_{3}\right), 66.0\left(\left(\mathrm{CH}_{3} \mathrm{CH}_{2}\right)_{2} \mathrm{O}\right), 123.4\left(p-\mathrm{C}_{6} \mathrm{H}_{3}\right), 128.0\left(o-\mathrm{C}_{6} \mathrm{H}_{3} \mathrm{Me}_{2}\right), 128.5\left(p-\mathrm{C}_{6} \mathrm{H}_{3} \mathrm{Me}_{2}\right), 130.5\left(m-\mathrm{C}_{6} \mathrm{H}_{3}\right)$, $136.0\left(o-\mathrm{C}_{6} \mathrm{H}_{3}\right), 137.4\left(m-\mathrm{C}_{6} \mathrm{H}_{3} \mathrm{Me}_{2}\right), 142.3\left(i-\mathrm{C}_{6} \mathrm{H}_{3} \mathrm{Me}_{2}\right), 143.1\left(i-\mathrm{C}_{6} \mathrm{H}_{3}\right) \mathrm{ppm}$. IR (Nujol, $\left.\mathrm{cm}^{-1}\right) \widetilde{v}=$ $1684 \mathrm{w}, 1602 \mathrm{~s}, 1558 \mathrm{~m}, 1541 \mathrm{~m}, 1490 \mathrm{~s}, 1398 \mathrm{~m}, 1280 \mathrm{~m}, 1176 \mathrm{~m}, 1036 \mathrm{~m}, 849 \mathrm{~s}, 795 \mathrm{~m}, 761 \mathrm{~m}, 704 \mathrm{~s}, 681 \mathrm{~s}, 668 \mathrm{~s}$. Anal. Calcd. for $\mathrm{C}_{48} \mathrm{H}_{52} \mathrm{IMgN} \mathrm{IM}_{3} \mathrm{O}$ C, 68.78; $\mathrm{H}, 6.25 ; \mathrm{N}, 5.01$. Found: $\mathrm{C}, 68.24 ; \mathrm{H}, 6.02 ; \mathrm{N}, 5.12$.

\subsubsection{Experimental Procedure for $\left[\mathrm{Mg}_{3}\left\{\mathrm{~N}_{3}(\mathrm{Dmp}) \mathrm{Tph}\right\}_{2} \mathrm{I}_{4}\right]$ (3a)}

To a stirred solution of triazene $1 \mathrm{a}(1.27 \mathrm{~g}, 2 \mathrm{mmol})$ in $60 \mathrm{~mL}$ of $n$-heptane, a $1.0 \mathrm{M}$ solution of di- $n$-butylmagnesium in $n$-heptane $(2 \mathrm{~mL}, 2 \mathrm{mmol})$ was added. After $30 \mathrm{~min}$, the reaction mixture was treated with iodine $(0.51 \mathrm{~g}, 2 \mathrm{mmol})$, and stirring was continued overnight. The volume of the resulting solution was reduced to incipient crystallization under reduced pressure, and the obtained precipitate was redissolved by slight warming. Storage at ambient temperature overnight afforded 3a as a pale yellow crystalline material. Yield: $<10 \%$, m.p.: $200{ }^{\circ} \mathrm{C}$ (dec.); ${ }^{1} \mathrm{H}$ NMR $(400.1 \mathrm{MHz}$, [D $\mathrm{D}_{6}$ ]benzene): $\delta 1.03\left(\mathrm{~d},{ }^{3} \mathrm{~J}_{\mathrm{HH}}=6.7 \mathrm{~Hz}, 12 \mathrm{H}, o-\mathrm{CH}\left(\mathrm{CH}_{3}\right)_{2}\right), 1.11\left(\mathrm{~d},{ }^{3} \mathrm{~J}_{\mathrm{HH}}=6.7 \mathrm{~Hz}, 12 \mathrm{H}, o-\mathrm{CH}\left(\mathrm{CH}_{3}\right)_{2}\right)$, $1.21\left(\mathrm{~d},{ }^{3} J_{\mathrm{HH}}=7.0 \mathrm{~Hz}, 12 \mathrm{H}, p-\mathrm{CH}\left(\mathrm{CH}_{3}\right)_{2}\right), 2.17\left(\mathrm{~s}, 12 \mathrm{H}, p-\mathrm{CH}_{3}\right), 2.36\left(\mathrm{~s}, 24 \mathrm{H}, o-\mathrm{CH}_{3}\right), 2.65\left(\mathrm{sept}^{3} J_{\mathrm{HH}}\right.$ $\left.=6.7 \mathrm{~Hz}, 4 \mathrm{H}, o-\mathrm{CH}\left(\mathrm{CH}_{3}\right)_{2}\right), 2.76\left(\mathrm{sept}^{3} J_{\mathrm{HH}}=7.0 \mathrm{~Hz}, 2 \mathrm{H}, p-\mathrm{CH}\left(\mathrm{CH}_{3}\right)_{2}\right), 6.51\left(\mathrm{~d},{ }^{3} J_{\mathrm{HH}}=8.2 \mathrm{~Hz}, 2 \mathrm{H}\right.$, 6- $\left.\mathrm{C}_{6} \mathrm{H}_{4}\right), 6.78-7.11\left(\mathrm{~m}, 24 \mathrm{H}\right.$, various aryl-H). ${ }^{13} \mathrm{C} \mathrm{NMR}\left(100.6 \mathrm{MHz},\left[\mathrm{D}_{6}\right]\right.$ benzene): $\delta 21.2\left(p-\mathrm{CH}_{3}\right)$, $22.6\left(o-\mathrm{CH}_{3}\right), 23.9,24.2,25.6\left(o+p-\mathrm{CH}\left(\mathrm{CH}_{3}\right)_{2}\right), 30.7\left(o-\mathrm{CH}\left(\mathrm{CH}_{3}\right)_{2}\right), 34.4\left(p-\mathrm{CH}\left(\mathrm{CH}_{3}\right)_{2}\right), 120.8$ (m-Trip), 128.5 (m-Mes), $130.5\left(m-\mathrm{C}_{6} \mathrm{H}_{3}\right), 123.2,123.5,125.6,127.6,132.6$ (aromatic $\mathrm{CH}$ ), 121.5, 131.5, 135.7, 136.2, $136.8,137.1,139.5,145.5,147.2,147.7,149.3$ (aromatic C). Anal. Calcd. for $\mathrm{C}_{90} \mathrm{H}_{104} \mathrm{I}_{4} \mathrm{Mg}_{3} \mathrm{~N}_{6}: \mathrm{C}, 58.42 ; \mathrm{H}$, 5.67; N, 4.54. Found: C, 58.28; H, 5.69; N, 4.50 .

\subsubsection{Experimental Procedure for $\left[\mathrm{Mg}_{3}\left\{\mathrm{~N}_{3}\left(\mathrm{Me}_{4} \mathrm{Ter}\right)_{2}\right\}_{2} \mathrm{I}_{4}\right]$ (3b)}

The synthesis was accomplished in a manner similar to the preparation of $3 \mathbf{a}$ using triazene $1 \mathbf{b}(0.61 \mathrm{~g}, 1.0 \mathrm{mmol}), 1 \mathrm{mmol}$ of di- $n$-butylmagnesium and iodine $(0.25 \mathrm{~g}, 1.0 \mathrm{mmol})$. The packing complex $\mathbf{3 b} \cdot\left(\mathrm{C}_{7} \mathrm{H}_{16}\right)_{1.5}$ was crystallized from $n$-heptane at ambient temperature. Yield: $<10 \%$, m.p.: $200{ }^{\circ} \mathrm{C}$ (dec.); IR (Nujol, $\mathrm{cm}^{-1}$ ) $\widetilde{v}=1746 \mathrm{w}, 1601 \mathrm{~s}, 1557 \mathrm{sh}, 1403 \mathrm{~m}, 1284 \mathrm{sh}, 1255 \mathrm{~s}, 1215 \mathrm{~m}, 1200 \mathrm{~m}, 1171 \mathrm{w}$, $1127 \mathrm{w}, 1037 \mathrm{~m}, 1008 \mathrm{w}, 893 \mathrm{~m}, 851 \mathrm{~s}, 795 \mathrm{~m}, 763 \mathrm{~m}, 757 \mathrm{sh}, 706 \mathrm{~s}, 683 \mathrm{~m}, 669 \mathrm{w}, 602 \mathrm{w}, 529 \mathrm{w}, 472 \mathrm{w}, 417 \mathrm{~m}$. No satisfactory CHN analysis could be obtained due to the co-crystallized solvent.

\subsubsection{Experimental Procedure for $\left[\mathrm{Mg}\left\{\mathrm{N}_{3}\left(\mathrm{Me}_{4} \mathrm{Ter}\right)_{2}\right\}_{2}\right](\mathbf{4 b})$}

To triazene $1 \mathbf{b}(0.61 \mathrm{~g}, 1 \mathrm{mmol})$ in $50 \mathrm{~mL}$ of $n$-heptane a $1.0 \mathrm{M}$ solution of di- $n$-butylmagnesium in $n$-heptane $(0.5 \mathrm{~mL}, 0.5 \mathrm{mmol})$ was added, and the mixture was stirred overnight. The obtained precipitate was dissolved by slight warming, and the resulting solution slowly cooled to ambient temperature to give pale yellow crystals of the packing complex $4 \mathbf{b} \cdot\left(\mathrm{C}_{7} \mathrm{H}_{16}\right)$. The material 
used for characterization was dried under reduced pressure to remove co-crystallized solvent. Yield: $0.46 \mathrm{~g}(0.37 \mathrm{mmol}, 74 \%)$; m.p.: $>300{ }^{\circ} \mathrm{C} ;{ }^{1} \mathrm{H}$ NMR $(400,1 \mathrm{MHz}$, [D 6 ]benzene, $333 \mathrm{~K}): \delta 1.96$ $\left(\mathrm{s}, 48 \mathrm{H}, \mathrm{CH}_{3}\right), 6.10\left(\mathrm{~s}, \mathrm{vbr}, 16 \mathrm{H}, o-\mathrm{C}_{6} \mathrm{H}_{3} \mathrm{Me}_{2}\right), 6.68\left(\mathrm{~s}, 8 \mathrm{H}, p-\mathrm{C}_{6} \mathrm{H}_{3} \mathrm{Me}_{2}\right), 6.96\left(\mathrm{t},{ }^{3} J_{\mathrm{HH}}=7.6 \mathrm{~Hz}, 4 \mathrm{H}\right.$, $\left.p-\mathrm{C}_{6} \mathrm{H}_{3} \mathrm{~N}\right), 7.10\left(\mathrm{~d},{ }^{3} \mathrm{~J}_{\mathrm{HH}}=7.1 \mathrm{~Hz}, 8 \mathrm{H}, m-\mathrm{C}_{6} \mathrm{H}_{3} \mathrm{~N}\right) .{ }^{13} \mathrm{C}$ NMR $\left(100,6 \mathrm{MHz},\left[\mathrm{D}_{6}\right]\right.$ benzene): $\delta 22.3(\mathrm{vbr}$, $\left.\mathrm{CH}_{3}\right), 123.9\left(p-\mathrm{C}_{6} \mathrm{H}_{3} \mathrm{~N}\right), 129.1\left(p-\mathrm{C}_{6} \mathrm{H}_{3} \mathrm{Me}_{2}\right), 131.1\left(m-\mathrm{C}_{6} \mathrm{H}_{3} \mathrm{~N}\right), 132.5\left(o-\mathrm{C}_{6} \mathrm{H}_{3} \mathrm{Me}_{2}\right), 136.4\left(o-\mathrm{C}_{6} \mathrm{H}_{3} \mathrm{~N}\right)$, $138.2\left(m-\mathrm{C}_{6} \mathrm{H}_{3} \mathrm{Me}_{2}\right), 142.2\left(i-\mathrm{C}_{6} \mathrm{H}_{3} \mathrm{Me}_{2}\right), 144.7\left(i-\mathrm{C}_{6} \mathrm{H}_{3} \mathrm{~N}\right)$. IR (Nujol, $\left.\mathrm{cm}^{-1}\right) \widetilde{v}=1748 \mathrm{w}, 1600 \mathrm{~s}, 1400 \mathrm{~m}$, 1321s, 1282s, 1171w, 1125m, 1076w, 1038m, 905w, 850s, 816m, 797s, 764s, 705s, 672m, 652m, 605w, 520w, $507 w, 483 w, 444 m$. Anal. Calcd. for $\mathrm{C}_{88} \mathrm{H}_{84} \mathrm{MgN}_{6}$ : C, 84.56; $\mathrm{H}, 6.77 ; \mathrm{N}, 6.72$. Found: $\mathrm{C}, 84.03 ; \mathrm{H}, 6.49$; $\mathrm{N}, 6.82$.

\subsubsection{Experimental Procedure for $\left[\mathrm{Mg}\left\{\mathrm{N}_{3}(\mathrm{Dmp}) \mathrm{Mph}\right\}_{2}\right](4 \mathrm{c})$}

The synthesis was accomplished in a manner similar to the preparation of $4 \mathbf{b}$ using triazene $1 \mathrm{c}$ $(1.1 \mathrm{~g}, 2.0 \mathrm{mmol})$ and $1 \mathrm{mmol}$ of di-n-butylmagnesium. The yellow packing complex $4 \mathbf{c} \cdot\left(\mathrm{C}_{7} \mathrm{H}_{8}\right)_{0.5}$ was crystallized from a mixture of $n$-heptane and toluene at $-17^{\circ} \mathrm{C}$. Yield: $1.04 \mathrm{~g}(0.89 \mathrm{mmol}, 89 \%)$; m.p.: $220{ }^{\circ} \mathrm{C}$ (dec.); ${ }^{1} \mathrm{H}$ NMR $\left(400.1 \mathrm{MHz},\left[\mathrm{D}_{8}\right]\right.$ toluene, $\left.373 \mathrm{~K}\right): \delta 1.59\left(\mathrm{~s}, 12 \mathrm{H}, p-\mathrm{CH}_{3}\right), 1.74\left(\mathrm{~s}, 24 \mathrm{H}, o-\mathrm{CH}_{3}\right)$, $2.01\left(\mathrm{~s}, 6 \mathrm{H}, p-\mathrm{CH}_{3}\right), 2.06\left(\mathrm{~s}, 12 \mathrm{H}, o-\mathrm{CH}_{3}\right), 5.58\left(\mathrm{~d},{ }^{3} \mathrm{~J}_{\mathrm{HH}}=7.8 \mathrm{~Hz}, 2 \mathrm{H}, 6-\mathrm{C}_{6} \mathrm{H}_{4}\right), 6.51(\mathrm{~s}, 4 \mathrm{H}, m-\mathrm{Mes}), 6.55$ (s, 8H, m-Mes), 6.53-7.00 (m, 12H, var. aryl-H). ${ }^{13} \mathrm{C}$ NMR (62.9 MHz, [D $\left.\mathrm{D}_{6}\right]$ benzene): $\delta 19.9\left(p-\mathrm{CH}_{3}\right.$, $\mathrm{Mph}), 21.0\left(\mathrm{p}-\mathrm{CH}_{3}, \mathrm{Dmp}\right), 21.1\left(\mathrm{o}-\mathrm{CH}_{3}, \mathrm{Mph}\right), 21.3\left(\mathrm{CH}_{3}\right.$, toluene), $21.4\left(o-\mathrm{CH}_{3}, \mathrm{Dmp}\right), 123.9\left(6-\mathrm{C}_{6} \mathrm{H}_{4}\right)$, $124.7\left(4-\mathrm{C}_{6} \mathrm{H}_{4}\right), 126.0\left(5^{\prime}-\mathrm{C}_{6} \mathrm{H}_{3}\right), 126.0(\mathrm{p}-\mathrm{CH}$, toluene), 127.6 ( $m$-Mes, Mph), 128.2 ( $m$-Mes, Dmp), 128.3 $\left(3-\mathrm{C}_{6} \mathrm{H}_{4}\right), 128.7$ ( $m-\mathrm{CH}$, toluene), $128.8\left(5-\mathrm{C}_{6} \mathrm{H}_{4}\right), 129.4\left(4^{\prime} / 6^{\prime}-\mathrm{C}_{6} \mathrm{H}_{3}\right), 129.7$ (o- $\mathrm{CH}$, toluene), 130.1 (br), 133.1, 134.8, 135.6, 135.9, 137.5, 138.7 (aromatic C), 151.8, $153.6\left(1-\mathrm{C}_{6} \mathrm{H}_{4}, 2^{\prime}-\mathrm{C}_{6} \mathrm{H}_{3}\right)$. IR (Nujol, cm ${ }^{-1}$ ) $\widetilde{v}=1734 \mathrm{~m}, 1717 \mathrm{~m}, 1700 \mathrm{~m}, 1695 \mathrm{~m}, 1684 \mathrm{~m}, 1675 \mathrm{w}, 1670 \mathrm{w}, 1653 \mathrm{~m}, 1635 \mathrm{~m}, 1616 \mathrm{~m}, 1609 \mathrm{~m}, 1576 \mathrm{~m}, 1570 \mathrm{~m}$, $1559 \mathrm{~m}, 1539 \mathrm{~m}, 1521 \mathrm{w}, 1506 \mathrm{~m}, 1419 \mathrm{sh}, 1308 \mathrm{~s}, 1272 \mathrm{~s}, 1032 \mathrm{~m}, 851 \mathrm{~s}, 804 \mathrm{~m}, 777 \mathrm{~m}, 755 \mathrm{~s}, 730 \mathrm{~s}, 694 \mathrm{w}, 668 \mathrm{~m}$, $646 \mathrm{~m}, 595 \mathrm{~m}, 578 \mathrm{~m}, 565 \mathrm{~m}, 547 \mathrm{w}, 521 \mathrm{~m}, 464 \mathrm{~m}, 431 \mathrm{~m}, 411 \mathrm{~m}$. Anal. Calcd. for $\mathrm{C}_{78} \mathrm{H}_{76} \mathrm{~N}_{6} \mathrm{Mg} \cdots 0.5 \mathrm{C}_{7} \mathrm{H}_{8}$ : C, 83.53; H, 7.22; N, 7.17. Found: C, 83.14; H, 7.43; N, 7.16.

\subsection{X-Ray Crystallography}

X-ray-quality crystals were obtained as described in the syntheses section. Crystals were removed from Schlenk tubes and immediately covered with a layer of viscous hydrocarbon oil (Paratone N, Exxon). A suitable crystal was selected, attached to a nylon loop, and instantly placed in a low temperature $\mathrm{N}_{2}$-stream. All data were collected at $173 \mathrm{~K}$ with $\mathrm{MoK} \alpha$ radiation using

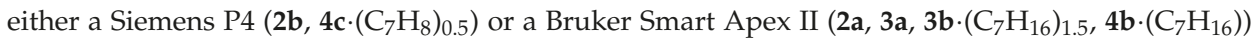
diffractometer. Calculations were performed with the SHELXTL PC 5.03a and SHELXL-97 program system [43]. The structures were solved by direct methods and refined on $F_{\mathrm{o}}{ }^{2}$ by full-matrix least-squares refinement. Crystal and refinement data are given below. For the iodo complexes, absorption corrections were applied by using semiempirical $\psi$-scans or the multi-scan method. For $\mathbf{3 b} \cdot\left(\mathrm{C}_{7} \mathrm{H}_{16}\right)_{1.5}$, co-crystallized solvent molecules were located in accessible cavities of the structure. Since they were severely disordered, their contribution was eliminated from the reflection data, using the BYPASS method [44] as implemented in the SQUEEZE routine of the PLATON98 [45] package. Values in brackets refer to the refinement that includes the contributions from the solvent. Crystallographic data (excluding structure factors) for the structures reported in this paper have been deposited with the Cambridge Crystallographic Data Centre. CCDC-1541009 \{2a $\},-1541010\{2 \mathbf{b}\}$, $-1541011\{3 \mathbf{a}\},-1541012\left\{3 \mathbf{b} \cdot\left(\mathrm{C}_{7} \mathrm{H}_{16}\right)_{1.5}\right\},-1541013\left\{\mathbf{4 b} \cdot\left(\mathrm{C}_{7} \mathrm{H}_{16}\right)\right\}$ and $-1541014\left\{\mathbf{4} \mathbf{c} \cdot\left(\mathrm{C}_{7} \mathrm{H}_{8}\right)_{0.5}\right\}$ contain the supplementary crystallographic data for this paper. These data can be obtained free of charge via http: / / www.ccdc.cam.ac.uk/conts/retrieving.html (or from the CCDC, 12 Union Road, Cambridge CB2 1EZ, UK; Fax: +44-1223-3360-33; E-mail: deposit@ccdc.cam.ac.uk).

Crystallographic data for $2 \mathrm{a}: \mathrm{C}_{49} \mathrm{H}_{62} \mathrm{IMgN} \mathrm{IM}_{3} \mathrm{O}, \mathrm{M}=860.2$, yellow rod $0.65 \times 0.35 \times 0.35 \mathrm{~mm}^{3}$, monoclinic, space group $P 22_{1} / n, a=8.9827(2), b=23.6098(6), c=22.1855(5) \AA, \beta=90.8180(10)^{\circ}$, $V=4704.62(19) \AA^{3}, Z=4, D_{\text {calc }}=1.215 \mathrm{~g} \mathrm{~cm}^{-3}, \mu=0.730 \mathrm{~mm}^{-1}, 67161$ collected $\left(3.6^{\circ} \leq 2 \Theta \leq 58.6^{\circ}\right)$ and 12780 unique reflections ( $\left.R_{\text {int }}=0.053\right), 521$ parameters, 1 restraint, $R_{1}=0.036$ for 7680 reflections 
with $I>2 \sigma(I), \mathrm{w} R_{2}=0.094$ (all data), Goodness of fit $(\mathrm{GOF})=0.934$. The methyl carbon atoms of one disordered $i$-propyl group were refined with split positions and side occupation factors of 0.67 (C443) and 0.33 (C444), respectively. The corresponding C441-C443 and C441-C444 distances were refined with restraints.

Crystallographic data for $\mathbf{2 b}: \mathrm{C}_{48} \mathrm{H}_{52} \mathrm{IMgN}_{3} \mathrm{O}, M=838.1$, yellow prism $0.50 \times 0.35 \times 0.25 \mathrm{~mm}^{3}$, monoclinic, space group $P 2{ }_{1} / c, a=19.848(4), b=9.373(2), c=23.033(4) \AA, \beta=90.386(14)^{\circ}, V=4284.9(14) \AA^{3}$, $Z=4, D_{\text {calc }}=1.299 \mathrm{~g} \mathrm{~cm}^{-3}, \mu=0.800 \mathrm{~mm}^{-1}, 10104$ collected $\left(4.7^{\circ} \leq 2 \Theta \leq 55.0^{\circ}\right)$ and 9823 unique reflections $\left(R_{\text {int }}=0.046\right), 501$ parameters, 0 restraints, $R_{1}=0.036$ for 6945 reflections with $I>2 \sigma(I)$, $\mathrm{w} R_{2}=0.090$ (all data), GOF $=0.886$.

Crystallographic data for 3a: $\mathrm{C}_{90} \mathrm{H}_{104} \mathrm{I}_{4} \mathrm{Mg}_{3} \mathrm{~N}_{6}, \quad M=1850.3$, pale yellow prism $0.30 \times 0.20 \times 0.15 \mathrm{~mm}^{3}$, orthorhombic, space group Pbca, $a=20.4142(4), b=22.2202(4)$, $c=39.3523(7) \AA, V=17,850.5(6) \AA^{3}, Z=8, D_{\text {calc }}=1.377 \mathrm{~g} \mathrm{~cm}^{-3}, \mu=1.462 \mathrm{~mm}^{-1}, 188607$ collected $\left(3.4^{\circ} \leq 2 \Theta \leq 54.8^{\circ}\right)$ and 21302 unique reflections $\left(R_{\text {int }}=0.254\right), 952$ parameters, 0 restraints, $R_{1}=0.041$ for 6128 reflections with $I>2 \sigma(I), \mathrm{w} R_{2}=0.067$ (all data), GOF $=0.653$.

Crystallographic data for $3 \mathbf{b} \cdot\left(\mathrm{C}_{7} \mathrm{H}_{16}\right)_{1.5}: \mathrm{C}_{88} \mathrm{H}_{84} \mathrm{I}_{4} \mathrm{Mg}_{3} \mathrm{~N}_{6}\left[\mathrm{C}_{98.5} \mathrm{H}_{108} \mathrm{I}_{4} \mathrm{Mg}_{3} \mathrm{~N}_{6}\right], \quad M=1806.1$ [1956.4], pale yellow prism $0.40 \times 0.35 \times 0.20 \mathrm{~mm}^{3}$, triclinic, space group $P \overline{1}, a=16.9933$ (5), $b=17.5771(5), c=17.8005(5) \AA, a=93.427(2)^{\circ}, \beta=99.534(2)^{\circ}, \gamma=109.991(2)^{\circ}, V=4888.5(2) \AA^{3}$, $Z=2, D_{\text {calc }}=1.227[1.329] \mathrm{g} \mathrm{cm}^{-3}, \mu=1.334[1.339] \mathrm{mm}^{-1}, 206993$ collected $\left(2.4^{\circ} \leq 2 \Theta \leq 59.1^{\circ}\right)$ and 27255 unique reflections $\left(R_{\text {int }}=0.064\right), 926$ parameters, 0 restraints, $R_{1}=0.067$ for 21930 reflections with $I>2 \sigma(I), \mathrm{w} R_{2}=0.134$ (all data), GOF $=1.921$. The contribution of one and a half co-crystallized $n$-heptane molecules was eliminated from the reflection data (see above).

Crystallographic data for $\mathbf{4 b} \cdot\left(\mathrm{C}_{7} \mathrm{H}_{16}\right): \mathrm{C}_{95} \mathrm{H}_{100} \mathrm{MgN}_{6}, \quad M=1350.1$, pale yellow prism $0.35 \times 0.25 \times 0.20 \mathrm{~mm}^{3}$, monoclinic, space group $P 2 / n, a=15.0589(12), b=13.0937(10), c=20.3232(16) \AA$, $\beta=99.013(3)^{\circ}, V=3957.8(5) \AA^{3}, Z=2, D_{\text {calc }}=1.133 \mathrm{~g} \mathrm{~cm}^{-3}, \mu=0.073 \mathrm{~mm}^{-1}, 67630$ collected $\left(3.1^{\circ} \leq 2 \Theta \leq 55.0^{\circ}\right)$ and 9087 unique reflections $\left(R_{\text {int }}=0.248\right), 464$ parameters, 8 restraints, $R_{1}=0.067$ for 3669 reflections with $I>2 \sigma(I), \mathrm{w} R_{2}=0.188$ (all data), $\mathrm{GOF}=0.887$. The co-crystallized $n$-heptane molecule is disordered over a center of inversion and was refined with a side occupation factor of 0.5 and isotropic displacement parameters. The 1,2-C-C and 1,3-C-C distances were restrained.

Crystallographic data for $4 \mathrm{c} \cdot\left(\mathrm{C}_{7} \mathrm{H}_{8}\right)_{0.5}: \quad \mathrm{C}_{81.5} \mathrm{H}_{84} \mathrm{MgN}_{6}, \quad M=1171.9$, yellow prism $0.50 \times 0.40 \times 0.30 \mathrm{~mm}^{3}$, monoclinic, space group $P 2_{1} / n, a=13.302(2), b=21.531(3), c=24.332(4) \AA$, $\beta=101.877(12)^{\circ}, V=6819.8(17) \AA^{3}, Z=4, D_{\text {calc }}=1.141 \mathrm{~g} \mathrm{~cm}^{-3}, \mu=0.075 \mathrm{~mm}^{-1}, 12550$ collected $\left(4.1^{\circ} \leq 2 \Theta \leq 50.0^{\circ}\right)$ and 11996 unique reflections $\left(R_{\text {int }}=0.074\right), 837$ parameters, 3 restraints, $R_{1}=0.044$ for 5484 reflections with $I>2 \sigma(I), \mathrm{w} R_{2}=0.098$ (all data), GOF $=0.727$. The arene ring of the co-crystallized toluene molecule, which is disordered over a center of inversion, was constrained to a regular hexagon. Additional restraints were applied regarding distances and angles to the toluene methyl carbon atom.

\subsection{Computational Details}

The Gaussian 09 package [46] was used for all energy and frequency calculations. The energies of the model compounds $5_{\mathrm{T}}$ and $\mathbf{5}_{\mathrm{SP}}$ were minimized using density functional theory (DFT) with the functional B3LYP $[47,48]$, starting from the crystallographically-determined or from other derived geometries and assuming $S_{4}$ symmetry for $5_{\mathrm{T}}$. The sum of the electronic energy and the zero-point energy was used to calculate the energy difference between both model complexes.

\section{Conclusions}

In summary, we have used sterically crowded diaryltriazenido ligands for the stabilization of several heteroleptic and homoleptic magnesium triazenides. The obtained iodo magnesium-triazenides are kinetically stable against ligand redistribution reactions and represent potential precursors for magnesium(I) triazenides. The synthesized homoleptic compounds are the first examples of unsolvated magnesium triazenides. Remarkably, the magnesium cations in these compounds feature different 
coordination geometries. Depending on the nature of the substituents, either the expected tetrahedral or a rather unusual square planar coordination is observed.

Supplementary Materials: The following are available online at www.mdpi.com/2304-6740/5/2/33/s1, ${ }^{1} \mathrm{H}$ VT NMR spectra and supporting molecular plots for Compounds $\mathbf{2 a}, \mathbf{4 b}$ and $\mathbf{4 c}$ (Figures S1, S2, S3b and S4), molecular structure plot showing intermolecular $\mathrm{C}-\mathrm{H} \cdots \mathrm{N}$ contacts in $4 \mathrm{~b}$ (Figure S3a), structural plots and coordinates for the DFT calculated model complexes $5_{\mathrm{T}}$ and $\mathbf{5}_{\mathrm{SP}}$ (Figure S5 and Tables S1 and S2), CIF files and checkcif reports.

Acknowledgments: We thank Karl Klinkhammer for generous financial support.

Author Contributions: Denis Vinduš synthesized and characterized all compounds, Mark Niemeyer planned the research, performed the DFT calculations, collected the X-ray data and refined the crystal structures. Denis Vinduš wrote the first draft, and Mark Niemeyer wrote the final version of the manuscript.

Conflicts of Interest: The authors declare no conflict of interest.

\section{References}

1. Gibson, V.C.; Spitzmesser, S.K. Advances in Non-Metallocene Olefin Polymerization Catalysis. Chem. Rev. 2003, 103, 283-315. [CrossRef] [PubMed]

2. Bourget-Merle, L.; Lappert, M.F.; Severn, J.R. The Chemistry of $\beta$-Diketiminatometal Complexes. Chem. Rev. 2002, 102, 3031-3065. [CrossRef] [PubMed]

3. Coles, M.P. Application of neutral amidines and guanidines in coordination chemistry. Dalton Trans. 2006, 37, 985-1001. [CrossRef] [PubMed]

4. Vrieze, K.; van Koten, G. Sulfurdiimine, Triazenido, Azabutadiene and Triatomic Hetero Anion Ligands. In Comprehensive Coordination Chemistry, 1st ed.; Wilkinson, G., Gillard, R.D., McCleverty, J., Eds.; Pergamon Press: Oxford, UK, 1987; Volume 2, pp. 195-206.

5. Hauber, S.-O.; Lissner, F.; Deacon, G.B.; Niemeyer, M. Stabilization of Aryl-Calcium, -Strontium, and -Barium Compounds by Designed Steric and $\pi$-Bonding Encapsulation. Angew. Chem. Int. Ed. 2005, 44, 5871-5875. [CrossRef] [PubMed]

6. Hauber, S.-O.; Niemeyer, M. Stabilization of Unsolvated Europium and Ytterbium Pentafluorophenyls by $\pi$-Bonding Encapsulation through a Sterically Crowded Triazenido Ligand. Inorg. Chem. 2005, 44, 8644-8646. [CrossRef] [PubMed]

7. Lee, H.S.; Niemeyer, M. Inverse Aggregation Behavior of Alkali-Metal Triazenides. Inorg. Chem. 2006, 45, 6126-6128. [CrossRef] [PubMed]

8. Lee, H.S.; Hauber, S.-O.; Vinduš, D.; Niemeyer, M. Isostructural Potassium and Thallium Salts of Sterically Crowded Triazenes: A Structural and Computational Study. Inorg. Chem. 2008, 47, 4401-4412. [CrossRef] [PubMed]

9. Balireddi, S.; Niemeyer, M. A sterically crowded triazene: 1,3 -Bis $\left(3,5,3^{\prime \prime}, 5^{\prime \prime}\right.$-tetramethyl-1, $1^{\prime}: 3^{\prime} ; 1^{\prime \prime}$-ter-phenyl2'-yl)triazene. Acta Crystallogr. 2007, E63, o3525. [CrossRef]

10. Lee, H.S.; Niemeyer, M. Homoleptic Heavy Alkaline Earth and Europium Triazenides. Inorg. Chem. 2010, 49, 730-735. [CrossRef] [PubMed]

11. Hauber, S.-O.; Seo, J.W.; Niemeyer, M. Halogenomercury Salts of Sterically Crowded Triazenides—Convenient Starting Materials for Redox-Transmetallation Reactions. Z. Anorg. Allg. Chem. 2010, 636, 750-757. [CrossRef]

12. Lee, H.S.; Niemeyer, M. Sterically crowded triazenides as novel ancillary ligands in copper chemistry. Inorg. Chim. Acta 2011, 374, 163-170. [CrossRef]

13. Hinz, A.; Schulz, A.; Villinger, A.; Wolter, J.-M. Cyclo-Pnicta-triazanes: Biradicaloids or Zwitterions? J. Am. Chem. Soc. 2015, 137, 3975-3980. [CrossRef] [PubMed]

14. Westhusin, S.; Gantzel, P.; Walsh, P.J. Synthesis and Crystal Structures of Magnesium and Calcium Triazenide Complexes. Inorg. Chem. 1998, 37, 5956-5959. [CrossRef]

15. Kalden, D.; Krieck, S.; Görls, H.; Westerhausen, M. 1,3-Bis(2,4,6-trimethylphenyl)triazenides of potassium, magnesium, calcium, and strontium. Dalton Trans. 2015, 44, 8089-8099. [CrossRef] [PubMed]

16. Nimitsiriwat, N.; Gibson, V.C.; Marshall, E.L.; Takolpuckdee, P.; Tomov, A.K.; White, A.J.P.; Williams, D.J.; Elsegood, M.R.J.; Dale, S.H. Mono-versus Bis-chelate Formation in Triazenide and Amidinate Complexes of Magnesium and Zinc. Inorg. Chem. 2007, 46, 9988-9997. [CrossRef] [PubMed] 
17. Groom, C.R.; Bruno, I.J.; Lightfoot, M.P.; Ward, S.C. The Cambridge Structural Database. Acta Crystallogr. 2016, B72, 171-179. [CrossRef] [PubMed]

18. Bonyhady, S.J.; Jones, C.; Nembenna, S.; Stasch, A.; Edwards, A.J.; McIntyre, G.J. $\beta$-Diketiminate-Stabilized Magnesium(I) Dimers and Magnesium(II) Hydride Complexes: Synthesis, Characterization, Adduct Formation, and Reactivity Studies. Chem. Eur. J. 2010, 16, 938-955. [CrossRef] [PubMed]

19. Stasch, A. Synthesis of a Dimeric Magnesium(I) Compound by an $\mathrm{Mg}^{\mathrm{I}} / \mathrm{Mg}^{\mathrm{II}}$ Redox Reaction. Angew. Chem. Int. Ed. 2014, 53, 10200-10203. [CrossRef] [PubMed]

20. Moxey, G.J.; Blake, A.J.; Lewis, W.; Kays, D.L. Alkaline Earth Complexes of a Sterically Demanding Guanidinate Ligand. Eur. J. Inorg. Chem. 2015, 2015, 5892-5902. [CrossRef]

21. MacNeil, C.S.; Johnson, K.R.D.; Hayes, P.G.; Boeré, R.T. Crystal structure of a dimeric $\beta$-diketiminate magnesium complex. Acta Crystallogr. 2016, E72, 1754-1756. [CrossRef] [PubMed]

22. Boutland, A.J.; Dange, D.; Stasch, A.; Maron, L.; Jones, C. Two-Coordinate Magnesium(I) Dimers Stabilized by Super Bulky Amido Ligands. Angew. Chem. Int. Ed. 2016, 55, 9239-9243. [CrossRef] [PubMed]

23. Brogan, M.A.; Blake, A.J.; Wilson, C.; Gregory, D.H. Magnesium diiodide, $\mathrm{MgI}_{2}$. Acta Crystallogr. 2003, C59, i136-i138. [CrossRef]

24. Akishin, P.A.; Spiridonov, V.P. Electron-diffraction investigation of magnesium iodide molecular structure. Zhurnal Fizicheskoi Khimii 1958, 32, 1682-1683.

25. Yang, L.; Powell, D.R.; Houser, R.P. Structural variation in copper(I) complexes with pyridylmethylamide ligands: Structural analysis with a new four-coordinate geometry index, $\tau_{4}$. Dalton Trans. 2007, 9, 955-964. [CrossRef] [PubMed]

26. Boeré, R.T.; Cole, M.L.; Junk, P.C. The syntheses and structures of some main group complexes of the sterically hindered $N, N^{\prime}$-bis(2,6-diisopropylphenyl)-4-toluamidinate ligand. New J. Chem. 2005, 29, 128-134. [CrossRef]

27. Moxey, G.J.; Ortu, F.; Goldney Sidley, L.; Strandberg, H.N.; Blake, A.J.; Lewis, W.; Kays, D.L. Synthesis and characterisation of magnesium complexes containing sterically demanding $N, N^{\prime}$-bis(aryl)amidinate ligands. Dalton Trans. 2014, 43, 4838-4846. [CrossRef] [PubMed]

28. Xia, A.; El-Kaderi, H.M.; Heeg, M.J.; Winter, C.H. Synthesis, structure, and properties of magnesium complexes containing cyclopentadienyl and amidinate ligand sets. J. Organomet. Chem. 2003, 682, 224-232. [CrossRef]

29. Sadique, A.R.; Heeg, M.J.; Winter, C.H. Monomeric and Dimeric Amidinate Complexes of Magnesium. Inorg. Chem. 2001, 40, 6349-6355. [CrossRef] [PubMed]

30. Schmidt, J.A.R.; Arnold, J. Synthesis and characterization of a series of sterically-hindered amidines and their lithium and magnesium complexes. J. Chem. Soc. Dalton Trans. 2002, 2890-2899. [CrossRef]

31. Sedai, B.; Heeg, M.J.; Winter, C.H. Magnesium complexes containing $\beta$-ketiminate and $\beta$-diketiminate ligands with dimethylamino substituents on the ligand core nitrogen atoms. J. Organomet. Chem. 2008, 693, 3495-3503. [CrossRef]

32. El-Kaderi, H.M.; Xia, A.; Heeg, M.J.; Winter, C.H. Factors that Influence $\pi$-versus $\eta^{2}$-Coordination of $\beta$-Diketiminato Ligands in Magnesium Complexes. Organometallics 2004, 23, 3488-3495. [CrossRef]

33. Caro, C.F.; Hitchcock, P.B.; Lappert, M.F. Monomeric magnesium 1-azaallyl and $\beta$-diketiminato complexes derived from the bis(trimethylsilyl)methyl ligand: The $\mathrm{X}$-ray structure of the four-coordinate planar magnesium complex $\left[\mathrm{Mg}\{\mathrm{N}(\mathrm{R}) \mathrm{C}(\mathrm{But}) \mathrm{C}(\mathrm{H}) \mathrm{R}\}_{2}\right]$ and of $\left[\mathrm{Mg}\left(\{\mathrm{N}(\mathrm{R}) \mathrm{C}(\mathrm{Ph})\}_{2} \mathrm{CH}\right)_{2}\right]$. Chem. Commun. 1999, 1433-1434. [CrossRef]

34. Byrn, M.P.; Curtis, C.J.; Goldberg, I.; Hsiou, Y.; Khan, S.I.; Sawin, P.A.; Tendick, S.K.; Strouse, C.E. Porphyrin sponges: Structural systematics of the host lattice. J. Am. Chem. Soc. 1991, 113, 6549-6557. [CrossRef]

35. Byrn, M.P.; Curtis, C.J.; Hsiou, Y.; Khan, S.I.; Sawin, P.A.; Tendick, S.K.; Terzis, A.; Strouse, C.E. Porphyrin sponges: Conservative of host structure in over 200 porphyrin-based lattice clathrates. J. Am. Chem. Soc. 1993, 115, 9480-9497. [CrossRef]

36. Mizuguchi, J. Crystal Structure of Magnesiumphthalocyanine and Its Polarized Reflection Spectra. J. Phys. Chem. A 2001, 105, 1121-1124. [CrossRef]

37. Janczak, J.; Kubiak, R. X-ray single crystal investigations of magnesium phthalocyanine. The 4+1 coordination of the Mg ion and its consequence. Polyhedron 2001, 20, 2901-2909. [CrossRef] 
38. Chandra, T.; Kraft, B.J.; Huffman, J.C.; Zaleski, J.M. Synthesis and Structural Characterization of Porphyrinic Enediynes: Geometric and Electronic Effects on Thermal and Photochemical Reactivity. Inorg. Chem. 2003, 42, 5158-5172. [CrossRef] [PubMed]

39. Grimme, S.; Djukic, J.-P. Cation-Cation "Attraction": When London Dispersion Attraction Wins over Coulomb Repulsion. Inorg. Chem. 2011, 50, 2619-2628. [CrossRef] [PubMed]

40. Grimme, S.; Schreiner, P.R. Steric Crowding Can Stabilize a Labile Molecule: Solving the Hexaphenylethane Riddle. Angew. Chem. Int. Ed. 2011, 50, 12639-12642. [CrossRef] [PubMed]

41. Harder, S.; Naglav, D.; Schwerdtfeger, P.; Nowik, I.; Herber, R.H. Metal Atom Dynamics in Superbulky Metallocenes: A Comparison of $\left(\mathrm{Cp}^{\mathrm{BIG}}\right)_{2} \mathrm{Sn}$ and ( $\left.\mathrm{Cp}^{\mathrm{BIG}}\right)_{2} \mathrm{Eu}$. Inorg. Chem. 2014, 53, 2188-2194. [CrossRef] [PubMed]

42. Franta, U. Synthese, Strukturchemie und Untersuchungen von Aluminium, Ytterbium und Lithiumkomplexen mit Sterisch Anspruchsvollen Triazenido-Liganden; Staatsexamensarbeit; Johannes Gutenberg-Universität: Mainz, Germany, 2011.

43. Sheldrick, G.M. A Short History of SHELX. Acta Crystallogr. 2008, A64, 112-122. [CrossRef] [PubMed]

44. van der Sluis, P.; Spek, A.L. BYPASS: An effective method for the refinement of crystal structures containing disordered solvent regions. Acta Crystallogr. 1990, A46, 194-201. [CrossRef]

45. Spek, A.L. PLATON-98; Utrecht University: Utrecht, The Netherlands, 1998.

46. Frisch, M.J.; Trucks, G.W.; Schlegel, H.B.; Scuseria, G.E.; Robb, M.A.; Cheeseman, J.R.; Scalmani, G.; Barone, V.; Petersson, G.A.; Nakatsuji, H.; et al. Gaussian 09; revision A.02; Gaussian, Inc.: Wallingford, CT, USA, 2016.

47. Becke, A.D. Density-functional thermochemistry. III. The role of exact exchange. J. Chem. Phys. 1993, 98, 5648-5652. [CrossRef]

48. Lee, C.; Yang, W.; Parr, R.G. Development of the Colle-Salvetti correlation-energy formula into a functional of the electron density. Phys. Rev. B 1988, 37, 785-789. [CrossRef]

(C) 2017 by the authors. Licensee MDPI, Basel, Switzerland. This article is an open access article distributed under the terms and conditions of the Creative Commons Attribution (CC BY) license (http:/ / creativecommons.org/licenses/by/4.0/). 
Article

\title{
Methanediide Formation via Hydrogen Elimination in Magnesium versus Aluminium Hydride Complexes of a Sterically Demanding Bis(iminophosphoranyl)methanediide
}

\author{
Christian P. Sindlinger ${ }^{1,2}$, Samuel R. Lawrence ${ }^{3}$, David B. Cordes ${ }^{3}$, Alexandra M. Z. Slawin ${ }^{3}$ \\ and Andreas Stasch 1,3,* \\ 1 School of Chemistry, Monash University, P.O. Box 23, Melbourne VIC 3800, Australia; \\ Christian-Sindlinger@gmx.de \\ 2 Institut für Anorganische Chemie, Auf der Morgenstelle 18, 72076 Tübingen, Germany \\ 3 EaStCHEM School of Chemistry, University of St. Andrews, North Haugh, St. Andrews KY16 9ST, UK; \\ sl264@st-andrews.ac.uk (S.R.L.); dbc21@st-andrews.ac.uk (D.B.C.); amzs@st-andrews.ac.uk (A.M.Z.S.) \\ * Correspondence: as411@st-andrews.ac.uk; Tel: +44-(0)-1334-463382
}

Academic Editor: Matthias Westerhausen

Received: 31 March 2017; Accepted: 20 April 2017; Published: 22 April 2017

\begin{abstract}
Substituted bis(iminophosphoranyl)methanes are $\mathrm{CH}$ acidic compounds that can form complexes with formally dianionic central carbon centres. The reaction of $\mathrm{H}_{2} \mathrm{C}\left(\mathrm{Ph}_{2} \mathrm{P}=\mathrm{NDip}\right)_{2}\left(\equiv \mathrm{H}_{2} \mathrm{~L}\right)$, Dip $=2,6$-diisopropylphenyl, with one equivalent of di- $n$-butylmagnesium afforded the methanide complex [HLMg $n \mathrm{Bu}$ ] 1. Treatment of Complex 1 with phenylsilane in aromatic solvents at elevated temperatures afforded the methanediide complex $\left[(\mathrm{LMg})_{2}\right] 2$ presumably via the $\mathrm{MgH}$ intermediate $\left[(\mathrm{HLMgH})_{n}\right](n=1$ or 2$)$. The reaction of $\mathbf{1}$ with $\mathrm{LiAlH}_{4}$ in diethyl ether yielded the AlH complex $\left[\mathrm{HLAlH}_{2}\right]$ 3. Alternatively, this complex was also obtained from the reaction of $\mathrm{H}_{2} \mathrm{~L}$ with $\mathrm{AlH}_{3} \cdot \mathrm{NMe}_{3}$. The molecular structures of $[\mathrm{HLMg} n \mathrm{Bu}] \mathbf{1},\left[(\mathrm{LMg})_{2}\right] 2$, and $\left[\mathrm{HLAlH}_{2}\right] 3$ are reported. Complex 3 shows no sign of $\mathrm{H}_{2}$ elimination to a methanediide species at elevated temperatures in contrast to the facile elimination of the putative reaction intermediate $\left[(\mathrm{HLMgH})_{n}\right](n=1$ or 2$)$ to form $\left[(\mathrm{LMg})_{2}\right]$ 2. The chemical properties of Complex 2 were investigated, and this complex appears to be stable against coordination with strong donor molecules.
\end{abstract}

Keywords: alane; aluminium; hydrogen formation; magnesium; magnesium hydride; metal hydrides; methanediides; $N, N^{\prime}$-chelation

\section{Introduction}

The chemistry of geminal diorganometallics is significantly underdeveloped compared with common monofunctional organometallics, despite unusual structural features, chemical bonding and reactivity of these former compound classes [1]. Complexes of methanediides (methandiides) that derive from P-oxidized bis(diphenylphosphino)methane species with electropositive metals have especially attracted widespread interest in recent years [2-8]. In these complexes, the dianionic bis(diphenylphosphoranyl)methanediide fragment $\mathbf{A}$ shows overall delocalization of the charge across the EPCPE fragment with a simplified charge distribution as shown in Figure 1. This delocalization allows the deprotonation of both hydrogen atoms of the central $\mathrm{CH}_{2}$ unit of the substituted "methane" pro-ligand with suitable strong bases. Methanediides show several bonding modes containing typically one or two coordinated metal centres [2-8]. Over the past years, several examples of alkaline earth metal complexes of substituted bis(phosphoranyl)methanides and -methanediides have been forthcoming [9-23] that show several coordination types B-E, see Figure 1. Most common is a dimeric 
structure (B) with central $\mathrm{M}_{2} \mathrm{C}_{2}$ four-membered ring and additional $\mathrm{M}-\mathrm{E}$ coordination, and monomeric complexes (C) with an $N, C, N^{\prime}$-chelating methanide ligand and additional donors coordinating to the metal centre. Complex D shows a similar monomeric structure with $S, C$-chelation of the $\mathrm{Mg}$ centre with one P-atom both protected and activated by a coordinating borane group [12]. Complex $\mathbf{E}$ is a dimeric methanediide species where the $\mathrm{Mg}$ centres are $S, S^{\prime}$-chelated by one methanediide ligand and coordinate to the methanediide carbon atom of a second ligand [13]. The metal coordination in the monomeric complexes $\mathbf{C}$ and $\mathbf{D}$ and the dimeric species $\mathbf{E}$ allow for the possibility of a formal $\mathrm{C}=\mathrm{M}$ double bond, though the interaction has to be considered as predominantly ionic [4] with the majority of electron density residing in carbon-based orbitals.

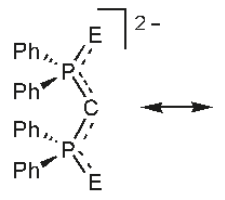

A $E=N R, O, S, S e$

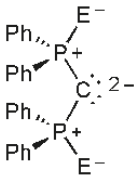

E-

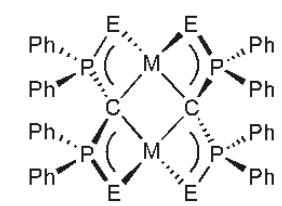

B $E=N R, S, S e$

$\mathrm{M}=\mathrm{Mg}, \mathrm{Ca}, \mathrm{Ca}$ (donors), $\mathrm{Ba}$ (donors)

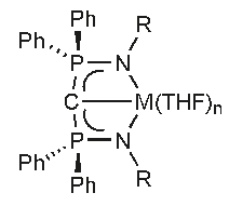

C $M=\mathrm{Ca}, \mathrm{Ba}$

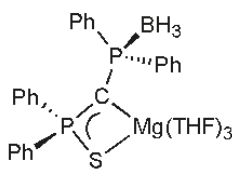

D

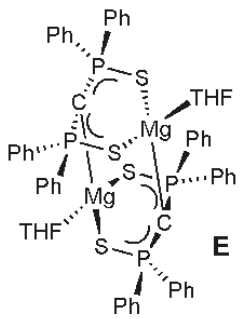

Figure 1. Bis(diphenylphosphoranyl)methanediide A and alkaline earth complex types B-E.

\section{Results and Discussion}

We targeted the synthesis of a homoleptic $\mathrm{Mg}$ complex with the sterically demanding methanediide ligand $\mathrm{L}^{2-}\left(\mathrm{H}_{2} \mathrm{~L}=\mathrm{H}_{2} \mathrm{C}\left(\mathrm{Ph}_{2} \mathrm{P}=\mathrm{NDip}\right)_{2}\right.$, Dip = 2,6-i $\left.\mathrm{Pr}_{2} \mathrm{C}_{6} \mathrm{H}_{3}\right)$ [24], for a number of reasons. Possible outcomes could be both monomeric or dimeric methanediide complexes when the bulk of the ligand and the relative small size of the $\mathrm{Mg}^{2+}$ cation are considered. In these compounds, the $\mathrm{Mg}$ centre(s) could show an environment with a relatively low coordination number and the close proximity of the formally dianionic carbon centre of the methanediide and the dicationic $\mathrm{Mg}^{2+}$ centre could allow for some interesting activation chemistry of small molecules. Secondly, the $\mathrm{Mg} \cdots \mathrm{Mg}$ separation in the known $\mathrm{Mg}$ complexes of structure type $\mathbf{B}$ (e.g., $2.87 \AA$ for $\mathrm{E}=\mathrm{NSiMe}_{3}$ ) [16] shows a distance similar to those in dimeric magnesium(I) complexes with unsupported $\mathrm{Mg}-\mathrm{Mg}$ bonds $[25,26]$. Thus, a stable dimeric complex may possibly serve as a starting material to a molecule with a supported $\mathrm{Mg}-\mathrm{Mg}$ bond.

Treating $\mathrm{H}_{2} \mathrm{~L}$ with one equivalent of di- $n$-butyl-magnesium in a hydrocarbon solvent afforded the heteroleptic methanide complex [HLMgnBu] 1 in good yield, see Scheme 1. The compound is highly soluble in hydrocarbon solvents and, after removal of the solvent, is initially obtained as an oily residue. The compound could be precipitated from $n$-pentane at low temperatures as a white solid, and some crystals suitable for single crystal X-ray diffraction were eventually obtained from a concentrated solution of 1 in $n$-hexane at $4{ }^{\circ} \mathrm{C}$. Single crystal X-ray diffraction shows the complex to be monomeric in the solid state with a planar, distorted three-coordinate $\mathrm{Mg}$ centre, see Figure 2. Three-coordinated $\mathrm{Mg}$ complexes with terminal $n \mathrm{Bu}$-groups are rare and are best 
described for the $\beta$-diketiminate class of ligand that allows some comparison with the sterics of $\mathrm{HL}^{-}$. Comparable monomeric complexes of $\left[\left\{\mathrm{HC}(\mathrm{RCNAr})_{2}\right\} \mathrm{Mg} n \mathrm{Bu}\right]$ with an overall molecular structure similar to 1 were found for $\mathrm{R}=\mathrm{Me}$ and $\mathrm{Ar}=2,6-\left(\mathrm{Ph}_{2} \mathrm{CH}\right)_{2}-4-\mathrm{MeC}_{6} \mathrm{H}_{2}$ (三 Ar ${ }^{*}$ [27], and $\mathrm{R}=t \mathrm{Bu}$ and $\mathrm{Ar}=\operatorname{Dip}$ [28]. For the respective complex with $\mathrm{R}=\mathrm{Me}$ and $\mathrm{Ar}=\mathrm{Dip}$ [29] and smaller $\beta$-diketiminates, molecular structures with bridging $n \mathrm{Bu}$ groups and four-coordinate $\mathrm{Mg}$ centres were found. Thus, the steric profile of $\mathrm{HL}^{-}$, at least when coordinated to $\mathrm{Mg}$, can be approximately compared with $\left[\left\{\mathrm{HC}(t \mathrm{BuCNDip})_{2}\right\}\right]^{-}$. When donor solvents are used, these types of compounds typically coordinate one equivalent of a donor molecule to afford a four-coordinate $\mathrm{Mg}$ centre, for example, in $\left[\mathrm{L}^{\prime} \mathrm{Mg} n \mathrm{Bu}(\mathrm{THF})\right]$, with $\mathrm{L}^{\prime-}=\left[(\mathrm{Dip}) \mathrm{NC}(\mathrm{Me}) \mathrm{C}(\mathrm{H}) \mathrm{P}\left(\mathrm{Cy}_{2}\right) \mathrm{NDip}^{-}\right.$, a relevant hybrid ligand between the two ligand classes discussed here [30].

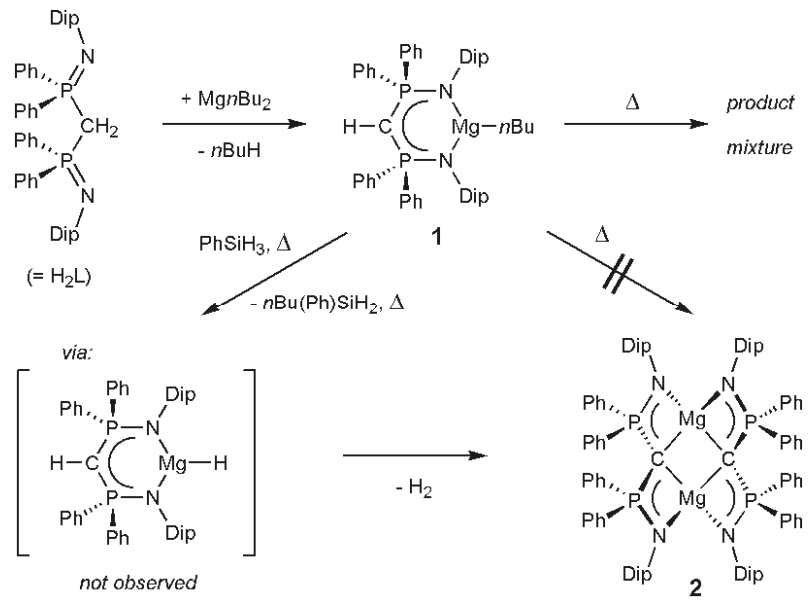

Scheme 1. Synthesis of Complexes 1 and 2.

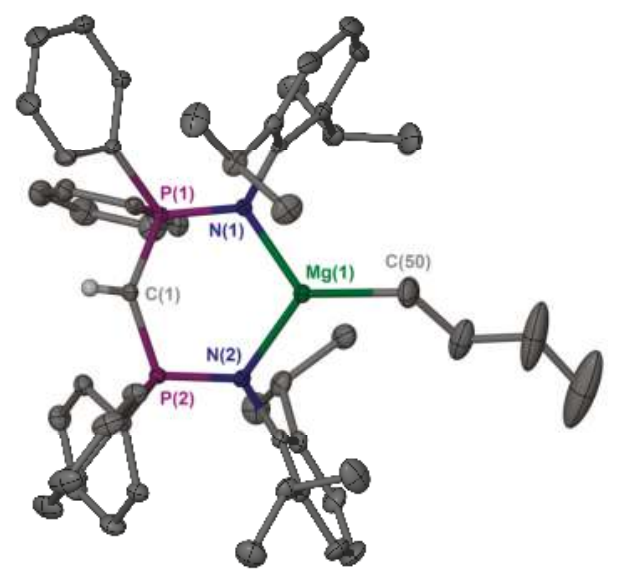

Figure 2. Molecular structure of [HLMgnBu] 1 (30\% thermal ellipsoids). Only the methanide hydrogen atom is shown. Selected bond lengths $(\AA)$ and angles $\left(^{\circ}\right)$ : $\mathrm{Mg}(1)-\mathrm{N}(1) 2.0359(14), \mathrm{Mg}(1)-\mathrm{N}(2)$ 2.0173(14), $\mathrm{Mg}(1)-\mathrm{C}(50)$ 2.122(2), $\mathrm{P}(1)-\mathrm{N}(1)$ 1.6185(13), $\mathrm{P}(2)-\mathrm{N}(2)$ 1.6195(14), $\mathrm{P}(1)-\mathrm{C}(1)$ 1.7138(15), $\mathrm{P}(2)-\mathrm{C}(1)$ 1.6965(16), N(2)-Mg(1)-N(1) 108.26(6), N(1)-Mg(1)-C(50) 125.09(8), N(2)-Mg(1)-C(50) 126.64(9), $\mathrm{P}(2)-\mathrm{C}(1)-\mathrm{P}(1)$ 131.54(10). 
In analogy to the synthesis of a sterically less hindered methanediide $\mathrm{Mg}$ complex of type

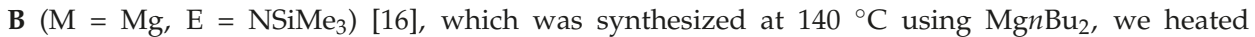
[HLMg $n \mathrm{Bu}] 1$ to various high temperatures (up to $200^{\circ} \mathrm{C}$ ) though only obtained a complex product mixture according to ${ }^{1} \mathrm{H}$ and ${ }^{31} \mathrm{P}\left\{{ }^{1} \mathrm{H}\right\}$ NMR spectroscopic experiments, that still contained some [HLMg $n \mathrm{Bu}] 1$ and small quantities of $\mathrm{H}_{2} \mathrm{~L}$ among other compounds. Similar heating experiments in sealed NMR tubes in deuterated benzene or toluene that were followed by ${ }^{1} \mathrm{H}$ and ${ }^{31} \mathrm{P}\left\{{ }^{1} \mathrm{H}\right\} \mathrm{NMR}$ spectroscopy only afforded product mixtures including unreacted $\mathbf{1}$. We then treated [HLMg $n \mathrm{Bu}] \mathbf{1}$ with phenylsilane, a reagent that previously converted similar precursor molecules to heteroleptic $\mathrm{MgH}$ complexes [27,30-32]. No reaction was observed between 1 and one equivalent of $\mathrm{PhSiH}_{3}$ at room temperature; however, at elevated temperatures, for example in toluene at $80^{\circ} \mathrm{C}$, this afforded colourless crystals of the new homoleptic methanediide complex $\left[(\mathrm{LMg})_{2}\right] 2$ in moderate isolated yield, see Scheme 1 and Figure 3. Hydrogen could be detected when the reaction was followed by ${ }^{1} \mathrm{H}$ NMR spectroscopy, and the metathesis by-product $n$-butylphenylsilane was furthermore found in ${ }^{1} \mathrm{H}$ NMR spectra of the reaction mixture. The expected magnesium hydride intermediate $\left[(\mathrm{HLMgH})_{n}\right](n=1$ or 2$)$ was not directly observed, suggesting that the $\mathrm{H}_{2}$ elimination is rapid under the reaction conditions. Both a monomeric and a dimeric aggregation state could be possible for this intermediate. Monomeric $\left[\left\{\mathrm{HC}(t \mathrm{BuCNDip})_{2}\right\} \mathrm{Mg} n \mathrm{Bu}\right]$ has previously been converted to dimeric $\left[\left(\left\{\mathrm{HC}(t \mathrm{BuCNDip})_{2}\right\} \mathrm{MgH}\right)_{2}\right]$ with an unusually coordinated $\mathrm{Mg}(\mu-\mathrm{H})_{2} \mathrm{Mg}$ core due to the approximately orthogonal arrangement of the $\beta$-diketiminate metal chelates caused by the steric bulk of the ligand [32]. The molecular structure of [ $\left.\left[\mathrm{HC}(\mathrm{MeCNAr})_{2}\right\} \mathrm{MgH}\right]$, however, does show that the monomeric coordination mode with a three-coordinate $\mathrm{Mg}$ centre is possible if sufficient steric protection from the ligand is provided [27].

During the course of this study, three different solvates of $\left[(\mathrm{LMg})_{2}\right] 2$ were structurally characterized and show very similar geometrical features, see Figure 3. These show Complex 2 to be of structure type $\mathbf{B}$ with a central four-membered $\mathrm{Mg}_{2} \mathrm{C}_{2}$ ring surrounded by four annulated $\mathrm{MgCPN}$-rings that bend up or down compared with the central $\mathrm{Mg}_{2} \mathrm{C}_{2}$ ring in an alternating manner. This feature of five interconnected four-membered rings is slightly more flattened in $\mathbf{2}$, having sterically demanding Dip-substituents compared with previously characterized examples. The $\mathrm{P}-\mathrm{N}$ bond distances (ca. 1.63-1.64 $\AA$ ) and the P-C bond distances (ca. 1.71-1.74 $\AA$ ) in the methanediide fragments of the three solvates of $\mathbf{2}$ are of a similar magnitude compared with both methanide and methanediide fragments of related $\mathrm{Mg}$ complexes. The $\mathrm{Mg}-\mathrm{C}$ bond distances in the solvates of 2 show each $\mathrm{Mg}$ centre to have one shorter (ca. 2.24-2.28 $\AA$ ) and one longer (ca. 2.38-2.47 $\AA$ ) contact each, whereas all $\mathrm{Mg}-\mathrm{C}$ distances are of the short type in Example $\mathbf{B}\left(\mathrm{M}=\mathrm{Mg}, \mathrm{E}=\mathrm{NSiMe}_{3}\right.$ : ca. 2.20-2.25 $\left.\mathrm{A}\right)$ [16]. Thus, the $\mathrm{Mg}-\mathrm{C}$ coordination approaches the extreme case that was previously found for [ $\left.\mathrm{L}\left(\mathrm{AlX}_{2}\right)_{2}\right][33]$. For $\mathrm{X}_{4}=\mathrm{Me}_{4}$ and $\mathrm{Me}_{2} \mathrm{I}_{2}$ each $\mathrm{Al}$ centre is $\mathrm{N}$,C-chelated with a central spirocyclic carbon atom, whereas for $\mathrm{X}_{4}=\mathrm{I}_{4}$ one Al-C coordination is lost in favour of a new iodide bridge. This distortion in 2 is likely due to steric reasons imposed by the bulky Dip groups in $\mathrm{L}^{2-}$. The $\mathrm{Mg} \cdots \mathrm{Mg}$ separation in $\mathbf{2}$ is ca. $2.87-2.90 \AA$.

In order to investigate a route to the likely reaction intermediate $\left[(\mathrm{HLMgH})_{n}\right](n=1$ or 2$)$ at lower reaction temperatures, [HLMgn $\mathrm{Bu}$ ] 1 was treated with pinacolborane (HBpin) in hydrocarbon solvents, a reagent that previously allowed the synthesis of well-defined $\mathrm{MgH}$ complexes [34]. This, however, yielded a product mixture with stoichiometric HBpin, including some unreacted $\mathbf{1}$, and a product mixture with one major L-containing species $\left({ }^{31} \mathrm{P}\left\{{ }^{1} \mathrm{H}\right\}\right.$ NMR resonance: $\left.\delta 22.8 \mathrm{ppm}\right)$ if an excess of HBpin is used. As a previously used alternative pathway to an $\mathrm{MgH}$ species on a sterically demanding monomeric tris(pyrazolyl)methanide MgnBu complex [35], [HLMg $n \mathrm{Bu}$ ] 1 has been reacted with $\mathrm{LiAlH}_{4}$ in diethyl ether at room temperature and afforded the aluminium complex $\left[\mathrm{HLAlH}_{2}\right] 3$ as a major product in moderate yield. Alternatively, this compound was also obtained by the reaction of $\mathrm{H}_{2} \mathrm{~L}$ with $\mathrm{AlH}_{3} \cdot \mathrm{NMe}_{3}$, see Scheme 2. [HLAlH 3 ] 3 crystallizes as colourless crystals with a similar

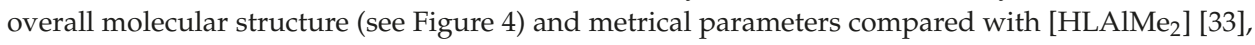


albeit with slightly shorter Al-N bond lengths for 3 (1.9022(12) and 1.9118(11) $\AA$ ) when compared with those of [HLAlMe 2 ] (1.9461(18) and 1.9461(17) ̊̊).
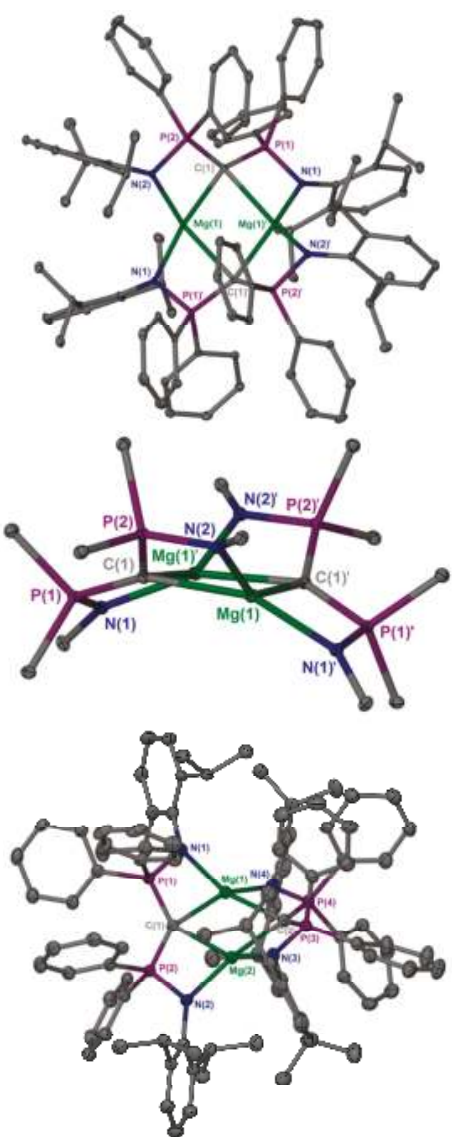

Figure 3. Molecular structures of three different solvates of $\left[(\mathrm{LMg})_{2}\right] 2$ (30\% thermal ellipsoids) in different views: $\mathbf{2}^{\prime}\left(\left[(\mathrm{LMg})_{2}\right] \cdot 4 \mathrm{C}_{6} \mathrm{H}_{6}\right.$, top) , $\mathbf{2}^{\prime \prime}\left(\left[(\mathrm{LMg})_{2}\right] \cdot 6 \mathrm{C}_{6} \mathrm{H}_{6}\right.$, middle, only the core of the molecule is shown), $2^{\prime \prime \prime}\left(\left[(\mathrm{LMg})_{2}\right] \cdot 4 \mathrm{THF}\right.$, bottom). Hydrogen atoms and solvent of crystallization omitted for clarity. Selected bond lengths $(\AA)$ and angles $\left(^{\circ}\right)$ for $2^{\prime}$ : $\mathrm{P}(1)-\mathrm{N}(1)$ 1.6306(18), $\mathrm{P}(2)-\mathrm{N}(2)$ 1.6360(17), $\mathrm{P}(1)-\mathrm{C}(1)$ 1.7144(19), C(1)-P(2) 1.730(2), Mg(1)-N(1) 2.0147(17), $\mathrm{Mg}(1)-\mathrm{N}(2)^{\prime} 1$ 2.0321(18), N(2)-Mg(1)'1 2.0321(18), $\mathrm{Mg}(1)-\mathrm{C}(1)^{\prime} 1$ 2.264(2), $\mathrm{Mg}(1)-\mathrm{C}(1)$ 2.425(2), $\mathrm{C}(1)-\mathrm{Mg}(1)^{\prime} 1$ 2.264(2), $\mathrm{Mg}(1) \cdots \mathrm{Mg}(1)^{\prime} 1$ 2.8881(15), N(1)-Mg(1)-N(2)'1 122.44(7), $\mathrm{P}(1)-\mathrm{C}(1)-\mathrm{P}(2)$ 123.98(12), $\mathrm{Mg}(1)^{\prime} 1-\mathrm{C}(1)-\mathrm{Mg}(1)$ 75.96(7), $\mathrm{N}(2)-\mathrm{P}(2)-\mathrm{C}(1)$ 101.67(9); $2^{\prime \prime}: \mathrm{P}(1)-\mathrm{N}(1)$ 1.6377(13), $\mathrm{P}(2)-\mathrm{N}(2)$ 1.6376(13), $\mathrm{P}(1)-\mathrm{C}(1)$ 1.7095(15), C(1)-P(2) 1.7370(14), $\mathrm{Mg}(1)-\mathrm{N}(1)$ 2.0088(13), $\mathrm{Mg}(1)-\mathrm{N}(2)^{\prime} 1$ 2.0380(13), N(2)-Mg(1)'1 2.0380(13), $\mathrm{Mg}(1)-\mathrm{C}(1)$ 2.4665(16), $\mathrm{Mg}(1)-\mathrm{C}(1)^{\prime} 12.2349(15), \mathrm{C}(1)-\mathrm{Mg}(1)^{\prime} 12.2348(15), \mathrm{Mg}(1) \cdots \mathrm{Mg}(1)^{\prime} 12.9006(13), \mathrm{N}(1)-\mathrm{P}(1)-\mathrm{C}(1)$ 104.98(7)， $\mathrm{N}(1)-\mathrm{Mg}(1)-\mathrm{N}(2)^{\prime} 1$ 123.16(6)， $\mathrm{P}(1)-\mathrm{C}(1)-\mathrm{P}(2)$ 124.27(9), $\mathrm{Mg}(1)^{\prime} 1-\mathrm{C}(1)-\mathrm{Mg}(1)$ 76.01(5); $2^{\prime \prime \prime}: \mathrm{P}(1)-\mathrm{N}(1) 1.638(2), \mathrm{P}(2)-\mathrm{N}(2)$ 1.638(3), $\mathrm{P}(3)-\mathrm{N}(3)$ 1.632(3), $\mathrm{P}(4)-\mathrm{N}(4)$ 1.629(3), $\mathrm{P}(1)-\mathrm{C}(1)$ 1.734(3), $\mathrm{C}(1)-\mathrm{P}(2)$ 1.712(3), C(2)-P(3) 1.724(3), C(2)-P(4) 1.720(3), $\mathrm{Mg}(1)-\mathrm{N}(4)$ 2.023(3), $\mathrm{Mg}(1)-\mathrm{N}(1)$ 2.027(3), $\mathrm{Mg}(2)-\mathrm{N}(3)$ 2.025(3), $\mathrm{Mg}(2)-\mathrm{N}(2)$ 2.028(3), $\mathrm{Mg}(1)-\mathrm{C}(1)$ 2.272(3), $\mathrm{Mg}(1)-\mathrm{C}(2)$ 2.400(3), $\mathrm{C}(1)-\mathrm{Mg}(2)$ 2.381(3), $\mathrm{Mg}(2)-\mathrm{C}(2)$ 2.283(3), $\mathrm{Mg}(1) \cdots \mathrm{Mg}(2)$ 2.8732(16), N(4)-Mg(1)-N(1) 123.95(11), N(3)-Mg(2)-N(2) 122.33(11), C(1)-Mg(1)-C(2) 103.55(11), C(2)-Mg(2)-C(1)103.84(11), $\mathrm{Mg}(1)-\mathrm{C}(1)-\mathrm{Mg}(2)$ 76.23(10), $\mathrm{Mg}(2)-\mathrm{C}(2)-\mathrm{Mg}(1)$ 75.65(10), N(1)-P(1)-C(1)101.55(13), N(2)-P(2)-C(1) 104.52(14), P(4)-C(2)-P(3) 125.13(19), N(3)-P(3)-C(2) 100.99(14), N(4)-P(4)-C(2) 104.70(14). 


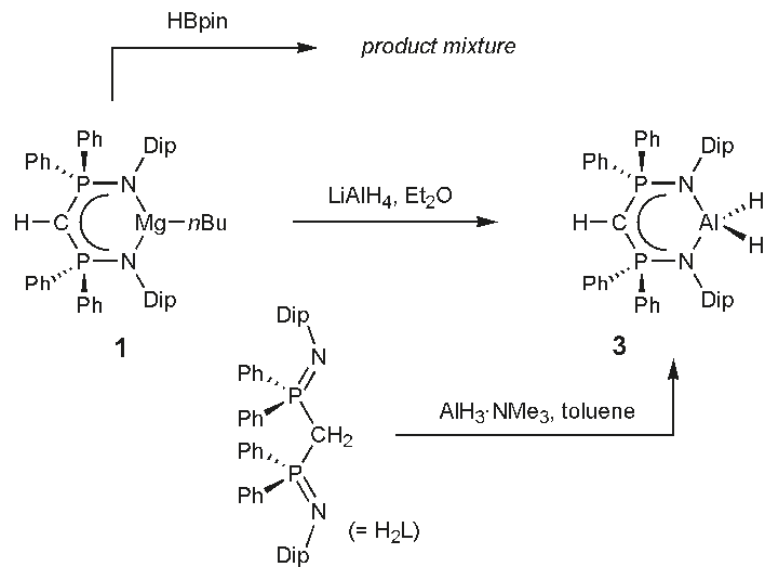

Scheme 2. Synthesis of Complex 3, HBpin = pinacolborane.

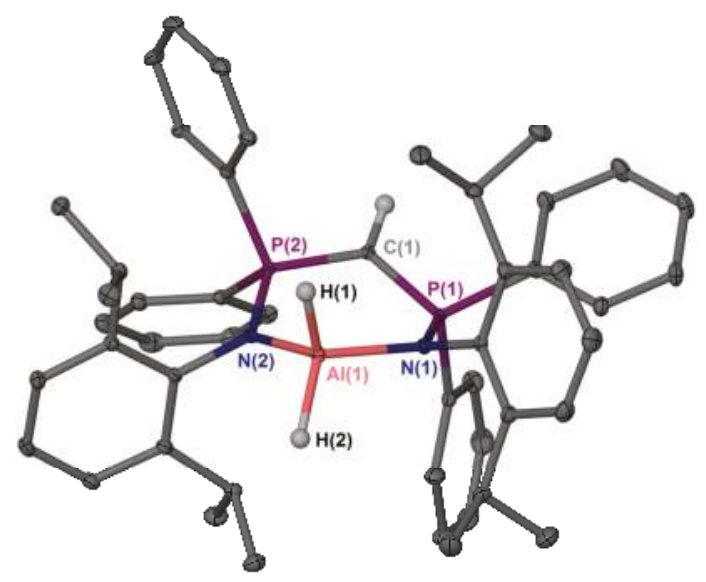

Figure 4. Molecular structures of $\left[\mathrm{HLAlH}_{2}\right] 3$ (30\% thermal ellipsoids). Only the $\mathrm{AlH}$ and methanide $\mathrm{H}$ atoms are shown. Selected bond lengths $(\AA)$ and angles $\left({ }^{\circ}\right)$ : $\mathrm{Al}(1)-\mathrm{N}(2) 1.9022(12), \mathrm{Al}(1)-\mathrm{N}(1) 1.9118(11)$, $\mathrm{P}(1)-\mathrm{N}(1)$ 1.6372(11), $\mathrm{P}(2)-\mathrm{N}(2)$ 1.6426(10), $\mathrm{P}(1)-\mathrm{C}(1)$ 1.7125(12), C(1)-P(2) 1.7009(12), Al(1)-H(1) 1.505(18), $\mathrm{Al}(1)-\mathrm{H}(2)$ 1.547(17), N(2)-Al(1)-N(1) 106.61(4), H(1)-Al(1)-H(2) 112.6(9), $\mathrm{P}(2)-\mathrm{C}(1)-\mathrm{P}(1)$ 125.60(7).

The spectroscopic data for Complexes 1-3 are largely as expected and are in support of their solid-state structures. The ${ }^{1} \mathrm{H}$ NMR spectrum of the $n$-butyl complex $\mathbf{1}$ shows one sharp septet for the methine isopropyl hydrogen environments and a broadened region for the methyl groups at $30{ }^{\circ} \mathrm{C}$; this sharpens to one broadened singlet at $60^{\circ} \mathrm{C}$. In line with the lower symmetry of the ligand environment, Complex 2 shows two septets and four doublets for the protons of the $i \operatorname{Pr}$ groups. Once crystallized, Complex 2 shows a relatively low solubility and NMR spectra were conveniently recorded at $60^{\circ} \mathrm{C}$. At this temperature, all septets and doublets appear as sharp resonances in ${ }^{1} \mathrm{H} N M R$ spectra. Complex 3 shows one sharp septet and two sharp doublets for the protons of the $i$ Pr groups, as was found for [HLAlMe 2 [ [33], and a very broad resonance ( $\delta$ ca. 4.9) for the Al-H units. The IR spectrum of 3 shows two strong bands (1819 and $\left.1777 \mathrm{~cm}^{-1}\right)$ for the $\mathrm{Al}-\mathrm{H}$ stretches. The methanide $\mathrm{CH}$ units in Compounds $\mathbf{1}$ and $\mathbf{3}$ appear as singlets at $\delta 1.77$ (1) and $\delta 2.00(\mathbf{3})$ in their ${ }^{1} \mathrm{H}$ NMR spectra 
and show that the ${ }^{2} J_{\mathrm{P}, \mathrm{H}}$ coupling constants are small and not resolved in this complex geometry. The ${ }^{13} \mathrm{C}\left\{{ }^{1} \mathrm{H}\right\}$ NMR spectra of Compounds $\mathbf{1}$ and $\mathbf{3}$ do show the expected triplets for the methanide carbon atoms with large ${ }^{1} J_{\mathrm{P}, \mathrm{C}}$ coupling constants at $\delta 20.2(141 \mathrm{~Hz})$ and $\delta 16.3(135 \mathrm{~Hz})$, respectively, whereas the resonance for the methanediide carbon atoms in $\left[(\mathrm{LMg})_{2}\right] 2$ were not observed. All three complexes show singlets in their ${ }^{31} \mathrm{P}\left\{{ }^{1} \mathrm{H}\right\} \mathrm{NMR}$ spectra in a narrow range; i.e., $\delta 25.1$ (1), $\delta 27.4$ (2), and $\delta 29.5(3)$.

Given the likely facile $\mathrm{H}_{2}$ elimination of $\left[(\mathrm{HLMgH})_{n}\right]$ to form $\left[(\mathrm{LMg})_{2}\right] 2$, we studied the attempted thermal elimination of $\mathrm{H}_{2}$ from $\left[\mathrm{HLAlH}_{2}\right] 3$. A sample of 3 in deuterated benzene or toluene was heated to elevated temperatures for longer time periods (e.g., $110{ }^{\circ} \mathrm{C}$ for one week) and showed no sign of decomposition and $\mathrm{H}_{2}$ formation. Complex 3 is thermally robust in the solid state and melts at around $264-266{ }^{\circ} \mathrm{C}$ without visible decomposition. We have previously conducted heating experiments with the aim of eliminating one equivalent of methane from the methanide [HLAlMe ${ }_{2}$, which remained unchanged after prolonged refluxing in toluene [33]. [HLAlMe 2 ] could be converted to the methanediide complex $\left[\mathrm{L}\left(\mathrm{AlMe}_{2}\right)_{2}\right]$ though required a second equivalent of $\mathrm{AlMe}_{3}$ at ca. $100^{\circ} \mathrm{C}$ to achieve the methanide to methanediide conversion [33].

The thermal lability of putative $\left[(\mathrm{HLMgH})_{n}\right]$ and the respective stability of $\left[\mathrm{HLAlH}_{2}\right] 3$ may highlight differences in these early main group metal hydride species [36]. $\mathrm{MgH}$ complexes are expected to have more ionic $\mathrm{M} \cdots \mathrm{H}$ interactions compared with more polar covalent $\mathrm{AlH}$ systems. Significantly fewer $\mathrm{MgH}$ complexes have been reported compared with $\mathrm{AlH}$ complexes, and the former ionic class is more reliant on suitable protecting ligands to prevent decomposition reactions and suppress redistribution equilibria that form insoluble $\mathrm{MgH}_{2}$ through precipitation (c.f. the Schlenk equilibrium). In comparison, AlH complexes can be thermally stable with suitable sterically demanding ligands. With small or more weakly coordinating ligands, $\mathrm{AlH}_{3}$ complexes rather decompose in a redox reaction to give $\mathrm{Al}_{\text {metal }}$ and $\mathrm{H}_{2}$ at elevated temperatures. This trend is also found for the decomposition temperatures of the bulk solids to the elements where $\mathrm{MgH}_{2}$ shows a higher decomposition temperature by ca. $180{ }^{\circ} \mathrm{C}$ compared with $\mathrm{AlH}_{3}$ [37]. In this respect, it is worth mentioning that $\mathrm{H}_{2}$ elimination from a $\beta$-diketiminate-stabilized $\mathrm{Mg}_{8} \mathrm{H}_{10}{ }^{6+}$ cluster compound was achieved at $200{ }^{\circ} \mathrm{C}$ under a high vacuum releasing 5 equivalents of $\mathrm{H}_{2}$. [38] Further differences between the $\mathrm{H}_{2}$ eliminations of $\left[(\mathrm{HLMgH})_{n}\right]$ and $\left[\mathrm{HLAlH}_{2}\right] 3$ could stem from the fact that the $\mathrm{Al}^{3+}$ cation is naturally smaller than $\mathrm{Mg}^{2+}$, and Complex 3 shows shorter $\mathrm{M}-\mathrm{N}$ distances than the $\mathrm{Mg}-\mathrm{N}$ distances in $\mathbf{1}$ by ca. $\geq 0.1 \AA$. Similarly, $\mathrm{M}-\mathrm{H}$ bond distances for $\mathrm{M}=\mathrm{Al}$ are significantly shorter and stronger than those typical for $\mathrm{M}=\mathrm{Mg}$. The $\mathrm{Mg}$ centre in a possible monomeric $\mathrm{MgH}$ species $[\mathrm{HLMgH}]$ is coordinatively more unsaturated as compared with the $\mathrm{Al}$ centre in 3 . The respective $\mathrm{M} \cdots \mathrm{C}_{\text {methanide }}$ distances in Compounds $\mathbf{1}$ and $\mathbf{3}$ are comparable. At this stage, a combination of both the different ionic properties and coordination numbers between the two metals, as well as steric grounds are likely to play a role in the different $\mathrm{H}_{2}$ elimination conditions.

The methanediide complex 2 with two $\mathrm{Mg}$ centres in distorted tetrahedral coordination environments does not appear to coordinate strong neutral donor ligands. It can be recrystallized in an uncoordinated form from neat THF and from a benzene solution that contains an excess of DMAP (4-dimethylaminopyridine). Methanediide complexes of $\mathrm{L}^{2-}$ with heavier alkaline earth metal ions are known to form monomeric complexes with THF coordination, structure type $\mathbf{C}$, for comparison $[18,19]$. The larger ionic radii of the heavier Group 2 metals likely allows for the accommodation of an $N, C, N^{\prime}$ coordination mode to balance charges. Interestingly, the $\mathrm{PS} / \mathrm{PBH}_{3}$ stabilized methanediide fragment in $\mathbf{D}$ achieves this for $\mathrm{Mg}$ with an S,C-chelating ligand and a short $\mathrm{Mg}-\mathrm{C}$ distance of 2.113(4) $\AA$ [12].

We reacted Complex 2 with an excess of dry ammonia at low temperatures and stirred the mixture at room temperatures overnight. This afforded the bis(iminophosphoranyl)methane proligand $\mathrm{H}_{2} \mathrm{~L}$ as the only soluble product and an unidentified insoluble residue, see Scheme 3. IR spectroscopy on the latter revealed no obvious or identifiable characteristic bands due to $\mathrm{NH}$ or $\mathrm{NH}_{2}$ groups. Attempts to reduce Compound 2 having two $\mathrm{Mg}^{2+}$ ions separated by ca. $2.87-2.90 \AA$ have so far met with failure. The use of $\mathrm{K}$ or $\mathrm{KC}_{8}$ in combinations of benzene or toluene with TMEDA 
$\left(N, N, N^{\prime}, N^{\prime}\right.$-tetramethylethylenediamine) or THF lead to some purple-brown coloured solutions. From these, some large light purple crystals that were analyzed by single crystal $X$-ray diffraction and NMR spectroscopy as consisting of Starting Material 2, likely with a minor coloured impurity, were obtained. Harsher reduction conditions have not yielded a new isolable compound so far.

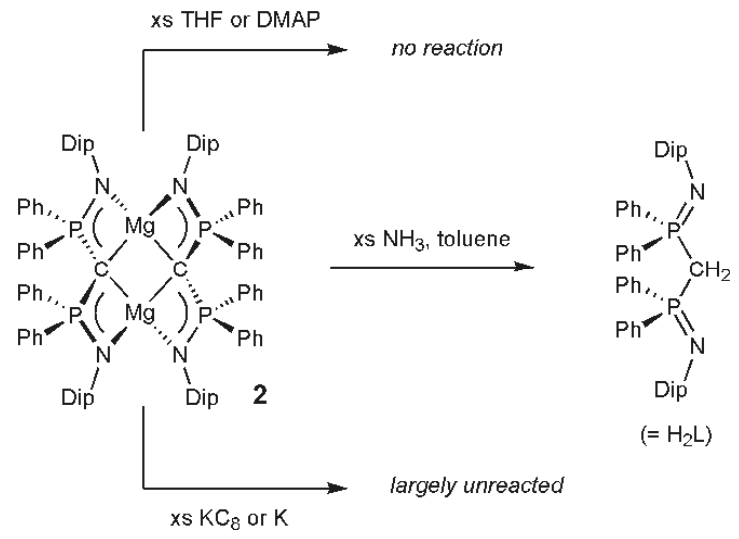

Scheme 3. Reactivity of Complex 2.

\section{Experimental Section}

\subsection{General Considerations}

All manipulations were carried out using standard Schlenk line and glove box techniques under an atmosphere of high purity dinitrogen or argon. Benzene, toluene, $n$-pentane, $n$-hexane, THF and diethyl ether were either dried and distilled over molten potassium, or taken from an MBraun solvent purification system and degassed prior to use. ${ }^{1} \mathrm{H},{ }^{13} \mathrm{C}\left\{{ }^{1} \mathrm{H}\right\}$, and ${ }^{31} \mathrm{P}\left\{{ }^{1} \mathrm{H}\right\}$ NMR spectra were recorded on a Bruker Avance 300, Avance 400, or AVIII 500 spectrometer (Billerica, MA, USA) in appropriately dried deuterated benzene or toluene, and were referenced to the residual ${ }^{1} \mathrm{H}$ or ${ }^{13} \mathrm{C}\left\{{ }^{1} \mathrm{H}\right\}$ NMR resonances of the solvent used, or external aqueous $\mathrm{H}_{3} \mathrm{PO}_{4}$ solutions. IR spectra were recorded using a Perkin Elmer RXI FT-IR spectrometer (Waltham, MA, USA) as Nujol mulls between $\mathrm{NaCl}$ plates. Melting points were determined in sealed glass capillaries under dinitrogen and are uncorrected. Elemental analyses were performed by the Elemental Analysis Service at London Metropolitan University. $\mathrm{H}_{2} \mathrm{~L}$ [24] was prepared according to literature procedures. All other reagents were used as received from commercial suppliers.

\subsection{Syntheses of Complexes $1-3$}

[HLMg $n \mathrm{Bu}$ ] 1: $\mathrm{Mg}(n \mathrm{Bu})_{2}$ (1.087 $\mathrm{mL}$ of a $1.0 \mathrm{~m}$ solution in heptane, $1.087 \mathrm{mmol} 1.05$ equiv.) was added to a cooled $\left(-80{ }^{\circ} \mathrm{C}\right)$ solution of $\mathrm{H}_{2} \mathrm{~L}(0.760 \mathrm{~g}, 1.035 \mathrm{mmol})$ in toluene $(30 \mathrm{~mL})$. The mixture was stirred whilst warming to room temperature and stirred for a further two hours, at which point all volatiles were removed under vacuum. The oily residue consists of [HLMg $n \mathrm{Bu}] \mathbf{1}$ in essentially quantitative yield as judged by ${ }^{1} \mathrm{H}$ and ${ }^{31} \mathrm{P}\left\{{ }^{1} \mathrm{H}\right\}$ NMR spectroscopy, and can be used for further reactions. The residue was further extracted by stirring with $n$-pentane $(25 \mathrm{~mL})$ to afford 1 as a white solid. The mixture was filtered, and the solution concentrated to ca. $10 \mathrm{~mL}$ and was stored at $-40{ }^{\circ} \mathrm{C}$ to afford a second crop of $\mathbf{1}$ as a white solid. This material shows no significant improvement in purity compared with the oily residue, though can be easier to handle. Some crystals of $\mathbf{1}$ that are suitable for single crystal $\mathrm{X}$-ray diffraction were in one instance obtained from a concentrated solution of 1 in $n$-hexane at $4{ }^{\circ} \mathrm{C}$ after several weeks. Yield: quantitative as an oily residue, or $0.412 \mathrm{~g}(51 \%)$ as a white solid. NMR data for 1 from an aliquot at two different temperatures: ${ }^{1} \mathrm{H}$ NMR $\left(\mathrm{C}_{6} \mathrm{D}_{6}\right.$, 
$300.1 \mathrm{MHz}, 303 \mathrm{~K}): \delta-0.28--0.21$ (m br, $\left.2 \mathrm{H}, \mathrm{Mg}-\mathrm{CH}_{2}-n \mathrm{Pr}\right), 0.5-1.5\left(\mathrm{vbr}, 31 \mathrm{H}, \mathrm{CH}\left(\mathrm{CH}_{3}\right)_{2}, \mathrm{CH}_{2}, \mathrm{CH}_{3}\right)$, $1.77\left(\mathrm{~s}, 1 \mathrm{H}, \mathrm{P}_{2} \mathrm{CH}\right), 3.88\left(\mathrm{sept}, J_{\mathrm{H}-\mathrm{H}}=6.8 \mathrm{~Hz}, 4 \mathrm{H}, \mathrm{CH}\left(\mathrm{CH}_{3}\right)_{2}\right), 6.82-7.18(\mathrm{~m}, 18 \mathrm{H}, \mathrm{Ar}-\mathrm{H}), 7.42-7.51(\mathrm{~m}$, $8 \mathrm{H}, \mathrm{Ar}-\mathrm{H}) ;{ }^{1} \mathrm{H}$ NMR $\left(\mathrm{C}_{6} \mathrm{D}_{6}, 300.1 \mathrm{MHz}, 333 \mathrm{~K}\right): \delta-0.26$ (vbr, $\left.2 \mathrm{H}, \mathrm{Mg}-\mathrm{CH}_{2}-n \mathrm{Pr}\right), 0.7-1.4(\mathrm{vbr}, 19 \mathrm{H}$, $\left.\mathrm{CH}\left(\mathrm{CH}_{3}\right)_{2}, \mathrm{CH}_{2}, \mathrm{CH}_{3}\right), 1.07$ (br, $\left.12 \mathrm{H}, \mathrm{CH}\left(\mathrm{CH}_{3}\right)_{2}\right) 1.78(\mathrm{~s}, 1 \mathrm{H}, \mathrm{CH}), 3.87$ (sept, $J_{\mathrm{H}-\mathrm{H}}=6.8 \mathrm{~Hz}, 4 \mathrm{H}$, $\left.\mathrm{CH}\left(\mathrm{CH}_{3}\right)_{2}\right), 6.88-7.13(\mathrm{~m}, 18 \mathrm{H}, \mathrm{Ar}-\mathrm{H}), 7.46-7.51(\mathrm{~m}, 8 \mathrm{H}, \mathrm{Ar}-\mathrm{H}) ;{ }^{13} \mathrm{C}\left\{{ }^{1} \mathrm{H}\right\}$ NMR $\left(\mathrm{C}_{6} \mathrm{D}_{6}, 125.7 \mathrm{MHz}\right.$, $333 \mathrm{~K}): \delta-1.9\left(\mathrm{MgCH}_{2}\right), 7.4\left(\mathrm{CH}_{2}\right), 12.1\left(\mathrm{CH}_{2}\right), 20.2\left(\mathrm{t}, J_{\mathrm{C}-\mathrm{P}}=141 \mathrm{~Hz}, \mathrm{P} 2 \mathrm{CH}\right), 24.0\left(\mathrm{br}, \mathrm{CH}\left(\mathrm{CH}_{3}\right)_{2}\right)$, $28.6\left(\mathrm{CH}\left(\mathrm{CH}_{3}\right)_{2}\right), 30.7\left(\mathrm{CH}\left(\mathrm{CH}_{3}\right)_{2}\right.$ or $\left.\mathrm{CH}_{2} \mathrm{CH}_{3}\right), 31.1\left(\mathrm{CH}\left(\mathrm{CH}_{3}\right)_{2}\right.$ or $\left.\mathrm{CH}_{2} \mathrm{CH}_{3}\right), 123.8(\mathrm{Ar}-\mathrm{C}), 124.0(\mathrm{Ar}-\mathrm{C})$, 127.5 (partially hidden by solvent resonance, Ar-C), 130.0 (Ar-C), 132.3 (vtr, not resolved, Ar-C), 136.1 (d, $\left.J_{\mathrm{C}-\mathrm{P}}=98.1 \mathrm{~Hz}, \mathrm{Ar}-\mathrm{C}\right), 141.9$ (vtr, not resolved, Ar-C), $145.9(\mathrm{Ar}-\mathrm{C}) ;{ }^{31} \mathrm{P}\left\{{ }^{1} \mathrm{H}\right\} \mathrm{NMR}\left(\mathrm{C}_{6} \mathrm{D}_{6}, 121.5 \mathrm{MHz}\right.$, $303 \mathrm{~K}): \delta 25.1$ (s).

[(LMg) $)_{2}$ 2: [HLMgn $\left.\mathrm{Bu}\right] \mathbf{1}(1.63 \mathrm{mmol})$ in toluene $(25 \mathrm{~mL})$ was prepared as described above. At room temperature, $\mathrm{PhSiH}_{3}(0.193 \mathrm{~g}, 0.220 \mathrm{~mL}, 1.78 \mathrm{mmol}, 1.09$ equiv.) was added and the mixture was stirred for two hours at $80{ }^{\circ} \mathrm{C}$. (This has been found to be sufficient for the generation of $\mathbf{2}$, additional heating has been used to ensure completion and encourage precipitation of 2 during work-up.) The mixture was heated under reflux overnight, cooled, and a white precipitate of $\mathbf{2}$ formed that was filtered off. The supernatant solution was concentrated under vacuum to ca. $6 \mathrm{~mL}, n$-hexane $(10 \mathrm{~mL})$ was added, and more 2 precipitated. This mixture was stored at $4{ }^{\circ} \mathrm{C}$ for one day, and 2 was filtered off. All crops were dried in vacuum. Yield: $0.565 \mathrm{~g}(46 \%)$. Crystals of 2.4 or $6 \mathrm{C}_{6} \mathrm{H}_{6}$ were obtained by recrystallization from hot benzene. Once crystallized, the compound shows a low solubility. Crystals of $\left[(\mathrm{LMg})_{2}\right] \cdot 4 \mathrm{THF}$ were obtained from a solution of 2 in neat THF at $-25^{\circ} \mathrm{C}$. m.p.: $254-258^{\circ} \mathrm{C}$ (decomp.); NMR spectra were recorded at $65^{\circ} \mathrm{C}$ to achieve a better solubility and sharper resonances. ${ }^{1} \mathrm{H}$ NMR $\left(\mathrm{C}_{6} \mathrm{D}_{6}, 300.1 \mathrm{MHz}, 338 \mathrm{~K}\right): \delta 0.06\left(\mathrm{~d}, J_{\mathrm{H}-\mathrm{H}}=6.8 \mathrm{~Hz}, 12 \mathrm{H}, \mathrm{CH}\left(\mathrm{CH}_{3}\right)_{2}\right), 0.23\left(\mathrm{~d}, J_{\mathrm{H}-\mathrm{H}}=6.8 \mathrm{~Hz}\right.$, $\left.12 \mathrm{H}, \mathrm{CH}\left(\mathrm{CH}_{3}\right)_{2}\right), 0.62\left(\mathrm{~d}, J_{\mathrm{H}-\mathrm{H}}=6.8 \mathrm{~Hz}, 12 \mathrm{H}, \mathrm{CH}\left(\mathrm{CH}_{3}\right)_{2}\right), 1.50\left(\mathrm{~d}, \mathrm{~J}_{\mathrm{H}-\mathrm{H}}=6.8 \mathrm{~Hz}, 12 \mathrm{H}, \mathrm{CH}\left(\mathrm{CH}_{3}\right)_{2}\right)$, $3.34\left(\mathrm{sept}, J_{\mathrm{H}-\mathrm{H}}=6.8 \mathrm{~Hz}, 4 \mathrm{H}, \mathrm{CH}\left(\mathrm{CH}_{3}\right)_{2}\right), 3.81\left(\mathrm{sept}, J_{\mathrm{H}-\mathrm{H}}=6.8 \mathrm{~Hz}, 4 \mathrm{H}, \mathrm{CH}\left(\mathrm{CH}_{3}\right)_{2}\right), 6.39-7.22(\mathrm{~m}, 52 \mathrm{H}$,

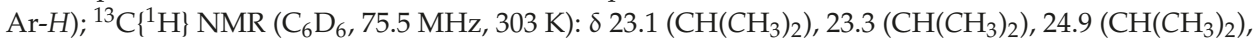
$27.2\left(\mathrm{CH}\left(\mathrm{CH}_{3}\right)_{2}\right), 29.0\left(\mathrm{CH}\left(\mathrm{CH}_{3}\right)_{2}\right), 29.1\left(\mathrm{CH}\left(\mathrm{CH}_{3}\right)_{2}\right), 123.5$ (vtr, $\left.\mathrm{Ar}-\mathrm{C}\right), 123.7$ (vtr, Ar-C), 124.8 (vtr, Ar- $\left.\mathrm{C}\right)$, 126.3 (vtr, $\left.J_{\mathrm{C}-\mathrm{P}}=5.3 \mathrm{~Hz}, \mathrm{Ar}-\mathrm{C}\right), 127.3$ (vtr br, Ar-C), 129.3 (Ar-C), 129.6 (Ar-C), 134.3 (vtr br, Ar-C), 134.9 (vtr, $\left.J_{\mathrm{C}-\mathrm{P}}=4.3 \mathrm{~Hz}, \mathrm{Ar}-\mathrm{C}\right), 143.8\left(\mathrm{vtr}, J_{\mathrm{C}-\mathrm{P}} \approx 1.3 \mathrm{~Hz}, \mathrm{Ar}-\mathrm{C}\right), 145.8$ (vtr, $\left.J_{\mathrm{C}-\mathrm{P}}=3.1 \mathrm{~Hz}, \mathrm{Ar}-\mathrm{C}\right)$, $147.3\left(\mathrm{vtr}, J_{\mathrm{C}-\mathrm{P}}=3.2 \mathrm{~Hz}, \mathrm{Ar}-\mathrm{C}\right)$; Note: the PCP carbon atoms were not observed. ${ }^{31} \mathrm{P}\left\{{ }^{1} \mathrm{H}\right\} \mathrm{NMR}\left(\mathrm{C}_{6} \mathrm{D}_{6}\right.$, $121.5 \mathrm{MHz}, 338 \mathrm{~K}$ ): $\delta 27.5$ (s); IR (nujol), ṽ / cm ${ }^{-1}: 1587$ w, 1573 w, 1460 s, 1433 s, 1378 m, 1361 m, 1347 m, 1309 m, 1246 m, 1198 m, 1100 s, 1077 s, 1069 s, 1027 m, 962 m, 823 m, 785 s, 737 m, 702 m, 656 m; elemental analysis (\%) (on a solvent-free sample precipitated using $n$-hexane and dried under vacuum) for $\mathrm{C}_{98} \mathrm{H}_{108} \mathrm{Mg}_{2} \mathrm{~N}_{4} \mathrm{P}_{2}$ (1514.44 $\mathrm{g} \mathrm{mol}^{-1}$ ): calcd: C 77.72, H 7.19, N 3.70; found: C 77.77, H 7.28, N 3.63.

[HLAlH ${ }_{2}$ ] 3: Method A: A solution of $\mathrm{AlH}_{3} \cdot \mathrm{NMe}_{3}$ in toluene $(1.25 \mathrm{~mL}$ of a $0.82 \mathrm{~m}$ solution, $1.03 \mathrm{mmol})$ was added to a cooled $\left(-60^{\circ} \mathrm{C}\right)$ solution of $\mathrm{H}_{2} \mathrm{~L}(0.72 \mathrm{~g}, 0.981 \mathrm{mmol})$ in toluene $(12 \mathrm{~mL})$, and the solution was stirred at room temperature overnight. All volatiles were removed under vacuum, $n$-hexane $(15 \mathrm{~mL})$ was added, the mixture was briefly stirred and the resulting white solid of 3 was filtered off. The solution was stored at $4{ }^{\circ} \mathrm{C}$ to give a crop of colourless crystals of 3 . The supernatant solution was concentrated to ca. $4 \mathrm{~mL}$ and again stored at $4{ }^{\circ} \mathrm{C}$ to obtain a smaller third crop of 3 . Combined yield: $0.51 \mathrm{~g}(67 \%)$. Method B: A mixture of [HLMg $n \mathrm{Bu}] \mathbf{1}(0.420 \mathrm{~g}, 0.515 \mathrm{mmol})$ and $\mathrm{LiAlH}_{4}$ $\left(0.040 \mathrm{~g}, 1.046 \mathrm{mmol}, 2.03\right.$ equiv.) was cooled to $-80{ }^{\circ} \mathrm{C}$, diethyl ether $(30 \mathrm{~mL})$ was added, and the mixture was stirred overnight at room temperature forming a white precipitate. All volatiles were removed under vacuum, and the residue was washed with $n$-hexane $(8 \mathrm{~mL})$. The solid was extracted with toluene $(20 \mathrm{~mL})$ and all volatiles were removed under vacuum to afford a white solid of $\left[\mathrm{HLAlH}_{2}\right] 3$. Yield: $0.160 \mathrm{~g}(41 \%)$. m.p.: $264-266^{\circ} \mathrm{C}$ (no visible decomposition observed up to the investigated limit of $\left.270{ }^{\circ} \mathrm{C}\right) ;{ }^{1} \mathrm{H}$ NMR $\left(\mathrm{C}_{6} \mathrm{D}_{6}, 300.1 \mathrm{MHz}, 303 \mathrm{~K}\right): \delta 0.50\left(\mathrm{~d}, J_{\mathrm{H}-\mathrm{H}}=6.9 \mathrm{~Hz}, 12 \mathrm{H}, \mathrm{CH}\left(\mathrm{CH}_{3}\right)_{2}\right), 1.47(\mathrm{~d}$, $\left.J_{\mathrm{H}-\mathrm{H}}=6.9 \mathrm{~Hz}, 12 \mathrm{H}, \mathrm{CH}\left(\mathrm{CH}_{3}\right)_{2}\right), 2.00\left(\mathrm{~s}, 1 \mathrm{H}, \mathrm{P}_{2} \mathrm{CH}\right), 4.03\left(\mathrm{sept}, J_{\mathrm{H}-\mathrm{H}}=6.9 \mathrm{~Hz}, 4 \mathrm{H}, \mathrm{CH}\left(\mathrm{CH}_{3}\right)_{2}\right), \mathrm{ca} .4 .9(\mathrm{vbr}$, $2 \mathrm{H}, \mathrm{AlH}), 6.84-7.28(\mathrm{~m}, 18 \mathrm{H}, \mathrm{Ar}-\mathrm{H}), 7.53-7.77(\mathrm{~m}, 8 \mathrm{H}, \mathrm{Ar}-\mathrm{H}) ;{ }^{13} \mathrm{C}\left\{{ }^{1} \mathrm{H}\right\}$ NMR $\left(\mathrm{C}_{6} \mathrm{D}_{6}, 75.5 \mathrm{MHz}, 303 \mathrm{~K}\right)$ : $\delta 16.3\left(\mathrm{t}, J_{\mathrm{C}-\mathrm{P}}=135 \mathrm{~Hz}, \mathrm{P}_{2} \mathrm{CH}\right), 23.0\left(\mathrm{CH}\left(\mathrm{CH}_{3}\right)_{2}\right), 27.9\left(\mathrm{CH}\left(\mathrm{CH}_{3}\right)_{2}\right), 29.3\left(\mathrm{CH}\left(\mathrm{CH}_{3}\right)_{2}\right), 124.9(\mathrm{Ar}-\mathrm{C})$, $126.1(\mathrm{Ar}-\mathrm{C}), 127.9$ (partially hidden by solvent resonance, vtr, $\left.J_{\mathrm{C}-\mathrm{P}}=5.7 \mathrm{~Hz}, \mathrm{Ar}-\mathrm{C}\right), 131.0(\mathrm{Ar}-\mathrm{C})$, 
$133.6\left(\mathrm{vtr}, J_{\mathrm{C}-\mathrm{P}}=4.9 \mathrm{~Hz}, \mathrm{Ar}-\mathrm{C}\right), 134.8\left(\mathrm{dd}, J_{\mathrm{C}-\mathrm{P}}=99.7,2.0 \mathrm{~Hz}, \mathrm{Ar}-\mathrm{C}\right), 139.2\left(\mathrm{vtr}, J_{\mathrm{C}-\mathrm{P}}=4.6 \mathrm{~Hz}, \mathrm{Ar}-\mathrm{C}\right)$, 148.7 (vtr, $\left.J_{\mathrm{C}-\mathrm{P}}=2.4 \mathrm{~Hz}, \mathrm{Ar}-\mathrm{C}\right) ;{ }^{31} \mathrm{P}\left\{{ }^{1} \mathrm{H}\right\}$ NMR $\left(\mathrm{C}_{6} \mathrm{D}_{6}, 121.5 \mathrm{MHz}, 303 \mathrm{~K}\right): \delta 29.5$ (s); IR (nujol), $\tilde{\mathrm{v}} / \mathrm{cm}^{-1}$ : $1819 \mathrm{~s}(\mathrm{AlH}), 1777 \mathrm{~s}$ (AlH), $1480 \mathrm{~m}, 1461 \mathrm{~s}, 1433 \mathrm{~s}, 1378 \mathrm{~s}, 1315 \mathrm{~m}, 1259 \mathrm{~m}, 1240 \mathrm{~m}, 1205 \mathrm{~m}, 1181 \mathrm{~s}, 1105 \mathrm{~s}$, 1042 m, 1003 m, 988 s, 834 m, 804 s, 785 s, 757 m, 741 m, 719 s, 696 s, 598 m, 564 s; elemental analysis (\%) for $\mathrm{C}_{49} \mathrm{H}_{57} \mathrm{AlN}_{2} \mathrm{P}_{2}$ (762.92 g. $\mathrm{mol}^{-1}$ ): calcd: C 77.14, H 7.53, N 3.67; found: C 77.57, H 7.51, N 3.72.

\subsection{X-ray Crystallography}

Suitable crystals were mounted in silicone oil and were either measured using a Rigaku FR-X Ultrahigh brilliance Microfocus RA generator/confocal optics and Rigaku XtaLAB P200 diffractometer (1) using the CrystalClear (Rigaku) program suite [39], or at the MX1 and MX2 beamlines [40] at the Australian Synchrotron (all other structures) with synchrotron radiation with a wavelength at or close to Mo K $\alpha$ radiation $(\lambda=0.71073 \AA)$. All structures were solved by direct methods and refined by full-matrix least-squares against $F^{2}$ using SHELXL [41]. All non-hydrogen atoms were refined anisotropically. Hydrogen atoms were placed in calculated positions (riding model), except for the $\mathrm{Al}-\mathrm{H}$ atoms in Compound 3, which were freely refined. Multiple attempts were made to model the apparent positional disorder in the $n$-butyl chain in 1 ; however, none of these resulted in satisfactory behaviour of the thermal ellipsoids. From examining the packing of the complex, it is apparent that there is volume available for the $n$-butyl chain to be positioned in, such that refinement of discrete orientations is likely impractical. In $\mathbf{2}^{\prime}$, one benzene molecule in the asymmetric unit is disordered and was modelled using two positions for each atom (54\% and $46 \%$ parts). Geometry restraints were applied to the refinement of all benzene lattice molecules in $\mathbf{2}^{\prime}$. Severely disordered solvent of crystallization was partially $\left(2^{\prime \prime}\right)$ or fully $\left(2^{\prime \prime \prime}\right)$ removed using the PLATON/SQUEEZE routine [42]. Further experimental and refinement details are given in the crystallographic information files. CCDC 1540806-1540810 contains the supplementary crystallographic data for this paper. These data can be obtained free of charge via https:/ / www.ccdc.cam.ac.uk/structures/ (or from the CCDC, 12 Union Road, Cambridge CB2 1EZ, UK; Fax: +44-1223-336033; E-mail: deposit@ccdc.cam.ac.uk).

1, [HLMg $n \mathrm{Bu}$ ], CCDC 1540806, $\mathrm{C}_{53} \mathrm{H}_{64} \mathrm{MgN}_{2} \mathrm{P}_{2}, M=815.31, T=173(2) \mathrm{K}$, Monoclinic, $P 2_{1} / \mathrm{c}$, $a=18.7343(17) \AA, b=11.6636(8) \AA, c=23.2790(18) \AA, \alpha=90^{\circ}, \beta=106.937(2)^{\circ}, \gamma=90^{\circ}, V=4866.0(7) \AA^{3}$, $Z=4, \varrho=1.113 \mathrm{Mg} / \mathrm{m}^{3}, F(000)=1752$, theta range: $1.829^{\circ}$ to $25.384^{\circ}$, indices $-21 \leq h \leq 22$, $-14 \leq k \leq 13,-28 \leq l \leq 28$, Reflections collected: 58239, Independent reflections: 8919 [R(int) $=0.0318$ ], Completeness to theta $\left(25.241^{\circ}\right): 99.8 \%$, Goof: 1.022 , Final $R$ indices $[I>2 \sigma(I)]: R_{1}=0.0406, w R_{2}=0.1080$, $R$ indices (all data): $R_{1}=0.0504, w R_{2}=0.1149$, Largest diff. peak and hole: 0.528 and $-0.283 \mathrm{e} \cdot \AA^{-3}$.

$2^{\prime}$, [(LMg) $)_{2} \cdot 4 \mathrm{C}_{6} \mathrm{H}_{6}, \mathrm{CCDC} 1540807, \mathrm{C}_{122} \mathrm{H}_{132} \mathrm{Mg}_{2} \mathrm{~N}_{4} \mathrm{P}_{4}, M=1826.81, T=100$ (2) $\mathrm{K}$, Monoclinic, $C 2 / c, a=20.547(4) \AA, b=22.500(5) \AA, c=22.000(4) \AA, \alpha=90^{\circ}, \beta=90.34(3)^{\circ}, \gamma=90^{\circ}, V=10171(4) \AA^{3}$, $Z=4, \varrho=1.193 \mathrm{Mg} / \mathrm{m}^{3}, F(000)=3904$, theta range: $1.342^{\circ}$ to $28.622^{\circ}$, indices $-27 \leq h \leq 27$, $-29 \leq k \leq 29,-28 \leq l \leq 28$, Reflections collected: 68,204, Independent reflections: 12,842 [ $R$ (int) $=0.1103$ ], Completeness to theta $\left(25.241^{\circ}\right): 99.7 \%$, Goof: 1.020 , Final $R$ indices $[I>2 \sigma(I)]: R_{1}=0.0554, w R_{2}=0.1248$, $R$ indices (all data): $R_{1}=0.0894, w R_{2}=0.1406$, Largest diff. peak and hole: 0.420 and $-0.419 \mathrm{e} \cdot \AA^{-3}$.

$2^{\prime \prime}$, [(LMg) $\left.)_{2}\right] 6 \mathrm{C}_{6} \mathrm{H}_{6}, \mathrm{CCDC} 1540809, \mathrm{C}_{134} \mathrm{H}_{144} \mathrm{Mg}_{2} \mathrm{~N}_{4} \mathrm{P}_{4}, M=1983.02, \mathrm{~T}=100$ (2) K, Monoclinic, $C 2 / c, a=19.080(4) \AA, b=34.382(7) \AA, c=16.790(3) \AA, \alpha=90^{\circ}, \beta=90.56(3)^{\circ}, \gamma=90^{\circ}, V=11014(4) \AA^{3}$, $Z=4, \varrho=1.196 \mathrm{Mg} / \mathrm{m}^{3}, F(000)=4240$, theta range: $1.728^{\circ}$ to $27.138^{\circ}$, indices $-24 \leq h \leq 24$, $-44 \leq k \leq 44,-21 \leq l \leq 21$, Reflections collected: 87100, Independent reflections: 12142 [ $R($ int $)=0.0499$ ], Completeness to theta $\left(25.241^{\circ}\right): 99.5 \%$, Goof: 1.051 , Final $R$ indices $[I>2 \sigma(I)]: R_{1}=0.0445, w R_{2}=0.1141$, $R$ indices (all data): $R_{1}=0.0495, w R_{2}=0.1184$, Largest diff. peak and hole: 0.280 and $-0.441 \mathrm{e} \cdot \AA^{-3}$.

$2^{\prime \prime \prime},\left[(\mathrm{LMg})_{2}\right] \cdot 4 \mathrm{THF}, \mathrm{CCDC} 1540810, \mathrm{C}_{114} \mathrm{H}_{140} \mathrm{Mg}_{2} \mathrm{~N}_{4} \mathrm{O}_{4} \mathrm{P}_{4}, M=1802.79, T=100(2) \mathrm{K}$, Triclinic, $P-1, a=13.510(3) \AA, b=14.400(3) \AA, c=29.430(6) \AA, \alpha=100.84(3)^{\circ}, \beta=100.81(3)^{\circ}$, $\gamma=100.62(3)^{\circ}, V=5379\left(2 \AA^{3}, Z=2, \varrho=1.113 \mathrm{Mg} / \mathrm{m}^{3}, F(000)=1936\right.$, theta range: $1.479^{\circ}$ to $27.131^{\circ}$, indices $-17 \leq h \leq 17,-18 \leq k \leq 18,-37 \leq l \leq 36$, Reflections collected: 84669, Independent reflections: $23560[R($ int $)=0.0782]$, Completeness to theta $\left(25.241^{\circ}\right): 99.4 \%$, Goof: 1.001 , Final $R$ indices $[I>2 \sigma(I)]$ : 
$R_{1}=0.0779, w R_{2}=0.2065, R$ indices (all data): $R_{1}=0.1198, w R_{2}=0.2280$, Largest diff. peak and hole: 0.912 and $-0.473 \mathrm{e} \cdot \AA^{-3}$.

3, [HLAlH $\left.\mathrm{HL}_{2}\right], \mathrm{CCDC}$ 1540808, $\mathrm{C}_{49} \mathrm{H}_{57} \mathrm{AlN}_{2} \mathrm{P}_{2}, M=762.88, T=100(2) \mathrm{K}$, Monoclinic, $P 2{ }_{1} / \mathrm{c}, \quad a=13.149(3) \AA, b=18.972(4) \AA, c=17.427(4) \AA, \alpha=90^{\circ}, \beta=99.58(3)^{\circ}, \gamma=90^{\circ}$, $V=4286.8(15) \AA^{3}, Z=4, \varrho=1.182 \mathrm{Mg} / \mathrm{m}^{3}, F(000)=1632$, theta range: $1.571^{\circ}$ to $28.604^{\circ}$, indices $-17 \leq h \leq 17,-25 \leq k \leq 25,-22 \leq l \leq 22$, Reflections collected: 75030, Independent reflections: $10752[R($ int $)=0.0395]$, Completeness to theta $\left(25.241^{\circ}\right): 99.1 \%$, Goof: 1.048 , Final $R$ indices $[I>2 \sigma(I)]$ : $R_{1}=0.0384, w R_{2}=0.0994, R$ indices (all data): $R_{1}=0.0408, w R_{2}=0.1021$, Largest diff. peak and hole: 0.366 and $-0.395 \mathrm{e} \cdot \AA^{-3}$.

\section{Conclusions}

In conclusion, we have successfully synthesized and characterized the $\mathrm{Mg}$ and $\mathrm{Al}$ complexes [HLMg $n \mathrm{Bu}]$ 1, $\left[(\mathrm{LMg})_{2}\right]$ 2, and $\left[\mathrm{HLAlH}_{2}\right]$ 3, where $\mathrm{H}_{2} \mathrm{~L}$ is $\mathrm{H}_{2} \mathrm{C}\left(\mathrm{Ph}_{2} \mathrm{P}=\mathrm{NDip}\right)_{2}$. [HLMg $\left.n \mathrm{Bu}\right] 1$ shows a rare three-coordinate $\mathrm{Mg}$ centre with terminal $n$-butyl group and the methanediide complex $\left[(\mathrm{LMg})_{2}\right]$ 2 shows a central folded core of five fused four-membered rings. The results from reactivity studies suggest that dihydrogen elimination from methanide metal hydride complexes of $\mathrm{HL}^{-}$is much more facile for a putative magnesium hydride species intermediate, whereas related aluminium complexes are more thermally stable and $\mathrm{H}_{2}$ elimination was not achieved. Once formed, $\left[(\mathrm{LMg})_{2}\right] 2$ is relatively inert with respect to donor molecules and strong reducing agents, likely for steric reasons though reacts with ammonia.

Supplementary Materials: The following are available online at www.mdpi.com/2304-6740/5/2/29/s1, cif and cif-checked files.

Acknowledgments: Andreas Stasch is grateful to the Australian Research Council for support and a fellowship, and the University of St Andrews. Christian P. Sindlinger thanks the DAAD and the Fonds der Chemischen Industrie for a scholarship. Part of this research was undertaken on the MX1 and MX2 beamlines at the Australian Synchrotron, Victoria, Australia.

Author Contributions: Christian P. Sindlinger, Samuel R. Lawrence, and Andreas Stasch carried out the experiments and compound characterization and wrote the experimental section. David B. Cordes, Alexandra M. Z. Slawin, and Andreas Stasch conducted the X-ray crystallographic analyses. Andreas Stasch conceived the project and wrote the main section of the manuscript with input from all authors.

Conflicts of Interest: The authors declare no conflict of interest.

\section{References}

1. Marek, I.; Normant, J.-F. Synthesis and reactivity of $\mathrm{sp}^{3}$-geminated organodimetallics. Chem. Rev. 1996, 96, 3241-3267. [CrossRef] [PubMed]

2. Gessner, V.H.; Becker, J.; Feichtner, K.-S. Carbene complexes based on dilithium methandiides. Eur. J. Inorg. Chem. 2015, 1841-1859. [CrossRef]

3. Chivers, T.; Konu, J.; Thirumoorthi, R. PCP-bridged chalcogen-centred anions: Coordination chemistry and carbon-based reactivity. Dalton Trans. 2012, 41, 4283-4295. [CrossRef] [PubMed]

4. Harder, S. Geminal dianions stabilized by phosphonium substituents. Coord. Chem. Rev. 2011, 255, 1252-1267. [CrossRef]

5. Liddle, S.T.; Mills, D.P.; Wooles, A.J. Early metal bis(phosphorus-stabilized)carbene chemistry. Chem. Soc. Rev. 2011, 40, 2164-2176. [CrossRef] [PubMed]

6. Liddle, S.T.; Mills, D.P.; Wooles, A.J. Bis(phosphorus-Stabilized)methanide and methandiide derivatives of group 1-5 and $f$-element metals. Organomet. Chem. 2010, 36, 29-55. [CrossRef]

7. Panda, T.K.; Roesky, P.W. Main-group and transition-metal complexes of bis(phosphinimino)methanides. Chem. Soc. Rev. 2009, 38, 2782-2804. [CrossRef] [PubMed]

8. Cantat, T.; Mézailles, N.; Auffant, A.; Le Floch, P. Bis-phosphorus stabilised carbene complexes. Dalton Trans. 2008, 15, 1957-1972. [CrossRef] [PubMed]

9. Birchall, C.; Moxey, G.J.; McMaster, J.; Blake, A.J.; Lewis, W.; Kays, D.L. A monomeric, heterobimetallic complex with an unsupported Mg-Fe bond. Inorg. Chim. Acta 2017, 458, 97-100. [CrossRef] 
10. Thirumoorthi, R.; Chivers, T. Potassium and magnesium complexes of the (iminophosphoranyl)(selenophosphoranyl)methanide ligand $\left[\mathrm{CH}\left(\mathrm{PPh}_{2} \mathrm{Se}\right)\left(\mathrm{PPh}_{2} \mathrm{NSiMe}_{3}\right)\right]^{-}$. Eur. J. Inorg. Chem. 2015, 2188-2192. [CrossRef]

11. Xie, H.; Mou, Z.; Liu, B.; Li, P.; Rong, W.; Li, S.; Cui, D. Phosphinimino-amino magnesium complexes: Synthesis and catalysis of heteroselective ROP of rac-lactide. Organometallics 2014, 33, 722-730. [CrossRef]

12. Heuclin, H.; Fustier-Boutignon, M.; Ho, S.Y.; Le Goff, X.; Carenco, S.; So, C.; Mézailles, N. Synthesis of phosphorus(V)-stabilized geminal dianions. The cases of mixed $\mathrm{P}=\mathrm{X} / \mathrm{P} \rightarrow \mathrm{BH}_{3}(\mathrm{X}=\mathrm{S}, \mathrm{O})$ and $\mathrm{P}=\mathrm{S} / \mathrm{SiMe}_{3}$ derivatives. Organometallics 2013, 32, 498-508. [CrossRef]

13. Thirumoorthi, R.; Chivers, T. Alkali metal, magnesium, and zinc complexes of bis(chalcogenophosphinoyl)methanide ligands. Eur. J. Inorg. Chem. 2012, 3061-3069. [CrossRef]

14. Marks, S.; Kuzdrowska, M.; Roesky, P.W.; Annunziata, L.; Guillaume, S.M.; Maron, L. Organometallic strontium borohydrides: Synthesis, X-ray structures, catalytic polymerization of $\varepsilon$-caprolactone, and density functional calculations. ChemPlusChem 2012, 77, 350-353. [CrossRef]

15. Leung, W.; Wan, C.; Mak, T.C.W. Synthesis and structure of magnesium and group 13 metal bis(thiophosphinoyl)methanediide complexes. Organometallics 2010, 29, 1622-1628. [CrossRef]

16. Guo, J.; Lee, J.; Foo, M.; Lau, K.; Xi, H.; Lim, K.H.; So, C. Synthesis and characterization of magnesium and aluminum bis(phosphoranyl)methanediide complexes. Organometallics 2010, 29, 939-944. [CrossRef]

17. Wiecko, M.; Marks, S.; Panda, T.K.; Roesky, P.W. Bis(phosphinimino)methanides as ligands in divalent ytterbium and strontium chemistry—Synthesis and structure. Z. Anorg. Allg. Chem. 2009, 635, 931-935. [CrossRef]

18. Orzechowski, L.; Harder, S. Syntheses, structures, and reactivity of barium carbene complexes with chelating bis-iminophosphorano arms. Organometallics 2007, 26, 5501-5506. [CrossRef]

19. Orzechowski, L.; Jansen, G.; Harder, S. Synthesis, structure, and reactivity of a stabilized calcium carbene: $\mathrm{R}_{2}$ CCa. J. Am. Chem. Soc. 2006, 128, 14676-14684. [CrossRef] [PubMed]

20. Ahmed, S.A.; Hill, M.S.; Hitchcock, P.B. Synthesis and $\mathrm{M}-\mathrm{C}_{\gamma}$ hemilability of group 2 bis(phosphinimino)methanides. Organometallics 2006, 25, 394-402. [CrossRef]

21. Panda, T.K.; Zulys, A.; Gamer, M.T.; Roesky, P.W. Bis(phosphinimino)methanides as ligands in divalent lanthanide and alkaline earth chemistry-Synthesis, structure, and catalysis. J. Organomet. Chem. 2005, 690, 5078-5089. [CrossRef]

22. Wei, P.; Stephan, D.W. Magnesium complexes of bis(phosphinimine)methane and -methanide ligands. Organometallics 2003, 22, 601-604. [CrossRef]

23. Hill, M.S.; Hitchcock, P.B. Bis(phosphinimino)methyl derivatives of Ca, Sr and Ba: Facile access to heavier alkaline earth organometallic chemistry. Chem. Commun. 2003, 1758-1759. [CrossRef]

24. Al-Benna, S.; Sarsfield, M.J.; Thornton-Pett, M.; Ormsby, D.L.; Maddox, P.J.; Brès, P.; Bochmann, M. Sterically hindered iminophosphorane complexes of vanadium, iron, cobalt and nickel: A synthetic, structural and catalytic study. J. Chem. Soc. Dalton Trans. 2000, 4247-4257. [CrossRef]

25. Green, S.P.; Jones, C.; Stasch, A. Stable magnesium(I) compounds with Mg-Mg bonds. Science 2007, 318, 1754-1757. [CrossRef] [PubMed]

26. Stasch, A.; Jones, C. Stable dimeric magnesium(I) compounds: From chemical landmarks to versatile reagents. Dalton Trans. 2011, 40, 5659-5672. [CrossRef] [PubMed]

27. Arrowsmith, M.; Maitland, B.; Kociok-Köhn, G.; Stasch, A.; Jones, C.; Hill, M.S. Mononuclear three-coordinate magnesium complexes of a highly sterically encumbered $\beta$-diketiminate ligand. Inorg. Chem. 2014, 53, 10543-10552. [CrossRef] [PubMed]

28. Balasanthiran, V.; Chisholm, M.H.; Choojun, K.; Durr, C.B.; Wambua, P.M. BDI*MgX(L) where $\mathrm{X}={ }^{n} \mathrm{Bu}$ and $\mathrm{O}^{t} \mathrm{Bu}$ and $\mathrm{L}=\mathrm{THF}$, py and DMAP. The rates of kinetic exchange of $\mathrm{L}$ where $\mathrm{BDI}^{*}=$ $\mathrm{CH}\left\{\mathrm{C}\left({ }^{t} \mathrm{Bu}\right) \mathrm{N}-2,6-{ }^{i} \mathrm{Pr}_{2} \mathrm{C}_{6} \mathrm{H}_{3}\right\}_{2}$. Polyhedron 2016, 103, 235-240. [CrossRef]

29. Jones, C.; Bonyhady, S.J.; Nembenna, S.; Stasch, A. New routes to soluble magnesium amidoborane complexes. Eur. J. Inorg. Chem. 2012, 2596-2601. [CrossRef]

30. Xie, H.; Hua, X.; Liu, B.; Wu, C.; Cui, D. Phosphinimino-amino supported complex: Synthesis, polymerization of ethylene and dearomatisation of pyridine. J. Organomet. Chem. 2015, 798, 335-340. [CrossRef]

31. Green, S.P.; Jones, C.; Stasch, A. Stable adducts of a dimeric magnesium(I) compound. Angew. Chem. Int. Ed. 2008, 47, 9079-9083. [CrossRef] [PubMed] 
32. Bonyhady, S.J.; Jones, C.; Nembenna, S.; Stasch, A.; Edwards, A.J.; McIntyre, G.J. $\beta$-Diketiminate-stabilized magnesium(I) dimers and magnesium(II) hydride complexes: Synthesis, characterization, adduct formation, and reactivity studies. Chem. Eur. J. 2010, 16, 938-955. [CrossRef] [PubMed]

33. Sindlinger, C.P.; Stasch, A. Aluminium complexes of a sterically demanding bis(iminophosphorane)methandiide. Aust. J. Chem. 2013, 66, 1219-1225. [CrossRef]

34. Arrowsmith, M.; Hadlington, T.J.; Hill, M.S.; Kociok-Köhn, G. Magnesium-catalysed hydroboration of aldehydes and ketones. Chem. Commun. 2012, 48, 4567-4569. [CrossRef] [PubMed]

35. Lalrempuia, R.; Stasch, A.; Jones, C. An extremely bulky tris(pyrazolyl)methanide: A tridentate ligand for the synthesis of heteroleptic magnesium(II) and ytterbium(II) alkyl, hydride, and iodide complexes. Chem. Asian J. 2015, 10, 447-454. [CrossRef] [PubMed]

36. Harder, S. Molecular early main group metal hydrides: Synthetic challenge, structures and applications. Chem. Commun. 2012, 48, 11165-11177. [CrossRef] [PubMed]

37. Grochalla, W.; Edwards, P.P. Thermal decomposition of the non-interstitial hydrides for the storage and production of hydrogen. Chem. Rev. 2004, 104, 1283-1315. [CrossRef] [PubMed]

38. Harder, S.; Spielmann, J.; Intemann, J.; Bandmann, H. Hydrogen storage in magnesium hydride: The molecular approach. Angew. Chem. Int. Ed. 2011, 50, 4156-4160. [CrossRef] [PubMed]

39. CrystalClear-SM Expert v2.1; Rigaku Americas: The Woodlands, TX, USA; Rigaku Corporation: Tokyo, Japan, 2013.

40. Cowieson, N.P.; Aragao, D.; Clift, M.; Ericsson, D.J.; Gee, C.; Harrop, S.J.; Mudie, N.; Panjikar, S.; Price, J.R.; Riboldi-Tunnicliffe, A.; et al. MX1: A bending-magnet crystallography beamline serving both chemical and macromolecular crystallography communities at the Australian Synchrotron. J. Synchrotron Radiat. 2015, 22, 187-190. [CrossRef] [PubMed]

41. Sheldrick, G.M. Crystal structure refinement with SHELXL. Acta Cryst. 2015, C71, 3-8.

42. Spek, A.L. PLATON SQUEEZE: A tool for the calculation of the disordered solvent contribution to the calculated structure factors. Acta Cryst. 2015, C71, 9-18.

(C) 2017 by the authors. Licensee MDPI, Basel, Switzerland. This article is an open access article distributed under the terms and conditions of the Creative Commons Attribution (CC BY) license (http:/ / creativecommons.org/licenses/by/4.0/). 


\title{
Article \\ Alkali and Alkaline Earth Metal Complexes Ligated by an Ethynyl Substituted Cyclopentadienyl Ligand
}

\author{
Tim Seifert and Peter W. Roesky * \\ Institute of Inorganic Chemistry, Karlsruhe Institute of Technology, 76131 Karlsruhe, Germany; \\ tim.seifert@kit.edu \\ * Correspondence: roesky@kit.edu; Tel.: +49-721-608-46117
}

Academic Editor: Matthias Westerhausen

Received: 30 March 2017; Accepted: 14 April 2017; Published: 20 April 2017

\begin{abstract}
Sodium, potassium, and calcium compounds of trimethyl((2,3,4,5tetramethylcyclopentadien-1-yl)ethynyl)silane $\left(\mathrm{CpMe}_{4}\left(\mathrm{C} \equiv \mathrm{CSiMe}_{3}\right)\right)$ were synthesized and characterized by $\mathrm{X}$-ray diffraction and standard analytical methods. The sodium derivative was obtained by deprotonation of $\mathrm{CpMe}_{4}\left(\mathrm{C} \equiv \mathrm{CSiMe}_{3}\right) \mathrm{H}$ with $\mathrm{Na}\left\{\mathrm{N}\left(\mathrm{SiMe}_{3}\right)_{2}\right\}$ to give a monomeric complex $\left[\mathrm{NaCpMe}_{4}\left(\mathrm{C} \equiv \mathrm{CSiMe}_{3}\right)(\mathrm{THF})_{3}\right]$. In a similar reaction, starting from $\mathrm{K}\left\{\mathrm{N}\left(\mathrm{SiMe}_{3}\right)_{2}\right\}$ the corresponding potassium compound $\left[\mathrm{KCpMe}_{4}\left(\mathrm{C} \equiv \mathrm{CSiMe}_{3}\right)(\mathrm{THF})_{2}\right]_{n}$, which forms a polymeric super sandwich structure in the solid state, was obtained. Subsequently, salt metathesis reactions were conducted in order to investigate the versatility of the $\mathrm{CpMe}_{4}\left(\mathrm{C} \equiv \mathrm{CSiMe}_{3}\right)^{-}$ligand in alkaline earth chemistry. The reaction of $\left[\mathrm{KCpMe}_{4}\left(\mathrm{C} \equiv \mathrm{CSiMe}_{3}\right)(\mathrm{THF})_{2}\right]_{n}$ with $\mathrm{CaI}_{2}$ afforded the dimeric complex $\left[\mathrm{CaCpMe}_{4}\left(\mathrm{C} \equiv \mathrm{CSiMe}_{3}\right) \mathrm{I}(\mathrm{THF})_{2}\right]_{2}$, in which both $\mathrm{CpMe}_{4}\left(\mathrm{C} \equiv \mathrm{CSiMe}_{3}\right) \mathrm{Ca}$ units are bridged by iodide in a $\mu^{2}$ fashion. In-depth NMR investigation indicates that $\left[\mathrm{CaCpMe} 4\left(\mathrm{C} \equiv \mathrm{CSiMe}_{3}\right) \mathrm{I}(\mathrm{THF})_{2}\right]_{2}$ is in a Schlenk equilibrium with $\left[\left\{\mathrm{CpMe}_{4}\left(\mathrm{C} \equiv \mathrm{CSiMe}_{3}\right)\right\}_{2} \mathrm{Ca}(\mathrm{THF})_{x}\right]$ and $\mathrm{CaI}_{2}(\mathrm{THF})_{2}$, as is already known for $\left[\mathrm{CaCp} *(\mathrm{THF})_{2}\right]$.
\end{abstract}

Keywords: calcium; cyclopentadienyl; potassium; sodium

\section{Introduction}

Cyclopentadienyl salts of the alkali metals are probably one of the most versatile reagents in organometallic chemistry. They have been used for the synthesis of countless cyclopentadienyl complexes. Potassium cyclopentadienyl (KCp) was first reported by J. Thiele, who reacted potassium and cyclopentadiene in benzene [1], while the analogous sodium cyclopentadienyl ( $\mathrm{NaCp}$ ) was discovered approximately 50 years later by the groups of E. O. Fischer [2,3] and K. Ziegler [4]. The alkali metal cyclopentadienyls are generally available either by deprotonation of cyclopentadiene with an alkali metal base such as $\mathrm{M}\left\{\mathrm{N}\left(\mathrm{SiMe}_{3}\right)_{2}\right\}, \mathrm{MH}, \mathrm{MO} t \mathrm{Bu}, \mathrm{MOH}$ or the alkali metal itself $[5,6]$. Some years ago, we showed that sodium and potassium cyclopentadienyl is most conveniently prepared in a one-pot synthesis directly from alkali metals with neat dicyclopentadiene at elevated temperature $[7,8]$. Especially in the chemistry of electron poor metals, cyclopentadienyl is often used in the form of its permethylated derivative pentamethylcyclopentadienyl $\eta^{5}-\mathrm{CpMe}_{5}\left(\mathrm{Cp}^{*}\right)[8,9]$, because of the higher solubility of the corresponding metal complexes and the enlarged steric demand of the ligand, which prevents polymerization. Furthermore, other derivatives of cyclopentadienyl are easily accessible and increase the versatility of the cyclopentadienyl ligand [10-12]. For this reason, we became aware of the ligand trimethysilylethynyltetramethylcyclopentadiene $\mathrm{CpMe}_{4}\left(\mathrm{C} \equiv \mathrm{CSiMe}_{3}\right) \mathrm{H}$. $\mathrm{CpMe}_{4}\left(\mathrm{C} \equiv \mathrm{CSiMe}_{3}\right)^{-}$has been used before in group 8 chemistry. The postmodification of $\eta^{5}-\mathrm{CpMe}_{4}\left(\mathrm{C} \equiv \mathrm{CSiMe}_{3}\right)^{-}$metal complexes may include access to metal acetylides $[13,14]$, metal alkyne complexes [15,16], Sonogashira couplings [17-19], click reactions [20,21] and cyclizations [22-24]. 
$\left[\mathrm{LiCpMe}_{4}\left(\mathrm{C} \equiv \mathrm{CSiMe}_{3}\right)\right]$ has been generated in situ but, to the best of our knowledge, s-block compounds have not been isolated.

\section{Results and Discussion}

$\mathrm{CpMe}_{4}(\mathrm{C} \equiv \mathrm{CSiMe}) \mathrm{H}$ was prepared in a modified procedure published by Pudelski et al. [23] (Scheme 1). $\mathrm{CpMe}_{4}\left(\mathrm{C} \equiv \mathrm{CSiMe}_{3}\right) \mathrm{H}$ was obtained in an overall yield of $55 \%$ as a light yellow oil.

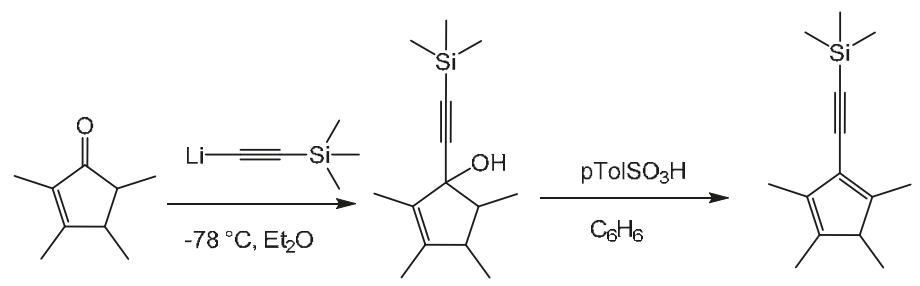

Scheme 1. Preparation of the ligand $\mathrm{CpMe}_{4}(\mathrm{C} \equiv \mathrm{CSiMe}) \mathrm{H}[23]$.

In the first metalation reaction, $\left.\mathrm{CpMe}_{4}(\mathrm{C} \equiv \mathrm{CSiMe})_{3}\right) \mathrm{H}$ was reacted with $\mathrm{Na}\left\{\mathrm{N}\left(\mathrm{SiMe}_{3}\right)_{2}\right\}$ in $\mathrm{THF}$. Upon reaction, the solution turned dark red, indicating the formation of $\left[\mathrm{NaCpMe}_{4}\left(\mathrm{C} \equiv \mathrm{CSiMe}_{3}\right)(\mathrm{THF})_{3}\right]$ (1) (Scheme 2). Single crystals suitable for X-ray diffraction formed in $50 \%$ yield upon cooling the concentrated solution to $-30^{\circ} \mathrm{C}$.

The sodium complex 1 crystallizes in the monoclinic space group $P 2_{1} / c$ with one molecule in the asymmetric unit (Figure 1). The molecular structure of 1 reveals a monomeric $\mathrm{NaCpMe}_{4}\left(\mathrm{C} \equiv \mathrm{CSiMe}_{3}\right)$ compound in the solid state, in which $\mathrm{CpMe}_{4}\left(\mathrm{C} \equiv \mathrm{CSiMe}_{3}\right)^{-}$coordinates in a $\eta^{5}$ fashion to the metal center. Furthermore, three THF molecules are attached to the sodium atom. The coordination polyhedron thus forms a three-legged piano-stool configuration. The bond distances between the carbon atoms of the five-membered $\mathrm{CpMe}_{4}\left(\mathrm{C} \equiv \mathrm{CSiMe}_{3}\right)$ ring and the sodium atom $\left(\mathrm{Na}-\mathrm{C}=2.672-2.736 \AA\right.$ ) are slightly elongated compared to $\mathrm{NaCp}^{*}$ [25], which is probably caused by the steric demand of the rather larger TMS-ethynyl substituent. The O-Na-O angles average to $96.2^{\circ}$. Compound 1 was also characterized in solution by NMR methods. The resonances of the methyl groups are split into two signals $\left(\delta\left({ }^{1} \mathrm{H}\right)=1.89\right.$ and $2.02 \mathrm{ppm} ; \delta\left({ }^{13} \mathrm{C}\right)=10.7$ and $\left.11.5 \mathrm{ppm}\right)$. The resonance attributed to the $\mathrm{Si}\left(\mathrm{CH}_{3}\right)_{3}$ moiety is slightly upfield shifted from $0.22 \mathrm{ppm} \mathrm{CpMe}\left(\mathrm{C} \equiv \mathrm{CSiMe}_{3}\right) \mathrm{H}$ to $0.12 \mathrm{ppm}(\mathbf{1})$ in the ${ }^{1} \mathrm{H}$ NMR spectrum. In the ATR-IR (ATR = Attenuated Total Reflection, IR = Infrared) spectrum, the $\mathrm{C} \equiv \mathrm{C}$ triple bond of the ethynyl moiety in $\mathbf{1}$ shows a stretching band at $2118 \mathrm{~cm}^{-1}$, which is slightly shifted compared to $\mathrm{CpMe}_{4}(\mathrm{C} \equiv \mathrm{CSiMe}) \mathrm{H}\left(2131 \mathrm{~cm}^{-1}\right)$.

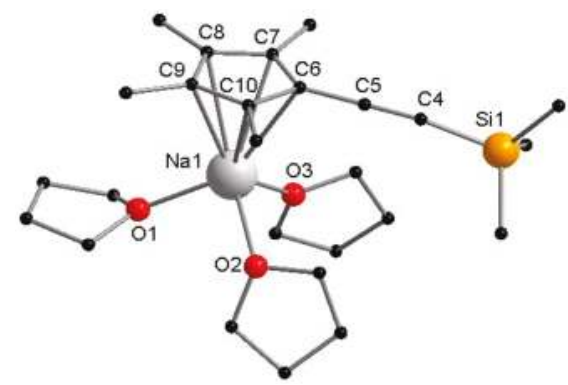

Figure 1. Molecular structure of $\mathbf{1}$ in the solid state. Hydrogen atoms are omitted for clarity. Selected bond lengths $[\AA]$ and angles $\left[^{\circ}\right]$ : Na1-C6 2.691(4), Na1-C7 2.673(4), Na1-C8 2.672(4), Na1-C9 2.717(4), Na1-C10 2.736(4), C4-C5 1.223(6), Na1-O1 2.289(3), Na1-O2 2.321(3), Na1-O3 2.293(3), O1-Na1-O2 96.70(2), O2-Na1-O3 95.75(12), O3-Na1-O1 96.14(12). 


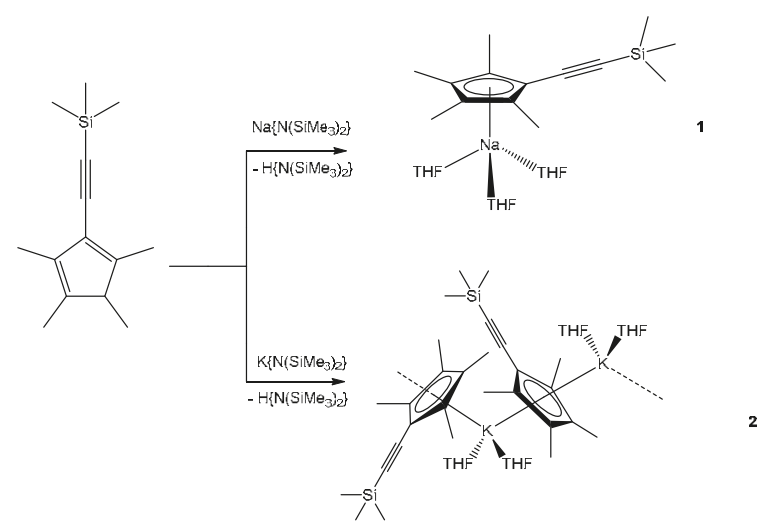

Scheme 2. Synthesis of $\left[\mathrm{NaCpMe}_{4}(\mathrm{C} \equiv \mathrm{CSiMe})(\mathrm{THF})_{3}\right]$ and $\left[\mathrm{KCpMe}_{4}\left(\mathrm{C} \equiv \mathrm{CSiMe}_{3}\right)(\mathrm{THF})_{2}\right]_{n}$.

Next, we reacted $\mathrm{CpMe}_{4}\left(\mathrm{C} \equiv \mathrm{CSiMe}_{3}\right) \mathrm{H}$ with $\mathrm{K}\left\{\mathrm{N}\left(\mathrm{SiMe}_{3}\right)_{2}\right\}$ in THF in order to compare the structural properties of different alkali metal complexes. Following the same synthetic and workup protocol as for 1, we isolated single crystals of $\left[\mathrm{KCpMe}_{4}\left(\mathrm{C} \equiv \mathrm{CSiMe}_{3}\right)(\mathrm{THF})_{2}\right]_{n}$ (2) in $19 \%$ yield (Scheme 2). The crystals were isolated by decantation from the mother liquor.

Compound 2 forms an infinite zig-zag chain in the solid state (Figure 2). It crystallizes in the chiral orthorhombic space group $P 2_{1} 2_{1} 2_{1}$ with one $\left\{\mathrm{KCpMe}_{4}\left(\mathrm{C} \equiv \mathrm{CSiMe}_{3}\right)(\mathrm{THF})_{2}\right\}$ subunit in the asymmetric unit. No chirality is observed in the super sandwich structure [26]. Investigation of the molecular structure of $\mathbf{2}$ in the solid state reveals that every potassium ion features a bent metallocene structure similar to the motive found in $\left[\mathrm{KCp} *(\mathrm{THF})_{2}\right]_{n}$ [27]. Besides the two $\mathrm{CpMe}_{4}\left(\mathrm{C} \equiv \mathrm{CSiMe}_{3}\right)^{-}$ligands, two molecules of THF are bound to each metal atom. Bond lengths and angles are nearly identical for $\left[\mathrm{KCp}^{*}(\mathrm{THF})_{2}\right]_{n}$ and 2 . The Cp-centroid-K-Cp-centroid angle of $133.33(1)^{\circ}$ is slightly smaller than in $\left[\mathrm{KCp}^{*}(\mathrm{THF})_{2}\right]_{n}\left(137.9^{\circ}\right)$. We suggest that the differences of the structures of compounds 1 and 2 are a result of the different ion radii. In solution, the NMR spectra reveal the expected signals. Thus, two singlets are observed for the protons of the methyl groups at 1.90 and $2.02 \mathrm{ppm}$ in the ${ }^{1} \mathrm{H}$ NMR spectrum. In the IR spectrum, the $\mathrm{C} \equiv \mathrm{C}$ bond stretching frequency is detected at $2130 \mathrm{~cm}^{-1}$, which is in the range of $\mathrm{CpMe}_{4}\left(\mathrm{C} \equiv \mathrm{CSiMe}_{3}\right) \mathrm{H}$.

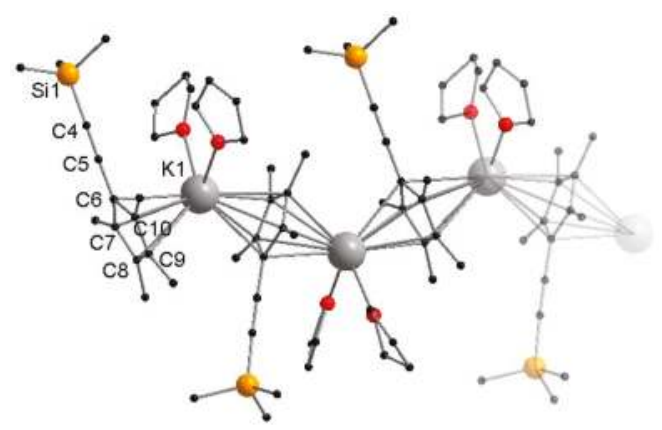

Figure 2. Cutout of the molecular structure of 2 in the solid state. Hydrogen atoms are omitted for clarity. Selected bond lengths [A] and angles [ $\left.{ }^{\circ}\right]$ : K1-C6 3.075(3), K1-C6 $6^{\prime} 3.020(3)$, K1-C7 3.020(3), K1-C7' 3.103(3), K1-C8 3.054(3), K1-C8' 3.070(3), K1-C9 3.002(3), K1-C9' 3.054(3), K1-C10 3.036(3), K1-C10' 3.011(3), C4-C5 1.212(5), K1-O1 2.796(3), K1-O2 2.720(2), $\mathrm{CpMe}_{4}\left(\mathrm{C} \equiv \mathrm{CSiMe}_{3}\right)$-Centroid-K1-CpMe $4\left(\mathrm{C} \equiv \mathrm{CSiMe}_{3}\right)$-Centroid 133.33(1), O1-K1-O2 90.20(8). 
In order to determine their potential in group 2 chemistry, we aimed to investigate salt metathesis reactions with alkaline earth metal halides. Thus, 2 was reacted with $\mathrm{CaI}_{2}$ in a 2:1 ratio in $\mathrm{THF}$ to obtain the desired sandwich complex $\left[\left\{\mathrm{CpMe}_{4}\left(\mathrm{C} \equiv \mathrm{CSiMe}_{3}\right)\right\}_{2} \mathrm{Ca}(\mathrm{THF})_{2}\right]$ as final product. Surprisingly, even after several attempts, only the iodide-bridged dimer $\left[\mathrm{CaCpMe}_{4}\left(\mathrm{C} \equiv \mathrm{CSiMe}_{3}\right) \mathrm{I}(\mathrm{THF})_{2}\right]_{2}$ (3) could be isolated as single product by crystallization. After adjusting the stochiometric ratio to 1:1, 3 was isolated as large yellow crystals in $29 \%$ yield (Scheme 3).

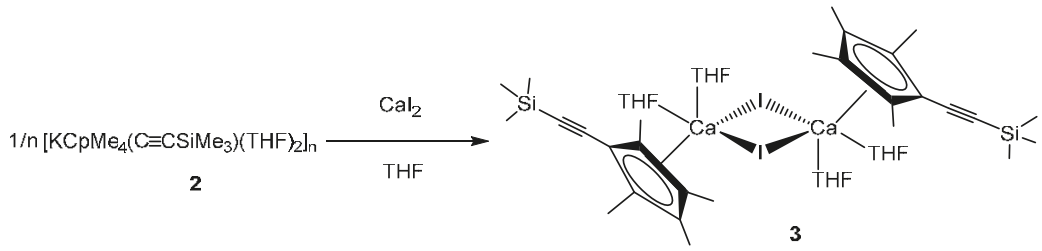

Scheme 3. Conversion of $\mathbf{2}$ with $\mathrm{CaI}_{2}$ yields in $\mathbf{3}$.

The calcium complex 3 crystallizes from toluene in the monoclinic space group $P 2_{1} / n$ with half of a molecule in the asymmetric unit. Compound 3 forms a halide-bridged dimer, in which both calcium atoms are coordinated by a single $\mathrm{CpMe}_{4}\left(\mathrm{C} \equiv \mathrm{CSiMe}_{3}\right)$ ring, two THF molecules and two bridging iodine atoms (Figure 3). A crystallographic C2 axis is observed along I and I'. The two bridging iodide anions show a short and a slightly elongated Ca-I bond (Ca1-I1 3.0920(7) ^ and Ca1-I1' $3.2039(7) \AA$ ). The average cyclopentadienyl carbon calcium distances in 3 (2.6948 $\AA$ ) are comparable to those in $\left[\mathrm{Cp}^{*} \mathrm{CaI}(\mathrm{THF})_{2}\right]_{2}(2.67 \AA)$ [28]. As a result of the steric demand, the two ethynyl substituents point to opposite directions. Compared to the sodium compound $\mathbf{1}$ and potassium compound 2, the $\mathrm{C} \equiv \mathrm{C}$ bond stretching frequency in the IR spectrum is shifted to a slightly lower wavenumber $\left(2108 \mathrm{~cm}^{-1}\right)$. In the ${ }^{1} \mathrm{H}$ and ${ }^{13} \mathrm{C}$ NMR spectra of 3 in THF- $d_{8}$, two sets of signals were identified, although single crystals of 3 were used for these studies. In the ${ }^{1} \mathrm{H}$ NMR spectrum, the methyl protons display four singlet resonances. These signals form two pairs of signals. The integral ratio of the first pair (1.89 ppm, $1.95 \mathrm{ppm})$ to the second pair (1.98 ppm, $2.04 \mathrm{ppm})$ can be ascertained to 63:37. In contrast, there is only one resonance for the $\mathrm{Si}\left(\mathrm{CH}_{3}\right)_{3}$ moieties, which may be a result of overlaid signals. The obvious anisochrony of the resonances of the methyl group suggests a Schlenk equilibrium as observed for $\left[\mathrm{Cp}{ }^{*} \mathrm{CaI}(\mathrm{THF})_{2}\right]_{2}$. According to Scheme 4 , each set can be assigned to either 3 or $\left[\left\{\mathrm{CpMe}_{4}\left(\mathrm{C} \equiv \mathrm{CSiMe}_{3}\right)\right\}_{2} \mathrm{Ca}(\mathrm{THF})_{x}\right]$, respectively.

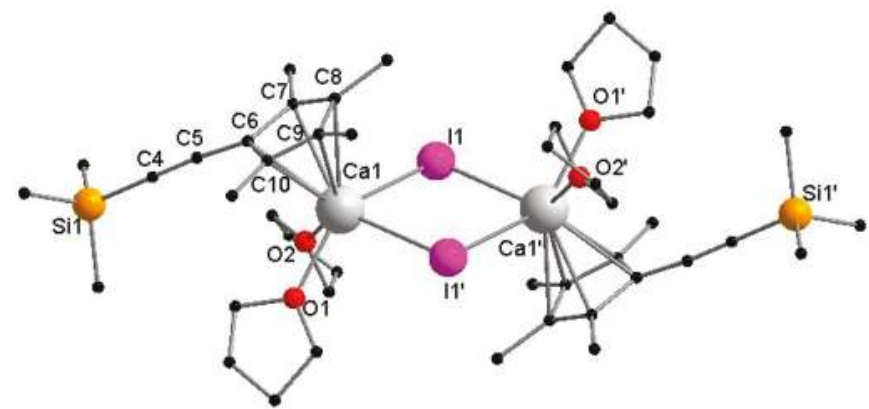

Figure 3. Molecular structure of 3 in the solid state. Hydrogen atoms are omitted for clarity. Selected bond lengths [Å] and angles [ ${ }^{\circ}$ ]: Ca1-I1 3.0920(7), Ca1-I1' 3.2039(7), Ca1-O1 2.369(3), Ca1-O2 2.410(3), Ca1-C6 2.634(3), Ca1-C7 2.686(4), Ca1-C8 2.734(5), Ca1-C9 2.733(5), Ca1-C10 2.687(4), C4-C5 1.199(5), I1-Ca1-I1' 83.109(2), Ca1-I1-Ca1' 96.891(2), O1-Ca1-O2 75.01(10), $\mathrm{CpMe}_{4}\left(\mathrm{C} \equiv \mathrm{CSSiMe}_{3}\right)$-Centroid-Ca1-I1 109.320(1), $\mathrm{CpMe}_{4}\left(\mathrm{C} \equiv \mathrm{CSiMe}_{3}\right)$-Centroid-Ca1-I1' 115.625(1). 


$$
\begin{aligned}
& 2 / n\left[\mathrm{KCpMe}_{4}\left(\mathrm{C} \equiv \mathrm{CSiMe}_{3}\right)(\mathrm{THF})_{2}\right]_{\mathrm{n}}+2 \mathrm{Cal}_{2} \underset{-2 \mathrm{KI}}{\stackrel{\mathrm{THF}}{\longrightarrow}}\left[\mathrm{CpMe}_{4}\left(\mathrm{C} \equiv \mathrm{CSiMe}_{3}\right) \mathrm{Cal}(\mathrm{THF})_{2}\right]_{2} \\
& \text { Schlenk eq. } \\
& {\left[\mathrm{CpMe}_{4}\left(\mathrm{C} \equiv \mathrm{CSiMe}_{3}\right) \mathrm{Cal}(\mathrm{THF})_{2}\right]_{2} \rightleftharpoons\left[\left\{\mathrm{CpMe}_{4}\left(\mathrm{C} \equiv \mathrm{CSiMe}_{3}\right)\right\}_{2} \mathrm{Ca}(\mathrm{THF})_{\mathrm{x}}\right]+\mathrm{Cal}_{2}(\mathrm{THF})_{2}}
\end{aligned}
$$

Scheme 4. Supposed Schlenk equilibrium between 3 and $\left[\left\{\mathrm{CpMe}\left(\mathrm{C} \equiv \mathrm{CSiMe}_{3}\right)\right\}_{2} \mathrm{Ca}(\mathrm{THF})_{x}\right]+\mathrm{CaI}_{2}(\mathrm{THF})_{2}$.

According to McCormick et al., separation of the analogous $\left[\mathrm{Cp} * \mathrm{CaI}(\mathrm{THF})_{2}\right]_{2}$ by solvent extraction is very difficult, since all components of the Schlenk equilibrium have a similar solvation behavior [16]. Thus, isolation can only be accomplished by crystallization. Unfortunately, we were not able to isolate $\left[\left\{\mathrm{CpMe}{ }_{4}(\mathrm{C} \equiv \mathrm{CSiMe})_{3}\right\}_{2} \mathrm{Ca}(\mathrm{THF})_{x}\right]$ as a crystalline material. However, besides 3 , the metallocene can be identified by mass spectrometry of a solution of crystalline compound 3 dissolved in THF. By changing the solvent for the ${ }^{1} \mathrm{H}$ NMR spectra from THF- $d_{8}$ to $\mathrm{C}_{6} \mathrm{D}_{6}$ and the temperature, we expected a shift of the Schlenk equilibrium. By using $\mathrm{C}_{6} \mathrm{D}_{6}$ instead of THF- $d_{8}$ as solvent, a downfield shift of the methyl resonance is observed (set 1: 2.03, $2.18 \mathrm{ppm}$; set 2: 2.35, $2.45 \mathrm{ppm}$ ). Furthermore, in ${ }^{1} \mathrm{H}$ NMR in $\mathrm{C}_{6} \mathrm{D}_{6}$ at room temperature, the intensity ratio of the two sets of resonances changed to $15: 85$, whereas at $333 \mathrm{~K}$ only two singlets at 2.25 and $2.40 \mathrm{ppm}$ are displayed. These observations indicate a dynamic process in solution. Although loss of THF in organo-alkaline-earth metal complexes is fairly common $[29,30]$ and is also known for organolanthanide systems [31], we could not detect any free THF in NMR experiments.

\section{Experimental}

\subsection{General Procedures}

All manipulations were performed under rigorous exclusion of moisture and oxygen in flame-dried Schlenk-type glassware or in an argon-filled MBraun glovebox (Garching, Germany). THF was distilled from potassium and benzophenone prior to use. Hydrocarbon solvents (diethyl ether, $n$-pentane) were dried using an MBraun solvent purification system (SPS-800). Deuterated solvents were obtained from Carl Roth GmbH (99.5 atom \% Deuterium) (Karlsruhe, Germany). NMR spectra were recorded on a BrukerAvance II $300 \mathrm{MHz}$ or Avance $400 \mathrm{MHz}$ (Bruker Biospin, Rheinstetten, Germany). ${ }^{1} \mathrm{H}$ and ${ }^{13} \mathrm{C}\left\{{ }^{1} \mathrm{H}\right\}$ chemical shifts were referenced to the residual ${ }^{1} \mathrm{H}$ and ${ }^{13} \mathrm{C}\left\{{ }^{1} \mathrm{H}\right\}$ resonances of the deuterated solvents and are reported relative to tetramethylsilane. IR spectra were obtained on a Bruker Tensor 37 (Bruker Optik, Ettlingen, Germany). Elemental analyses were carried out with an Elementar Micro Cube (Elementar Analysensysteme $\mathrm{GmbH}$, Langenselbold, Germany). Mass spectra were recorded on a LTQ Orbitrap XL Q Exactive mass spectrometer (Thermo Fisher Scientific, San Jose, CA, USA) equipped with an HESI II probe. The instrument was calibrated in the $m / z$ range 74-1822 using premixed calibration solutions (Thermo Fisher Scientific, San Jose, CA, USA). A constant spray voltage of $4.6 \mathrm{kV}$, a dimensionless sheath gas of 8 , and a dimensionless auxiliary gas flow rate of 2 were applied. The capillary temperature and the S-lens RF level were set to $320^{\circ} \mathrm{C}$ and 62.0 , respectively. Trimethyl $\left(\left(2,3,4,5\right.\right.$-tetramethylcyclopentadien-1-yl)ethynyl)silane $\left(\mathrm{CpMe}_{4}\left(\mathrm{C} \equiv \mathrm{CSiMe}_{3}\right) \mathrm{H}\right)$ was prepared according to literature procedures [23]. $\mathrm{Na}\left\{\mathrm{N}\left(\mathrm{SiMe}_{3}\right)_{2}\right\}, \mathrm{K}\left\{\mathrm{N}\left(\mathrm{SiMe}_{3}\right)_{2}\right\}$ and $\mathrm{CaI}_{2}$ were purchased from Sigma-Aldrich (Schnelldorf, Germany) and used as received.

\subsection{1. $\left[\mathrm{NaCpMe}_{4}\left(\mathrm{C} \equiv \mathrm{CSiMe}_{3}\right)(\mathrm{THF})_{3}\right](\mathbf{1})$}

$\mathrm{Na}\left\{\mathrm{N}\left(\mathrm{SiMe}_{3}\right)_{2}\right\}(462 \mathrm{mg}, 2.52 \mathrm{mmol})$ was dissolved in THF $(10 \mathrm{~mL})$ and $\mathrm{CpMe}_{4}\left(\mathrm{C} \equiv \mathrm{CSiMe}_{3}\right) \mathrm{H}$ (550 mg, $2.52 \mathrm{mmol}$ ) was slowly added by using a syringe. The solution instantly turned dark red upon addition. After complete addition, the solvent was reduced to approximately $5 \mathrm{~mL}$ and the flask was stored at $-30^{\circ} \mathrm{C}$. Colorless needles of $\left.\left[\mathrm{NaCpMe}_{4}(\mathrm{C} \equiv \mathrm{CSiMe})_{3}\right)(\mathrm{THF})_{3}\right]$ formed after $6 \mathrm{~h}$. The needles 
were filtered off, washed with precooled $n$-hexane and dried under vacuum. Yield: $305 \mathrm{mg}(50 \%$, single crystals).

${ }^{1} \mathrm{H}$ NMR (THF- $\left.d_{8}, 300 \mathrm{MHz}\right): \delta[\mathrm{ppm}]=0.07\left(\mathrm{~s}, 9 \mathrm{H}, \mathrm{Si}\left(\mathrm{CH}_{3}\right)_{3}\right), 1.67-1.71(\mathrm{~m}, \mathrm{THF})$,

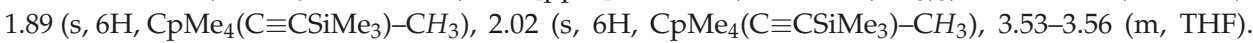
${ }^{13} \mathrm{C}\left\{{ }^{1} \mathrm{H}\right\}$ NMR $\left(\mathrm{THF}-d_{8}, 75 \mathrm{MHz}\right): \delta[\mathrm{ppm}]=0.79\left(\mathrm{Si}\left(\mathrm{CH}_{3}\right)_{3}\right), 10.7\left(\mathrm{CpMe}_{4}\left(\mathrm{C} \equiv \mathrm{CSiMe}_{3}\right)-\mathrm{CH}_{3}\right)$,

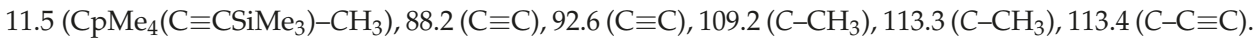
IR: $\tilde{v}\left(\mathrm{~cm}^{-1}\right)=2959(\mathrm{w}), 2118(\mathrm{w}), 1586(\mathrm{vw}), 1438(\mathrm{w}), 1376(\mathrm{vw}), 1247(\mathrm{~s}), 1078(\mathrm{w}), 996(\mathrm{w}), 859(\mathrm{w})$, 837 (vs), 757 (s), 695 (w), 663 (w), 527 (vw). Elemental Analysis: calcd. (\%) for $\mathrm{C}_{26} \mathrm{H}_{45} \mathrm{NaO}_{3} \mathrm{Si}: \mathrm{C}$ 68.38, H 9.93; found: C 67.60, H 8.94 .

\subsection{2. $\left[\mathrm{KCpMe}_{4}\left(\mathrm{C} \equiv \mathrm{CSiMe}_{3}\right)(\mathrm{THF})_{2}\right]_{n}(2)$}

$\left[\mathrm{KCpMe}_{4}\left(\mathrm{C} \equiv \mathrm{CSiMe}_{3}\right)(\mathrm{THF})_{2}\right]_{n}$ was synthesized in a similar way as $\left[\mathrm{NaCpMe}_{4}\left(\mathrm{C} \equiv \mathrm{CSiMe}_{3}\right)(\mathrm{THF})_{3}\right]$ from $\mathrm{K}\left\{\mathrm{N}\left(\mathrm{SiMe}_{3}\right)_{2}\right\}(435 \mathrm{mg}, 2.18 \mathrm{mmol})$ and $\mathrm{CpMe}_{4}\left(\mathrm{C} \equiv \mathrm{CSiMe}_{3}\right) \mathrm{H}(476 \mathrm{mg}, 2.18 \mathrm{mmol})$. Yield: $105 \mathrm{mg}$ (19\%, single crystals).

${ }^{1} \mathrm{H}$ NMR $\left(\mathrm{THF}-d_{8}, 300 \mathrm{MHz}\right): \delta[\mathrm{ppm}]=0.10\left(\mathrm{~s}, 9 \mathrm{H}, \mathrm{Si}\left(\mathrm{CH}_{3}\right)_{3}\right), 1.71-1.75(\mathrm{~m}, \mathrm{THF})$, 1.90 (s, 6H, CpMe $\left.4\left(\mathrm{C} \equiv \mathrm{CSiMe}_{3}\right)-\mathrm{CH}_{3}\right), 2.02\left(\mathrm{~s}, 6 \mathrm{H}, \mathrm{CpMe}_{4}\left(\mathrm{C} \equiv \mathrm{CSiMe}_{3}\right)-\mathrm{CH}_{3}\right), 3.57-3.59$ (m, THF). ${ }^{13} \mathrm{C}\left\{{ }^{1} \mathrm{H}\right\}$ NMR $\left(\mathrm{THF}-d_{8}, 75 \mathrm{MHz}\right): \delta[\mathrm{ppm}]=0.87\left(\mathrm{Si}\left(\mathrm{CH}_{3}\right)_{3}\right), 10.6\left(\mathrm{CpMe}_{4}\left(\mathrm{C} \equiv \mathrm{CSiMe}_{3}\right)-\mathrm{CH}_{3}\right)$, $11.4\left(\mathrm{CpMe}_{4}\left(\mathrm{C} \equiv \mathrm{CSiMe}_{3}\right)-\mathrm{CH}_{3}\right), 88.3(\mathrm{C} \equiv \mathrm{C}), 93.5(\mathrm{C} \equiv \mathrm{C}), 109.9\left(\mathrm{C}-\mathrm{CH}_{3}\right), 114.2\left(\mathrm{C}-\mathrm{CH}_{3}\right), 128.0(\mathrm{C}-\mathrm{C} \equiv \mathrm{C})$. IR: $\tilde{v}\left(\mathrm{~cm}^{-1}\right)=2961(\mathrm{w}), 2129(\mathrm{w}), 1581(\mathrm{w}), 1422(\mathrm{w}), 1376(\mathrm{vw}), 1247(\mathrm{~s}), 1073(\mathrm{w}), 861(\mathrm{w}), 838(\mathrm{vs})$, 757 (s), 696 (w), 663 (s), 528 (w). Elemental Analysis: calcd. (\%) for $\mathrm{C}_{22} \mathrm{H}_{37} \mathrm{KO}_{2} \mathrm{Si}: \mathrm{C}$ 65.94, $\mathrm{H}$ 9.31; found: C $65.86, \mathrm{H} 8.217$.

\subsection{3. $\left[\mathrm{CpMe}_{4}\left(\mathrm{C} \equiv \mathrm{CSiMe}_{3}\right) \mathrm{CaI}(\mathrm{THF})_{2}\right]_{2}(3)$}

$\left[\mathrm{KCpMe}_{4}\left(\mathrm{C} \equiv \mathrm{CSiMe}_{3}\right)(\mathrm{THF})_{2}\right]_{n}(312 \mathrm{mg}, 0.78 \mathrm{mmol})$ and $\mathrm{CaI}_{2}(229 \mathrm{mg}, 0.78 \mathrm{mmol})$ were placed in a Schlenk flask and THF $(10 \mathrm{~mL})$ was added. The mixture was stirred overnight at room temperature and all volatiles were removed under reduced pressure. The residue was extracted with toluene $(10 \mathrm{~mL})$ and filtered. The orange solution was concentrated to approximately $5 \mathrm{~mL}$ and stored at $-30{ }^{\circ} \mathrm{C}$. Blocks of $\left[\mathrm{CpMe}_{4}\left(\mathrm{C} \equiv \mathrm{CSiMe}_{3}\right) \mathrm{CaI}(\mathrm{THF})_{2}\right]_{2}$ formed within a period of one week. The crystals were filtered off, washed with $n$-pentane $(5 \mathrm{~mL})$ and dried under vacuum. Yield: $121 \mathrm{mg}(29 \%$, single crystals).

${ }^{1} \mathrm{H}$ NMR $\left(\mathrm{THF}-d_{8}, 300 \mathrm{MHz}\right): \quad \delta[\mathrm{ppm}]=0.11\left(\mathrm{~s}, \mathrm{Si}\left(\mathrm{CH}_{3}\right)_{3}\right), 1.67-1.71 \quad(\mathrm{~m}, \mathrm{THF})$, $1.89\left(\mathrm{~s}, \mathrm{CpMe}_{4}\left(\mathrm{C} \equiv \mathrm{CSiMe}_{3}\right)_{\mathrm{a}}-\mathrm{CH}_{3}\right), 1.95\left(\mathrm{~s}, \mathrm{CpMe}_{4}\left(\mathrm{C} \equiv \mathrm{CSiMe}_{3}\right)_{a}-\mathrm{CH}_{3}\right), 1.98\left(\mathrm{~s}, \mathrm{CpMe}_{4}\left(\mathrm{C} \equiv \mathrm{CSiMe}_{3}\right)_{b}-\mathrm{CH}_{3}\right)$, $2.04\left(\mathrm{~s}, \mathrm{CpMe}_{4}\left(\mathrm{C} \equiv \mathrm{CSiMe}_{3}\right)_{b}-\mathrm{CH}_{3}\right), 3.53-3.55(\mathrm{~m}, \mathrm{THF}) .{ }^{1} \mathrm{H}$ NMR $\left(\mathrm{C}_{6} \mathrm{D}_{6}, 300 \mathrm{MHz}\right): \delta[\mathrm{ppm}]=0.29$ (s, $\left.\mathrm{Si}\left(\mathrm{CH}_{3}\right)_{3}\right), 1.40-1.49(\mathrm{~m}, \mathrm{THF}), 2.03\left(\mathrm{~s}, \mathrm{CpMe}_{4}\left(\mathrm{C} \equiv \mathrm{CSiMe}_{3}\right)_{a}-\mathrm{CH}_{3}\right), 2.18\left(\mathrm{~s}, \mathrm{CpMe}_{4}\left(\mathrm{C} \equiv \mathrm{CSiMe}_{3}\right)_{a}-\mathrm{CH}_{3}\right)$, 2.35 (s, $\left.\mathrm{CpMe}_{4}\left(\mathrm{C} \equiv \mathrm{CSiMe}_{3}\right)_{b}-\mathrm{CH}_{3}\right), \quad 2.45$ (s, $\left.\mathrm{CpMe}_{4}\left(\mathrm{C} \equiv \mathrm{CSiMe}_{3}\right)_{b}-\mathrm{CH}_{3}\right), \quad 3.77-3.91 \quad$ (m, THF). ${ }^{13} \mathrm{C}\left\{{ }^{1} \mathrm{H}\right\} \mathrm{NMR}\left(\mathrm{THF}-d_{8}, 75 \mathrm{MHz}\right) * \quad \delta[\mathrm{ppm}]=0.07\left(\mathrm{Si}\left(\mathrm{CH}_{3}\right)_{3}\right), 10.8\left(\mathrm{CpMe}_{4}\left(\mathrm{C} \equiv \mathrm{CSiMe}_{3}\right)_{a}-\mathrm{CH}_{3}\right)$, $11.5\left(\mathrm{CpMe}_{4}\left(\mathrm{C} \equiv \mathrm{CSiMe}_{3}\right)_{b}-\mathrm{CH}_{3}\right), 11.6\left(\mathrm{CpMe}_{4}\left(\mathrm{C} \equiv \mathrm{CSiMe}_{3}\right)_{b}-\mathrm{CH}_{3}\right), 11.7\left(\mathrm{CpMe}_{4}\left(\mathrm{C} \equiv \mathrm{CSiMe}_{3}\right)_{a}-\mathrm{CH}_{3}\right), 91.8$, 97.8, 98.1, 107.6, 114.6, 116.1, 117.8, 118.0. ${ }^{13} \mathrm{C}\left\{{ }^{1} \mathrm{H}\right\} \mathrm{NMR}\left(\mathrm{C}_{6} \mathrm{D}_{6}, 75 \mathrm{MHz}\right)$ (some signals could not be assigned to the corresponding nuclei): $\delta[\mathrm{ppm}]=0.75\left(\mathrm{Si}\left(\mathrm{CH}_{3}\right)_{3}\right), 10.9\left(\mathrm{CpMe}_{4}\left(\mathrm{C} \equiv \mathrm{CSiMe}_{3}\right)_{a}-\mathrm{CH}_{3}\right)$, $11.8\left(\mathrm{CpMe}_{4}\left(\mathrm{C} \equiv \mathrm{CSiMe}_{3}\right)_{\mathrm{a}}-\mathrm{CH}_{3}\right), 12.4\left(\mathrm{CpMe}_{4}\left(\mathrm{C} \equiv \mathrm{CSiMe}_{3}\right)_{b}-\mathrm{CH}_{3}\right), 12.5\left(\mathrm{CpMe}_{4}\left(\mathrm{C} \equiv \mathrm{CSiMe}_{3}\right)_{b}-\mathrm{CH}_{3}\right), 86.9$, 92.6, 99.5, 107.0, 115.6, 117.3, 119.4. Elemental Analysis: calcd. (\%) for $\mathrm{C}_{44} \mathrm{H}_{74} \mathrm{Ca}_{2} \mathrm{I}_{2} \mathrm{O}_{4} \mathrm{Si}_{2}: \mathrm{C} 49.99$, H 7.06; found: C 49.58, H 7.105. ESI-MS: $m / z=\left[\left[\mathrm{CaCpMe}_{4}\left(\mathrm{C} \equiv \mathrm{CSiMe}_{3}\right) \mathrm{I}(\mathrm{THF})_{2}\right]_{2}-\mathrm{SiMe}_{4}-\mathrm{H}^{+}\right]=$calcd. 967.168; found $966.906, m / z=\left[\mathrm{CaCpMe}_{4}\left(\mathrm{C} \equiv \mathrm{CSiMe}_{3}\right)_{2}-\mathrm{SiMe}_{4}+\mathrm{H}^{+}\right]=$calcd. 387.182; found 387.142 .

\subsection{X-ray Crystallographic Studies of 1-3}

Suitable crystals 1-3 were covered in mineral oil (Aldrich) and mounted onto a glass fiber. The crystals were transferred directly into the cold stream of a Stoe IPDS 2 or StadiVari diffractometer (STOE \& Cie GmbH, Darmstadt, Germany).

All structures were solved by using the program SHELXS/T [32]. The remaining non-hydrogen atoms were located from successive difference Fourier map calculations. The refinements were 
carried out by using full-matrix least-squares techniques on $F^{2}$ by using the program SHELXL [32]. The hydrogen atom contributions of all of the compounds were calculated, but not refined. In each case, the locations of the largest peaks in the final difference Fourier map calculations, as well as the magnitude of the residual electron densities, were of no chemical significance.

3.2.1. $\left[\mathrm{NaCpMe}_{4}\left(\mathrm{C} \equiv \mathrm{CSiMe}_{3}\right)(\mathrm{THF})_{3}\right]$

$\mathrm{C}_{26} \mathrm{H}_{45} \mathrm{NaO}_{3} \mathrm{Si}, M_{\mathrm{r}}=456.70$, monoclinic, $P 2{ }_{1} / c$ (No. 14), $a=8.1123(16) \AA, b=14.126(3) \AA$, $c=24.766(5) \AA, \beta=99.36(3)^{\circ}, V=2800.4(10) \AA^{3}, T=100 \mathrm{~K}, Z=4, Z^{\prime}=1, \mu(\mathrm{Mo} \mathrm{K} \alpha)=0.121$, 12,871 reflections measured, 5468 unique $\left(R_{\text {int }}=0.1124\right)$ which were used in all calculations. The final $w R_{2}$ was 0.2846 (all data) and $R_{1}$ was $0.0931(I>4 \sigma(I))$.

3.2.2. $\left[\mathrm{KCpMe}_{4}\left(\mathrm{C} \equiv \mathrm{CSiMe}_{3}\right)(\mathrm{THF})_{2}\right]_{n}(2)$

$\mathrm{C}_{22} \mathrm{H}_{37} \mathrm{KO}_{2} \mathrm{Si}, M_{\mathrm{r}}=400.70$, orthorhombic, $P 2{ }_{1} 2_{1} 2_{1}$ (No. 19), $a=10.287(2) \AA, b=11.429(2) \AA$, $c=20.495(4) \AA, V=2409.6(8) \AA^{3}, T=100 \mathrm{~K}, Z=4, Z^{\prime}=1, \mu(\mathrm{Mo} \mathrm{K} \alpha)=0.282,19,379$ reflections measured, 4731 unique $\left(R_{\text {int }}=0.0584\right)$ which were used in all calculations. The final $w R_{2}$ was 0.1043 (all data) and $R_{1}$ was $0.0414(I>4 \sigma(I))$.

3.2.3. $\left[\mathrm{CaCpMe}_{4}\left(\mathrm{C} \equiv \mathrm{CSiMe}_{3}\right) \mathrm{I}(\mathrm{THF})_{2}\right]_{2}(3)$

$\mathrm{C}_{44} \mathrm{H}_{74} \mathrm{Ca}_{2} \mathrm{I}_{2} \mathrm{O}_{4} \mathrm{Si}_{2}, M_{\mathrm{r}}=1057.17$, monoclinic, $P 2_{1} / n$ (No. 14), $a=9.4746(4) \AA, b=14.9924(8) \AA$, $c=21.7467(8) \AA, \beta=101.490(3)^{\circ}, V=3027.1(2) \AA^{3}, T=220 \mathrm{~K}, \mathrm{Z}=2, \mathrm{Z}^{\prime}=0.5, \mu(\mathrm{Mo} \mathrm{K} \alpha)=1.278$, 14,525 reflections measured, 5910 unique $\left(R_{\text {int }}=0.0286\right)$ which were used in all calculations. The final $w R_{2}$ was 0.1181 (all data) and $R_{1}$ was $0.0392(I>4 \sigma(I))$.

Crystallographic data (excluding structure factors) for the structures reported in this paper have been deposited with the Cambridge Crystallographic Data Centre and the relevant codes are: 1541197-1541199. Copies of the data can be obtained free of charge on application to CCDC, 12 Union Road, Cambridge CB21EZ, UK (fax: (+(44)1223-336-033; email: deposit@ccdc.cam.ac.uk).

\section{Conclusions}

The trimethylsilylethynyl-substituted cyclopentadienyl ligand $\mathrm{CpMe}_{4}\left(\mathrm{C} \equiv \mathrm{CSiMe}_{3}\right)^{-}$was introduced into the chemistry of the s-block metals. The sodium and potassium derivatives were obtained by deprotonation of the corresponding cyclopentadiene with $\mathrm{Na}\left\{\mathrm{N}\left(\mathrm{SiMe}_{3}\right)_{3}\right\}$ and $\mathrm{K}\left\{\mathrm{N}\left(\mathrm{SiMe}_{3}\right)_{3}\right\}$. Whereas the sodium compound is monomeric, the potassium species forms a zig-zag chain in the solid state. Determination of the versatility in alkaline earth chemistry was carried out by subsequent reaction of compound 2 with $\mathrm{CaI}_{2}$, which resulted in the iodide bridged dimer $\left[\mathrm{CpMe}_{4}\left(\mathrm{C} \equiv \mathrm{CSiMe}_{3}\right) \mathrm{CaI}(\mathrm{THF})_{2}\right]_{2}$. The solid-state structure shows similarities to organolanthanide compounds, whereas in solution a Schlenk equilibrium typical for heavier organometallic group 2 compounds was observed. The corresponding metallocene $\left[\left\{\mathrm{CpMe}_{4}\left(\mathrm{C} \equiv \mathrm{CSiMe}_{3}\right)\right\}_{2} \mathrm{Ca}(\mathrm{THF})_{x}\right]$ was detected by NMR spectroscopy and mass spectrometry but could not be isolated as a crystalline solid.

Supplementary Materials: The following are available online at www.mdpi.com/2304-6740/5/2/28/s1, Crystallographic data, NMR Spectra, IR Spectra, Mass spectra, cif and cif-checked files.

Author Contributions: Tim Seifert and Peter W. Roesky conceived and designed the experiments, analyzed the data and wrote the paper; Tim Seifert performed the experiments; Peter W. Roesky contributed reagents/materials/analysis tools.

Conflicts of Interest: The authors declare no conflict of interest.

\section{References}

1. Thiele, J. Ueber Abkömmlinge des Cyclopentadiëns. Eur. J. Inorg. Chem. 1901, 34, 68-71. [CrossRef]

2. Fischer, E.; Jira, R.Z. Di-cyclopentadienyl-kobalt (II). Naturforschung B 1953, 8, 327-328. 
3. Fischer, E.; Hafner, W.; Stahl, H.Z. Über Cyclopentadienyl-metall-carbonyl-wasserstoffe des Chroms, Molybdäns und Wolframs. Anorg. Allg. Chem. 1955, 282, 47-62. [CrossRef]

4. Ziegler, K.; Froitzheim-Kühlhorn, H.; Hafner, K. Metallorganische Verbindungen XXI: Metallverbindungen des Cyclopentadiens. Chem. Ber. 1956, 89, 434-443. [CrossRef]

5. Panda, T.K.; Gamer, M.T.; Roesky, P.W. An improved synthesis of sodium and potassium cyclopentadienide. Organometallics 2003, 22, 877-878. [CrossRef]

6. Borisov, A.; Makhaev, V. The synthesis of potassium and sodium cyclopentadienides by the interaction of cyclopentadiene with alkalis. Organomet. Chem. USSR 1989, 2, 680.

7. Panda, T.K.; Gamer, M.T.; Roesky, P.W.; Yoo, H.; Berry, D.H. Sodium and Potassium Cyclopentadienide. In Inorganic Syntheses; John Wiley \& Sons, Inc.: New Jersey, NJ, USA, 2014; Volume 36.

8. Kohl, F.X.; Jutzi, P. An improved synthesis of 1,2,3,4,5-pentamethylcyclopentadiene. J. Organomet. Chem. 1983, 243, 119-121. [CrossRef]

9. DeVries, L. Communications-Preparation of 1,2,3,4,5-Pentamethyl-cyclopentadiene, 1,2,3,4,5,5-Hexamethylcyclopentadiene, and 1,2,3,4,5-Pentamethyl-cyclopentadienylcarbinol. J. Org. Chem. 1960, 25, 1838. [CrossRef]

10. Sawtelle, S.M.; Johnston, R.F.; Cook, C.C. An investigation of electron transfer properties of $(\mathrm{Cp}) \mathrm{Mn}(\mathrm{CO})_{3}$ and substituted Cp derivatives. Inorg. Chim. Acta 1994, 221, 85-92. [CrossRef]

11. Ye, B.; Cramer, N. Chiral cyclopentadienyl ligands as stereocontrolling element in asymmetric $\mathrm{C}-\mathrm{H}$ functionalization. Science 2012, 338, 504-506. [CrossRef] [PubMed]

12. Shaw, A.P.; Norton, J.R.; Buccella, D.; Sites, L.A.; Kleinbach, S.S.; Jarem, D.A.; Bocage, K.M.; Nataro, C. Synthesis, Electrochemistry, and Reactivity of Half-Sandwich Ruthenium Complexes Bearing Metallocene-Based Bisphosphines. Organometallics 2009, 28, 3804-3814. [CrossRef]

13. Powell, C.E.; Humphrey, M.G. Nonlinear optical properties of transition metal acetylides and their derivatives. Coord. Chem. Rev. 2004, 248, 725-756. [CrossRef]

14. Yam, V.W.W.; Lo, K.K.; Wong, K.M.C. Luminescent polynuclear metal acetylides. J. Organomet. Chem. 1999, 578, 3-30. [CrossRef]

15. Dias, H.R.; Flores, J.A.; Wu, J.; Kroll, P. Monomeric copper(I), silver(I), and gold(I) alkyne complexes and the coinage metal family group trends. J. Am. Chem. Soc. 2009, 131, 11249-11255. [CrossRef] [PubMed]

16. Das, A.; Dash, C.; Celik, M.A.; Yousufuddin, M.; Frenking, G.; Dias, H.R. Tris(alkyne) and Bis(alkyne) Complexes of Coinage Metals: Synthesis and Characterization of (cyclooctyne ${ }_{3} \mathrm{M}^{+}(\mathrm{M}=\mathrm{Cu}, \mathrm{Ag})$ and (cyclooctyne) ${ }_{2} \mathrm{Au}^{+}$and Coinage Metal $(\mathrm{M}=\mathrm{Cu}, \mathrm{Ag}, \mathrm{Au})$ Family Group Trends. Organometallics 2013, 32 , 3135-3144. [CrossRef]

17. Kabalka, G.W.; Wang, L.; Pagni, R.M. Sonogashira coupling and cyclization reactions on alumina: A route to aryl alkynes, 2-substituted-benzo [b] furans and 2-substituted-indoles. Tetrahedron 2001, 57, 8017-8028. [CrossRef]

18. Yi, C.; Hua, R. Efficient copper-free $\mathrm{PdCl}_{2}\left(\mathrm{PCy}_{3}\right)_{2}$-catalyzed sonogashira coupling of aryl chlorides with terminal alkynes. J. Org. Chem. 2006, 71, 2535-2537. [CrossRef] [PubMed]

19. Liang, B.; Dai, M.; Chen, J.; Yang, Z. Copper-free Sonogashira coupling reaction with $\mathrm{PdCl}_{2}$ in water under aerobic conditions. J. Org. Chem. 2005, 70, 391-393. [CrossRef] [PubMed]

20. Liang, L.; Astruc, D. The copper(I)-catalyzed alkyne-azide cycloaddition (CuAAC) "click" reaction and its applications. An overview. Coord. Chem. Rev. 2011, 255, 2933-2945. [CrossRef]

21. Crowley, J.D.; Bandeen, P.H. A multicomponent CuAAC "click" approach to a library of hybrid polydentate 2-pyridyl-1,2,3-triazole ligands: New building blocks for the generation of metallosupramolecular architectures. Dalton Trans. 2010, 39, 612-623. [CrossRef] [PubMed]

22. Zhang, J.; Chen, H.; Lin, C.; Liu, Z.; Wang, C.; Zhang, Y. Cobalt-Catalyzed Cyclization of Aliphatic Amides and Terminal Alkynes with Silver-Cocatalyst. J. Am. Chem. Soc. 2015, 137, 12990-12996. [CrossRef] [PubMed]

23. Pudelski, J.K.; Callstrom, M.R. Structure, reactivity, and electronic properties of [4]ferrocenophanes and [4]ruthenocenophanes prepared via a novel heteroannular cyclization reaction. Organometallics 1994, 13, 3095-3109. [CrossRef]

24. Yao, X.; Li, C.J. Water-Triggered and Gold(I)-Catalyzed Cascade Addition/Cyclization of Terminal Alkynes with ortho-Alkynylaryl Aldehyde. Org. Lett. 2006, 8, 1953-1955. [CrossRef] [PubMed]

25. Tedesco, C.; Dinnebier, R.E.; Olbrich, F.; Smaalen, S.V. Disordered crystal structure of pentamethylcyclopentadienylsodium as seen by high-resolution X-ray powder diffraction. Acta Crystallogr. Sect. B Struct. Sci. 2001, 57, 673-679. [CrossRef] 
26. Pidcock, E. Achiral molecules in non-centrosymmetric space groups. Chem. Commun. 2005, 3457-3459. [CrossRef] [PubMed]

27. Evans, W.J.; Brady, J.C.; Fujimoto, C.H.; Giarikos, D.G.; Ziller, J.W. The bent metallocene geometries of potassium polyalkyl cyclopentadienyl THF solvates: Monosolvated $\left[(\mathrm{THF}) \mathrm{K}\left(\mu-\mathrm{C}_{5} \mathrm{Me}_{5}\right)\right]_{n}$, disolvated $\left[(\mathrm{THF})_{2} \mathrm{~K}\left(\mu-\mathrm{C}_{5} \mathrm{Me}_{5}\right)\right]_{n}$ and the tethered olefin complex $\left[(\mathrm{THF}) \mathrm{K}\left(\mu-\mathrm{C}_{5} \mathrm{Me}_{4} \mathrm{SiMe}_{2} \mathrm{CH}_{2} \mathrm{CH}=\mathrm{CH}_{2}\right)\right]_{n}$. J. Organomet. Chem. 2002, 649, 252-257. [CrossRef]

28. McCormick, M.J.; Sockwell, S.C.; Davies, C.E.; Hanusa, T.P.; Huffman, J.C. Synthesis of a monopentamethylcyclopentadienyl halide complex of calcium. The X-ray crystal structure of $\left[\left(\mathrm{Me}_{5} \mathrm{C}_{5}\right) \mathrm{Ca}(\mu-\mathrm{I})(\mathrm{THF})_{2}\right]_{2}$. Organometallics 1989, 8, 2044-2049. [CrossRef]

29. McCormick, M.; Williams, R.; Levine, L.; Hanusa, T. Solution synthesis of calcium, strontium and barium metallocenes. Polyhedron 1988, 7, 725-730. [CrossRef]

30. Westerhausen, M.Z. Recent Developments in the Organic Chemistry of Calcium-An Element with Unlimited Possibilities in Organometallic Chemistry? Anorg. Allg. Chem. 2009, 635, 13-32. [CrossRef]

31. Evans, W.J.; Meadows, J.H.; Hanusa, T.P. Organolanthanide and organoyttrium hydride chemistry. 6. Direct synthesis and proton NMR spectral analysis of the trimetallic yttrium and yttrium-zirconium tetrahydride complexes, $\left\{\left[\left(\mathrm{C}_{5} \mathrm{H}_{5}\right)_{2} \mathrm{YH}\right]_{3} \mathrm{H}\right\}\left\{\mathrm{Li}(\mathrm{THF})_{4}\right\}$ and $\left\{\left[\left(\mathrm{CH}_{3} \mathrm{C}_{5} \mathrm{H}_{4}\right)_{2} \mathrm{YH}\right]_{2}\left[\left(\mathrm{CH}_{3} \mathrm{C}_{5} \mathrm{H}_{4}\right)_{2} \mathrm{ZrH}\right] \mathrm{H}\right\}$. J. Am. Chem. Soc. 1984, 106, 4454-4460. [CrossRef]

32. Sheldrick, G.M. A short history of SHELX. Acta Crystallogr. Sect. A 2008, 64, 112-122. [CrossRef] [PubMed]

(C) 2017 by the authors. Licensee MDPI, Basel, Switzerland. This article is an open access article distributed under the terms and conditions of the Creative Commons Attribution (CC BY) license (http:/ / creativecommons.org/licenses/by/4.0/). 


\title{
Editorial
}

\section{Kudos and Renaissance of s-Block Metal Chemistry}

\author{
Sven Krieck ${ }^{1}$ and Matthias Westerhausen ${ }^{1, *}$ \\ Institute of Inorganic and Analytical Chemistry, Friedrich Schiller University Jena, Humboldtstrasse 8, \\ D-07743 Jena, Germany; sven.krieck@uni-jena.de \\ * Correspondence: m.we@uni-jena.de; Tel.: +49-3641-9-48110 \\ Academic Editor: Peter W. Roesky \\ Received: 13 March 2017; Accepted: 21 March 2017; Published: 21 March 2017
}

\begin{abstract}
In recent years, the organometallic and coordination chemistry of the alkali and alkaline earth metals has experienced tremendous progress to tackle the needs of today's society. Enhanced ecological awareness and global availability favor research on the chemistry of the essential s-block metals. Nowadays, the s-block metals are conquering new chemical fields based on sophisticated theoretical and preparative achievements. Recent investigations show a huge impact of the s-block elements on stoichiometric and catalytic processes.
\end{abstract}

Keywords: s-block metals; catalysis; Grignard reagents; alkali metals; alkaline earth metals

The s-block metals subsume the elements of the first two groups of the periodic table-the alkali and alkaline earth metals. The non-radioactive elements were all discovered by the middle of the 19th century [1] (Table 1), initiating a profound s-block metal-based chemistry with a very long tradition. Generally, the toxicity is low and highly toxic congeners are limited to the radioactive metals and beryllium [2], justifying the underrepresented extent of their chemistry.

Table 1. Year of discovery [1] and selected properties [3] of the s-block metals (radii are given in pm; cation radii are given for six-coordinate ions).

\begin{tabular}{|c|c|c|c|c|c|c|}
\hline & Year of Discovery & Allred-Rochow Electronegativity & Atomic Radius & Cation Radius & Element Essential & Toxicity of Element \\
\hline $\mathrm{Li}$ & 1817 & 0.97 & 157 & 90 & - & + \\
\hline $\mathrm{Na}$ & 1807 & 1.01 & 191 & 116 & + & - \\
\hline $\mathrm{K}$ & 1807 & 0.91 & 235 & 152 & + & - \\
\hline $\mathrm{Rb}$ & 1861 & 0.89 & 250 & 166 & - & + \\
\hline Cs & 1860 & 0.86 & 272 & 181 & - & - \\
\hline $\mathrm{Fr}$ & 1939 & 0.86 & 270 & 194 & - & +++ \\
\hline $\mathrm{Be}$ & 1797 & 1.47 & 111.3 & 59 & - & +++ \\
\hline $\mathrm{Mg}$ & 1755 & 1.23 & 159.9 & 86 & + & - \\
\hline $\mathrm{Ca}$ & 1808 & 1.04 & 197.4 & 114 & + & - \\
\hline $\mathrm{Sr}$ & 1790 & 0.99 & 215.1 & 132 & - & - \\
\hline $\mathrm{Ba}$ & 1808 & 0.97 & 224 & 149 & - & + \\
\hline $\mathrm{Ra}$ & 1898 & 0.97 & 230 & 162 & - & +++ \\
\hline
\end{tabular}

The organic and coordination chemistry of these highly electropositive metals is dominated by mainly ionic bonds and the salt-like nature of their compounds. The most electropositive non-radioactive element, cesium, has an Allred-Rochow electronegativity of 0.86 [3] (Table 1). Generally, these elements are redox inert and oxidation states of $+-\mathrm{I}$ and $+\mathrm{II}$ of the alkali and alkaline earth metals, respectively, are maintained throughout the chemical transformations; exceptions include the thermally stable magnesium(I) [4] and calcium(I) complexes [5]. Polar organometallic chemistry has recently gained tremendous interest due to a paradigm shift in the principles and practice, widening the tasks and applications of these reagents [6].

Organomagnesium compounds have been known for more than a century, and in 1912, Victor Grignard was awarded with the Nobel Prize for the achievement of introducing organomagnesium halides, the so-called Grignard reagents, to organic and organometallic 
chemistry [7]. Still today, the coordination and organic chemistry of magnesium offers many facets for future tasks [8-11]. A few years after the discovery of the Grignard reagents, organolithium chemistry was developed by the research groups of Gilman [12] and Schlenk [13] and long lasting, extensive research efforts now allow us to understand the chemistry of these light s-block metals [14]. The chemistry of the heavier congeners poses severe challenges due to diverse reasons. The salt-like nature of the organometallics of the heavy alkali metals leads to solubility problems in common organic solvents. In addition, the strongly heteropolar nature of bonds to non-metallic p-block elements increases the nucleophilic character of the anions. This enhanced reactivity eases side-reactions with solvents and substrates (such as ligand coordination, aggregation, solvent and ligand degradation, as well as Wurtz-type coupling reactions) and hampers the straightforward direct synthesis. The heavy alkaline earth metals are high-melting elements and activation is required to reduce the discrepancy between the inertness of the metal itself and the enormous reactivity of its organometallics.

In very recent years, the interest in the chemistry of the s-block metals has gained tremendously in importance due to increased environmental and ecological awareness and, hence, the need for non-toxic reagents with a broad diversity of properties with respect to availability, reactivity, applicability, and costs has become evident. This fact led to the increasing impact of this chemistry in all fields of chemistry (Figure 1), especially in organometallic and catalytic applications $[15,16]$. Thus, the delayed development of a sophisticated organic [17] and coordination chemistry of calcium [18] led to the nickname of "sleeping beauty" for this dormant element [18,19]. Lithium (and to a lesser extend sodium and magnesium) will become the foundation for car batteries, ensuring electric-based transport and, hence, the demand (as well as the price) will increase significantly. Recent studies have elucidated the suitability of magnesium hydrides as storage materials for hydrogen, one of the future energy carriers. In the recent past, increasing efforts have been undertaken to develop a sophisticated chemistry of these elements [19-21]. The chemistry of methanediides [22] and the relevance of secondary interactions [23], discussed in this Special Issue, may be viewed as representative examples.

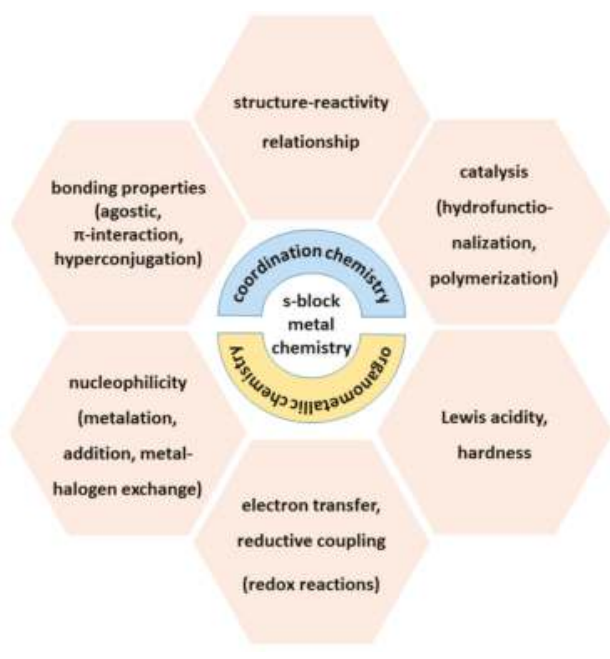

Figure 1. Representation of the broadness and importance of s-block metals in coordination and organometallic chemistry, covering unique structures and bonding properties as well as applications in stoichiometric and catalytic reactions.

In contrast to lithium, the heavier homologous elements, sodium and potassium as well as calcium, are globally abundant, easily available, inexpensive and of low toxicity. Whereas the mining and salt production of these metals (e.g., rock salt, lime and gypsum) are routinely performed in 
industrial processes in very large scale, the organic and organometallic as well as coordination chemistry of the heavier alkali and alkaline earth metals is now awakening and diverse research groups are focusing on specific aspects of the demanding chemistry of s-block metal compounds. On the one hand, the electropositive nature of the metals increases toward the heavier congeners (decreasing electronegativity), leading to the enhanced heteropolar nature of bonds to carbon, nitrogen and oxygen. On the other hand, Lewis acidity is related to the charge-to-radius (or charge-to-surface) ratio with cesium being the softest element in the periodic table. Softness of an element or ion is directly related to its polarizability and compressibility. Thus, lithium and calcium have very similar electronegativity values and, hence, comparable bond polarities but a significantly enhanced Lewis acidic character of the calcium ions can be expected. This consideration might emblematize the reason for stronger bonds to even very weak Lewis bases such as $\sigma$-bonds (agostic bonds) and $\pi$-electron density ( $\pi$-interactions).

Future tasks related to the chemistry of these s-block organometallics include stability and reactivity [17], catalysis and stoichiometric conversions [18,21], Lewis acidity and nucleophilicity [24]. Quantum chemical calculations are valuable tools to elucidate the agostic and $\pi$-interactions between the s-block metal ions and multiple bonds $[25,26]$. Isoelectronic ion pairs such as $\mathrm{Na}^{+} / \mathrm{Mg}^{2+}, \mathrm{K}^{+} / \mathrm{Ca}^{2+} / \mathrm{Sc}^{3+}, \mathrm{Rb}^{+} / \mathrm{Sr}^{2+} / \mathrm{Y}^{3+}$, and $\mathrm{Cs}^{+} / \mathrm{Ba}^{2+} / \mathrm{La}^{3+}$ allow one to deduce the influence of electronegativity, size and hardness on reactivity and bonding parameters. The isoelectronic relations demonstrate that the heavy alkaline earth metals calcium, strontium and barium have intermediate positions between the alkali metal ions (highly electropositive, polarizable, highly ionic character) and the early transition metal ions (highly Lewis acidic, d-orbital participation, catalytic reactivity). This fact interrelates the chemistry of these heavy alkaline earth metals to the catalytic activity of complexes of the scandium group.

Understanding the diverse characteristics of these highly reactive compounds will expand the knowledge on reactivity and property; this will enable one to commonly tackle future challenges related to these highly polar organometallic and coordination compounds and catalysts that often have unique reaction patterns and mechanisms.

Conflicts of Interest: The authors declare no conflict of interest.

\section{References}

1. Emsley, J. The Elements; Clarendon Press: Oxford, NY, USA, 1989.

2. Naglav, D.; Buchner, M.R.; Bendt, G.; Kraus, F.; Schulz, S. Off the beaten track-A hitchhiker's guide to beryllium chemistry. Angew. Chem. Int. Ed. 2016, 55, 10562-10576. [CrossRef] [PubMed]

3. Holleman, A.F.; Wiberg, E.; Wiberg, N. Lehrbuch der Anorganischen Chemie (Holleman-Wiberg), 102nd ed.; de Gruyter: Berlin, Germany, 2007.

4. Stasch, A.; Jones, C. Stable Dimeric Magnesium(I) Compounds: From chemical landmarks to versatile reagents. Dalton Trans. 2011, 40, 5659-5672. [CrossRef] [PubMed]

5. Krieck, S.; Görls, H.; Yu, L.; Reiher, M.; Westerhausen, M. Stable "inverse" sandwich complex with unprecedented organocalcium(I): crystal structures of $\left[(\text { thf })_{2} \mathrm{Mg}(\mathrm{Br})-\mathrm{C}_{6} \mathrm{H}_{2}-2,4,6-\mathrm{Ph}_{3}\right]$ and [(thf $\left.)_{3} \mathrm{Ca}\left\{\mu-\mathrm{C}_{6} \mathrm{H}_{3}-1,3,5-\mathrm{Ph}_{3}\right\} \mathrm{Ca}(\text { thf })_{3}\right]$. J. Am. Chem. Soc. 2009, 131, 2977-2985. [CrossRef] [PubMed]

6. Hevia, E.; Mulvey, R. Towards a paradigm shift in the principles and practice of polar organometallic chemistry (EPSRC Fund). Available online: https://pure.strath.ac.uk/portal/en/projects/towards-aparadigm-shift-in-the-principles-and-practice-of-polar-organometallic-chemistry(5f1b83e5-44b1-49938de8-4ea484510c7d).html (accessed on 10 March 2017).

7. Seyferth, D. The Grignard reagents. Organometallics 2009, 28, 1598-1605. [CrossRef]

8. Westerhausen, M.; Krieck, S. Magnesium. Available online: http://www.aktuelle-wochenschau.de/ main-navi/archiv / chemie-der-elemente-2016/kw51-magnesium.html?gid=108266Andreas (accessed on 10 March 2017).

9. Benischke, A.D.; Ellwart, M.; Becker, M.R.; Knochel, P. Polyfunctional zinc and magnesium organometallics for organic synthesis: Some perspectives. Synthesis 2016, 48, 1101-1107. 
10. Martínez-Martínez, A.J.; O’Hara, C.T. Lithium, sodium, and potassium magnesiate chemistry: A structural overview. Adv. Organomet. Chem. 2016, 65, 1-46.

11. Harrison-Marchand, A.; Mongin, F. Mixed AggregAte (MAA): A single concept for all dipolar organometallic aggregates. 1. Structural data. Chem. Rev. 2013, 113, 7470-7562. [CrossRef] [PubMed]

12. Eisch, J.J. Henry Gilman: American pioneer in the rise of organometallic chemistry in modern science and technology. Organometallics 2002, 21, 5439-5463. [CrossRef]

13. Seyferth, D. Alkyl and aryl derivatives of the alkali metals: Strong bases and reactive nucleophiles. 2. Wilhelm Schlenk's organoalkali-metal chemistry. The metal displacement and the transmetalation reactions. Metalation of weakly acidic hydrocarbons. Superbases. Organometallics 2009, 28, 2-33. [CrossRef]

14. Capriati, V.; Perna, F.M.; Salomone, A. "The great beauty" of organolithium chemistry: A land still worth exploring. Dalton Trans. 2014, 43, 14204-14210. [CrossRef] [PubMed]

15. Smith, J.D. Organometallic compounds of the heavier s-block elements-What next? Angew. Chem. Int. Ed. 2009, 48, 6597-6599. [CrossRef] [PubMed]

16. Ritter, S.K. Calcium's awakening. Chem. Eng. News 2011, 89, 49-51. [CrossRef]

17. Westerhausen, M.; Koch, A.; Görls, H.; Krieck, S. Heavy Grignard reagents: Synthesis, physical and structural properties, chemical behavior and reactivity. Chem. Eur. J. 2017, 23, 1456-1483. [CrossRef] [PubMed]

18. Harder, S. From limestone to catalysis: Application of calcium compounds as homogeneous catalysts. Chem. Rev. 2010, 110, 3852-3876. [CrossRef] [PubMed]

19. Harder, S. (Ed.) Alkaline-earth Metal Compounds: Oddities and Applications; Springer: Heidelberg, Germany, 2013.

20. Hanusa, T.P. (Ed.) The Lightest Metals: Science and Technology from Lithium to Calcium; Wiley: Chichester, UK, 2015.

21. Hill, M.S.; Liptrot, D.J.; Weetman, C. Alkaline earths as main group reagents in molecular catalysis. Chem. Soc. Rev. 2016, 45, 972-988. [CrossRef] [PubMed]

22. Feichtner, K.S.; Gessner, V.H. Synthesis and characterization of a sulfonyl- and imino-phosphorylfunctionalized methanide and methanediide. Inorganics 2016, 4, 40. [CrossRef]

23. Roşca, S.C.; Roueindeji, H.; Dorcet, V.; Roisnel, T.; Carpentier, J.F.; Sarazin, Y. $\mathrm{K}^{+} \ldots \mathrm{C}_{\pi}$ and $\mathrm{K}^{+} \ldots$ F non-covalent interactions in $\pi$-functionalized potassium fluoroalkoxides. Inorganics 2017, 5, 13. [CrossRef]

24. Leboeuf, D.; Gandon, V. Carbon-carbon and carbon-heteroatom bond-forming transformations catalyzed by calcium(II) triflimide. Synthesis 2017, 49, 1500-1508. [CrossRef]

25. Dufrois, Q.; Vendier, L.; Etienne, M. $\alpha$-CC agostic structures and aggregation diversity in cyclopropyllithium derivatives. Chem. Commun. 2016, 52, 6781-6784. [CrossRef] [PubMed]

26. Roşca, S.C.; Dinoi, C.; Caytan, E.; Dorcet, V.; Etienne, M.; Carpentier, J.F.; Sarazin, Y. Alkaline earth-olefin complexes with secondary interactions. Chem. Eur. J. 2016, 22, 6505-6509. [CrossRef] [PubMed]

(C) 2017 by the authors. Licensee MDPI, Basel, Switzerland. This article is an open access article distributed under the terms and conditions of the Creative Commons Attribution (CC BY) license (http:/ / creativecommons.org/licenses/by/4.0/). 
MDPI AG

St. Alban-Anlage 66

4052 Basel, Switzerland

Tel. +41616837734

Fax +41 613028918

http://www.mdpi.com

Inorganics Editorial Office

E-mail: inorganics@mdpi.com

http://www.mdpi.com/journal/inorganics

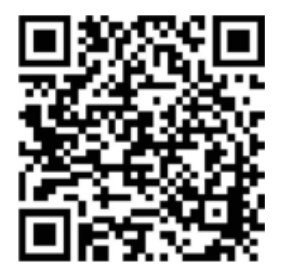



MDPI AG

St. Alban-Anlage 66

4052 Basel

Switzerland

Tel: +41 616837734

Fax: +41 613028918 